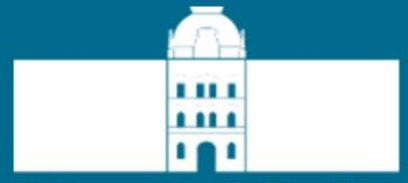

University of Maribor

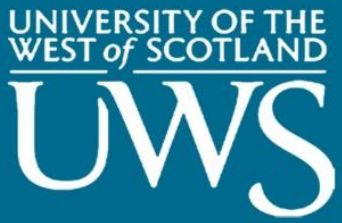

\title{
$10^{\mathrm{TH}}$ International Conference on Sustainable Energy and Environmental Protection:
}

\section{Bioenergy and Biofuels}

(June $27^{T H}-30^{T H}, 2017$, Bled, Slovenia)

(Conference Proceedings)

\section{Editors:}

Emeritus Prof. dr. Jurij Krope Prof. dr. Abdul Ghani Olabi

Prof. dr. Darko Goričanec

Prof. dr. Stanislav Božičnik 
University of Maribor Press 


\title{
$10^{\mathrm{TH}}$ International Conference on Sustainable Energy and Environmental Protection
}

\author{
Bioenergy and Biofuels
}

(June 27 ${ }^{\mathrm{TH}}-30^{\mathrm{TH}}, 2017$, Bled, Slovenia)

(Conference Proceedings)

Editors:

Emeritus Prof. dr. Jurij Krope

Prof. dr. Abdul Ghani Olabi

Prof. dr. Darko Goričanec

Prof. dr. Stanislav Božičnik 
Title: $\quad 10^{\mathrm{TH}}$ International Conference on Sustainable Energy and Environmental Protection (June $27^{\mathrm{TH}}-30^{\mathrm{TH}}, 2017$, Bled, Slovenia) (Conference Proceedings)

Subtitle: Bioenergy and Biofuels

Editors: Emeritus Prof. Jurij Krope, Ph.D. (University of Maribor, Slovenia), Prof. Abdul Ghani Olabi, Ph.D. (University of the West of Scotland, UK), Asso. Prof. Darko Goričanec, Ph.D. (University of Maribor, Slovenia), Asso. Prof. Stanislav Božičnik (University of Maribor, Slovenia).

Review: Prof. Željko Knez, Ph.D. (University of Maribor, Slovenia), Prof. Niko Samec, Ph.D. (University of Maribor, Slovenia).

Tehnical editors : Jan Perša (University of Maribor Press), Armin Turanović (University of Maribor Press).

Design and layout: University of Maribor Press

Conference: $\quad 10^{\mathrm{TH}}$ International Conference on Sustainable Energy and Environmental Protection

Honorary Committee:

Abdul Ghani Olabi, Ph.D. (Honorary President, University of the West of Scotland, United Kingdom), Igor Tičar, Ph.D (Rector of the University of Maribor, Slovenia), Niko Samec Ph.D. (Pro-rector of University of Maribor, Slovenia), Zdravko Kravanja, Ph-D. (Dean of the Faculty of Chemistry and Chemical Engineering, University of Maribor, Slovenia).

Organising Committee:

Jurij Krope, Ph.D. (University of Maribor, Slovenia), Darko Goričanec, Ph.D. (University of Maribor, Slovenia), Stane Božičnik, Ph.D. (University of Maribor, Slovenia), Peter Trop, Ph.D. (University of Maribor, Slovenia), Danijela Urbancl, Ph.D. (University of Maribor, Slovenia), Sonja Roj (University of Maribor, Slovenia), Željko Knez, Ph.D. (University of Maribor, Slovenia), Bojan Štumberger, Ph.D. (University of Maribor, Slovenia), Franci Čuš, Ph.D. (University of Maribor, Slovenia), Miloš Bogataj, Ph.D. (University of Maribor, Slovenia), Janez Žlak, Ph.D (Mine Trbovlje Hrastnik, Slovenia), LL. M. Tina Žagar (Ministry of Economic Development and Technology), Igor Ivanovski, MSc. (IVD Maribor, Slovenia), Nuša Hojnik, Ph.D. (Health Center Maribor).

Programme Committee:

Prof. Abdul Ghani Olabi (UK), Emeritus Prof. Jurij Krope (Slovenia), Prof. Henrik Lund (Denmark), Prof. Brian Norton (Ireland), Prof. Noam Lior (USA), Prof. Zdravko Kravanja (Slovenia), Prof. Jirí Jaromír Klemeš (Hungary), Prof. Stane Božičnik (Slovenia), Prof. Bojan Štumberger (Slovenia), Prof. Soteris Kalogirou (Cyprus), Prof. Stefano Cordiner (Italy), Prof. Jinyue Yan (Sweden), Prof. Umberto Desideri (Italy), Prof. M.S.J. Hashmi (Ireland), Prof. Michele Dassisti (Italy), Prof. Michele Gambino (Italy), Prof. S. Orhan Akansu (Turkey), Dr. David Timoney (Ireland), Prof. David Kennedy (Ireland), Prof. Bekir Sami Yilbas (Saudi Arabia), Dr. Brid Quilty (Ireland), Prof. B. AbuHijleh (UAE), Prof. Vincenc Butala (Slovenia), Prof. Jim McGovern (Ireland), Prof. Socrates Kaplanis (Greece), Dr. Hussam Jouhara (UK), Prof. Igor Tičar (Slovenia), Prof. Darko Goričanec (Slovenia), Dr. Joseph Stokes (Ireland), Prof. Antonio Valero (Spain), Prof. Aristide F. Massardo (Italy), Prof. Ashwani Gupta (USA), Dr. Aoife Foley (UK), Dr. Athanasios Megartis (UK), Prof. Francesco Di Maria (Italy), Prof. George Tsatsaronis (Germany), Prof. Luis M. Serra (Spain), Prof. Savvas Tassou (UK), Prof. Luigi Alloca (Italy), Prof. Faek Diko (Germany), Dr. F. Al-Mansour (Slovenia), Dr. Artur Grunwald (Germany), Dr. Peter Trop (Slovenia), Prof. Philippe Knauth (France), Prof. Paul Borza (Romania), Prof. Roy Douglas (UK), Prof. Dieter Meissner (Austria), Dr. Danijela Urbancl (Slovenia), Prof. Daniel Favrat (Switzerland), Prof. Erik Dahlquist (Sweden), Prof. Eric Leonhardt (USA), Prof. GianLuca Rospi (Italy), Prof. Giuseppe Casalino (Italy), Prof. J. Dawson (USA), Dr. Josè Simoes (Portugal), Prof. Kadir Aydin (Turkey), Dr. Khaled Benyounis (Ireland), Prof. Laszlo Garbai (Hungary), Prof. Mariano Martin (Spain), Prof. Masahiro Ishida (Japan), Prof. Michael Seal (USA), Prof. Marco Spinedi (Italy), Prof. Michio Kitano (Japan), Prof. Milovan Jotanović (BiH), Prof. Nafiz Kahraman (Turkey), Prof. Na Zhang (China), Prof. Naotake Fujita (Japan), Prof. Niko Samec (Slovenia), Prof. Oleksandr Zaporozhets (Ukraine), Prof. Osama Al-Hawaj (Kuwait), Prof. Petar Varbanov (Hungary), Prof. Peter Goethals (Belgium), Prof. Qi Zhang (China), Prof. Rik Baert (The Netherlands), Prof. Rolf Ritz (USA), Dr. Stephen Glover (UK), Prof. Signe Kjelstrup (Norway), Dr. Sumsun Naher (UK), Prof. Sven Andersson (Sweden), Dr. Salah Ibrahim (UK), Prof. Sebahattin Unalan (Turkey), Prof. Sabah Abdul-Wahab Sulaiman (Oman), Prof. Somrat Kerdsuwan (Thailand), Prof. T. Hikmet Karakoç (Turkey), Prof. Tahir Yavuz (Turkey), Prof. Hon Loong Lam (Thailand), LL.M. Tina Žagar (Slovenia), Prof. A.M.Hamoda (Qatar), Prof. Gu Hongchen (China), Prof. Haşmet Turkoglu (Turkey), Dr. Hussam Achour (Ireland), Dr. James Carton (Ireland), Dr. Eivind Johannes (Norway), Prof. Elvis Ahmetović (BiH), Prof. 
D.G.Simeonov (Bulgaria), Prof. Abdelakder Outzourhit (Morocco), Prof. Bilge Albayrak Çeper (Turkey), Prof. Bekir Zühtü Uysal (Turkey), Prof. D. Bradley (UK), Dr. Silvia Tedesco (UK), Dr. Valentin Ivanov (Germany), Dr. Vincent Lawlor (Austria), Prof. Yonghua Cheng (Belgium), Prof. Yasufumi Yoshimoto (Japan), Prof. Yahya Erkan Akansu (Turkey), Prof. Yunus Ali Çengel (Turkey), Prof. Zeljko Knez (Slovenia), Prof. Zoltan Magyar (Hungary), Dr. William Smith (Ireland), Dr. Abed Alaswad (UK).

First published in 2017 by

University of Maribor Press

Slomškov trg 15, 2000 Maribor, Slovenia

tel. +386225042 42, fax +38622523245

http://press.um.si, zalozba@um.si

\section{Co-published by}

University of Maribor, Faculty of Chemistry and Chemical Engineering

Smetanova ulica 17,2000 Maribor, Slovenia

tel. +386 (0)2 2294 400, faks + $386(0) 22527774$

http://www.fkkt.um.si, fkkt@um.si

Published: 5. July 2017

\section{(C) University of Maribor Press}

All rights reserved. No part of this book may be reprinted or reproduced or utilized in any form or by any electronic, mechanical, or other means, now known or hereafter invented, including photocopying and recording, or in any information storage or retrieval system, without permission in writing from the publisher.

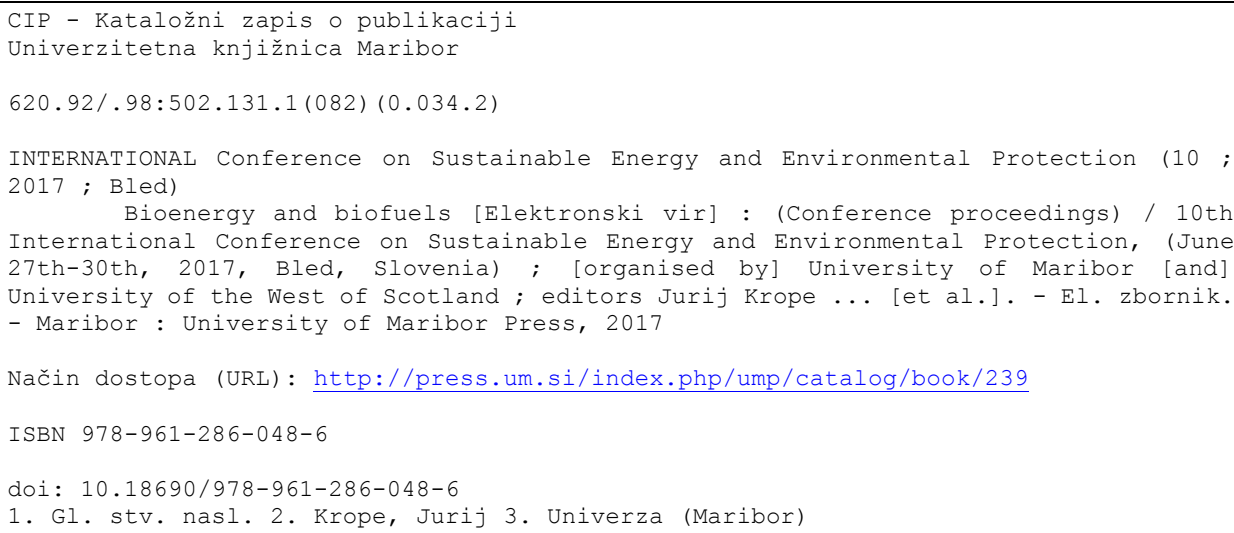

ISBN 978-961-286-048-6

DOI: https://doi.org/10.18690/978-961-286-048-6

Price: Free copy

For publisher: $\quad$ Prof. Igor Tičar, Ph.D., rector (University of Maribor) 
$10^{\mathrm{TH}}$ InTERNATIONAL CONFERENCE ON Sustainable ENERGy AND Environmental Protection (June 27 $7^{\mathrm{TH}}-30^{\mathrm{TH}}$, 2017, BLed, SLOVENIA), BIOENERGY AND BiofUELS

J. Krope, A.Ghani Olabi, D. Goričanec \& S. Božičnik

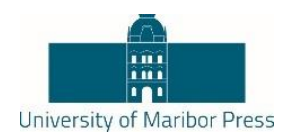

\section{Preface}

The $10^{\text {th }}$ International Conference on Sustainable Energy and environmental Protection SEEP 2017 was organised on June $27^{\text {th }}-30^{\text {th }} 2017$ in Bled, Slovenia, by:

- Faculty of Chemistry and Chemical Engineering, University of Maribor, Slovenia,

- University of the West of Scotland, School of Engineering and

The aim of SEEP2017 is to bring together the researches within the field of sustainable energy and environmental protection from all over the world.

The contributed papers are grouped in 18 sessions in order to provide access to readers out of 300 contributions prepared by authors from 52 countries.

We thank the distinguished plenary and keynote speakers and chairs who have kindly consented to participate at this conference. We are also grateful to all the authors for their papers and to all committee members.

We believe that scientific results and professional debates shall not only be an incentive for development, but also for making new friendships and possible future scientific development projects.

General chair

Emeritus Prof. dr. Jurij Krope
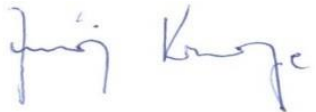
$10^{\mathrm{TH}}$ International CONFERENCE ON Sustainable ENERGy AND Environmental Protection (June 27 $7^{\mathrm{TH}}-30^{\mathrm{TH}}$, 2017, Bled, SLOVENIA), BIOENERGY AND BIOFUELS

J. Krope, A.Ghani Olabi, D. Goričanec \& S. Božičnik

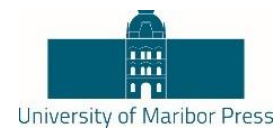

\section{Plenary Talk on \\ The Relation between Renewable Energy and Circular Economy}

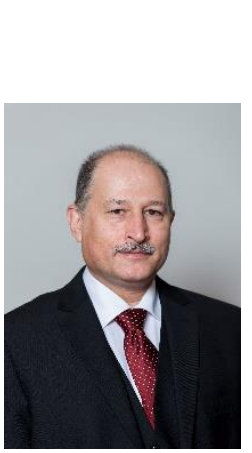

ABDUl GHANI OLABI - BIBLIOGRAPHY

Prof Olabi is director and founding member of the Institute of Engineering and Energy Technologies (www.uws.ac.uklieet) at the University of the West of Scotland. He received his M.Eng and Ph.D. from Dublin City University, since 1984 he worked at SSRC, HIAST, CNR, CRF, DCU and UWS. Prof Olabi has supervised postgraduate research students (10 M.Eng and 30PhD) to successful completion. Prof Olabi has edited 12 proceedings, and has published more than 135 papers in peer-reviewed international journals and about 135 papers in international conferences, in addition to 30 book chapters. In the last 12 months Prof Olabi has patented 2 innovative projects. Prof Olabi is the founder of the International Conference on Sustainable Energy and Environmental Protection SEEP, www.seepconference.co.uk

$\mathrm{He}$ is the Subject Editor of the Elsevier Energy Journal https://www.journals.elsevier.com/energy/editorial-board/abdul-ghani-olabi, also Subject editor of the Reference Module in Materials Science and Materials Engineering http://scitechconnect.elsevier.com/reference-module-material-science/ and board member of a few other journals. Prof Olabi has coordinated different National, EU and International Projects. He has produced different reports to the Irish Gov. regarding: Hydrogen and Fuel Cells and Solar Energy.

Correspondence AdDress: Abdul Ghani Olabi, Ph.D., Professor, University of the West of Scotland, School of Engineering and Computing, D163a, McLachlan Building, Paisley, United Kingdom, e-mail: Abdul.Olabi@uws.ac.uk. 
$10^{\mathrm{TH}}$ InTERNATIONAL CONFERENCE ON Sustainable ENERGy AND

Environmental Protection (June 27 $7^{\mathrm{TH}}-30^{\mathrm{TH}}$, 2017, Bled,

SLOVENIA), BIOENERGY AND BIOFUELS

J. Krope, A.Ghani Olabi, D. Goričanec \& S. Božičnik

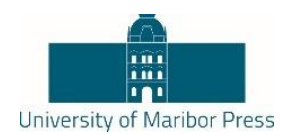

\title{
Plenary Talk on \\ Energy Footprints Reduction and Virtual Footprints Interactions
}

\author{
JIŘí JAROMÍR KLEMEŠ \& PETAR SABEV VARBANOV
}

Increasing efforts and resources have been devoted to research during environmental studies, including the assessment of various harmful impacts from industrial, civic, business, transportation and other economy activities. Environmental impacts are usually quantified through Life Cycle Assessment (LCA). In recent years, footprints have emerged as efficient and useful indicators to use within LCA. The footprint assessment techniques has provided a set of tools enabling the evaluation of Greenhouse Gas (GHG) - including $\mathrm{CO}_{2}$, emissions and the corresponding effective flows on the world scale. From all such indicators, the energy footprint represents the area of forest that would be required to absorb the GHG emissions resulting from the energy consumption required for a certain activity, excluding the proportion absorbed by the oceans, and the area occupied by hydroelectric dams and reservoirs for hydropower.

An overview of the virtual GHG flow trends in the international trade, associating the GHG and water footprints with the consumption of goods and services is performed. Several important indications have been obtained: (a) There are significant GHG gaps between producer's and consumer's emissions - US and EU have high absolute net imports GHG budget. (b) China is an exporting country and increasingly carries a load of GHG emission and virtual water export associated with consumption in the relevant importing countries. (c) International trade can reduce global environmental pressure by redirecting import to products produced with lower intensity of GHG emissions and lower water footprints, or producing them domestically.

To develop self-sufficient regions based on more efficient processes by combining neighbouring countries can be a promising development. A future direction should be focused on two main areas: (1) To provide the self-sufficient regions based on more efficient processes by combining production of surrounding countries. (2) To develop the shared mechanism and market share of virtual carbon between trading partners regionally and internationally.

CORRESPONDENCE AdDRESS: Jiř́ Jaromír Klemeš, DSc, Professor, Brno University of Technology - VUT Brno, Faculty of Mechanical Engineering, NETME Centre, Sustainable Process Integration Laboratory - SPIL, Technická 2896/2, 61669 Brno, Czech Republic, e-mail: klemes@fme.vutbr.cz. Petar Sabev Varbanov, Ph.D., Associate Professor, Brno University of Technology - VUT Brno, Faculty of Mechanical Engineering, NETME Centre, Sustainable Process Integration Laboratory - SPIL, Technická 2896/2, 61669 Brno, Czech Republic, e-mail: varbanov@fme.vutbr.cz. 
$10^{\mathrm{TH}}$ International CONFERENCE ON Sustainable ENERGy AND Environmental Protection (June 27 $7^{\mathrm{TH}}-30^{\mathrm{TH}}$, 2017, Bled, SLOVENIA), BIOENERGY AND BIOFUELS

J. Krope, A.Ghani Olabi, D. Goričanec \& S. Božičnik

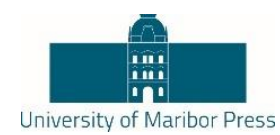

\section{JIŘÍ JAROMÍR KLEMEŠ - BIBLIOGRAPHY}

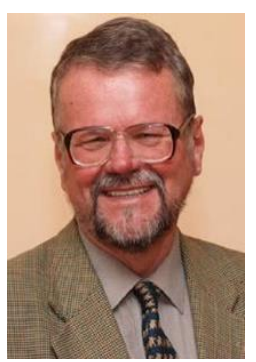

Head of "Sustainable Process Integration Laboratory - SPIL", NETME Centre, Faculty of Mechanical Engineering, Brno University of Technology - VUT Brno, Czech Republic and Emeritus Professor at "Centre for Process Systems Engineering and Sustainability", Pázmány Péter Catholic University, Budapest, Hungary.

Previously the Project Director, Senior Project Officer and Hon Reader at Department of Process Integration at UMIST, The University of Manchester and University of Edinburgh, UK. Founder and a long term Head of the Centre for Process Integration and Intensification - CPI2, University of Pannonia, Veszprém, Hungary. Awarded by the EC with Marie Curies Chair of Excellence (EXC). Track record of managing and coordinating 91 major EC, NATO and UK Know-How projects. Research funding attracted over $21 \mathrm{M€}$.

Co-Editor-in-Chief of Journal of Cleaner Production ( $\mathrm{IF}=4.959)$. The founder and President for 20 $\mathrm{y}$ of PRES (Process Integration for Energy Saving and Pollution Reduction) conferences. Chairperson of CAPE Working Party of EFCE, a member of WP on Process Intensification and of the EFCE Sustainability platform.

He authored nearly 400 papers, h-index 40. A number of books published by McGraw-Hill; Woodhead; Elsevier; Ashgate Publishing Cambridge; Springer; WILEY-VCH; Taylor \& Francis).

Several times Distinguished Visiting Professor for Universiti Teknologi Malaysia, Xi'an Jiaotong University; South China University of Technology, Guangzhou; Tianjin University in China; University of Maribor, Slovenia; University Technology Petronas, Malaysia; Brno University of Technology and the Russian Mendeleev University of Chemical Technology, Moscow. Doctor Honoris Causa of Kharkiv National University "Kharkiv Polytechnic Institute" in Ukraine, the University of Maribor in Slovenia, University POLITEHNICA Bucharest, Romania. "Honorary Doctor of Engineering Universiti Teknologi Malaysia", "Honorary Membership of Czech Society of Chemical Engineering", "European Federation of Chemical Engineering (EFCE) Life-Time Achievements Award" and "Pro Universitaire Pannonica" Gold Medal.

CORRESPONDENCE AdDRESS: Jiří Jaromír Klemeš, DSc, Professor, Brno University of Technology - VUT Brno, Faculty of Mechanical Engineering, NETME Centre, Sustainable Process Integration Laboratory - SPIL, Technická 2896/2, 61669 Brno, Czech Republic, e-mail: klemes@fme.vutbr.cz. 
$10^{\mathrm{TH}}$ InTERNATIONAL CONFERENCE ON Sustainable ENERGy AND Environmental Protection (June 27 $7^{\mathrm{TH}}-30^{\mathrm{TH}}$, 2017, Bled, SLOVENIA), BIOENERGY AND BIOFUELS

J. Krope, A.Ghani Olabi, D. Goričanec \& S. Božičnik

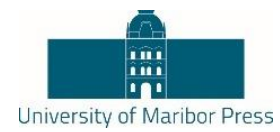

\title{
Plenary Talk on \\ Renewable energy sources for environmental protection
}

\author{
HAKAN SERHAD SOYHAN
}

Development in energy sector, technological advancements, production and consumption amounts in the countries and environmental awareness give shape to industry of energy. When the dependency is taken into account in terms of natural resources and energy, there are many risks for countries having no fossil energy sources. Renewable and clean sources of energy and optimal use of these resources minimize environmental impacts, produce minimum secondary wastes and are sustainable based on current and future economic and social societal needs. Sun is one of the main energy sources in recent years. Light and heat of sun are used in many ways to renewable energy. Other commonly used are biomass and wind energy. To be able to use these sources efficiently national energy and natural resources policies should be evaluated together with the global developments and they should be compatible with technological improvements. Strategic plans with regard to energy are needed more intensively and they must be in the qualification of a road map, taking into account the developments related to natural resources and energy, its specific needs and defining the sources owned by countries. In this presentation, the role of supply security was evaluated in term of energy policies. In this talk, new technologies in renewable energy production will be shown and the importance of supply security in strategic energy plan will be explained.

Correspondence Address: Hakan Serhad Soyhan, Ph.D., Professor, Sakarya University, Engineering Faculty, Esentepe Campus, M7 Building, 54187 - Esentepe /Sakarya, Turkey, e-mail: hsoyhan@sakarya.edu.tr. 
$10^{\mathrm{TH}}$ InTERNATIONAL CONFERENCE ON Sustainable ENERGY AND Environmental Protection (June 27 $7^{\mathrm{TH}}-30^{\mathrm{TH}}$, 2017, Bled, SLOVENIA), BioENERGY AND BiofUELS

J. Krope, A.Ghani Olabi, D. Goričanec \& S. Božičnik

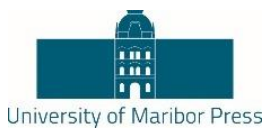

\section{HAKAN SERHAD SOYHAN - BIBLIOGRAPHY}

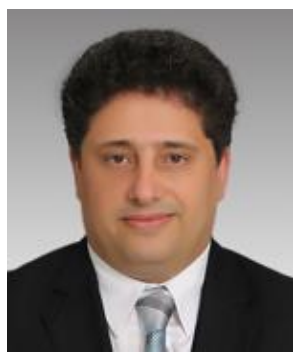

Professor at Sakarya University, Engineering Faculty. $50 \%$ fot teaching and the rest for reasearch activities.

Teaching, courses taught:

Graduate courses:

- Combustion technology;

- Modelling techniques;

Undergraduate courses:

- Combustion techniques;

- Internal combustion engines;

- Fire safety.

Tehnical skills and competences professional societies:

- 25 jurnal papers in SCI Index. 23 conference papers;

- $\quad$ Editor at FCE journal. Co-editor at J of Sakarya University;

- Head of Local Energy Research Society (YETA);

- Member od American Society of Mechanical engineers (ASME);

- Member of Turkish Society of Mechanical Engineers (TSME).

Correspondence AdDress: Hakan Serhad Soyhan, Ph.D., Professor, Sakarya University, Engineering Faculty, Esentepe Campus, M7 Building, 54187 - Esentepe /Sakarya, Turkey, e-mail: hsoyhan@sakarya.edu.tr. 

$10^{\mathrm{TH}}$ InTERnAtional CONFERENCE ON Sustainable ENERgy AND Environmental Protection (June 27 $7^{\mathrm{TH}}-30^{\mathrm{TH}}, 2017$, BLed, SLOVENIA), BIOENERGY AND BiOFUELS

J. Krope, A.Ghani Olabi, D. Goričanec \& S. Božičnik

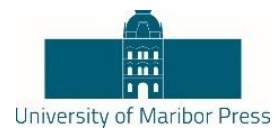

\section{Table of Contents}

\section{CONFERENCE PROCEEDINGS}

Enhanced Methane Production from Waste Paper Through

Anaerobic Co-Digestion with Macroalgae

Cristina Rodriguez, Zaki El-Hassan \& Abdul G. Olabi

Biogas Production from Three-Phase Olive Mill Solid Waste in Lab-Scale Continuously Stirred Tank Reactor

Rafat. Al Afif \& Bernd Linke

Organosolv Plus Supercritival Carbon Dioxide PreTreatment of Cotton Stalks for Methane Production

Rafat Al Afif, Martin Wendland, Lutz Christian Krapf, Thomas Amon \& Christoph Pfeifer

Chemical Looping Combustion of Biomass: Clou Experiments with a Cu-Mn Mixed Oxide

Teresa Mendiara, Iñaki Adánez-Rubio, Antón Pérez-Astray, María Teresa Izquierdo, Alberto Abad, Pilar Gayán, Luis F. de Diego, Francisco García-Labiano \& Juan Adánez

Complete Analysis of Castor Oil Methanolysis for Biodiesel Production

Omar Aboelazayem, Nour Sh. El-Gendy, Fatma H. Ashour \& Mohamed A. Sadek

Optimising Bidiesel Production from High Acid Value Waste Cooking Oil Using Supercritical Methanol

Omar Aboelazayem, Mamdouh Gadalla \& Basudeb Saha

Ampelodesmos Mauritanicus Pyrolysis Biochar in Anaerobic

Digestion Process: Evaluation of the Biogas Yield

Fabio Codignole Luz, Stefano Cordiner, Alessandro Manni, Vincenzo Mulone, Vittorio Rocco, Roberto Braglia \& Antonella Canini

Thermocatalytic Refining of Gaseous Products Produced by 
ii $\mid 10^{\mathrm{TH}}$ International CONFERENCE on Sustainable EnERgy AND ENVIRONMENTAL Protection (June $27^{\mathrm{TH}}-30^{\mathrm{TH}}, 2017$, BLED, SLOVENiA), Bioenergy AND Biofuels

Table of Contents

Ghg Reduction Targets in Germany: 80 - 95\% - What Does it Mean for Bioenergy and the Heating Sector in Particular?

Nora Szarka, Daniela Thrän \& Volker Lenz

Kinetic Study for the Co-Pyrolysis of Lignocellulosic Biomass 99 and Plastics Using the Distributed Activation Energy Model María Victoria Navarro, José Manuel López, Alberto Veses, María Soledad Callén \& Tomás García

Removal of Steryl Glucosides in Biodiesel Using 111 Diatomaceous Earth as Adsorbent

Ratanaporn Yuangsawad, Suttirat Khambung, Pattarin Laungthaleongpong \& Duangkamol Na-Ranong

Upgrading of Biogas to Biomethane: Experimental and Process Analysis Applied to an Industrial Plant

Francesco Ferella, Katia Gallucci \& Pier Ugo Foscolo

A Kinetic Study of Cassava Mash Hydrolysis in a 135 Combination with Solid State Catalyst Mixed-Milling Reaction

Kanpichcha Intaramas, Woranart Jonglertjunya, Navadol Laosiripojana $\&$ Chularat Sakdaronnarong

Oil Characteristics of Biosludge Pyrolysis by a Microwave 147 Heating System

Kuo-Hsiung Lin, Nina Lai, Jun-Yan Zeng \& Hung-Lung Chiang

Fast Pyrolysis of Brown Alga Saccharina Japonica in a 153 Bubbling Fluidized-Bed Reactor: Effects of Anaerobic Fermentaion Pretreatment

Jae Hyung Choi, Hee Chul Woo, Jinsoo Kim \& Seung-Soo Kim

Effect of Dolomite Catalyst on Bio-Oil Production During 163 Pyrolysis of Tulip Tree (Liriodendron) in Fluidized-Bed Reactor

Seung-Soo Kim, Jinsoo Kim \& Hoang Vu Ly

Advances in Biomass Pretreatment and Cellulosic Bioethanol Production Using Microwave Heating

Pranjali D. Muley \& Dorin Boldor 
Optimization of the Biohydrogen Production by Anaerobic

Granular Sludge Using Mixtures of Wheat Straw Hydrolysate and Cheese Whey as Substrates

Angel Mario Lopez-Hidalgo, Zazil Donaxi Alvarado-Cuevas, Jose Tomas Ornelas Salas \& Antonio De Leon-Rodriguez

Bioreactor Study of Using Medicinal Herbs and Edible Flora 189 to Stimulate Microbial Fuel Cells for ElectrochemicallySteered Bioremediation

Bor-Yann Chen, An-Wei Hsu, Jia-Hui Liao, Chia-Chyi Wu \& ChungChuan Hsueh

Bioethanol Production Power Plants from Sugarcane: First and Second Generation

Marcus Vinicius Roncari Mari, Joao Marcos Roncarci Mari, Maykon Cesar Spolti Ferreira, W.A.dos S. Conceição \& Cid Marcos Goncalves Andrade

Optimization of in-Silico Ethanol Production Using a Hybrid Evolutionary Algorithm

Hanniel Ferreira Sarmento Freitas, Jose Eduardo Olivo \& Cid Marcos Goncalves Andrade

Modeling the Production Process of Bioethanol in Free Software Using Metabolic Pathways

Matheus Yuri Gritzenco De Giovanni, Renam Luis Acorsi, Igor Rossi Fermo, Cid Marcos Gonçalves Andrade \& José Eduardo Olivo

Preliminary Exergy Analysis of Biodiesel Production Routes: A Brief Review Joao Marcos Roncarci Mari, Marcus Vinicius Roncari Mari, Maykon Cesar Spolti Ferreira, Eugenia Leandro Almeida, W.A.dos S. Conceição \& Cid Marcos Goncalves Andrade

Sorption Enhanced Reforming of Different Fuel Types for the Production of a Hydrogen-Rich Reduction Gas Josef Fuchs, Stefan Müller, Johannes Christian Schmid, Hermann Hofbauer, Hugo Stocker, Nina Kieberger \& Thomas Bürgler

Mixtures of Silica Sand and Calcite as Bed Material for Dual Fluidized Bed Steam Gasification

Anna Magdalena Mauerhofer, Florian Benedikt, Johannes Christian Schmid \& Hermann Hofbauer 
$\begin{array}{lllll}\text { Continuous } & \text { Hydrocarbon } & \text { Production } & \text { by } & 267\end{array}$

Hydrodeoxygenation of Liquid Phase Pyrolysis Oil

Klara Treusch, Nikolaus Schwaiger, Klaus Schlackl, Roland Nagl, Peter Pucher \& Matthäus Siebenhofer

2,5 Dmf Production from Biomass Using Heterogenous

\section{Catalysts}

Nerea Viar, Jesus Requies, Ion Agirre \& Pedro Luis Arias

Can Various Bioenergy Technologies Add Value to Each 285 Other?

Katrin Heinsoo \& Kadri Tali

Operational Experience of Biomass Combustion Using 293

Chemical Looping Processes

Francisco García-Labiano, Alberto Abad, Teresa Mendiara, María Teresa Izquierdo, Pilar Gayán, Luis Francisco de Diego \& Juan Adánez

Comparison on Compositions of Bio-Oil Derived from Mulberry Bark Hydrothermal Liquefaction in Sub/CriticalWater and Ethanol-Water Co-Solvents

Congjin Chen, Jingxian Zhu, Shuang Jia, Zhangfa Tong, Zhixia Li \& Mingfei Li

Biodiesel Production. A Brief Review

Eugênia Leandro Almeida, Cid Marcos Gonçalves Andrade \& Onélia Aparecida Andreo dos Santos

Biodiesel Production Process Versus Bioethanol Production

Process. Preliminary Analysis

Eugênia Leandro Almeida, Sérgio Inácio Gomes, Cid Marcos Gonçalves

Andrade \& Onélia Aparecida Andreo dos Santos

Comparative Study of Steam- and Nitrogen Explosion

Pretreatment Methods

Merlin Raud, Klaus Krennhuber, Alexander Jäger \& Timo Kikas

Direct Conversion of Ethanol Into Linear A-Alcohols in the 
Original Pt-Sn/A12O3 Catalyst for Selective 355 Hydrodeoxygenation of Vegetable Oils

Polina A. Zharova, Andrey V. Chistyakov, Sergey S. Shapovalov, Alexander A. Pasynskii \& Mark V. Tsodikov

Modeling of an Biohydrogen Generation Process Using 363 Artificial Neural Networks and Meta-Heuristic Algorithms Hanniel Ferreira, Sarmento de Freitas, Eugênia Leandro Almeida, José Eduardo Olivo \& Cid Marcos Gonçalves Andrade

Heating Value of Torrified Oak Wood and Sewage Sludge 373 Depending on Temperature

Marko Agrež, Danijela Urbancl, Sanja Potrč \& Darko Goričanec

Managing Soil Sustainability Indicators for Sustainable 383 Bioenergy Production

Sheikh Adil Edrisi \& Purushothaman Chirakkuzhyil Abhilash 
vi $\mid 10^{\mathrm{TH}}$ InTERnATIONAL CONFERENCE ON Sustainable ENERGy AND ENVIRONMENTAL Protection (June $27^{\mathrm{TH}}-30^{\mathrm{TH}}, 2017$, Bled, Slovenia), Bioenergy ANd Biofuels Table of Contents 
$10^{\mathrm{TH}}$ InTERnational CONFERENCE ON Sustainable ENERgy AND ENVIRONMENTAL Protection (June $27^{\mathrm{TH}}-30^{\mathrm{TH}}$, 2017, Bled, SLOVENIA), BIOENERGY AND BIOFUELS

J. Krope, A.Ghani Olabi, D. Goričanec \& S. Božičnik

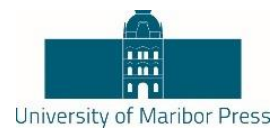

\title{
Enhanced Methane Production from Waste Paper Through Anaerobic Co-Digestion with Macroalgae
}

\author{
CRISTINA RodRIGUEZ, ZAKI El-HASSAN \& ABDUl G. OlaBI
}

\begin{abstract}
This study investigates the effect on methane production from waste paper when co-digested with macroalgal biomass as a source of nitrogen. Both feedstocks were previously mechanically pretreated in order to reduce their particle size. Methane potential assays were carried out at laboratory scale in batch mode for 28 days. The highest methane yield (386 $\mathrm{ml} / \mathrm{g}$ of volatile solids (VS)) was achieved at a F/I ratio of 0.2 and a WP/MA ratio of 50:50. The methane yield at a ratio WP/MA of 50:50, which represents an increase of $30 \%$ compare with mono-digestion of algae and $22 \%$ with mono-digestion of waste paper. Synergistic effect was found for the WP/MA ratio of 50:50 and all F/I ratios. It was concluded that methane production from waste paper improves significantly when co-digested with macroalgae biomass. The methane yields from co-digestion were also found higher that from macroalgae mono-digestion.
\end{abstract}

Keywords: - Algae $・$ Anaerobic co-digestion $・$ Biomass $・$ Renewable energy $\bullet$ Waste paper $\bullet$

CORRESPONDENCE ADDRESS: Cristina Rodriguez, University of the West of Scotland, Institute of Engineering and Energy Technologies, Paisley, PA1 2BE United Kingdom, e-mail: cristina.rodriguez@uws.ac.uk. Zaki El-Hassan, Lecturer, University of the West of Scotland, Institute of Engineering and Energy Technologies, Paisley, PA1 2BE, United Kingdom, e-mail: zaki.elhassan@uws.ac.uk. Abdul G. Olabi, Professor, University of the West of Scotland, Institute of Engineering and Energy Technologies, Paisley, PA1 2BE, United Kingdom, e-mail: abdul.olabi@uws.ac.uk. 
2 10 $10^{\text {TH }}$ International Conference on Sustainable EnERgy AND ENVIRONMENTAL Protection (June $27^{\mathrm{TH}}-30^{\mathrm{TH}}, 2017$, BLed, Slovenia), Bioenergy AND Biofuels

C. Rodriguez, Z. El-Hassan \& A. G. Olabi: Enhanced Methane Production from Waste Paper Through Anaerobic Co-Digestion with Macroalgae

Introduction

By 2020, EU aims to get the $20 \%$ of energy consumption from renewable resources, $10 \%$ coming specifically from biofuels [1], [2]. Biogas con be used as a car fuel, as a replacement of natural gas, or in fuel cells [3].

Paper and cardboard account for 25-30\% of municipal solids waste (MSW); the biggest source of waste paper is industry and businesses with the 52\% of the total [4]. Anaerobic digestion of waste paper was usually studied as part of the anaerobic digestion of MSW, in some cases the study was carried out about the MSW different fractions that resulted in methane yields for newsprint paper from 58 to $100 \mathrm{ml} / \mathrm{gVS}$ [5], [6]; for office paper 208-369ml/gVS [5]-[9] and for cardboard 96 and $217 \mathrm{ml} / \mathrm{gVS}$ [5], [9].

The ratio carbon/nitrogen $(\mathrm{C} / \mathrm{N})$ is one of the most important factor in anaerobic digestion nutrients balance. Carbon is the source of energy for the process and nitrogen is needed for the formation of enzymes that perform metabolism. A high $\mathrm{C} / \mathrm{N}$ ratio is an indication of rapid consumption of nitrogen by methanogens and results in lower gas production, while a low $\mathrm{C} / \mathrm{N}$ ratio causes ammonia accumulation and $\mathrm{pH}$ rises excessively. Most authors consider an optimal $\mathrm{C} / \mathrm{N}$ ratio needs to be in the range 10-30 [10]. Paper materials have a carbon-to-nitrogen $(\mathrm{C} / \mathrm{N})$ ratio ranging from 173/1 to greater than 1000/1 [11], these values are very high for anaerobic digestion so a balance of nutrients can be achieved through co-digestion with biomass that contains nitrogen and lower the $\mathrm{C} / \mathrm{N}$ ratio.

Co-digestion is the simultaneous digestion of a mixture of two or more substrates and offers many advantages, including ecological, technological, and economic benefits, compared to digestion of a single substrate [12]. The purpose of co-digestion is usually to balance nutrients ( $\mathrm{C} / \mathrm{N}$ ratio and macro- and micronutrients) and dilute inhibitors/toxic compounds. Moreover, the co-digestion of two or more complementary substrates may induce a synergetic effect on their biodegradability, causing an increase in the methane yield and production rate [13]. Successful examples of co-digestion include: cow dung and water hyacinth [14]; algal sludge and waste paper [15]; cattle manure and crude glycerine [16]; grass and sludge and [17]; municipal sludge, microalgae and waste paper [10]; algae biomass residue and lipid waste [18] and hay and soybean [12].

The innovation in this study is that it is the first to assess the optimised conversion of waste paper to biogas through co-digestion with macroalgae $(P$. Canaliculata) as a source of nitrogen to balance the $\mathrm{C} / \mathrm{N}$ ratio in the process. Both feedstock were previously mechanically pretreated in a Hollander beater according to [19]-[21]. The study was planned to check different levels of feedstock/inoculum ratio (F/I) and waste paper/macroalgal (WP/MA) mixing percentages. 


\section{$2 \quad$ Materials and Methods}

\subsection{Feedstock and inoculum}

Pelvetia Canaliculata, a brown macroalgae commonly known as channelled wrack, was collected on-shore in Rothesay (Isle of Bute, Scotland) in March 2016 and store in a fridge at $4^{\circ} \mathrm{C}$ and used within 4 days. Waste paper was collected from recycle bins at the School of Computing and Engineering at the University of West of Scotland (UWS) in Paisley, Scotland. The sludge used as inoculum was provided by the Strathendrick Biogas Plant (Balfron, Scotland).

\subsection{Biomethane potential test}

Erlenmeyer flasks of $500 \mathrm{ml}$ with a working volume of $400 \mathrm{ml}$ were used as bioreactors; the biogas was collected in airtight Linde PLASTIGAS bags. Nitrogen was flushed into the headspace of each reactor to preserve the anaerobic conditions and clear up any trace of oxygen from the system. The bioreactors were placed in a water-bath to maintain the mesophilic temperature at $37^{\circ} \mathrm{C}$. Average results were reported in this paper from duplicated tests. Methane yields are given for a dry gas in standard conditions of temperature $\left(0^{\circ} \mathrm{C}\right)$ and pressure $(1 \mathrm{~atm})$.

\subsection{Kinetics modelling}

The methane production is simulated with a first order model as described as follows:

$$
M(t)=F\left(1-e^{-k t}\right)
$$

where $\mathrm{M}(\mathrm{t})$ is the cumulative methane yield ( $\mathrm{ml} / \mathrm{gVS}$ ), $\mathrm{F}$ is the maximum methane production $(\mathrm{ml} / \mathrm{gVS}), \mathrm{k}$ is the methane production rate constant $(\mathrm{d}-1)$, and $\mathrm{t}$ is the time (d).

\subsection{Methane production potential}

Buswell equation provides stoichiometric calculation on the products from the anaerobic breakdown of a generic organic material of chemical composition $\mathrm{C}_{n} \mathrm{H}_{\mathrm{a}} \mathrm{O}_{\mathrm{b}} \mathrm{N}_{\mathrm{n}} \mathrm{S}_{\mathrm{s}}$, calculated based on the yield estimates of carbohydrates, lipids, and proteins [22]:

$$
\begin{aligned}
& \mathrm{C}_{c} \mathrm{H}_{h} \mathrm{O}_{o} \mathrm{~N}_{n} S_{s}+\frac{1}{4}(4 c-h-2 o+3 n+2 s) \mathrm{H}_{2} \mathrm{O} \rightarrow \\
& \frac{1}{8}(4 c-h+2 o+3 n+2 s) \mathrm{CH}_{4}+ \\
& \frac{1}{8}(4 c+h 22 o-3 n-2 s) \mathrm{CO}_{2}+n \mathrm{NH}_{3}+n S_{2} \mathrm{~N}
\end{aligned}
$$


$10^{\mathrm{TH}}$ InTERnATIONAL CONFERENCE ON Sustainable ENERGy AND ENVIRONMENTAL Protection (June $27^{\mathrm{TH}}-30^{\mathrm{TH}}, 2017$, Bled, Slovenia), Bioenergy AND Biofuels

C. Rodriguez, Z. El-Hassan \& A. G. Olabi: Enhanced Methane Production from Waste Paper Through Anaerobic Co-Digestion with Macroalgae

The equation is derived by balancing the total conversion of the organic material mainly to $\mathrm{CH} 4$ and $\mathrm{CO} 2$ with $\mathrm{H} 2 \mathrm{O}$ as the only external source as under anaerobic conditions. From this equation, the biodegradability index could be determined. The biodegradability index (BI) is defined as the ratio of the experimental methane yield to the theoretical methane yield (from the Buswell equation).

3

\section{Results and Discussion}

\subsection{Methane production rate and yield}

The experiments were carried out at three different feedstock/inoculums (F/I) ratios $(0.2$, 0.3 and 0.4 ) and five mixing condition of waste paper and macroalgae (WP/MA ratio), 0:100 (mono-digestion of macroalgae), 25:75, 50:50, 75:25 and 100:0 (mono-digestion of paper). The experimental conditions of the assays are shown in Table 1. Reactor with a WP/MA ratio 50:50 produced the highest methane yields for the three F/I ratios studied over a 28-day period, with a maximum value of $386 \mathrm{ml} / \mathrm{gVS}$ for an F/I 0.2 which represents an increase of $30 \%$ compare with mono-digestion of algae and $22 \%$ with mono-digestion of waste paper. At higher $\mathrm{F} / \mathrm{I}$ ratios the increase in methane yield of WP/MA 50:50 compared with digestion of single substrates is even higher (48\% and 50\% compared with WP/MA 0:100 and 100:0 respectively for an F/I ratio 0.4). Although the effect of 50:50 co-digestion is more noticeable at higher F/I ratios, the methane yield increased with decreasing $\mathrm{F} / \mathrm{I}$ ratios regardless the ratio of substrates mixture. An optimum $\mathrm{F} / \mathrm{I}$ ratio ensures the presence of the groups of microorganisms required for the complete anaerobic digestion. Knowing the optimum F/I ratio allows a better exploitation of the feedstock. Feeding the reactor with high quantities of biomass that the inoculum is not able to process lead to a loss of feedstock, that is not digested [23]. Similar results were achieved on the anaerobic degradation of sunflower oil cake, with methane yield decreasing considerably from 227 to $107 \mathrm{ml} / \mathrm{gVS}$ when the $\mathrm{F} / \mathrm{I}$ increased from 0.33 to 2, showing a marked influence of this parameter on methane yield [24]. A decrease in methane yield in the range of 4\% (WP/MA 50:50) to 22\% (WP/MA 100:0) was found when comparing F/I 0.3 with F/I 0.2. Results from kinetic modelling of waste paper and macroalgae co-digestion are shown in Table 1; faster degradation rates, indicated by higher methane production rate $(\mathrm{k})$ were achieved for co-digestion test compared with mono-digestion. WP/MA of 50/50 achieved the highest methane production rate for the three different $\mathrm{F} / \mathrm{I}$ ratios with a maximum $\mathrm{k}$ of $0.23 \mathrm{~d}^{-1}$ at a $\mathrm{F} / \mathrm{I}$ ratio of 0.2 . Higher methane production rate constants were achieved from WP/MA of 15/75 and 25/75 compared with the mono-digestion test even though the increase in methane yields was not significantly high. Constant rates increased with decreasing $\mathrm{F} / \mathrm{I}$ ratios for feedstock mono-digestion and co-digestion at 50:50. For WP/MA ratios of 25:75 and 75:25, no evident trend can be noticed on kinetic constants with F/I variation, the values maintains constants around $0.16 \pm 0.2 \mathrm{~s}-1$. 
$10^{\mathrm{TH}}$ InTERNATIONAL CONFERENCE ON SUSTAINABLE ENERGY AND ENVIRONMENTAL

Protection (June $27^{\mathrm{TH}}-30^{\mathrm{TH}}, 2017$, Bled, Slovenia), Bioenergy AND Biofuels

C. Rodriguez, Z. El-Hassan \& A. G. Olabi: Enhanced Methane Production from Waste Paper Through Anaerobic Co-Digestion with Macroalgae

Table 1. Experimental results obtained at the end of the biodegradability tests

\begin{tabular}{ccccc}
\hline F/I & WP/MA & C/N & $\begin{array}{c}\mathrm{CH}_{4} \text { yield } \\
(\mathrm{ml} / \mathrm{gVS})\end{array}$ & $\mathrm{k}\left(\mathrm{s}^{-1}\right)$ \\
\hline \multirow{4}{*}{0.2} & $0: 100$ & 15 & 297 & 0.16 \\
& $25: 75$ & 18 & 341 & 0.18 \\
& $50: 50$ & 26 & 386 & 0.23 \\
& $75: 25$ & 42 & 325 & 0.13 \\
& $100: 0$ & 123 & 316 & 0.17 \\
\hline \multirow{6}{*}{0.3} & $0: 100$ & 15 & 250 & 0.10 \\
& $25: 75$ & 18 & 294 & 0.15 \\
& $50: 50$ & 26 & 370 & 0.18 \\
& $75: 25$ & 42 & 280 & 0.15 \\
0.4 & $100: 0$ & 123 & 247 & 0.14 \\
\hline \multirow{6}{*}{0.100} & 15 & 163 & 0.11 \\
& $25: 75$ & 18 & 207 & 0.16 \\
& $50: 50$ & 26 & 257 & 0.16 \\
& $75: 25$ & 42 & 185 & 0.15 \\
& $100: 0$ & 123 & 193 & 0.08 \\
\hline
\end{tabular}

\subsection{Feedstock elemental composition}

In Table 2 is detailed the characterization of the macroalgae and the waste paper. The contents of elemental carbon, nitrogen and hydrogen were measured by elemental analysis while the oxygen content of the samples was estimated by subtracting carbon, hydrogen, nitrogen and ash content from the total solids [25]. Carbon content is similar for both feedstocks, macroalgae contents $52 \%$ more hydrogen and $776 \%$ more nitrogen than waste paper, note than nitrogen in waste paper is almost a trace material. Optimum levels of $\mathrm{C} / \mathrm{N}$ ratio for anaerobic digestion are in the range 20 to 30 [15]. Digestion of nitrogenous substrates $(\mathrm{C} / \mathrm{N}$ ratio less than 15$)$ can lead to problematic digestion caused by excess levels of ammonia, increasing the $\mathrm{pH}$ levels in the digester leading to a toxic effect on methanogens population. $\mathrm{C} / \mathrm{N}$ for macroalgae mono-digestion was 15 while for waste paper the $\mathrm{C} / \mathrm{N}$ ratio was 123 (Table 1). Highers methane yields were obtained at WP/MA 50:50 (386 ml/gVS for F/I 0.2, $369 \mathrm{ml} / \mathrm{gVS}$ for F/I 0.3 and $357 \mathrm{ml} / \mathrm{gVS}$ for F/I 0.4 ) which correspond to a $\mathrm{C} / \mathrm{N}$ ratio of 26 , these findings corroborate the optimum levels given for anaerobic digestion process.

Table 2. Feedstock and co-digestion ratio elemental composition

\begin{tabular}{lcc}
\hline Parameters & MA & WP \\
\hline Total Solids (\%) & 6.17 & 2.55 \\
Volatile Solids (\% of TS) & 80.18 & 97.30 \\
Ash content (\%) & 19.82 & 2.70 \\
Carbon (\% of TS) & 38.15 & 36.87 \\
Hydrogen (\% of TS) & 5.48 & 3.61 \\
Nitrogen (\% of TS) & 2.63 & 0.30 \\
Oxygen (\% of TS) & 34.32 & 56.52 \\
\hline
\end{tabular}


$10^{\mathrm{TH}}$ InTERnAtional CONFERENCE ON Sustainable EnERgy AND ENVIRONMENTAL Protection (June $27^{\mathrm{TH}}-30^{\mathrm{TH}}, 2017$, BLed, Slovenia), Bioenergy AND Biofuels

C. Rodriguez, Z. El-Hassan \& A. G. Olabi: Enhanced Methane Production from Waste Paper Through Anaerobic Co-Digestion with Macroalgae

Methane yields form reactors at WP/MA 25/75 and 75/25 (C/N ratios 18 and 42 respectively) are similar with differences less than $13 \%$. $\mathrm{C} / \mathrm{N}$ ratio of 18 (correspondent WP/MA 25/75) achieved $15 \%$ and $27 \%$ extra methane than mono-digestion of algae for $\mathrm{F} / \mathrm{I}$ ratios of 0.2 and 0.4 respectively, compared with waste paper digestion these values were around $8 \%$. Smaller increases were found for $\mathrm{C} / \mathrm{N}$ ratio of 45 (correspondent WP/MA 75/25), where for the lowest F/I ratio, the increase on methane yield compared to macroalgae digestion was $9 \%$ and for the highest $\mathrm{F} / \mathrm{I}$ ratio was $13 \%$. Compared with a $\mathrm{C} / \mathrm{N}$ of 123 (waste paper), a $\mathrm{C} / \mathrm{N}$ of 42 achieved similar methane yields.

\subsection{Synergistic or antagonistic effect}

Co-digestion can result in a positive effect (named synergistic effect) on the degradation of each individual substrate in the mixture and/or an increase in the methane yield kinetics [26]. This improvement may arise from the contribution of additional alkalinity, nutrients, enzymes and trace elements that a feedstock by itself may lack and an increased buffering capacity in. Evenly allocated nutrients in co-digestion would support microbial growth for efficient digestion, while increased buffering capacity would help maintain the stability of the anaerobic digestion system [27]. Synergistic effect is evaluated based on the weighted methane yield from the mixture co-digestion (Equation 3), calculated as the sum of the products of the methane yield of each individual substrate multiplied by its percentage in the mixture.

Wieghted $\mathrm{CH}_{4}$ yield $=\mathrm{CH}_{4}$ yield $(\mathrm{WP}) * \% \mathrm{WP}$

$+\mathrm{CH}_{4}$ yield (MA)*\%MA

Table 3 summarizes this analysis for co-digestion mixtures of waste paper with macroalgae $P$. Canaliculata, showing the differences between the methane yields from co-digestion samples and the weighted methane yields calculated from Equation 3. A synergistic effect was found for co-digestion ratio of WP/MA 50:50 at the three different $\mathrm{F} / \mathrm{I}$ ratios, with an improvement of $44 \%$ on methane yield for high $\mathrm{F} / \mathrm{I}$ ratio while a $15 \%$ on low F/I ratio. The increase of cellulase activity when waste paper is present in the mixture is a possible reason of the increased methane yield. Cellulose hydrolysis is considered the rate-limiting step in the anaerobic digestion of high cellulosic content biomass. It was suggested that the presence of waste paper in the digestion might induce cellulase excretion by bacteria such as Clostridium themocellum [28]. 
$10^{\mathrm{TH}}$ INTERNATIONAL CONFERENCE ON SUSTAINABLE ENERGY AND ENVIRONMENTAL

Protection (June $27^{\mathrm{TH}}-30^{\mathrm{TH}}, 2017$, BLed, Slovenia), Bioenergy AND Biofuels

C. Rodriguez, Z. El-Hassan \& A. G. Olabi: Enhanced Methane Production from Waste Paper Through Anaerobic Co-Digestion with Macroalgae

Table 3. Co-digestion effect for waste paper and macroalgae and biodegradability index

\begin{tabular}{ccccccc}
\hline F/I & WP/MA & $\begin{array}{c}\text { Theoretical } \mathrm{CH}_{4} \\
\text { yield (Buswell eq) }\end{array}$ & BI & $\begin{array}{c}\text { Weighted } \\
\mathrm{CH}_{4} \text { yield }\end{array}$ & $\begin{array}{c}\text { Increasing on } \\
\mathrm{CH}_{4} \text { yield (\%) }\end{array}$ & Effect \\
\hline \multirow{4}{*}{0.2} & $0: 100$ & 436 & 0.68 & 297 & 0 & n/a \\
& $25: 75$ & 441 & 0.77 & 302 & 11 & Synergistic \\
& $50: 50$ & 446 & 0.87 & 307 & 21 & Synergistic \\
& $75: 25$ & 450 & 0.72 & 311 & 4 & Synergistic \\
& $100: 0$ & 455 & 0.69 & 316 & 0 & $\mathrm{n} / \mathrm{a}$ \\
\hline \multirow{4}{*}{0.3} & $0: 100$ & 436 & 0.57 & 250 & 0 & $\mathrm{n} / \mathrm{a}$ \\
& $25: 75$ & 441 & 0.67 & 249 & 15 & Synergistic \\
& $50: 50$ & 446 & 0.83 & 249 & 33 & Synergistic \\
& $75: 25$ & 450 & 0.62 & 248 & 12 & Synergistic \\
& $100: 0$ & 455 & 0.54 & 247 & 0 & $\mathrm{n} / \mathrm{a}$ \\
\hline \multirow{4}{*}{0.4} & $0: 100$ & 436 & 0.37 & 163 & 0 & $\mathrm{n} / \mathrm{a}$ \\
& $25: 75$ & 441 & 0.47 & 171 & 17 & Synergistic \\
& $50: 50$ & 446 & 0.58 & 178 & 31 & Synergistic \\
& $75: 25$ & 450 & 0.41 & 186 & 0 & $\mathrm{n} / \mathrm{a}$ \\
& $100: 0$ & 455 & 0.42 & 193 & 0 & $\mathrm{n} / \mathrm{a}$ \\
\hline
\end{tabular}

Smaller increases in methane yield were found on samples WP/MA 25:75 and 75:25 compared with their weighted methane yields. Increasing in methane yield and the synergistic effect increased with increasing F/I ratio for WP/MA 25:75 (11\% increase on methane yield for F/I 0.2 and 17\% for F/I 0.4). While for WP/MA 75:25 the synergistic effect was null for $\mathrm{F} / \mathrm{I}$ ratios of 0.2 and 0.4 and an increase on methane yield of $12 \%$ was achieved for F/I 0.3 . Similar synergistic results were found on the co-digestion of primary sludge and paper pulp reject with an improvement of 32\% on methane yield [43] and the co-digestion of Taihu blue algae with corn straw (up to 60\% extra methane) [40].

\subsection{Theoretical methane yield}

Table 3 summarizes the theoretical methane yields obtained from the Buswell equation (Equation 3) the BI for the co-digestion of waste paper and macroalgae. Biodegradability index increases with decreasing $\mathrm{F} / \mathrm{I}$ ratios, with a maximum percentage of degradation of $87 \%$ at a F/I 0.2 and WP/MA 50:50. Studies have shown that the Buswell formula does not account for around $12-15 \%$ of the organic matter fed to the reactor as this is consumed by the cell protoplasm [41], [44], so the $87 \%$ of degradation for a $50 \%$ mixture waste paper and macroalgae means a complete degradation of the substrate. For a F/I of 0.3 , the BI of WP/MA 50:50 reactor is still high (0.83), but a big decreased is found for F/I 0.4 (0.58). For mono-digestion of macroalgae, BI range from 0.68 for low F/I and 0.37 for high F/I. Similar values were found for mono-digestion of waste paper, with a BI of 0.69 for $0.2 \mathrm{~F} / \mathrm{I}$ and 0.42 for $0.4 \mathrm{~F} / \mathrm{I}$. Reactors with WP/MA of 27:75 and 75:25 showed comparable behaviour on their $\mathrm{BI}$, ranging from $0.44 \pm 0.3$ for high $\mathrm{F} / \mathrm{I}$ to $0.74 \pm 0.02$ for low F/I. 
8 10 $10^{\text {TH }}$ International Conference on Sustainable Energy and Environmental Protection (June $27^{\mathrm{TH}}-30^{\mathrm{TH}}, 2017$, BLed, Slovenia), Bioenergy AND Biofuels

C. Rodriguez, Z. El-Hassan \& A. G. Olabi: Enhanced Methane Production from Waste Paper Through Anaerobic Co-Digestion with Macroalgae

\section{Conclussion}

Mixing rate of 50:50 achieved a maximum methane yield of $386 \mathrm{ml} / \mathrm{gVS}$ for a F/I of 0.2. The biodegradability index of 0.87 indicates a complete conversion of the feedstock at a $\mathrm{C} / \mathrm{N}$ ratio of 26 . The anaerobic biodegradability of the mixture decreases with increasing F/I ratio, which indicates a better performance of the process and better exploitation of the biomass. Synergistic effect was found for 25:75, 50:50 and 75:25 mixing ratios compared with the mono-digestion of waste paper and macroalgae. These results showed that co-digestion of waste paper with macroalgae P. Canaliculata at low F/I ratios is an efficient option for methane production and waste management.

\section{References}

[1] Council of the European Union, "Directive 2009/28/EC of the European Parliament and of the Council of 23 April 2009 on the promotion of the use of energy from renewable sources and amending and subsequently repealing Directives 2001/77/EC and 2003/30/EC," 2009.

[2] T. Wilberforce, A. Alaswad, A. Palumbo, M. Dassisti, and A. G. Olabi, "Advances in stationary and portable fuel cell applications," Int. J. Hydrogen Energy, vol. 41, no. 37, pp. 16509-16522, 2015.

[3] T. Wilberforce, A. Al Makky, A. Baroutaji, R. Sambi, and A. G. Olabi, "Computational Fluid Dynamic simulation and modelling (CFX) of flow plate in PEM fuel cell using aluminum open cellular foam material," in 2017 IEEE Texas Power and Energy Conference (TPEC), 2017, pp. 1-6.

[4] The Bureau of International Recycling, "Ten questions on paper recovery and recycling." [Online]. Available: http://www.bir.org/industry/paper/ten-questions-on-paper-recoveryand-recycling/. [Accessed: 13-Feb-2015].

[5] J. P. Y. Jokela, V. A. Vavilin, and J. A. Rintala, "Hydrolysis rates, methane production and nitrogen solubilisation of grey waste components during anaerobic degradation.," Bioresour. Technol., vol. 96, no. 4, pp. 501-8, Mar. 2005.

[6] J. M. Owens and D. P. Chynoweth, "Biochemical methane potential of Municipal Solid Waste (MSW) components," vol. 27, no. 2, Jan. 1993.

[7] W. Xiao and W. W. Clarkson, "Acid solubilization of lignin and bioconversion of treated newsprint to methane," Biodegradation, vol. 8, no. 1, pp. 61-66.

[8] W. E. Eleazer, W. S. Odle, Y.-S. Wang, and M. A. Barlaz, "Biodegradability of Municipal Solid Waste Components in Laboratory-Scale Landfills," Environ. Sci. Technol., vol. 31, no. 3, pp. 911-917, Mar. 1997.

[9] X. Yuan, Y. Cao, J. Li, B. Wen, W. Zhu, X. Wang, and Z. Cui, "Effect of pretreatment by a microbial consortium on methane production of waste paper and cardboard.," Bioresour. Technol., vol. 118, pp. 281-8, Aug. 2012.

[10] A. Ajeej, J. V Thanikal, C. M. Narayanan, and R. Senthil Kumar, "An overview of bio augmentation of methane by anaerobic co-digestion of municipal sludge along with microalgae and waste paper," Renew. Sustain. Energy Rev., vol. 50, pp. 270-276, Oct. 2015.

[11] P. Stroot, "Anaerobic codigestion of municipal solid waste and biosolids under various mixing conditions-I. digester performance," Water Res., vol. 35, no. 7, pp. 1804-1816, May 2001.

[12] J. Zhu, Y. Zheng, F. Xu, and Y. Li, "Solid-state anaerobic co-digestion of hay and soybean 
$10^{\mathrm{TH}}$ InTERNATIONAL CONFERENCE ON SUSTAINABLE ENERGY AND ENVIRONMENTAL

Protection (June $27^{\mathrm{TH}}-30^{\mathrm{TH}}, 2017$, BLED, Slovenia), Bioenergy AND Biofuels

C. Rodriguez, Z. El-Hassan \& A. G. Olabi: Enhanced Methane Production from Waste Paper Through Anaerobic Co-Digestion with Macroalgae

processing waste for biogas production.," Bioresour. Technol., vol. 154, pp. 240-7, Feb. 2014.

[13] J. V. Oliveira, M. M. Alves, and J. C. Costa, "Design of experiments to assess pre-treatment and co-digestion strategies that optimize biogas production from macroalgae Gracilaria vermiculophylla," Bioresour. Technol., vol. 162, pp. 323-330, 2014.

[14] M. O. L. Yusuf and N. L. Ify, "The effect of waste paper on the kinetics of biogas yield from the co-digestion of cow dung and water hyacinth," Biomass and Bioenergy, vol. 35, no. 3, pp. 1345-1351, Mar. 2011.

[15] H.-W. Yen and D. E. Brune, "Anaerobic co-digestion of algal sludge and waste paper to produce methane," Bioresour. Technol., vol. 98, no. 1, pp. 130-134, 2007.

[16] L. Castrillón, Y. Fernández-Nava, P. Ormaechea, and E. Marañón, “Optimization of biogas production from cattle manure by pre-treatment with ultrasound and co-digestion with crude glycerin.," Bioresour. Technol., vol. 102, no. 17, pp. 7845-9, Sep. 2011.

[17] F. Wang, T. Hidaka, and J. Tsumori, "Enhancement of anaerobic digestion of shredded grass by co-digestion with sewage sludge and hyperthermophilic pretreatment.," Bioresour. Technol., vol. 169, pp. 299-306, Oct. 2014.

[18] S. Park and Y. Li, "Evaluation of methane production and macronutrient degradation in the anaerobic co-digestion of algae biomass residue and lipid waste.," Bioresour. Technol., vol. 111, pp. 42-8, May 2012.

[19] C. Rodriguez, A. Alaswad, Z. El-Hassan, and A. Olabi, "Optimization of Anaerobic Digestion for Mechanically Pretreated Waste Paper," in 11th Conference on Sustainable Development of Energy, Water and Environment Systems, SDEWES, 2016, p. 0678 1-13.

[20] C. Rodriguez, A. Alaswad, Z. El-Hassan, and A. Olabi, "Optimization of the anaerobic digestion process of mechanically pretreated algae," in 11th Conference on Sustainable Development of Energy, Water and Environment Systems, SDEWES, 2016, p. 0679 1-12.

[21] C. Rodriguez, A. Alaswad, T. Prescott, and A. G. Olabi, "Effects of Mechanical Pretreatment on Biogas Production from Waste Paper," in Proceedings of the 8th International Conference on Sustainable Energy \& Environmental Protection - Part 1, 2015, no. August, pp. 1-6.

[22] A. M. Buswell and H. F. Mueller, "Mechanism of Methane Fermentation," Ind. Eng. Chem., vol. 44, no. 3, pp. 550-552, Mar. 1952.

[23] F. Ali Shah, Q. Mahmood, M. Maroof Shah, A. Pervez, and S. Ahmad Asad, "Microbial ecology of anaerobic digesters: the key players of anaerobiosis.," ScientificWorldJournal., vol. 2014, p. 183752, 2014.

[24] F. Raposo, R. Borja, B. Rincon, and A. M. Jimenez, "Assessment of process control parameters in the biochemical methane potential of sunflower oil cake," Biomass and Bioenergy, vol. 32, no. 12, pp. 1235-1244, 2008.

[25] P. P. Nieto, D. Hidalgo, R. Irusta, and D. Kraut, "Biochemical methane potential (BMP) of agro-food wastes from the Cider Region (Spain)," Water Sci. Technol., vol. 66, no. 9, p. 1842, Aug. 2012.

[26] J. Mata-Alvarez, J. Dosta, M. S. Romero-Güiza, X. Fonoll, M. Peces, and S. Astals, "A critical review on anaerobic co-digestion achievements between 2010 and 2013," Renew. Sustain. Energy Rev., vol. 36, pp. 412-427, 2014.

[27] W. Zhong, Z. Zhang, Y. Luo, W. Qiao, M. Xiao, and M. Zhang, "Biogas productivity by co-digesting Taihu blue algae with corn straw as an external carbon source," Bioresour. Technol., vol. 114, pp. 281-286, 2012.

[28] M. Suto and F. Tomita, "Induction and catabolite repression mechanisms of cellulase in fungi,” J. Biosci. Bioeng., vol. 92, no. 4, pp. 305-311, Jan. 2001. 
$10 \quad 10^{\mathrm{TH}}$ International Conference on Sustainable Energy and Environmental Protection (June $27^{\mathrm{TH}}-30^{\mathrm{TH}}, 2017$, Bled, Slovenia), Bioenergy AND Biofuels 
$10^{\mathrm{TH}}$ InTERnational CONFERENCE ON Sustainable ENERgy AND ENVIRONMENTAL Protection (June $27^{\mathrm{TH}}-30^{\mathrm{TH}}$, 2017, Bled, SLOVENIA), BIOENERGY AND BIOFUELS

J. Krope, A.Ghani Olabi, D. Goričanec \& S. Božičnik

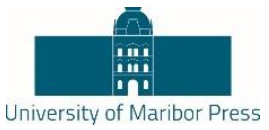

\title{
Biogas Production from Three-Phase Olive Mill Solid Waste in Lab-Scale Continuously Stirred Tank Reactor
}

\author{
RAFAT AL AFIF \& BERND LINKE
}

\begin{abstract}
Biogas production of three-phase olive mill solid waste (3POMSW) was studied in lab-scale continuously stirred tank reactors (CSTR) at organic loading rates of $1.5-2.0 \mathrm{~g}$ VS $\mathrm{L}-1 \mathrm{~d}-1$ and temperatures of 35 and $55^{\circ} \mathrm{C}$. In order to improve the biogas yield, the effect of adding an enzyme (MethaPlus ${ }^{\circledR}$ ) was investigated. Results have shown that thermophilic processing increased the biogas yield by about $8 \%$ compared to results at mesophilic condition. Moreover, adding an enzyme to $3 \mathrm{POMSW}$ at $55^{\circ} \mathrm{C}$ helped in stabilizing the process and increased the cumulative biogas production. On the other hand, addition of the enzyme under mesophilic condition did not have a significant effect on biogas yield and reactor performance. The methane concentrations in biogas for all experiments ranged from 50.0 to $57.8 \%$. However, long term experiments have shown beginning reactor failure.
\end{abstract}

Keywords: - Biogas - Three-phase olive mill solid waste - CSTR • Addition of enzyme • Thermophilic condition •

CoRrespondence AdDress: Rafat Al Afif, Ph.D., Associate Professor, University of Natural Resources and Life Sciences, Institute of Chemical and Energy Engineering, Muthgasse 107, 1190 Vienna, Austria, e-mail: rafat.alafif@boku.ac.at. Bernd Linke, Ph.D., Professor, Leibniz-Institute for Agricultural Engineering, Department Bioengineering, Max-Eyth-Allee 100, D-14469 Potsdam-Bornim, Germany, e-mail: blinke@atb-potsdam.de. 
12 10 $10^{\mathrm{TH}}$ International Conference on Sustainable EnERgy and Environmental Protection (June $27^{\mathrm{TH}}-30^{\mathrm{TH}}, 2017$, BLed, Slovenia), BioENERGy AND Biofuels

R. Al Afif \& B. Linke: Biogas Production from Three-Phase Olive Mill Solid Waste in Lab-Scale Continuously Stirred Tank Reactor

Introduction

One major environmental concern in Mediterranean countries is the management of olive mill waste generated by the olive oil producing industry. Olive oil production is a very important economic activity, particularly for Spain, Italy, Greece and Syria. Waste from production is also contributing to substantial environmental problems of current concern in the Mediterranean basin. The traditional three-phase continuous centrifugation process generally yields an oily phase (20\%), a solid residue (30\%), and an aqueous phase (50\%). Large quantities of water, needed for carrying out the three-phase process, generate a high volume of olive mill wastewater. In some countries, the "ecological friendly" twophase process was developed. The quantity of water required to carry out the two-phase process is much lower than for the three-phase process and thus a considerable reduction in two-phase olive mill wastewater is achieved. However, the two-phase process led to a slight increase in solid waste. The amount of two-phase olive mill solid waste (2POMSW) is $60 \%$ larger than that from the three-phase system (3POMSW). Currently, both elaboration systems, three- and two-phase, coexist in the Mediterranean area [1]. Spain, the largest producer of olive oil in the world, currently uses the two-phase system in $98 \%$ of its olive mills. In other olive oil producing countries such as Cyprus, Portugal and Italy, only around 5\% of the mills use the two-phase system [2]. Other large producers such as Greece, Turkey, Tunisia and Syria have continued using mainly the three-phase system, but the two-phase system is introduced slowly. The high quantities of waste produced in both systems makes a sustainable treatment necessary.

Yet there is still no established environmentally acceptable treatment and recycling method available for the waste generated during olive oil production, not only due to technical and economical limitations, but also due to the scattered nature of olive mills across the Mediterranean basin [3]. Traditional methods such as composting and incineration are not suitable to process the solid organic waste for different reasons: On the one hand, solid waste contains too small concentrations of nitrogen for composting and too large amounts of solid grain for complete decomposition. On the other hand, smoke and exhaust emission from incineration cause environmental pollution. Therefore, the utilization of potential anaerobic treatments for biogas production appear to be particularly interesting. As a renewable and sustainable source of energy, several countries have used biogas as a preferred option [4]. Furthermore, use of sludge on arable land can provide both N, P and other nutrients and therefore contribute to the recycling of nutrients in agricultural production, which is consistent with the aim of developing a circular economy, and can also contribute to maintaining the concentration of soil organic carbon (SOC) [5]. The solid waste from three-phase olive oil industry (3POMSW) is rich in carbohydrates and organic matter, and thus it could be an ideal substrate for production of energy in the form of hydrogen and methane [6]. Recently, Al Afif and Amon demonstrated that $3 \mathrm{POMSW}$ is a very suitable substrate for methane production with approximately $139 \mathrm{~L} \mathrm{~kg}-1 \mathrm{VS} / 60 \mathrm{~d}$ [7], also they indicated that there is a possibility to obtain more methane from 3POMSW, since the coefficient of anaerobic energy turnover was $22.6 \%$. Thus additional experiments are necessary to further improve the methane production potential from 3POMSW. It is worth noting that special 
$10^{\mathrm{TH}}$ INTERNATIONAL CONFERENCE ON SUSTAINABLE ENERGY AND ENVIRONMENTAL

emphasis for biogas reactor processing is given to the organic loading rate (OLR) for both mono-substrate and co-substrate. In case of higher OLRs, the accumulation of volatile fatty acids (VFA) results in inhibition of anaerobic digestion because of $\mathrm{pH}$ drop [8]. On the other hand, some studies have indicated that high olive mill waste digestion efficiencies can be achieved by pre-treating the waste [9]. In recent studies on improving biogas production within continuously stirred tank reactors (CSTR), co-fermentation of two-phase olive mill solid waste with food waste [10] or pig slurry [11] were analysed. However, the anaerobic digestion of olive pulp from three-phase olive mill industries with specific enzymes utilizing CSTR has not been studied before. Reviewing previous works emphasized that anaerobic digestion in CSTR will be one of the preferred processes and it was generally considered that for degradation of 3POMSW hydrolysis is the rate-limiting step. The objective of this study is to investigate the effects of temperature and specific enzymes on biogas production from 3POMSW in continuously stirred tank reactors.

\section{$2 \quad$ Material and Methods}

\subsection{Raw material}

Three-phase olive mill solid waste (3POMSW) from various Syrians olive-mills was used as sun-dried material. Before digestion, the 3POMSW was milled into particle size in the range of $0.1-0.3 \mathrm{~cm}$ and stored in air tight containers at room temperature until used for experiments.

Nutrient compositions of 3POMSW and inoculum were determined by analyzing the following ingredients: Total solids (TS), volatile solids (VS), total Kjeldahl nitrogen (TKN), crude fat (XL), crude fibre (XF), and starch (XS). These analyses were performed according to the German standard methods [12]. The results of the chemical analyses are presented in Table 1 (3POMSW: three-phase olive mill solid waste; TM: dry matter; VS: volatile solids. All amounts, except $\mathrm{pH}$ and VS are expressed in $\mathrm{g} \mathrm{kg}-1$. VS are expressed in percentage $\%$ of fresh mass).

Table 1. Chemical analysis of inoculum and three-phase olive mill solid waste

\begin{tabular}{lll}
\hline Parameter & Inoculum & 3POMSW \\
\hline DM / fresh mass & 32.8 & 941 \\
VS \% DM & 60.6 & 97.9 \\
pH & 8.02 & 5.28 \\
Total Kjeldahl nitrogen & 2.71 & 8.65 \\
Crude fibre & - & 485 \\
Starch & - & 26.6 \\
Crude fat & - & 59.0 \\
\hline
\end{tabular}


$14 \quad 10^{\mathrm{TH}}$ International CONFERENCE ON Sustainable EnERgy AND ENVIRONMENTAL Protection (June $27^{\mathrm{TH}}-30^{\mathrm{TH}}, 2017$, BLED, SLOVENiA), Bioenergy AND Biofuels

R. Al Afif \& B. Linke: Biogas Production from Three-Phase Olive Mill Solid Waste in Lab-Scale Continuously Stirred Tank Reactor

\subsection{Supplemental enzyme}

Obtaining maximum methane yield from solid substrates requires some form of optimization process of biodegradation. The breaking up of long-chain molecules, either physical or biochemical, is essential for biogas production.

There are many advantages of using supplemental microbial enzymes in the process of biodegradation, when they have been specifically selected on the basis of each enzyme's unique characteristics [13]. The enzyme, which has been tested in the experiments, was MethaPlus ${ }^{\circledR}$. This enzyme was provided by Biopract $\mathrm{GmbH}$ and chosen on its ability to be catalysed at mesophilic and thermophilic temperature. MethaPlus ${ }^{\circledR}$ belongs to the group of cellulose enzyme complexes of Trichoderma Reesei for application in biogas plants and has its major impact on cellulose degradation into glucose, cellobiose and oligomeres groups.

\subsection{Operation of CSTR}

All lab-scale experiments regarding the anaerobic digestion of 3POMSW with and without enzyme were carried out in continuously stirred tank reactors (CSTR) with a total volume of 8 litres for each reactor.

Over a period of 100 days, the reactors were operated in a daily fill, draw mode, and mixed slowly by a stirrer at ca. $100 \mathrm{~min}-1$ for $15 \mathrm{~min}$ every 2 hours. The constant temperatures of 35 and $55^{\circ} \mathrm{C}$ were maintained by a thermostat controlled heated water jacket. The biogas was collected in a gasbag, measured daily by a multi-chamber rotor gas meter (Ritter, Bochum, Germany), and normalized at the standard temperature and pressure $\left(0{ }^{\circ} \mathrm{C}, 1013\right.$ mbar $)$. The methane content of the biogas was analysed twice a week by a gas analyser (Pronova, Berlin, Germany). The experiments of anaerobic digestion were carried out in accordance with VDI standard 4630 [14].

\section{Description of start-up phase}

For acclimation of micro-organisms to 3POMSW, two CSTRs, R-35 and R-55, were filled with inoculum (digested from animal slurry and plant material) and processed at 35 and $55{ }^{\circ} \mathrm{C}$, respectively, for 40 days, starting with OLR of $0.5 \mathrm{~g}$ VS L-1 d-1 with a stepwise increase to $1.5 \mathrm{~g} \mathrm{VS} \mathrm{L}-1 \mathrm{~d}-1$ (Fig. 1). 
$10^{\mathrm{TH}}$ INTERNATIONAL CONFERENCE ON SUSTAINABLE ENERGY AND ENVIRONMENTAL

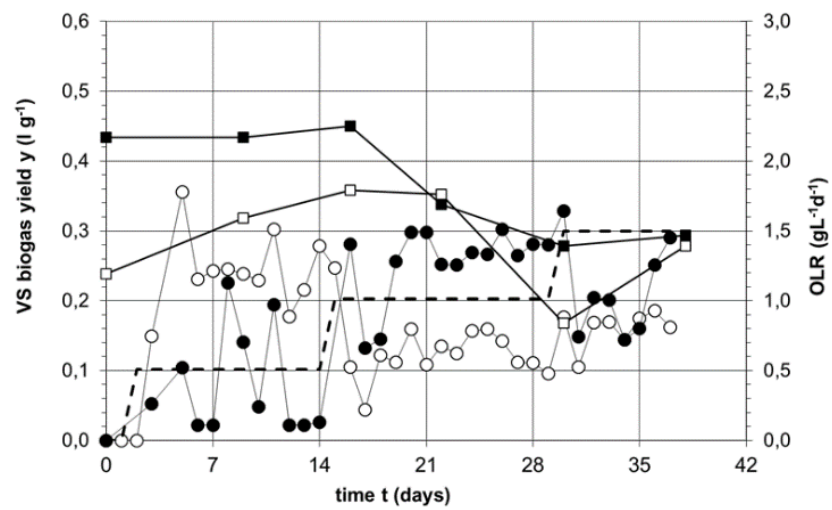

Fig. 1 Reactor performance during start-up phase: $\bigcirc$ y $35^{\circ} \mathrm{C}, \bigcirc$ y $55^{\circ} \mathrm{C}, \square$ VFA $35^{\circ} \mathrm{C}$, - VFA $55^{\circ} \mathrm{C}$, ORL: - -

Due to the high TS content of the 3POMSW, two parts of water (w/w) were added to each part of 3 POMSW. Results showed high biogas yield at $35^{\circ} \mathrm{C}$ at the beginning of acclimation. After three weeks, the biogas yield of the thermophilic reactor was about twice as high as the yield of the mesophilic reactor. Volatile fatty acids (VFA) and $\mathrm{pH}$ were observed in a normal range and did not indicate any process failure. After 40 days, the digested material of the two reactors was used to start the experiments to investigate the effect of supplementing enzyme to 3POMSW on biogas yield. The operational conditions applied to reactors R-35, R-55, R1-35, R2-35, R3-55, and R4-55 are presented in Table 2. (SU: start-up phase; CF: continuous feeding phase). 
16 10 $10^{\mathrm{TH}}$ International Conference on Sustainable EnERgy and Environmental Protection (June $27^{\mathrm{TH}}-30^{\mathrm{TH}}, 2017$, BLED, SLOVENiA), Bioenergy AND Biofuels

R. Al Afif \& B. Linke: Biogas Production from Three-Phase Olive Mill Solid Waste in Lab-Scale Continuously Stirred Tank Reactor

Table 2. Experimental conditions of the anaerobic digestion at different OLRs (*: addition of enzyme after 48 days).

\begin{tabular}{|c|c|c|c|c|c|}
\hline $\begin{array}{l}\text { Pha- } \\
\text { se }\end{array}$ & $\begin{array}{l}\text { Reac- } \\
\text { tor }\end{array}$ & $\begin{array}{l}\mathrm{T} \\
{ }^{\circ} \mathrm{C}\end{array}$ & $\begin{array}{l}\text { Feed } \\
\text { Flow Rate } \\
\left(\mathrm{gVS} \mathrm{d}^{-1}\right)\end{array}$ & $\begin{array}{l}\text { OLR } \\
(\mathrm{gVS} \\
\left.\mathrm{L}^{-1} \mathrm{~d}^{-1}\right)\end{array}$ & $\begin{array}{l}\text { time } \\
\text { (days) }\end{array}$ \\
\hline \multirow{5}{*}{ SU } & \multirow{4}{*}{$\mathrm{R}-35$} & 35 & 4 & 0.5 & $0-14$ \\
\hline & & 35 & 8 & 1 & $15-28$ \\
\hline & & 35 & 12 & 1.5 & $29-40$ \\
\hline & & 55 & 4 & 0.5 & $0-14$ \\
\hline & \multirow[t]{3}{*}{ R-55 } & 55 & 8 & 1 & $15-28$ \\
\hline \multirow{11}{*}{ CF } & & 55 & 12 & 1.5 & $29-40$ \\
\hline & & 35 & 12 & 1.5 & $0-20$ \\
\hline & \multirow[t]{3}{*}{ R1-35 } & 35 & 22 & 2 & $21-48^{*}$ \\
\hline & & 35 & 22 & 2 & $49-102$ \\
\hline & & 35 & 12 & 1.5 & $0-20$ \\
\hline & \multirow{2}{*}{$\mathrm{R} 2-35$} & 35 & 22 & 2 & $21-102$ \\
\hline & & 55 & 12 & 1.5 & $0-20$ \\
\hline & \multirow[t]{3}{*}{ R3-55 } & 55 & 16 & 2 & $21-48^{*}$ \\
\hline & & 55 & 16 & 2 & $49-102$ \\
\hline & & 55 & 12 & 1.5 & $0-20$ \\
\hline & R4-55 & 55 & 22 & 2 & $21-102$ \\
\hline
\end{tabular}

The two reactors R1-35 and R2-35 were filled with mesophilic, and two reactors R3-55 and R4-55 were filled with thermophilic digestate. In order to get $8 \mathrm{~L}$ reactor volume each reactor was filled up with $4 \mathrm{~L}$ inoculums which were used in the start-up phase. Afterwards, under mesophilic and thermophilic conditions, the 3POMSW was applied as mono-substrate without enzymes in the R2-35 and R4-55 reactor. Beginning with an OLR of $1.5 \mathrm{~g} \mathrm{VS} \mathrm{L}-1 \mathrm{~d}-1$ in the first three weeks, then the daily input was increased to an OLR of $2.0 \mathrm{~g}$ VS L $-1 \mathrm{~d}-1$. Also, anaerobic digestion experiments of 3POMSW with enzyme were applied under mesophilic and thermophilic conditions in the reactors R135 and R3-55. The OLR was increased in the range of about 1.5 to $2.0 \mathrm{~g} \mathrm{VS} \mathrm{L}-1 \mathrm{~d}-1$; the addition of enzyme to 3POMSW of $0.5 \mathrm{mg}$ g-1 VS 3POMSW was started after seven weeks of digestion.

The reactor effluent was measured weekly for $\mathrm{pH}, \mathrm{TS}, \mathrm{VS}, \mathrm{VFA}$, total N, electrical conductivity (EC), and ammonium-N (NH4-N). 


\section{$3 \quad$ Results and Discussion}

\subsection{CSTR performance under mesophilic temperature}

In figures 2, 3 and 4 the variation of CSTR performance data in the course of time for the 3POMSW with and without enzyme are plotted. Special emphasis was given to biogas yield, VFA concentration in the effluent, $\mathrm{pH}, \mathrm{EC}$, TS (\% FM), VS (\% FM), total N, and NH4-N under OLRs $1.5-2.0 \mathrm{~g}$ VS L $-1 \mathrm{~d}-1$ at $35^{\circ} \mathrm{C}$.

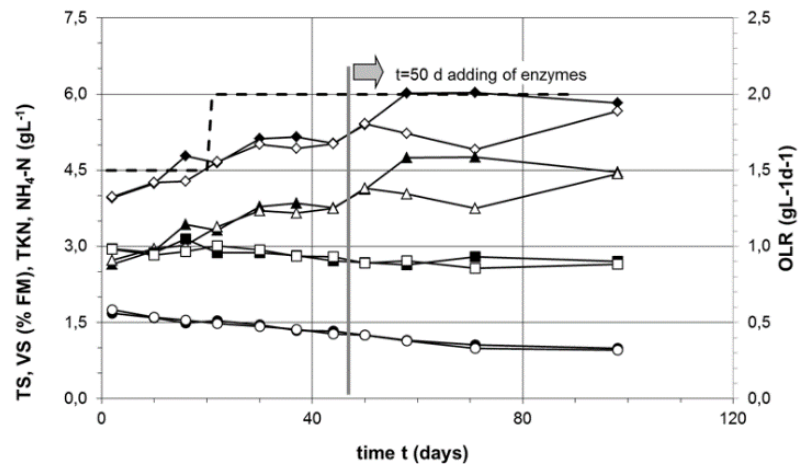

Fig. 2: Reactor performance data at $35^{\circ} \mathrm{C}$ for control (R2-35: $\diamond \mathrm{TS}, \triangle \mathrm{VS}, \square \mathrm{TKN}, \bigcirc$ NH4-N) and enzyme reactor (R1-35: $\bullet$ TS, $\boldsymbol{\Delta}$ VS, $\square$ TKN, $\bullet$ NH4-N); OLR: - - -

Total VS and TS of the effluents rose with increase of OLR. The decreases of total $\mathrm{N}$ and Ammonium-N were observed when OLR increased from 1.5 to $2.0 \mathrm{~g} \mathrm{VS} \mathrm{L}-1 \mathrm{~d}-1$ (Fig.2), caused by removing parts of nitrogen while adding water to the substrate. The approximately parallel decrease of $\mathrm{N}$ and $\mathrm{NH} 4-\mathrm{N}$ could refer to a low turnover of organic nitrogen during the fermentation process.

As shown in Fig. 3, the range of $\mathrm{pH}$ values obtained during these experiments (7.9 - 7.5) are within the optimal $\mathrm{pH}$ for methanogenic processes [15]. There was a slight decrease in electrical conductivity over time from 18.3 to $13.8 \mathrm{mS} \mathrm{cm}-1$. 
$10^{\mathrm{TH}}$ International CONFerence on Sustainable Energy and Environmental Protection (June $27^{\mathrm{TH}}-30^{\mathrm{TH}}, 2017$, BLED, SLOVENIA), Bioenergy AND Biofuels

R. Al Afif \& B. Linke: Biogas Production from Three-Phase Olive Mill Solid Waste in Lab-Scale Continuously Stirred Tank Reactor

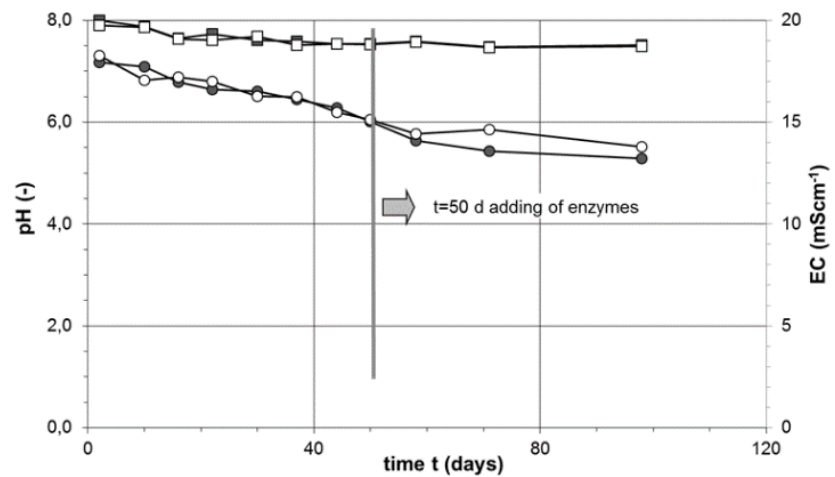

Fig.3 Reactor performance data at $35^{\circ} \mathrm{C}$ for control (R2-35: $\square \mathrm{pH}, \bigcirc \mathrm{EC}$ ) and enzyme reactor $(\mathrm{R} 1-35: \square \mathrm{pH}, \bigcirc \mathrm{EC})$

Variations of biogas yield in standardized litres per $\mathrm{g}$ of volatile solids added, and volatile fatty acids obtained during anaerobic digestion of 3POMSW with and without enzyme after 50 days of HRT at $35^{\circ} \mathrm{C}$ are shown in figure 4 .

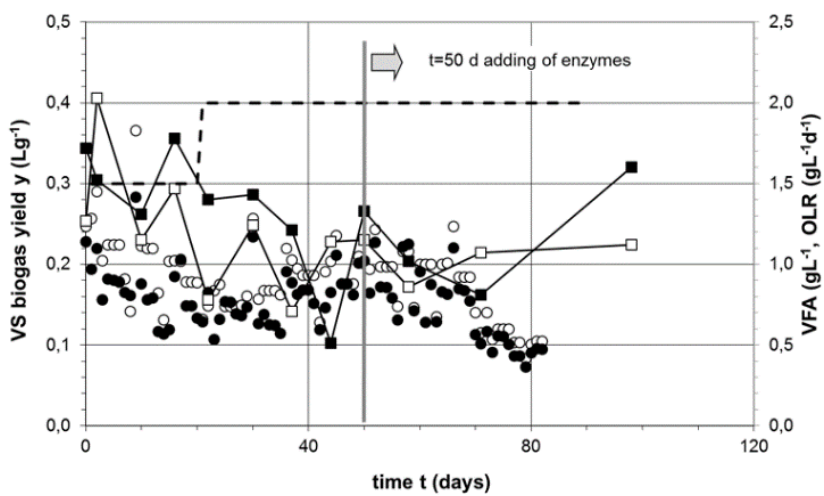

Fig. 4: Reactor performance data at $35^{\circ} \mathrm{C}$ for control (R2-35: $\bigcirc \mathrm{y}, \square$ VFA) and enzyme reactor (R1-35: y, $\mathbf{Q} \mathrm{VFA})$; ORL: - - -

After the start-up phase of the experiment at an OLR of $1.5 \mathrm{~g} \mathrm{VS} \mathrm{L}^{-1} \mathrm{~d}^{-1}$, biogas yield and VFA decreased for both 3POMSW fermentation with and without enzyme. Increasing of OLR to $2 \mathrm{~g} \mathrm{VS} \mathrm{L}^{-1} \mathrm{~d}^{-1}$ resulted in continued decrease of VFA concentration in the effluent, but the VS-biogas yield increased slightly from 0.13 to $0.2 \mathrm{Lg}^{-1} \mathrm{VS}$. Addition of enzyme to 3POMSW after 50 days of processing time did not have an effect the biogas yield and volatile fatty acids concentration in the effluent.

It is worth noting that after 70 days of processing time a sharp decrease of biogas yield and small increase of VFA were observed for all experiments. These results indicate the beginning of reactor failure. Under the presented technology of processing 3POMSW in CSTR, it has to be presumed that substantial amounts of phenolic compounds, which can 
inhibit the degradation of biodegradable organic fractions and their own biodegradation, were probably accumulated with increasing OLR to $2 \mathrm{~g} \mathrm{VS} \mathrm{L}-1 \mathrm{~d}-1$ for 3POMSW during the fermentation time. These phenolic compounds were not detected, but it is expected that increasing their concentration in the substrates will result in an increment in toxicity of methanization, since previous studies indicated that the major limitation of anaerobic digestion of olive mill waste is the inhibition of methanogenic bacteria by simple phenolic compounds and polyphenols [16]. Others reported that the 50\% inhibition of biodegradation of biomass during the anaerobic digestion was in the range of 120 to 594 $\mathrm{mg}$ of compound/g VS [17].

\subsection{CSTR performance under thermo-philic temperature}

When the reactor were fed with 3POMSW with and without enzyme, after 50 days of processing time OLRs of $1.5-2.0 \mathrm{~g} \mathrm{VS} \mathrm{L}-1 \mathrm{~d}-1$ at $55^{\circ} \mathrm{C}$ provided a biogas yield of 0.03 $-0.3 \mathrm{Lg}-1 \mathrm{VS}(50-57.6 \% \mathrm{CH} 4)$ and a VFA concentration in the effluent of $1.00-1.79 \mathrm{~g}$ L-1 (Fig. 5). Other reactor performances were as following: acid $\mathrm{pH}(7.7-8.2)$, electrical conductivity $(12.5-15.0 \mathrm{mS} \mathrm{cm}-1)$, total VS $(2.5-4.5 \% \mathrm{FM})$, total $\mathrm{N}(2.5-2.57 \mathrm{~g} \mathrm{~kg}$ $1)$, and NH4-N (0.99 - 1.37g kg-1).

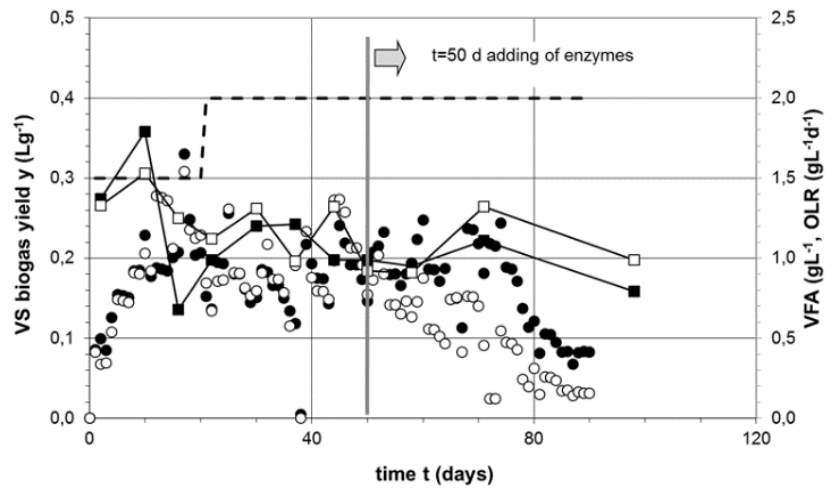

Fig. 5. Reactor performance data at $55^{\circ} \mathrm{C}$ for control (R4-55: $\bigcirc \mathrm{y}, \square$ VFA) and enzyme reactor $(\mathrm{R} 3-55: \bigcirc \mathrm{y}, \boldsymbol{V F A})$; ORL: - - -

As can be seen ( Fig.5), in the first 20 days at OLR $1.5 \mathrm{~g} \mathrm{VS} \mathrm{L}-1 \mathrm{~d}-1$ the biogas production was increased from 0.08 to $0.27 \mathrm{Lg}$-1VS. Increasing OLR to $2.0 \mathrm{~g}$ VS L-1 d-1 resulted in stability of biogas production, after 70 days of HRT a sharp decrease of biogas yield was observed. Addition of enzymes (MethaPlus ${ }^{\circledR}$ ) to 3 POMSW after 50 days of HRT helped in continuing the process stability until 70 days of HRT and increased the cumulate biogas production. The results confirmed that the thermophilic conditions led to an increase of biogas yield of about $8 \%$ compared with the yields under mesophilic temperature. 
$20 \mid 10^{\text {TH }}$ InTERnational Conference on Sustainable ENERgy AND ENVIRONMENTAL Protection (June $27^{\mathrm{TH}}-30^{\mathrm{TH}}, 2017$, BLed, SLOVENiA), Bioenergy AND Biofuels

R. Al Afif \& B. Linke: Biogas Production from Three-Phase Olive Mill Solid Waste in Lab-Scale Continuously Stirred Tank Reactor

\subsection{Quality of biogas}

The analyses show that the methane concentrations (by volume) in biogas under mesophilic and thermophilic temperature were between $51.7-57.8 \%$ and $50.0-57.6 \%$ respectively; the remainder was mostly $\mathrm{CO} 2$. It is clearly shown that the temperature and the addition of enzyme to 3POMSW had no significant effect on methane content during the periods of biogas production. It is worth noting that the quality of biogas produced by digestion of 3POMSW under mesophilic and thermophilic temperature was satisfactory.

\section{$4 \quad$ Conclusions}

The aim of this study was to investigate the feasibility of mono-fermentation of 3POMSW in CSTRs. On the basis of the obtained experimental results, it can be concluded that thermophilic anaerobic digestion of 3POMSW is the preferred temperature scenario; because the VFA, $\mathrm{pH}, \mathrm{N}$, and $\mathrm{NH}_{4}-\mathrm{N}$ were observed in a normal range and did not indicate any process failure. Furthermore, thermophilic treatment results in an increase of biogas yield of about $8 \%$ compared to mesophilic temperature. Adding of enzyme to 3POMSW under thermophilic condition helped to stabilize the process and increased the cumulative biogas production. It was also observed that the addition of the enzyme under mesophilic condition did not have a significant effect on biogas yield and reactor performance. It is worth noting that the temperature and the addition of enzyme to 3POMSW had no significant effect on methane content during the different periods of biogas production. The quality of biogas was satisfactory (50.0$57.8 \% \mathrm{CH}_{4}$ ). However, in long term lab-scale experiments it could be demonstrated that mono-fermentation is not applicable for treatment of 3POMSW from olive mill processing. After 70 days of processing time, beginning reactor failure was observed for all experiments due to the sharp decrease of biogas yield. It is suggested, that accumulation of phenolic compounds in the 3POMSW is responsible for such reactor failure.

\section{Acknowledgements}

We thank Prof. Dr. Martin Wendland (BOKU, Vienna) for his comments that greatly improved the manuscript.

\section{References}

[1] M. Niaounakis, and C. P. Halvadakis, Olive-Mill Waste Management:Literature review and Patent Survey. Typothito - George Dardanos Publications, Athens, Greece, 2004.

[2] P. Vossen, "Olive Oil: History, Production, and Characteristics of the World's Classic Oils," HortScience, vol. 42, pp. 1093-1100, Aug. 2007.

[3] J. A. Morillo, B. Antizar-Ladislao, M. Monteoliva-Sánchez, A.Ramos-Cormenzana, and N. J. Russell, "Bioremediation and biovalorisation of olive-mill wastes," Applied Microbiolo. and Biotechnolo., vol. 82, pp. 25-39, 2009..

[4] B. Amigun, J. K. Musango, and W. Stafford, "Biofuels and sustainability in Africa," Renewable and Sustainable Energy Reviews, vol. 15, 2, pp. 1360-1372, 2011. 
$10^{\mathrm{TH}}$ INTERNATIONAL CONFERENCE ON SUSTAINABLE ENERGy AND ENVIRONMENTAL

Protection (June 27 $7^{\mathrm{TH}}-30^{\mathrm{TH}}, 2017$, BLed, Slovenia), Bioenergy ANd Biofuels

R. Al Afif \& B. Linke: Biogas Production from Three-Phase Olive Mill Solid Waste in Lab-Scale Continuously Stirred Tank Reactor

[5] M. Brady, K. Hedlund, C. RongGang, L. Hemerik, and S. Hotes, "Farmer's costs of supplying soil services in diverse EU regions," Soilservice Deliverable D18, April 2012.

[6] E. Sanchez, B. Rincon, R. Borja, L. Travieso, F. Raposo, and M. F. Colmenarejo, "Aerobic degradation kinetic of the effluent derived from the anaerobic digestion of two-phase olive mill solid residue," Internat. Biodeteriorat. \& Biodegradat., vol. 60, pp. 60-67, 2007.

[7] R. Al Afif, and T. Amon, "Biogas production from olive pulp and cattle manure - Effect of co-fermentation and enzymes on methane productivity," Damascus University journal for the Agricultural, vol. 28, pp. 18-36, 2008.

[8] B. Linke, "Kinetic study of thermophilic anaerobic digestion of solid wastes from potato processing," Biomass and Bioenergy, vol. 30, pp. 892-896, 2006.

[9] N. Azbar, T. Keskin, and E. C. Catalkaya, "Improvement in anaerobic degradation of olive mill effluent (OME) by chemical pre-treatment using batch systems," Biochemical Engineering, vol. 38, pp. 379-383, 2008.

[10] J. Al-Mallahi, T. Furuichi, and K. Ishii, "Appropriate conditions for applying NaOHpretreated two-phase olive milling waste for codigestion with food waste to enhance biogas production," Waste Management, vol. 48, pp. 430-439, 2016.

[11] M. Orive, M. Cebrian, and J. Zufia, "Techno-economic anaerobic co-digestion feasibility study for two-phase olive oil mill pomace and pig slurry," Renewable Energy, vol. 97, pp. 532-540, 2016.

[12] VCH Verlagsgesellschaft mbH, Deutsche Einheitsverfahren zur Wasser-, Abwasser- und Schlammuntersuchung, Weinheim, 1989.

[13] E. Bruni, A. P. Jensen, I. Angelidaki, " Comparative study of mechanical, hydrothermal, chemical and enzymatic treatments of digested biofibers to improve biogas production," Bioresource Technology, vol. 101, pp. 8713-8717, 2010.

[14] VDI 4630, Fermentation of Organic Materials. Characterisation of the Substrates, Sampling, Collection of Material Data, Fermentation Tests. VDI-Handbuch Energietechnik, 2006.

[15] M. A. Latif, G. M. Mehta and D. Batstone, "Influence of low pH on continuous anaerobic digestion of waste activated sludge," Water Research, vol. 113, pp. 42-49, April 2017.

[16] H. Dhaouadi and B. Marrot, "Olive mill waste water treatment in a membrane bioreactor: Process feasibility and performances," Chemical Engineering Journal, vol. 145, pp. 225231, 2008.

[17] J. E. Hernandez and R. G. J. Edyvean, "Inhibition of biogas production and biodegradability by substituted phenolic compounds in anaerobic sludge," Journal of Hazardous Materials, vol. 160, pp. 20-28, 2008. 
$22 \mid 10^{\text {TH }}$ International Conference on Sustainable EnERgy and EnVironmental Protection (June $27^{\mathrm{TH}}-30^{\mathrm{TH}}, 2017$, Bled, Slovenia), Bioenergy AND Biofuels 
$10^{\mathrm{TH}}$ InTERnational CONFERENCE ON Sustainable ENERgy AND

ENVIRONMENTAL Protection (June $27^{\mathrm{TH}}-30^{\mathrm{TH}}$, 2017, Bled,

SLOVENIA), BIOENERGY AND BIOFUELS

J. Krope, A.Ghani Olabi, D. Goričanec \& S. Božičnik

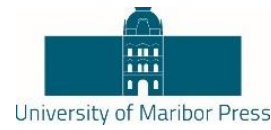

\title{
Organosolv Plus Supercritival Carbon Dioxide Pre-Treatment of Cotton Stalks for Methane Production
}

\author{
Rafat Al AFif, Martin Wendland, Lutz Christian Krapf, ThOMAS AMON \& \\ CHRISTOPH PFEIFER
}

\begin{abstract}
Cotton stalks (CS) are an abundant, renewable lignocellulose residue, which is usually burnt on fields to prevent propagation of vegetal diseases, causing economic costs and environmental concerns. As an alternative, production of biogas is considered. This work aims to improve the biogas production from CS by steam or organosolv plus supercritical carbon dioxide $(\mathrm{scCO} 2)$ pre-treatment. All samples were pre-treated in a $500 \mathrm{~mL}$ autoclave for 140 minutes at $180^{\circ} \mathrm{C}$ and fermented in $1 \mathrm{~L}$ eudiometer batch digesters for 42 days at $37.5^{\circ} \mathrm{C}$. Biogas and methane yield achieved from untreated CS were 250 and 137 norm litres per $\mathrm{kg}$ of volatile solids (1N kg-1 VS), respectively. The pre-treatment of CS samples with steam or organosolv plus scCO2 process increased the methane yield up to $20 \%$ compared with the untreated samples. The highest methane yield of $177 \mathrm{lN} \mathrm{kg-1} \mathrm{VS} \mathrm{was} \mathrm{achieved} \mathrm{by} \mathrm{organosolv} \mathrm{plus} \mathrm{scCO2} \mathrm{pre-treatment} \mathrm{at}$ 100 bars and $180^{\circ} \mathrm{C}$ for 140 minutes. Moreover, the pre-treatment of CS led to a significant reduction in the optimal retention time for biogas production down to 20 days from 30 days for untreated CS.
\end{abstract}

Keywords: • Biogas • Anaerobic digestion • Cotton stalks $\bullet$ Pre-treatment • Organosolv plus supercritical carbon dioxide •

CoRresPondence AdDress: Rafat Al Afif, Ph.D., Assoc. Prof., University of Natural Resources and Life Sciences, Vienna, Institute of Chemical and Energy Engineering, Muthgasse 107, 1190 Vienna, Austria, e-mail: rafat.alafif@boku.ac.at. Martin Wendland, Ph.D., ao. Univ. Prof., University of Natural Resources and Life Sciences, Vienna, Institute of Chemical and Energy Engineering, Muthgasse 107, 1190 Vienna, Austria, e-mail: martin.wendland@boku.ac.at. Lutz Christian Krapf, Ph.D., University of Natural Resources and Life Sciences, Vienna, Institute of Chemical and Energy Engineering, Muthgasse 107, 1190 Vienna, Austria, e-mail: krapf.christian@gmail.com. Thomas Amon, Ph.D., Univ. Prof., Division of Agricultural Engineering, Department of Sustainable Agricultural Systems, University of Natural Resources and Life Sciences, Vienna, Peter-Jordan Strasse 82, 1190 Vienna, Austria, current address: Leibniz Institut für Agrartechnik, Potsdam Bornim e.V. Max-Eyth-Allee 100, 14469 Potsdam Germany, e-mail: tamon@atb-potsdam.de. Christoph Pfeifer, Ph.D., Univ. Prof., University of Natural Resources and Life Sciences, Vienna, Institute of Chemical and Energy Engineering, Muthgasse 107, 1190 Vienna, Austria, e-mail: christoph.pfeifer@boku.ac.at.

https://doi.org/10.18690/978-961-286-048-6.3

ISBN 978-961-286-048-6

(C) 2017 University of Maribor Press

Available at: http://press.um.si. 
$24 \mid 10^{\text {TH }}$ InTERnational CONFERENCE ON Sustainable ENERGy AND ENVIRONMENTAL Protection (June $27^{\mathrm{TH}}-30^{\mathrm{TH}}, 2017$, BLed, Slovenia), Bioenergy AND Biofuels R. Al Afif, M. Wendland, L.C. Krapf, T. Amon \& C. Pfeifer: Organosolv Plus Supercritival Carbon Dioxide Pre-Treatment of Cotton Stalks for Methane Production

Agricultural by-products and waste from agro-industrial processes such as bio-refineries are expected to gain importance as a source of energy supply in the near future. Cotton stalks (CS) is one of the most dominant harvestable crop residues that can be used for bioenergy applications. At present, CS is mulched with soil or removed from the cropland or burnt on fields to restrict future pest infestations, causing economic costs and environmental concerns. Therefore, cotton waste must be utilized if sustainable agriculture is targeted. Usage of cotton waste for energy production became a subject of many studies in the last years. Researchers generally focused on the production of ethanol or the production of fuel pellets or briquettes. There were only few studies on the subject of biogas production from cotton wastes. Isci and Demirer [1] studied the biogas production potential of cotton wastes. They indicated that cotton wastes can be digested anaerobically yielding 65 to $86 \mathrm{l}_{\mathrm{N}} \mathrm{CH}_{4} \mathrm{~kg}^{-1} \mathrm{VS}(24 \mathrm{~d})^{-1}$. A two-stage digestion technique for biogas production from co-fermentation of organic wastes (rice, maize, cotton) was also investigated [2]. These studies indicated that under anaerobic conditions from the main components in CS the cell wall carbohydrates were well preserved, while the level of soluble carbohydrate was low. Pre-treatment of lignocellulosic biomass is a necessary step to overcome the hindrance of lignin and to increase solubilisation [3]. The organosolv process is considered as thermo-chemical method for pre-treatment of biomass for bio-refinery as it is effective for cleaving alkali-labile ester bonds between monolignols and hemicelluloses [4]. It is worth mentioning that supercritical carbon dioxide $\left(\mathrm{scCO}_{2}\right)$ explosion of pure cellulose or pre-treated cellulosic materials with addition of aqueous buffer solutions improved the glucose yield from the enzymatic cellulose hydrolysis [5]. Another important pre-treatment process is the steam explosion process. Krapf et al. [6] studied the effect of organosolv plus $\mathrm{scCO}_{2}$ pre-treatment of rye straw on biogas production. They indicated that this combined pre-treatment (160 bars, $180^{\circ} \mathrm{C}$ for 140 minutes, $11 \%$ solid content and $50 \% \mathrm{v} / \mathrm{v}$ ethanol content in the solvent) increased the methane yield up to $13 \%$ compared with the untreated samples. Here, steam explosion and organosolv process is combined with $\mathrm{scCO}_{2}$, which results in the steam and the organosolv plus $\mathrm{scCO}_{2}$ processes. Presently, there are no systematic studies known about pre-treatment of cotton stalks for biogas production with both processes, steam and organosolv plus $\mathrm{scCO}_{2}$. Therefore, some form of optimization process of pretreatment is required. This work seeks to improve the biogas production from CS by steam or organosolv plus $\mathrm{scCO}_{2}$ pre-treatment.

\section{$2 \quad$ Materials and Methods}

\subsection{Raw materials and inoculm}

Cotton stalks (shredded and baled) were harvested in early October 2010 from the Research Station of Cotton Bureau in Syria. The moisture content of the cotton stalks was 4.8\% (DM: 95.2\%). The samples were chopped to a length of 1-3 mm, and stored in air tight containers at room temperature until used for experiments. Active sludge from a commercial biogas plant in Austria was used as inoculum. The specific methane potential 
$10^{\mathrm{TH}}$ INTERNATIONAL CONFERENCE ON SUSTAINABLE ENERGY AND ENVIRONMENTAL 25 Protection (June 27 $7^{\mathrm{TH}}-30^{\mathrm{TH}}, 2017$, BLed, SLOveniA), Bioenergy AND Biofuels R. Al Afif, M. Wendland, L.C. Krapf, T. Amon \& C. Pfeifer: Organosolv Plus Supercritival Carbon Dioxide Pre-Treatment of Cotton Stalks for Methane Production

of the inoculum was measured as well. The inoculum showed low specific methane potential of only $15 \mathrm{l}_{\mathrm{N}} \mathrm{kg}^{-1} \mathrm{VS}$.

\subsection{Analytical Methods}

Nutrient composition of CS was analysed (dry matter DM $=95.2 \% \mathrm{FM}$ (fresh material), volatile solids $\mathrm{VS}=91.6 \% \mathrm{DM}$, crude protein $\mathrm{XP}=6 \% \mathrm{DM}$, crude fibre $\mathrm{XF}=45.7 \%$ $\mathrm{DM}$, crude fat $\mathrm{XL}=0.7 \% \mathrm{DM}$, and ash $\mathrm{XA}=1.25 \% \mathrm{DM}$ ) according to standard procedures [7]. $\mathrm{N}$-free extracts $(\mathrm{XX}=43.9 \% \mathrm{DM})$ were calculated and constitute that part of the DM not incorporated in XP, XF, XL and XA. The elemental analysis (carbon $\mathrm{C}=55.8 \% \mathrm{VS}$, hydrogen $\mathrm{H}=6.4 \% \mathrm{VS}$, nitrogen $\mathrm{N}=0.95 \% \mathrm{VS}$, sulfur $\mathrm{S}=0.06 \% \mathrm{VS}$, oxygen $\mathrm{O}=36.8 \% \mathrm{VS}$ ) was performed ac-cording to standard procedures [8].

\subsection{Pre-treatment of cotton stalks}

For steam or organosolv plus $\mathrm{scCO}_{2}$ pre-treatment, $40 \mathrm{~g}$ of milled, air-dry CS with specific amount of either pure water or water-ethanol solution were placed in a $400 \mathrm{ml}$ glass bead-packed high-pressure vessel. $\mathrm{ScCO}_{2}$ was delivered to the high-pressure vessel by a supercritical fluid control and delivery system [6]. The high-pressure vessel was heated to a desired pre-treatment temperature by an electric heater. The pressure was kept on a constant level during the process (Figure 1).

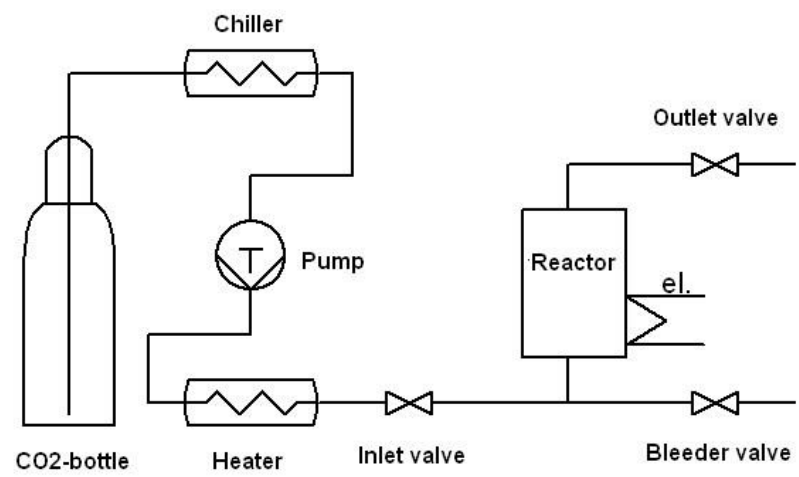

Figure 1. Pre-treatment scheme for CS

After pre-treatment, one sample of the autoclaved CS was filtered by a fluted filter (Rotabilo, $150 \mathrm{~mm}$, through-put time 30s) and washed with 1 litre of a water-ethanol $(80: 20, \mathrm{v} / \mathrm{v})$ mixture to remove parts of the solvent which might contain inhibitors. The pulp was oven-dried at $120^{\circ} \mathrm{C}$ for $24 \mathrm{~h}$. The liquid phase containing dissolved organic compounds, water and ethanol, is distilled in order to recycle ethanol [6]. After distillation the water insoluble lignin crystallizes in the water phase and is separated by sedimentation. The recycled ethanol can be reused for the washing process [9]. All 
26 10 $10^{\text {TH }}$ InTERnational Conference on Sustainable ENERgy AND ENVIRONMENTAL Protection (June $27^{\mathrm{TH}}-30^{\mathrm{TH}}, 2017$, BLed, Slovenia), Bioenergy AND Biofuels R. Al Afif, M. Wendland, L.C. Krapf, T. Amon \& C. Pfeifer: Organosolv Plus Supercritival Carbon Dioxide Pre-Treatment of Cotton Stalks for Methane Production

samples were kept in a refrigerator until being used for anaerobic digestion. The experimental design of the pre-treatment of cotton stalks is shown in Table 1.

\subsection{Anaerobic digestion experiments}

Anaerobic digestion experiments to measure the biochemical methane potential were conducted by the anaerobic digestion laboratory of the University of Natural Resources and Life Sciences, Vienna. The experiments were carried out in accordance with VDI [10]. Eudiometer batch digesters of 1 litre capacity were used. The temperature was set to $37.5^{\circ} \mathrm{C}$. Analysed samples and inoculum were weighed out in a ratio of 1:3 (based on DM). The produced amount of biogas was monitored on a daily basis. Biogas and methane production is given in norm litres ( $273 \mathrm{~K}$ and $1013 \mathrm{mbar}$ ) per $\mathrm{kg}$ of volatile solids $\left(1_{\mathrm{N}} \mathrm{kg}^{-1} \mathrm{VS}\right)$. The determination of biogas composition $\left(\mathrm{CH}_{4}, \mathrm{CO}_{2}\right)$ is determined with GC-SRI instruments model "Multiple Gas Analyzer \#2" using a separating column (FS-FFAP-CB, $\mathrm{d}_{\mathrm{f} .}=0.5 \mu \mathrm{m}$ ). It is equipped with a helium ionization detector (HID) in addition to a thermal conductivity detector (TCD).

Table 1. Design of pre-treatment process

\begin{tabular}{ccccccc}
\hline $\begin{array}{c}\text { sam- } \\
\text { ple }\end{array}$ & $\begin{array}{c}\mathrm{CS} \\
{[\mathrm{g}]}\end{array}$ & $\begin{array}{c}\mathrm{H}_{2} \mathrm{O} \\
{[\mathrm{g}]}\end{array}$ & $\begin{array}{c}\mathrm{C}_{2} \mathrm{H}_{5} \mathrm{OH} \\
{[\mathrm{g}]}\end{array}$ & $\begin{array}{c}\mathrm{p} \\
\text { bar }\end{array}$ & $\begin{array}{c}\mathrm{t} \\
{ }^{\circ} \mathrm{C}\end{array}$ & $\begin{array}{c}\text { time } \\
\text { min }\end{array}$ \\
\hline $\mathrm{A}$ & 40 & - & - & - & - & - \\
$\mathrm{B}$ & 40 & 90 & - & 72 & 180 & 140 \\
$\mathrm{C}$ & 40 & 40 & - & 100 & 180 & 140 \\
$\mathrm{D}^{*}$ & 40 & 40 & - & 100 & 180 & 140 \\
$\mathrm{E}$ & 40 & 20 & 16 & 100 & 180 & 140 \\
\hline \multicolumn{6}{c}{$*$}
\end{tabular}

* washing with $\mathrm{H}_{2} \mathrm{O}+\mathrm{C}_{2} \mathrm{H}_{5} \mathrm{OH}(20: 80, \mathrm{v} / \mathrm{v})$

Results of the elementary analysis can be utilized for estimating theoretical biogas and methane yields as well as concentrations of the trace gases ammonia and hydrogen sulphide. The estimated methane yield according to Boyle's equation is given by [11]:

$$
\begin{aligned}
& \mathrm{C}_{a} \mathrm{H}_{b} \mathrm{O}_{c} \mathrm{~N}_{d} \mathrm{~S}_{e}+\left(a-\frac{b}{4}-\frac{c}{2}+3 \frac{d}{4}+\frac{e}{2}\right) \mathrm{H}_{2} \mathrm{O} \\
& \rightarrow\left(\frac{a}{2}+\frac{b}{8}-\frac{c}{4}-3 \frac{d}{8}-\frac{e}{4}\right) C H_{4}+\left(\frac{a}{2}-\frac{b}{8}+\frac{c}{4}+3 \frac{d}{8}+\frac{e}{4}\right) \mathrm{CO}_{2}+d \mathrm{NH}_{3}+e \mathrm{H}_{2} \mathrm{~S}
\end{aligned}
$$

This equation is used to balance the carbon converted into methane during anaerobic fermentation. Therefore, the methane yield measured in batch-fermenter experiments is compared to the estimated methane yield. 
$10^{\mathrm{TH}}$ INTERNATIONAL CONFERENCE ON SUSTAINABLE ENERGY AND ENVIRONMENTAL Protection (June $27^{\mathrm{TH}}-30^{\mathrm{TH}}, 2017$, Bled, SLOvenia), BioENERGy AND Biofuels R. Al Afif, M. Wendland, L.C. Krapf, T. Amon \& C. Pfeifer: Organosolv Plus Supercritival Carbon Dioxide Pre-Treatment of Cotton Stalks for Methane Production

\subsection{Statistical data analysis}

Data given in tables and figures present mean and standard deviations of performed experiments. Statistical analysis was carried out using SPSS Version 15. Data were analysed by one-way ANOVA, followed by Tukey's test for post hoc comparison. The level of significance was set at $p<0.05$.

\section{$3 \quad$ Results and Discussions}

\subsection{Biogas and methane production from pre-treated cotton stalks}

To find the effect of the pre-treatment on methane and biogas production, the CS samples pre-treated under different conditions (Table 1) were anaerobically digested. Table 2 and 3 show the accumulated biogas and methane yield in normal litres per $\mathrm{kg}$ of volatile solids, obtained during anaerobic digestion of untreated and pre-treated cotton stalks, which ranged from 221-308 and 129.8-177.4 $1_{\mathrm{N}} \mathrm{kg}^{-1} \mathrm{VS}$, respectively. It is worth noting that the final methane productivity of untreated cotton stalks reached up to $137.5 \mathrm{l}_{\mathrm{N}} \mathrm{kg}^{-1}$ VS, whereas, Krapf et al. [6] reported that methane yield from rye straw was $262 \mathrm{l}_{\mathrm{N}} \mathrm{kg}^{-1}$ VS. The difference in yield can be attributed to the difference in biochemical compositions. To explain this, we should consider that the high concentration of lignin (21 wt\% DM) in CS, compared to its concentration in rye straw (17 wt\% DM) [12], yields to poor degradation during anaerobic digestion. Öhgren et al. [13] showed that the presence of lignin is considered as major hindrance to enzymatic hydrolysis. Due to the existence of lignin-carbohydrate complexes, the polysaccharides are chemically linked to lignin. The cellulose fibrils are physically encased by surrounding lignin, which constitutes a barrier against enzymatic degradation of the polysaccharides in the cell walls [14]. This shielding effect reduces the rate and extent of lignocellulose hydrolysis and therefore limits the transformation of polysaccharides into biogas.

Biogas and methane production from untreated and pre-treated CS samples with two different liquid to CS ratios ( $90 \mathrm{~g} \mathrm{H}_{2} \mathrm{O} / 40 \mathrm{~g} \mathrm{CS}$ - organosolv variant $\mathrm{E}$ - and $40 \mathrm{~g} \mathrm{H}_{2} \mathrm{O} / 40$ $\mathrm{g}$ CS -steam variants $\mathrm{B}, \mathrm{C}$ and $\mathrm{D}$ ) are shown in Table 2 and 3 . The methane yield for $\mathrm{B}$, $\mathrm{C}$ and $\mathrm{D}$ was $137.5,147.1$, and $163.0 \mathrm{l}_{\mathrm{N}} \mathrm{kg}^{-1} \mathrm{VS}$, respectively. This means that the steam plus $\mathrm{scCO}_{2}$ pre-treatment with two different moisture contents increased the specific methane yield between 7 and $20.5 \%$ compared to untreated samples. Furthermore, increasing the pressure for the $\mathrm{scCO}_{2}$ from 72 to 100 bar showed an improvement in methane yield by $11 \%$. The primary reason for these facts is that 72 bar is still subcritical. It was reported that water and $\mathrm{scCO}_{2}$ could form weak carbonic acid at a high pressure [15]. Also Gao et al. [16] concluded that $\mathrm{scCO}_{2}$ pre-treatment rendered fibres relatively fluffy and soft, which enhanced cellulose enzymatic hydrolysis. 
$10^{\mathrm{TH}}$ InTERNATIONAL CONFERENCE ON Sustainable ENERGy AND ENVIRONMENTAL Protection (June $27^{\mathrm{TH}}-30^{\mathrm{TH}}, 2017$, BLed, Slovenia), Bioenergy AND Biofuels R. Al Afif, M. Wendland, L.C. Krapf, T. Amon \& C. Pfeifer: Organosolv Plus Supercritival Carbon Dioxide Pre-Treatment of Cotton Stalks for Methane Production

Table 2: Specific biogas yield of untreated (A) and pre-treated CS

\begin{tabular}{lllll}
\hline \multirow{2}{*}{ sample } & \multicolumn{4}{c}{ biogas yield } \\
{$\left[1_{\mathrm{N}} \mathrm{kg}^{-1} \mathrm{VS}\right]$} \\
\cline { 2 - 5 } & $\mathrm{n}$ & $\mathrm{Av}$. & $\mathrm{SD}$ & $\mathrm{P}$ \\
\hline $\mathrm{A}$ & 3 & 251.0 & 8.7 & - \\
$\mathrm{B}$ & 3 & 264.8 & 13,7 & 0.18 \\
$\mathrm{C}$ & 3 & 286.0 & 20.7 & 0.998 \\
$\mathrm{D}$ & 3 & 221.0 & 6.6 & 0.308 \\
$\mathrm{E}$ & 3 & $295.0^{*}$ & 21.2 & 0.037 \\
\hline
\end{tabular}

Table 3: Specific methane yield of untreated (A) and pre-treated CS as well as the biogas methane concentration in $\%$

\begin{tabular}{llllll}
\hline \multirow{5}{*}{ sample } & \multicolumn{5}{c}{ methane yield } \\
{$\left[l_{\mathrm{N}} \mathrm{kg}^{-1} \mathrm{VS}\right]$} & & \\
\cline { 2 - 6 } & $\mathrm{n}$ & $\mathrm{Av}$. & $\mathrm{SD}$ & $\mathrm{P}$ & $\%$ \\
\hline $\mathrm{A}$ & 3 & 137.5 & 4.8 & - & 54.8 \\
$\mathrm{~B}$ & 3 & 147,1 & 9.0 & 0.28 & 55.5 \\
$\mathrm{C}$ & 3 & 163.0 & 13.0 & 0.074 & 57.0 \\
$\mathrm{D}$ & 3 & 129.8 & 3.9 & 0.877 & 58.7 \\
$\mathrm{E}$ & 3 & $177.4^{*}$ & 12.8 & 0.007 & 60.1 \\
\hline
\end{tabular}

The effect of washing pre-treated samples with water-ethanol mixture $(20: 80, \mathrm{v} / \mathrm{v})$ on biogas and methane yield was determined for the extraction of lignin. Washing of pretreated samples resulted in the decrease of methane yield by $26 \%$ comparing with the same samples without washing. Nevertheless, removal of lignin from cotton stalks should increase the hydrolysis, as lignin limits the rate and extension of (enzymatic) hydrolysis by acting as a shield, preventing the digestible parts of the substrate to be hydrolysed [17]. The decrease of methane yield from washed pre-treated samples was probably caused by removing parts of soluble carbohydrates during the washing process. This assumption refers to an investigation made by Krapf et al. [6] who stated that the separation process of the pre-treated straw, which included steps of washing, distillation, lignin precipi-tation, and drying negatively affected the microbial fermentation process.

The significantly highest specific methane yield of $177.4 \mathrm{l}_{\mathrm{N}} \mathrm{kg}^{-1} \mathrm{VS}$ (Tukey's test, $\mathrm{p}<$ 0.05 ) was found for organosolv plus $\mathrm{scCO}_{2}$ pre-treated CS (Table 2, variant E) at 100 bar and $180^{\circ} \mathrm{C}$ for $140 \mathrm{~min}$. To explain this result, it should be considered that ethanol acts as a co-solvent in the supercritical phase, drastically increasing the solubility of water and other volatile compounds. Water is transported much better into the solid matrix with $\mathrm{scCO}_{2}$. Also ethanol helps to keep the lignin solved in the liquid phase and prevents reprecipitation to the solid after depres-surisation. Montañés et al. [18] reported that the solubility of tagatose, galactose, lactulose and lactose in $\mathrm{scCO}_{2}$ with ethanol-water mixture was in the range of $0.02-1.09 \mathrm{mg} \mathrm{g}^{-1}$. 
$10^{\mathrm{TH}}$ INTERNATIONAL CONFERENCE ON SUSTAINABLE ENERGY AND ENVIRONMENTAL Protection (June $27^{\mathrm{TH}}-30^{\mathrm{TH}}, 2017$, BLED, SLOVENiA), Bioenergy AND Biofuels R. Al Afif, M. Wendland, L.C. Krapf, T. Amon \& C. Pfeifer: Organosolv Plus Supercritival Carbon Dioxide Pre-Treatment of Cotton Stalks for Methane Production

\subsection{Quality of biogas}

The quality of biogas produced from different pre-treated samples is illustrated in Table 3. The methane concentration (by volume) in biogas was between 55.5 and $60.1 \%$, the rest of the gas mostly consisted of $\mathrm{CO}_{2}$. The highest methane concentration was obtained from the organosolv plus $\mathrm{scCO}_{2}$ pre-treated cotton stalks (variant $\mathrm{E}$ ). These results show that the quality of biogas produced by digestion of pre-treated and untreated cotton stalks was good. Nevertheless, further process optimisation is needed.

\subsection{Energy turnover}

Specific methane yield from untreated CS and from the variants B, C, D and E of pretreated samples measured in the eudiometer batch digesters were compared with the values estimated with a theoretical calculation [11]. As shown in Table 4, the estimate differed considerably from the measurements.

The coefficients of anaerobic energy turnover $\eta$ ranged between 23.1 and $31.5 \%$. These results have shown the principal possibility to obtain more methane yield from pre-treated CS. Addi-tional experiments are necessary to further improve the methane production potential from CS. Future investigations need to focus on:

- Optimization of physical-thermal or biochemical pre-treatment, which breaks up the long-chained molecules and solid components of cotton stalks.

- Optimization of the enzyme use, co-fermentation and the organic loading rates that would enhance methane production.

Table 4. Comparison between experimental results and theoretical estimates

\begin{tabular}{cccc}
\hline samples & \multicolumn{2}{c}{$\begin{array}{c}\text { Specific methane yield } \\
\text { experiment }\end{array}$} & \multirow{2}{*}{$\begin{array}{c}\eta \\
\end{array}$} \\
\cline { 2 - 3 } & $\mathrm{l}_{\mathrm{N}} \mathrm{kg}^{-1} \mathrm{VS}$ & $\mathrm{l}_{\mathrm{N}} \mathrm{kg}^{-1} \mathrm{VS}$ & \\
\hline $\mathrm{A}$ & 137.5 & 562.9 & 24.4 \\
$\mathrm{~B}$ & 147.1 & 562.9 & 26.1 \\
$\mathrm{C}$ & 163.0 & 562.9 & 29.0 \\
$\mathrm{D}$ & 129.8 & 562.9 & 23.1 \\
$\mathrm{E}$ & 177.4 & 562.9 & 31.5 \\
\hline
\end{tabular}

\subsection{Retention time}

The effect of pre-treatment of CS under different conditions on retention time (RT) was investigated. As seen in Figure 2 during the first two days of digestion, specific methane yields per hour of pre-treated samples increased between 1.9 and $2.8 \mathrm{l}_{\mathrm{N}} \mathrm{kg}^{-1} \mathrm{VS} \mathrm{h}^{-1}$, while the methane yield per hour from untreated sample A increased to $0.6 \mathrm{l}_{\mathrm{N}} \mathrm{kg}^{-1} \mathrm{VS} \mathrm{h}^{-1}$ in the 
$10^{\text {Th }}$ International Conference on Sustainable Energy and Environmental Protection (June $27^{\mathrm{TH}}-30^{\mathrm{TH}}, 2017$, BLed, Slovenia), Bioenergy AND Biofuels R. Al Afif, M. Wendland, L.C. Krapf, T. Amon \& C. Pfeifer: Organosolv Plus Supercritival Carbon Dioxide Pre-Treatment of Cotton Stalks for Methane Production

first five days. After that observed rise, methane production per hour from all samples decreased exponentially and at the end of the $20^{\text {th }}$ day the digestion reached the stationary phase. The pre-treatment decreased the digestion period to 27 days, when the minimum methane yield was approximately $0.03\left(l_{\mathrm{N}} \mathrm{kg}^{-1} \mathrm{VS} \mathrm{h}^{-1}\right)$. The amount of methane produced from pre-treated samples during the first 20 days, equalled $89 \%$ of the whole methane amount produced during 42 days. On the other hand, $90 \%$ of methane production received from the untreated samples was achieved during the first 30 days.

As shown in Figure 2, a longer RT would be detrimental to a higher methane production yield. Besides, the cost of the reactor capital was basically considered the major investment in the anaerobic digestion [19]. Therefore, introducing shorter RT to minimize the reactor volume required could be a good choice for having an economical competitive digestion process. Therefore, the necessary RT to achieve a high rate biodegradation is recommended to be about 20 days for CS pre-treated by oganosolv plus $\mathrm{scCO}_{2}$, and about 30 days for the untreated $\mathrm{CS}$.

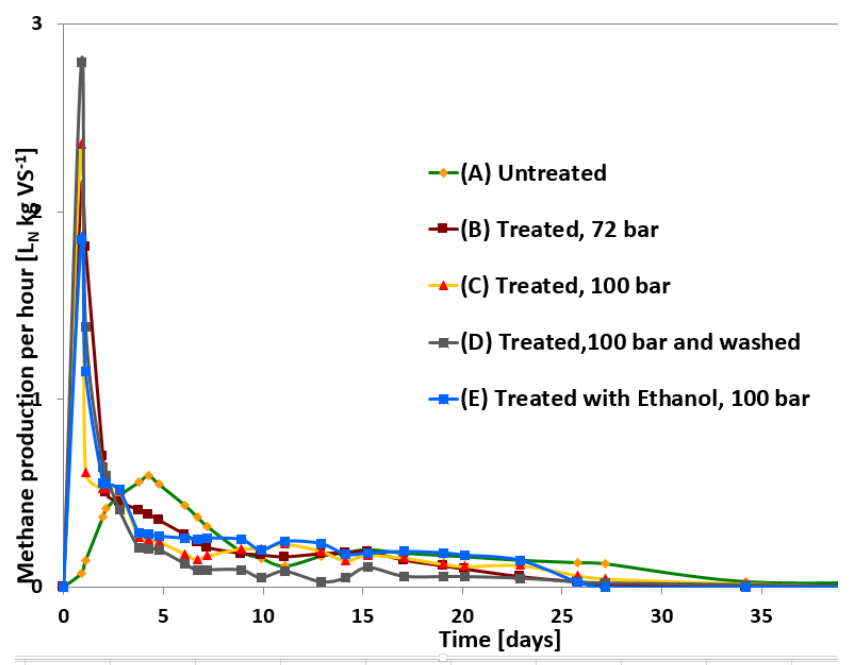

Figure 2. Specific methane yields per hour.

\section{Conclusions}

Aim of this study was to investigate the feasibility of the steam and the organosolv plus $\mathrm{scCO}_{2}$ pre-treatment of CS for methane produc_tion. Experimental results are already promising. Nevertheless, pre-treatment conditions have to be optimized to maximize methane production, as the coefficient of anaerobic energy turnover is not high and ranged between 23.1 and $31.5 \%$.

Based on the results, it can be concluded that both, the steam and the organosolv plus $\mathrm{scCO}_{2}$ pre-treatment of CS increased the methane yield with 20 and 29\%, respectively, 
$10^{\mathrm{TH}}$ INTERNATIONAL CONFERENCE ON SUSTAINABLE ENERGY AND ENVIRONMENTAL

Protection (June $27^{\mathrm{TH}}-30^{\mathrm{TH}}, 2017$, BLed, Slovenia), BioENERGY AND Biofuels

R. Al Afif, M. Wendland, L.C. Krapf, T. Amon \& C. Pfeifer: Organosolv Plus

Supercritival Carbon Dioxide Pre-Treatment of Cotton Stalks for Methane Production

compared to the untreated sample. On the other hand, washing pre-treated samples of CS led to a decrease in methane yield with $6 \%$. But the quality of biogas was always good $\left(55-60 \% \mathrm{CH}_{4}\right)$.

\section{Acknowledgements}

The research was supported by the University of Natural Resources and Life Sciences, Vienna. We thank Prof. Tobias Pröll for his comments, that greatly improved the manuscript, and special thank is due to Dr. Alexander Bauer for his continuous help.

\section{References}

[1] A. Isci and G.N. Demirer, "Biogas production potential from cotton wastes", Renewable Energy, vol. 32, pp. 750-757, 2007.

[2] M.M. El-Shinnawi, M. El-Houssieni, S.A. Aboel-Naga, and S. Fahmy, "Chemical changes during a two-stage digestion technique for biogas production from combinations of organic wastes", Resour Conserv Recycling, vol. 3, pp. 217-230, 1990.

[3] Y. Zheng, J. Shi, and Y. Cheng, "Principles and Development of Lignocellulosic Biomass Pretreatment for Biofuels," Advances in Bioenergy, In Press, 2017.

[4] R.C. Sun, X.F. Sun, S.Q. Wang, W. Zhu, and X.Y. Wang, "Ester and ether linkages between hydroxycinnamic acids and lignins from wheat, rice, rye, and barley straws, maize stems, and fast-growing poplar wood," Industrial Crops and Products, vol. 15, pp. 179$188,2002$.

[5] K. Kim, and J. Hong, "Supercritical $\mathrm{CO}_{2}$ pretreatment of lignocellulose enhance enzymatic cellulose hydrolysis," Biore-source Technology, vol. 77, pp. 1139-144, 2001.

[6] C. Krapf, A. Bauer, T. Amon, E. Haimer and M. Wendland. "Hochdruckverfahren zum Aufschluss von Lignocellulose aus Stroh", Chem.-Ing.-Tech. vol. 81, pp. 1213-1214, 2009. (C. Krapf, Master Thesis, Vienna, 2008.)

[7] K. Naumann, R. Bassler, Methodenbuch. Band III. Die chemische Untersuchung von Futtermitteln (5th ed.) VDLUFA-Verlag, Darmstadt, Germany, 2004.

[8] J. Theiner, Elemental C/H/N/S Analysis. Austria: Microanalytical Laboratory, University of Vienna, 2003.

[9] D. Pasquini, M.T. Borges Pimenta, and L.H. Ferreira, "Extraction of lignin from sugar cane bagasse and Pinus taeda wood chips using ethanol-water mixtures and carbon dioxide at high pressures", The Journal of Supercritical Fluids, vol. 36, pp. 31-39, 2005.

[10] VDI 4630, Fermentation of organic materials. In: Characterisation of Substrate, Sampling, Collection of Material Data, Fermentation Tests. Germany: Verein Deuscher Ingenieure, Düsseldor, 2003.

[11] W.C Boyle, "Energy recovery from sanitary landfills - a review.” In: H-G. Schlegel and J. Barnea, Microbial Energy Conversion. Oxford: Pergamon Press, 1976, pp. 119-138.

[12] Phyllis2 - Database for biomass and waste - ECN. https://www.ecn.nl/phyllis2

[13] K. Öhgren, R. Bura, J. Saddler, and G. Zacchini "Effect of hemicellulose and lignin removal on enzymatic hydrolysis of steam pretreated corn stover", Bioresource Technology, vol. 98, pp. 2503-2510, 2007.

[14] B. Yang, and C.E. Wyman "Pretreatment: the key to unlocking low-cost cellulosoic ethanol", Biofuels Bioproducts and Biorefining, vol. 2, pp. 26-40, 2008.

[15] A. Mouahid, C. Crampon, S. A. Toudji, and E. Badens "Effects of high water content and drying pre-treatment on supercritical $\mathrm{CO} 2$ extraction from Dunaliella salina microalgae: 
$10^{\text {Th }}$ International Conference on Sustainable Energy and Environmental Protection (June $27^{\mathrm{TH}}-30^{\mathrm{TH}}, 2017$, BLed, Slovenia), Bioenergy AND Biofuels

R. Al Afif, M. Wendland, L.C. Krapf, T. Amon \& C. Pfeifer: Organosolv Plus Supercritival Carbon Dioxide Pre-Treatment of Cotton Stalks for Methane Production

Experiments and modelling”, The Journal of Supercritical Fluids, vol. 116, pp. 271-280, October 2016.

[16] M. Gao, F. Xu, Li, X. Ji, S. Chen, and D. Zhang "Effect of $\mathrm{SC}^{-\mathrm{CO}_{2}}$ pretreatment in increasing rice straw biomass conversion", Biosystems Engineering, vol. 106, pp. 470-475, October 2010.

[17] V.S. Chang, and M.T. Holtzapple "Fundamental factors affecting enzymatic reactivity", Applied biochemistry and biotechnology, vol. 84, pp. 5-37, March 2000.

[18] F. Montañés, T. Fornari, R. Stateva, A. Olano, and E. Ibáñez "Solubility of carbohydrates in supercritical carbon dioxide with (ethanol + water) cosolvent", The Journal of Supercritical Fluids, vol. 49, pp. 16-22, May 2009.

[19] I. A. Hilkiah, M.J. Ayotamuno, C.L. Eze, S.O.T. Ogaji, and S.D. Probert "Designs of anaerobic digesters for producing biogas from municipal solid-waste", Applied Energy, vol. 85, pp. 430-438, June 2008. 
$10^{\mathrm{TH}}$ INTERNATIONAL CONFERENCE ON Sustainable ENERgy AND ENVIRONMENTAL Protection (June $27^{\mathrm{TH}}-30^{\mathrm{TH}}$, 2017, Bled, SLOVENIA), BIOENERGY AND BIOFUELS

J. Krope, A.Ghani Olabi, D. Goričanec \& S. Božičnik

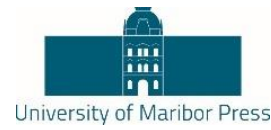

\title{
Chemical Looping Combustion of Biomass: Clou Experiments with a Cu-Mn Mixed Oxide
}

\author{
TERESA MENDIARA, IÑAKI AdÁNEZ-Rubio, ANTÓN PÉREZ-ASTRAY, MARÍA TERESA \\ IZQuierdo, Alberto ABAD, PILAR GAYÁn, Luis F. DE DIEGO, FrANCISCO GARCÍA- \\ LABIANO \& JUAN ADÁNEZ
}

\begin{abstract}
Chemical looping combustion (CLC) is a low-cost CO2 capture technology with a low energy penalty. The use of biomass as a fuel combined with carbon capture and storage (BECCS) creates a potential for negative $\mathrm{CO} 2$ emissions. The oxygen needed for combustion in CLC is supplied by a solid oxygen carrier circulating between the fuel reactor (FR) and air reactor (AR). In this work, the combustion of pine sawdust is studied in a continuous $1.5-\mathrm{kW}$ th CLC unit. A Cu-Mn mixed oxide was used as the oxygen carrier. This material releases gaseous oxygen when it is reduced by chemical looping with oxygen uncoupling (CLOU). The released oxygen reacts with both the volatiles and char generated from biomass in the FR. The oxygen carrier is reoxidized in air inside the AR. High CO2 capture and 100\% combustion efficiencies were achieved. The $\mathrm{O} 2$ concentration inside the AR did not affect $\mathrm{CO} 2$ capture efficiency.
\end{abstract}

Keywords: • CO2 capture • Chemical looping combustion • CLOU • Biomass • BECCS •

CoRRESPONDENCE ADDRESS: Teresa Mendiara, Ph.D., "Ramón y Cajal" Postdoctoral Researcher, Instituto de Carboquímica (ICB-CSIC), Miguel Luesma Castán 4, 50018 Zaragoza, Spain, e-mail: tmendiara@icb.csic.es. Iñaki Adánez-Rubio, Ph.D., Postdoctoral Researcher, Instituto de Carboquímica (ICBCSIC), Miguel Luesma Castán 4, 50018 Zaragoza, Spain, e-mail: iadanez@icb.csic.es. Antón Pérez-Astray, $\mathrm{Ph}$.D. student, Instituto de Carboquímica (ICB-CSIC), Miguel Luesma Castán 4, 50018 Zaragoza, Spain, email: aperez@icb.csic.es. María Teresa Izquierdo, Ph.D., Tenured Scientist, Instituto de Carboquímica (ICBCSIC), Miguel Luesma Castán 4, 50018 Zaragoza, Spain, e-mail: mizq@icb.csic.es. Alberto Abad, Ph.D., Tenured Scientist, Instituto de Carboquímica (ICB-CSIC), Miguel Luesma Castán 4, 50018 Zaragoza, Spain, e-mail: abad@icb.csic.es. Pilar Gayán, Ph.D., Tenured Scientist, Instituto de Carboquímica (ICB-CSIC), Miguel Luesma Castán 4, 50018 Zaragoza, Spain, e-mail: pgayan@icb.csic.es. Luis F. de Diego, Ph.D., Tenured Scientist, Instituto de Carboquímica (ICB-CSIC), Miguel Luesma Castán 4, 50018 Zaragoza, Spain, e-mail: ldediego@icb.csic.es. Francisco García-Labiano, Ph.D., Tenured Scientist, Instituto de Carboquímica (ICB-CSIC), Miguel Luesma Castán 4, 50018 Zaragoza, Spain, e-mail: glabiano@icb.csic.es. Juan Adánez, Ph.D., Research Professor, Instituto de Carboquímica (ICB-CSIC), Miguel Luesma Castán 4, 50018 Zaragoza, Spain, e-mail: jadanez@icb.csic.es.

https://doi.org/10.18690/978-961-286-048-6.4

ISBN 978-961-286-048-6

(C) 2017 University of Maribor Press

Available at: http://press.um.si. 
$34 \mid 10^{\text {TH }}$ InTERnational CONFERENCE ON Sustainable ENERGy AND ENVIRONMENTAL Protection (June $27^{\mathrm{TH}}-30^{\mathrm{TH}}, 2017$, BLed, Slovenia), Bioenergy AND Biofuels

T. Mendiara, I. Adánez-Rubio, A. Pérez-Astray, M. Teresa Izquierdo, A. Abad, P. Gayán, L. F. de Diego, F. García-Labiano \& J. Adánez: Chemical Looping Combustion of Biomass: Clou Experiments with a $\mathrm{Cu}-\mathrm{Mn}$ Mixed Oxide

According to the Paris Agreement (2015) [1], in order to limit global temperature increase to $2{ }^{\circ} \mathrm{C}$ or less, it is necessary to reduce $\mathrm{CO}_{2}$ emissions into the atmosphere, and even to obtain negative $\mathrm{CO}_{2}$ emissions in the course of this century. Carbon capture and storage (CCS) technologies enable $\mathrm{CO}_{2}$ capture from large stationary combustion sources. If biomass is used in these processes as fuel, then these technologies are known as bioenergy with carbon capture and storage (BECCS) technologies [2]. Biomass is a $\mathrm{CO}_{2}$ neutral fuel. Therefore, BECCS technologies allow $\mathrm{CO}_{2}$ to be removed from the atmosphere, making the concept of negative $\mathrm{CO}_{2}$ emissions possible [3].

One of the CCS technologies with the lowest associated energy penalty and cost is chemical looping combustion (CLC) technology [4]. The basic principle behind CLC is the avoidance of contact between fuel and air during the combustion process. Therefore, inherent $\mathrm{CO}_{2}$ capture is obtained in the process. In CLC, the oxygen needed for combustion is supplied by a solid oxygen carrier, normally a metal oxide,

circulating between two interconnected reactors: the fuel and air reactors. The fuel is burnt inside the fuel reactor to $\mathrm{CO}_{2}$ and $\mathrm{H}_{2} \mathrm{O}$ as the oxygen carrier is reduced. The reduced oxygen carrier is then transferred to the air reactor where it is reoxidized in air before a new cycle begins. Certain oxygen carriers are able to release gaseous oxygen as they are reduced. This is known as chemical looping with oxygen uncoupling (CLOU). The gaseous oxygen is able to burn the volatiles and char generated once the solid fuel has been introduced into the fuel reactor.

The feasibility of the CLC of biomass under CLOU mode has already been demonstrated by Adánez-Rubio et al. [5] using a Cu-based oxygen carrier, in which high $\mathrm{CO}_{2}$ capture and combustion efficiencies were achieved. No more works on CLOU of biomass have been found in the literature to date. Therefore, the aim of the present work is to further analyse this process. A new oxygen carrier was used in the present experiments that allowed fuel reactor operation at even lower temperatures (up to $850^{\circ} \mathrm{C}$ ).

\section{$2 \quad$ Experimental}

\subsection{Materials}

$\mathrm{A} \mathrm{Cu}-\mathrm{Mn}$ mixed oxide was used as the oxygen carrier for the CLOU process. The oxygen carrier was prepared by spray granulation in a spouted bed system at ICB-CSIC. The CuO content of particles was $34 \mathrm{wt} \%$ and the remaining $66 \mathrm{wt} \%$ comprised $\mathrm{Mn}_{3} \mathrm{O}_{4}$. The particles were calcined for $2 \mathrm{~h}$ at $1125^{\circ} \mathrm{C}$. The active phase in the mixed oxide was $\mathrm{Cu}_{1.5} \mathrm{Mn}_{1.5} \mathrm{O}_{4}$. Reaction (1) describes the release of gaseous oxygen by the oxygen carrier.

$2 \mathrm{Cu}_{1.5} \mathrm{Mn}_{1.5} \mathrm{O}_{4} \leftrightarrow 3 \mathrm{CuMnO}_{2}+\mathrm{O}_{2}$ 
$10^{\mathrm{TH}}$ INTERNATIONAL CONFERENCE ON SUSTAINABLE ENERGY AND ENVIRONMENTAL

T. Mendiara, I. Adánez-Rubio, A. Pérez-Astray, M. Teresa Izquierdo, A. Abad, P. Gayán, L. F. de Diego, F. García-Labiano \& J. Adánez: Chemical Looping Combustion of Biomass: Clou Experiments with a $\mathrm{Cu}-\mathrm{Mn}$ Mixed Oxide

Table 1 shows the main properties of the oxygen carrier. The particle size used was $+100-$ $300 \mu \mathrm{m}$. The oxygen carrier is subsequently referred to as Cu34Mn66-GR.

Table 1. Properties of the oxygen carrier.

\begin{tabular}{lc}
\hline Oxygen transport capacity, $\mathrm{R}_{\mathrm{OC}}(\mathrm{wt} \%)$ & 4.0 \\
Crushing strength $(\mathrm{N})$ & 1.9 \\
Real density $\left(\mathrm{kg} / \mathrm{m}^{3}\right)$ & 3900 \\
Porosity $(\%)$ & 12 \\
Specific surface area, BET $\left(\mathrm{m}^{2} / \mathrm{g}\right)$ & $<0.5$ \\
XRD main phases & $\mathrm{Cu}_{1.5} \mathrm{Mn}_{1.5} \mathrm{O}_{4}, \mathrm{Mn}_{3} \mathrm{O}_{4}$ \\
\hline
\end{tabular}

A pine sawdust biomass was used for the combustion experiments. The properties of this biomass are given in Table 2 . The particle size used for this study was $+500-2000 \mu \mathrm{m}$.

Table 2. Properties of the biomass.

\begin{tabular}{|c|c|c|c|}
\hline \multicolumn{2}{|c|}{ Proximate Analysis (wt\%) } & \multicolumn{2}{|c|}{ Ultimate Analysis (wt\%) } \\
\hline Moisture & 4.2 & $\mathrm{C}$ & 51.3 \\
\hline Ash & 0.4 & $\mathrm{H}$ & 6.0 \\
\hline Volatile matter & 81.0 & $\mathrm{~N}$ & 0.3 \\
\hline Fixed carbon & 14.4 & $\mathrm{~S}$ & 0.0 \\
\hline & & $\mathrm{O}^{*}$ & 37.8 \\
\hline LHV $(\mathrm{kJ} / \mathrm{kg})$ & & & \\
\hline
\end{tabular}

*Calculated by difference.

\subsection{The experimental set-up}

A schematic view of the plant is shown in Figure 1. The set-up basically comprised two interconnected fluidized bed reactors - the air and fuel reactors - joined by a loop seal, a riser for solids transport from the air reactor to the fuel reactor, a cyclone, and a solids valve to control the solids circulation flow rate in the system. A diverting solids valve located below the cyclone allowed the measurement of the solids flow rates at any time. Therefore, this design allowed the solids circulation flow rate between both reactors to be controlled and measured.

The fuel reactor consisted of a bubbling fluidized bed with an inner diameter of $5 \mathrm{~cm}$ and a bed height of $20 \mathrm{~cm}$. The fuel reactor was fluidized with $\mathrm{N}_{2}$ for an accurate analysis of the results. The gas flow was $250 \mathrm{LN}_{\mathrm{N}} / \mathrm{h}$, corresponding to a gas velocity of $\sim 0.15 \mathrm{~m} / \mathrm{s}$ at $900{ }^{\circ} \mathrm{C}$. Biomass was fed by a screw feeder at the bottom of the bed, directly above the fuel reactor distributor plate, in order to maximize the time that the fuel and volatile matter were in contact with the bed material. A small $\mathrm{N}_{2}$ flow $\left(24 \mathrm{~L}_{\mathrm{N}} / \mathrm{h}\right)$ was introduced at the beginning of the screw feeder to avoid any possible reverse gas flow. The oxygen carrier was reduced in the fuel reactor and burnt the fuel. Reduced oxygen carrier particles overflowed into the air reactor through a U-shaped fluidized bed loop seal with an inner diameter of $3 \mathrm{~cm}$, to prevent gas mixing between the fuel and air. A $\mathrm{N}_{2}$ flow of $90 \mathrm{~L}_{\mathrm{N}} / \mathrm{h}$ was introduced into the loop seal. 
$10^{\text {Th }}$ International Conference on Sustainable Energy and Environmental Protection (June $27^{\mathrm{TH}}-30^{\mathrm{TH}}, 2017$, BLed, Slovenia), Bioenergy AND Biofuels

T. Mendiara, I. Adánez-Rubio, A. Pérez-Astray, M. Teresa Izquierdo, A. Abad, P. Gayán, L. F. de Diego, F. García-Labiano \& J. Adánez: Chemical Looping Combustion of Biomass: Clou Experiments with a $\mathrm{Cu}-\mathrm{Mn}$ Mixed Oxide

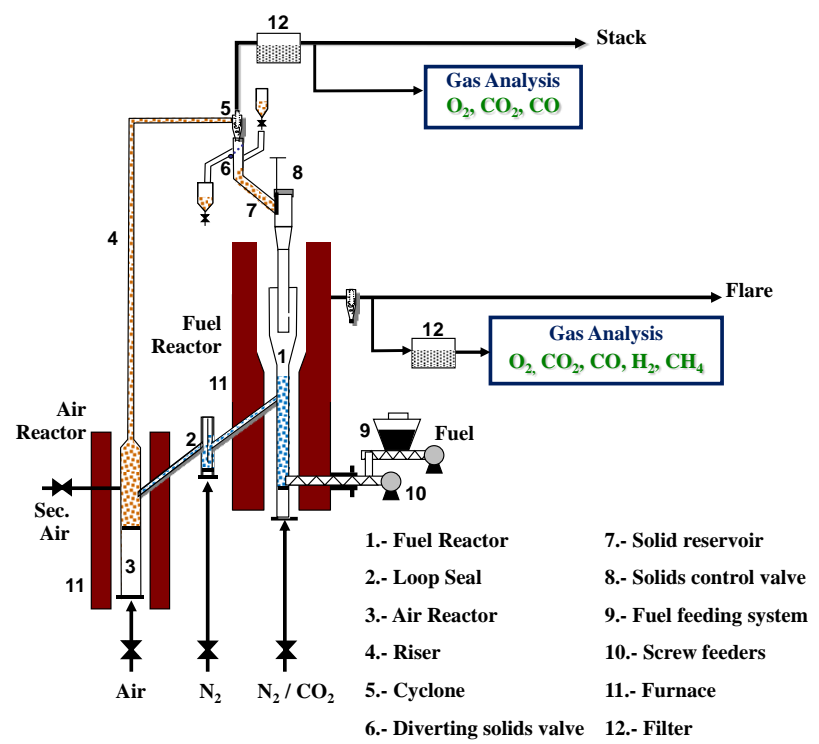

Figure 1. Schematic view of the ICB-CSIC-s1 unit.

Oxidation of the carrier took place in the air reactor, consisting of a bubbling fluidized bed with an inner diameter of $8 \mathrm{~cm}$ and a bed height of $10 \mathrm{~cm}$, followed by a riser. The air flow was $2100 \mathrm{~L}_{\mathrm{N}} / \mathrm{h}$. In addition, a secondary air flow $\left(600 \mathrm{~L}_{\mathrm{N}} / \mathrm{h}\right)$ was introduced at the top of the bubbling bed to assist particle entrainment. $\mathrm{N}_{2}$ and unreacted $\mathrm{O}_{2}$ left the air reactor and passed through a high-efficiency cyclone and a filter before reaching the stack. The oxidized solid particles recovered by the cyclone were sent to a solids reservoir, leaving the oxygen carrier ready to start a new cycle. Moreover, these particles would act as a loop seal to prevent the leakage of gas between the fuel reactor and the riser. The regenerated oxygen carrier particles were returned to the fuel reactor by gravity from the solids reservoir through a solids valve, which controlled the flow rate of solids entering the fuel reactor.

The total oxygen carrier inventory in the system was $3 \mathrm{~kg}$, with about $1 \mathrm{~kg}$ in the fuel reactor. The concentration of $\mathrm{CO}, \mathrm{CO}_{2}, \mathrm{H}_{2}, \mathrm{CH}_{4}$ and $\mathrm{O}_{2}$ at the fuel reactor outlet, and that of $\mathrm{CO}, \mathrm{CO}_{2}$ and $\mathrm{O}_{2}$ from the air reactor were continuously recorded. A non-dispersive infrared (NDIR) analyser (Siemens Ultramat 23) was used to measure $\mathrm{CH}_{4}, \mathrm{CO}$ and $\mathrm{CO}_{2}$ concentrations; a paramagnetic analyser (Siemens Ultramat 23 and Oxymat 6) was used to measure $\mathrm{O}_{2}$ concentrations; and a thermal conductivity detector (Siemens Calomat 6) was used for $\mathrm{H}_{2}$. 
$10^{\mathrm{TH}}$ INTERNATIONAL CONFERENCE ON SUSTAINABLE ENERGY AND ENVIRONMENTAL

Protection (June $27^{\mathrm{TH}}-30^{\mathrm{TH}}, 2017$, Bled, Slovenia), Bioenergy AND Biofuels

T. Mendiara, I. Adánez-Rubio, A. Pérez-Astray, M. Teresa Izquierdo, A. Abad, P. Gayán, L. F. de Diego, F. García-Labiano \& J. Adánez: Chemical Looping Combustion of Biomass: Clou Experiments with a $\mathrm{Cu}-\mathrm{Mn}$ Mixed Oxide

\subsection{Experimental planning}

Table 3 provides a summary of the main variables used in each test. In total, the same batch of oxygen carrier particles was used during $21 \mathrm{~h}$ of hot fluidization conditions, of which $14 \mathrm{~h}$ corresponded to biomass combustion.

Table 3. Operating variables in CLOU tests.

\begin{tabular}{ccccccc}
\hline Test & $\mathrm{T}_{\mathrm{FR}}$ & {$\left[\mathrm{O}_{2}\right]_{\text {in,FR }}$} & $\square$ & $\dot{\mathrm{m}}_{\mathrm{OC}}$ & Power & $\mathrm{m}_{\mathrm{FR}}^{*}$ \\
\hline & $\left({ }^{\circ} \mathrm{C}\right)$ & $(\mathrm{vol} . \%)$ & $\square$ & $(\mathrm{kg} / \mathrm{h})$ & $(\mathrm{W})$ & $\left(\mathrm{kg} / \mathrm{MW}_{\mathrm{th}}\right)$ \\
\hline $\mathrm{T} 01$ & $\mathbf{7 7 5}$ & 21 & 3.9 & 22.5 & 740 & 1200 \\
$\mathrm{~T} 02$ & $\mathbf{8 0 0}$ & 21 & 3.9 & 22.5 & 740 & 1200 \\
$\mathrm{~T} 03$ & $\mathbf{8 2 5}$ & 21 & 3.9 & 22.5 & 740 & 1200 \\
$\mathrm{~T} 04$ & $\mathbf{8 5 0}$ & 21 & 3.9 & 22.5 & 740 & 1200 \\
$\mathrm{~T} 05$ & 800 & $\mathbf{1 0}$ & 3.9 & 22.5 & $\mathbf{7 4 0}$ & 1200 \\
$\mathrm{~T} 06$ & 800 & $\mathbf{1 0}$ & 3.4 & 28.5 & $\mathbf{1 0 0 0}$ & 900 \\
$\mathrm{~T} 07$ & 800 & $\mathbf{1 0}$ & 2.6 & 28.5 & $\mathbf{1 3 3 0}$ & 715 \\
\hline
\end{tabular}

Pine sawdust biomass was fed into the fuel reactor, allowing analysis of the combustion efficiency of biomass in the CLOU system. The fuel reactor temperature was varied between $775^{\circ} \mathrm{C}$ and $850^{\circ} \mathrm{C}$ (Tests T01-T04). The temperature in the air reactor was maintained at around $800{ }^{\circ} \mathrm{C}$. The solids circulation rate ( $\dot{\mathrm{m}}_{\mathrm{OC}}$ ) was 22.5 or $28.5 \mathrm{~kg} / \mathrm{h}$. The biomass feeding rate was in the range of $0.140-0.250 \mathrm{~kg} / \mathrm{h}$, which corresponds to a power input range of 740 to $1330 \mathrm{~W}_{\text {th }}$ (Tests T05-T07). The oxygen concentration available in the air reactor and its effect on combustion and $\mathrm{CO}_{2}$ capture efficiencies was also studied. The oxygen carrier to fuel ratio, $\phi$, defined by Equation (1), varied between 2.6 and 3.9.

The oxygen carrier to fuel ratio $(\phi)$ was defined by the following equation:

$$
\phi=\frac{\text { Oxygen supplied by the oxygen carrier }}{\text { Oxygen demanded by the fuel for full combustion }}
$$

To analyse the performance of the CLOU process, both combustion efficiency in the fuel reactor and $\mathrm{CO}_{2}$ capture efficiency were calculated. Calculations are based on the molar flow of every gas analysed, $\mathrm{F}_{\mathrm{i}}$, which is determined from the measured concentrations. Mass balances were performed and a carbon balance closure of about $95 \%$ was found. Combustion efficiency in the fuel reactor was calculated by means of the ratio between the oxygen required to fully burn unconverted gases $\left(\mathrm{CH}_{4}, \mathrm{CO}\right.$ and $\left.\mathrm{H}_{2}\right)$ at the fuel reactor exit and the oxygen demanded by the biomass converted in the fuel reactor. Thus, the oxygen demanded by the carbon bypassed to the air reactor, $\mathrm{F}_{\mathrm{CO}_{2}, \mathrm{AR}}$, is subtracted from the oxygen demanded by biomass in the denominator. Therefore, the combustion efficiency in the fuel reactor was calculated as: 
$10^{\mathrm{TH}}$ INTERNATIONAL CONFERENCE ON SUSTAINABLE ENERGy AND ENVIRONMENTAL Protection (June $27^{\mathrm{TH}}-30^{\mathrm{TH}}, 2017$, BLed, Slovenia), Bioenergy and Biofuels

T. Mendiara, I. Adánez-Rubio, A. Pérez-Astray, M. Teresa Izquierdo, A. Abad, P. Gayán, L. F. de Diego, F. García-Labiano \& J. Adánez: Chemical Looping Combustion of Biomass: Clou Experiments with a $\mathrm{Cu}-\mathrm{Mn}$ Mixed Oxide

$$
\eta_{\text {comb }, \mathrm{FR}}=1-\frac{4 \mathrm{~F}_{\mathrm{CH}_{4}, \mathrm{FR}}-\mathrm{F}_{\mathrm{CO}, \mathrm{FR}}+\mathrm{F}_{\mathrm{H}_{2}, \mathrm{FR}}}{\frac{1}{\mathrm{M}_{\mathrm{O}_{2}}} 2 \Omega_{\mathrm{SF}} \dot{\mathrm{m}}_{\mathrm{SF}}-2 \mathrm{~F}_{\mathrm{CO}_{2}, \mathrm{AR}}}
$$

where $\Omega_{\mathrm{SF}}$ is the stoichiometric mass of the $\mathrm{O}_{2}$ required to convert $1 \mathrm{~kg}$ of biomass $(\mathrm{kg} / \mathrm{kg}) ; \dot{\mathrm{m}}_{\mathrm{SF}}$ is the mass-based flow of biomass fed into the fuel reactor $(\mathrm{kg} / \mathrm{s}) ;$ and $\mathrm{M}_{\mathrm{O} 2}$ the molecular weight of $\mathrm{O}_{2}(\mathrm{~kg} / \mathrm{mol})$.

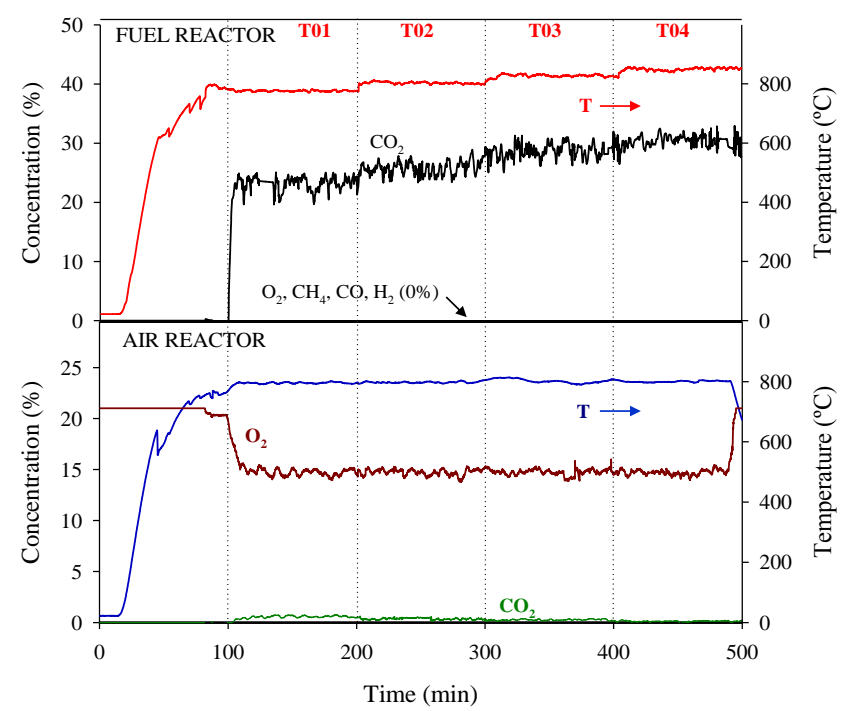

Figure 2. Evolution of the gas composition in the air and fuel reactors as temperature in the fuel reactor was varied. Tests T01-T04. $\dot{\mathrm{m}}_{\mathrm{OC}}=22.5 \mathrm{~kg} / \mathrm{h} ; \dot{\mathrm{m}}_{\mathrm{SF}}=0.140 \mathrm{~kg} / \mathrm{h}$.

The $\mathrm{CO}_{2}$ capture efficiency, $\eta_{C C}$, was defined as the fraction of carbon initially present in the fed-in biomass which is actually at the outlet of fuel reactor as $\mathrm{CO}_{2}$. This is the actual $\mathrm{CO}_{2}$ captured in the CLOU system; the rest exits together with nitrogen at the air reactor outlet.

$$
\eta_{\mathrm{CC}}=1-\frac{\mathrm{F}_{\mathrm{CO}_{2}, \mathrm{AR}}}{\mathrm{F}_{\mathrm{CO}_{2}, \mathrm{FR}}+\mathrm{F}_{\mathrm{CO}, \mathrm{FR}}+\mathrm{F}_{\mathrm{CH}_{4}, \mathrm{FR}}+\mathrm{F}_{\mathrm{CO}_{2}, \mathrm{AR}}}
$$

Carbon capture efficiency depends on the conversion of char in the fuel reactor. The char conversion in the fuel reactor, $\mathrm{X}_{\mathrm{char}}$, was calculated considering the carbon contained in the fed-in biomass remaining in the char, i.e. fixed carbon, and the carbon not converted in the fuel reactor, which exits as $\mathrm{CO}_{2}$ from the air reactor. 
$10^{\mathrm{TH}}$ INTERNATIONAL CONFERENCE ON SUSTAINABLE ENERGY AND ENVIRONMENTAL

T. Mendiara, I. Adánez-Rubio, A. Pérez-Astray, M. Teresa Izquierdo, A. Abad, P. Gayán, L. F. de Diego, F. García-Labiano \& J. Adánez: Chemical Looping Combustion of Biomass: Clou Experiments with a $\mathrm{Cu}-\mathrm{Mn}$ Mixed Oxide

$\mathrm{X}_{\text {char }}=\frac{x_{\mathrm{fc}} \dot{\mathrm{m}}_{\mathrm{SF}}-\mathrm{M}_{\mathrm{C}} \mathrm{F}_{\mathrm{CO}_{2}, \mathrm{AR}}}{x_{\mathrm{fc}} \dot{\mathrm{m}}_{\mathrm{SF}}}$

where $x_{\mathrm{fc}}$ is the mass fraction of fixed carbon in biomass and $\mathrm{M}_{\mathrm{C}}$ is atomic weigh of $\mathrm{C}$ $(\mathrm{kg} / \mathrm{mol})$.

\section{$3 \quad$ Results}

To investigate the combustion of biomass by a CLOU system, different tests were conducted under continuous operation in the ICB-CSIC-s1 experimental rig. The composition of the gases exiting the fuel and air reactors was determined. $\mathrm{N}_{2}$ was used as the fluidizing gas instead of $\mathrm{CO}_{2}$ in order to improve accuracy for calculating the $\mathrm{C}$ burnt in the fuel reactor. The effect of the fuel reactor temperature and power input on the combustion and $\mathrm{CO}_{2}$ capture efficiencies were investigated. A total of $14 \mathrm{~h}$ of biomass combustion was carried out without agglomeration of the oxygen carrier.

The composition of the exit gases from the fuel and air reactors was determined for every experimental condition. An example is given in Figure 2, which shows the concentration of gases (dry basis) measured as a function of the operating time, where the fuel reactor temperature was varied between $775^{\circ} \mathrm{C}$ and $850{ }^{\circ} \mathrm{C}$, and each temperature was maintained at a steady state for at least $60 \mathrm{~min}$.

When the temperature was varied, a transition period appeared and stable combustion was reached usually in less than $20 \mathrm{~min}$. The steady state was reached when the oxygen transferred from the oxygen carrier to the fuel was equal to the oxygen transferred from the air to the oxygen carrier. At the steady state, the gas outlet concentration and temperature remained uniform throughout the entire combustion time. It can be seen that even at low temperatures $\left(775^{\circ} \mathrm{C}\right)$ no $\mathrm{CH}_{4}, \mathrm{CO}$ or $\mathrm{H}_{2}$ were detected in the gases exiting from the fuel reactor, only $\mathrm{CO}_{2}$ and $\mathrm{H}_{2} \mathrm{O}$. Therefore, volatiles were fully converted into $\mathrm{CO}_{2}$ and $\mathrm{H}_{2} \mathrm{O}$ in the fuel reactor by reaction with the oxygen released from the Cu34Mn66-GR decomposition.

Figure 3 shows combustion, $\mathrm{CO}_{2}$ capture efficiency and char conversion as a function of fuel reactor temperature (Tests T01-T04). The complete combustion of biomass to $\mathrm{CO}_{2}$ and $\mathrm{H}_{2} \mathrm{O}$ was achieved in the fuel reactor for all the experiments, i.e. $\eta_{\text {comb,FR }}=100 \%$. The specific solids inventory in the fuel reactor, $\mathrm{m}_{\mathrm{FR}}^{*}$, was about $1200 \mathrm{~kg} / \mathrm{MW}_{\text {th }}$ in all tests. Nevertheless, complete combustion could be expected even with a lower solids inventory. The pine sawdust used contained $81 \%$ volatile matter; therefore, even with this high volatile matter content, the results show full combustion of the biomass in all tests. Note that unburnt compounds are always present at the fuel reactor outlet when materials without oxygen uncoupling properties are used, even if they are highly reactive materials or a high solids inventory is used [6]. 
T. Mendiara, I. Adánez-Rubio, A. Pérez-Astray, M. Teresa Izquierdo, A. Abad, P. Gayán, L. F. de Diego, F. García-Labiano \& J. Adánez: Chemical Looping Combustion of Biomass: Clou Experiments with a $\mathrm{Cu}-\mathrm{Mn}$ Mixed Oxide

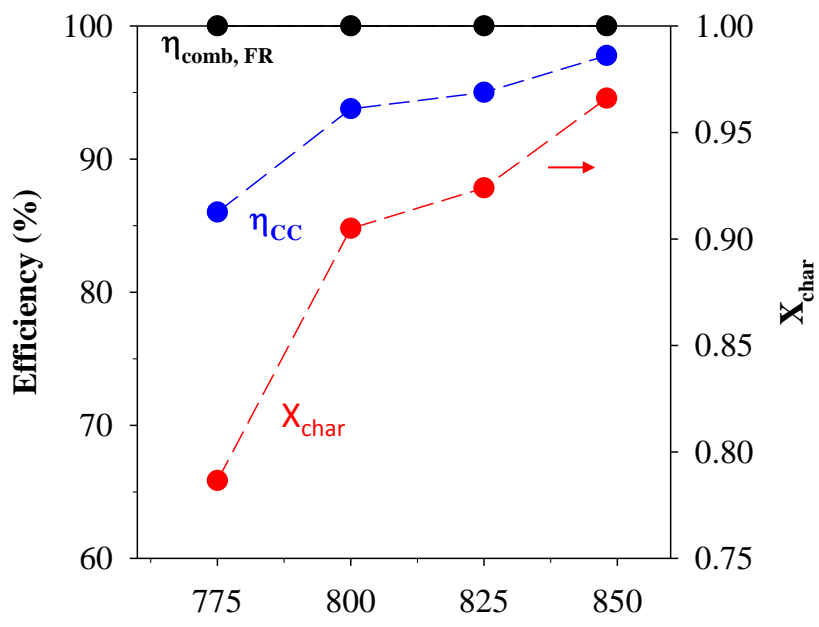

Fuel reactor temperature $\left({ }^{\circ} \mathrm{C}\right)$

Figure 3. Effect of fuel reactor temperature on the CLOU process performance.

Tests T01-T04.

On the other hand, $\mathrm{CO}_{2}$ capture efficiency in the CLOU system is determined by char conversion in the fuel reactor, because the unburnt char is transferred to the air reactor where it is burnt and the resulting gases released into the atmosphere. High values of $\mathrm{CO}_{2}$ capture efficiency are seen to have been obtained in all cases $(>90 \%)$ with temperatures higher than $800^{\circ} \mathrm{C}$.

Figure 3 shows the positive effect of fuel reactor temperature on $\mathrm{CO}_{2}$ capture efficiency. The $\mathrm{CO}_{2}$ capture efficiency increased from $86 \%$ to $95 \%$ with an increase of $50{ }^{\circ} \mathrm{C}$ in the fuel reactor temperature. When the fuel reactor temperature reached $850{ }^{\circ} \mathrm{C}$, the value of the $\mathrm{CO}_{2}$ capture efficiency increased to $98 \%$. At these conditions, $\mathrm{CO}_{2}$ capture efficiency showed a value as high as $98 \%$, without the presence of a carbon separation system, e.g. use of a carbon stripper could be avoided. This high value of $\mathrm{CO}_{2}$ capture efficiency is particularly remarkable given the relatively low temperature in the fuel reactor. With a $\mathrm{Cu}$-based CLOU oxygen carrier in the same continuous unit and using the same biomass as fuel, temperatures higher than $920^{\circ} \mathrm{C}$ were needed to achieve the same $\mathrm{CO}_{2}$ capture efficiency value [5]. The high $\mathrm{CO}_{2}$ capture efficiencies with $\mathrm{Cu}-\mathrm{Mn}$ mixed oxides are due to the fact that these carriers are able to produce high gaseous $\mathrm{O}_{2}$ concentrations at lower temperatures, between $800{ }^{\circ} \mathrm{C}$ and $900{ }^{\circ} \mathrm{C}$ [7], and therefore there is a faster conversion of char in the fuel reactor. 
$10^{\mathrm{TH}}$ INTERNATIONAL CONFERENCE ON SUSTAINABLE ENERGY AND ENVIRONMENTAL

T. Mendiara, I. Adánez-Rubio, A. Pérez-Astray, M. Teresa Izquierdo, A. Abad, P. Gayán, L. F. de Diego, F. García-Labiano \& J. Adánez: Chemical Looping Combustion of Biomass: Clou Experiments with a $\mathrm{Cu}-\mathrm{Mn}$ Mixed Oxide

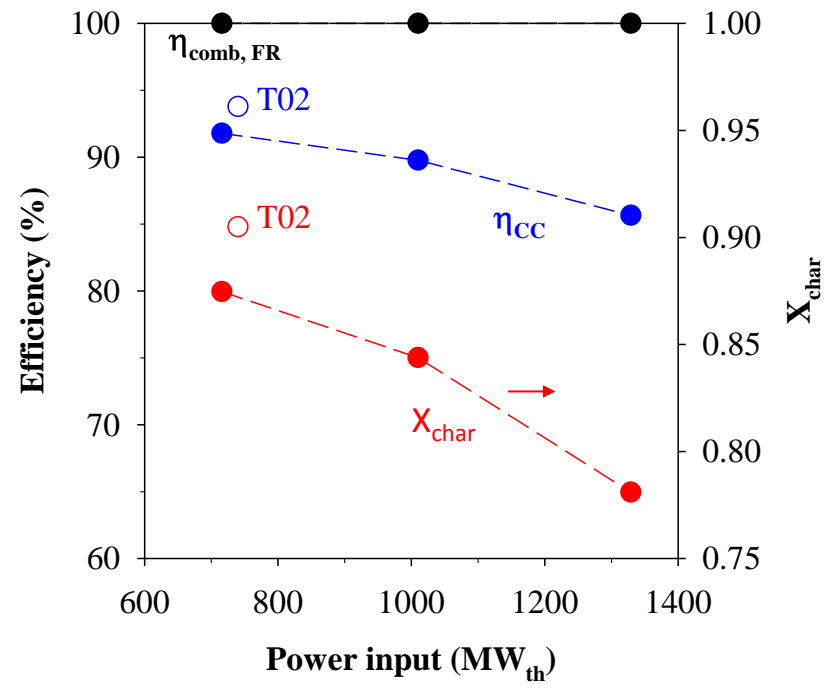

Figure 4. Effect of power input on the CLOU process performance. Tests T05-T07.

Figure 3 also shows how char conversion values increased with the temperature. By increasing the fuel reactor temperature, char combustion rates were higher, thus reducing the amount of unburnt char transferred to the air reactor.

The biomass feeding rate (power input) had a lower effect on CLC performance than fuel reactor temperature (Tests T05-T06). However, an effect on the $\mathrm{CO}_{2}$ capture efficiency could be appreciated that was directly related to char conversion in the fuel reactor, see Figure 4. However, when the biomass feeding rate was increased, $\mathrm{CO}_{2}$ capture efficiency became lower as a result of the decrease in char conversion in the fuel reactor. When the biomass feeding rate increases, the value of $\phi$ and the oxygen carrier inventory decreases; see Table 3. A decrease in this value increases oxygen carrier conversion in the fuel reactor, and decreases the $\mathrm{O}_{2}$ release rate of $\mathrm{Cu}-\mathrm{Mn}$ mixed oxides. Thus, char conversion depends on oxygen carrier conversion [7]. We would point out that even with a power input of $1330 \mathrm{~W}_{\text {th }}$ and at such a low fuel reactor temperature as $800{ }^{\circ} \mathrm{C}$, there was complete combustion of the biomass. Higher $\mathrm{CO}_{2}$ capture efficiency can be obtained by increasing the temperature to $850^{\circ} \mathrm{C}$, an optimum temperature at which to operate the fuel reactor when using the $\mathrm{Cu} 34 \mathrm{Mn} 66-\mathrm{GR}$ oxygen carrier.

Moreover, Tests T05-T07 analysed the effect of the oxygen concentration available to regenerate the oxygen in the air reactor on $\mathrm{CO}_{2}$ capture efficiency and char conversion. It can be seen that with a $10 \mathrm{vol} \%$ of $\mathrm{O}_{2}$ at the inlet flow to the air reactor $\left(\mathrm{O}_{2}\right.$ concentration of $4 \mathrm{vol} \%$ in the outlet stream), the $\mathrm{CO}_{2}$ capture efficiency and char conversion were stable at around $92 \%$ and 0.89 respectively, when comparing tests $\mathrm{T} 02$ 
$10^{\text {Th }}$ International Conference on Sustainable Energy and Environmental Protection (June $27^{\mathrm{TH}}-30^{\mathrm{TH}}, 2017$, BLed, Slovenia), Bioenergy AND Biofuels

T. Mendiara, I. Adánez-Rubio, A. Pérez-Astray, M. Teresa Izquierdo, A. Abad, P. Gayán, L. F. de Diego, F. García-Labiano \& J. Adánez: Chemical Looping Combustion of Biomass: Clou Experiments with a $\mathrm{Cu}-\mathrm{Mn}$ Mixed Oxide

and T05. It can be concluded that it is possible to oxidize in the air reactor with an inlet oxygen concentration of $10 \mathrm{vol} \%$.

\section{Conclusions}

Combustion of pine sawdust biomass in a $1.5 \mathrm{~kW}_{\text {th }}$ CLOU system was carried out during a period of $14 \mathrm{~h}$ using a $\mathrm{Cu}-\mathrm{Mn}$ mixed oxide as an oxygen carrier. With a temperature as low as $775^{\circ} \mathrm{C}$ in the fuel reactor, unburnt compounds were not present in the fuel reactor outlet; $\mathrm{CO}_{2}, \mathrm{H}_{2} \mathrm{O}$ and $\mathrm{O}_{2}$ were the only products. In most cases the $\mathrm{CO}_{2}$ capture efficiency was higher than $95 \%$ at fuel reactor temperatures as low as $850{ }^{\circ} \mathrm{C}$.

Char combustion was improved at higher temperatures, with a conversion of $96.6 \%$ achieved at $850{ }^{\circ} \mathrm{C}$. At this condition, $\mathrm{CO}_{2}$ capture efficiency showed a value as high as $98 \%$, avoiding the need of a carbon stripper.

On the other hand, higher $\phi$ values produce higher char conversion rates in the fuel reactor due to the fact that the oxygen generation rate of this carrier depends on reduction conversion. The lower the reduction conversion, the higher the oxygen generation rate, giving higher char conversion rate and $\mathrm{CO}_{2}$ capture efficiency.

The effect of the oxygen available to regenerate the oxygen carrier in the air reactor was also analysed. It was concluded that it is possible to oxidize in the air reactor with an oxygen concentration of $10 \mathrm{vol} \%$ at the inlet ( $4 \mathrm{vol} \%$ at the outlet) to achieve high $\mathrm{CO}_{2}$ capture efficiencies.

\section{Acknowledgements}

This work was supported by the Spanish Ministry of Economy and Competitiveness (MINECO Project: ENE2014-56857-R) and the European Regional Development Fund (ERDF). A. PérezAstray thanks MINECO for the BES-2015-074651 pre-doctoral fellowship co-financed by the ERDF. T. Mendiara is grateful for the "Ramón y Cajal" post-doctoral contract awarded by MINECO.

\section{References}

[1] IPCC, "Climate Change 2014: Synthesis Report. Contribution of Working Groups I, II and III to the Fifth Assessment," Report of the Intergovernmental Panel on Climate Change; Geneva (Switzerland), p. 151, 2014.

[2] F. Creutzig, N. H. Ravindranath, G. Berndes, S. Bolwig, R. Bright, F. Cherubini, et al., "Bioenergy and climate change mitigation: An assessment," GCB Bioenergy, vol. 7, pp. 916-944, 2015.

[3] S. Fuss, J. G. Canadell, G. P. Peters, M. Tavoni, R. M. Andrew, P. Ciais, et al., "Betting on negative emissions," Nature Climate Change, vol. 4, pp. 850-853, 2014.

[4] E. S. Rubin, J. E. Davison, and H. J. Herzog, "The cost of $\mathrm{CO}_{2}$ capture and storage," International Journal of Greenhouse Gas Control, vol. 40, pp. 378-400, 2015. 
$10^{\mathrm{TH}}$ INTERNATIONAL CONFERENCE ON SUSTAINABLE ENERGY AND ENVIRONMENTAL

Protection (June $27^{\mathrm{TH}}-30^{\mathrm{TH}}, 2017$, Bled, Slovenia), Bioenergy AND Biofuels

T. Mendiara, I. Adánez-Rubio, A. Pérez-Astray, M. Teresa Izquierdo, A. Abad, P. Gayán, L. F. de Diego, F. García-Labiano \& J. Adánez: Chemical Looping Combustion of Biomass: Clou Experiments with a $\mathrm{Cu}-\mathrm{Mn}$ Mixed Oxide

[5] I. Adánez-Rubio, A. Abad, P. Gayán, L. F. De Diego, F. García-Labiano, and J. Adánez, "Biomass combustion with $\mathrm{CO}_{2}$ capture by chemical looping with oxygen uncoupling (CLOU)," Fuel Processing Technology, vol. 124, pp. 104-114, 2014.

[6] T. Mendiara, A. Abad, L. F. de Diego, F. García Labiano, P. Gayán, and J. Adánez, "Biomass combustion in a CLC system using an iron ore as an oxygen carrier," International Journal of Greenhouse Gas Control, vol. 19, pp. 322-330, 2013.

[7] I. Adánez-Rubio, A. Abad, P. Gayán, I. Adánez, L. de Diego, F. García-Labiano, et al., "Use of Hopcalite-Derived $\mathrm{Cu}-\mathrm{Mn}$ Mixed Oxide as Oxygen Carrier for Chemical Looping with Oxygen Uncoupling Process," Energy \& Fuels, 2016. 
44 | $10^{\text {TH }}$ International Conference on Sustainable Energy and EnVIRONMENTal Protection (June $27^{\mathrm{TH}}-30^{\mathrm{TH}}, 2017$, Bled, Slovenia), Bioenergy AND Biofuels 
$10^{\mathrm{TH}}$ InTERnational CONFERENCE ON Sustainable ENERgy AND

ENVIRONMENTAL Protection (June $27^{\mathrm{TH}}-30^{\mathrm{TH}}$, 2017, Bled, SLOVENIA), BIOENERGY AND BIOFUELS

J. Krope, A.Ghani Olabi, D. Goričanec \& S. Božičnik

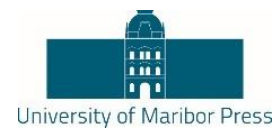

\title{
Complete Analysis of Castor Oil Methanolysis for Biodiesel Production
}

\author{
OMAR AboelaZAyem, Nour Sh. El-Gendy, FAtMa H. Ashour \& MoHAMED A. \\ SADEK
}

\begin{abstract}
In this study, biodiesel production from castor oil has been analysed. Response Surface Methodology (RSM) via Central Composite Design (CCD) has been used to evaluate the main reaction variables affecting biodiesel yield. The optimum conditions have been concluded using numerical optimisation for maximum production of biodiesel at minimum reaction conditions, reaching $97.82 \%$ biodiesel yield at methanol to oil (M:O) molar ratio of $5.4: 1, \mathrm{KOH}$ concentration of $0.73 \%$, reaction temperature of $64 \mathrm{oC}$, reaction time of $2.5 \mathrm{~h}$ and mixing rate of $320 \mathrm{rpm}$. Predicted optimum conditions have been validated with $0.59 \%$ relative error from the experimental results. Moreover, a case study investigating the performance and emissions of a direct injection (DI) diesel engine of single cylinder and four strokes with biodiesel/petro-diesel blends $(5,10$, 15 and $20 \% \mathrm{v}: \mathrm{v}$ ) has been performed at a rated engine speed. Brake specific fuel consumption (bsfc) and fuel conversion efficiency ( $\eta f)$ have been used to analyse the engine performance. Emission analysis has been also performed for different exhaust components including carbon monoxide $(\mathrm{CO})$, carbon dioxide (CO2), hydrocarbons ( $\mathrm{HC})$, nitrogen oxides (NOx), Oxygen $(\mathrm{O} 2)$ and liquid particulates emissions.
\end{abstract}

Keywords: - Biodiesel - Castor oil - Optimisation - Response surface methodology $\bullet$ Diesel engine test $\bullet$

CORRESPONDENCE AdDRESS: Omar Aboelazayem, M.Sc. Student, The British University in Egypt, Department of Chemical Engineering, Misr-Ismailia Road, El-Sherouk City 11837, Cairo, Egypt, e-mail: omar.azayem@bue.edu.eg. Nour Sh, El-Gendy, Ph.D., Professor, Petroleum Biotechnology Laboratory, Egyptian Petroleum Research Institute, Nasr City 11727, Cairo, Egypt, e-mail: nourepri@yahoo.com. Fatma H. Ashour, Ph.D., Professor, Cairo University, Chemical Engineering Department, Giza 12613, Egypt, e-mail: fhashour@yahoo.com. Mohamed S. Sadek, , Ph.D., Professor, The British University in Egypt, Department of Chemical Engineering, MisrIsmailia Road, El-Sherouk City 11837, Cairo, Egypt, e-mail: shahir.sadek@ bue.edu.eg.

https://doi.org/10.18690/978-961-286-048-6.5

ISBN 978-961-286-048-6

(C) 2017 University of Maribor Press

Available at: http://press.um.si. 
$10^{\mathrm{TH}}$ International Conference on Sustainable EnERgy and Environmental Protection (June $27^{\mathrm{TH}}-30^{\mathrm{TH}}, 2017$, BLed, Slovenia), Bioenergy AND Biofuels

O. Aboelazayem, N. Sh. El-Gendy, F. H. Ashour \& M. A. Sadek: Complete Analysis of

Castor Oil Methanolysis for Biodiesel Production

Introduction

The steady increase of the prices of petroleum-based fuels and the environmental concerns regarding their pollutant effect are boosting the attention towards alternative fuels as replacement for fossil fuels. In addition, the increase of the global energy demand has recently widened the gap between the fuels availability and demand while stressing on the fact about the shortly depletion of petroleum-based fuels. These factors have directed the research toward searching for alternative sustainable, renewable and environmentally benign sources of energy [1].

Biodiesel has been considered a promising diesel fuel substitute since it is a clean renewable fuel which could be used for direct conventional diesel engines without any modifications [2]. Biodiesel is a renewable, biodegradable, non-toxic, eco-friendly, environmentally friendly and economically competitive fuel. Biodiesel is defined as a mixture of alkyl esters of long chain fatty acid derived from vegetable oils or animal fats. It is synthesised through transesterification and esterification of triglycerides and free fatty acids (FFA). Biodiesel offers many benefits including reduction of the greenhouse gases emissions, regional development and social structure for developing countries. Moreover, biodiesel improves the lubrication of biodiesel-diesel blend reaching 66\% better than pure diesel fuel [3]. Biodiesel feedstocks have been categorised into two main categories; first generation feedstock and second generation feedstock. First generation feedstock including fresh edible oils and fats are the most commonly used for biodiesel production. About $95 \%$ of the biodiesel productions process are based on edible vegetable oils which presents an intense competition with the food industry resulting in global imbalance between market demands and supply. Accordingly, second generation feedstocks including non-edible oils and waste cooking oils have gained large interest from the researches in the recent years [2].

Non-edible oils as a type of second generation feedstocks represent potential resource for future energy supply. Non-edible oils are gaining global attention due to their availability and their ability to grow in degraded lands which are not suitable for edible crops thus, having benefits of lowering the feedstock price and redevelopment of unused lands [4]. Castor oil plant (Ricinus communis) is originally a shrubby or tree like plant depending on the cultivated variety. In Egypt, it has been observed under different climatic and soil conditions in the Nile Delta and desert regions [5]. Castor oil seed contains 40-55\% which is very high oil content compared with the most commonly used crops. In addition, the plantation cost is estimated to be $50 \%$ and $25 \%$ lower than the cost of planting rapeseed and jatropha plants, respectively [4].

Castor oil composition is mainly 80-90\% ricinoliec acid (12-hydroxy-9-cis-octadecenoic acid), which is a very unique composition. This composition leads the viscosity of castor oil to be 7 times higher than other vegetable oils. Accordingly, produced biodiesel viscosity will be higher than the usual biodiesel produced from other vegetable oils. Blending biodiesel produced from castor oil with petro-diesel is one of the methods to overcome the mentioned problem [4]. 
$10^{\mathrm{TH}}$ INTERNATIONAL CONFERENCE ON SUSTAINABLE ENERGY AND ENVIRONMENTAL

The main objective of this research is to conclude the optimum conditions for biodiesel production from castor oil; in addition, to analyse the effect of reaction variables, i.e. M:O molar ratio, catalyst concentration, reaction temperature, reaction time and mixing rate, on the biodiesel yield; finally, to examine the effect of different biodiesel/petrodiesel blends on diesel engine performance and analyse the variation in the emissions.

\section{$2 \quad$ Materials and Methods}

\subsection{Materials used}

Castor oil has been purchased from Egyptian local market. Methanol (MeOH) 99\% and potassium hydroxide $(\mathrm{KOH})$ were purchased from Morgan Chemical Ltd., Egypt.

\subsection{Experimental setup}

The batch reaction took place in a 500-mL 3-neck round glass reactor. $\mathrm{KOH}$ with a specific weight has been mixed with methanol to produce potassium methoxide. Then, oil and potassium methoxide have been mixed in the reactor and heated through controlled hot plate to the desired temperature with continuous stirring by a magnetic stirrer. The reaction time starts when the reactor reaches the required reaction temperature. After reaching the prescribed reaction time, the mixture was transferred to separating funnel where glycerol in the bottom layer was separated from biodiesel. Unreacted methanol has been recovered using simple distillation. Biodiesel was then washed with warm water to remove the dissolved $\mathrm{KOH}$. Finally, biodiesel weight has been measured for yield calculations using Equation (1) [6].

Yield $(\%)=($ weight of biodiesel $/$ weight of Oil $) \times 100$

\subsection{Experimental design}

RSM has been recognised to achieve the optimum conditions for biodiesel production. CCD has been used to generate the uncertainty matrix for analysing the relationship between the reaction variables and reaction response. Five independent variables have been chosen for the analysis including M:O molar ratio, $\mathrm{KOH}$ concentration, temperature, time and mixing rate, which were labelled as A, B, C, D and E, respectively. Three levels for each variable have been coded as $-1,0,1$ as shown in Table 1 . Biodiesel and glycerol yields have been selected as reaction responses. Twenty-six experiments have been performed in a randomised order where the responses have been calculated for each experiment. 
$10^{\mathrm{TH}}$ InTERnATIONAL CONFERENCE ON Sustainable ENERGy AND ENVIRONMENTAL Protection (June $27^{\mathrm{TH}}-30^{\mathrm{TH}}, 2017$, BLed, Slovenia), Bioenergy AND Biofuels O. Aboelazayem, N. Sh. El-Gendy, F. H. Ashour \& M. A. Sadek: Complete Analysis of Castor Oil Methanolysis for Biodiesel Production

Table 1. Experimental Design Variables

\begin{tabular}{|l|l|l|l|l|}
\hline Factor & Code & \multicolumn{3}{l|}{ Levels } \\
\hline & & -1 & 0 & 1 \\
\hline M:O (molar ratio) & A & 3 & 6 & 9 \\
\hline $\begin{array}{l}\text { KOH concentration } \\
(\mathrm{wt} \%)\end{array}$ & B & 0.3 & 0.6 & 0.9 \\
\hline Temperature $\left({ }^{\circ} \mathrm{C}\right)$ & $\mathrm{C}$ & 50 & 60 & 70 \\
\hline Time $(\mathrm{h})$ & $\mathrm{D}$ & 1 & 2 & 3 \\
\hline Mixing rate (rpm) & $\mathrm{E}$ & 200 & 300 & 400 \\
\hline
\end{tabular}

\subsection{Statistical analysis}

The general quadratic equation has been used to define the model. Statistical significance has been investigated using ANOVA by calculating the Fisher's F-test at $95 \%$ confidence level. Statistical significance of the results has been presented by p-value, where the result is considered to be significant when p-value is less than 0.05 .

Numerical optimisation of the reaction variables has been constructed based on certain goals. The goals were identified by maximising the biodiesel yield and minimising the glycerol yield at minimum M:O molar ratio, $\mathrm{KOH}$ concentration, temperature, time and mixing rate of the reaction.

Design of experiments, regression analysis, graphical analysis and numerical optimisation have been performed using Design Expert 10 software (Stat-Ease Inc., Minneapolis, MN, USA).

\subsection{Analysis of physicochemical properties}

The raw castor oil, final pure biodiesel at the concluded optimum conditions and the blended biodiesel/petro-diesel samples have been analysed for investigating their chemical and physical properties. Analysis results have been compared to the European standard of biodiesel, EN14214. The analysed properties have been replicated twice and the final results have been obtained as an average of the two results. Table 3. showed the properties of the crude castor oil.

Kinematic viscosity, standard density, Total acid number (TAN), Calorific value of the analysed samples have been calibrated according to ASTM D445, ASTM D4052, ASTM D974 and ASTM D-5865, respectively. 
$10^{\mathrm{TH}}$ INTERNATIONAL CONFERENCE ON SUSTAINABLE ENERGY AND ENVIRONMENTAL Protection (June $27^{\mathrm{TH}}-30^{\mathrm{TH}}, 2017$, BLed, Slovenia), Bioenergy AND Biofuels

O. Aboelazayem, N. Sh. El-Gendy, F. H. Ashour \& M. A. Sadek: Complete Analysis of Castor Oil Methanolysis for Biodiesel Production

Table 2. Raw Castor Oil Properties

\begin{tabular}{|l|l|l|}
\hline Test & Unit & Castor Oil \\
\hline $\begin{array}{l}\text { Standard } \\
\text { Density }\end{array}$ & $\mathrm{kg} / \mathrm{m}^{3}$ & 963.4 \\
\hline $\begin{array}{l}\text { Kinematic } \\
\text { viscosity }\end{array}$ & $\mathrm{cSt}$ & 248 \\
\hline TAN & $\mathrm{mg} \mathrm{KOH} / \mathrm{g}$ oil & 0.1 \\
\hline
\end{tabular}

\subsection{Diesel engine test}

The performance and emissions of a direct injection (DI) diesel engine of single cylinder and four strokes with biodiesel/petro-diesel blends have been studied. Different levels (5, 10,15 and $20 \mathrm{vol} \%$ ) of biodiesel at the rated engine speed of $1500 \mathrm{rpm}$, have been used throughout the study. Brake specific fuel consumption (bsfc) and fuel conversion efficiency $(\eta f)$ have been used to analyse engine performance. Emission analysis has been performed for different exhaust components including carbon monoxide (CO), carbon dioxide $\left(\mathrm{CO}_{2}\right)$, hydrocarbons $(\mathrm{HC})$, nitrogen oxides $(\mathrm{NOx})$, Oxygen $\left(\mathrm{O}_{2}\right)$ and liquid particulates emissions.

\section{$3 \quad$ Results and Discussion}

\subsection{Predicted model validation}

Using the reduced CCD has concluded relatively few combination of variables while covering wide range of their levels. The number of experiments have been reduced to 26 experiments instead higher number of experiments are required in case full factorial design is used. However, CCD would possibly conclude higher relative error, where adequacy checking of the predicted model would analyse it. For simplicity, this paper represents only the analysis and results for biodiesel yield response. A polynomial quadratic model as shown in Equation (2) has been concluded to fit the experimental results where $\mathrm{Y}$ is the dependant variable (biodiesel yield); $\mathrm{A}, \mathrm{B}, \mathrm{C}, \mathrm{D}$ and $\mathrm{E}$ are the independent variables; M:O molar ratio, $\mathrm{KOH}$ concentration, temperature, time and mixing rate, respectively.

$Y=86.28+14.52 A+8.79 B+10.71 C+10.41 D+6.10 E-0.85 A B+2.7 E-3 A C+$ $0.5 A D+1.27 A E+3.07 B C+0.87 B D-1.07 B E+4.42 C D+2.48 C E+0.28 D E-$ $8.06 A^{2}-5.18 B^{2}-5.97 C^{2}-5.8 D^{2}-3.65 E^{2}$

The proposed model has been examined for adequacy to identify any errors associated with the normality assumptions. ANOVA has been applied to the model using F-test and p-value tests, these values have been concluded as 36.33 and 0.0004 , respectively which prove that the developed quadratic model is statistically significant with $95 \%$ confidence level. The determination coefficient values, $\mathrm{R}^{2}$ and $\mathrm{R}_{\text {adj }}^{2}$, which measure the reliability of 
$10^{\text {Th }}$ International Conference on Sustainable Energy and Environmental Protection (June 27 ${ }^{\mathrm{TH}}-30^{\mathrm{TH}}, 2017$, BLed, Slovenia), Bioenergy AND Biofuels

O. Aboelazayem, N. Sh. El-Gendy, F. H. Ashour \& M. A. Sadek: Complete Analysis of Castor Oil Methanolysis for Biodiesel Production

the model fitting, have been calculated to be 0.9932 and 0.9658 , respectively. These values indicate the high significance of the model, where only $0.68 \%$ of the total variation was not explained by the model. The "Adeq precision" measures the signal to noise ratio where ratios greater than 4 are desirable. For the predicted polynomial model the ratio is 21.8 indicating a satisfactory signal. Figure 1 illustrates the relation between predicted values generated by the model and actual experimental values.

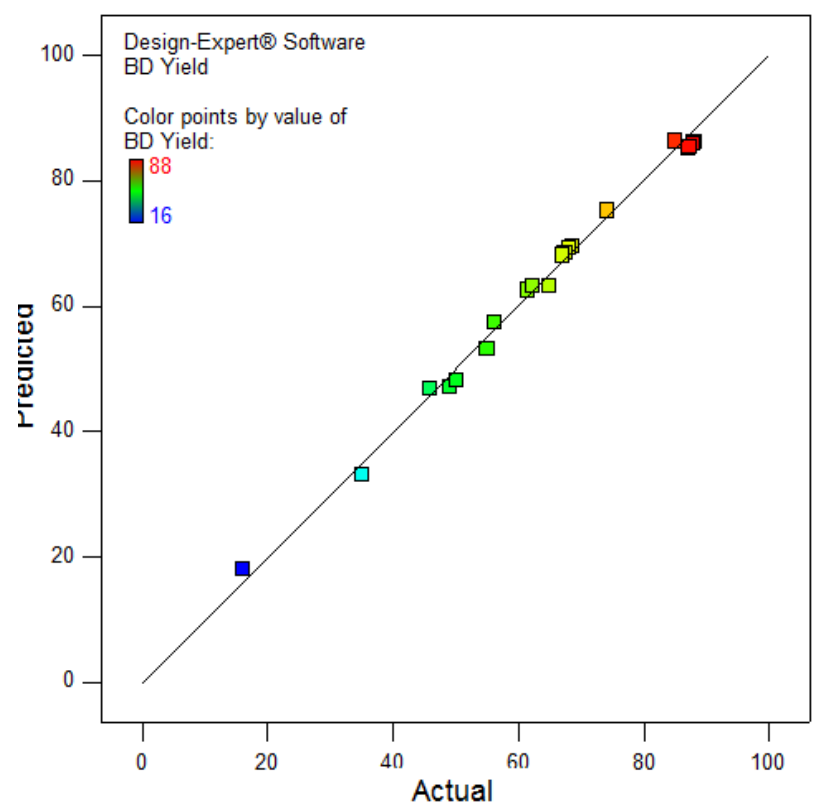

Figure 1. Predicted Data Verses Experimental Actual Data

\subsection{Effect of process variables}

\section{Effect of M:O molar ratio}

M:O molar ratio is an important variable for biodiesel production. From the stochiometric balance of the transesterification reaction, three moles of methanol are required for every mole of triglycerides. Accordingly, M:O molar ratio have been chosen within range of 3:1 to 9:1 as shown in Table 1. in order to investigate the effect of wide range of excess methanol on the biodiesel yield. From the ANOVA results, it has been concluded that M:O molar ratio has highly significant effect on biodiesel yield with p-value of 0.0001 and F-value of 116.32. M:O molar ratio has a directly proportional relationship with biodiesel yield from range of 3:1 to 7:1. Then, the effect of increasing M:O molar ratio has no valuable effect on biodiesel yield. Figure 2 illustrates the effect of M:O molar ratio 
and $\mathrm{KOH}$ concentration on biodiesel yield where the other variables were constant at their centre points.

\section{Effect of KOH concentration}

The low TAN of the crude castor oil ( $0.1 \mathrm{mg} \mathrm{KOH}$ per $\mathrm{g}$ oil) has boosted the use of alkaline catalyst through the transesterification reaction. Catalyst concentration has been measured as a weight percent from the weight of oil used. Analysing the effect of catalyst concentration is important for optimisation step. Minimising catalyst concentration would reduce the cost the process separations. ANOVA result showed that catalyst concentration has significant effect on biodiesel yield where $\mathrm{p}$-value was concluded to be 0.0013 and F-value was 42.56. It is clearly shown in Figure 2. that increasing KOH concentration affects biodiesel yield positively from the range between $0.3-0.65 \%$. While at higher concentration, it has no substantial effect on biodiesel yield.

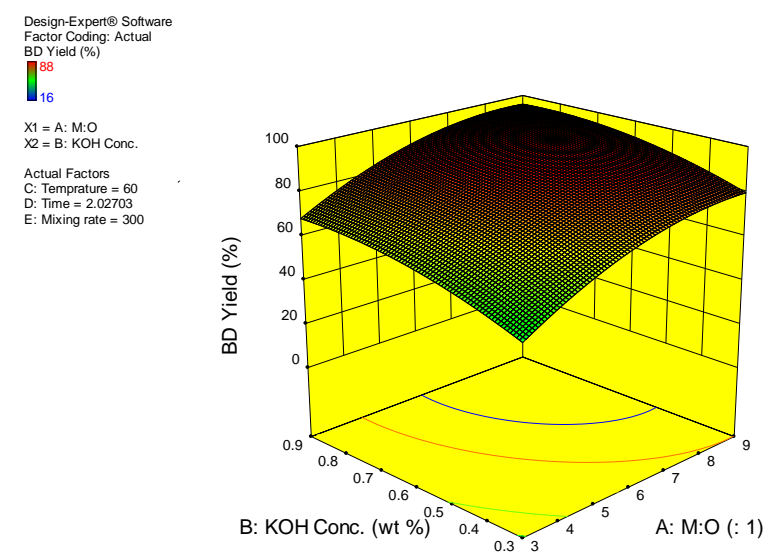

Figure 2. 3-D Plot Showing The Effect Of M:O Molar Ratio and KOH Concentration on Yield

\section{Effect of reaction temperature}

Ricinoleic acid, which is the main component of castor oil, includes hydroxyl group which shows special physical and chemical properties. These properties include high density, high viscosity, high hygroscopicity, low iodine value and high solubility in alcohols [2]. Its high solubility in alcohols tolerates its ability to perform the transesterification reaction at low temperatures. According to the ANOVA results, reaction temperatures showed highly significant effect on biodiesel yield with p-value of 0.0005 and F-value of 63.22. As shown in Figure 3 increasing temperature has direct increasingly effect on biodiesel yield from range of $50^{\circ} \mathrm{C}$ to $65^{\circ} \mathrm{C}$. However, the effect is not significant at temperature higher than $65^{\circ} \mathrm{C}$. 


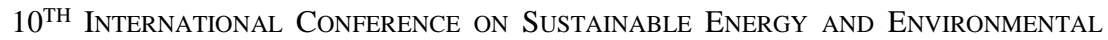
Protection (June $27^{\mathrm{TH}}-30^{\mathrm{TH}}, 2017$, Bled, Slovenia), Bioenergy AND Biofuels

O. Aboelazayem, N. Sh. El-Gendy, F. H. Ashour \& M. A. Sadek: Complete Analysis of Castor Oil Methanolysis for Biodiesel Production

\section{Effect of reaction time}

According to the ANOVA results, reaction time showed highly significant effect on biodiesel yield with p-value of 0.0006. This significant effect is clearly shown in Figure 3 where increasing time has positive effect on biodiesel yield from time range between 1-2.5 h. Then, reaction time more than $2.5 \mathrm{hrs}$ has no effect on biodiesel yield.

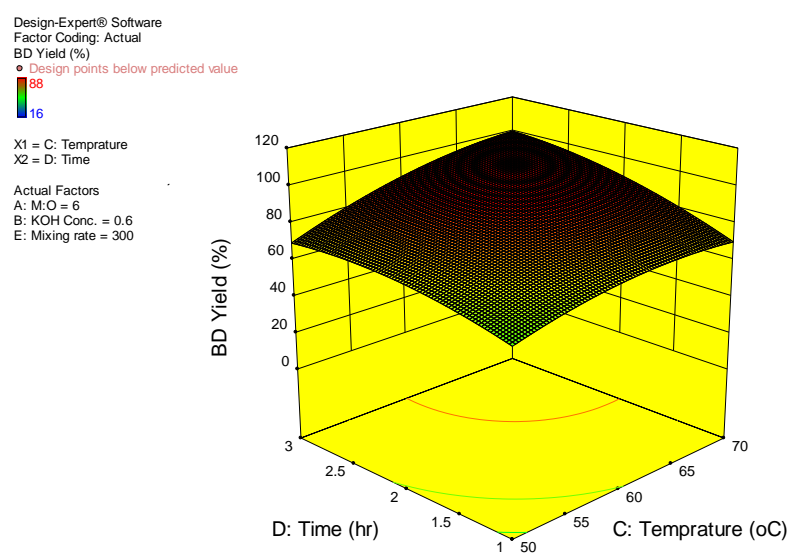

Figure 3. 3-D Plot Showing the Effect of Temperature and Time on Yield

\section{Effect of mixing rate}

Mixing rate has significant effect on biodiesel yield. It has been concluded from the ANOVA results that its p-value is 0.006 and F-value of 20.4. Figure 4 illustrates the effect of mixing rate on biodiesel yield. 


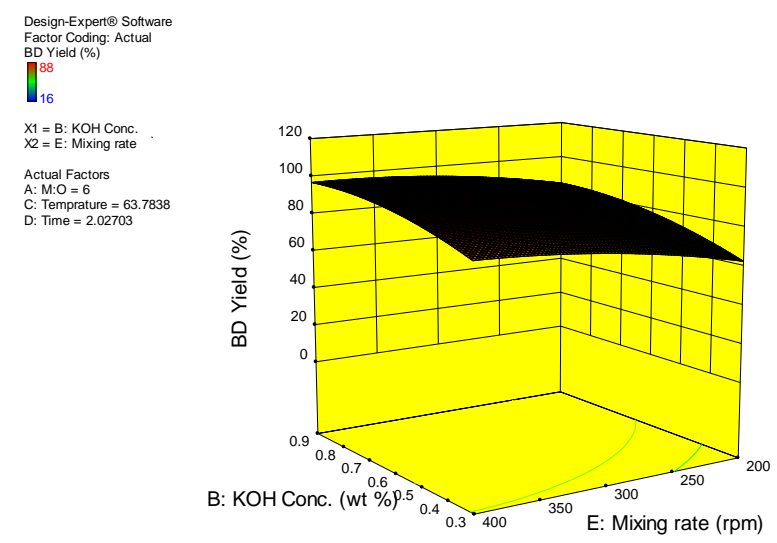

Figure 4. 3-D plot showing the effect of $\mathrm{KOH}$ concentration and mixing rate on yield

\subsection{Optimisation of reaction conditions}

Optimisation of the transesterification reaction conditions has been carried out to conclude the optimum reaction variables resulting in maximum biodiesel yield. The optimum conditions have been concluded using numerical optimisation at $\mathrm{M}: \mathrm{O}$ molar ratio of 5.4:1, $\mathrm{KOH}$ concentration of $0.73 \%$, reaction temperature of $64^{\circ} \mathrm{C}$, reaction time of $2.5 \mathrm{~h}$ and mixing rate of $320 \mathrm{rpm}$ resulting in $97.82 \%$ and $2.05 \%$ for biodiesel and glycerol yields, respectively.

\subsection{Predicted optimum conditions validation}

In order to validate the proficiency of the predicted model and its predicted optimum conditions, experiments have been performed at the concluded optimum conditions. Predicted optimum conditions have been validated with $0.59 \%$ relative error from the experimental results. The similarity between the experimental response results and the predicted optimal response confirms and verifies the accuracy and adequacy of the predicted quadratic model.

\subsection{Physicochemical properties}

The physicochemical properties of the final biodiesel product have been analysed and compared to the European Biodiesel Standard, EN14214. Table 3. shows the concluded properties in comparison with the standard limits of EN14214. Density and viscosity of the produced biodiesel exceeds the limits of biodiesel standard due to the existence of the hydroxyl group in ricinoleic acid as previously mentioned. Accordingly, blends between biodiesel and petro-diesel have been analysed. 
$10^{\mathrm{TH}}$ InTERnAtional CONFERENCE ON Sustainable ENERGy AND ENVIRONMENTAL Protection (June $27^{\mathrm{TH}}-30^{\mathrm{TH}}, 2017$, BLed, Slovenia), Bioenergy AND Biofuels O. Aboelazayem, N. Sh. El-Gendy, F. H. Ashour \& M. A. Sadek: Complete Analysis of Castor Oil Methanolysis for Biodiesel Production

Table 3. Produced Biodiesel Properties

\begin{tabular}{|l|l|l|l|}
\hline Test & Unit & $\begin{array}{l}\text { Produced } \\
\text { biodiesel }\end{array}$ & $\begin{array}{l}\text { Biodiesel } \\
(\text { EN14214) }\end{array}$ \\
\hline Density & $\mathrm{kg} / \mathrm{m}^{3}$ & 935 & $860-900$ \\
\hline $\begin{array}{l}\text { Kinematic } \\
\text { viscosity }\end{array}$ & $\mathrm{cSt}$ & 18.6 & $3.5-5$ \\
\hline TAN & $\begin{array}{l}\mathrm{mg} \\
\mathrm{KOH} / \mathrm{g} \\
\mathrm{oil}\end{array}$ & 0.15 & $<0.5$ \\
\hline $\begin{array}{l}\text { Calorific } \\
\text { value }\end{array}$ & $\mathrm{MJ} / \mathrm{kg}$ & 35.2 & $>32.9$ \\
\hline
\end{tabular}

\subsection{Diesel engine test}

As a confirmation step of the physical properties of the blended biodiesel/petro-diesel fuel, diesel engine performance and emissions test has been performed. Four different blends have been prepared by adding 5, 10, 15 and 20 volume $\%$ of biodiesel to petrodiesel. Table 4. Illustrates the gas emission analysis for each blended sample. Concentration of $\mathrm{CO}_{2}, \mathrm{CO}$ and $\mathrm{O}_{2}$ gases has been represented by \%volume while for hydrocarbons (HC) and NOx, it has been represented by part per million (ppm). Table. 5 shows the performance analysis of the blended sample where it is clearly shown that the fuel conversion efficiency decreases and fuel consumption increases with the increase of biodiesel percent in the blended samples. These results are in agreement with other research that analyse the performance with canola oil based biodiesel [7].

Table 4. Diesel Engine Emissions Analysis

\begin{tabular}{|l|l|l|l|l|l|l|}
\hline Blend & $\mathrm{CO}$ & $\mathrm{CO}_{2}$ & $\mathrm{HC}$ & $\mathrm{O}_{2}$ & $\mathrm{~L}$ & NOx \\
\hline B0 & 0.048 & 3.61 & 36 & 16.09 & 6.17 & 229 \\
\hline B5 & 0.043 & 3.23 & 32 & 16.4 & 5.32 & 250 \\
\hline B10 & 0.036 & 2.86 & 29 & 16.82 & 5.035 & 265 \\
\hline B15 & 0.033 & 2.62 & 24 & 16.9 & 4.43 & 303 \\
\hline B20 & 0.032 & 2.31 & 21 & 17.49 & 4.056 & 344 \\
\hline
\end{tabular}


Table 5. Diesel Engine Performance Analysis

\begin{tabular}{|l|l|l|}
\hline Blend & bsfc & Fuel Efficiency \\
\hline B0 & 858.71 & 9.4892 \\
\hline B5 & 968.71 & 8.6065 \\
\hline B10 & 1030 & 8.1435 \\
\hline B15 & 1051.4 & 8.064 \\
\hline B20 & 1118.4 & 7.6626 \\
\hline
\end{tabular}

\section{Conclusions}

Castor oil is a competitive second generation feedstock for biodiesel production. It has been concluded that the optimum reaction conditions are at M:O molar ratio of 5.4:1, $\mathrm{KOH}$ concentration of $0.73 \%$, reaction temperature of $64^{\circ} \mathrm{C}$, reaction time of $2.5 \mathrm{~h}$ and mixing rate of $320 \mathrm{rpm}$ resulting in $97.82 \%$ biodiesel yield. Predicted optimum conditions have been validated with $0.59 \%$ relative error from the experimental results. Diesel Engine test for biodiesel/petro-diesel blends shows effective reduction in greenhouse gases and confirms the reliability of biodiesel derived from castor oil.

\section{Acknwledgements}

The authors acknowledge The British University in Egypt (BUE) for funding this research.

\section{References}

[1] S. Lee, D. Posarac, and N. Ellis, "Process simulation and economic analysis of biodiesel production processes using fresh and waste vegetable oil and supercritical methanol," Chem. Eng. Res. Des., vol. 89, no. 12, pp. 2626-2642, 2011.

[2] N. Sánchez, R. Sánchez, J. M. Encinar, J. F. González, and G. Martínez, “Complete analysis of castor oil methanolysis to obtain biodiesel," Fuel, vol. 147, pp. 95-99, 2015.

[3] M. M. K. Bhuiya, M. G. Rasul, M. M. K. Khan, N. Ashwath, and A. K. Azad, "Prospects of 2nd generation biodiesel as a sustainable fuel - Part: 1 Selection of feedstocks, oil extraction techniques and conversion technologies," Renew. Sustain. Energy Rev., vol. 55, pp. 1109-1128, 2016.

[4] J. M. Dias, J. M. Araújo, J. F. Costa, M. C. M. Alvim-Ferraz, and M. F. Almeida, "Biodiesel production from raw castor oil," Energy, vol. 53, pp. 58-66, 2013.

[5] M. A. Zahran and A. J. Willis, The vegetation of Egypt, vol. 2. 2009.

[6] N. S. El-Gendy, A. A. S. A. El-Gharabawy, S. S. Abu Amr, and F. H. Ashour, "Response surface optimization of an alkaline transesterification of waste cooking oil," Int. J. ChemTech Res., vol. 8, no. 8, pp. 385-398, 2015.

[7] M. M. Roy, W. Wang, and M. Alawi, "Performance and emissions of a diesel engine fueled by biodiesel-diesel, biodiesel-diesel-additive and kerosene-biodiesel blends," Energy Convers. Manag., vol. 84, pp. 164-173, 2014. 
56 10 $10^{\mathrm{TH}}$ International Conference on Sustainable EnERgy and Environmental Protection (June $27^{\mathrm{TH}}-30^{\mathrm{TH}}, 2017$, Bled, Slovenia), Bioenergy AND Biofuels 
$10^{\mathrm{TH}}$ InTERnational CONFERENCE ON Sustainable ENERgy AND ENVIRONMENTAL Protection (June $27^{\mathrm{TH}}-30^{\mathrm{TH}}$, 2017, Bled, SLOVENIA), BIOENERGY AND BIOFUELS

J. Krope, A.Ghani Olabi, D. Goričanec \& S. Božičnik

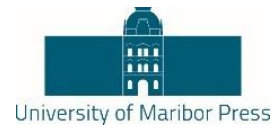

\title{
Optimising Bidiesel Production from High Acid Value Waste Cooking Oil Using Supercritical Methanol
}

\author{
OMAR ABoelaZAYEM, MAMdouh GADAlla \& BASUdeb SAHA
}

\begin{abstract}
In this study, biodiesel production from a typical Egyptian waste cooking oil (WCO) with high acid value content (18 mg KOH/g oil) has been analysed by studying the main factors affecting biodiesel and glycerol yields. Response Surface Methodology (RSM) via Central Composite Design (CCD) has been used to analyse the effect of four independent variables, i.e. methanol to oil (M:O) molar ratio, temperature, pressure and time on the reaction responses. A quadratic model for each response has been concluded representing the interrelationships between reaction variables and reaction responses. In addition, the predicted models' adequacy has been evaluated through Analysis of Variance (ANOVA) method. Numerical optimisation technique has been applied to conclude the optimum reaction conditions for maximum production of biodiesel resulting in $98 \%$ and $2.05 \%$ for biodiesel and glycerol yields at M:O molar ratio, temperature, pressure and time of 25:1, 265oC, 110 bar and 20 minutes, respectively. Experimental validation has been analysed for the predicted optimum conditions resulting in $98.82 \%$ biodiesel yield with $0.83 \%$ relative error.
\end{abstract}

Keywords: - Biodiesel • Waste cooking oil • Supercritical transesterification $\bullet$ Optimisation $\bullet$ Response surface methodology •

CORRESPONDENCE ADDRESS: Omar Aboelazayem, Ph.D Student, London South Bank University, School of Engineering, 103 Borough Road SE1 0AA, London, United Kingdom, e-mail: aboelazo@1sbu.ac.uk. Mamdouh Gadalla, Ph.D., Associate Professor, The British University in Egypt, Department of Chemical Engineering, Misr-Ismailia Road, El-Sherouk City 11837, Cairo, Egypt, e-mail: mamdouh.gadalla@bue.edu.eg. Basudeb Saha, Ph.D., Professor, London South Bank University, School of Engineering, 103 Borough Road SE1 0AA, London, United Kingdom, e-mail: b.saha@1sbu.ac.uk. 
$10^{\mathrm{TH}}$ International Conference on Sustainable EnERgy and Environmental Protection (June $27^{\mathrm{TH}}-30^{\mathrm{TH}}, 2017$, BLed, Slovenia), Bioenergy AND Biofuels O. Aboelazayem, M. Gadalla \& B. Saha: Optimising Bidiesel Production from High Acid Value Waste Cooking Oil Using Supercritical Methanol

The unstable price and depletion of world's crude oil reserves are the main reasons for searching for alternative fuels, specifically for the transportation sector. Biofuels have been considered as effective replacement for fossil fuels including biodiesel, bioethanol, biohydrogen and biogas. Biodiesel has been observed as an efficient replacement for petroleum based diesel fuel (petro-diesel). It is biodegradable, nontoxic, provide better engine lubricity and produced cleaner combustion compared to petro-diesel with significant reduction in carbon monoxide, unburned hydrocarbons and particulates. Biodiesel could also be blended with petro-diesel in various proportions for cleaner exhaust and to avoid engine modification requirements [1].

Biodiesel is defined as a mono alkyl ester of long chain fatty acid derived from vegetable oil or animal fats. It is mostly produced by esterification and/or transesterification of various feedstock with methanol or ethanol [2]. Biodiesel production form firstgeneration feedstock including fresh edible oils (palm oil, sunflower oil, corn oil and soybean oil) and animal fats (beef tallow, lamb and chicken fats) has been considered as an intense competition with food industry resulting in the increase of prices for these edible oils and fats due to the high demand from both food and biodiesel industries. Accordingly, researches have been directed towards utilisation of second-generation feedstocks including nonedible oils and waste cooking oils (WCO). Their advantages over the first-generation feedstocks that they are lower in cost and most importantly they do not affect food security [3]. WCO has been considered as an ideal feedstock for biodiesel production since it adds to the benefits of second-generation feedstocks advantages that it contributes in waste reduction and utilisation. Moreover, it reduces the cost of waste water treatment plants since most of the residences get rid of their waste oils through the sewage causing severe problems for the treatment plants [4].

However, WCO has some disadvantages as a feedstock including the high free fatty acids (FFA) and water content results from the cooking process. Accordingly, pre-treatment for the WCO feedstock is essential for alkaline homogenous catalyst processes to avoid saponification reaction by two steps production including esterification of FFA then transesterification of triglycerides [4]. Currently most of the biodiesel production processes use homogenous acidic and/or alkaline catalysts for biodiesel production from WCO. These homogenous catalysts have number of drawbacks including equipment corrosion, generation of significant amount of wastewater, existence of side reactions and the high production cost due to difficulties of catalyst separation and recovery [1].

The use of heterogenous catalyst has proven simpler production and separation processes for biodiesel production compared to homogenous catalysts since they can be easily separated by settling. However, heterogenous catalysts are very sensitive for waste content which then requires effective water removal pre-treatment for the feedstock [5].

Non-catalytic supercritical methanol production technique is a special method for biodiesel production without considering any of the previously mentioned restrictions. 
$10^{\mathrm{TH}}$ INTERNATIONAL CONFERENCE ON SUSTAINABLE ENERGY AND ENVIRONMENTAL

Protection (June $27^{\mathrm{TH}}-30^{\mathrm{TH}}, 2017$, BLED, Slovenia), Bioenergy AND Biofuels

O. Aboelazayem, M. Gadalla \& B. Saha: Optimising Bidiesel Production from High

Acid Value Waste Cooking Oil Using Supercritical Methanol

This technique has proven efficient production of biodiesel from low quality feedstock with high FFA and water contents. It tolerates esterification and transesterification reactions at the same time resulting in one step production of biodiesel [6].

The main goal of this research is to investigate the applicability of supercritical methanol technique for biodiesel production from a typical Egyptian WCO with high total acid value (18 $\mathrm{mg} \mathrm{KOH} / \mathrm{g}$ oil). In addition, to optimise the reaction conditions including $\mathrm{M}: \mathrm{O}$ molar ratio, temperature, pressure and time to maximise biodiesel yield.

\section{$2 \quad$ Materials and Methods}

\subsection{Materials used}

WCO collected from Egyptian random local restaurants and industries were exported to the UK. Methanol 99\% (MeOH) was purchased from Fisher Scientific, UK. The standard methyl esters used for preparing calibration curves and the heptadecanoic acid methyl ester used as an internal standard were purchased from Sigma-Aldrich, UK. The liquid $\mathrm{CO}_{2}$ cylinder (99.9\%) equipped with a dip tube was purchased from BOC Ltd., UK.

\section{$2.2 \quad$ Experimental setup}

WCO have been filtered in order to remove the cooking process residuals. The reaction took place in a 100-mL high pressure reactor made of stainless steel (model 49590, Parr Instrument Company, USA) which washas been fitted with a thermocouple (type J), heating mantle, controller (model 4848) and a mechanical stirrer. Oil was heated to $30^{\circ} \mathrm{C}$ to convert it to the liquid state. Then, it was weighted and mixed with methanol (based on specific ratio) to the reactor and heated with continuously stirring at constant rate of $300 \mathrm{rpm}$ to the target temperature. Then, supercritical fluid pump (model SFT-10, Analytix Ltd., U.K) was used to compress $\mathrm{CO}_{2}$ to the targeted pressure from the cylinder to the reactor. The reaction time starts when the reactor reaches the required reaction temperature and pressure. After the reaction time, the reactor was quenched using an ice bath to stop the reaction and then the reactor was then depressurised. Unreacted methanol has been recovered using simple distillation. The reaction products were separated using a centrifuge (1500 rpm, 3 min per cycle) to biodiesel and glycerol. Finally, biodiesel and glycerol weights were measured for yields calculations. Yields have been calculated by Equation (1) [6].

Yield $(\%)=$ mass of Product $/$ mass of Oil

\subsection{Experimental design}

RSM has been established to conclude the optimum conditions for biodiesel production by analysing the relationship of reaction parameters with reaction responses. Four independent variables have been chosen for the analysis including $\mathrm{M}: \mathrm{O}$ molar ratio, temperature, pressure and time, which were labelled as A, B, C, D respectively. Three 
$60 \mid 10^{\text {TH }}$ InTERnational Conference on Sustainable ENERgy AND ENVIRONMENTAL Protection (June $27^{\mathrm{TH}}-30^{\mathrm{TH}}, 2017$, BLed, Slovenia), Bioenergy AND Biofuels

O. Aboelazayem, M. Gadalla \& B. Saha: Optimising Bidiesel Production from High Acid Value Waste Cooking Oil Using Supercritical Methanol

levels for each variable have been coded as $-1,0,1$ as shown in Table 1. Biodiesel and glycerol yields have been selected as reaction responses. Thirty experiments have been performed in a randomised order where the responses have been calculated for each experiment.

Table 1. Experimental Design Variables

\begin{tabular}{|l|l|l|l|l|}
\hline Factor & Code & \multicolumn{2}{|l|}{ Levels } \\
\hline & & -1 & 0 & 1 \\
\hline M:O (molar ratio) & A & 20 & 30 & 40 \\
\hline Temperature $\left({ }^{\circ} \mathrm{C}\right)$ & B & 240 & 260 & 280 \\
\hline Pressure (bar) & C & 85 & 135 & 185 \\
\hline Time (min) & D & 7 & 22 & 27 \\
\hline
\end{tabular}

\section{$2.4 \quad$ Statistical analysis}

The general quadratic equation has been used to define the model. Statistical significance has been investigated using ANOVA by calculating the Fisher's F-test at $95 \%$ confidence level. Statistical significance of the results has been presented by p-value, where the result is considered to be significant when p-value is less than 0.05 .

Numerical optimisation of the reaction variables has been constructed based on certain goals. The goals were identified by maximising biodiesel yield and minimising glycerol yield at minimum temperature, pressure and time of the reaction.

Design of experiments, regression analysis, graphical analysis and numerical optimisation have been performed using Design Expert 10 software (Stat-Ease Inc., Minneapolis, MN, USA).

\subsection{Physicochemical properties analysis}

The final pure biodiesel at the concluded optimum conditions has been analysed for investigating its chemical and physical properties. Analysis results have been compared to the European standard of biodiesel, EN14214. The analysed properties have been replicated twice and the final results have been obtained as an average of the two results. Total acid number (TAN), standard density and kinematic viscosity of the produced biodiesel have been calibrated according to ASTM D974, ASTM D4052 and ASTM D445, respectively.

\subsection{Gas chromatography analysis}

Fatty acids composition of the WCO was analysed according to BS EN ISO 129662:2011 by converting them to methyl esters as shown in Table 2. WCO and biodiesel samples were analysed using gas chromatograph (GC) (Thermo- Scientific, Trace 1310) equipped with a capillary column (TR-BD $30 \mathrm{~m} \times 0.25 \mathrm{~mm} \times 0.25 \mu \mathrm{m})$ and flame 
$10^{\mathrm{TH}}$ INTERNATIONAL CONFERENCE ON SUSTAINABLE ENERGY AND ENVIRONMENTAL Protection (June 27 $7^{\mathrm{TH}}-30^{\mathrm{TH}}, 2017$, BLed, Slovenia), Bioenergy ANd Biofuels

O. Aboelazayem, M. Gadalla \& B. Saha: Optimising Bidiesel Production from High Acid Value Waste Cooking Oil Using Supercritical Methanol

ionisation detector (FID). Both injector and detector temperatures have been adjusted at $250^{\circ} \mathrm{C}$. Helium was used as the carrier gas. The temperature programme started from $60^{\circ} \mathrm{C}$ and held for $2 \mathrm{~min}$. Then it ramped with $10^{\circ} \mathrm{C} / \mathrm{min}$ to $200^{\circ} \mathrm{C}$ and directly ramped with $1^{\circ} \mathrm{C} / \mathrm{min}$ to $210^{\circ} \mathrm{C}$. Finally, the temperature was increased to $240^{\circ} \mathrm{C}$ with a ramp rate of $20^{\circ} \mathrm{C} / \mathrm{min}$ and remained for 7 minutes.

Table 2. Fatty Acids Compositions in WCO

\begin{tabular}{|l|l|}
\hline Fatty Acid & Weight (\%) \\
\hline Methyl Oleate & 48.2 \\
\hline Methyl Palmitate & 41.6 \\
\hline Methyl Linoleate & 9.3 \\
\hline Methyl Myristate & 0.8 \\
\hline
\end{tabular}

\section{$3 \quad$ Results and Discussion}

\subsection{Model adequacy checking}

After performing the 30 experiments generated using $\mathrm{CCD}$ and calculating the responses for each run, two regression equations representing an empirical relationship between reaction variables and each response have been concluded. For simplicity, this paper will represent only the analysis and results for biodiesel yield response. The polynomial model as shown in Equation (2) has been used to fit the experimental results where $\mathrm{Y}$ is the dependant variable (biodiesel yield); A, B, C and D are the independent variables (M:O molar ratio, temperature, pressure and time respectively).

$Y=88.64-1.31 A-B-0.65 C+0.32 D-2.34 A B-0.17 A C-1.54 A D-1.04 B C-$ $0.17 B D-0.86 C D-0.18 A^{2}+0.32 B^{2}+2.23 C^{2}+1.28 D^{2}$

The proposed model has been examined for adequacy to identify any errors associated with the normality assumptions. ANOVA has been used to model using F-test and pvalue tests, these values have been concluded as 121.52 and $<0.0001$, respectively which prove that the developed quadratic model is statistically significant with $95 \%$ confidence level. Lack-of-fit test has been applied for the model concluding p-value of 0.088 , which has successfully represented most of the experimental data. The determination coefficient values, $R^{2}$ and $R^{2}$ adj, which measure the reliability of the model fitting, have been calculated to be 0.9913 and 0.9831 , respectively. These values indicate that only 0.087 of the total variation is not well clarified by the developed model, which ensure the model fitting to the experimental data. Figure 1 illustrates the relation between predicted values generated by the model and actual experimental values. 


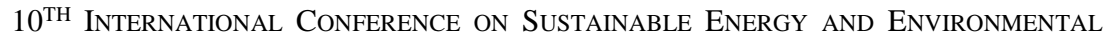
Protection (June $27^{\mathrm{TH}}-30^{\mathrm{TH}}, 2017$, BLed, Slovenia), Bioenergy ANd Biofuels

O. Aboelazayem, M. Gadalla \& B. Saha: Optimising Bidiesel Production from High Acid Value Waste Cooking Oil Using Supercritical Methanol

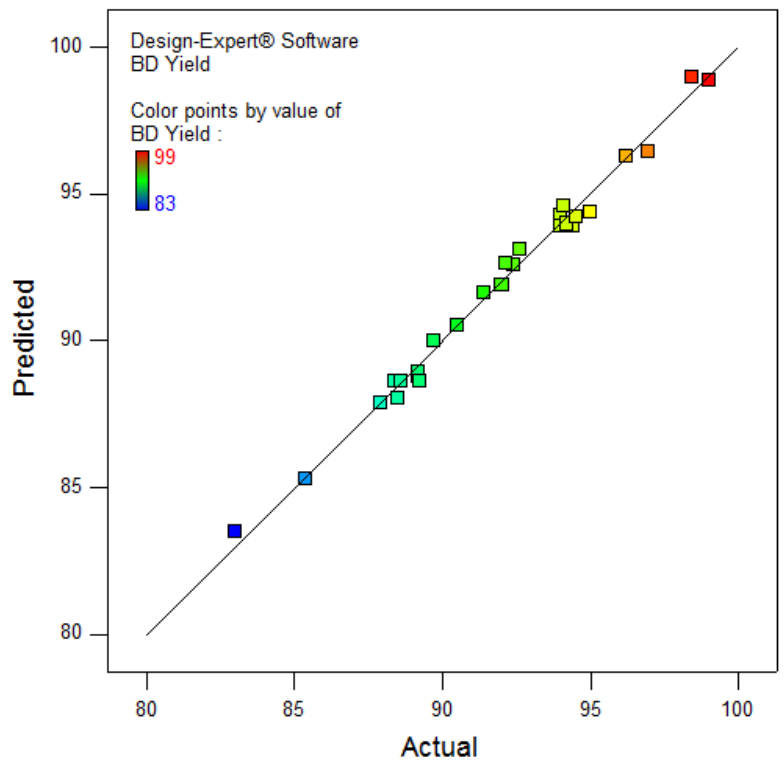

Figure 1. Predicted Data Verses Experimental Actual Data

\subsection{Effect of process variables}

\section{Effect of M:O molar ratio}

One of the drawbacks of using supercritical methanol technique for biodiesel production is the usage of large excess of methanol where, it is very important to investigate it's effect of the biodiesel yield for optimisation considerations. Experimental runs have been carried out at M:O molar ratio between 20:1 and 40:1. The ANOVA results for M:O molar ratio with p-value less than 0.0001 indicates that it has highly significant effect on biodiesel yield. Figure 2 illustrates a 3-D plot for $\mathrm{M}: \mathrm{O}$ molar ratio and temperature verses biodiesel yield where the other two variables, i.e. pressure and time, are kept constant at their centre points. At constant temperature of $250^{\circ} \mathrm{C}$, it is clearly shown that there is a direct proportional relationship between $\mathrm{M}: \mathrm{O}$ molar ratio and biodiesel yield. However, at higher temperatures its effect decreases to constant at $260^{\circ} \mathrm{C}$ reaching negative effect at higher temperatures.

\section{Effect of reaction temperature}

Reaction temperature is an important parameter for supercritical production of biodiesel. Since the critical temperature of methanol is $240^{\circ} \mathrm{C}$, the studied temperatures ranges have been chosen between $250^{\circ} \mathrm{C}$ and $270^{\circ} \mathrm{C}$. It has been concluded from the ANOVA results that reaction temperature has significant effect on biodiesel yield with p-value less than 0.0001. Figure 2 demonstrates the effect of temperature on biodiesel yield where the 
relation showed increase of biodiesel yield while increasing temperature at low M:O molar ratio range. The temperature has negative effect with an increase $\mathrm{M}: \mathrm{O}$ molar ratio.

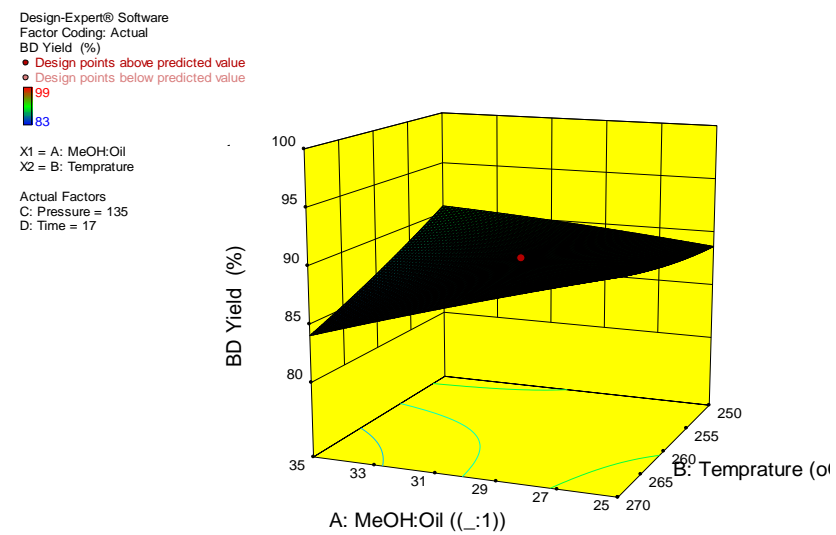

Figure 2. 3-D Plot Showing the Effect of M:O Molar Ratio and Temperature on Yield

\section{Effect of reaction pressure}

Carbon dioxide gas has been used to pressurise the reaction to the targeted pressure using a high-pressure pump. In addition, carbon dioxide acts as a co-solvent where it enhances the solubility of methanol in oil [7]. According to the ANOVA results, reaction pressure showed highly significant effect on biodiesel yield. As shown in Figure 3 the pressure has inversely proportional relationship with the yield from pressure range of $110 \mathrm{bar}$ to 130 bar then, the yield increases slightly by increasing the pressure more than 130 bar.

\section{Effect of reaction time}

According to the ANOVA results, reaction time showed significant effect on biodiesel yield with p-value of 0.005. This significance effect is clearly shown in Figure 3, where increasing time has negative effect on biodiesel yield from time range between $12 \mathrm{~min}$ to 16 min. Reaction time more than 16 min has no effect on biodiesel yield. 
$10^{\mathrm{TH}}$ International CONFerence on Sustainable Energy and Environmental Protection (June $27^{\mathrm{TH}}-30^{\mathrm{TH}}, 2017$, BLed, Slovenia), Bioenergy and Biofuels

O. Aboelazayem, M. Gadalla \& B. Saha: Optimising Bidiesel Production from High Acid Value Waste Cooking Oil Using Supercritical Methanol

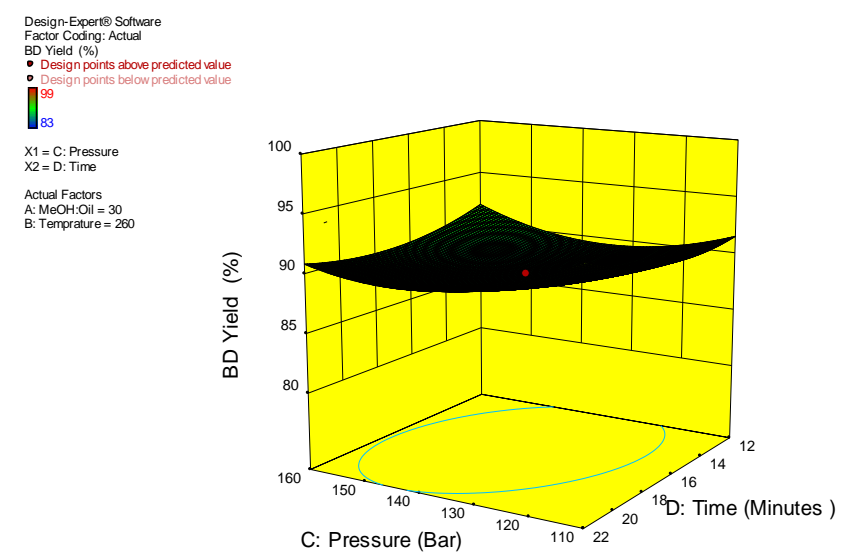

Figure 3. 3-D Plot Showing the Effect of Pressure and Time on Yield

\subsection{Optimisation of reaction conditions}

Optimisation of supercritical methanol production of biodiesel has been studied to conclude the optimum values of the independent variables (M:O molar ratio, temperature, pressure and time) affecting the dependant response variables (biodiesel and glycerol yields). Numerical optimisation technique has been carried out using Design Expert software. In order to conclude the optimum conditions, a set of targets must be defined on the software to guide the optimisation process. Targets of the independent variables have been set based on environmental and economic considerations. Reaction temperature, pressure and time have been set to be minimised in order to optimise energy consumption. Responses targets have been set to maximise the biodiesel yield while minimising glycerol yield.

The numerical optimisation technique has concluded that according to the set goals the optimum conditions for production of biodiesel is at $25: 1,265^{\circ} \mathrm{C}, 110$ and 20 minutes for M:O molar ratio, temperature, pressure and time, respectively. These optimum conditions has concluded biodiesel yield of $98 \%$ and glycerol yield of $2.1 \%$.

\subsection{Optimum conditions validation}

In order to validate the efficiency of the predicted model and it's predicted optimum conditions, experiments have been performed at the concluded optimum conditions. The experimental results showed similar response value to the predicted optimal response of $98.82 \%$ with relative error of $0.83 \%$. The similarity between the experimental response results and the predicted optimal response confirms and verifies the accuracy and adequacy of the predicted quadratic model. 
$10^{\text {TH }}$ INTERNATIONAL CONFERENCE ON SUSTAINABLE ENERGY AND ENVIRONMENTAL Protection (June $27^{\mathrm{TH}}-30^{\mathrm{TH}}, 2017$, BLED, Slovenia), Bioenergy AND Biofuels

O. Aboelazayem, M. Gadalla \& B. Saha: Optimising Bidiesel Production from High

Acid Value Waste Cooking Oil Using Supercritical Methanol

\subsection{Physicochemical properties}

The physicochemical properties of the final biodiesel product have been analysed and compared to the European Biodiesel Standard, EN14214. Table 3. shows the concluded properties in comparison with the standard limits of EN14214. The agreement of the biodiesel's properties with the biodiesel standard properties insures the quality of the produced biodiesel.

Table 3. Produced Biodiesel Properties

\begin{tabular}{|l|l|l|l|}
\hline Test & Unit & $\begin{array}{l}\text { Produced } \\
\text { biodiesel }\end{array}$ & $\begin{array}{l}\text { Biodiesel } \\
\text { (EN14214) } \\
\text { Standard }\end{array}$ \\
\hline $\begin{array}{l}\text { Density at } \\
15^{\circ} \mathrm{C}\end{array}$ & $\mathrm{kg} / \mathrm{m}^{3}$ & 884 & $860-900$ \\
\hline $\begin{array}{l}\text { Kinematic } \\
\text { viscosity at } \\
40^{\circ} \mathrm{C}\end{array}$ & $\mathrm{cSt}$ & 4.62 & $3.5-5$ \\
\hline TAN & $\begin{array}{l}\mathrm{mg} \\
\mathrm{KOH} / \\
\mathrm{g} \mathrm{oil}\end{array}$ & 0.3 & $<0.5$ \\
\hline
\end{tabular}

\section{Conclusions}

Using supercritical methanol technique has been proved to be an efficient technique for biodiesel production from high acidity feedstock in single step reaction. Both esterification and transesterifications reactions have been achieved in parallel through the reaction time. The optimum biodiesel yield has been found to be $98 \%$ at M:O molar ratio of $25: 1$, reaction temperature of $265^{\circ} \mathrm{C}$ and reaction pressure of 110 bar in 20 minutes. The optimisation results have been validated experimentally resulting in biodiesel yield of $98.82 \%$, which shows the adequacy of the predicted optimum conditions with $0.83 \%$ relative error from the experimental results. The main properties of the produced biodiesel have been analysed and compared to the European Biodiesel Standard (EN14214) showing excellent agreement with the standards specified range, which insure the quality of the produced biodiesel.

\section{Acknowledgements}

The authors acknowledge The British University in Egypt (BUE) and London South Bank University (LSBU) for funding this research.

\section{References}

[1] S. Z. Abidin, K. F. Haigh, and B. Saha, "Esterification of free fatty acids in used cooking oil using ion-exchange resins as catalysts: An efficient pretreatment method for biodiesel 
$10^{\mathrm{TH}}$ International Conference on Sustainable EnERgy and Environmental Protection (June $27^{\mathrm{TH}}-30^{\mathrm{TH}}, 2017$, BLed, Slovenia), Bioenergy AND Biofuels

O. Aboelazayem, M. Gadalla \& B. Saha: Optimising Bidiesel Production from High Acid Value Waste Cooking Oil Using Supercritical Methanol

feedstock," Ind. Eng. Chem. Res., vol. 51, no. 45, pp. 14653-14664, 2012.

[2] J. Van Gerpen, "Biodiesel processing and production," Fuel Process. Technol., vol. 86, no. 10, pp. 1097-1107, 2005.

[3] L. K. Ong, A. Kurniawan, A. C. Suwandi, C. X. Lin, X. S. Zhao, and S. Ismadji, "Transesterification of leather tanning waste to biodiesel at supercritical condition: Kinetics and thermodynamics studies," J. Supercrit. Fluids, vol. 75, pp. 11-20, 2013.

[4] M. Hajjari, M. Tabatabaei, M. Aghbashlo, and H. Ghanavati, "A review on the prospects of sustainable biodiesel production: A global scenario with an emphasis on waste-oil biodiesel utilization," Renew. Sustain. Energy Rev., vol. 72, no. November 2016, pp. 445464, 2017.

[5] S. Semwal, A. K. Arora, R. P. Badoni, and D. K. Tuli, "Biodiesel production using heterogeneous catalysts," Bioresour. Technol., vol. 102, no. 3, pp. 2151-2161, 2011.

[6] S. M. Ghoreishi and P. Moein, "Biodiesel synthesis from waste vegetable oil via transesterification reaction in supercritical methanol," J. Supercrit. Fluids, vol. 76, pp. 24 $31,2013$.

[7] H. Han, W. Cao, and J. Zhang, "Preparation of biodiesel from soybean oil using supercritical methanol and CO2 as co-solvent," Process Biochem., vol. 40, no. 9, pp. 3148$3151,2005$. 
$10^{\mathrm{TH}}$ InTERnational CONFERENCE ON Sustainable ENERgy AND ENVIRONMENTAL Protection (June $27^{\mathrm{TH}}-30^{\mathrm{TH}}$, 2017, Bled, SLOVENIA), BIOENERGY AND BIOFUELS

J. Krope, A.Ghani Olabi, D. Goričanec \& S. Božičnik

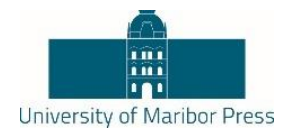

\title{
Ampelodesmos Mauritanicus Pyrolysis Biochar in Anaerobic Digestion Process: Evaluation of the Biogas Yield
}

\author{
FABio Codignole LuZ, Stefano CoRdiner, Alessandro MANni, VincenZO \\ Mulone, VitToRio RocCO, RoBERTO BRAGLIA \& ANTONELLA CANINI
}

\begin{abstract}
Biogas production through the use pyrolysis biochar as direct substrate for anaerobic digestion at laboratory scale has been analyzed. Biochar obtained from the Ampelodesmos Mauritanicus pyrolysis at 450 ${ }^{\circ} \mathrm{C}, 500{ }^{\circ} \mathrm{C}$ and $550{ }^{\circ} \mathrm{C}$ in an experimental reactor has been used for this purpose. The intermediate pyrolysis process can allow a better substrate bioavailability, reducing the process initial lag phase while maintaining the biochar positive effects on the anaerobic digestion. Three reactors have been setup with $5 \mathrm{~g}$ of biochar and continuously monitored for 15 days at $37{ }^{\circ} \mathrm{C}$. Both the cumulated and gVS specific methane productivity have been evaluated: a higher conversion efficiency for biochars produced at lower temperature has been observed per mass of substrate. Conversely, a greater conversion efficiency in terms of $\mathrm{gVS}$ has been measured for higher temperature biochars. A modified Gompertz equation has been used to describe the experimental campaign: the higher the biochar production temperature, the shorter the lag phase.
\end{abstract}

Keywords: - Anaerobic digestion - Pyrolysis - Ampelodesmos mauritanicus $\bullet$ Gompertz equation • Biogas •

CoRrespondence AdDRess: Fabio Codignole Luz, Ph.D. student, University of Rome Tor Vergata, 1.Dpt. of Industrial Engineering, Via Del Politecnico 1 ,00133 Roma, Italy, e-mail: fabio.codignole.luz@uniroma2.it. Stefano Cordiner, Ph.D., Full Professor, University of Rome Tor Vergata, Dpt. of Industrial Engineering, Via Del Politecnico 1 ,00133 Roma, Italy, e-mail: cordiner@uniroma2.it. Alessandro Manni, Ph.D., University of Rome Tor Vergata, Dpt. of Industrial Engineering, Via Del Politecnico 1,00133 Roma, Italy, e-mail: alessandro.manni@uniroma2.it. Vincenzo Mulone University of Rome Tor Vergata, Dpt. of Industrial Engineering, Via Del Politecnico 1 ,00133 Roma, Italy, e-mail: mulone@ uniroma2.it. Vittorio Rocco, University of Rome Tor Vergata, Dpt. of Industrial Engineering, Via Del Politecnico 1 ,00133 Roma, Italy, e-mail:, rocco@uniroma2.it. Roberto Braglia , Ph.D., University of Rome Tor Vergata, Dpt. of Biology, Via della Ricerca Scientifica ,00133 Roma, Italy, e-mail: roberto.braglia@uniroma2.it. Antonella Canini, Ph.D., Full Professor , University of Rome Tor Vergata, Dpt. of Biology, Via della Ricerca Scientifica ,00133 Roma, Italy, email: canini@uniroma2.it. 
$10^{\mathrm{TH}}$ International Conference on Sustainable EnERgy and Environmental Protection (June $27^{\mathrm{TH}}-30^{\mathrm{TH}}, 2017$, BLed, Slovenia), Bioenergy AND Biofuels

F. Codignole Luz, S.Cordiner, A. Manni, V. Mulone, V. Rocco, R. Braglia \& A. Canini: Ampelodesmos Mauritanicus Pyrolysis Biochar in Anaerobic Digestion Process: Evaluation of the Biogas Yield

The sustainability of current energy scenario is critical, and thus energy-economic environmental models have been applied to support states policies in order to plan carbon mitigation strategies towards alternative energy solution [1] such as bioenergy from thermochemical [2] or biochemical processes. As a result, intense research activities have been done worldwide to support the utilization of renewable sources and generate electric [3] and thermal [4] power to cope up with the continuously increasing demand for energy with limited emissions. In this context, biomass conversion into gaseous products such as biogas from anaerobic digestion processes is one of the most assessed conversion options. Biogas is most commonly produced by using animal manure, although the interest in wastes to biogas conversion has been growing leading toward the design of highly integrated system concepts. The integration among processes, as for example pyrolysis by-products [5], is an effective way toward the improvement of sustainability. From this perspective, biochar, a solid by-product of the pyrolysis process, can promote the production of biomethane by means of different mechanisms [6]. Thus, system integration of biogas and biochar is able to give profitable synergies. At the same time, water soluble species obtained from thermochemical processes, and mostly cellulose derivates, may be proper substrates for the biomethanation process. In the given scenario, the usage of biochar in the anaerobic digestion process may be of utmost importance; this paper aims at studying the biogas yield potential given by intermediate pyrolysis biochar obtained from Ampelodesmos Mauritanicus in an experimental facility [7, 8] by means of a fifteen days digestion in batch reactors.

\section{Experimental Setup and Method}

The reactors, described in [9] (figure 1),have been fed with Ampelodesmos Mauritanicus intermediate pyrolysis biochar produced at three different temperatures, 450,500 e 550 ${ }^{\circ} \mathrm{C}$. Another reactor has been charged with inoculum only to evaluate the reference gas production characteristics. The reference has been removed to take into account the effect of biochar only to the production of biogas. The reactors have then been divided into three groups: $\mathrm{RB}_{1} 450, \mathrm{RB}_{2} 500$ and $\mathrm{RB}_{3} 550$.

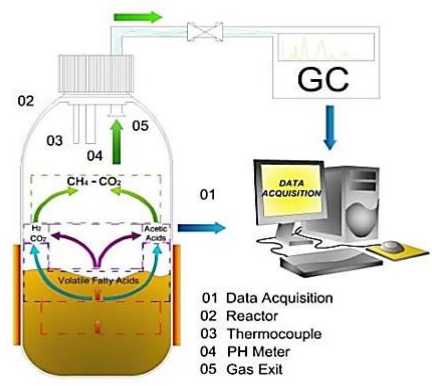

Figure 1 - Integrated analysis system 
$10^{\mathrm{TH}}$ INTERNATIONAL CONFERENCE ON SUSTAINABLE ENERGY AND ENVIRONMENTAL Protection (June 27 $7^{\mathrm{TH}}-30^{\mathrm{TH}}, 2017$, BLed, Slovenia), Bioenergy and Biofuels

F. Codignole Luz, S.Cordiner, A. Manni, V. Mulone, V. Rocco, R. Braglia \& A. Canini: Ampelodesmos Mauritanicus Pyrolysis Biochar in Anaerobic Digestion Process:

Evaluation of the Biogas Yield

An amount of $5 \mathrm{~g}$ for each biochar has been used as substrate mixed with 1.51 water. An average inoculum ratio of 0.9 , in terms of $\mathrm{g}$ volatile solids (VS) substrate per $\mathrm{gVS}$ of inoculum has been added according with the optimal values reported in [10]. All the reactors have been inoculated with digested food waste $4 \% \mathrm{VS}$. The reactors have been maintained at a constant temperature of $37^{\circ} \mathrm{C}$ for fifteen days. The amount and composition of biogas produced has been measured daily. As reported in table 1, the $\mathrm{pH}$ has been measured at the beginning of the experiments shoving a value of 7 and then has been continuously monitored during operation with a final value of 7.5 with no major oscillations.

Table 1. Simulation parameters

\begin{tabular}{|c|c|c|c|c|}
\hline Component & $\begin{array}{c}\text { Biochar } \\
\mathbf{4 5 0}^{\circ} \mathbf{C}\end{array}$ & $\begin{array}{c}\text { Biochar } \\
\mathbf{5 0 0}^{\circ} \mathbf{C}\end{array}$ & $\begin{array}{c}\text { Biochar } \\
\mathbf{5 5 0}^{\circ} \mathbf{C}\end{array}$ & Inoculum \\
\hline $\mathbf{C}(\%)$ & 64.56 & 66.9 & 70.75 & 41.65 \\
\hline H (\%) & 3.35 & 2.91 & 2.52 & 5.81 \\
\hline N (\%) & \multicolumn{5}{|c|}{ negligible } & 1.91 \\
\hline S (\%) & 0.047 & 0.05 & 0.005 & 0.27 \\
\hline O (\%) & 32.04 & 30.13 & 26.68 & 49.46 \\
\hline C/N & \multicolumn{5}{|c|}{-} & 21.8 \\
\hline TS (g) & 5 & 5 & 5 & 14 \\
\hline VS (\%) & 68 & 62 & 56 & 30 \\
\hline Moisture (\%) & \multicolumn{5}{|c|}{7} & 86 \\
\hline LHV (kJ/g) & 21.86 & 22.41 & 23.69 & 14.75 \\
\hline Initial-Final pH & \multicolumn{5}{|c|}{$7-7.5$} \\
\hline
\end{tabular}

The experiment has been repeated at same operating conditions and biomass characteristics for assessment. Substrates and Inoculum have been analyzed by means of ultimate and proximate measurements respectively with an Elementar vario MACRO cube and a Leco TGA 701. The values shown in the table are averages of several analyses performed according to the international standards. All the parameters have been then evaluated on a dry basis.

\section{Biomethane Theoretical Potential Evaluation}

The biomethane theoretical evaluation is a method used to predict the potential biomethane production BMP $\left(\mathrm{B}_{0}\right)$ of a specific organic substrate. It can be calculated by the amount of organic material removed or by the chemical oxygen demand COD [11].That calculation, expressed in $\mathrm{mlCH}_{4}$, can be performed using an empirical formula based on the elemental analysis $(\mathrm{C}-\mathrm{a}, \mathrm{H}-\mathrm{b}, \mathrm{O}-\mathrm{c}, \mathrm{N}-\mathrm{d})$; assuming the complete conversion of organic matter to methane and carbon dioxide, the Boyle-Buswell equation [11] has been widely used to calculate the ideal methane production. In general, this theoretical 
$10^{\mathrm{TH}}$ International Conference on Sustainable Energy and Environmental Protection (June 27 ${ }^{\mathrm{TH}}-30^{\mathrm{TH}}, 2017$, Bled, Slovenia), Bioenergy ANd Biofuels

F. Codignole Luz, S.Cordiner, A. Manni, V. Mulone, V. Rocco, R. Braglia \& A. Canini: Ampelodesmos Mauritanicus Pyrolysis Biochar in Anaerobic Digestion Process: Evaluation of the Biogas Yield

calculation takes into account the whole organic matter. According to [12], the biomass Volatile fraction, if known, can be otherwise considered to have a more reliable evaluation. Then the $\mathrm{CH}_{4}$ theoretical limit for gVS can be evaluated as:

$B_{0}=\frac{\left(\frac{a}{2}+\frac{b}{8}-\frac{c}{4}\right) \times 22.400}{12 a+b+16 c} \cdot V S_{\%}\left[\frac{\mathrm{mL}}{\mathrm{gVS}}\right]$

Values of $\mathrm{CH}_{4}$ yield, range from 40 to $880 \mathrm{ml} \mathrm{CH}_{4} / \mathrm{gVS}$ added.

\section{$4 \quad$ Batch Digestion Analysis by Modified Gompertz Equation}

In this paper, the cumulative methane yield for all the three cases has been checked for the alignment to the modified Gompertz equation $[13,14]$. That equation assumes that the rate of gas production is proportional to the bacterial growth and metabolic activity. The Gompertz correlation [15], has been firstly chosen in order to determine the lag phase $\lambda$ and the methane production rate $\kappa$ :

$B(t)=B_{o} \exp \left\{-\exp \left[\left(\frac{k}{B_{0}}\right) \cdot(\lambda-t) \cdot e^{1}+1\right]\right\}$

Where $\mathrm{B}(\mathrm{t})$ is the cumulative methane production expressed in $\mathrm{mlCH}_{4} / \mathrm{gVS}, \mathrm{B}_{0}$ the ultimate methane yield, $\mathrm{k}$ the methane production rate, $\lambda$ the lag phase expressed in days and e the Euler's or Napier's constant. Since the main objective and results corresponds from the first 15 days, the evaluation has been done over a reduced time and consequently the constant $\mathrm{B}_{0}$ has been assumed coherently with the theoretical one evaluated with the VS fraction. The constants $\mathrm{k}$ and $\lambda$ have then been evaluated by means of a nonlinear regression by the MATLAB fit toolbox.

\section{$5 \quad$ Energy balance}

The global energy balance considers the whole all initial substrates and final products by means of their energy content as also sketched in the graphical abstract. The input energy $\Sigma_{\text {in }}$ then takes into account both the initial total biochar mass $g_{B C}$ and the inoculum $\mathrm{M}_{\mathrm{I}}$ masses with their lower heating values and the thermal energy $\mathrm{E}_{\mathrm{th}}$ required to maintain the system at $37^{\circ} \mathrm{C}$. The last value has been evaluated as an average value from literature[16]. Thus, the total input energy per gram of biochar added can be evaluated as:

$E_{\text {in }}=\frac{\left(\mathrm{LHV}_{\mathrm{BC}} * \mathrm{~g}_{\mathrm{BC}}\right)+\left(\mathrm{LHV}_{\mathrm{i}} * \mathrm{M}_{\mathrm{I}}\right)+\mathrm{E}_{\mathrm{th}}}{\mathrm{g}_{\mathrm{BC}}} \quad\left[\frac{\mathrm{kJ}}{\mathrm{g}}\right]$

Where $\mathrm{LHV}_{\mathrm{BC}}$ and $\mathrm{LHV}_{\mathrm{i}}$ are respectively the biochar and inoculum lower heating values evaluated by their elemental analyses reported in table 1 . Then, the specific total energy 
recovered by the process $\mathrm{E}_{\mathrm{Biogas}}$ can be evaluated multiplying the volume of biogas produced $\mathrm{V}_{\text {biogas }}$ with the respective $\mathrm{LHV}_{\mathrm{g}}$, averaged over i-volume, as:

$\mathrm{E}_{\text {Biogas }}=\frac{\mathrm{V}_{\text {biogas }} \times \mathrm{LHV}_{\mathrm{g}}}{\mathrm{g}_{\text {BioChar }}}\left[\frac{\mathrm{kJ}}{\mathrm{g}}\right]$

The apparent energy conversion efficiency can be finally evaluated as:

$\eta=\frac{E_{B i o g a s}}{E_{\text {in }}}$

\section{$6 \quad$ Analysis of Results}

In Figures 3-5 gas production profiles of the three reactors RB1450, RB2500 and RB3550 are reported. These trends, which on average (Figure 6) present methane fractions between 50 and $60 \%$ and $\mathrm{CO} 2$ between 30 and $40 \%$, show comparable gas heating values between 25.8 and $28.6 \mathrm{~kJ} / \mathrm{g}$. It's evident that, between $450^{\circ} \mathrm{C}$ to $550^{\circ} \mathrm{C}$, the first peak of methane production increases with the biochar temperature production.

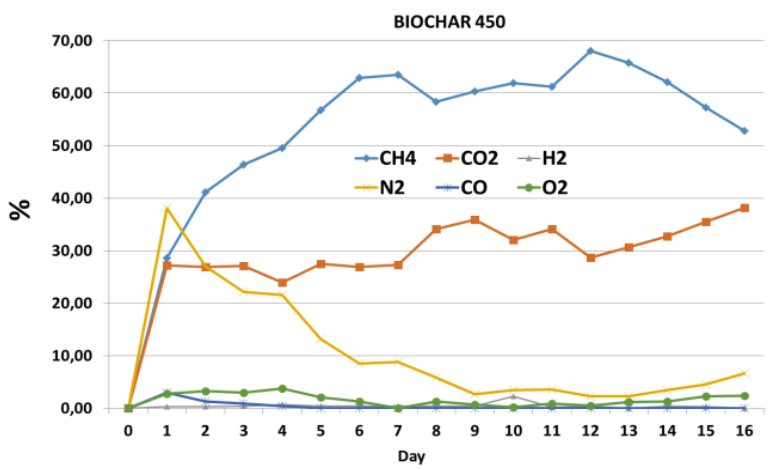

Figure 3 Biogas composition biochar $450^{\circ} \mathrm{C}$

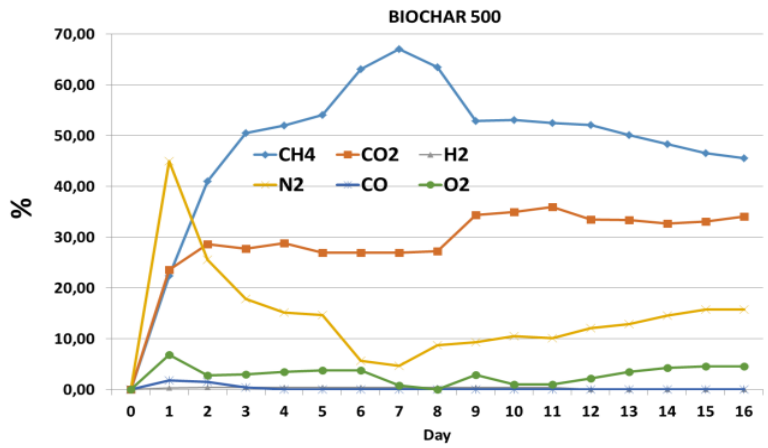

Figure 4 Biogas composition biochar $500^{\circ} \mathrm{C}$ 
$10^{\mathrm{TH}}$ International Conference on Sustainable Energy and Environmental Protection (June $27^{\mathrm{TH}}-30^{\mathrm{TH}}, 2017$, Bled, Slovenia), BioENERGy AND Biofuels

F. Codignole Luz, S.Cordiner, A. Manni, V. Mulone, V. Rocco, R. Braglia \& A. Canini: Ampelodesmos Mauritanicus Pyrolysis Biochar in Anaerobic Digestion Process: Evaluation of the Biogas Yield

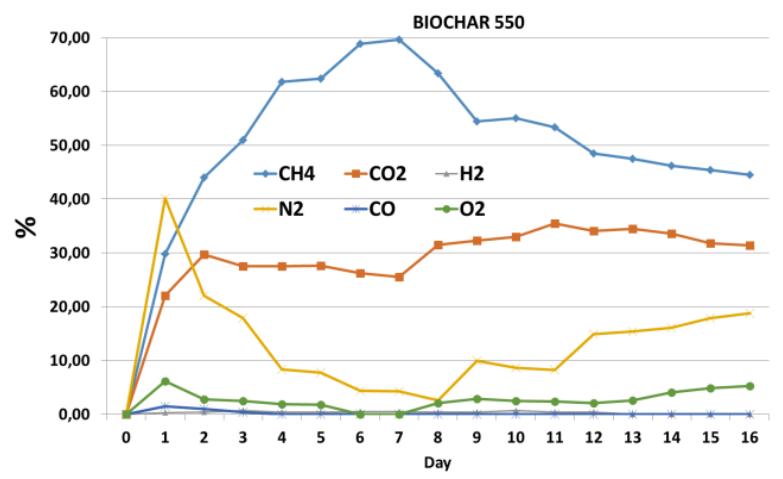

Figure 5 Biogas composition biochar $550^{\circ} \mathrm{C}$

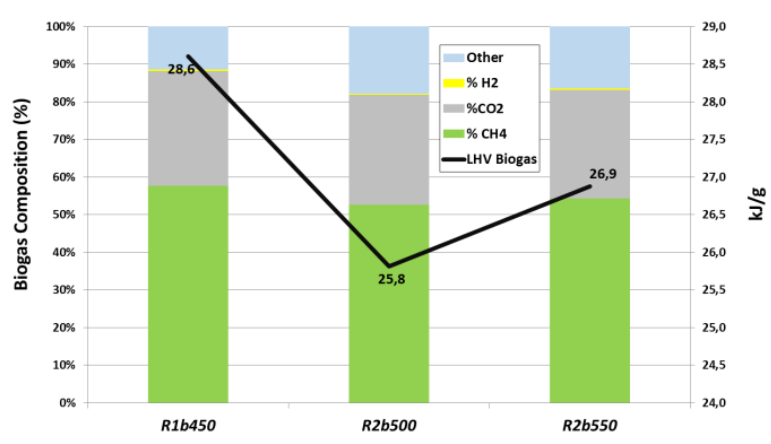

Figure 6 Biogas average composition and LHV

Such methane production peak, occurring for all the cases approximately at the seventh day, presents a quantitative peak for the biochar B450 of about $62 \%, 67 \%$ for B500, and $70 \%$. for the B550. The biochar produced at $450{ }^{\circ} \mathrm{C}$ shows a second peak at nearly $69 \%$, that is a very interesting result. This peak can be justified assuming the occurrence of a slower hydrolysis of some components not available in the early stages of the digestion process. This can then be considered as a sign of dependence between the availability of the biochar organic content and its production temperature. In figures 7-9 are then shown the single methane production profiles expressed in $\mathrm{mL} / \mathrm{gVS}$. The experimental data were interpolated through a Gompertz curve where the upper limit value has been fixed in according to the previous comments. 
$10^{\mathrm{TH}}$ INTERNATIONAL CONFERENCE ON SUSTAINABLE ENERGY AND ENVIRONMENTAL

Protection (June $27^{\mathrm{TH}}-30^{\mathrm{TH}}, 2017$, Bled, Slovenia), Bioenergy and Biofuels

F. Codignole Luz, S.Cordiner, A. Manni, V. Mulone, V. Rocco, R. Braglia \& A. Canini: Ampelodesmos Mauritanicus Pyrolysis Biochar in Anaerobic Digestion Process:

Evaluation of the Biogas Yield

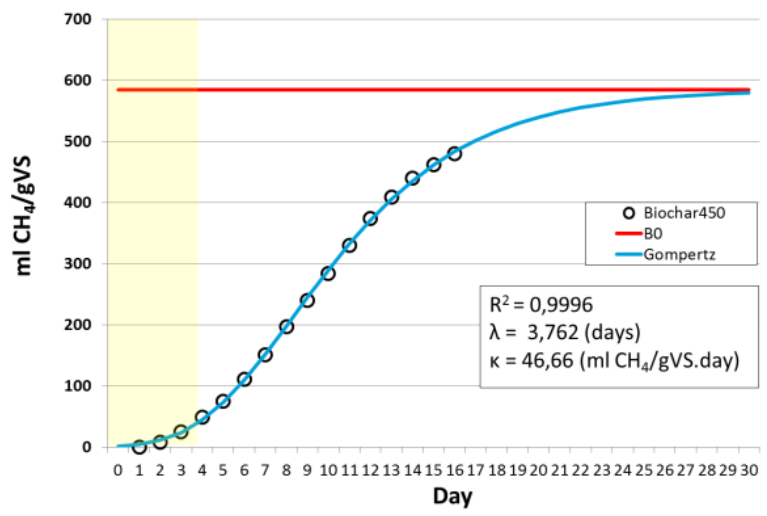

Figure 7 Cumulated $\mathrm{CH}_{4}$ :Biochar $450^{\circ} \mathrm{C}$

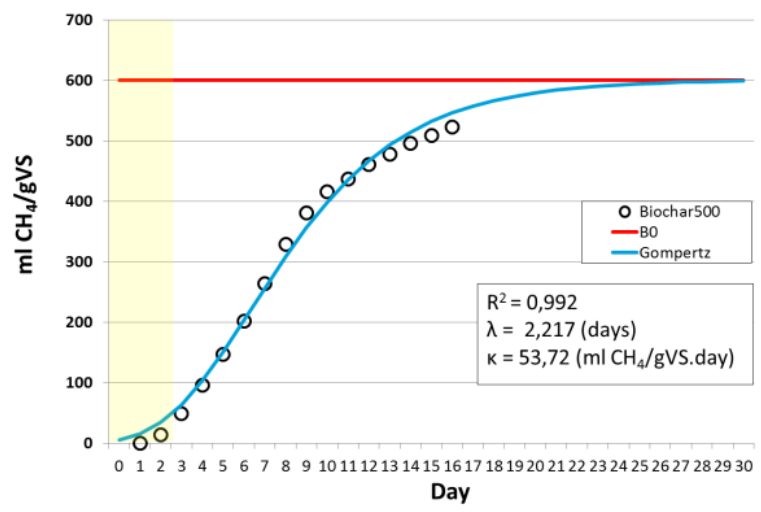

Figure 8 Cumulated $\mathrm{CH}_{4}$ :Biochar $500^{\circ} \mathrm{C}$

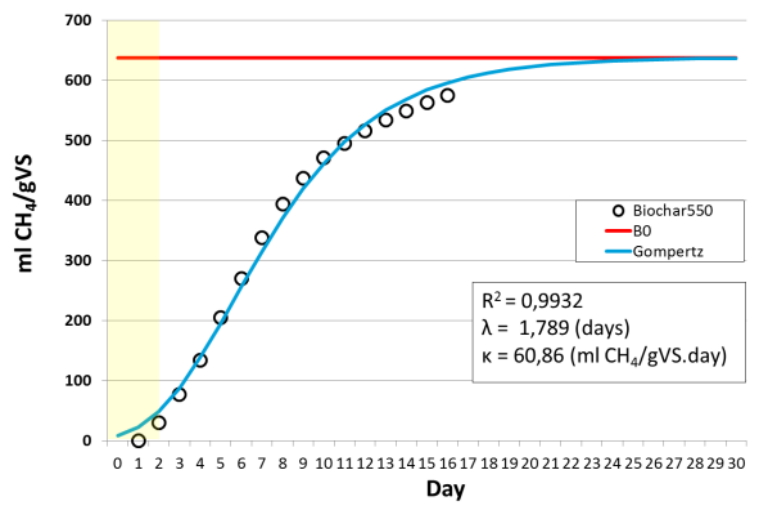

Figure 9 Cumulated $\mathrm{CH}_{4}$ :Biochar $550^{\circ} \mathrm{C}$ 
74 10 $10^{\text {TH }}$ International Conference on Sustainable ENERgy AND ENVIRONMENTAL Protection (June 27 ${ }^{\mathrm{TH}}-30^{\mathrm{TH}}, 2017$, Bled, Slovenia), Bioenergy ANd Biofuels

F. Codignole Luz, S.Cordiner, A. Manni, V. Mulone, V. Rocco, R. Braglia \& A. Canini: Ampelodesmos Mauritanicus Pyrolysis Biochar in Anaerobic Digestion Process: Evaluation of the Biogas Yield

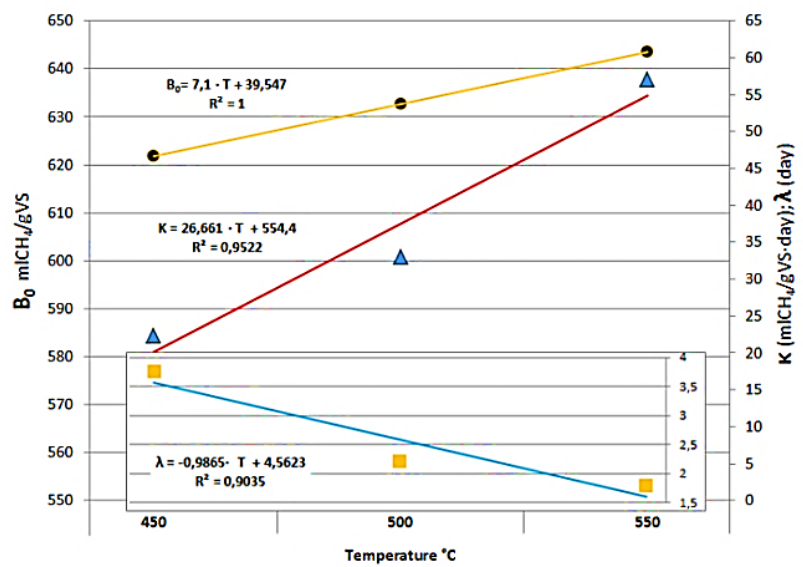

Figure 10 Gompertz regression parameters

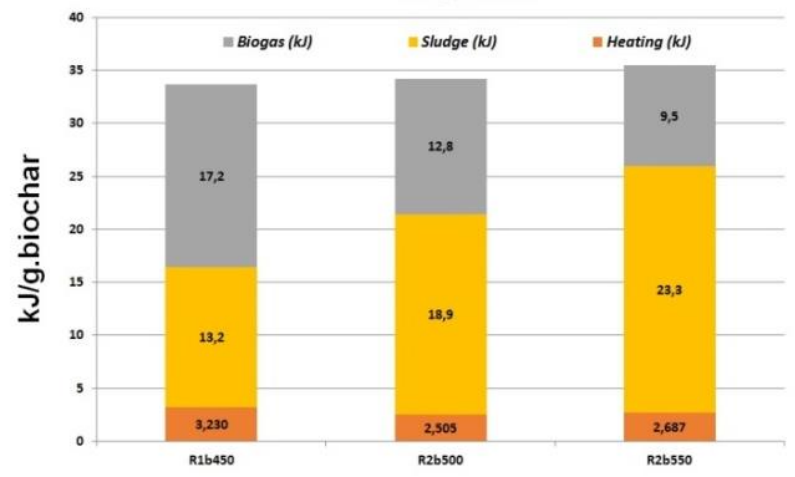

Figure 11 Energy balance

The theoretical production of methane is reported in table 3 with the cumulated experimental value and the total energy input. Once this value has been assumed, the parameters of specific productivity rate $\mathrm{k}$ and the lag time $\lambda$ have been set.

Table 3 Energy input, $\mathrm{B}_{0}$ and experimental methane yield

$\begin{array}{ccccc}\text { Component } & \begin{array}{c}\text { Biochar } \\ \mathbf{4 5 0}^{\circ} \mathbf{C}\end{array} & \begin{array}{c}\text { Biochar } \\ \mathbf{5 0 0}^{\circ} \mathbf{C}\end{array} & \begin{array}{c}\text { Biochar } \\ \mathbf{5 5 0}^{\circ} \mathbf{C}\end{array} & \begin{array}{c}\text { Inoculum } \\ \text { Energy Input (kJ) }\end{array} \\ 168 & 171 & 177 & 59 \\ \text { CH4Th (ml_CH4/g- } & 584.51 & 600.82 & 637.83 & 158.65 \\ \text { VS) } & 496.5 & 540.4 & 547.6 & 147 \\ \text { CH4Exp (ml_CH4/g- } & 61 \% & 45 \% & 34 \% & - \\ \text { VS) } & & & & \end{array}$


$10^{\mathrm{TH}}$ INTERNATIONAL CONFERENCE ON SUSTAINABLE ENERGY AND ENVIRONMENTAL

Protection (June $27^{\mathrm{TH}}-30^{\mathrm{TH}}, 2017$, Bled, Slovenia), Bioenergy AND Biofuels

F. Codignole Luz, S.Cordiner, A. Manni, V. Mulone, V. Rocco, R. Braglia \& A. Canini: Ampelodesmos Mauritanicus Pyrolysis Biochar in Anaerobic Digestion Process:

Evaluation of the Biogas Yield

As shown in the figures, all the interpolating curves showed a $\mathrm{R}^{2}$ greater than 0.99 which implies reliable data regression reliable. It's evident that increasing the biochar production temperature a corresponding reduction of the lag time can be observed. This fact, as already highlighted, describes a faster digestion first phase, for the biochar reacted at a higher temperature. Comparing B450 and B550 $\lambda$ in fact, this value is more than halved. According to this conclusion, the value of $\mathrm{k}$ production rate increases with the production temperature as well, indicating a more rapid growth of the bacterial population thanks to a greater availability of nutrients. The values of the two constants were then reported along with $\mathrm{B} 0$ in Figure 10 where, by means of a linear interpolation, the close correlation between $\mathrm{k} \lambda$ and temperature supported by $\mathrm{R} 2$ values higher than $90 \%$ is highlighted. These considerations do not necessarily mean that the biochar produced at a higher temperature is necessarily better for anaerobic digestion purposes than others. In fact, the TGA analysis shows an edible fraction in B450 of Volatile Solids greater than the other two cases. This implies a virtually greater available energy content of that biochar if compared to the other produced at higher temperature. This energy, on the other hand, is limited in the low residence time apparatus by the speed of the whole digestion process. In Figure 11 the energy balances for the three cases at the end of 15 days are then shown, evaluated per gram of biochar added. The total energy content of each column is clearly represented by the sum of energy inputs. It's evident that the fraction of energy recovered from the B450 is greater, although the specific production per $\mathrm{gVS}$ is lesser. The residual sludge energy content has been evaluated through the energy balance.

\section{$7 \quad$ Conclusions}

The production of biogas from mixing of intermediate pyrolysis biochar with activated food waste as inoculum has been studied in this paper. Three reactors, and namely $\mathrm{RB}_{1} 450, \mathrm{RB}_{2} 500$ and $\mathrm{RB}_{3} 550$ depending on the biochar production temperature, have been charged with $5 \mathrm{~g}$ of Ampelodesmos Mauritanicus biochar and maintained at a constant temperature of $37^{\circ} \mathrm{C}$ for fifteen days. The experiments have been repeated keeping same operating conditions and biomass characteristics. The following synthetic conclusions may be stated:

- The lower the biochar temperature production is, the higher the biogas production results according to the amount of $\mathrm{gVS}$ available: $\mathrm{RB}_{1} 450$ showed a 25\% higher yield than $\mathrm{RB}_{2} 500$ and $19 \%$ higher than $\mathrm{RB}_{3} 550$.

- The $\mathrm{RB}_{1} 450$ showed an efficiency $26 \%$ greater than RB2500 and $45 \%$ greater than RB3550 for gTS added.

- The higher the biochar production temperature is, the higher the gVS specific methane production results. $\mathrm{RB}_{3} 550$ showed $547 \mathrm{~mL} / \mathrm{gVS}$ vs $496 \mathrm{~mL} / \mathrm{gVS}$ of $\mathrm{RB}_{1} 450$.

- On the given data, a regression analysis following the modified Gompertz equation has been done to highlight the parameters controlling the process. 
$10^{\mathrm{TH}}$ International Conference on Sustainable Energy and EnVironmental Protection (June 27 ${ }^{\mathrm{TH}}-30^{\mathrm{TH}}, 2017$, BLed, Slovenia), Bioenergy ANd Biofuels

F. Codignole Luz, S.Cordiner, A. Manni, V. Mulone, V. Rocco, R. Braglia \& A. Canini: Ampelodesmos Mauritanicus Pyrolysis Biochar in Anaerobic Digestion Process: Evaluation of the Biogas Yield

- The analysis showed an estimated lag phase of 1.8 days for RB1450, 2.2 days for RB2500 and 3.8 days for RB3550, that is inversely proportional to the biochar production temperature.

\section{Graphical abstract}

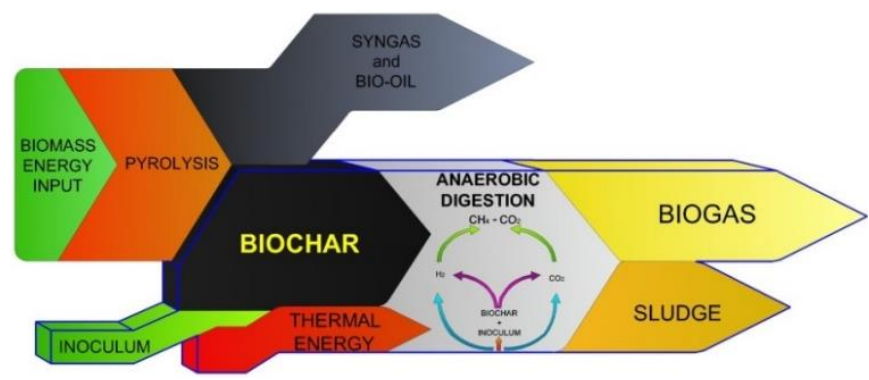

\section{Acknowledgements}

The author Fabio Codignole would like to acknowledge CSF/CAPES (BEX-11965/13-4) Brazilian Federal Agency for Support and Evaluation of Graduate Education within the Ministry of Education of Brazil.

\section{References}

[1] P. Fortes, R. Pereira, A. Pereira, and J. Seixas, "Integrated technological-economic modeling platform for energy and climate policy analysis," Energy, vol. 73, pp. 716-730, 2014.

[2] C.-C. Kung and N. Zhang, "Renewable energy from pyrolysis using crops and agricultural residuals: An economic and environmental evaluation," Energy, vol. 90, Part 2, pp. 1532-1544, 10// 2015.

[3] S. Cordiner and V. Mulone, "Experimental-numerical analysis of a biomass fueled microgeneration power-plant based on microturbine," Applied Thermal Engineering, vol. 71, pp. 905-912, 2014.

[4] S. Cordiner, G. De Simone, and V. Mulone, "Experimental-numerical design of a biomass bubbling fluidized bed gasifier for paper sludge energy recovery," Applied energy, vol. 97, pp. 532-542, 2012.

[5] S. A. Opatokun, V. Strezov, and T. Kan, "Product based evaluation of pyrolysis of food waste and its digestate," Energy, vol. 92, Part 3, pp. 349-354, 12/1/ 2015.

[6] M. O. Fagbohungbe, B. M. Herbert, L. Hurst, C. N. Ibeto, H. Li, S. Q. Usmani, et al., "The challenges of anaerobic digestion and the role of biochar in optimizing anaerobic digestion," Waste Management, 2016.

[7] M. A. Cordiner S, Mulone V, Rocco V, "Biomass pyrolysis modeling of systems at laboratory scale," International Journal of Numerical Methods for Heat and Fluid Flow, SUBMITTED 2017. 
$10^{\mathrm{TH}}$ INTERNATIONAL CONFERENCE ON SUSTAINABLE ENERGY AND ENVIRONMENTAL

Protection (June $27^{\mathrm{TH}}-30^{\mathrm{TH}}, 2017$, BLed, Slovenia), Bioenergy AND Biofuels

F. Codignole Luz, S.Cordiner, A. Manni, V. Mulone, V. Rocco, R. Braglia \& A. Canini: Ampelodesmos Mauritanicus Pyrolysis Biochar in Anaerobic Digestion Process:

Evaluation of the Biogas Yield

[8] F. Codignole Luz, S. Cordiner, A. Manni, V. Mulone, and V. Rocco, "Analysis of Residual Biomass fast pyrolysis at laboratory scale: experimental and numerical evaluation of spent coffee powders energy content," Energy Procedia (in press), 2017.

[9] F. Codignole Luz, S. Cordiner, A. Manni, V. Mulone, and V. Rocco, "Anaerobic digestion of liquid fraction coffee grounds at laboratory scale: evaluation of the biogas yield," Energy Procedia (in press), 2017.

[10] V. Moset, N. Al-zohairi, and H. B. Møller, "The impact of inoculum source, inoculum to substrate ratio and sample preservation on methane potential from different substrates," Biomass and Bioenergy, vol. 83, pp. 474-482, 12// 2015.

[11] F. Raposo, V. Fernández-Cegrí, M. De la Rubia, R. Borja, F. Béline, C. Cavinato, et al., "Biochemical methane potential (BMP) of solid organic substrates: evaluation of anaerobic biodegradability using data from an international interlaboratory study," Journal of Chemical Technology and Biotechnology, vol. 86, pp. 1088-1098, 2011.

[12] I. Angelidaki and W. Sanders, "Assessment of the anaerobic biodegradability of macropollutants," Re/Views in Environmental Science \& Bio/Technology, vol. 3, pp. 117129, 2004.

[13] M. Zwietering, I. Jongenburger, F. Rombouts, and K. Van't Riet, "Modeling of the bacterial growth curve," Applied and environmental microbiology, vol. 56, pp. 18751881, 1990.

[14] Y. Wong, J. Juan, A. Ting, and T. Wu, "High efficiency bio-hydrogen production from glucose revealed in an inoculum of heat-pretreated landfill leachate sludge," Energy, vol. 72, pp. 628-635, 2014.

[15] A. Nielfa, R. Cano, M. Vinot, E. Fernández, and M. Fdz-Polanco, "Anaerobic digestion modeling of the main components of organic fraction of municipal solid waste," Process Safety and Environmental Protection, vol. 94, pp. 180-187, 2015.

[16] H. Reichhalter, A. Bozzo, S. Dal-Salvio, and T. Guerra, "Energetic, Environmental and Economic Analysis of Biogas Plants in Bolzano Province," ed: Area Energia \& Ambiente TIS innovation park, 2011, p. 106. 
78 10 $10^{\mathrm{TH}}$ International Conference on Sustainable EnERgy and EnVironmental Protection (June $27^{\mathrm{TH}}-30^{\mathrm{TH}}, 2017$, Bled, Slovenia), Bioenergy AND Biofuels 
$10^{\mathrm{TH}}$ InTERnational CONFEREnCE ON Sustainable ENERgy AND EnVironmental Protection (June $27^{\mathrm{TH}}-30^{\mathrm{TH}}$, 2017, Bled, SLOVENIA), BIOENERGY AND BIOFUELS

J. Krope, A.Ghani Olabi, D. Goričanec \& S. Božičnik

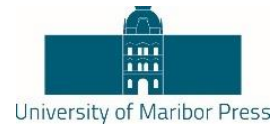

\title{
Thermocatalytic Refining of Gaseous Products Produced by Fast Pyrolysis of Flax Shive
}

\author{
Yury V. Lugovoy, Kirill V. Chalov, Oleg V. ManaenKov, Esther M. Sulman \& \\ YURY YU. KOSIVTSOV
}

\begin{abstract}
The current work describes thermocatalytic refining of gaseous products obtained through fast pyrolysis of flax shive. The influence of such parameters as temperature and reaction time on biomass waste pyrolysis process was studied. The gaseous products obtained by fast pyrolysis contained 0.75 wt. $\%$ of resins which decreased the heat value; thus gas purification is a required stage to produce highly qualified gaseous fuel. The pyrolysis gases were refined through thermocatalytic destruction at $600{ }^{\circ} \mathrm{C}$ in the presence of natural aluminosilicates and zeolites. H-ZSM5 zeolite modified with iron subgroup metals was also used as gas refining catalyst. The use of zeolite catalysts leads to the decrease in resins amount in a pyrolysis gas. Co-containing catalyst was found to be the most active catalyst for resins degradation in a pyrolysis gas.
\end{abstract}

Keywords: • Fast pyrolysis • Pyrolysis gas • Upgrading • Alumosilicate • Flax Shive •

CorRespondence AdDREss: Yury V. Lugovoy, Ph.D., Associate Professor, Tver State Technical University, Faculty of Chemical Engineering, A.Nikitin emb. 22, 170026 Tver, Russia, e-mail: pnjust@yandex.ru. Kirill V. Chalov, Ph.D., Assistant Professor, Tver State Technical University, Faculty of Chemical Engineering, A.Nikitin emb. 22, 170026 Tver, Russia, e-mail: tschalov_k@mail.ru. Oleg V. Manaenkov, Ph.D., Associate Professor, Tver State Technical University, Faculty of Chemical Engineering, A.Nikitin emb. 22, 170026 Tver, Russia, e-mail: ovman@yandex.ru. Esther M. Sulman, Dr. of Sc., Professor, Tver State Technical University, Faculty of Chemical Engineering, A.Nikitin emb. 22, 170026 Tver, Russia, e-mail: sulman@online.tver.ru. Yury Yu. Kosivtsov, Dr. of Sc., Professor, Tver State Technical University, Faculty of Chemical Engineering, A.Nikitin emb. 22, 170026 Tver, Russia, e-mail: kosivtsov@science.tver.ru. 
$10^{\mathrm{TH}}$ InTERnATIONAL CONFERENCE ON Sustainable ENERGy AND ENVIRONMENTAL Protection (June 27 ${ }^{\mathrm{TH}}-30^{\mathrm{TH}}, 2017$, BLED, SLOVENiA), Bioenergy AND Biofuels Y. V. Lugovoy, K. V. Chalov, O. V. Manaenkov, E. M. Sulman \& Y. Yu. Kosivtsov: Thermocatalytic Refining of Gaseous Products Produced by Fast Pyrolysis of Flax Shive

In recent decades the problem of biomass processing has been of great interest [1]. The complexity and variability of biomass composition do not allow solving the problems of effective complex processing of biomass for energy production [2]. The difficulties of biomass processing are also determined by the differences in physical chemical characteristics, biomass origin, storage conditions and biomass harvesting methods. These factors strongly affect the initial humidity, ash content and as the result heatgeneration.

The thermal treatment conducted in inert medium is the most promissing method of biomass utilization to produce heat, electricity, liquid fuels and sorbents. Fast pyrolysis is the most effective and ecologically justified method leading to the maximum yield of valuable products [3-5]. Among the advantages of the fast pyrolysis, continuous process cycle, high yields of gaseous and liquid products, low probability of secondary processes decreasing the quality of the obtained fuels can be highlighted. The use of catalysts during fast pyrolysis increases gaseous and liquid products yield, the amount of branched hydrocarbons in a liquid fraction and aromatic compounds concentration. Thus the development of novel catalysts for biomass fast pyrolysis is the centre of attention $[2,6]$.

Fast pyrolysis is widely used for electricity generation from plant-based biomass waste. Such technologies are focused on the increase in the conversion of the initial raw material to the combustible gases with high heat value and low resin content $[7,8]$.

Thermocatalytic refining of gaseous products of fast pyrolysis is a technological method directed at the reducing of high-boiling fractions content and resins. According to the technology, the pyrolysis gas flows through the catalyst layer which provides thermal destruction of high-molecular components. The significant amount of gaseous hydrocarbons is forming during the thermocatalytic destruction of gaseous products. The addition of the refining stage also increases the heat value of the gaseous products.

However the main problem of the catalysts of the thermal refining of gaseous products is the high cost and fast activity loss due to the carbonization of catalyst surface [9]. Thus the development of the cheap and effective catalysts of the thermal refining of pyrolysis gaseous products is one of the main challenges for the researchers. Therefore the study of fast pyrolysis process involving the stage of gas refining is one of the ways of renewable feedstock processing for energy generation.

\section{Experimental}

In this work we studied low-temperature fast pyrolysis of flax shive. The samples of flax shive with $30 \%$ decomposition degree and 5\% ash content were used as the feedstock. Both natural aluminosilicate (bentonite clay, kaolin clay, clay mergel, cambrian clay) and synthetic zeolites (H-Mord-20, H-Beta-25, HY, H-ZSM-5 and H-Beta-150 purchased 
Y. V. Lugovoy, K. V. Chalov, O. V. Manaenkov, E. M. Sulman \& Y. Yu. Kosivtsov:

from "Zeolyst International" (USA)) were used as the catalysts. H-ZSM-5 was modified with different metals $(\mathrm{Fe}, \mathrm{Ni}, \mathrm{Co})$ and was also used as a catalyst for the refining process.

The investigation of the thermal stability of biomass samples was carried out by thermogravimetric analysis method. Thermogravimetric analysis was performed on the thermoanalyser NETZSCH 2000 . The samples were heated at a constant rate $\left(10^{\circ} \mathrm{C} / \mathrm{min}\right)$ under nitrogen in the temperature range $50-600{ }^{\circ} \mathrm{C}$.

The fast pyrolysis of flax shive was performed under inert atmosphere (nitrogen) in the laboratory reactor equipped with gaseous product catalytic refining system. The feedstock mass loaded into the reactor was $500 \mathrm{~g}$. The residence time of the feed in the reaction zone of fast pyrolysis reactor was less than 5 seconds. The temperature was varied in the range $450-650^{\circ} \mathrm{C}$. Gaseous pyrolysis products were passed through the discharge hopper to remove solid products and were transferred to catalytic column. The gaseous samples were taken before and after the catalytic column to estimate the catalytic activity.

The gaseous products analysis was performed by the gas chromatography method. The analysis of the fast pyrolysis gaseous products which consisted of $\mathrm{C}_{1}-\mathrm{C}_{4}$ hydrocarbon, carbon oxides and hydrogen content definition, as well as the express analysis of the lower specific heat value. The chromatographic analysis of the gaseous products was performed on the base of chromatograph "Kristallux" 4000M and modified chromatograph "Gasochrom 2000".

\section{$3 \quad$ Results and Discussion}

To evaluate the temperature range for flash pyrolysis process, thermal stability of flax shive was studied using Differential Scanning Calorimetry. Two weight loss peaks can be observed in Figure 1: temperature $105^{\circ} \mathrm{C}$ corresponds to the dehydration process, while $349^{\circ} \mathrm{C}$ characterises thermal destruction of biomass components - hemicellulose, cellulose and lignin [10].

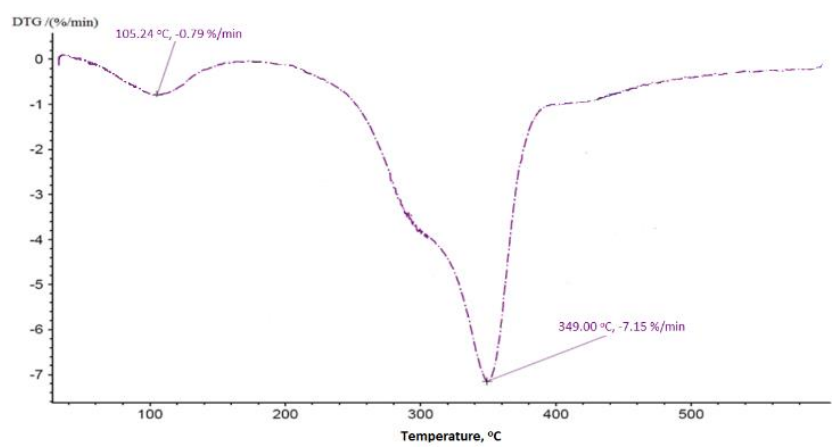

Figure 1. DTG data of flax shive sample 
$10^{\mathrm{TH}}$ INTERNATIONAL CONFERENCE ON SUSTAINABLE ENERGy AND ENVIRONMENTAL Protection (June $27^{\mathrm{TH}}-30^{\mathrm{TH}}, 2017$, BLED, SLOVENIA), BioENERGY AND Biofuels

Y. V. Lugovoy, K. V. Chalov, O. V. Manaenkov, E. M. Sulman \& Y. Yu. Kosivtsov: Thermocatalytic Refining of Gaseous Products Produced by Fast Pyrolysis of Flax Shive

As the heating time of the feedstock in the fast pyrolysis process is short, the higher temperature range $450-650{ }^{\circ} \mathrm{C}$ was chosen for the study to reach the higher conversion of the feedstock.

The influence of temperature on the fast pyrolysis product distribution is shown in Figure 2.

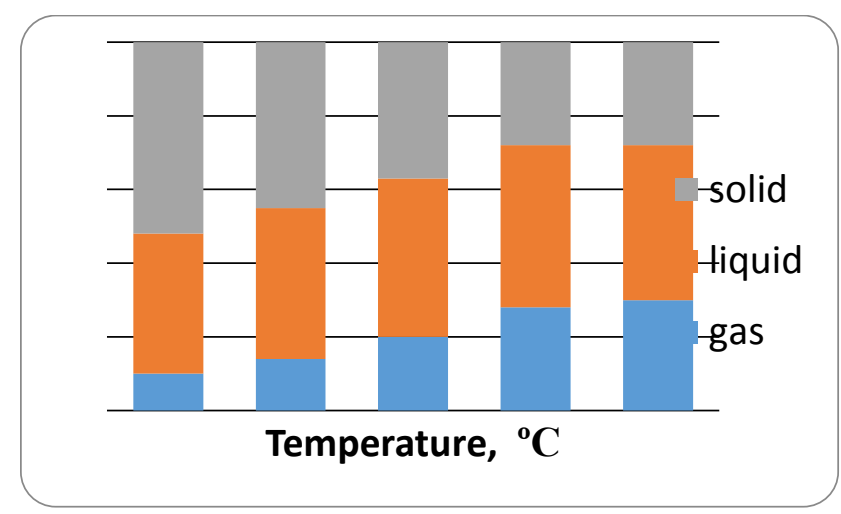

Figure 2. Temperature effect on flax shive pyrolysis (residence time $-2 \mathrm{sec}$ )

The optimal process temperature was found to be $600 \mathrm{C}$. As it can be seen, the increase in temperature in the range 450-600 $\mathrm{C}$ decreases the formation of solid carbon residue while the temperature further increase does not lead to the growth in gaseous and liquid product yield. Moreover the experiments showed that at $600{ }^{\circ} \mathrm{C}$ the highest heat value of gaseous mixture $\left(17.14 \mathrm{MJ} / \mathrm{m}^{3}\right)$ was observed, while at a temperature above $600{ }^{\circ} \mathrm{C}$ the heat value of gaseous products decreases due to the formation of low molecular weight gases - hydrogen and carbon monoxide (II).

The reaction time is also an important parameter in fast pyrolysis process. We studied the influence of the feedstock residence time on the formation of pyrolysis solid residue (Figure 3). It was found that the increase in reaction time above 2 second does not affect the solid residue yield. 
$10^{\mathrm{TH}}$ INTERNATIONAL CONFERENCE ON SUSTAINABLE ENERGY AND ENVIRONMENTAL

Protection (June $27^{\mathrm{TH}}-30^{\mathrm{TH}}, 2017$, Bled, Slovenia), BioENERGy ANd Biofuels

Y. V. Lugovoy, K. V. Chalov, O. V. Manaenkov, E. M. Sulman \& Y. Yu. Kosivtsov: Thermocatalytic Refining of Gaseous Products Produced by Fast Pyrolysis of Flax Shive

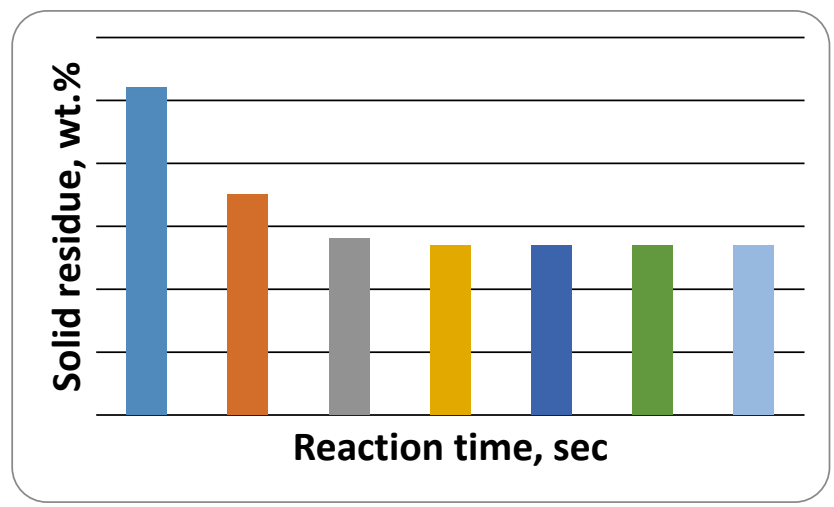

Figure 3. Solid residue yield dependence on fast pyrolysis time

Thus the further experiments were conducted at the chosen conditions: temperature $600 \mathrm{C}$, residence time of feedstock in the reactor zone -2 second, flax shive particle size $0.5 \mathrm{~mm}$.

The gaseous mixture obtained after flax shive fast pyrolysis was catalytically destructed to reduce resin content. The initial gaseous products contained $0.75 \mathrm{wt}$. $\%$ of resins. The experiments on fast pyrolysis gases refining were conducted at $600 \mathrm{C}$ in the presence of natural aluminosilicates (bentonite clay, cembrian clay, caoline clay and clay mergel) and synthetic zeolites (H-Beta-25 and H-Mord). The influence of the catalyst type and loading on the heat value of the obtained gases is shown in Figure 4.

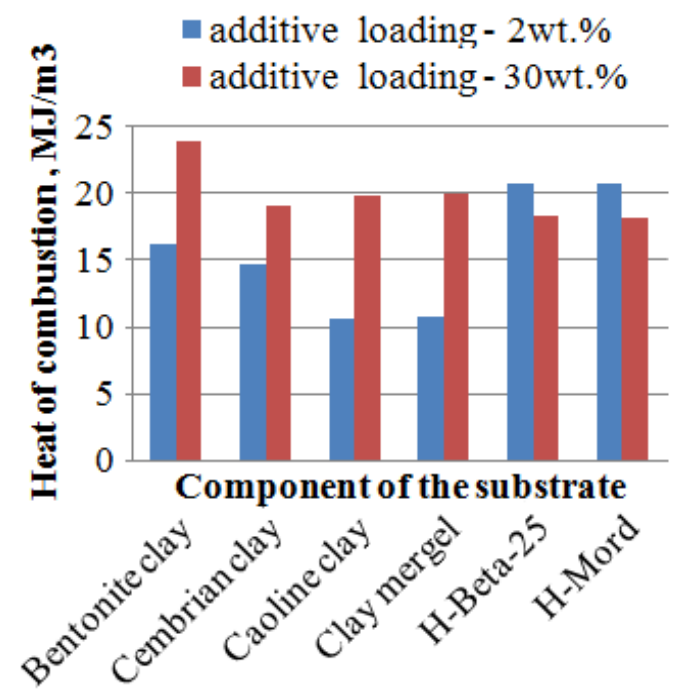

Figure 4. Influence of the catalyst type and loading on the heat value of gaseous products 


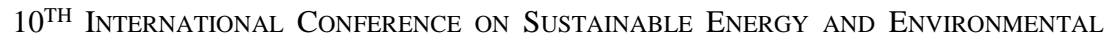
Protection (June 27 ${ }^{\mathrm{TH}}-30^{\mathrm{TH}}, 2017$, BLED, SLOVENiA), Bioenergy AND Biofuels

Y. V. Lugovoy, K. V. Chalov, O. V. Manaenkov, E. M. Sulman \& Y. Yu. Kosivtsov:

Thermocatalytic Refining of Gaseous Products Produced by Fast Pyrolysis of Flax Shive

It was found that the addition of 2 wt. \% of natural aluminosilicate either does not affect the gas calorific value (for bentonite clay) or decreases that one (in the case of cembrian clay, caoline clay and clay mergel). At the same time, the increase in aluminosilicate loading (up to $30 \mathrm{wt}$. \%) leads to the increase in heat value up to $24 \mathrm{MJ} / \mathrm{m}^{3}$ in the case of bentonite clay. The addition of zeolites leads to the increase in gas heat value in both cases ( 2 and $30 \mathrm{wt} . \%$ ), however $2 \mathrm{wt}$. \% additive were the most effective. It is noteworthy that zeolite type does not affect the heat value of the resulting gaseous mixture $(20.5$ $\mathrm{MJ} / \mathrm{m}^{3}$ at 2 wt. $\%$ of catalyst).

The use of the catalyst allows obtaining higher content of hydrocarbons in the resulting gaseous mixture. The increase in the heat value of gaseous products is caused by the higher content of alkanes and alkenes.

In this work we also studied the influence of iron subgroup metal-promoted H-ZSM-5 zeolite on the catalytic refining of fast pyrolysis gaseous products.

The following metals (5 wt. \%) supported on zeolite H-ZSM-5 were used as catalysts: $\mathrm{Fe}, \mathrm{Co}, \mathrm{Ni}$. The optimal catalyst size was chosen according to the unit capacity of the gaseous product formation and the system pressure. Figure 5 shows that the minimal resin content of the resulting gaseous mixture was obtained while using 5\%-Co-ZSM-5 catalyst.

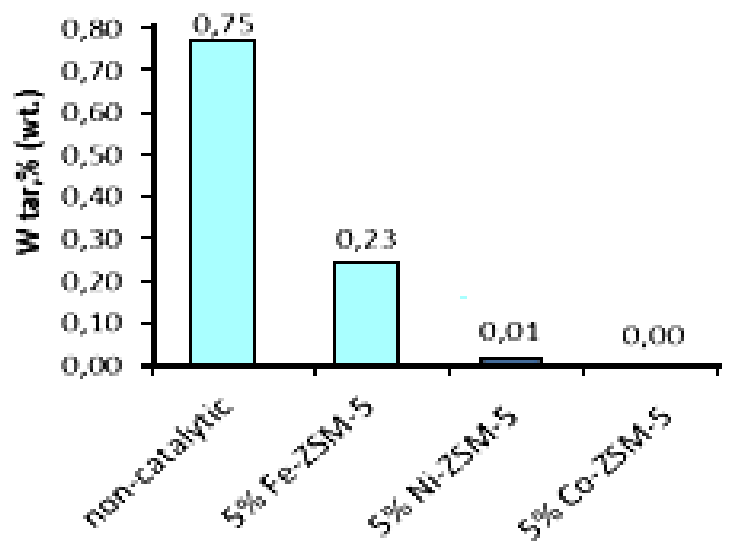

Figure 5. Resins concentration of fast pyrolysis gas after the refining process

The use of Me-zeolite catalyst in gas refining stage leads to the changes in gas volume and heat value. It is caused by the changes in hydrogen, $\mathrm{C}_{1}-\mathrm{C}_{4}$ hydrocarbons and carbon oxides concentration compared to non-refining process.

Figure 6 shows the effect of metal type on the distribution of gaseous products. The concentration of $\mathrm{C}_{1}-\mathrm{C}_{4}$ hydrocarbons increases by $1.39 ; 1.66$ and 1.52 times when using $5 \% \mathrm{Fe}-\mathrm{ZSM}, 5 \% \mathrm{Co}-\mathrm{ZSM}$ and $5 \% \mathrm{Ni}$-ZSM catalysts respectively compared to a non- 
$10^{\mathrm{TH}}$ INTERNATIONAL CONFERENCE ON SUSTAINABLE ENERGY AND ENVIRONMENTAL Protection (June $27^{\mathrm{TH}}-30^{\mathrm{TH}}, 2017$, Bled, Slovenia), BioENERGy ANd Biofuels

Y. V. Lugovoy, K. V. Chalov, O. V. Manaenkov, E. M. Sulman \& Y. Yu. Kosivtsov: Thermocatalytic Refining of Gaseous Products Produced by Fast Pyrolysis of Flax Shive

catalytic process. Hydrogen concentration also grows from Fe to Ni catalysts compared to a non-catalytic process.

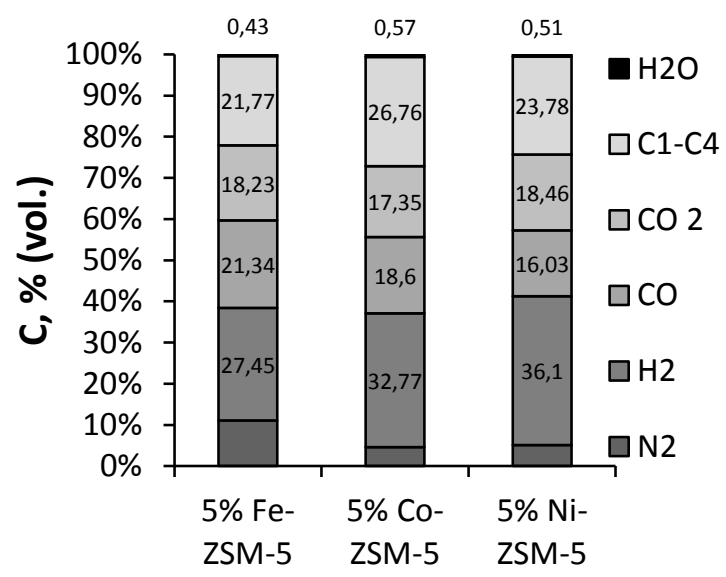

Figure 6. Influence of metal H-ZSM-5 supported catalysts on gas composition

Thus Co-H-ZSM-5 was found to be the most effective catalyst for the refining of gaseous products of flax shive fast pyrolysis.

\section{Conclusions}

The influence of the studied catalysts on fast pyrolysis gas composition can be explained by the catalyst high activity during the high temperature destruction processes and thermal decomposition of tars and high-boiling fractions of the pyrolysis liquid products. The catalysts studied also affect the carbon oxides (II) and (IV) yields. The use of zeolite catalysts on the base of iron subgroup metals led to the decrease in tars content in the thermolysis gas as well as to the increase in $\mathrm{C}_{1}-\mathrm{C}_{4}$ hydrocarbons amount, hydrogen and carbon monoxide (II) concentration compared to non-catalytic process.

\section{Acknowledgements}

This work was financially supported by the Russian Foundation of Basic Researches (grant 15-0801752).

\section{References}

[1] M. Balat, E. Kirtay and H. Balat "Main routes for the thermo-conversion of biomass into fuels and chemicals. Part 1: Pyrolysis systems", Energy Convers. Manag, vol. 50, pp. 31473157. 2009.

[2] G.W. Huber, S. Iborra and A. Corma "Synthesis of transportation fuels from biomass: Chemistry, catalysts, and engineering", Chem. Rev., vol. 106, pp. 4044-4098. 2006. 
$10^{\mathrm{TH}}$ International Conference on Sustainable EnERgy and Environmental Protection (June 27 ${ }^{\mathrm{TH}}-30^{\mathrm{TH}}, 2017$, BLED, SLOVENiA), Bioenergy AND Biofuels

Y. V. Lugovoy, K. V. Chalov, O. V. Manaenkov, E. M. Sulman \& Y. Yu. Kosivtsov: Thermocatalytic Refining of Gaseous Products Produced by Fast Pyrolysis of Flax Shive

[3] A.V. Bridgwater "Review of fast pyrolysis of biomass and product upgrading", Biomass and bioenergy, vol. 38, pp. 68-94. 2012.

[4] W.T. Tsai, M.K. Lee and Y. M. Chang "Fast pyrolysis of rice straw, sugarcane bagasse and coconut shell in an induction-heating reactor", Journal of Analytical and Applied Pyrolysis, vol. 76, No. 1, pp. 230-237. 2006.

[5] Y. Yu, X. Li, L. Su, Y. Zhang, Y. Wang and H. Zhang "The role of shape selectivity in catalytic fast pyrolysis of lignin with zeolite catalysts", Applied Catalysis A: General, vol. 447, pp. 115-123. 2012.

[6] Russian market of cereal crops, Analytical review, Vol. 2, 2014.

[7] Th. Dickerson and J. Soria "Catalytic Fast Pyrolysis: A Review", Energies, vol. 6, pp. 514538. 2013.

[8] V. Kosov, V. Kosov, V. Zaichenko "Experimental Research of Heterogeneous Cracking of Pyrolysis Tars", Chemical Engineering Transactions, vol. 37, pp. 211-216. 2014.

[9] T.A. Milne and R.J. Evans "Biomass Gasifier "Tars": Their Nature, Formation and Conversion", National Renewable Energy Laboratory Managed by Midwest Research Institute for the U.S. Department of Energy under contract No. DE-AC36-83CH10093 Prepared under Task No. BP811010, 67. 1998.

[10] J. De Wild, H. Reith and H.J. Heeres "Biomass pyrolysis for chemicals", Biofuels, vol. 2, No. 2, pp. 185-208. 2011. 
$10^{\mathrm{TH}}$ InTERnational CONFERENCE ON Sustainable ENERgy AND ENVIRONMENTAL Protection (June $27^{\mathrm{TH}}-30^{\mathrm{TH}}$, 2017, Bled, SLOVENIA), BIOENERGY AND BIOFUELS

J. Krope, A.Ghani Olabi, D. Goričanec \& S. Božičnik

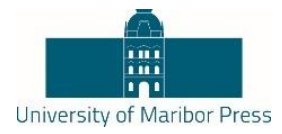

\title{
Ghg Reduction Targets in Germany: 80 - 95\% - What Does it Mean for Bioenergy and the Heating Sector in Particular?
}

\author{
NORA SZARKA, DANIELA THRÄN \& VOLKER LENZ
}

\begin{abstract}
The future provision of heat from biomass is strongly influenced by Germany's climate policy goals, such as the target of an $80-95 \%$ reduction in GHG emissions by 2050 . But how might the differences in how these goals are emphasised shape the bioenergy and heating sector? The aim of this paper is to analyse long-term model results, with a special focus on their possible influence on the bioenergy sector.

The findings show that a $95 \%$ cut in GHG emissions in Germany would lead to a system that is almost completely based on renewables with a significant proportion of fluctuating energies. In this case, the role of bioenergy will shift away from being efficient base-load generation, towards being an effective "stabiliser" of the energy system. The study shows comparative results of scenario parameters and analyses the consequences for bioenergy in the heating sector. It concludes with the need for research and for policy adjustment.
\end{abstract}

Keywords: • Bioenergy • Heat • Policy • GHG targets • $2050 \bullet$

CorresPondence AdDress: Nora Szarka, Ph.D., Work Group leader, DBFZ Deutsches Biomasseforschungszentrum gemeinnützige $\mathrm{GmbH}$, Department of Bioenergy Systems, Torgauer Str. 116, Leipzig, Germany, e-mail: nora.szarka@dbfz.de. Lenz Volker, PhD, department leader, DBFZ Deutsches Biomasseforschungszentrum gemeinnützige $\mathrm{GmbH}$, Thermo-chemical Conversion Department, Torgauer Str. 116, Leipzig, Germany, e-mail: lenz.volker@dbfz.de. Daniela Thrän, Prof., department leader, UFZ Helmholtz Centre for Environmental Research, Leipzig, Germany, Department of Bioenergy, e-mail: daniela.thraen@ufz.de.

https://doi.org/10.18690/978-961-286-048-6.9

ISBN 978-961-286-048-6

(C) 2017 University of Maribor Press

Available at: http://press.um.si. 
$10^{\mathrm{TH}}$ International Conference on Sustainable Energy and Environmental Protection (June 27 $7^{\mathrm{TH}}-30^{\mathrm{TH}}, 2017$, BLed, Slovenia), Bioenergy AND Biofuels

N. Szarka, D. Thrän \& V. Lenz: Ghg Reduction Targets in Germany: 80 - 95\% - What

Does it Mean for Bioenergy and he Heating Sector in Particular?

Introduction

Heat generation from biomass is traditionally a very important source, making up more than $80 \%$ of renewables worldwide and in Germany (the silent giant) [1]. This, despite there is being no or only little support for biomass-to-heat concepts. How the use of biomass for heat provision is shaped in the future depends on several factors, with policies playing a significant role. Such policies include the Energy Saving Ordinance (EnEV, [2]), which regulates energy use requirements in new and renovated buildings, the Renewable Energy Heat Act (EEWärmeG [3]) which targets a $14 \%$ share of renewables in the heating of buildings by 2020, the Heat and Power Cogeneration Act (KWKG [4]), which is designed to increase combined heat and power (CHP) generation in Germany to 120 TWh by 2025, and the Technical Instructions on Air Quality Control [5], which sets requirements for heat plants. In addition, the German government's energy concept "Energiekonzept" [6] aims to cut GHG emissions by 80 - $95 \%$ by 2050. In this regard, the Climate Action Plan 2050 [7] provides guidance towards achieving the climate goals set forth in the Paris Agreement in all areas of activities and measures, especially for the 2030 interim target. The study concludes that, by 2030, the energy sector will have to be the primary contributor to climate change activities, cutting GHG emissions by $61-62 \%$ over 1990 levels.

However, a thorough analysis and assessment of the comparison of the influences of such different GHG goals on the bioenergy sector has yet to be carried out. Therefore, this work sets out to assess the implications of the set goals, especially those of the GHG reduction targets, with regard to bioenergy with a special focus on the heating sector.

\section{Methods}

To achieve this goal, first relevant studies have been selected that deal with an $80 \%$ reduction, a $95 \%$ reduction, or both. Further criteria when selecting studies included a relevant impact on policy, the inclusion of long-term scenarios until 2050, and publication in the past 5 - 6 years. Relevant drivers of the biomass-to-heat sector were identified in the form of expert and policy workshops and questionnaires. Finally, the studies were analysed using the criteria and to identify possible correlations between the parameters. This paper analyses the six most relevant studies dealing with future scenarios of an $80 \%$ GHG reduction, $95 \%$ reduction or both. Table 1 summarises the most important parameters of these studies. 
$10^{\mathrm{TH}}$ INTERNATIONAL CONFERENCE ON SUSTAINABLE ENERGY AND ENVIRONMENTAL Protection (June $27^{\mathrm{TH}}-30^{\mathrm{TH}}, 2017$, BLed, Slovenia), Bioenergy ANd Biofuels

N. Szarka, D. Thrän \& V. Lenz: Ghg Reduction Targets in Germany: 80 - 95\% - What Does it Mean for Bioenergy and he Heating Sector in Particular?

Table 1. Selected studies and long-term scenarios with $80-95 \%$ GHG reduction targets

\begin{tabular}{|c|c|c|}
\hline $\begin{array}{l}\text { Title/ } \\
\text { commissioner/ } \\
\text { publication } \\
\text { year }\end{array}$ & $\begin{array}{l}\text { Climate scenario } \\
\text { 2050/BMUB/2015 }\end{array}$ & $\begin{array}{l}\text { Climate-neutral } \\
\text { building stock } \\
\text { 2050/ } \\
\text { UBA/2016 }\end{array}$ \\
\hline Authors & ÖI, ISI & ÖI, ISE \\
\hline $\begin{array}{ll}\text { GHG } & \text { goal } \\
2050 & \\
\end{array}$ & $80-95 \%$ & $80 \%$ \\
\hline Scenarios & KS80, KS95 & KliNeG (80) \\
\hline Reference & {$[8]$} & [9] \\
\hline $\begin{array}{l}\text { Title/ } \\
\text { commissioner/ } \\
\text { publication } \\
\text { year }\end{array}$ & $\begin{array}{l}\text { Greenhouse gas } \\
\text { neutral Germany in } \\
\text { 2050/UBA/2014 }\end{array}$ & $\begin{array}{l}\text { Long term } \\
\text { scenarios } \\
\text { /BMU/2012 }\end{array}$ \\
\hline Authors & & $\begin{array}{l}\text { DLR, IWES. } \\
\text { IFNE }\end{array}$ \\
\hline $\begin{array}{ll}\text { GHG } & \text { goal } \\
2050 & \\
\end{array}$ & $95 \%$ & $80-95 \%$ \\
\hline Scenarios & THGND (95 \%) & $\begin{array}{l}\text { LS2011 (80\%); } \\
\text { LS2011 (95\%) - } \\
\text { achieved in } 2060\end{array}$ \\
\hline Reference & [10] & [11] \\
\hline $\begin{array}{l}\text { Title/ } \\
\text { commissioner/ } \\
\text { publication } \\
\text { year }\end{array}$ & $\begin{array}{l}\text { Interaction renewable } \\
\text { power, heat and } \\
\text { transport/BMWi/2015 }\end{array}$ & $\begin{array}{l}\text { Development of } \\
\text { energy markets } \\
-\quad \text { energy } \\
\text { reference } \\
\text { forecast } \\
/ \mathrm{BMWi} / 2014\end{array}$ \\
\hline Authors & IWES, IBP, IFEU & $\begin{array}{l}\text { Prognos, EWI, } \\
\text { GWS }\end{array}$ \\
\hline $\begin{array}{ll}\text { GHG } & \text { goal } \\
2050 & \end{array}$ & $80 \%$ & $80 \%$ \\
\hline Scenarios & $\begin{array}{l}\text { RS }(80 \%), \text { KraftS (80 } \\
\%), \text { BS }(80 \%)\end{array}$ & ERP goal $(80 \%)$ \\
\hline Reference & [12] & [13] \\
\hline
\end{tabular}

The following parameters were selected in order to analyse the impacts of the different scenarios on bioenergy and heat, especially on conversion technologies and concepts: GHG targets (main parameter), biomass potential, heat demand (influenced by the GHG targets), and power demand (influenced by the GHG targets). 
$10^{\text {TH }}$ InTERnational CONFERENCE ON Sustainable ENERgy AND ENVIRONMENTAL Protection (June $27^{\mathrm{TH}}-30^{\mathrm{TH}}, 2017$, BLED, Slovenia), Bioenergy AND Biofuels

N. Szarka, D. Thrän \& V. Lenz: Ghg Reduction Targets in Germany: 80 - 95\% - What

Does it Mean for Bioenergy and he Heating Sector in Particular?

3 Results: Possible Impacts of the Scenarios on the Bioenergy and Heating Sector

\section{1 $\quad$ GHG targets}

\section{Possible Impacts On The Bioenergy Technologies And Concepts In The Heating Sector}

If the target is an $80 \%$ reduction in GHG emissions, then about $10 \%$ of the GHG emissions for all energy purposes in 1990 are still allowed in 2050. About $15-20 \%$ of the required energy could be generated by, for example, natural gas, which would be available to compensate for the fluctuation in energy demand and supply. As a consequence, the task of bioenergy would be to optimise economic and energetic efficiency and contribute to decreasing environmental impacts. In this case, existing technologies should be further developed, e.g. optimised firing, emission control systems and measuring technologies. In most cases heat would only be generated with high fullload hours, possibly combined with electrical surplus heating. The decision in favour of hybrid systems - a combination with other renewables - or flexible operation would only occur if there were economic incentives or other advantages and thus a clear economic advantage over natural gas. For objects with a high yearly heat demand, solid biomass CHP plants would gain in relevance for each scale. Biowaste disposal would probably focus on big centralised plants.

On the other hand, if the policy aims for a $95 \%$ GHG reduction, all the sectors where decarbonisation is possible must fully contribute. Due to massive fluctuations in the energy system, supply security and supply stability will become even more important than today. In addition to power accumulators, heat buffer tanks and all options of powerto-x $(\mathrm{PtX})$, flexible biomass utilisation will have to contribute in both the short and long term in the form of flexible heat and power generation systems and innovative control concepts.

\subsection{Biomass potential}

In addition to goals for reducing GHG emissions, biomass potential has been identified as being a critical driving force for the bioenergy sector. However, among the analysed studies (see Figure 1) there is a wide range in biomass potential in Germany by 2050. 
$10^{\mathrm{TH}}$ INTERNATIONAL CONFERENCE ON SUSTAINABLE ENERGY AND ENVIRONMENTAL Protection (June $27^{\mathrm{TH}}-30^{\mathrm{TH}}, 2017$, BLed, Slovenia), Bioenergy AND Biofuels N. Szarka, D. Thrän \& V. Lenz: Ghg Reduction Targets in Germany: 80 - 95\% - What Does it Mean for Bioenergy and he Heating Sector in Particular?

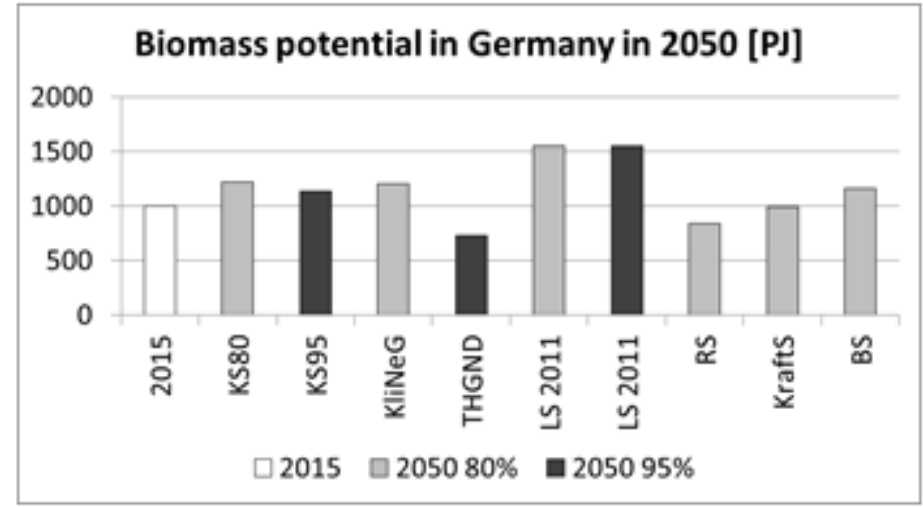

Figure 1. Biomass potential in Germany in 2050 (abbreviations as per Table 1)

All revised studies agree that biomass will be used in large part - in some cases uniquely - for energy in the form of residues and by-products. Should cascade use gain in importance, new biomass types, qualities and amounts will be available at the end of a cascade used for energetic purposes. Among the investigated scenarios, no direct correlation can be found in terms of the amount of available biomass; however, in the 95 $\%$ scenarios a higher emphasis on cascade use and residues can be assumed (e.g. the THGND mentions a high potential of cascade use in the industrial sector ( $\mathrm{p} 76)$ ). In all cases, biomass is expected to be of lower quality in cascade use than in the case of firsttime energetic use.

\section{Impacts On The Bioenergy Technologies And Concepts In The Heating Sector}

If the target is an $80 \%$ reduction in GHG emissions, the decision to heat with biomass is mainly influenced by economic reasons. The utilisation of available wood resources for heating purposes (wood chip boilers, pellet boilers and wood stoves) are expected to increase. Improved material handling and preparation can contribute to high-quality wood fuels. In order to increase the biowaste market, incineration CHP plants that are integrated into (existing) district heating systems could help to handle the waste problem. Primary technological developments have to take place with regard to flue gas cleaning, also in small and medium scale conversion units. When approaching the $80 \%$ rate of renewable energies in the system there might be some emphasis on storage concepts for solid biomass including storing biowaste for six months to up to one year in order to bridge heat and power supply gaps in winter time. In the $95 \%$ scenarios there will be an increased demand to upgrade biomass resources to storable quality fuels and a need for more flexible conversion technologies due to a growing necessity for energy storage and capacity back-up. Therefore, mechanical sorting, cleaning, washing, hydrothermal carbonisation and torrefication could become more important. In order to guarantee a certain biofuel quality, online analysis technologies have to be improved and adapted to industrial production. Appropriate sensors and control systems are needed to adjust fuel quality and conversion units to meet fluctuating demand. It is likely that more 
$10^{\text {Th }}$ International Conference on Sustainable Energy and Environmental Protection (June $27^{\mathrm{TH}}-30^{\mathrm{TH}}, 2017$, Bled, Slovenia), Bioenergy AND BIOfuels

N. Szarka, D. Thrän \& V. Lenz: Ghg Reduction Targets in Germany: 80 - 95\% - What Does it Mean for Bioenergy and he Heating Sector in Particular?

decentralised and specialised value chains will be developed and adjusted to local waste and by-product biomass resources and local heat (and power) demand.

\subsection{Heat demand}

The analysed studies show that heat demand will decrease in the next decades in all scenarios (see Figure 2).

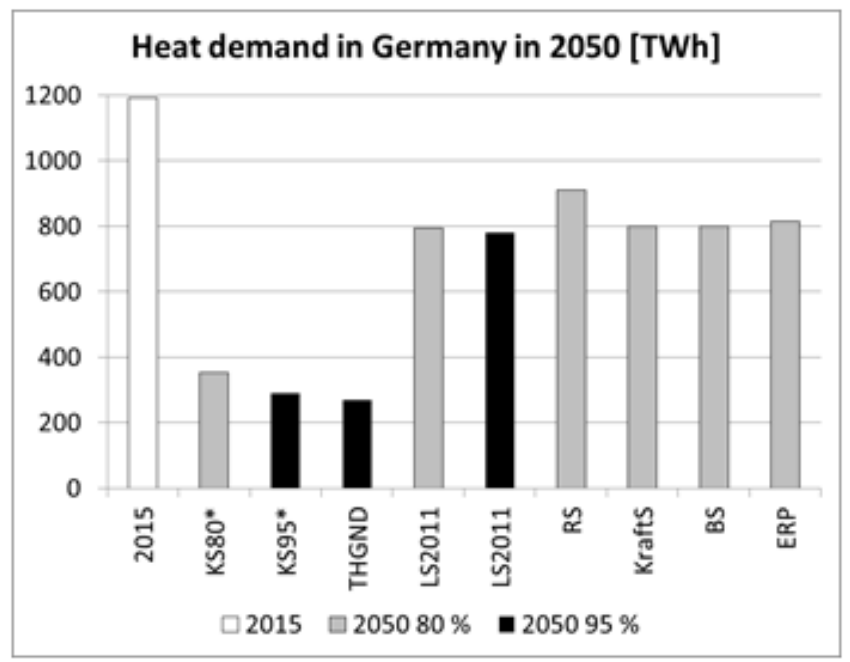

Figure 2. Final energy demand for heat in Germany by 2050 based on the scenarios

(* excluding industry)

Most of the $80 \%$ studies assume a heat demand of around $800 \mathrm{TWh}$ in 2050 and a reduction by one third over 2015 levels; in the 95\% scenarios even less demand is expected. This can be explained by the very strong efficiency measures used to significantly reduce energy demands. In addition to looking at the total amount of heat demand, it is also important to examine the specific demand of space heat or process heat, as well as the division between the different sectors households, industry, trade, etc. For example, the use of biomass for high process heat in industry as well as buildings that are hard to renovate are expected in the scenarios [12] and for stationary heat production and CHP plants in the [11] study.

For household heating, there is a trend towards a lower heat demand per square metre of living space in all cases; however, some buildings will continue to have high heat demands due to insulation restrictions. 
$10^{\mathrm{TH}}$ INTERNATIONAL CONFERENCE ON SUSTAINABLE ENERGY AND ENVIRONMENTAL Protection (June $27^{\mathrm{TH}}-30^{\mathrm{TH}}, 2017$, BLed, Slovenia), Bioenergy ANd Biofuels N. Szarka, D. Thrän \& V. Lenz: Ghg Reduction Targets in Germany: 80 - 95\% - What Does it Mean for Bioenergy and he Heating Sector in Particular?

\section{Impacts On The Bioenergy Technologies And Concepts In The Heating Sector}

There are two base cases where heat from biomass can be economically feasible. Either for a base load with a high number of yearly full load hours in combination with cheap biofuels, or for supply security to fill gaps and heat demands with no other renewable or waste heat options including electricity. In the $80 \%$ scenarios, solid biomass is probably only used for heat in cases with the lowest heating costs, such as base load boilers, base load CHP, or monovalent boilers (e.g. pellet boilers). As renewable power from wind and solar increases, there might be hybrid systems that combine solid biomass conversion with power heaters $(\mathrm{PtH})$ for excess power. In addition to minimising the size of biofuel and conversion technologies, solid biomass will be increasingly used for buildings with less insulation or district heating grids.

In the $95 \%$ scenarios, heat pumps, electrical heating (air conditioning), waste heat utilisation, solar-thermal and geothermal technologies will gain in relevance to ensure security of supply when there are low heat demands per unit of space. Heat from biomass will probably become one of the most expensive and the only secure source of heat. Depending on the development of electrical accumulators, it could become reasonable to develop very flexible operating heat sources from solid biomass in all power dimensions - ideally as CHP technologies to lower power demand and simultaneously produce the required power, which requires very constant biofuel qualities. Utilisation of biomass for heat will be in conjunction with other renewables and in sectors where other options are scarce: the building sector, as high-temperature (above $500^{\circ} \mathrm{C}$ ) industrial process heat (in addition to electricity or waste incineration), and to replace coal in production processes.

\subsection{Power demand}

Figure 3 shows the development of power demand in Germany by 2050. Reasons for the deviation in results may be caused by the different assumptions about the choice of technologies, productivity or the role of PtX concepts. It is expected that, due to efficiency measures, power demands will decrease by 2030. However, an increase in consumption will occur later on when PtX technologies are available on the market: a moderate increase in the $80 \%$ scenarios and a remarkable one in the $95 \%$ scenarios, since there will be a greater push towards climate friendly solutions. 
$10^{\mathrm{TH}}$ InTERnAtional CONFERENCE ON Sustainable EnERgy AND ENVIRONMENTAL Protection (June $27^{\mathrm{TH}}-30^{\mathrm{TH}}, 2017$, BLED, Slovenia), Bioenergy AND Biofuels

N. Szarka, D. Thrän \& V. Lenz: Ghg Reduction Targets in Germany: 80 - 95\% - What Does it Mean for Bioenergy and he Heating Sector in Particular?

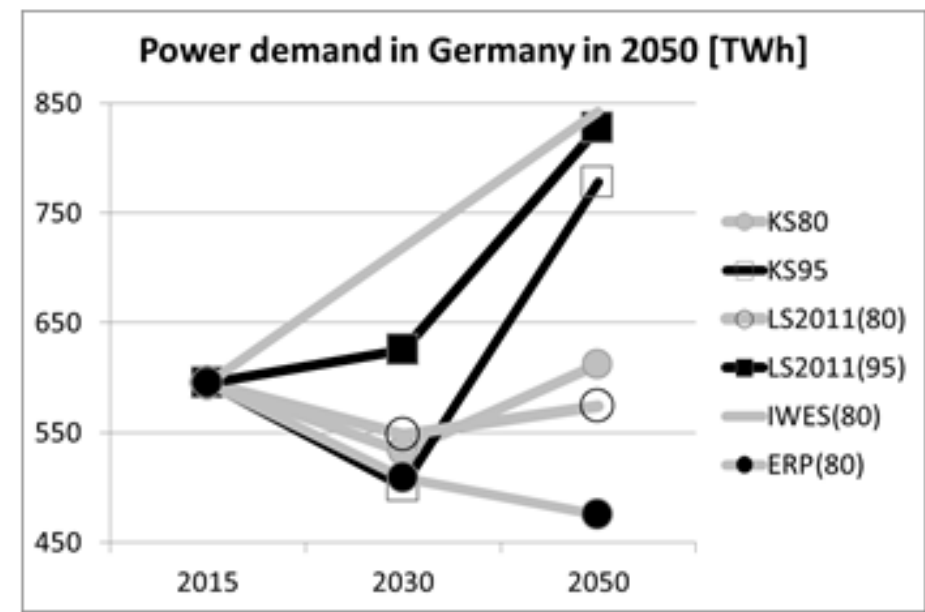

Figure 3. Power demand in Germany by 2050 based on the scenarios

\section{Impacts On The Bioenergy Technologies And Concepts In The Heating Sector}

CHP technologies, also for solid biomass, have advantages over systems that solely produce heat. Thus, in both cases, the ratio of CHP systems will increase in the future so that, by 2050, almost all new installations will probably be CHP systems. Nevertheless, in an $80 \%$ scenario, the biomass CHP should have as many full load hours as possible so that operation is economically feasible. If possible, intelligent control systems can be implemented to adjust to the availability of wind and solar power to mirror today's shifting of power generated by biogas plants within a day. $95 \%$ scenarios need to use all renewable options to stabilise the power grid as well as the supply of heat. Hence biomass CHP has to be very flexible and will only operate based on power demands and price signals from the power exchange, storing the heat for utilisation timeframes.

\section{Summary and Recommendations}

As a result of this analysis, the following statements can be made: 1) There is a significant difference between $80 \%$ and $95 \%$ reduction scenarios in terms of the development and implementation of biomass heating technologies. 2) $80 \%$ scenarios go on like today, searching for the most economical cases: base load and monovalent production. 3) $95 \%$ scenarios require power grid stabilisation and heat supply security in combination with other renewable technologies in almost all cases. 4) In both scenarios buildings with high heat demand per unit of space and high temperature requirements are promising cases for biomass utilisation. 5) In all cases CHP, also using solid biomass, will increase in importance. 6) In all cases the quality of the biomass raw material will decrease, but hightech preparation will probably only become reasonable in the $95 \%$ scenario. 7) In the long run, even in the $80 \%$ scenario, further development will lead to most of the technologies used in the $95 \%$ scenario. 
$10^{\mathrm{TH}}$ INTERNATIONAL CONFERENCE ON SUSTAINABLE ENERGY AND ENVIRONMENTAL Protection (June $27^{\mathrm{TH}}-30^{\mathrm{TH}}, 2017$, BLed, SLOVEniA), Bioenergy AND Biofuels N. Szarka, D. Thrän \& V. Lenz: Ghg Reduction Targets in Germany: 80 - 95\% - What Does it Mean for Bioenergy and he Heating Sector in Particular?

After Germany signed the latest global climate agreement in Paris, the country started to revise its energy policy and develop and adopt long-term energy scenarios. Heat demand and supply has many driving forces, such as the development of the building stock (incl. insulation), policy framework and technology development (e.g. the role of CHP or the intelligent transformation of electric energy into heat (power-to-heat)).

Based on the current revision, some questions are still open, for example, the future heat demand in different long-term scenarios does not show a clear correlation with GHG goals (stricter GHG reduction goals do not lead in every case to lower heat demands). The picture is even more complex when it comes to future heat provision from biomass.

This can partially be explained by the uncertainties surrounding the potential for available biomass, the allocation of other final energy supply options (power, heat or transport fuels), and the lack of an agreed bioenergy strategy. This heterogeneous picture is reflected in the scenarios as well [14]. Furthermore, scenarios are often only optimised for cost and overlook other hurdles or opportunities such as innovations from outside the energy system which affect energy demands, consumer behaviour, acceptance etc. In order to deal with these constraints, research and development that is open to different technologies is very important.

To make use of the biomass-to-heat options for GHG reduction, the current uncertainties surrounding the availability and future role of bioenergy need to be reduced. Long-term bioenergy scenarios are urgently needed and a coherent bioenergy strategy with goals and milestones has to be developed. With this in mind, heat scenarios have been developed for Germany until 2050 as part of the research project Bioplan W, with the participation of research, industry and policymakers [15] [16].

Heat from biomass can offer comparable economic options for reducing GHG emissions. Scenarios for the provision of power and transport fuels based on biomass have additionally concluded that there is a high persistence of heat provision from biomass in future energy systems [17]. Biomass-to-heat systems can also contribute to the German "Energiewende" close to the final energy user e.g. by upgrading heat to CHP systems with local grid stabilisation functions, through integrated heat provision from biomass, and other renewables in buildings with a remarkably specific heat demand.

However, the current policy and support framework does not support the development and integration of such strategically important concepts into the energy system. Adjustments are necessary, especially to the Renewable Energy Heat Act, where support for the combination of different renewables has yet to be considered.

The ongoing adjustments and debates also show that there will be no single best solution in the future. Instead a wide range of smart technologies and concepts are necessary to provide integrated solutions for future energy supply. 
$10^{\mathrm{TH}}$ InTERnATIONAL CONFERENCE ON Sustainable ENERGy AND ENVIRONMENTAL Protection (June $27^{\mathrm{TH}}-30^{\mathrm{TH}}, 2017$, BLED, SLOVENiA), Bioenergy AND Biofuels

N. Szarka, D. Thrän \& V. Lenz: Ghg Reduction Targets in Germany: 80 - 95\% - What Does it Mean for Bioenergy and he Heating Sector in Particular?

\section{Acknowledgements}

The authors would like to thank to the BMEL and to the BMWi for supporting the research project Bioplan W as part of the funding programme "Energetische Biomassenutzung", in the framework of which this investigation was carried out.

\section{References}

[1] International Energy Agency, Ed., "Medium-Term Renewable Energy Market Report 2015".

[2] Deutscher Bundestag, Verordnung über energiesparenden Wärmeschutz und energiesparende Anlagentechnik bei Gebäuden: EnEV, 2001, Bundesgesetzblatt no. 59, pp. 3085-3102.

[3] Deutscher Bundestag, Gesetz, zur Förderung Erneuerbarer Energien im Wärmebereich: EEWärmeG, 2008, Bundesgesetzblatt no. 36, pp. 1658-1665.

[4] Deutscher Bundestag, Gesetz zur Neuregelung des Kraft-Wärme-Kopplungsgesetzes: KWKG, 2015, Bundesgesetzblatt no. 55, pp. 2498-2516.

[5] Bundesministerium für Umwelt, Naturschutz, Bau und Reaktorsicherheit (BMUB), Erste Allgemeine Verwaltungsvorschrift zum Bundes-Immissionsschutzgesetz: TA Luft, 2002.

[6] Bundesministerium für Wirtschaft und Energie (BMWi), Ed., "Energiekonzept für eine umweltschonende, zuverlässige und bezahlbare Energieversorgung", Sep. 2010. [Online] Available at: http://www.bmwi.de/Redaktion/DE/Downloads/E/energiekonzept2010.pdf?_blob=publicationFile\&v=3.

[7] Bundesministerium für Umwelt, Naturschutz, Bau und Reaktorsicherheit (BMUB), Ed., "Klimaschutzplan 2050", Nov. 2016. [Online] Available at: http://www.bmub.bund.de/fileadmin/Daten_BMU/Download_PDF/Klimaschutz/klimasch utzplan_2050_bf.pdf.

[8] J. Repenning et al., "Klimaschutzszenario 2050 - 2. Endbericht", Dec. 2015. [Online] Available at: https://www.oeko.de/oekodoc/2441/2015-598-de.pdf.

[9] V. Bürger et al., "Klimaneutraler Gebäudebestand 2050", Dessau-Roßlau, Feb. 2016. [Online] Available at: https://www.umweltbundesamt.de/sites/default/files/medien/378/publikationen/climate_c hange_06_2016_klimaneutraler_gebaeudebestand_2050.pdf.

[10] Umweltbundesamt, Ed., "Treibhausgasneutrales Deutschland". Studie, Jul. 2014. [Online] Available at:

https://www.umweltbundesamt.de/sites/default/files/medien/378/publikationen/07_2014_ climate_change_dt.pdf.

[11] J. Nitsch et al., "Langfristszenarien und Strategien für den Ausbau der erneuerbaren Energien in Deutschland bei Berücksichtigung der Entwicklung in Europa und global". Schlussbericht BMU - FKZ 03MAP146, Mar. 2012. [Online] Available at: http://www.dlr.de/dlr/Portaldata/1/Resources/bilder/portal/portal_2012_1/leitstudie2011_ bf.pdf.

[12] N. Gerhardt et al., "Interaktion EE-Strom, Wärme und Verkehr", Nov. 2015. [Online] Available at: http://www.energiesystemtechnik.iwes.fraunhofer.de/content/dam/iwesneu/energiesystemtechnik/de/Dokumente/Veroeffentlichungen/2015/Interaktion_EEStro m_Waerme_Verkehr_Endbericht.pdf.

[13] M. Schlesinger et al., "Entwicklung der Energiemärkte - Energiereferenzprognose". Endbericht, Prognos AG; EWI; GWS, Basel/Köln/Osnabrück, Jun. 2014. [Online] 
[14] N. Szarka, M. Eichhorn, R. Kittler, A. Bezama, and D. Thrän, "Interpreting long-term energy scenarios and the role of bioenergy in Germany," Renewable and Sustainable Energy Reviews, vol. 68, Part 2, pp. 1222-1233, 2017.

[15] Deutsches Biomasseforschungszentrum gGmbH (DBFZ), Helmholtz-Zentrum für Umweltforschung GmbH (UFZ), and the Center for Environmental Systems Research Universität Kassel (CESR), Bioplan W. [Online] Available at: https://www.energetischebiomassenutzung.de/en/projects/projects-list/projects/03kb106a_eliras_copy_2.html. Accessed on: Apr. 052017.

[16] N. Szarka and D. Thrän, "Biomass Heat Scenarios in Germany," EUBCE. Session reference: 4AV.1.43, 2017.

[17] D. Thrän et al., "The MILESTONES modeling framework: An integrated analysis of national bioenergy strategies and their global environmental impacts," Environmental Modelling \& Software, vol. 86, pp. 14-29, 2016. 
98 10 $10^{\text {TH }}$ InTERnational Conference on Sustainable ENERGy AND EnVIRONMENTAL Protection (June $27^{\mathrm{TH}}-30^{\mathrm{TH}}, 2017$, Bled, Slovenia), Bioenergy AND Biofuels 
$10^{\mathrm{TH}}$ InTERnational CONFERENCE ON Sustainable ENERgy AND

ENVIRONMENTAL Protection (June $27^{\mathrm{TH}}-30^{\mathrm{TH}}$, 2017, Bled, SLOVENIA), BIOENERGY AND BIOFUELS

J. Krope, A.Ghani Olabi, D. Goričanec \& S. Božičnik

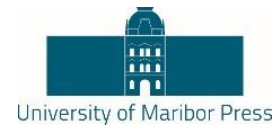

\title{
Kinetic Study for the Co-Pyrolysis of Lignocellulosic Biomass and Plastics Using the Distributed Activation Energy Model
}

\author{
María Victoria NAVARro, José Manuel LÓPEZ, Alberto VeSes, MarÍa Soledad \\ CALLÉN \& TOMÁS GARCÍA
}

\begin{abstract}
The pyrolysis of lignocellulosic biomass is a promising alternative for obtaining liquid biofuels from a renewable source, while reducing the negative impact of petrochemical processes on climate change. Among the strategies for upgrading the bio-oil obtained from the pyrolysis of biomass, numerous studies have shown that co-feeding with plastic waste could be a feasible solution, since the presence of radical interactions between the molecules released during the heating process could lead to an improved fuel. The Distributed Activation Energy Model (DAEM) was applied to predict the behaviour of biomass/plastic mixtures under flash pyrolysis conditions. Pine forestry residues and six different waste plastics were studied. Thermogravimetric analyses of pure feedstocks at low heating rates were used to obtain the kinetic parameters of the model. With these data, the model allowed the study of important aspects of the co-pyrolysis process at high heating rates, such as radical interactions and optimum pyrolysis temperature.
\end{abstract}

Keywords: • Co-pyrolysis • Kinetics • DAEM • Biomass • Plastics •

Correspondence AdDress: María Victoria Navarro, Ph.D., Tenured Scientist, Instituto de Carboquímica, ICB-CSIC, C/ Miguel Luesma Castán 4, 50018 Zaragoza, Spain, e-mail: navarro@icb.csic.es. José Manuel López, Ph.D., Postdoctoral researcher, Instituto de Carboquímica, ICB-CSIC, C/ Miguel Luesma Castán 4, 50018 Zaragoza, Spain, e-mail: jmlopez@icb.csic.es. Alberto Veses, Ph.D., Postdoctoral researcher, Instituto de Carboquímica, ICB-CSIC, C/ Miguel Luesma Castán 4, 50018 Zaragoza, Spain, e-mail: a.veses@icb.csic.es. María Soledad Callén, Ph.D., Tenured Scientist, Instituto de Carboquímica, ICB-CSIC, C/ Miguel Luesma Castán 4, 50018 Zaragoza, Spain, e-mail: marisol@icb.csic.es. Tomás García, Ph.D., Tenured Scientist, Instituto de Carboquímica, ICB-CSIC, C/ Miguel Luesma Castán 4, 50018 Zaragoza, Spain, e-mail: tomas@icb.csic.es. 
$100 \quad 10^{\mathrm{TH}}$ InTERNATIONAL CONFERENCE ON Sustainable ENERGY AND ENVIRONMENTAL Protection (June $27^{\mathrm{TH}}-30^{\mathrm{TH}}, 2017$, BLED, SLOVEniA), BioENERGY AND Biofuels M. Victoria Navarro, J. Manuel López, A. Veses, M. Soledad Callén \& T. García: Kinetic Study for the Co-Pyrolysis of Lignocellulosic Biomass and Plastics Using the Distributed Activation Energy Model

The use of lignocellulosic biomass provides an opportunity to obtain liquid biofuels and chemical products from a renewable source, while significantly reducing the negative impact of petrochemical processes on climate change. Its use also contributes to the sustainable management of a regional or local raw material such as forestry debris, to job creation, and to the application of subproducts with no added value. It is in this context that the development of small-scale production units capable of processing a few tonnes of biomass per day is attracting great interest. These could efficiently produce a bio-oil of a higher energy density compared to that of the starting biomass, which would significantly reduce the costs associated with the handling and transportation of biofuel.

The main challenge faced by the scientific community is that of improving the quality of bio-oil obtained from biomass by means of conventional pyrolysis processes. Despite bio-oil being environmentally friendly, its fuel characteristics are lower than those of fossil fuels because of its high oxygen content, the results of which are a low calorific value, corrosion problems and instability [1]. Many studies have been undertaken to achieve this goal by means of upgrading techniques. Among these, numerous studies have focused on the co-pyrolysis of biomass with plastic wastes [1,2]. This approach has proved that it is possible to obtain bio-oils with improved quality, while synergetic effects have even been found in the yield to liquids, water content, and heating value compared to those results found for the pyrolysis of the separate components [3]. These synergetic effects are linked to the promotion of interactions between radicals released from both substances during the devolatilisation process. For instance, results obtained from the copyrolysis of different mixtures of lignocellulosic biomass and waste tyres [3] showed positive synergetic effects in both bio-oil yield and various bio-fuel chemical and physical properties such as acidity, viscosity and oxygen content.

For the purpose of accelerating the study of different biomass/plastic mixtures, it would be of great interesting to have a kinetic model of the co-pyrolysis process in order to identify those plastics that can enhance the quality of bio-oil at relevant heating rates for pyrolysis processes, because they release radicals at the same time as biomass does [1]. The Distributed Activation Energy Model (DAEM) is considered an accurate and versatile approach in this regard $[4,5]$. Varhegyi et al. [6] pointed out that the DAEM is the best method available for mathematically representing the physical and chemical heterogeneity of biomass during a devolatilisation process.

The present study applied the DAEM in order to predict the behaviour of different biomass/plastic mixtures under flash pyrolysis conditions. Six different waste plastics (waste tyre (NFU), polylactic acid (PLA), polystyrene (PS), polyethylene terephthalate (PET), polypropylene (PP) and high density polyethylene (HDPE)) were evaluated as potential promoters during the flash pyrolysis of lignocellulosic biomass obtained from pine forestry residues (PINE). First, data from the thermogravimetric analysis of pure feedstocks were used to obtain the kinetic parameters of the model. By using these data, 
the model allowed important aspects of the co-pyrolysis process to be studied at high heating rates such as the possibility of radical interactions and optimum pyrolysis temperature.

\section{Experimental}

\subsection{Feedstocks}

Pine woodchips (PINE-15 mm nominal size) and waste tyre crumb (NFU-5 mm nominal size) were used for the experiments. The PINE sample consisted of Aleppo pine (Pinus halepensis), containing bark, from forestry debris. It was dried, crushed and sieved to a particle size of less than $250 \square \mathrm{m}$ prior to the experiments. The NFU sample consisted of rubber crumb from waste tyres after removal of the steel thread and the textile netting. The biopolymer PLA, PP and HDPE samples came in granulated form. The PS and PET samples were obtained from used packaging. All the NFU and plastic samples were subjected to cryogenic crushing and sieved to a particle size smaller than $250 \square \mathrm{m}$. The moisture, ash and volatiles contents of the samples were determined according to the ISO589-1981, ISO-1171-1976 and ISO-5326-1974, standards, respectively. Ultimate analyses were carried out in a Thermo Flash 1112 analyser device. The higher heating value was measured in a IKA C-2000 calorimeter and determined according to UNE 164001EX, for the biomass, and ISO-1929-76, for the plastic samples. Table 1 shows the feedstock characterisation.

Table 1. Proximate and ultimate analyses (wt $\%)$ and calorific value $(\mathrm{kcal} / \mathrm{kg})$ of stabilised samples.

\begin{tabular}{|l|l|l|l|l|l|l|l|}
\hline & PINE & PLA & NFU & PS & PET & PP & HDPE \\
\hline Moisture & 6.3 & 0.4 & 1.1 & 0.5 & 0.4 & 0.2 & 0.1 \\
\hline Ash & 0.6 & 0.0 & 8.1 & 0.3 & 0.1 & 0.1 & 0.0 \\
\hline Volatiles & 77.6 & 99.3 & 62.5 & 99.0 & 89.2 & 99.8 & 100 \\
\hline $\begin{array}{l}\text { Fixed } \\
\text { carbon }\end{array}$ & 15.5 & 0.3 & 28.2 & 0.2 & 10.3 & 0.0 & 0.0 \\
\hline & & & & & & & \\
\hline Carbon & 49.7 & 51.1 & 84.6 & 97.9 & 62.7 & 85.4 & 85.5 \\
\hline Hydrogen & 6.6 & 5.8 & 7.7 & 8.3 & 4.4 & 14.5 & 14.5 \\
\hline Nitrogen & 0.1 & 0.0 & 0.4 & 0.0 & 0.0 & 0.0 & 0.0 \\
\hline Sulphur & 0.0 & 0.0 & 1.2 & 0.0 & 0.0 & 0.0 & 0.0 \\
\hline Oxygen & 44.4 & 44.0 & 4.3 & 0.0 & 32.8 & 0.0 & 0.0 \\
\hline & & & & & & & \\
\hline HHV & 4.6 & 4.4 & 8.8 & 9.8 & 5.5 & 11.0 & 11.1 \\
\hline LHV & 4.2 & 4.1 & 8.4 & 9.4 & 5.3 & 10.3 & 10.3 \\
\hline
\end{tabular}

HHV. Higher heating value

LHV. Lower heating value 
$10^{\text {Th }}$ International Conference on Sustainable Energy and Environmental Protection (June $27^{\mathrm{TH}}-30^{\mathrm{TH}}, 2017$, BLED, SLOVENIA), BioENERGY AND Biofuels M. Victoria Navarro, J. Manuel López, A. Veses, M. Soledad Callén \& T. García: Kinetic Study for the Co-Pyrolysis of Lignocellulosic Biomass and Plastics Using the Distributed Activation Energy Model

\subsection{Thermogravimetric analysis}

Thermogravimetric analyses were performed in a Netzsch Libra F1 Thermobalance. All the tests in this study were run at a constant nitrogen flow of $50 \mathrm{ml}_{\mathrm{n}} / \mathrm{min}$ in a reactor with a $13 \mathrm{~mm}$ internal diameter. The sensitivity of this apparatus was $0.1 \square \mathrm{g}$. The samples were placed in an alumina crucible forming a small fixed bed with an initial mass of approximately $9 \mathrm{mg}$. Sets of experiments at different heating rates of 5, 10, 20 and 100 ${ }^{\circ} \mathrm{C} / \mathrm{min}$ were performed for every sample.

The fraction of mass remaining (X) was calculated according to equation (1):

$$
X=\frac{M(t)}{M_{0}}
$$

where $M_{0}$ is the initial sample weight at $150{ }^{\circ} \mathrm{C}$ and $M(t)$ is the sample weight at any time.

\section{$3 \quad$ Results and Discussion}

\subsection{Kinetic study for pyrolysis of pure solids}

The DAEM was applied to study the devolatilisation of the different raw materials. This model assumes that each solid is a mixture of components that decomposes during pyrolysis into a variety of chemical groups following a distribution of first-order reactions with characteristic activation energies [7]. There are several developments of the DAEM depending on the form of activation energy distribution applied, the approach proposed to solve the double integral of activation energies and mass fractions, the conditions for measuring devolatilisation, the number of data sets used, etc. The algorithm developed by Scott et al. [7] was used in this work to describe the devolatilisation of the pure samples with the basic equation (2):

$$
X=w+\sum_{i} f_{i, 0} \exp \left[-A_{i} \int_{0}^{t} \exp \left(\frac{-E_{i}}{R T(t)}\right) d t\right]
$$

where, $w$ is the fraction of inert material, $f_{i, 0}$, is the fraction of $M_{0}$ that decomposes with an activation energy $E_{i}(\mathrm{~kJ} / \mathrm{mol})$, pre-exponential factor $A_{i}\left(\mathrm{~s}^{-1}\right), t$ is time (s), $T$ is temperature $(\mathrm{K})$ and $\mathrm{R}$ is the ideal gas constant $(\mathrm{kJ} / \mathrm{mol} \cdot \mathrm{K})$. The algorithm is intended to solve the problem of determining the kinetics for a material using two test curves at low heating rates. The accuracy of fit was studied by comparing the experimental and calculated data at these two heating rates. The applicability of the model to higher heating rates was assessed by comparing the calculated and experimental data at higher heating rates. 
Figure 1 shows the results obtained for selected samples as an example of the notable comparison between experimental and calculated data. A very good fit of the model is observed for heating rates of $5{ }^{\circ} \mathrm{C} / \mathrm{min}$ and $10{ }^{\circ} \mathrm{C} / \mathrm{min}$. It is also observed that the model with the fitted kinetic parameters accurately predicts the shift to higher temperatures of the devolatilisation curves with increasing heating rates of $20^{\circ} \mathrm{C} / \mathrm{min}$ and $100{ }^{\circ} \mathrm{C} / \mathrm{min}$. Moreover, the model simulates the entire range of experimental fractions of mass remaining and the final residual mass with differences less than $5 \%$.

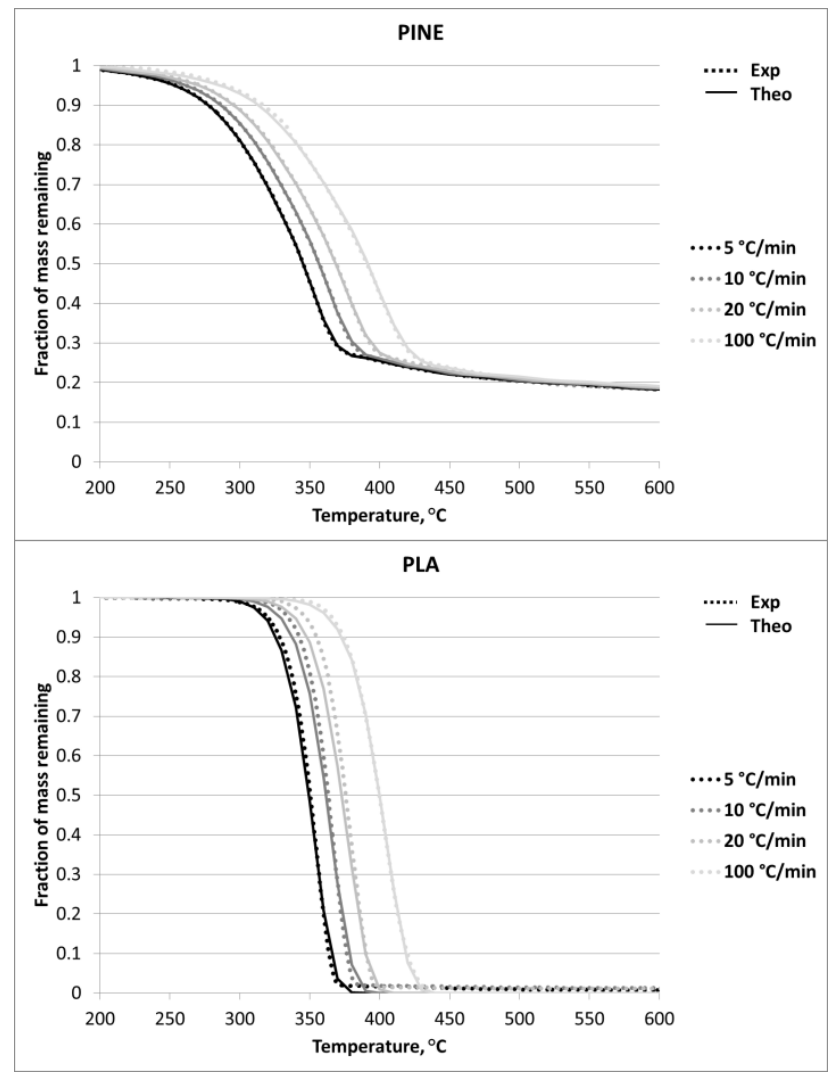


104 10 $10^{\mathrm{TH}}$ International CONFERENCE ON Sustainable ENERGy AND ENVIRONMENTAL Protection (June $27^{\mathrm{TH}}-30^{\mathrm{TH}}, 2017$, Bled, SLOVENiA), Bioenergy AND Biofuels

M. Victoria Navarro, J. Manuel López, A. Veses, M. Soledad Callén \& T. García: Kinetic Study for the Co-Pyrolysis of Lignocellulosic Biomass and Plastics Using the Distributed Activation Energy Model

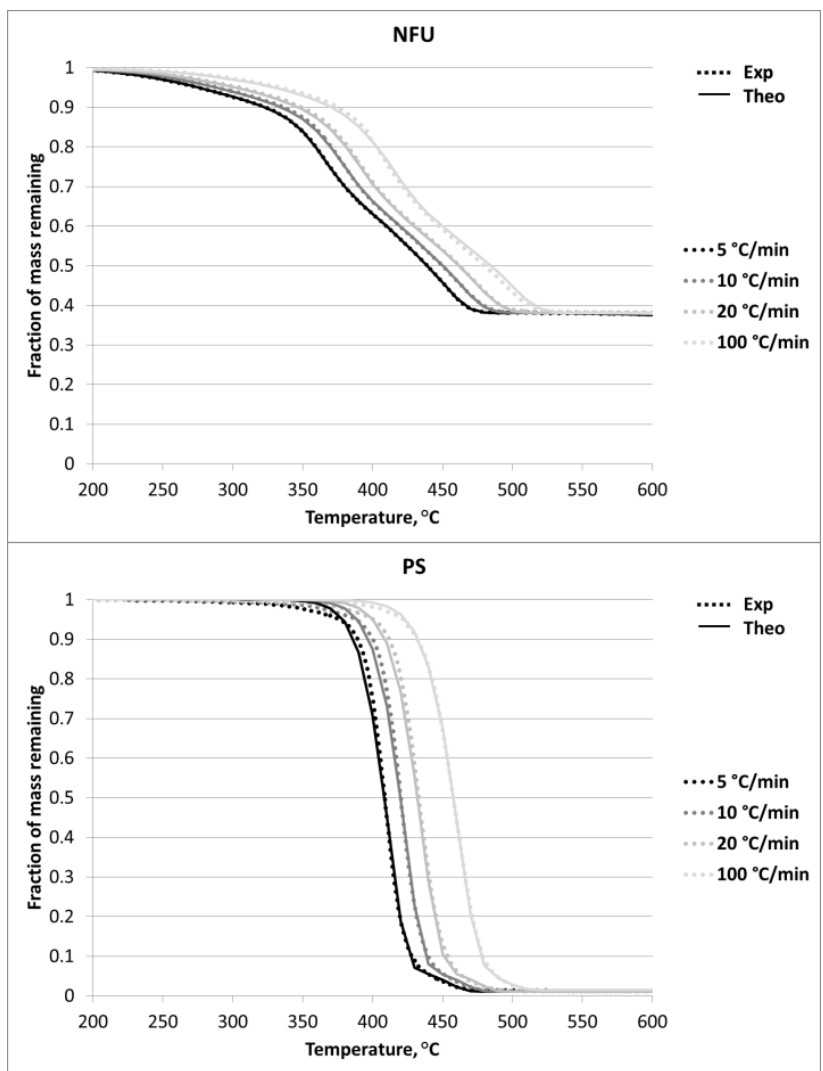

Figure 1. Fraction of mass remaining vs Temperature. Comparison of experimental data (points) and curves generated (lines) with the DAEM algorithm at $5{ }^{\circ} \mathrm{C} / \mathrm{min}, \quad 10$ ${ }^{\circ} \mathrm{C} / \mathrm{min}, 20^{\circ} \mathrm{C} / \mathrm{min}$ and $100{ }^{\circ} \mathrm{C} / \mathrm{min}$.

This good comparison allows a projection to be made of results at higher heating rates. Figure 2 shows the results corresponding to $1000{ }^{\circ} \mathrm{C} / \mathrm{min}$, which is a heating rate closer to those found in flash pyrolysis processes. 


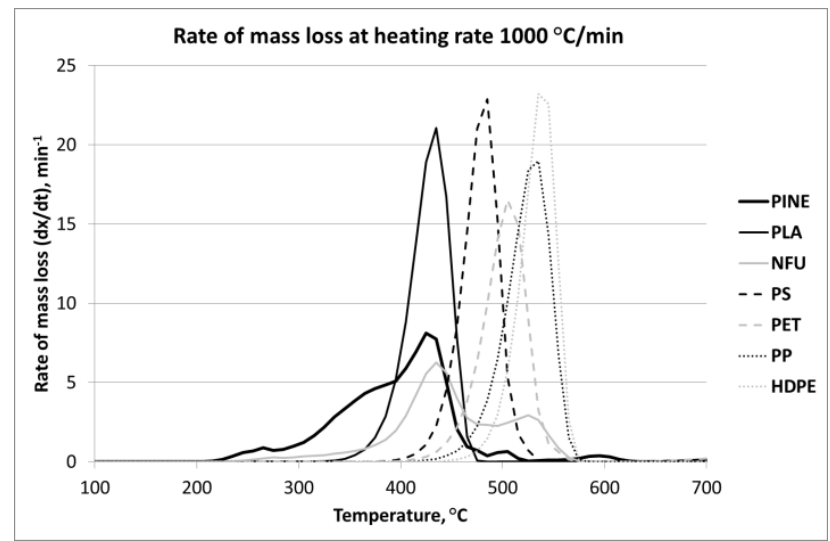

Figure 2. Rate of mass loss vs Temperature. Comparison of curves generated at 1000 ${ }^{\circ} \mathrm{C} /$ min heating rate

The results of all the samples were compared by rate of mass loss (dx/dt), which allows the observation of the main decomposition temperatures with higher values of $\mathrm{dx} / \mathrm{dt}$ for all the samples. The interaction of radicals from the different samples is favoured when the $\mathrm{dx} / \mathrm{dt}$ curves of the solids overlap. As shown by a previous study [9], wood decomposition mainly takes place, in three steps: the slow decomposition of lignin, which lasts up to $500{ }^{\circ} \mathrm{C}$, followed by the rapid decomposition of hemicellulose and, finally, the also rapid decomposition of cellulose. It can be observed that working temperatures lower than $500{ }^{\circ} \mathrm{C}$ could lead to the incomplete pyrolysis of the pine sample, depending on the reaction time.

It is observed in Figure 2 that the major overlap with the curve generated for the PINE sample was obtained with the devolatilisation of the PLA biopolymer, which points to its renewable plant origin. The overlap occurs in the middle region of PINE devolatilisation, where devolatilisation of cellulose should be taking place. Thus, major interaction between the devolatilisation of polylactic acid and cellulose molecules can be expected during the co-pyrolysis of both materials. An overlap can also be observed between the PINE and NFU curves, mostly in the region of cellulose and lignin from the PINE sample and additives and natural rubber from the NFU sample [10]. Finally, an overlap of devolatilisation curves is observed with PS in the latter part of the region of cellulose and lignin devolatilisation. The other plastics produced from fossil sources - PET, PP and HDPE - have barely commenced their pyrolysis at the temperatures required for pyrolysis of the PINE sample at a heating rate of $1000{ }^{\circ} \mathrm{C} / \mathrm{min}$. Therefore, no major interaction can be expected during their co-pyrolysis processes.

\subsection{Kinetic study for the co-pyrolysis of mixtures}

The results obtained for pure solids were introduced into the previously described and implemented model [8] suitable for feed mixtures comprising two components. In this 
last development, a coefficient that takes into account the fraction of mass allocated for every reaction for every component was introduced in order to calculate the evolution of total mass remaining with temperature in the following equation (3):

$$
\begin{aligned}
& X=a w_{a}+\sum_{i} a f_{a, i, 0} \exp \left[-A_{a, i} \int_{0}^{t} \exp \left(\frac{-E_{a, i}}{R T(t)}\right) d t\right] \\
& +b w_{b}+\sum_{i} b f_{b, i, 0} \exp \left[-A_{b, i} \int_{0}^{t} \exp \left(\frac{-E_{b, i}}{R T(t)}\right) d t\right]
\end{aligned}
$$

where, $a$ and $b$ are the fractions of components a and $\mathrm{b}$ in the feed mixture. Equation 3 considers an additive effect of pure components at low heating rates to calculate the devolatilisation of the mixture at different proportions and at higher heating rates. The accuracy of this assertion was verified in this work with mixtures of PINE and plastics in different proportions and at different heating rates. Figure 3 shows the results obtained for mixtures of PINE with PLA, NFU and PS, respectively.

With regard to the results for mixtures of PINE and PLA given in Figure 3, the small difference (less than 5\%) observed between the experimental and the simulated data means that it is possible to apply the model to the study of the mixture. However, it is should be noted that the model predicts both a slightly higher temperature needed to reach each conversion value and a lower value for the residual fraction of mass remaining, and that those differences increase with the proportion of PLA in the mixture. The experimental results obtained from the PINE/NFU mixture showed comparable results to those obtained by simulation with accuracy higher than $95 \%$ for all the tests performed. Neither the increase in the proportion of NFU nor in the heating rate modified the remarkable fit found between the experimental and the simulated results. Therefore, the model perfectly reproduces the devolatilisation process of the mixture, supporting the additive behaviour of the components with regard to the fraction of mass remaining. 
$10^{\mathrm{TH}}$ INTERNATIONAL CONFERENCE ON SUSTAINABLE ENERGY AND ENVIRONMENTAL

Protection (June $27^{\mathrm{TH}}-30^{\mathrm{TH}}, 2017$, BLed, Slovenia), Bioenergy ANd Biofuels

M. Victoria Navarro, J. Manuel López, A. Veses, M. Soledad Callén \& T. García: Kinetic Study for the Co-Pyrolysis of Lignocellulosic Biomass and Plastics Using the Distributed Activation Energy Model

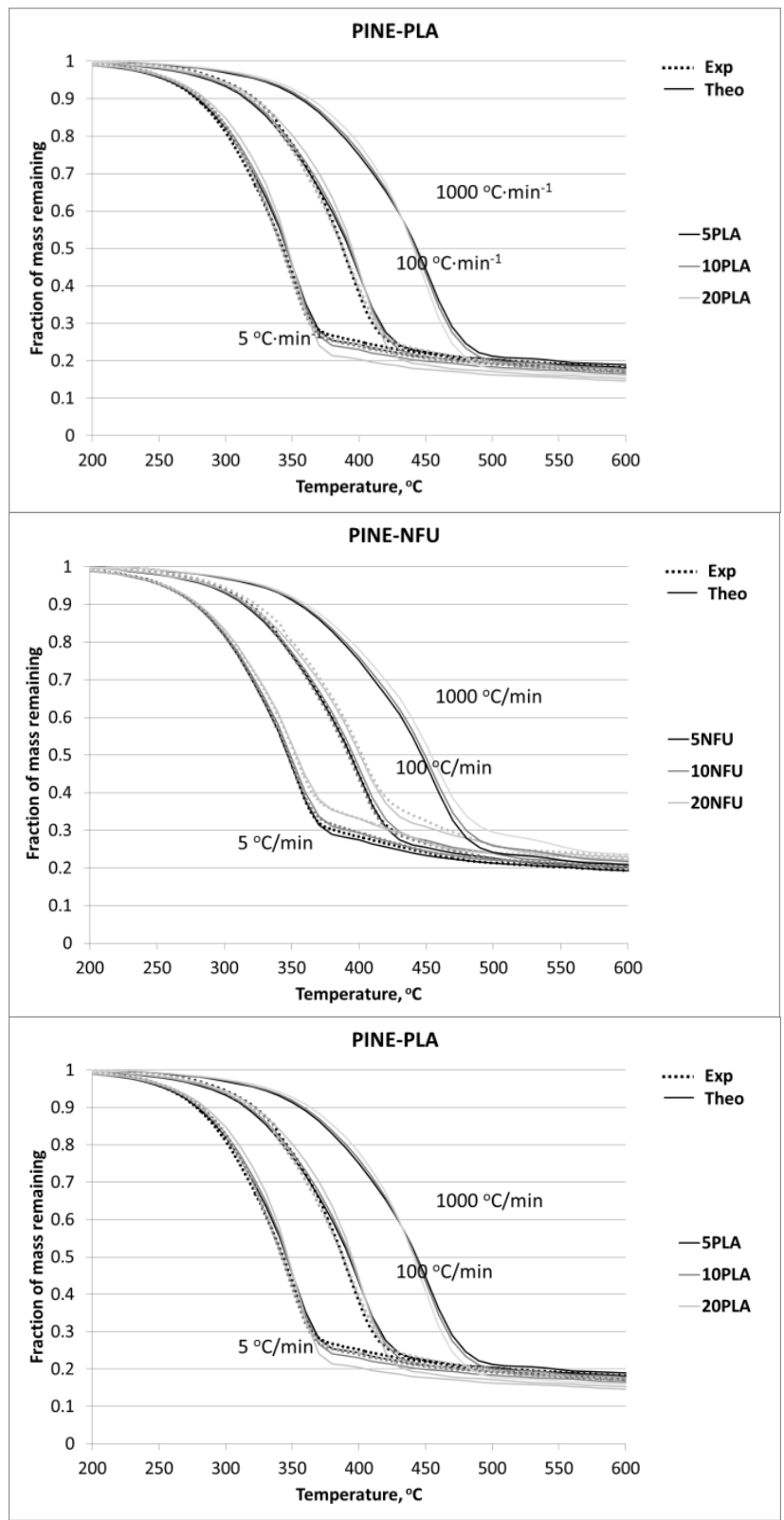

Figure 3. Fraction of mass remaining vs Temperature. Comparison of experimental data (points) and curves generated (lines) with the DAEM algorithm at $5{ }^{\circ} \mathrm{C} / \mathrm{min}, 100{ }^{\circ} \mathrm{C} / \mathrm{min}$ and $1000{ }^{\circ} \mathrm{C} / \mathrm{min}$ 
In the case of the PINE-PS mixture, a different trend is observed from that shown by the previous samples (Figure 3). At the lower heating rate of $5^{\circ} \mathrm{C} / \mathrm{min}$, the experimental fraction of mass remaining at temperatures between $380^{\circ} \mathrm{C}$ and $450{ }^{\circ} \mathrm{C}$ is higher than the simulated fraction, while the residual mass was correctly predicted by the DAEM. From the results given by the pure components (Figure 1), it is seen that PS decomposition mainly takes place in this temperature range. Thus, the pyrolysis of the PINE/PS mixture between $380^{\circ} \mathrm{C}$ and $450{ }^{\circ} \mathrm{C}$ can be mainly attributed to the contribution from the devolatilisation of PS, the reactivity of which is reduced in the mixture. It should be noted that the differences between the experimental and simulated results are significantly reduced at the higher heating rate of $100^{\circ} \mathrm{C} / \mathrm{min}$. The fact that increasing the heating rate reduces the discrepancies between experimental and simulated data supports the reliability of the model to be applied at high heating rates, although an interaction is observed between PINE and PS samples during their co-pyrolysis at low heating rates.

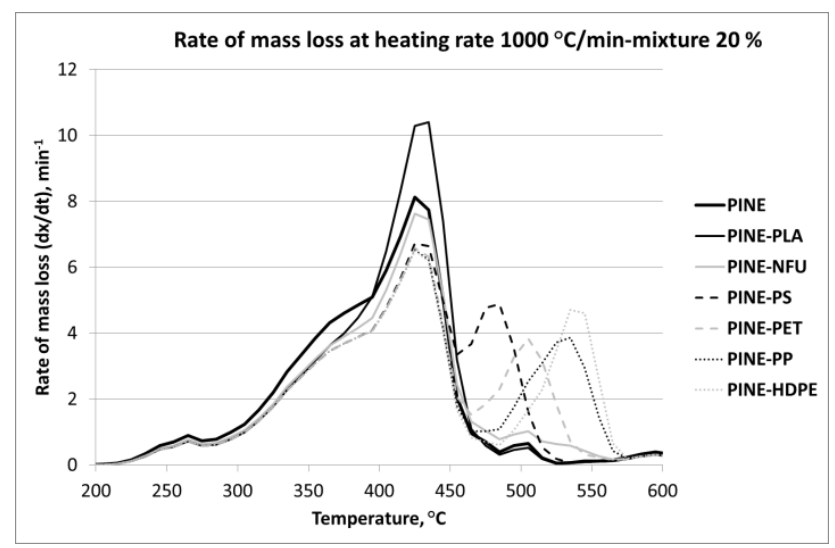

Figure 4. Rate of mass loss vs Temperature. Comparison of curves generated for biomass/plastic mixtures of $80: 20 \mathrm{wt} \%$ at $1000{ }^{\circ} \mathrm{C} / \mathrm{min}$ heating rate

The model has demonstrated its ability to produce close projections at high heating rates regardless of minor differences between the additional behaviour of components simulated by the model and the experimental results obtained for some samples. Thus, the calculated rates of mass loss in Figure 4 were compiled at a heating rate of 1000 ${ }^{\circ} \mathrm{C} / \mathrm{min}$ for the different biomass/plastic mixtures (80:20 wt\%). It is observed that PLA highly increases the rate of mass loss for the pure PINE. It can therefore be assumed that the devolatilisation of both materials takes place simultaneously. Similarly, the rate of mass loss of the PINE/NFU mixture is also mainly produced in the same temperature range as that of pure PINE. With regard to the plastics synthesised from fossil sources, only the devolatilisation of PS is cohabitant with the devolatilisation of PINE, but the final pyrolysis temperature should be increased $\left(550^{\circ} \mathrm{C}\right)$ to assure the total decomposition of both components. The main decomposition temperatures of the PET, PP and HDPE lay outside of the temperature range of PINE pyrolysis. Therefore, the presence of radical 
M. Victoria Navarro, J. Manuel López, A. Veses, M. Soledad Callén \& T. García: Kinetic Study for the Co-Pyrolysis of Lignocellulosic Biomass and Plastics Using the Distributed Activation Energy Model

interaction is only expected for three of the initially proposed plastics, PLA, NFU and PS, which in turn, could lead to a bio-oil with improved properties.

In summary, the DAEM has been successfully applied to the study of the co-pyrolysis of mixtures comprising lignocellulosic biomass and plastics. The notable comparison between experimental and simulated results allows the reliable application of the model under flash pyrolysis conditions from the results obtained from pure materials at low heating rates. The potential presence of radical interaction between biomass and three different plastics (PLA, NFU and PS) has been reported

\section{Acknowledgements}

Authors thank to Spanish MINECO and European Union FEDER funds (project ENE2015-68320 R).

\section{References}

[1] F. Abnisa, W.N.A. Wan Daud, "A review on co-pyrolysis of biomass: An optional technique to obtain a high-grade pyrolysis oil" Energy Conversion and Management vol. 87, pp. 71-85, Nov. 2014.

[2] H. Hassan, J.K. Lim, B.H. Hameed, "Recent progress on biomass co-pyrolysis conversion into high-quality bio-oil", Bioresource Technology, col. 221, pp. 645-655, Dec. 2016.

[3] J.D. Martínez, A. Veses, A.M. Mastral, R. Murillo, M.V. Navarro, N. Puy, A. Artigues, J. Bartroli, T. García, "Co-pyrolysis of biomass with waste tyres: upgrading of liquid biofuel", Fuel Processing Technology, vol. 119, pp. 263-271, March 2014.

[4] T. Sobone, N, Worasuwannarak, "Kinetic analyses of biomass pyrolysis using the distributed activation energy model", Fuel, vol. 87, pp. 414-421, March 2008.

[5] T. Mani, P. Murugan, N. Mahinpey, "Determination of distributed energy model kinetic parameters using simulated annealing optimization method for nonisothermal pyrolysis of lignin", Industrial and Engineering Chemistry Research, vol. 48, pp. 1464-1467, Dec. 2008.

[6] G. Varhegyi, P. Szabo, M.J. Antal Jr., Kinetics of charcoal devolatilization, Energy \& Fuels, vol. 16, pp. 724-731, March 2002.

[7] S.A. Scott, J.S. Dennis, J.F. Davidson, A.N. Hayhurst, "An algorithm for determining the kinetics of devolatilisation of complex solid fuels from thermogravimetric experiments", Chemical Engineering Science, vol. 61, pp. 2339-2348, April 2006.

[8] M.V. Navarro, A. Aranda, T. García, R. Murillo, A.M. Mastral, "Application of the distributed activation energy model to blends devolatilisation", Chemical Engineering Journal, vol. 142, pp. 87-94, Aug. 2008.

[9] M.V. Navarro, R. Murillo, A.M. Mastral, N. Puy, J. Bartroli, "Application of the Distributed Activation Energy Model to Biomass and Biomass Constituents Devolatilization", AIChE J, vol. 55, pp. 2700-2715, Oct 2009.

[10] E. Aylón, M.S. Callén, J.M. López, A.M. Mastral, R. Murillo, M.V. Navarro, S. Stelmach, "Assessment of tire devolatilization kinetics", Journal of Analytical and Applied Pyrolysis, vol. 74, pp. 259-264, April 2005. 
$110 \mid 10^{\mathrm{TH}}$ International CONFERENCE on Sustainable EnERgy and ENVIRONMENTal Protection (June 27 $7^{\mathrm{TH}}-30^{\mathrm{TH}}, 2017$, Bled, Slovenia), Bioenergy AND Biofuels 
$10^{\mathrm{TH}}$ INTERNATIONAL CONFERENCE ON Sustainable ENERgy AND Environmental Protection (June $27^{\mathrm{TH}}-30^{\mathrm{TH}}$, 2017, Bled, SLOVENIA), BIOENERGY AND BIOFUELS

J. Krope, A.Ghani Olabi, D. Goričanec \& S. Božičnik

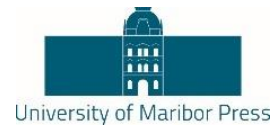

\title{
Removal of Steryl Glucosides in Biodiesel Using Diatomaceous Earth as Adsorbent
}

\author{
RATANAPORN YUANGSAWAD, SUTTIRAT KHAMBUNG, PATTARIN \\ LAUNGTHALEONGPONG \& DUANGKAMOL NA-RANONG
}

\begin{abstract}
Steryl glucosides (SG) causes precipitation in biodiesel. In this study, SG was removed from palm oil biodiesel (PO-B100) by adsorption using diatomaceous earth (DE). Effects of adsorbent loading and temperature on the efficiency of DE in SG removal were investigated in the ranges of $0.5-3 \mathrm{wt} \%$ and $65-80{ }^{\circ} \mathrm{C}$, respectively. Using PO-B100 containing $97.6 \mathrm{mg} / \mathrm{kg}$ of SG as a feedstock, adsorption of SG reached its equilibrium within $1 \mathrm{~h}$. DE showed the best performance at $3 \mathrm{wt} \%$ and 80 ${ }^{\circ} \mathrm{C}$, where $70.4 \%$ of SG was removed, with the maximum selectivity towards SG adsorption of $43.3 \%$, with respect to mono-, di- and triglycerides. The spent DE was regenerated by desorption at $65{ }^{\circ} \mathrm{C}$ using several organic solvents (e.g. methanol, ethanol, isopropanol, hexaneisopropanol (Hex-IPA) and acetone). Based on the amount of SG desorbed from the spent DE, Hex-IPA was considered as the best solvent for the regeneration step.
\end{abstract}

Keywords: • Adsorption • Biodiesel • Diatomaceous earth • Desorption • Steryl glucosides •

CORRESPONDENCE ADDRESS: Ratanaporn Yuangsawad, D.Eng., Lecturer, Rajamangala University of Technology Krungthep, Faculty of Engineering, Division of Chemical Engineering, 2 Nanglinchii, Sathorn, Bangkok, 10120, Thailand, e-mail: y.ratanaporn@gmail.com. Suttirat Khambung, B. Eng., Assistant, King Mongkut's Institute of Technology Ladkrabang, Faculty of Engineering, Department of Chemical Engineering, 1, Chalongkrung 1, Ladkrabang, Bangkok, 10520, Thailand, e-mail: s.khambung@gmail.com. Pattarin Laungthaleongpong, B. Eng., Assistant, King Mongkut's Institute of Technology Ladkrabang, Faculty of Engineering, Department of Chemical Engineering, 1, Chalongkrung 1, Ladkrabang, Bangkok, 10520, Thailand, e-mail: pattarin08@gmail.com. Duangkamol Na-Ranong, D. Eng., Associate Professor, King Mongkut's Institute of Technology Ladkrabang, Faculty of Engineering, Department of Chemical Engineering, 1, Chalongkrung 1, Ladkrabang, Bangkok, 10520, Thailand, e-mail: dnaranong@hotmail.com. 
112 10 $10^{\mathrm{TH}}$ International CONFERENCE ON Sustainable ENERGy AND ENVIRONMENTAL Protection (June $27^{\mathrm{TH}}-30^{\mathrm{TH}}, 2017$, BLed, Slovenia), Bioenergy AND Biofuels

R. Yuangsawad, S. Khambung, P. Laungthaleongpong \& D. Na-Ranong: Removal of Steryl Glucosides in Biodiesel Using Diatomaceous Earth as Adsorbent

Introduction

Biodiesel is widely used as renewable fuel. In commercial scale production, it is generally produced from transesterification of vegetable oils and by-products from vegetable oil refinery plants with methanol using a basic catalyst and is obtained as a mixture of fatty acid methyl esters (FAME). After the transesterification, crude biodiesel is obtained from gravimetric phase separation between glycerol and FAME. In order to remove contaminants, including catalyst, glycerol, soap, salts and methanol, the crude biodiesel is then washed with hot water. In the last step, the washed biodiesel is then heated under vacuum in order to remove the remaining water. To be used as an alternative fuel, biodiesel (B100) must have the amount of minor contaminants within the specification according to ASTM D 6751 or EN-14214.

Many researchers reported observation of white solid precipitates in high quality biodiesel produced from various types of vegetable oil [1-6]. This white precipitate make biodiesel became turbid and can be observed within an hour after storing the biodiesel at room temperature. The amount of the precipitate and the speed of its formation depend on raw material as well as the conditions used in the production process.

In the case of palm oil derived biodiesel (PO-B100), this precipitation is mainly due to steryl glucosides (SG) and might be accelerated by the co-existing monoglycerides and diglycerides [6-8]. Since this white precipitate leads to laborious maintenance of production lines in biodiesel plants and causes plugging in diesel engine system, SG must be removed from PO-B100, even there is no standard to control the amount of SG in POB100.

Adsorption was reported as a promising post-treatment method using to remove SG from PO-B100 [9-10]. To design an adsorption process with reasonable operating cost, it is necessity to find a cheap adsorbent which has high efficiency in SG removal and can be easily regenerated.

Diatomaceous earth (DE) is widely used as a cheap natural adsorbent for many applications. Therefore, this study aimed to investigate the feasibility DE for removing SG from PO-B100. Performance of DE in SG removal and effects of two important operating parameters of adsorption treatment (adsorbent loading and adsorption temperature) on the efficiency of DE in SG removal were investigated. Regeneration of the spent DE was performed by desorption using several organic solvents and the efficiencies of the organic solvents in desorption of SG were comparatively evaluated. 


\section{Experimental}

\subsection{Chemicals}

Palm oil based biodiesel (PO-B100) obtained from a commercial biodiesel production plant in Thailand was used as received. The temperature of PO-B100 was carefully maintained above $70{ }^{\circ} \mathrm{C}$ in order to prevent the formation of solid particles before adsorption test. DE was dried in an oven at $110{ }^{\circ} \mathrm{C}$ for $24 \mathrm{~h}$ before being used in the adsorption test. Commercial grade methanol, ethanol, isopropanol, hexane and acetone purchased from local suppliers were used as received, for regeneration of the spent DE.

\subsection{Characterization of DE}

Composition of DE was analysed using X-ray Fluorescence Spectrometer (SRS3400; Siemens). Morphological structure of DE was analysed by a scanning electron microscope (EVO ${ }^{\circledR} \mathrm{MA10}$; ZEISS). $\mathrm{N}_{2}$ adsorption-desorption isotherm was performed using a BELSORP-max (BEL Japan, Inc.). Specific surface area, total pore volume and mean pore diameter were calculated using Brunauer, Emmett and Teller (BET) method.

\subsection{Batch Adsorption}

PO-B100 was heated and continuously stirred in a hot oil bath to attain the desired temperature for adsorption test. $80 \mathrm{ml}$ of the hot PO-B100, transparent without presenting of any solids, was mixed with DE in a $250 \mathrm{ml}$ Erlenmeyer flask and shaken in an orbital shaker (4000ic; IKA) at $220 \mathrm{rpm}$. Adsorbent loading was varied from 0.5 to $3 \mathrm{wt} \%$ and adsorption temperature was varied from 65 to $80{ }^{\circ} \mathrm{C}$. The amounts of SG in PO-B100 before and after adsorption were quantified using a gas chromatograph equipped with flame ionized detector (GC-FID).

Efficiency of DE in SG removal was evaluated from reduction amount of SG $\left(R_{\mathrm{SG}}\right.$, Eq. (1)), selectivity towards SG removal ( $S_{\mathrm{SG}}$, Eq. (2)) and SG adsorption capacity $\left(q_{\mathrm{SG}}\right.$, Eq. (3)). Amounts of monoglycerides (MG), diglycerides (DG) and triglycerides (TG) adsorbed on DE were calculated from Eq. (3).

$$
\begin{aligned}
& R_{\mathrm{SG}}=\frac{C_{\mathrm{SG}, 0}-C_{\mathrm{SG}, \mathrm{t}}}{C_{\mathrm{SG}, 0}} \times 100 \\
& S_{\mathrm{SG}}=\frac{q_{\mathrm{SG}}}{q_{\mathrm{SG}}+q_{\mathrm{MG}}+q_{\mathrm{DG}}+q_{\mathrm{TG}}} \times 100
\end{aligned}
$$


114 10 $10^{\mathrm{TH}}$ International CONFERENCE ON Sustainable ENERGy AND ENVIRONMENTAL Protection (June $27^{\mathrm{TH}}-30^{\mathrm{TH}}, 2017$, BLed, Slovenia), Bioenergy AND Biofuels

R. Yuangsawad, S. Khambung, P. Laungthaleongpong \& D. Na-Ranong: Removal of Steryl Glucosides in Biodiesel Using Diatomaceous Earth as Adsorbent

$$
q_{\mathrm{i}}=\frac{W_{\mathrm{B} 100}\left(C_{\mathrm{i}, 0}-C_{\mathrm{i}, \mathrm{t}}\right)}{W_{\mathrm{ads}}}
$$

\subsection{Regeneration of spent $\mathrm{DE}$}

Methanol, ethanol, isopropanol, a mixture of equal volume of hexane and isopropanol (Hex-IPA) and acetone were used to desorp SG from the spent DE. In order to compare the desorption efficiencies of these organic solvents, adsorption of SG in PO-B100 was performed $\left(65^{\circ} \mathrm{C}, 3 \mathrm{wt} \%\right.$ and $\left.2 \mathrm{~h}\right)$ and the spent DE was then separated from PO-B100 by vacuum filtration through a filter paper (pore diameter of $0.2 \mu \mathrm{m}$ ). The solid cake remaining on the filter paper, the spent DE, was mixed with the solvent $(0.25 \mathrm{wt} \%)$ and the mixture was shaken at $65^{\circ} \mathrm{C}$ for $2 \mathrm{~h}$. Then, vacuum filtration through $0.2 \mu \mathrm{m}$ filter paper was used to separate the solvent from the regenerated DE and the organic solvent was removed from the filtrate by heating at $60{ }^{\circ} \mathrm{C}$ in a vacuum oven. Total amount of SG desorbed from the spent DE was quantified using a GC-FID.

\subsection{Analytical methods}

Amounts of FAME, glycerol, MG, DG, TG and SG were quantified using a GC-FID. Equipment and conditions used were the same as previous work [9]. Quantification of SG was performed by the method adapted from ASTM D6584, similar to the one used in the previous work [9]. Tricaprin ( $8 \mathrm{mg} / \mathrm{ml}$ in pyridine) was used as an internal standard (ISTD2). Calibration curve of SG in PO-B100 matrix was made. $250 \mu \mathrm{l}$ of a mixture of biodiesel $(130 \mu \mathrm{l})$, ISTD2 $(20 \mu \mathrm{l})$ and SG $(5-50 \mu \mathrm{g})$ in pyridine was prepared. The mixture was silylated with N-Methyl-N-trime-thylsilytrifluoroacetamide (MSTFA, 350 $\mu \mathrm{l})$ at $60{ }^{\circ} \mathrm{C}$. After complete silylation, heptane $(6 \mathrm{ml})$ was added to the vial. $1 \mu \mathrm{l}$ of silylated solution was injected to the GC-FID. The obtained calibration curve was a straight line expressed as $W_{\mathrm{SG}}=119.2\left(A_{\mathrm{SG}} / A_{\mathrm{ISTD} 2}\right) ; R^{2}=0.992$. For quantitative analysis of SG in samples, pyridine $(200 \mu \mathrm{l})$ and ISTD2 $(20 \mu \mathrm{l})$ were added to $130 \mu \mathrm{l}$ of each sample. It was silylated and analyzed with the same procedure used in the preparation of calibration curve.

\section{$3 \quad$ Results and Discussion}

\subsection{Properties of diatomaceous earth}

Composition analysis by XRF revealed that DE consisted of $\mathrm{SiO}_{2}(75.13 \mathrm{wt} \%), \mathrm{Al}_{2} \mathrm{O}_{3}$ $(12.12 \mathrm{wt} \%), \mathrm{Fe}_{2} \mathrm{O}_{3}(9.25 \mathrm{wt} \%)$ with trace amount of $\mathrm{K}_{2} \mathrm{O}(2.25 \mathrm{wt} \%)$. Figure 1 shows that DE has a flake-like broken structure. DE contains nearly regular array of submicron pores with diameters in the order of about $0.5-1 \mu \mathrm{m}$. The result obtained from $\mathrm{N}_{2}$ adsorption-desorption isotherm revealed that DE had adsorption isotherm of Type IV according to IUPAC system and DE had BET specific surface area, total pore volume and mean pore diameter of $25.4 \mathrm{~m}^{2} / \mathrm{g}, 0.0298 \mathrm{~cm}^{3} / \mathrm{g}$ and $4.69 \mathrm{~nm}$, respectively. 


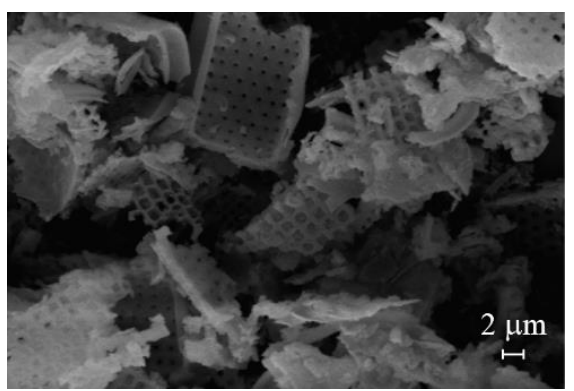

Figure 1. SEM image of diatomaceous earth

\subsection{Properties of PO-B100}

Quantitative analysis using GC-FID revealed that the composition of PO-B100 fulfilled the requirements of ASTM D 6751 and EN-14214. It contained FAME, glycerol, mono-, di- and triglycerides with the amounts of 97.1, 0, 0.7, 0.18 and 0.02 mass $\%$, respectively. Quantitative analysis of SG confirmed that PO-B100 contained SG with very low concentration $(97.6 \mathrm{mg} / \mathrm{kg})$. Moreover, it was found that PO-B100 became highly turbid due to the formation of fine particles within $1 \mathrm{~h}$ after the temperature of PO-B100 was reduced to the room temperature, about $30^{\circ} \mathrm{C}$.

\subsection{Efficiency of DE in adsorption of SG}

Adsorption of SG on DE was investigated in the temperature range of $65-80{ }^{\circ} \mathrm{C}$. Firstly, time required to reach the equilibrium of adsorption was measured at the lowest temperature $\left(65^{\circ} \mathrm{C}\right)$. At this temperature, after PO-B100 was treated with DE $(1 \mathrm{wt} \%)$, the concentration of SG decreased rapidly in the first $10 \mathrm{~min}$ and it became constant at around $64.9 \mathrm{mg} / \mathrm{kg}$ within $1 \mathrm{~h}$. Accordingly, time to reach the equilibrium of $\mathrm{SG}$ adsorption was considered as $1 \mathrm{~h}$ and the performance of DE evaluated at $1 \mathrm{~h}$ will be used for further discussion in this work.

\section{Effect of Adsorbent Loading}

Figure 2(a) shows the amount of SG removed from PO-B100 $\left(R_{\mathrm{SG}}\right)$ by DE when POB100 was treated with various amounts of DE. $R_{\mathrm{SG}}$ increased with the increase of adsorbent loading from 0.5 to $3.0 \mathrm{wt} \%$. However, the effect at higher temperature $\left(80^{\circ} \mathrm{C}\right)$ was slightly more significant comparing with the effect in the lower range of temperatures $\left(65-75^{\circ} \mathrm{C}\right)$. Figure $2(\mathrm{~b})$ shows that the amount of $\mathrm{SG}$ adsorbed on DE $\left(q_{\mathrm{SG}}\right)$ decreased with the increase of adsorbent loading. The effect in the range of lower adsorbent loading (0.5-1.0 wt $\%)$ was more significant comparing with the effect in the range of higher adsorbent loading (1.0-3.0 wt \%). The lowest concentration of SG $(28.9 \mathrm{mg} / \mathrm{kg})$ in PO$\mathrm{B} 100$ was obtained after adsorption at $80{ }^{\circ} \mathrm{C}$ and $3.0 \mathrm{wt} \%$, corresponding to $R_{\mathrm{SG}}=70.4 \%$. 
116 10 $10^{\mathrm{TH}}$ International Conference on Sustainable Energy and ENVIRONMENTal Protection (June $27^{\mathrm{TH}}-30^{\mathrm{TH}}, 2017$, Bled, SLOVENIA), BioENERGY AND Biofuels

R. Yuangsawad, S. Khambung, P. Laungthaleongpong \& D. Na-Ranong: Removal of Steryl Glucosides in Biodiesel Using Diatomaceous Earth as Adsorbent
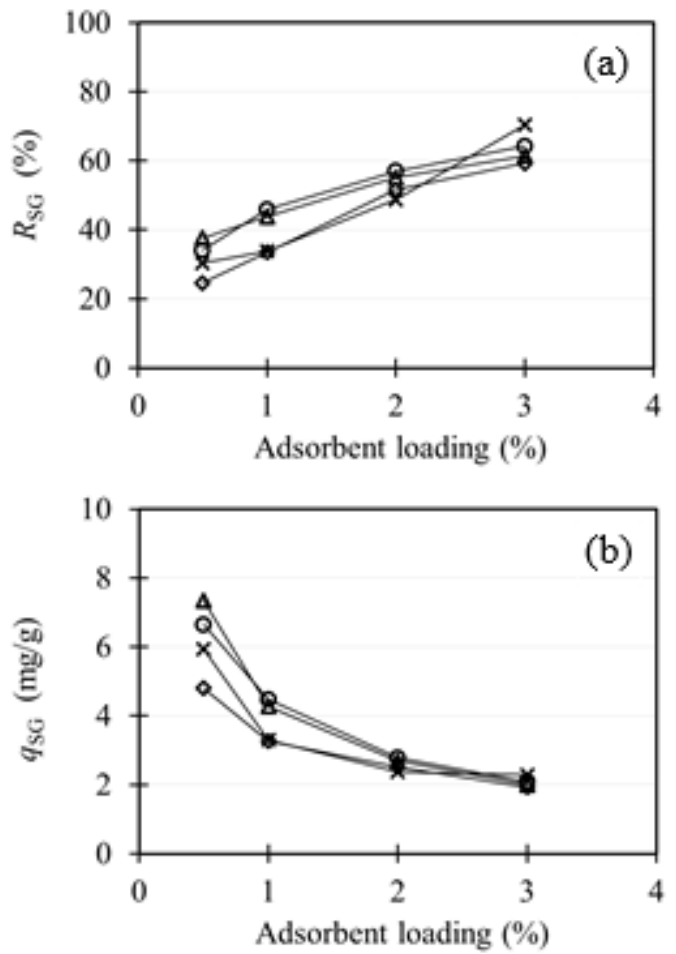

Figure 2. Effects of adsorbent loading on efficiency of DE in SG removal at $T($ ) 65 , (O) $70,(\Delta) 75,(\times) 80{ }^{\circ} \mathrm{C} ; C_{\mathrm{SG}, 0}=97.6 \mathrm{mg} / \mathrm{kg}$

\section{Effect of adsorption temperature}

Figure 3 reveals that effect of temperature on $q_{\mathrm{SG}}$ was significant at low adsorbent loading (0.5-1.0 wt $\%)$ and the effect became insignificant when the adsorbent loading was 2.0 wt $\%$ and higher. At low adsorbent loading, $q_{\mathrm{SG}}$ reached the maximum values at temperature around $70-75{ }^{\circ} \mathrm{C}$. This similar characteristic was also observed when magnesium silicate or bleaching earth was used as adsorbent for removing SG from POB100 [9]. This characteristic implied that some other minor components presenting in PO-B100 were simultaneously adsorbed on DE while SG adsorption occurred. 


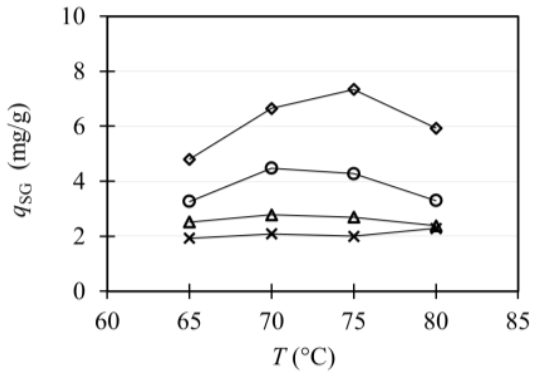

Figure 3. Effect of temperature on efficiency of DE in SG removal at $W_{\text {ads }}=($ ) 0.5 , (O) $1,(\Delta) 2,(\times) 3 \mathrm{wt} \% ; C_{\mathrm{SG}, 0}=97.6 \mathrm{mg} / \mathrm{kg}$

\subsection{Effect of DE on other components}

Since biodiesel has many minor components and quantification of all the minor components is difficult, MG, DG and TG, which are strictly controlled according to ASTM D 6751 and EN-14214, were quantified and their effects on SG adsorption by DE were further discussed in this study. Figure 4 shows the reduction amounts of SG, MG, DG and TG when PO-B100 was treated with DE (1 wt $\%)$ at various temperatures. At these conditions, more than $30 \%$ of SG was removed whereas less than $4 \%$ of MG, DG and TG were removed from PO-B100. As shown in Figure 5, the selectivity of DE towards SG adsorption $\left(S_{\mathrm{SG}}\right)$ at temperatures in the range of $65-75^{\circ} \mathrm{C}$ was small (around $11.0-15.2 \%$ ). This small value of $S_{\mathrm{SG}}$ indicated that DE was mostly occupied by MG, DG and TG. This result suggested that to obtain high efficiency of DE in SG removal in this range of adsorption temperature, the amounts of MG, DG and TG in biodiesel feedstock must be low enough, to reduce competitive effect from MG, DG and TG adsorptions. In contrast, when the adsorption was performed at the higher temperature $\left(80{ }^{\circ} \mathrm{C}\right), S_{\mathrm{SG}}$ was as high as $43.3 \%$.

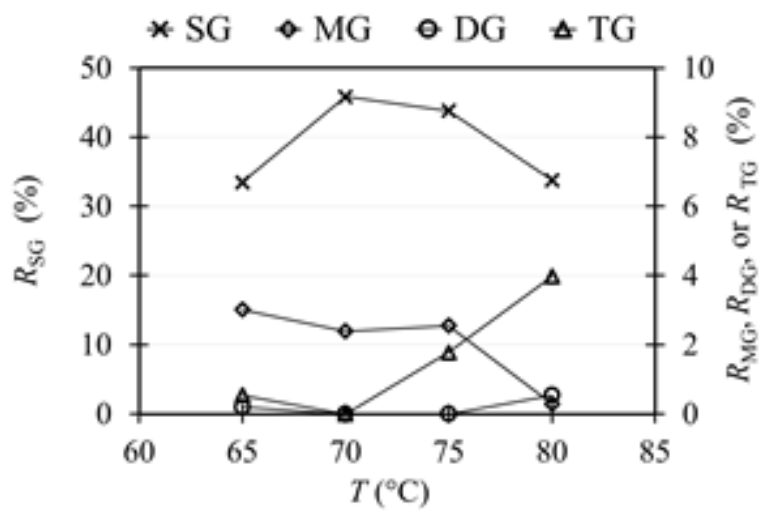

Figure 4. Effect of adsorption temperature on reductions of $\mathrm{SG}, \mathrm{MG}, \mathrm{DG}$ and $\mathrm{TG}\left(C_{\mathrm{SG}, 0}\right.$ $=97 \mathrm{mg} / \mathrm{kg}$, adsorbent loading $=1 \mathrm{wt} \%$ ) 
$10^{\text {TH }}$ International Conference on Sustainable Energy and Environmental Protection (June 27 ${ }^{\mathrm{TH}}-30^{\mathrm{TH}}, 2017$, BLed, Slovenia), Bioenergy AND Biofuels

R. Yuangsawad, S. Khambung, P. Laungthaleongpong \& D. Na-Ranong: Removal of Steryl Glucosides in Biodiesel Using Diatomaceous Earth as Adsorbent

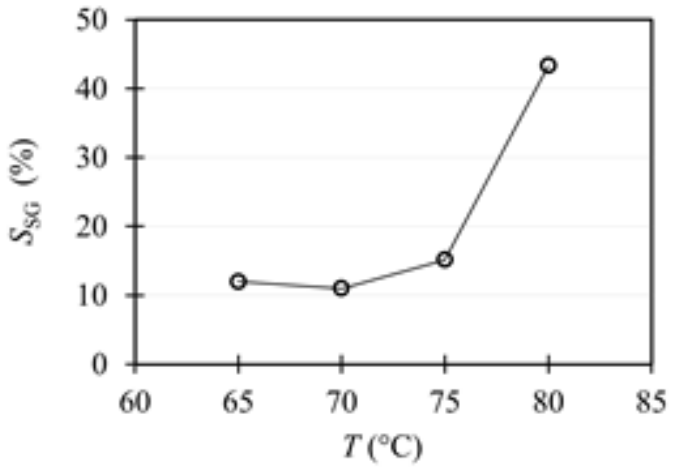

Figure 5. Selectivity towards SG adsorption; $W_{\mathrm{ads}}=1 \mathrm{wt} \%, C_{\mathrm{SG}, 0}=97.6 \mathrm{mg} / \mathrm{kg}$

\subsection{Regeneration of spent DE}

Since SG is one derivative of sterol and it has high value, desorption of SG from the spent DE should be challenged. As presented in Table 1, Hex-IPA was the best solvent that can be used to desorb SG from the spent DE in the regeneration step. However, desorption at this condition could desorb only $4.4 \%$ of the adsorbed SG. Since it is well known that SG has very specific molecular structure and has extremely low solubility in commonly used solvents, the low efficiency in SG desorption was considered as a result of the low solubility of SG in Hex-IPA. To increase the amount of SG that can be recovered in the regeneration step, continuous desorption should be performed.

Table 1. Desorption of SG $\left(W_{\mathrm{ads}}=0.25 \mathrm{wt} \%, T_{\mathrm{des}}=65^{\circ} \mathrm{C}, t_{\mathrm{des}}=2 \mathrm{~h}\right)$

\begin{tabular}{|l|r|}
\hline Solvent & $W_{\text {SG, des }}(\mu \mathrm{g})$ \\
\hline methanol & 66.8 \\
\hline ethanol & 86.4 \\
\hline isopropanol & 185.9 \\
\hline Hex-IPA & 253.2 \\
\hline acetone & 19.7 \\
\hline
\end{tabular}

\section{$4 \quad$ Conclusions}

Diatomaceous earth was used as adsorbent to reduce the amount of steryl glucosides (SG) in palm oil based biodiesel. At $80{ }^{\circ} \mathrm{C}$ and $3 \mathrm{wt} \%$, it could remove up to $70.4 \%$ of SG presenting in a feedstock containing $97.6 \mathrm{mg} / \mathrm{kg}$ of SG and it had the selectivity towards SG adsorption, with respect to mono-, di- and triglycerides, of $43.3 \%$. A mixture of equal volume of hexane and isopropanol was the best solvent for regeneration of the spent diatomaceous earth 


\section{Acknowledgements}

Financial supports from National Research Council of Thailand and Faculty of Engineering, King Mongkut's Institute of Technology Ladkrabang are gratefully acknowledged.

\section{Nomenclatures}

$A_{\mathrm{SG}} \quad$ area under the peaks of SG $(\mu \mathrm{V} \cdot \mathrm{s})$

$A_{\text {ISTD2 }}$ area under the peaks of ISTD2 $(\mu \mathrm{V} \cdot \mathrm{s})$

$C_{\mathrm{i}, 0} \quad$ initial concentration of "i" ( $\left.\mathrm{mg} / \mathrm{kg}\right)$

$C_{\mathrm{i}, \mathrm{t}} \quad$ concentration of "i" at any time $(\mathrm{mg} / \mathrm{kg})$

$q_{\mathrm{i}} \quad$ amount of "i" adsorbed on DE (mg/g-DE)

$R_{\mathrm{SG}} \quad$ reduction amount of SG $(\%)$

$S_{\mathrm{SG}} \quad$ selectivity to $\mathrm{SG}$ removal (\%)

$T$ adsorption temperature $\left({ }^{\circ} \mathrm{C}\right)$

$T_{\text {des }}$ desorption temperature $\left({ }^{\circ} \mathrm{C}\right)$

$t \quad$ adsorption time (h)

$t_{\text {des }} \quad$ desorption time (h)

$W_{\text {ads }} \quad$ weight of DE $(\mathrm{g})$

$W_{\mathrm{B} 100}$ weight of PO-B100 (g)

\section{Subscript}

$\begin{array}{ll}\text { DG } & \text { diglycerides } \\ \text { MG } & \text { monoglycerides } \\ \text { SG } & \text { steryl glucosides } \\ \text { TG } & \text { triglycerides }\end{array}$

\section{References}

[1] I. Lee, L. M. Pfalzgraf, G. B. Poppe, E. Powers, and T. Haines, "The role of sterol glucosides on filter plugging," Biodiesel Magazine, Vol. 4, pp. 105-112, 2007.

[2] R. A. Moreau, K. M. Scott, and M. J. Haas "The identification and quantification of steryl glucosides in precipitates from commercial biodiesel," Journal of the American Oil Chemists' Society, Vol. 85, pp. 761-770, Aug. 2008.

[3] H. Tang, S. O. Salley, K. Y. Simon Ng, "Fuel properties and precipitate formation at low temperature in soy-, cottonseed-, and poultry fat-based biodiesel blends," Fuel, Vol. 87, pp. 3006-3017, Oct. 2008.

[4] H. Wang, H. Tang, S. Salley, and K. Y. Simon Ng, "Analysis of sterol glycosides in biodiesel and biodiesel precipitates," Journal of the American Oil Chemists' Society, Vol. 87, pp. 215-221, Feb. 2010.

[5] H. Tang, R. C. De Guzman, S. O. Salley, and K. Y. S. Ng, "Formation of insolubles in palm oil-, yellow grease-, and soybean oil-based biodiesel blends after cold soaking at $4{ }^{\circ} \mathrm{C}$," Journal of the American Oil Chemists' Society, Vol. 85, pp. 1173-1182, Dec. 2008.

[6] D. Na-Ranong, and P. Kitchaiya, "Precipitation above cloud point in palm oil based biodiesel during production and storage," Fuel, Vol. 122, pp. 287-293, Apr. 2014.

[7] R.O. Dunn, "Effect of monoacylglycerols on the cold flow properties of biodiesel," Journal of the American Oil Chemists' Society, Vol. 89, pp. 1509-1520, Aug. 2012. 
$120 \mid 10^{\mathrm{TH}}$ International Conference on Sustainable ENERgy AND ENVIRONMENTAL Protection (June $27^{\mathrm{TH}}-30^{\mathrm{TH}}, 2017$, Bled, Slovenia), Bioenergy AND BIOFuels

R. Yuangsawad, S. Khambung, P. Laungthaleongpong \& D. Na-Ranong: Removal of Steryl Glucosides in Biodiesel Using Diatomaceous Earth as Adsorbent

[8] V. Plata, P. Gauthier-Maradei, and V. Kafarov, "Influence of minor components on precipitate formation and filterability of palm oil biodiesel," Fuel, Vol. 144, pp. 130-136, Mar. 2015.

[9] D. Na-Ranong, P. Laungthaleongpong, and S. Khambung, "Removal of steryl glucosides in palm oil based biodiesel using magnesium silicate and bleaching earth," Fuel, Vol. 143, pp. 229-235, Mar. 2015.

[10] V. Plata, D. Haagenson, A. Datdelen, D. Wiesenborn, and V. Kafarov, "Improvement of palm oil biodiesel filterability by adsorption methods," Journal of the American Oil Chemists' Society, Vol. 92, pp. 893-903, Jun. 2015. 
$10^{\mathrm{TH}}$ INTERNATIONAL CONFERENCE ON Sustainable ENERgy AND ENVIRONMENTAL Protection (June $27^{\mathrm{TH}}-30^{\mathrm{TH}}$, 2017, Bled, SLOVENIA), BIOENERGY AND BIOFUELS

J. Krope, A.Ghani Olabi, D. Goričanec \& S. Božičnik

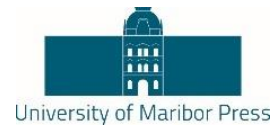

\title{
Upgrading of Biogas to Biomethane: Experimental and Process Analysis Applied to an Industrial Plant
}

\author{
Francesco Ferella, Katia Gallucci \& Pier Ugo Foscolo
}

\begin{abstract}
This paper deals with carbon dioxide capture from $\mathrm{CO} 2 / \mathrm{CH} 4$ mixture by pressure swing adsorption (PSA) at low pressure using zeolites produced from power plant spent fly ash. Commercial sorbents like activated carbon, blue silica gel and zeolite $13 \mathrm{X}$ were also tested. The best zeolite showed that the recovery of $\mathrm{CH} 4$ and $\mathrm{CO} 2$ was $95.2 \%$ and $98.1 \%$, respectively, with a purity of $98 \% \mathrm{vol}$ and $99.6 \% \mathrm{vol}$ at 2 barg. Three zeolites produced from fly ash also underwent cyclic adsorption-desorption tests: after five cycles, no loss in adsorption capacity of $\mathrm{CO} 2$ was determined, so that they fully recovered their activity and selectivity after regeneration. The revamp of a $1 \mathrm{MWel}$. biogas plant with a $\mathrm{CO} 2$ separation by means of a PSA technology using one of the zeolites synthesized in this work was also evaluated. The techno-economic analysis showed that the investment is highly profitable, taking into account the green subsidy provided by new Italian regulations.
\end{abstract}

Keywords: • CO2 • Biogas • Biomethane $\bullet$ Zeolite $\bullet$ PSA •

CORRESPONDENCE ADDRESS: Francesco Ferella, Ph.D., Research Assistant, University of L'Aquila, Faculty of Engineering, Department of Industrial Engineering, Information and Economics, Via G. Gronchi 18, 67100 L'Aquila, Italy, e-mail: francesco.ferella@univaq.it. Katia Gallucci, Ph.D., Associate Professor, University of L'Aquila, Faculty of Engineering, Department of Industrial Engineering, Information and Economics, Via G. Gronchi 18, 67100 L'Aquila, Italy, e-mail: katia.gallucci@univaq.it. Pier Ugo Foscolo, Full Professor, University of L'Aquila, Faculty of Engineering, Department of Industrial Engineering, Information and Economics, Via G. Gronchi 18, 67100 L'Aquila, Italy, e-mail: pierugo.fuscolo@univaq.it.

https://doi.org/10.18690/978-961-286-048-6.12

ISBN 978-961-286-048-6

(C) 2017 University of Maribor Press

Available at: http://press.um.si. 
$10^{\mathrm{TH}}$ InTERNATIONAL CONFERENCE ON SuSTAINABLE ENERGy AND ENVIRONMENTAL Protection (June $27^{\mathrm{TH}}-30^{\mathrm{TH}}, 2017$, BLED, Slovenia), Bioenergy AND Biofuels

F. Ferella, K. Gallucci \& P. Ugo Foscolo: Upgrading of Biogas to Biomethane: Experimental and Process Analysis Applied to an Industrial Plant

\section{Introduction}

This study was carried out in collaboration with ThinkEco Agri, an Italian company that owns a $1 \mathrm{MW}_{\mathrm{el}}$ biogas plant in Abruzzo Region, approximately $100 \mathrm{~km}$ East of Rome. That plant is fed with around 50\%wt of maize silage, $10 \%$ of poultry manure and the rest is composed of seasonal material from food industry like potato, fennel and carrot waste. As known, biogas is a gaseous mixture mainly consisting of $55 \%$ to $70 \%$ vol methane and $30 \%$ to $45 \%$ vol carbon dioxide, produced by anaerobic digestion of organic matter. $\mathrm{CO}_{2}$ can be separated from $\mathrm{CH}_{4}$ in order to produce biomethane, that can be used as transportation fuel or, alternatively, injected in the national distribution network. Moreover, the separated $\mathrm{CO}_{2}$ can be stored and treated in order to get food- or technicalgrade $\mathrm{CO}_{2}$, that could be an interesting alternative method considering that the geological $\mathrm{CO}_{2}$ extracted in Italy is going to end in the incoming years. Alternatively, raw $\mathrm{CO}_{2}$ could also be used to grow autotrophic algae in photo-bioreactors or raceway open ponds. Several techniques for separation of $\mathrm{CO}_{2}$ already exists, some of those already well established in full-scale plants [1]. The aim of this paper is the separation of $\mathrm{CO}_{2}$ for the upgrading of biogas to biomethane by pressure swing adsorption (PSA): in particular, molecular sieves like zeolites were synthesized from spent fly ash, in order to give new life to a waste produced in huge amounts in the World. Fly ash is an agglomerate of microspheres, called cenospheres, that are mainly composed of $\mathrm{Si}$ and $\mathrm{Al}$ with minor amounts of $\mathrm{Fe}, \mathrm{Na}, \mathrm{Mg}, \mathrm{K}, \mathrm{Ca}, \mathrm{P}, \mathrm{Ti}$, and $\mathrm{S}$. The major mineral compound is amorphous aluminosilicates but other crystalline minerals are also present, such as mullite, quartz, hematite, magnetite, lime, anhydrites, and feldspars. Some authors have already studied the adsorption capacity of zeolites produced from spent fly ash [2-14]. A synthetic biogas was used in the adsorption tests. The performance of these zeolites were also compared to those of commercial sorbents like zeolite 13X, activated carbon and silica gel. The results of the best zeolite were used to develop a profitability analysis of the upgrading PSA process, in order to add the $\mathrm{CO}_{2}$ capture plant to the existing biogas plant operated by ThinkEco Agri.

\section{$2 \quad$ Materials \& Methods}

\subsection{Synthesis of zeolites}

Two different synthesis procedures were applied, adapted from [13,14]: procedure A involved the following stages: (1) washing of the original fly ash with $10 \%$ vol $\mathrm{HNO}_{3}$ solution, with a solid to liquid ratio of $100 \mathrm{~g} / \mathrm{L}$, under mechanical stirring in a water bath (Dubnoff, ISCO) for $1 \mathrm{~h}$ at room temperature; (2) vacuum filtration of the suspension by a paper filter and washing of the solid with distilled water until neutral $\mathrm{pH}$ is achieved; (3) drying overnight at $110^{\circ} \mathrm{C}$; (4) addition of solid $\mathrm{NaOH}$ to the powder with a ratio of $1.2 \mathrm{~g} \mathrm{NaOH} / \mathrm{g}$ fly ash; (5) roasting at $600^{\circ} \mathrm{C}$ in a muffle oven for $1 \mathrm{~h}$; (6) after cooling, addition of $6 \mathrm{~mL}$ distilled water/g of the roasted fly ash in a closed flask, with mechanical stirring for $8 \mathrm{~h}$ at room temperature; (7) further hydrothermal reaction at $80^{\circ} \mathrm{C}$ for $24 \mathrm{~h}$ in the same closed flask; (8) vacuum filtration of the suspension by a paper filter and 
washing of the solid with distilled water until neutral $\mathrm{pH}$ is achieved; (9) drying at $110^{\circ} \mathrm{C}$ for $24 \mathrm{~h}$.

Procedure B, instead, was carried out in the following way: (1) washing of the original fly ash with $10 \%$ vol $\mathrm{HNO}_{3}$ solution, with a solid to liquid ratio of $100 \mathrm{~g} / \mathrm{L}$, under mechanical stirring in a water bath for $1 \mathrm{~h}$ at room temperature; (2) vacuum filtration of the suspension by a paper filter and washing of the solid with distilled water until neutral $\mathrm{pH}$ is achieved; (3) drying overnight at $110^{\circ} \mathrm{C}$; (4) addition of solid $\mathrm{NaOH}$ to the powder with a ratio of $1.2 \mathrm{~g} \mathrm{NaOH} / \mathrm{g}$ fly ash; (5) roasting at $560^{\circ} \mathrm{C}$ in a muffle oven for $1 \mathrm{~h}$; (6) after cooling, addition of $10 \mathrm{~mL}$ distilled water/g of the roasted fly ash in a closed flask, with mechanical stirring for $12 \mathrm{~h}$ at room temperature; (7) further hydrothermal reaction in an autoclave (pressure reactor 4540 , Parr) at $110^{\circ} \mathrm{C}$ for $6 \mathrm{~h}$; (8) vacuum filtration of the suspension by a paper filter and washing of the solid with distilled water until neutral $\mathrm{pH}$ is achieved; (9) drying at $110^{\circ} \mathrm{C}$ for $24 \mathrm{~h}$. The zeolites and the three commercial materials tested in this research are listed in Table 1.

\subsection{Characterization of zeolites}

The grain size distribution of the samples was carried out by the optical instrument Mastersizer 2000 (Malvern). The element concentration of the spent fly ash and synthesized zeolites was determined by X-ray fluorescence (XRF, Spectro, Xepos). Brunauer-Emmet-Teller (BET) and Barrett-Joiner-Halenda (BJH) are two methods used to determine the specific surface area (SSA) and pore size of powder samples. This analysis was carried out by a NOVA 1200e (Quantachrome) porosimeter. The mineralogical analyses were performed by X-ray diffraction (XRD) with PANalytical $X$ 'Pert PRO apparatus using CuK $\alpha$ radiation $(\lambda=0.154 \mathrm{~nm})$. The SEM-EDS analysis was performed by a $20 \mathrm{kV}$ Philips XL30 CP microscope. 
$124 \quad 10^{\mathrm{TH}}$ InTERNATIONAL CONFERENCE ON SUSTAINABLE ENERGY AND ENVIRONMENTAL Protection (June $27^{\mathrm{TH}}-30^{\mathrm{TH}}, 2017$, BLed, SLOVENiA), Bioenergy AND Biofuels

F. Ferella, K. Gallucci \& P. Ugo Foscolo: Upgrading of Biogas to Biomethane: Experimental and Process Analysis Applied to an Industrial Plant

Table 1. List of tested materials

\begin{tabular}{|c|c|c|c|c|}
\hline Test & Sample & $\begin{array}{l}\text { Synthesis } \\
\text { method }\end{array}$ & $\begin{array}{c}\text { Pressure } \\
\text { (barg) }\end{array}$ & Notes \\
\hline 1 & Blank & - & $2-4-5-6$ & - \\
\hline 2 & A1 & A & $2-4-5-6$ & - \\
\hline 3 & A2 & A & $2-4-5-6$ & $\begin{array}{l}\text { Without } \mathrm{HNO}_{3} \\
\text { washing } \\
\text { (started from } \\
\text { point (4)) }\end{array}$ \\
\hline 4 & A3 & A & $2-4-5-6$ & $\begin{array}{ll}\text { Addition } & \text { of } \\
1 \% \text { wt* } & \text { of } \\
\text { pulverized } & \\
\text { activated } & \\
\text { carbon } & \\
\end{array}$ \\
\hline 5 & A4 & A & $2-4-5-6$ & $\begin{array}{l}\text { With } 1.0 \mathrm{~g} \\
\mathrm{NaOH} / \mathrm{g} \\
\text { ash in point }(4) \\
\end{array}$ \\
\hline 6 & $\mathrm{~B} 1$ & $\mathrm{~B}$ & $2-4-5-6$ & - \\
\hline 7 & B2 & B & $2-4-5-6$ & $\begin{array}{l}\text { Without } \mathrm{HNO}_{3} \\
\text { washing } \\
\text { (started from } \\
\text { point (4)) }\end{array}$ \\
\hline 8 & $\begin{array}{l}\text { Silica } \\
\text { gel }\end{array}$ & Commercial & $2-4-5-6$ & - \\
\hline 9 & GAC & Commercial & $2-4-5-6$ & - \\
\hline 10 & $\begin{array}{c}\text { Zeolite } \\
13 X\end{array}$ & Commercial & $2-4-5-6$ & - \\
\hline 11 & A1 & - & 6 & 5 cycles \\
\hline 12 & A2 & - & 6 & 5 cycles \\
\hline 13 & B2 & - & 6 & 5 cycles \\
\hline
\end{tabular}

\subsection{Adsorption tests}

Continuous dynamic tests have been performed in order to evaluate the sorption capacity under industrial relevant conditions, in particular using a synthetic biogas $\mathrm{CH}_{4} / \mathrm{CO}_{2}$ with composition of approximately 53/47\%vol. The detailed experimental apparatus and procedure for conducting the adsorption tests are described in [15]. The best samples, i.e. $\mathrm{A} 1, \mathrm{~A} 2$ and $\mathrm{B} 2$ underwent cyclic tests with $\mathrm{CO}_{2} / \mathrm{CH}_{4}$ mixture at 6 barg and room temperature. Cyclic tests were carried in order to determine if any hysteresis occurs with a resulting decrease in the adsorbing capacity of zeolites. The mathematical model proposed in this work to determine the amount of the adsorbed $\mathrm{CO}_{2}$ is a first-order model with dead time flow distribution [16]. $\mathrm{CO}_{2}$ is the recovered gas during desorption, 
whereas $\mathrm{CH}_{4}$ is the purified gas recovered during the adsorption phase. Recovery and purity are calculated as follows:

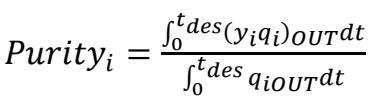

where $y_{i}$ is the concentration of the specific gas (\%vol), $q_{i}$ is the total gas flow measured by the mass flow meter MFM ( $\mathrm{mL} / \mathrm{min})$ and $t$ is time. Purity of each gas component is defined by its own quantity at the outlet during the materials saturation period divided by the total quantity of the gas at the outlet for the same period. The gas recovery rate is defined by the ratio of the quantity of gas recovered at the outlet over the quantity introduced:

Recovery $y_{i}=\frac{\int_{0}^{t} \operatorname{des}\left(y_{i} q_{i}\right)_{\text {oUT }} d t}{\int_{0}^{t} \operatorname{des}\left(y_{i} q_{i}\right)_{I N} d t}$

where $y_{i}$ is the concentration of the specific gas (\%vol), $q_{i}$ is the total gas flow measured by the mass flow meter MFM ( $\mathrm{mL} / \mathrm{min})$ and $t$ is time.

\section{$3 \quad$ Results \& Discussion}

\subsection{Characterization of zeolites}

From XRF analysis, it can be inferred that there is no significant difference between original and washed fly ash samples, except for a small decrease in $\mathrm{Al}, \mathrm{Si}$ and $\mathrm{Fe}$ concentration that were leached by the strong nitric acid solution. From BET analysis, it was found that the washed fly ash has a superficial area of $0.886 \mathrm{~m}^{2} / \mathrm{g}$ instead of 0.480 $\mathrm{m}^{2} / \mathrm{g}$ measured in the original one. Hence, the surface is partially vitrified. Regarding XRD analysis, the main crystalline phases found in the original and washed fly ash samples were mullite and silica. The Sauter's diameter D[3,2] of the original and washed fly ash was 95.6 and $87.0 \mu \mathrm{m}$, respectively. XRD spectra of the zeolites are shown in Fig. 1 , where the spectrum of the commercial zeolite $13 \mathrm{X}$ is also reported. $13 \mathrm{X}$ is taken as reference since is a very efficient molecular sieve for $\mathrm{CO}_{2}$ capture. As it can be inferred from such spectra, a full synthesis into zeolite $13 \mathrm{X}$ was never achieved; nevertheless, a very good synthesis was obtained in sample $\mathrm{A} 1, \mathrm{~A} 2$ and $\mathrm{A} 3$ where the $13 \mathrm{X}$ phase was the prevalent crystalline structure, followed by $4 \mathrm{~A}$ phase. The Reference Intensity Ratio (RIR) method gave the following relative concentrations for 13X/4A phases: 83/17\%wt in sample A1, 84/16\% in sample A2 and $87 / 13 \%$ in sample A3. Zeolite 4A is another type of small pore zeolite that is largely applied for purification of gases like air, nitrogen, methane, natural gas and hydrogen as well as removal of $\mathrm{CO}_{2}$. 
$10^{\mathrm{TH}}$ InTERNATIONAL CONFERENCE ON Sustainable ENERGy AND ENVIRONMENTAL Protection (June $27^{\mathrm{TH}}-30^{\mathrm{TH}}, 2017$, BLed, Slovenia), Bioenergy AND Biofuels

F. Ferella, K. Gallucci \& P. Ugo Foscolo: Upgrading of Biogas to Biomethane: Experimental and Process Analysis Applied to an Industrial Plant

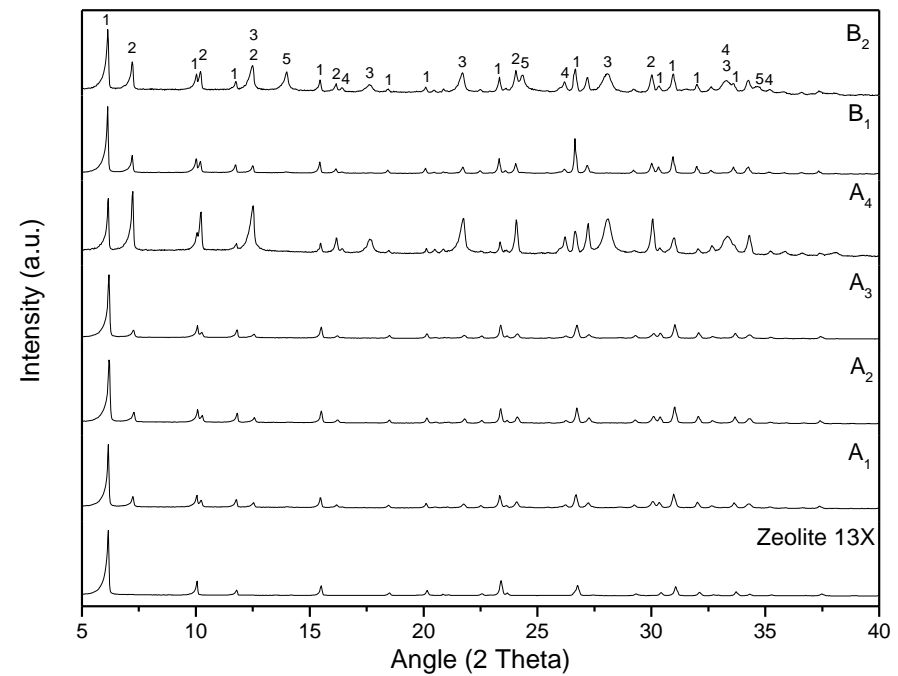

Figure 1. XRD patterns of zeolites. (Legend: 1-Zeolite 13X; 2-Zeolite 4A; 3-Zeolite P1; 4-Mullite; 5-Sodalite).

The greatest BET surface areas were achieved in sample A1, A2 and A3 (255, 329, 315 $\mathrm{m}^{2} / \mathrm{g}$, respectively). In all the SEM pictures octahedral crystals can be easily detected: this is the typical octahedral crystal structure of Na-faujasite zeolites like 13X. Moreover, cubic crystals can also be recognized: this is the typical morphology of zeolite A particles (Fig. 2). A needle-shaped crystalline structure is also present: such crystals belong to mullite and are acicular particles not converted during the hydrothermal process.
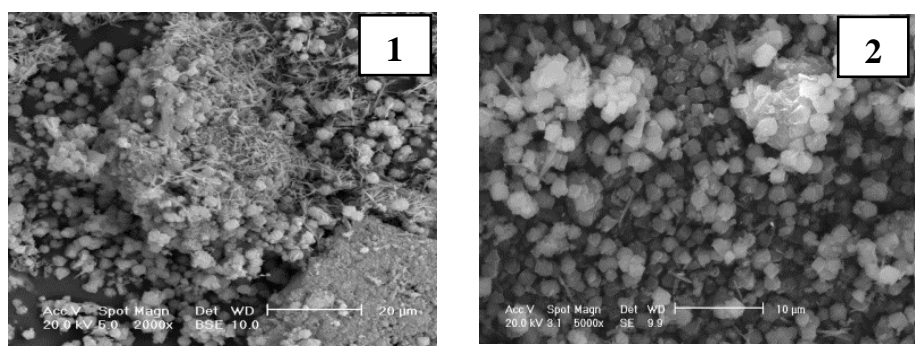

Figure 2. SEM images of zeolites A2 (1) and B1 (2).

\subsection{Adsorption tests}

All the results obtained in $\mathrm{CO}_{2}$ adsorption tests are shown in detail in [15]. Among all zeolites from fly ash, the best sample was A2, that showed the best recovery rates and purities of $\mathrm{CO}_{2}$ and $\mathrm{CH}_{4}$. Table 2 lists some of the aforementioned results. 
$10^{\mathrm{TH}}$ INTERNATIONAL CONFERENCE ON SUSTAINABLE ENERGY AND ENVIRONMENTAL Protection (June $27^{\mathrm{TH}}-30^{\mathrm{TH}}, 2017$, BLed, Slovenia), Bioenergy AND Biofuels F. Ferella, K. Gallucci \& P. Ugo Foscolo: Upgrading of Biogas to Biomethane: Experimental and Process Analysis Applied to an Industrial Plant

Table 2. Results of A2 adsorption tests

\begin{tabular}{|c|c|c|c|c|c|}
\hline & Pressure & 2 barg & 4 barg & 5 barg & 6 barg \\
\hline (m) & $\begin{array}{l}\mathrm{CO}_{2} \\
\mathrm{CO}_{2} / \mathrm{kg} \text { ads) }\end{array}$ & 0.191 & 0.294 & 0.334 & 0.371 \\
\hline$(\mathrm{m}$ & $\begin{array}{l}\mathrm{2}^{2} \mathrm{CH}_{4} \\
\mathrm{CH}_{4} / \mathrm{kg} \text { ads) }\end{array}$ & 0.000 & 0.032 & 0.052 & 0.058 \\
\hline & lectivity & - & 9.21 & 6.62 & 6.40 \\
\hline $\mathrm{CO}$ & $\begin{array}{l}\text { Purity } \\
\text { (\%vol) }\end{array}$ & 99.6 & 79.1 & 76.9 & 75.6 \\
\hline $\mathrm{CU}_{2}$ & $\begin{array}{l}\text { Recovery } \\
(\%)\end{array}$ & 98.1 & 97.9 & 98.3 & 98.0 \\
\hline $\mathrm{CH}$ & $\begin{array}{l}\text { Purity } \\
(\% \text { vol })\end{array}$ & 98.0 & 96.9 & 97.4 & 96.9 \\
\hline$C 114$ & $\begin{array}{l}\text { Recovery } \\
(\%)\end{array}$ & 95.2 & 66.9 & 63.5 & 60.8 \\
\hline
\end{tabular}

As an example, the adsorption curves of $\mathrm{CH}_{4}$ and $\mathrm{CO}_{2}$ as a function of time at 6 barg are shown in Fig. 3.

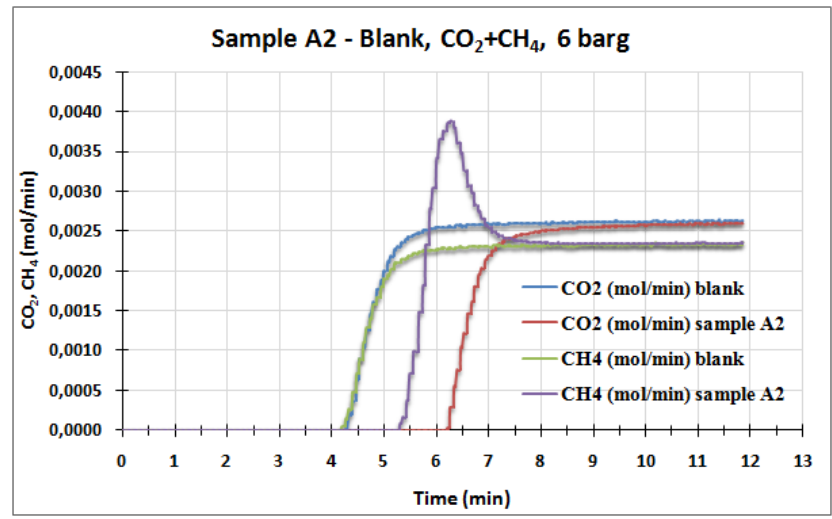

Figure 3. Adsorption curves of sample A2

The higher the pressure, the greater the delay in releasing the gas mixture, since the gas is obviously hold inside the reactor to keep the pressure constant and only $50 \mathrm{~mL} / \mathrm{min}$ are released by the pressure controller downstream the reactor. In fact, this effect takes also place with the blank sample, that obviously does not adsorb neither $\mathrm{CO}_{2}$ nor $\mathrm{CH}_{4}$. Regarding $\mathrm{CO}_{2}$, a sigmoid-shaped pathway was observed for each sample at all the pressure levels. Instead, the behaviour of $\mathrm{CH}_{4}$ (violet curve, Fig. 3) was very different due to the fact that when the $\mathrm{CO}_{2}$ is adsorbed, the $\mathrm{CH}_{4}$ concentration, and thus its flowrate, automatically increases, starting decreasing to its set-up concentration once the bed is exhaust, i.e. when the concentration of $\mathrm{CO}_{2}$ rises to the set point. The results, in terms of $\mathrm{CO}_{2}$ adsorption per unit of sorbent are lower than those obtained from other authors, 
$10^{\mathrm{TH}}$ InTERNATIONAL CONFERENCE ON Sustainable ENERGY AND ENVIRONMENTAL Protection (June $27^{\mathrm{TH}}-30^{\mathrm{TH}}, 2017$, BLed, Slovenia), Bioenergy AND Biofuels

F. Ferella, K. Gallucci \& P. Ugo Foscolo: Upgrading of Biogas to Biomethane: Experimental and Process Analysis Applied to an Industrial Plant

both with single gases, $\mathrm{CO}_{2} / \mathrm{N}_{2}$ and $\mathrm{CO}_{2} / \mathrm{CH}_{4}$ mixtures [2,12]. The main reason is that our investigation was based on a continuous dynamic study and the equilibrium batch results cannot be compared; moreover, regarding synthesized zeolites, a full conversion to zeolite $13 \mathrm{X}$ was never obtained, so that other crystalline phases were not, or partially, active in the adsorption process, resulting in a further reduction of the amount adsorbed. Regarding $\mathrm{CO}_{2}$, its recovery and purity has to be evaluated during the regeneration phase, when the pressure is suddenly decreased to the atmospheric value. Considering the setup of the experimental system used in this research, such measurement was not possible. Hence, $\mathrm{CO}_{2}$ recovery was computed indirectly using the total amount of $\mathrm{CO}_{2}$ adsorbed, and thus released ideally during the desorption, compared to the total amount entered the reactor. As regards $\mathrm{CO}_{2}$ purity, it was calculated taking into account the small amount of $\mathrm{CH}_{4}$ adsorbed in the bed, determined as difference between the total amount of $\mathrm{CH}_{4}$ entered the reactor and the amount of the same gas actually released from the bed during the adsorption of $\mathrm{CO}_{2}$. Zeolite A2 gave the lowest amount of $\mathrm{CH}_{4}$ adsorbed, that obviously resulted in the best selectivity. Selectivity of a sample to $\mathrm{CO}_{2}$ can be expressed as:

Selectivity $=\frac{\mathrm{mol}_{\mathrm{CO}_{2}} / \mathrm{kg}_{\text {sample }}}{\mathrm{mol}_{\mathrm{CH}_{4}} / \mathrm{kg}_{\text {sample }}}$

\subsection{Cyclic tests}

Samples A1, A2 and B2 underwent cyclic tests with $\mathrm{CH}_{4} / \mathrm{CO}_{2}$ mixture at 6 barg. Fig. 4 shows the results for sample A2. Some sort of material degradation occurred from the second cycle forward. In fact, the greatest adsorption capacity of $\mathrm{CO}_{2}$ and $\mathrm{CH}_{4}$ took place in the first cycle, although such decrease was $13 \%$ only. Purity and recovery rate of both $\mathrm{CH}_{4}$ and $\mathrm{CO}_{2}$ were constant in each cycle. After the tests, it seems that the surface area increased: such effect can be attributed to the pressure of 6 barg that could have broken small particles.

\section{Techno-Economic Analysis}

A techno-economic analysis was developed with the best zeolite sample, i.e. A2, taking into consideration the investment for the $\mathrm{CO}_{2}$ capture plant, its operating cost and green incentives provided for biomethane to use as transportation fuel or injected in the distribution network. 
$10^{\mathrm{TH}}$ INTERNATIONAL CONFERENCE ON SUSTAINABLE ENERGY AND ENVIRONMENTAL Protection (June $27^{\mathrm{TH}}-30^{\mathrm{TH}}, 2017$, BLed, Slovenia), Bioenergy ANd Biofuels

F. Ferella, K. Gallucci \& P. Ugo Foscolo: Upgrading of Biogas to Biomethane: Experimental and Process Analysis Applied to an Industrial Plant

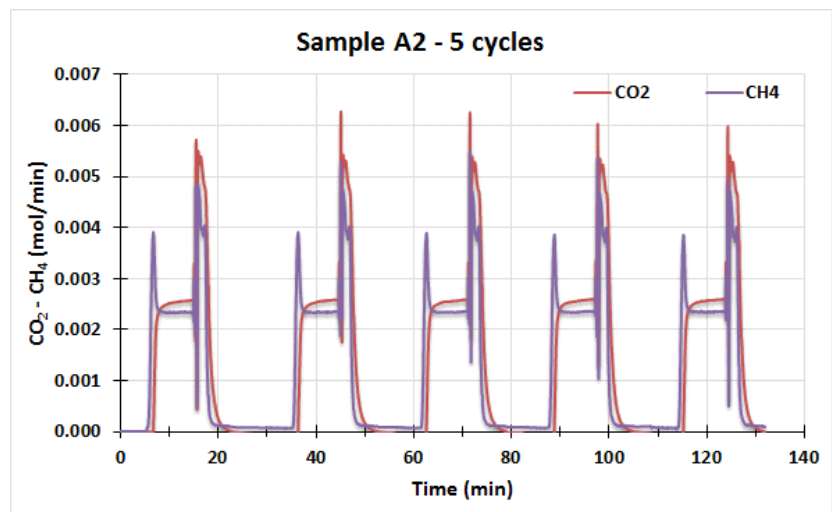

Figure 4. A2 adsorption-desorption curves

The aim is to understand if the use of such zeolite in PSA can be profitable to ThinkEco Agri s.r.l. as an alternative PSA method to separate $\mathrm{CO}_{2}$ from biogas and produce biomethane. For such purpose, the minimum biomethane grade must be $\geq 95 \%$ vol, with $\mathrm{CO}_{2}$ concentration not greater than $3 \%$ vol.

Zeolite A2 expressed its best performance at $2 \mathrm{barg}$, when it adsorbed $0.191 \mathrm{~mol} \mathrm{CO}_{2} / \mathrm{kg}$ zeolite, whereas $\mathrm{CH}_{4}$ adsorbed at the same time was negligible. This also results in a cheaper compressor and lower operating costs for compression work. It is easy to reckon that at higher pressure the specific adsorption of $\mathrm{CO}_{2}$ increases, i.e. $\mathrm{mol} \mathrm{CO}_{2} / \mathrm{kg}$ zeolite. Instead, recovery of methane with a fixed purity will be lower, since it is simultaneously adsorbed together with $\mathrm{CO}_{2}$ : the latter, in the same manner, would be contaminated by $\mathrm{CH}_{4}$ in case one would reuse it for commercial purposes. Once stripped, such high-grade $\mathrm{CO}_{2}(>99 \%$ vol) has a wide market (beverage, fire extinguishers, raw material in chemical industry, refrigeration, metal inert gas welding, etc..), so that it represents an additional revenue of the plant. The biogas flow-rate of the ThinkEco's plant is $11500 \mathrm{~m}^{3} /$ day, with a $\mathrm{CH}_{4} / \mathrm{CO}_{2}$ ratio of $53 / 46 \%$ vol and impurities like $\mathrm{H}_{2} \mathrm{~S}(150 \mathrm{ppm}), \mathrm{N}_{2}(<1 \%), \mathrm{O}_{2}$ $(>0.6 \% \mathrm{vol})$. In this plant, the biomethane grade was set at $98 \% \mathrm{vol}$, so that $\mathrm{CO}_{2}$ is $<3 \% \mathrm{vol}$. When the biomethane grade decreases below $98 \%$, the control system automatically switches the flow-rate to another column, and the first one undergoes regeneration by decreasing the pressure to 1 bar or lower values.

The plant is composed of one biogas compressor (one spare), four columns, one vacuum pump for the regeneration phase, a chiller and one heat exchanger to cool biogas to $20^{\circ} \mathrm{C}$. Moreover, there are other devices like one methane spherical storage tank and one compressor (one spare) to pressurize it to $6 \mathrm{bar}$, one horizontal buffer tank for storage of $\mathrm{CO}_{2}$ during regeneration and one insulated tank to store liquid $\mathrm{CO}_{2}$ at 20 bar and $-25^{\circ} \mathrm{C}$. Hence, there is a small liquefaction plant with a multistage compressor and an ammonia chiller. Another water chiller is used for intercooling of the compressor. $\mathrm{CO}_{2}$ is also dehydrated by a water separator and a desiccant column. 
The switching time of each column was set at $15 \mathrm{~min}$. Four columns were provided in order to have a good flexibility of the system. The dimensions of each carbon steel column are $\mathrm{D}=1.8 \mathrm{~m}$ and $\mathrm{H}=7 \mathrm{~m}$, with a net zeolite bed height and volume of $6 \mathrm{~m}$ and $15.2 \mathrm{~m}^{3}$, respectively. The total equipment purchase cost (TEPC) is estimated to be around 1.74 M€, including small and auxiliary equipment like valves, pumps etc.. Considering all the other items (installation, piping, instrumentation/automation, insulation, electricals, buildings and equipment foundations, yard improvement, engineering and construction) the direct fixed capital (DFC) invested is $2,658,617 €$. Regarding raw materials, zeolite was calculated to be 12.5 tonnes/column (zeolite adsorption capacity of $8.4 \mathrm{~g} \mathrm{CO}_{2} / \mathrm{kg}$ zeolite), and under the hypothesis of one replacement per year the total amount required is 50 tonnes/year. The purchase cost of such zeolite was set at $800 € /$ tonne. Obviously, the production cost of biogas has to be considered as it takes into account the investment and all the operating costs of the biogas plant upstream the $\mathrm{CO}_{2}$ capture section: this cost is equal to $0.39 € / \mathrm{m}^{3}$. There are two main revenues from the plant: selling of biomethane with the relevant market price and green incentives, and selling of food-grade $\mathrm{CO}_{2}$, according to the food-gas directive 96/77/EC. $\mathrm{CO}_{2}$ selling price is $300 € /$ tonne. Its overall recovery was estimated to be $97 \%$ wt with respect to the amount contained in the biogas $(46 \% \mathrm{vol})$. The overall recovery of biomethane was set at $95 \%$ as a percentage of the amount contained in the biogas. The market selling price of biomethane is $0.80 € / \mathrm{Nm}^{3}$. Green incentives are calculated according to the guidelines provided by the Italian regulation DM 5/12/2013 [17]: one green certificate corresponds to $5 \mathrm{Gcal}(20.9 \mathrm{GJ})$ put into the national energy market, with a relevant price of $296.15 \mathrm{E} /$ certificate. Hence, the revenue from biomethane is $1,690,753 € /$ year plus $1,046,097 € /$ year as green incentives, whereas the revenue from $\mathrm{CO}_{2}$ is $1,056,329 € /$ year. Depreciation is equal to $265,862 € /$ year, considering a depreciation period of 10 years. Annual operating costs include raw materials, labourdependent, facility- dependent, laboratory, R\&D and analyses, consumables, waste and wastewater treatment/disposal, utilities, ordinary maintenance, insurances, licences, royalties and miscellaneous. Other hypotheses are project lifetime 20 years (duration of green incentives), interest rate 5\%, continuous operating mode of the plant. Table 3 lists all the economic items involved in the investment. Net present value (NPV) is 5,338,229 $€(7 \%$ interest rate) and the internal return rate (IRR) is $22.3 \%$. 
$10^{\mathrm{TH}}$ INTERNATIONAL CONFERENCE ON SUSTAINABLE ENERGY AND ENVIRONMENTAL Protection (June $27^{\mathrm{TH}}-30^{\mathrm{TH}}, 2017$, BLed, Slovenia), Bioenergy ANd Biofuels

F. Ferella, K. Gallucci \& P. Ugo Foscolo: Upgrading of Biogas to Biomethane: Experimental and Process Analysis Applied to an Industrial Plant

Table 3. EER of the $\mathrm{CO}_{2}$ capture plant

\begin{tabular}{|l|r|}
\hline Item & \multicolumn{1}{|c|}{ Value } \\
\hline Direct Fixed Capital & $2,658,617 €$ \\
\hline Working Capital & $1,900,475 €$ \\
\hline Start-up cost & $10,000 €$ \\
\hline Up-front R\&D & $10,000 €$ \\
\hline Up-front royalties & $-€$ \\
\hline Total investment & $4,579,092 €$ \\
\hline Revenues & $3,793,180 € / \mathrm{y}$ \\
\hline Annual operating cost & $2,174,171 € / \mathrm{y}$ \\
\hline Gross profit & $1,619,009 € / \mathrm{y}$ \\
\hline Taxes (40\%) & $647,603 € / \mathrm{y}$ \\
\hline Net profit & $971,405 € / \mathrm{y}$ \\
\hline Gross margin & $42.7 \%$ \\
\hline Return on investment & $21.2 \%$ \\
\hline Payback time & $4.7 \quad$ years \\
\hline NPV (7\%) & $5,338,229 €$ \\
\hline IRR & $22.3 \%$ \\
\hline
\end{tabular}

Fig. 5 shows the cash flows of the investment. From the profitability analysis it is inferred that the upgrading of biogas to biomethane is a very interesting investment, as biomethane is currently strongly subsidized in Italy. Nevertheless, from the $1^{\text {st }}$ to the $10^{\text {th }}$ year, the subsidy is increased by 50\%. Moreover, PSA with zeolite also leads to recovery of foodgrade $\mathrm{CO}_{2}$ that is valorised as an additional revenue, i.e. as by-product, of the capture plant.

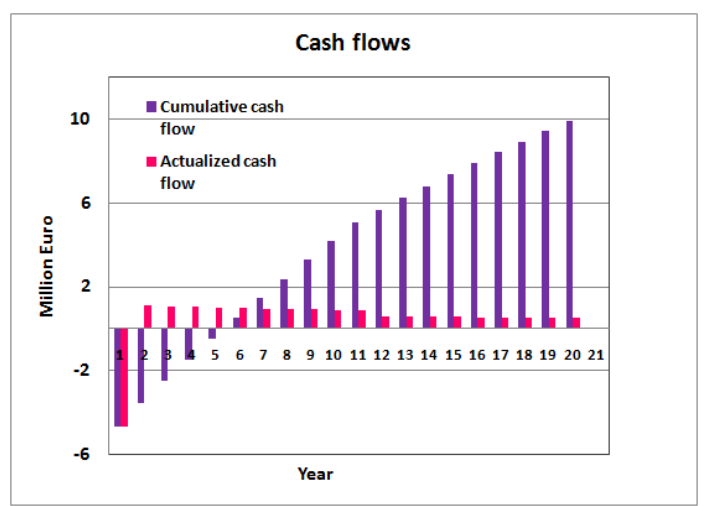

Figure 5. Cash flows of the capture plant 
132 10 $10^{\mathrm{TH}}$ InTERNATIONAL CONFERENCE ON Sustainable ENERGY AND ENVIRONMENTAL Protection (June $27^{\mathrm{TH}}-30^{\mathrm{TH}}, 2017$, BLed, SLOVENia), Bioenergy AND Biofuels

F. Ferella, K. Gallucci \& P. Ugo Foscolo: Upgrading of Biogas to Biomethane:

Experimental and Process Analysis Applied to an Industrial Plant

\section{$5 \quad$ Conclusions}

PSA tests were carried out by zeolites produced from fly ash and commercial materials like zeolite $13 \mathrm{X}$, activated carbon and silica gel. Two different hydrothermal syntheses were applied. Synthesis procedure A was more efficient in conversion of fly ash into zeolite $13 \mathrm{X}$ molecular sieve. The best results were achieved at 2 barg with zeolite sample A2: $98.1 \%$ of the incoming $\mathrm{CO}_{2}$ in the biogas mixture was recovered with a grade of 99.6\% vol: at the same time, $95.2 \%$ of $\mathrm{CH}_{4}$ was separated with a purity of $98 \%$ vol, suitable to be injected in the distribution network or, alternatively, used as transportation fuel. Zeolite A2 was produced without preliminary washing of fly ash by nitric acid: this is an additional advantage since lowers the operating costs of the synthesis process. Moreover, treatment of an acid waste stream is avoided. The three best zeolites (A1, A2 and B2) underwent five adsorption-desorption cycles that demonstrated that no loss of capture yield occurred, so that the zeolites can be regenerated with a simple depressurization to ambient pressure. A profitability study demonstrated that the upgrading of a $1 \mathrm{ME}_{\mathrm{el}}$ biogas plant with a $\mathrm{CO}_{2}$ capture plant by PSA based on zeolite synthesized from fly ash is a very good investment, considering the green incentive provided for biomethane and selling of food-grade $\mathrm{CO}_{2}$. The gross margin would be $42.7 \%$, ROI $21.2 \%$, IRR $22.3 \%$ with a payback time of 4.7 years. Additional work is needed to test the best zeolites produced in this research activity by using real biogas, in order to understand whether and how the performance of such sorbents is affected by impurities like $\mathrm{H}_{2} \mathrm{O}, \mathrm{H}_{2} \mathrm{~S}$ and possible minor compounds. Afterwards, more reliable data would be available to refine the profitability study and go on with the construction of a pilot and thus a full-scale plant

\section{Acknowledgements}

Authors would like to thank ThinkEco Agri s.r.l. and Abruzzo Region that has funded the present research in the ambit of the ReBios project.

\section{References}

[1] D. Deublein and A. Steinhauser,Biogas from Waste and Renewable Resources: An Introduction. Weinheim: Wiley VCH, 2010.

[2] S. Cavenati, C.A. Grande and A.E. Rodrigues, "Adsorption equilibrium of methane, carbon dioxide, and nitrogen on zeolite $13 \mathrm{X}$ at high pressures",J. Chem. Eng. Data, vol. 49, pp. 1095-1101, 2004.

[3] S. Cavenati, C.A. Grande and A.E. Rodrigues, "Separation of $\mathrm{CH}_{4} / \mathrm{CO}_{2} / \mathrm{N}_{2}$ mixtures by layered pressure swing adsorption for upgrade of natural gas", Chem. Eng. J., vol. 118, pp. 3893-3906, 2006.

[4] C.F. Wang, J.S. Li, L.J. Wang and X.Y. Sun, "Influence of $\mathrm{NaOH}$ concentrations on synthesis of pure-form zeolite A from fly ash using two-stage method", J. Hazard. Mater., vol. 155 , pp. 58-64, 2008.

[5] Z. Liang, M. Marshall and A.L. Chaffee, "Comparison of Cu-BTC and zeolite 13X for adsorbent based CO2 separation", Energy Procedia, vol. 1, pp.1265-1271, 2009. 
[6] A. Alonso-Vicario, J.R. Ochoa-Gómez, S. Gil-Río, O.G. Jiménez-Aberasturi, C.A. Ramírez-López, J. Torrecilla-Soria and A. Domínguez, "Purification and upgrading of biogas by pressure swing adsorption on synthetic and natural zeolites", Microporous Mesoporous Mater., vol. 134, pp. 100-107, 2010.

[7] T. Montanari, E. Finocchio, E. Salvatore, G. Garuti, A. Giordano, C. Pistarino and G. Busca, " $\mathrm{CO}_{2}$ separation and landfill biogas upgrading: A comparison of $4 \mathrm{~A}$ and $13 \mathrm{X}$ zeolite adsorbents", Energy, vol. 36, pp. 314-319, 2011.

[8] O. Babajide, N. Musyoka, L. Petrik and F. Ameer, "Novel zeolite Na-X synthesized from fly ash as a heterogeneous catalyst in biodiesel production", Catal. Today, vol. 190, pp. 5460, 2012.

[9] J.E. Park, H.K. Youn, S.T. Yang and W.S. Ahn, "CO capture and MWCNTs synthesis using mesoporous silica and zeolite $13 \mathrm{X}$ collectively prepared from bottom ash", Catal. Today, vol. 190, pp. 15-22, 2012.

[10] M. Kacem, M. Pellerano and A. Delebarre, "Pressure swing adsorption for CO2/N2 and $\mathrm{CO}_{2} / \mathrm{CH}_{4}$ separation: Comparison between activated carbons and zeolites performances", Fuel Process. Technol., vol. 138, pp. 271-283, 2015.

[11] K. Shaila, D. Nisha, P. Pralhad and P. Deepa, "Zeolite synthesis strategies from coal fly ash: A Comprehensive Review of Literature", Int. Res. J. Environ. Sci., vol.4, pp. 93-99, 2015.

[12] Y. Park, Y. Ju, D. Park and C.H. Lee, "Adsorption equilibria and kinetics of six pure gases on pelletized zeolite $13 \mathrm{X}$ up to $1.0 \mathrm{MPa}: \mathrm{CO}_{2}, \mathrm{CO}, \mathrm{N}_{2}, \mathrm{CH}_{4}, \mathrm{Ar}$ and $\mathrm{H}_{2}$ ", Chem. Eng. J., vol. 292, pp. 348-365, 2016.

[13] N. Shigemoto, H. Hayashi and K. Miyaura, "Selective formation of Na-X zeolite from coal fly ash by fusion with sodium hydroxide prior to hydrothermal reaction", J. Mater. Sci., vol. 28, pp. 4781-4786, 1993.

[14] P. Kumar, N. Mal, Y. Oumi, K. Yamana, and T. Sano, "Mesoporous materials prepared using coal fly ash as the silicon and aluminium source", J. Mater. Chem., vol. 11, pp. 32853290, 2001.

[15] F. Ferella, A. Puca, G. Taglieri, L. Rossi and K. Gallucci, "Separation of carbon dioxide for biogas upgrading to biomethane", J. Clean. Prod., submitted, 2017.

[16] L. Di Felice, P. Foscolo and L.G. Gibilaro, "CO 2 capture by dolomite particles in a gas fluidized bed: Experimental Data and Numerical Simulations", Int. J. Chem. React. Eng., vol. A55 , p. 9, 2011. 
134 10 $10^{\mathrm{TH}}$ International CONFERENCE on Sustainable EnERgy and ENVIRONMENTal Protection (June $27^{\mathrm{TH}}-30^{\mathrm{TH}}, 2017$, Bled, Slovenia), Bioenergy AND Biofuels 
$10^{\mathrm{TH}}$ InTERnational CONFERENCE ON Sustainable ENERgy AND ENVIRONMENTAL Protection (June $27^{\mathrm{TH}}-30^{\mathrm{TH}}$, 2017, Bled, SLOVENIA), BIOENERGY AND BIOFUELS

J. Krope, A.Ghani Olabi, D. Goričanec \& S. Božičnik

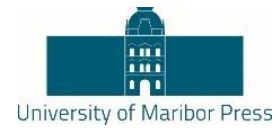

\title{
A Kinetic Study of Cassava Mash Hydrolysis in a Combination with Solid State Catalyst Mixed-Milling Reaction
}

\author{
KANPICHCHA INTARAMAS, WORANART JONGLERTJUNYA, NAVADOL LAOSIRIPOJANA \& \\ CHULARAT SAKDARONNARONG
}

\begin{abstract}
Carbonaceous solid acid catalysts have been recently studied in starch hydrolysis owing to their high catalytic activity, recyclability, ease to separate and environmental advantages. However, the solid state reaction of heterogeneous catalyst and starch molecules requires specific interaction between active sites in catalyst and $\alpha, 1-4$ glycosidic bonds in starch. Therefore, catalyst mixed-milling was conducted prior to thermal hydrolysis of cassava mash at $140^{\circ} \mathrm{C}$ for glucose production. Different kinetic models were proposed for quantitative study of mixed-milling effect on cassava mash hydrolysis to oligomers and glucose. The results showed that catalyst mixed-milling process gave highest starch conversion of $93.72 \%$ corresponding to $37.45 \%$ glucose yield and $83 \%$ selectivity at $140^{\circ} \mathrm{C}$ for $6 \mathrm{~h}$. From kinetic study, the rate constant of cassava mash-tooligomers conversion (k1) using catalyst mixed-milling was 1.77 times higher than using ball-milling while rate constants of oligomers-to-glucose conversion (k2) were not signficantly different between two approaches. This indicated that mixed-milling significantly provided complete cassava mash conversion and enhanced selectivity, hydrolysis efficiency and rate of starch depolymerization reaction.
\end{abstract}

Keywords: - Cassava mash • Carbonaceous solid acid catalyst • Ballmilling $\bullet$ Mixed-milling $\bullet$ Starch hydrolysis $\bullet$

CORRESPONDENCE ADDRESS: Kanpichcha Intaramas, M.Eng, Mahidol University, Faculty of Chemical Engineering, Nakorn Pathom 73170, Thailand, e-mail: i.kanpichcha@ hotmail.com. Woranart Jonglertjunya, Ph.D., Assistant Professor, Mahidol University, Faculty of Chemical Engineering, Nakorn Pathom 73170, Thailand, e-mail: woranart.jon@mahidol.ac.th. Navadol Laosiripojana, Ph.D., Professor, The Joint Graduate School of Energy and Environment (JGSEE), King Mongkut's University of Technology Thonburi, Tungkru, Bangkok 10140, Thailand, e-mail: navadol@jgsee.kmutt.ac.th. Chularat Sakdaronnarong, Ph.D., Assistant Professor, Mahidol University, Faculty of Chemical Engineering, Nakorn Pathom 73170, Thailand, e-mail: chularat.sak@mahidol.ac.th. 
$10^{\mathrm{TH}}$ InTERNATIONAL CONFERENCE ON Sustainable ENERGY AND ENVIRONMENTAL Protection (June $27^{\mathrm{TH}}-30^{\mathrm{TH}}, 2017$, BLed, Slovenia), Bioenergy AND Biofuels

K. Intaramas, W. Jonglertjunya, N. Laosiripojana \& C. Sakdaronnarong: A Kinetic Study of Cassava Mash Hydrolysis in a Combination with Solid State Catalyst MixedMilling Reaction

\section{Introduction}

Cassava is one of the most plentiful carbohydrate resources suitable for biofuel production in Asia Pacific region, especially in Thailand. Apart from its high availability, it is cheap and has well established supply chain and logistic management for industrialization [1]. Typical mature cassava roots are composed of two main parts, peel and parenchyma. Peel consists mostly of lignocellulose while parenchyma contains high amount of starch component and small amount of cellulose known as fibers. Both parts of cassava usually consist of glucose repeating units connected through $\alpha-1,4$ and $\beta-1,4$ glycosidic linkages for starch and cellulose, respectively. Thus, cassava roots are considered to be inexhaustible raw material for sustainable production of chemicals and fuels via sugar platform [2]. To produce ethanol from cassava root, liquefaction and saccharification prior to fermentation are required. Overall process efficiency of ethanol production from cassava could be enhanced by several approaches e.g. shorten the process duration, reduce energy utilization, chemical costs, and reduce wastewater treatment cost, etc. Although mineral acids and enzyme are most common used catalysts for the hydrolysis reaction of polysaccharides but mineral acid catalytic reaction possess a series of problems such as reactor corrosion, wastewater treatment, and poor recyclability. Enzyme catalytic reaction although achieves high selectivity but low process reliability as the cost of enzyme depends solely on companies having genetic engineering knowhow. Apart from that, low process efficiency was obtained as long reaction time for more than two days is needed [2]. To solve the mentioned troubles, recent development of starch hydrolysis catalysed by heterogeneous catalysts has been widely investigated. Yabushita and coworkers [3] reported that the mixed-milling of cellulose and catalyst (K26) with alumina balls was more active than the single-milling of cellulose. From mixed-milling pretreatment and subsequent dilute hydrochloric acid hydrolysis, $98.0 \%$ cellulose conversion was achieved at $180^{\circ} \mathrm{C}$ for $20 \mathrm{~min}$. For more selective catalytic hydrolysis reaction, carbonaceous solid acid catalysts have been recently used in starch hydrolysis process owing to their high catalytic activities, recyclability, ease to separate and economic impact [4]. However, the solid-state reaction between heterogeneous catalyst having high amount of sulfonic acid groups in the chemical structure and starch molecules requires specific interaction between active sites in catalyst and $\alpha, 1-4$ glycosidic bonds in starch. To enhance the possible contact between substrate and catalyst that leads to an increased catalytic conversion, the effect of mixedmilling process was used to investigate in pre-hydrolysis step of cassava mash in glucose production for biorefinery process. Kinetic models to predict the rate of reaction were also investigated. 
$10^{\mathrm{TH}}$ INTERNATIONAL CONFERENCE ON SUSTAINABLE ENERGY AND ENVIRONMENTAL Protection (June $27^{\mathrm{TH}}-30^{\mathrm{TH}}, 2017$, BLed, SloveniA), Bioenergy AND Biofuels

K. Intaramas, W. Jonglertjunya, N. Laosiripojana \& C. Sakdaronnarong: A Kinetic Study of Cassava Mash Hydrolysis in a Combination with Solid State Catalyst MixedMilling Reaction

\section{Experimental}

\subsection{Chemical reagents}

Lignin (Alkali lignin, low sulfonate content), standard glucose, xylose, maltose, maltotriose and dextrins were purchased from Sigma-Aldrich. Standard formic acid and acetic acid were purchased from Ajfa Aesar and EMSURE®, respectively. Concentrated sulfuric acid was purchased from RCI Labscan Co., Ltd. Hydrochloric acid was purchased from Ajax Finechem. Cassava roots and cassava starch were contributed from Corn Products (Thailand) Co., Ltd.

\subsection{Preparation of catalysts}

Carbonaceous solid acid catalysts were synthesized using hydrochloric acid (HA) dipping and sulfonation $\left(-\mathrm{SO}_{3} \mathrm{H}\right)$ techniques represented as $\mathrm{HA}-\mathrm{X}-\mathrm{SO}_{3} \mathrm{H}$ catalyst where $\mathrm{X}$ could be $\mathrm{L}$ for lignin in the present study. For $\mathrm{HA}-\mathrm{L}-\mathrm{SO}_{3} \mathrm{H}$ catalyst, lignin was dipped in $10 \%$ $\mathrm{HCl}$, stirred for 30 minutes and subjected to filtration. Subsequently, sulfonation of $\mathrm{HCl}-$ pretreated substrate (HA-L) was performed by $98 \%$ sulfuric acid at $170^{\circ} \mathrm{C}$ for $18 \mathrm{~h}$. The obtained catalyst was sequentially rinsed using deionized water until the $\mathrm{pH}$ of washing liquid was neutral. The $\mathrm{HA}-\mathrm{L}-\mathrm{SO}_{3} \mathrm{H}$ catalyst was then re-washed with hot deionized water at $90^{\circ} \mathrm{C}$ and dried in an oven at $105^{\circ} \mathrm{C}$ overnight.

\subsection{Catalyst characterization}

To measure surface area and total pore volumn of catalyst, Brunauer-Emmett-Teller (BET) was performed by 39-point BET analysis using HK method (Quantachrome AUTOSORB 1-AG, USA). Morphology of the catalysts has been analyzed by scanning electron microscopic image analysis (SEM, Quanta $450 \mathrm{FEI}$ ) at an accelerating potential of $5 \mathrm{kv}$. The total amount and distribution of acid sites of synthesized catalyst were analyzed by ammonia-temperature programmed desorption $\left(\mathrm{NH}_{3}\right.$-TPD) using Chemisorption analyser (BEL JAPAN Inc.). X-ray photoelectron spectroscopic analysis (XPS, AXIS Ultra) was performed on microprobe with a monochromatized 75 microfocused Al X-ray source. The binding energy was calibrated by $\mathrm{C} 1 \mathrm{~s}$ as reference energy $(\mathrm{C} 1 \mathrm{~s} 284.8 \mathrm{eV})$ to characterized surface atomic concentration of catalyst.

\subsection{Ball-milling and Mixed-milling reaction}

Dry cassava root was ground to $100-150$ mesh $(10 \mathrm{~g})$ and subjected to ball-milling in 250$\mathrm{mL}$ plastic bottle containing 33\% v/v alumina balls (5 and $10 \mathrm{~mm}$ in diameter) at $170 \mathrm{rpm}$ rotor speed for $24 \mathrm{~h}$. Milling of cassava root and solid catalyst so called mixed-milling was carried out in the same condition for $10 \mathrm{~g}$ dry cassava root and $6 \mathrm{~g}$ solid catalysts [substrate/catalyst (S/C) ratio of 1.67]. The morphology of cassava root after ball and mixed-milling was analyzed by SEM. The pre-treated cassava roots were analyzed by powder X-ray diffraction (XRD; Rigaku MiniFlex, $\mathrm{Cu} \mathrm{K} \alpha$ ) at $40 \mathrm{kV}, 30 \mathrm{~mA}$ with two 
138 10 $10^{\mathrm{TH}}$ InTERNATIONAL CONFERENCE ON SUSTAINABLE ENERGY AND ENVIRONMENTAL Protection (June $27^{\mathrm{TH}}-30^{\mathrm{TH}}, 2017$, BLed, Slovenia), Bioenergy ANd Biofuels

K. Intaramas, W. Jonglertjunya, N. Laosiripojana \& C. Sakdaronnarong: A Kinetic Study of Cassava Mash Hydrolysis in a Combination with Solid State Catalyst MixedMilling Reaction

theta angle ranged between 3 and 40 degrees. Crystallinity was quantified by integrating the area under the crystalline peaks $\left(15,17,18\right.$ and $\left.23^{\circ}\right)$ where $\mathrm{I}_{\mathrm{cr}}$ and $\mathrm{I}_{\mathrm{am}}$ are the integral area of crystalline phase amorphous phase respectively.

$\%$ Crystallinity $=\frac{I_{C r}-I_{A m}}{I_{C r}} \times 100$

\section{Hydrolysis reaction of ball-milled and mixed-milled cassava root}

After milling, the thermal hydrolysis of ball-milled and mixed-milled cassava root was conducted at $140^{\circ} \mathrm{C}$ in a stainless steel reactor in the presence of deionized water. Kinetic study of thermal hydrolysis was carried out for $1 \mathrm{~g}$ of ball-milled or mixed-milled cassava root, $0.6 \mathrm{~g}$ of synthesized $\mathrm{HA}-\mathrm{L}-\mathrm{SO}_{3} \mathrm{H}$ catalyst and $10.7 \mathrm{~mL}$ of deionized water. During reaction, liquid phase was taken every 15 minutes within first $2 \mathrm{~h}$ and every $6 \mathrm{~h}$ until 12 $\mathrm{h}$ of reaction. After 12-h hydrolysis reaction, the solid phase and liquid phase were separated by vacuum filtration. Amount of unreacted cassava root was weighed to calculate the starch conversion. The amount of total reducing sugar (TRS) in liquid phase was measured using DNS method. Glucose, oligomers (maltose, maltotriose and dextrins) and by-products were analyzed by high performance liquid chromatography (HPLC) using $300 \mathrm{~mm} \times 7.8 \mathrm{~mm}$ Aminex HPX-87H Ion Exclusion Column (BioRad) at column temperature of $65^{\circ} \mathrm{C}$. Percentage of glucose yield, oligomer yield and selectivity were calculated based on dry basis of substrate weight.

Table 1 Physical and chemical properties of $\mathrm{HA}-\mathrm{L}-\mathrm{SO}_{3} \mathrm{H}$ catalyst in comparison with other studies

\begin{tabular}{|c|c|c|c|c|c|c|c|c|c|}
\hline \multirow[t]{2}{*}{ Catalyst } & \multicolumn{4}{|c|}{$\begin{array}{l}\text { Surface atomic concentration } \\
(\%)\end{array}$} & \multicolumn{2}{|c|}{$\begin{array}{c}\text { Acid sites } \\
\left.\text { densitv(mmol } \mathrm{g}^{-1}\right)\end{array}$} & \multirow{2}{*}{$\begin{array}{c}\text { Surface } \\
\text { area } \\
\left(\mathrm{m}^{2} \mathrm{~g}^{-1}\right)\end{array}$} & \multirow{2}{*}{$\begin{array}{l}\text { Total pore } \\
\text { volumn } \\
\left(\mathrm{cm}^{3} \mathrm{~g}^{-1}\right)\end{array}$} & \multirow[t]{2}{*}{ References } \\
\hline & C & o & $\mathrm{Cl}$ & $\mathbf{S}$ & Total & $-\mathrm{SO}_{3} \mathrm{H}$ & & & \\
\hline HA-L-SO ${ }_{3} \mathbf{H}$ & 76.15 & 23.30 & 0.10 & 0.45 & 17.23 & 15.53 & 7.30 & $1.69 \times 10^{-3}$ & In this work \\
\hline LC-SO3H & - & - & - & - & - & - & 7.62 & $1.85 \times 10^{-3}$ & [4] \\
\hline $\mathrm{HA}-\mathrm{CC}-\mathrm{SO}_{2} \mathrm{H}$ & 88.15 & 11.44 & 0.14 & 0.27 & - & - & - & - & [5] \\
\hline $\begin{array}{l}\text { Sulfonated- } \\
\text { cellulose catalyst }\end{array}$ & - & - & - & - & - & 1.8 & $<5$ & 0.5 & [6] \\
\hline ICS-SOHH & - & - & - & - & 12.54 & 6.97 & 1240 & 0.51 & {$[7]$} \\
\hline $\begin{array}{l}\text { Sulfonated-waste } \\
\text { vegetable }\end{array}$ & $=$ & $=$ & $=$ & $=$ & 2.04 & $=$ & 7.48 & $=$ & [8] \\
\hline
\end{tabular}

${ }^{a} \mathrm{LC}-\mathrm{SO}_{3} \mathrm{H}$ defined as lignin which was synthesized by carbonization and subsequent sulfonation by fuming sulfuric acid.

${ }^{b}$ ICS-SO $\mathrm{SO}_{3} \mathrm{H}$ defined as incomplete carbonization of starch and subsequent sulfonation process.

\section{$3 \quad$ Results and Discussion}

\subsection{Characterization of carbonaceous solid acid catalyst}

XPS analysis for surface atomic concentration of HA- $-\mathrm{LO}_{3} \mathrm{H}$ catalyst was shown in Table1. The results of catalyst analysis demonstrated that hydrochloric acid dipping 
$10^{\mathrm{TH}}$ INTERNATIONAL CONFERENCE ON SUSTAINABLE ENERGY AND ENVIRONMENTAL 139

Protection (June $27^{\mathrm{TH}}-30^{\mathrm{TH}}, 2017$, Bled, Slovenia), Bioenergy ANd Biofuels

K. Intaramas, W. Jonglertjunya, N. Laosiripojana \& C. Sakdaronnarong: A Kinetic Study of Cassava Mash Hydrolysis in a Combination with Solid State Catalyst Mixed-

Milling Reaction

process (HA) apparently increased the content of chorine atom in catalyst. When compared with synthesized catalysts from other work, amount of -Cl group on carbon carrier derived from carbonized cellulose $\left(\mathrm{HA}-\mathrm{CC}-\mathrm{SO}_{3} \mathrm{H}\right)$ was slightly higher than HA$\mathrm{L}-\mathrm{SO}_{3} \mathrm{H}$ from derived lignin in the present study [5]. This was possibly due to higher temperature of $\mathrm{HA}-\mathrm{CC}-\mathrm{SO}_{3} \mathrm{H}$ synthesis that affected the efficiency to adding the $-\mathrm{Cl}$ onto carbon support. However, HA-L-SO ${ }_{3} \mathrm{H}$ also showed higher amount of sulfur groups on catalyst surface compared with $\mathrm{HA}-\mathrm{CC}-\mathrm{SO}_{3} \mathrm{H}$ [5]. The main reason was due to different synthesized methods and structure of lignin which contains high amount of phenolic acid group. For chemical structure of lignin, the existence of $-\mathrm{OH}$ and - $\mathrm{COOH}$ groups significantly provides hydrophilic chemical structure accessible for sulfuric acid to react.

BET results of $\mathrm{HA}-\mathrm{L}-\mathrm{SO}_{3} \mathrm{H}$ in Table 1 shows a high surface area and total pore volumn of $7.30 \mathrm{~m}^{2} \mathrm{~g}^{-1}$ and $1.697 \times 10^{-3} \mathrm{~cm}^{3} \mathrm{~g}^{-1}$, respectively. An increase of pore volumn and surface area of synthesized HA-L-SO ${ }_{3} \mathrm{H}$ catalyst corresponded to SEM images as shown in Figure 2(d), 2(e) and 2(f). Similar surface area was found in a previous work [4] when

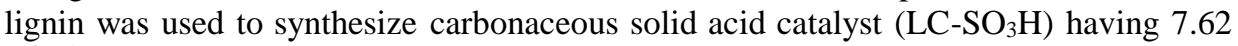
$\mathrm{m}^{2} \mathrm{~g}^{-1}$ surface area by sulfonation in fuming sulfuric acid $\left(15 \mathrm{wt} \% \mathrm{SO}_{3}\right)$ at $100^{\circ} \mathrm{C}$ for 18

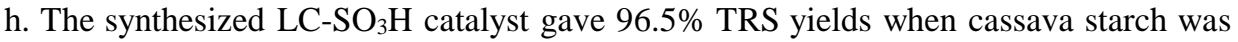
hydrolyzed at $140^{\circ} \mathrm{C}$ for $3 \mathrm{~h}$ [4]. This suggested that high surface area and pore volumn of catalyst led to more possibility to increase solid-solid contact efficiency between cassava root and catalyst to achieve high yield of glucose.

\subsection{Ball-milling, mixed-milling of cassava root and thermal hydrolysis reaction}

The predominant role on the crystallinity of cassava root after ball-milling and mixedmilling on catalytic thermal hydrolysis reaction was investigated. As shown in Figure 1, the spectrum of untreated starch and untreated cassava root samples showed a typical Atype pattern associated with four strong reflections at $2 \theta$ of about $15.28^{\circ}, 17.32^{\circ}, 18.10^{\circ}$ and $22.98^{\circ}$ that indicated crystalline regions in starch [3]. After ball-milling treatment for $24 \mathrm{~h}$, the definite diffraction peaks of sample were partially decreased, and all the diffraction peaks of mixed-milling sample almost disappeared 
$140 \quad 10^{\mathrm{TH}}$ International Conference on Sustainable ENERGy AND ENVIRONMENTAL Protection (June $27^{\mathrm{TH}}-30^{\mathrm{TH}}, 2017$, BLed, Slovenia), Bioenergy AND Biofuels

K. Intaramas, W. Jonglertjunya, N. Laosiripojana \& C. Sakdaronnarong: A Kinetic Study of Cassava Mash Hydrolysis in a Combination with Solid State Catalyst MixedMilling Reaction

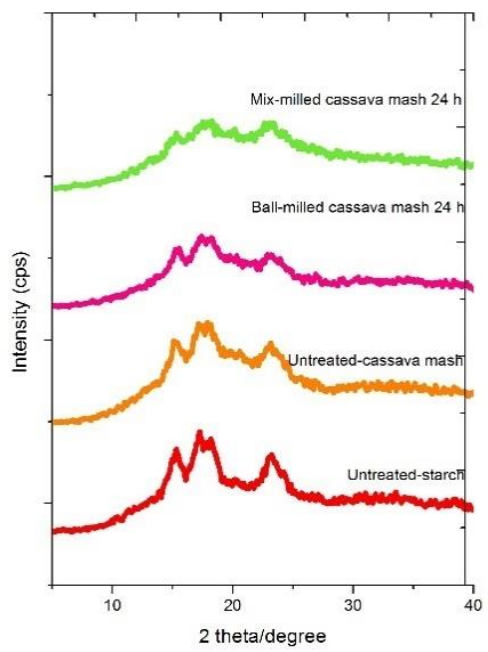

Figure 1. XRD patterns of mixed-milling of samples containing cassava mash and the solid catalysts
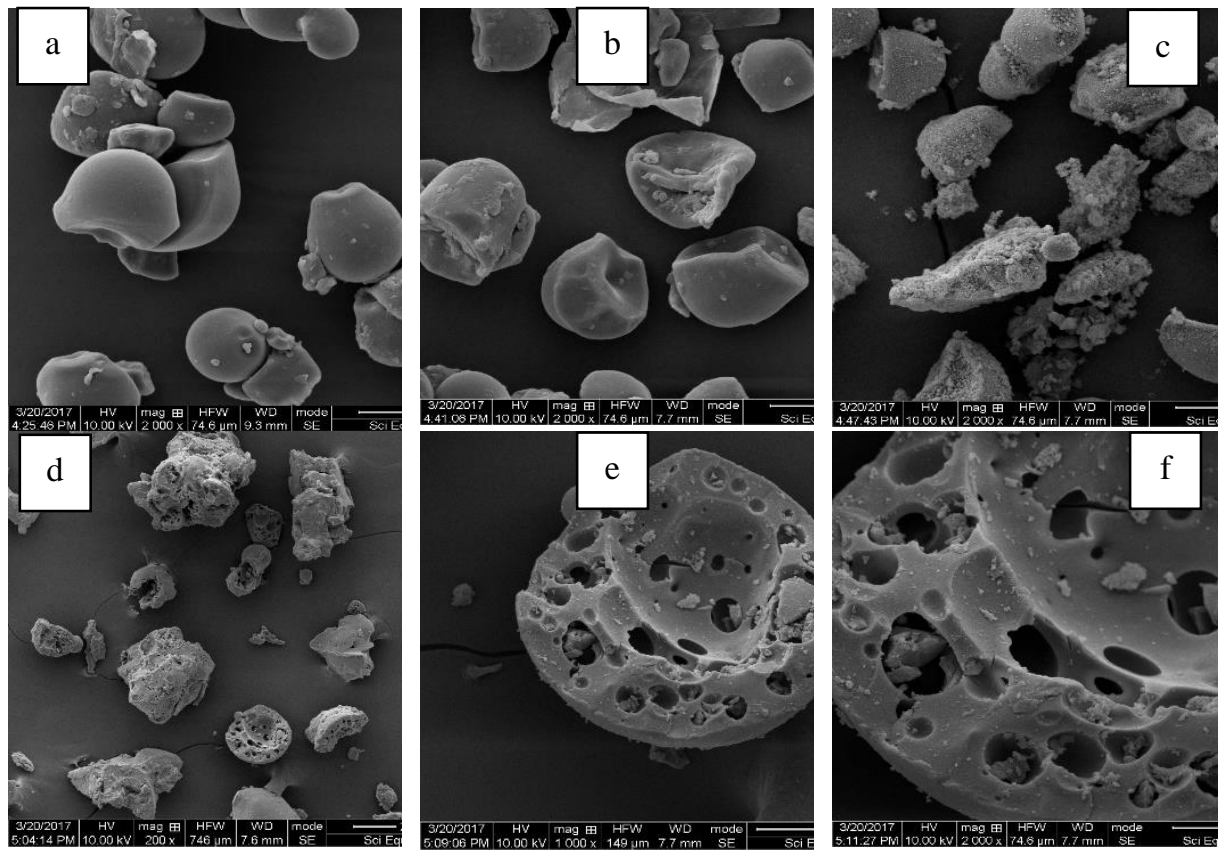

Figure2 SEM images of (a) untreated cassava root, (b) 24-h ball-milled cassava root, (c) 24-h mixed-milled sample containing cassava root and $\mathrm{HA}-\mathrm{L}-\mathrm{SO}_{3} \mathrm{H}$ catalysts, and (d) to (f) HA-L-SO ${ }_{3} \mathrm{H}$ catalyst at 200, 1000 and 2000 magnifications. 
Crystallinity of untreated starch, cassava root, ball-milling and mixed-milled cassava root were $23.59,23.20,17.85$ and $14.21 \%$, respectively. It was suggested that crystalline structure of starch was substantially destroyed and substrate becomes amorphous. This crystallinity reduction approach is a promising pre-treatment technique for promoting the hydrolysis efficiency of cassava root. From SEM image analysis (Figure 2(a)), untreated cassava granules were oval or polyhedral in shape, and have some smooth or some porous surfaces. When compared with the surface morphology of cassava root treated by ball milling and mixed-milling process as shown in Figure 2(b) and 2(c), respectively, mixed-milled starch granules were disintegrated into smaller particle sizes and become more flat shape with the catalyst coated on granular surfaces. In accordance, XRD patterns, crystallinity and SEM image analysis, it can be pointed out that mixedmilling of cassava root in the presence of $\mathrm{HA}-\mathrm{L}-\mathrm{SO}_{3} \mathrm{H}$ catalyst was apparently more effective than the ball-milling of solely cassava root for promoting subsequent thermal hydrolysis reaction. The proof of this hypothesis was confirmed by the reaction selectivity, catalytic yield and starch conversion.

\subsection{Kinetic study of mixed-milling pre-treatment of cassava root}

Kinetic study of ball-milling and mixed-milling of cassava root, and subsequent thermal hydrolysis at $140^{\circ} \mathrm{C}$ was conducted. Figure 3 (a) and 3 (b) show the product yield over time-course of the thermal depolymerization of ball-milled and mixed-milled cassava root, respectively. In the initial reaction period, remaining mixed-milled cassava root decreased while oligomers namely dextrins, maltotriose and maltose increased. The yield of oligomers was maximum at $2 \mathrm{~h}(80.66 \%)$ and then gradually decreased as oligomers were further decomposed to glucose. Production of glucose was observed in good accordance with reduction of oligomers. Thermal hydrolysis of cassava mash from mixed-milling gave $93.72 \%$ conversion with $37.45 \%$ glucose yield and $83 \%$ selectivity at $6 \mathrm{~h}$ of reaction, as shown in Table 2 . The yield of by-products from mixedmilling such as formic acid and acetic acid was less than that from ball-milling and it started to increase after $6 \mathrm{~h}$ due to further degradation of sugar as shown in Figure 2(a). In comparison, mixed-milling gave significantly higher \%conversion and glucose selectivity relative to ball-milling. 
142 10 $10^{\mathrm{TH}}$ InTERnAtional CONFERENCE ON Sustainable ENERGY AND ENVIRONMENTAL Protection (June $27^{\mathrm{TH}}-30^{\mathrm{TH}}, 2017$, BLed, Slovenia), Bioenergy AND Biofuels

K. Intaramas, W. Jonglertjunya, N. Laosiripojana \& C. Sakdaronnarong: A Kinetic Study of Cassava Mash Hydrolysis in a Combination with Solid State Catalyst MixedMilling Reaction
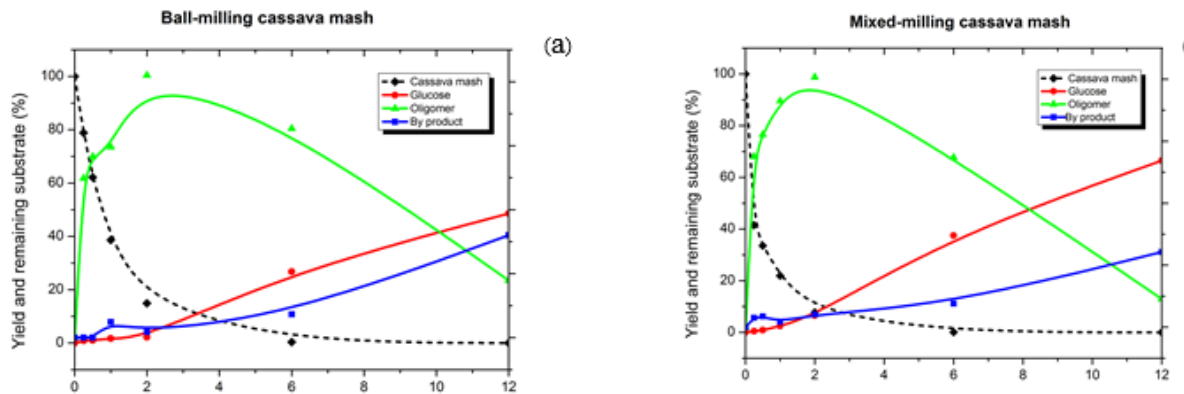

(b)
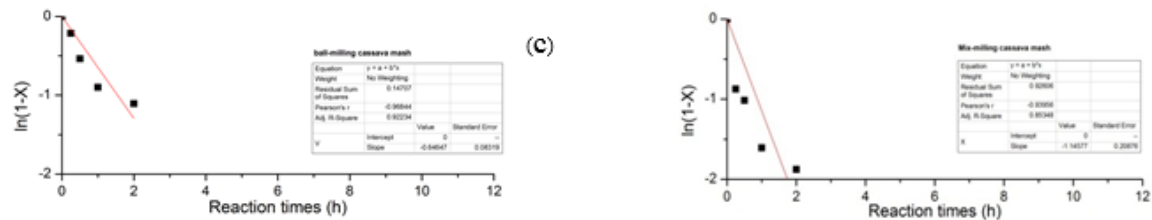

(d)

Figure 3 Yield and remaining substrate during time course of cassava mash hydrolysis at $140^{\circ} \mathrm{C}$ of (a) ball-milled and (b) mixed-milled cassava mash containing $\mathrm{HA}-\mathrm{L}-\mathrm{SO}_{3} \mathrm{H}$ catalyst, and first order kinetic reaction of cassava mash to oligomers conversion during $2 \mathrm{~h}$ using (c) ball milling and (d) catalyst mixed-milling respectively.

Starch $\stackrel{k_{1}}{\rightarrow}$ Oligomer $\stackrel{k_{2}}{\rightarrow}$ Glucose $\stackrel{k_{3}}{\rightarrow}$ By product

$\frac{d[\text { Starch }]}{d t}=-k_{1}[$ Starch $]$

$\frac{d[\text { oligomer }]}{d t}=k_{1}[$ Starch $]-k_{2}[$ Oligomer $]$

$\frac{d[\text { Glucose }]}{d t}=k_{2}[$ Oligomer $]-k_{3}[$ Glucose $]$

$\frac{d[\text { Byproduct }]}{d t}=k_{3}[$ Glucose $]$

$\ln \left(\frac{[\text { Starch }]}{[\text { Starch }]_{0}}\right)=\ln (1-X)=-k_{1} t$

$[$ Oligomer $]=[\text { Starch }]_{0} \frac{k_{1} k_{2}}{k_{1}-k_{2}}\left(e^{-k_{2} t}-e^{-k_{1} t}\right)$

$[$ Glucose $]=[\text { Starch }]_{0} \frac{k_{1} k_{2}}{k_{1}-k_{2}} \times$

$[$ By product $]=[\text { Starch }]_{0}-[$ Starch $]-[$ Oligomer $]-[$ Glucose $]$ 
$10^{\mathrm{TH}}$ INTERNATIONAL CONFERENCE ON SUSTAINABLE ENERGY AND ENVIRONMENTAL Protection (June $27^{\mathrm{TH}}-30^{\mathrm{TH}}, 2017$, BLed, SloveniA), Bioenergy AND Biofuels

K. Intaramas, W. Jonglertjunya, N. Laosiripojana \& C. Sakdaronnarong: A Kinetic Study of Cassava Mash Hydrolysis in a Combination with Solid State Catalyst MixedMilling Reaction

Where $[S \operatorname{Starch}]_{0}$ is the initial concentration of starch, $\mathrm{k}_{1} \neq \mathrm{k}_{2} \neq \mathrm{k}_{3}$ and $\mathrm{X}$ is conversion of starch

$\%$ Conversion $(X)=\left(\frac{m_{\text {starch }, 0}-m_{\text {starch }}}{m_{\text {starch }, 0}}\right) \times 100$

$\%$ Selectivity $=\frac{\text { Yield }_{\text {sugar }}}{\text { Conversion }} \times 100$

Theoretically, hydrolysis of cassava mash consists of three steps as shown in equation (2). Rate constants $\left(\mathrm{k}_{1}, \mathrm{k}_{2}\right.$ and $\left.\mathrm{k}_{3}\right)$ of reaction were calculated based on equation (3) to (6) where [Starch], [Oligomer], [Glucose] and [By-product] are concentration of respective compounds and $t$ is time. The integration of these formulae gives equation (7) to (10), respectively. Rate constant of starch-to-oligomers conversion $\left(\mathrm{k}_{1}\right)$ was assumed as pseudo-first order reaction and determined from curve fitting of starch conversion during first $2 \mathrm{~h}$ as shown in Figure 3(c) and 3(d). From mathematical computation, three step rate constants of mixed-milling using $\mathrm{HA}-\mathrm{L}-\mathrm{SO}_{3} \mathrm{H}$ namely starch-to-oligomers $\left(\mathrm{k}_{1}\right)$, oligomers-to-glucose $\left(\mathrm{k}_{2}\right)$ and glucose-to-by product $\left(\mathrm{k}_{3}\right)$ were $1.15,0.14$ and $0.059 \mathrm{~h}^{-1}$, respectively. The ratio of rate constant of cassava mash-to-soluble oligosaccharides and oligosaccharides-to-glucose conversion $\left(\mathrm{k}_{1} / \mathrm{k}_{2}\right)$ from mixed-milling was 7.97 indicating that the rate-determining step of the overall cassava hydrolysis was starch-tooligosaccharides conversion. Concentrations of remaining cassava mash, glucose, oligomers and by-product were converted to \%yield and plotted in Fig. 3(b) where solid lines represent the mathematical models from equations (7) to (10) and scatter plots represent experimental data.

Table 2 Effect of pre-treatment process of substrate and catalyst on hydrolysis under hydrothermal condition at $140^{\circ} \mathrm{C}$ for 6 and $12 \mathrm{~h}$

\begin{tabular}{|c|c|c|c|c|c|c|c|c|c|}
\hline \multirow[b]{2}{*}{ Substrate } & \multirow[b]{2}{*}{ Catalyst } & \multirow{2}{*}{$\begin{array}{l}\text { Times } \\
\text { (h) }\end{array}$} & \multirow{2}{*}{$\begin{array}{c}\text { Pre- } \\
\text { treatment }\end{array}$} & \multicolumn{3}{|c|}{ Yield (\%) } & \multirow{2}{*}{$\begin{array}{c}\text { Conversion } \\
(\%)\end{array}$} & \multirow{2}{*}{$\begin{array}{l}\text { Glucose } \\
\text { selectivity } \\
(\%)\end{array}$} & \multirow{2}{*}{$\begin{array}{l}\text { TRS } \\
(\%)\end{array}$} \\
\hline & & & & ${ }^{\mathrm{a}} \mathrm{Olg}$ & Glucose & $\begin{array}{c}{ }^{\mathrm{b}} \mathrm{By} \\
\text { product }\end{array}$ & & & \\
\hline \multirow[t]{4}{*}{$\begin{array}{l}\text { Cassava } \\
\text { mash }\end{array}$} & $\begin{array}{l}\mathrm{HA}-\mathrm{L}- \\
\mathrm{SO}_{3} \mathrm{H}\end{array}$ & 6 & $\begin{array}{l}\text { Idividual } \\
\text { milled cassava } \\
\text { mash }\end{array}$ & 65.38 & 26.73 & 7.34 & 71.69 & 78.21 & 75.10 \\
\hline & & & Mixed-milling & 54.78 & 37.45 & 7.63 & 93.72 & 83.00 & 76.81 \\
\hline & & 12 & $\begin{array}{l}\text { Idividual } \\
\text { milled cassava } \\
\text { mash }\end{array}$ & 17.90 & 48.58 & 32.01 & 76.9 & 59.17 & 76.32 \\
\hline & & & Mixed-milling & 9.12 & 66.48 & 24.24 & 86.53 & 73.15 & 82.46 \\
\hline
\end{tabular}

${ }^{a}$ Water-soluble oligosaccharides included maltose, maltotriose and dextrins.

${ }^{\mathrm{b}} \mathrm{By}$ products included formic acid and acetic acid.

Ball-milled cassava root and subsequent thermal hydrolysis in the presence of HA-L$\mathrm{SO}_{3} \mathrm{H}$ catalyst provided rate constants of $\mathrm{k}_{1}, \mathrm{k}_{2}$ and $\mathrm{k}_{3}$ about $0.65,0.15$ and $0.016 \mathrm{~h}^{-1}$ respectively. Interestingly, the result of $\mathrm{k}_{1}$ was prominently lower when compared with mixed-milling process while the values of $\mathrm{k}_{2}$ and $\mathrm{k}_{3}$ were not significantly different between two milling methods. From the result, the ratio of $k_{1} / k_{2}$ from ball-milling was 
$144 \quad 10^{\mathrm{TH}}$ International CONFERENCE ON Sustainable ENERGy AND ENVIRONMENTAL Protection (June $27^{\mathrm{TH}}-30^{\mathrm{TH}}, 2017$, BLed, Slovenia), Bioenergy AND Biofuels

K. Intaramas, W. Jonglertjunya, N. Laosiripojana \& C. Sakdaronnarong: A Kinetic Study of Cassava Mash Hydrolysis in a Combination with Solid State Catalyst MixedMilling Reaction

4.3 which was also smaller than that from mixed-milling. This suggested that the hydrolysis of cassava mash to soluble oligomers was the rate-determining step. In comparison, it can be pointed out that mixed-milling gave superior starch hydrolysis efficiency due to more effective solid-solid contact area between catalytic active sites in catalyst $\left(\mathrm{Cl}-\right.$ and $\left.\mathrm{SO}_{3} \mathrm{H}\right)$ and $\alpha, 1-4$ glycosidic bonds in starch [2]. Drastically increased first order kinetic rate constant $\left(\mathrm{k}_{1}\right)$ of cassava mash to oligomers reaction using mixedmilling was about 1.77 -folds higher than using ball milling in the solid state reaction.

\section{Conclusion}

Selective cassava mash hydrolysis was achieved when using HA-L- $\mathrm{SO}_{3} \mathrm{H}$ catalyst. High glucose yield depended greatly on suitable solid acid catalyst synthesis method which provided catalysts with superior physical properties and chemical structure. Moreover, the predominant role of mixed-milling was to improve solid-solid contact area between cassava mash and catalyst which was in accordance to mechanocatalytic hydrolysis reaction. This indicated that to achieve complete conversion of cassava mash to glucose in thermal hydrolysis, mixed-milling with effective catalyst critically enhanced reaction selectivity, hydrolysis efficiency as well as the rate of starch depolymerization reaction.

\section{Acknowledgements}

This work was supported by Mahidol University. K.I. was thankful to the grant from the Research and Researchers for Industries (RRi), Master scholarship (MSD59I0041) from The Thailand Research Fund (TRF) and Corn Products (Thailand) Co., Ltd co-funding.

\section{References}

[1] Wichitchan C, Skolpap W. Optimum Cost for Ethanol Production from Cassava Roots and Cassava Chips. Energy Procedia. 2014;52:190-203.

[2] Breuninger WF, Piyachomkwan K, Sriroth K, BeMiller J, Whistler R. Chapter 12 Tapioca/Cassava Starch: Production and Use. Starch (Third Edition). San Diego: Academic Press; 2009. p. 541-68.

[3] Yabushita M, Kobayashi H, Hara K, Fukuoka A. Quantitative evaluation of ball-milling effects on the hydrolysis of cellulose catalysed by activated carbon. Catalysis Science \& Technology. 2014;4(8):2312-7.

[4] Namchot W, Panyacharay N, Jonglertjunya W, Sakdaronnarong C. Hydrolysis of delignified sugarcane bagasse using hydrothermal technique catalyzed by carbonaceous acid catalysts. Fuel. 2014;116:608-16.

[5] Pang Q, Wang L, Yang H, Jia L, Pan X, Qiu C. Cellulose-derived carbon bearing -Cl and -SO3H groups as a highly selective catalyst for the hydrolysis of cellulose to glucose. RSC Advances. 2014;4(78):41212-8.

[6] Okamura M, Takagaki A, Toda M, Kondo JN, Domen K, Tatsumi T, et al. Acid-Catalyzed Reactions on Flexible Polycyclic Aromatic Carbon in Amorphous Carbon. Chemistry of Materials. 2006;18(13):3039-45. 
[7] Lokman IM, Rashid U, Taufiq-Yap YH. Meso- and macroporous sulfonated starch solid acid catalyst for esterification of palm fatty acid distillate. Arabian Journal of Chemistry. 2016;9(2):179-89.

[8] Okuhara T. Water-Tolerant Solid Acid Catalysts. Chemical Reviews. 2002;102(10):364166.

[9] Huang Z-Q, Xie X-1, Chen Y, Lu J-p, Tong Z-F. Ball-milling treatment effect on physicochemical properties and features for cassava and maize starches. Comptes Rendus Chimie. 2008;11(1-2):73-9.

[10] Shuai L, Pan X. Hydrolysis of cellulose by cellulase-mimetic solid catalyst. Energy \& Environmental Science. 2012;5(5):6889-94. 
146 10 $10^{\mathrm{TH}}$ International CONFERENCE on Sustainable EnERgy and ENVIRONMENTal Protection (June $27^{\mathrm{TH}}-30^{\mathrm{TH}}, 2017$, Bled, Slovenia), Bioenergy AND Biofuels 
$10^{\mathrm{TH}}$ InTERnAtional CONFERENCE ON Sustainable ENERgy AND EnVironmental Protection (June $27^{\mathrm{TH}}-30^{\mathrm{TH}}$, 2017, Bled, SLOVENIA), BIOENERGY AND BIOFUELS

J. Krope, A.Ghani Olabi, D. Goričanec \& S. Božičnik

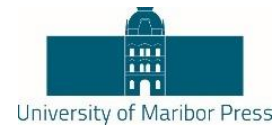

\title{
Oil Characteristics of Biosludge Pyrolysis by a Microwave Heating System
}

\author{
KuO-HSIUNG Lin, NinA LAI, Jun-YAN ZENG \& HuNG-Lung CHIANG
}

\begin{abstract}
Sludge disposal is a challenge due to its rapidly increasing amount and potential risks to human and environmental health. But sludge produced from biological wastewater treatment plants could be a useful renewable energy source because of its high organic materials content. Sludge obtained from the biological wastewater treatment facility of a chemical plant was pyrolyzed for reuse via microwave heating. The dried sludge contained $46.7 \pm 5.9 \%$ carbon, $5.80 \pm 0.58 \%$ hydrogen, $6.81 \pm 0.59 \%$ nitrogen and $1.34 \pm 0.27 \%$ sulfur. The process was employed to produce 16 $24 \mathrm{wt} \%$ of oil. At $400-800 \mathrm{oC}$,carbon was $71-74 \%$, hydrogen was $5.6-8.2 \%$, nitrogen was $5.5-8.5 \%$ and sulfur was $0.08-0.17 \%$. The heat values of liquid oils ranged from $7600-8300 \mathrm{kcal} \mathrm{kg}-1$.
\end{abstract}

Keywords: • Sludge • Microwave heating • Biofuel oil • Hydrogen • Biological

Correspondence AdDress: Kuo-Hsiung Lin, Ph D, Associate Professor, Fooyin University, Department of Environmental Engineering and Science, Kaohsiung, Taiwan. email:xx407@fy.edu.tw. Nina Lai, National Cheng Kung University, Instrument Department Center, Tainan, Taiwan. email:z7805010@email.ncku.edu.tw. Jun-Yan Zeng, Master, Fooyin University, Department of Environmental Engineering and Science, Kaohsiung, Taiwan. email:x yann731@gmail.com. Hung-Lung Chiang, Ph D, Professor, China Medical University, Department of Health Risk Management, Taichung, Taiwan. e-mail: hlchiang@mail.cmu.edu.tw.

https://doi.org/10.18690/978-961-286-048-6.14

ISBN 978-961-286-048-6

(C) 2017 University of Maribor Press

Available at: http://press.um.si. 
$10^{\mathrm{TH}}$ InTERNATIONAL CONFERENCE ON Sustainable ENERGy AND ENVIRONMENTAL Protection (June 27 ${ }^{\mathrm{TH}}-30^{\mathrm{TH}}, 2017$, BLed, Slovenia), Bioenergy AND Biofuels K.-Hsiung Lin, N. Lai, J.-Yan Zeng \& H.-Lung Chiang: Oil Characteristics of Biosludge Pyrolysis by a Microwave Heating System

\section{$1 \quad$ Introduction}

Fossil fuels are believed to be an important factor in climate change, prompting interest in the development of renewable energy sources. Biomass, which is high in organic carbon content, could be a renewable resource to produce valuable biofuel and useful materials [1].

Biosludge, which is produced from biological wastewater treatment, could be a candidate for renewable energy while also solving the waste problem of sludge. However, the intrinsic characteristics of sludge, such as high moisture content, inconvenient storage, microorganisms, decomposition, odor, low thermal efficiency and high treatment cost, could limit its applications [2]. Based on the concept of high potential energy recovery for renewable strategy and technology, sewage sludge has the potential for sustainable development in the future [3]. Sewage sludge can be regarded as a biomass resource because of its considerable organic content such as proteins, lipids, or fats, and carbohydrates, [4],[5] and its organic fraction could be a source of energy, oil and gas fuels or valuable chemical products after suitable treatment [6],[7],[8],[9].

Sludge is a product of urban and industrial wastewater treatment plants, and it should be carefully disposed of to reduce the release of contaminants into the environment. However, due to its rapidly increasing amount and potential risks to human health and the environment, the disposal of sludge can be a real challenge in biological wastewater treatment procedures. The treatment and disposal of waste sludge can represent more than $50 \%$ of the operating costs of wastewater treatment plants [10]. Reduce, reuse, and recycle are the basic concepts of sludge treatment and disposal [11].

For the pyrolysis process, the sludge undergoes thermal degradation [12], and the sludge volume reduction is similar to that achieved with incineration or gasification. Pyrolysis technology has many benefits, but the high moisture content in sludge could reduce the efficiency of pyrolysis. Therefore, a microwave technique has been developed for sludge pyrolysis over the past decade to improve energy efficiency [13],[14],[15],[16]. Sludge was obtained from a wastewater treatment plant of the chemical industry and treated by microwave heating pyrolysis technology.

\section{Experimental}

\subsection{Materials}

Sludge samples were obtained from the wastewater treatment facility of a chemical plant in Taiwan.

In addition, sludge contains microorganisms obtained from an activated sludge process of wastewater treatment plants. A total of more than $300 \mathrm{~kg}$ of sludge cake was sampled for all experiments to ensure consistent sludge characteristics during the experiment. 
$10^{\mathrm{TH}}$ INTERNATIONAL CONFERENCE ON SUSTAINABLE ENERGY AND ENVIRONMENTAL 149 Protection (June $27^{\mathrm{TH}}-30^{\mathrm{TH}}, 2017$, BLED, SLOVENiA), BioENERGy AND Biofuels K.-Hsiung Lin, N. Lai, J.-Yan Zeng \& H.-Lung Chiang: Oil Characteristics of Biosludge Pyrolysis by a Microwave Heating System

Sludge was stored at 4oC until it was pyrolyzed. One hundred grams of the sludge sample were put into the reactor for each run.

\subsection{Microwave pyrolysis}

Sludge drying and pyrolysis was carried out in an integrated single process using a multimode-microwave oven. The wet sludge $(\sim 100 \mathrm{~g})$ was put into a quartz reactor, which was placed inside the microwave heating oven. Nitrogen flowed through the reaction bed at a rate of $200 \mathrm{~mL} / \mathrm{min}$ for $30 \mathrm{~min}$ to maintain an inert atmosphere during treatment.

\subsection{Elemental analysis}

\subsubsection{Major element constituents}

An element analyzer (Heraeus CHN-O Rapid Element analyzer, USA) was employed to determine the carbon, hydrogen, nitrogen and oxygen constituents in the raw material and sludge oil. Sulfur and chloride concentrations were measured with the Tacussel Coloumax 78 (USA) element analyzer. Sulfanilic acid and 1-chloro-2, 4-dinitrobenzene were selected as standards of the elemental analyzer.

\subsection{Chemical composition of liquid oil}

The sludge oil was separated from the primary pyrolysis liquid product by distillation technology. The distillation temperature program of liquid products was conducted as follows: heating to $120^{\circ} \mathrm{C}(20 \mathrm{oC} \mathrm{min}-1)$ for $10 \mathrm{~min}$ to remove water and then heating to $250^{\circ} \mathrm{C}\left(10^{\circ} \mathrm{C} \mathrm{min}^{-1}\right)$ for $15 \mathrm{~min}$ to collect liquid oils. After that, the temperature was increased to $350^{\circ} \mathrm{C}\left(10^{\circ} \mathrm{C} \mathrm{min}{ }^{-1}\right)$ for $10 \mathrm{~min}$, which volatilized most of the liquid and left some char in the bottom of the distillate bottle. Over $80 \%$ of the liquid oil was collected at $200-250^{\circ} \mathrm{C}$ [17]. Gas chromatography with mass spectrometry was employed to analyze the constituents of the pyrolysis oil.

The composition of oil products was analyzed by a gas chromatography apparatus coupled with a mass spectrometer (GC-MS, model QP-2010; Shimadzu, Japan). The temperature program using the DB-5 column $(0.25 \mathrm{~mm} \times 30 \mathrm{~m}, 0.25 \mu \mathrm{m}$ film thickness, Agilent $\mathrm{J} \& \mathrm{~W}$ ) was as follows: $60 \mathrm{oC}$ for $10 \mathrm{~min}$, then raised to $325^{\circ} \mathrm{C}$ at a rate of $5^{\circ} \mathrm{C}$ per min; injector and detector temperatures $250^{\circ} \mathrm{C}$; carrier gas nitrogen $(2 \mathrm{~mL}$ min-1); detector dual FID; split ratio 1:30; and injection of $0.5 \mu \mathrm{L}$. GC peaks were identified by comparing the MS fragmentation pattern and relative retention time with those of the reference compounds available. The relative proportions of the liquid constituents were expressed as percentages obtained by FID peak-area normalization. 
$10^{\mathrm{TH}}$ International Conference on Sustainable EnERgy and Environmental Protection (June $27^{\mathrm{TH}}-30^{\mathrm{TH}}, 2017$, BLED, SLOVENIA), BioENERGY AND Biofuels K.-Hsiung Lin, N. Lai, J.-Yan Zeng \& H.-Lung Chiang: Oil Characteristics of Biosludge Pyrolysis by a Microwave Heating System

\section{$3 \quad$ Results and Discussion}

\subsection{Raw material}

The microwave heating system was set at $100-110$ oC to dry the sludge raw material. An elemental analyzer was employed to determine the carbon, hydrogen, nitrogen, sulfur, and chlorine content in the dried sludge material. Results indicated that the element contents in the dried sludge were carbon $46.7 \%$, hydrogen $5.80 \%$, nitrogen $6.81 \%$ and sulfur $1.34 \%$. Chloride content was less than the detection limit $(<0.01 \%)$.

\subsection{Pyrolysis mass distribution}

Sludge cakes containing $34.5 \%$ water were obtained from the wastewater treatment plant of the chemical industry. The sludge content was $58.3 \%$ combustible constituents and $41.7 \%$ ash. The microwave-dried sludge was pyrolyzed to gain the fraction of products in the gas phase, liquid phase, and solid residue, which were $18-38,16-24$, and $42-65 \%$, respectively, at pyrolytic temperatures from $400-800^{\circ} \mathrm{C}$ (shown in Table 1). High temperature reduces the yield of residues and enhances the gas products. The liquid product reached a high yield at $500^{\circ} \mathrm{C}$, after which, increasing the temperature reduced the yield of liquid product because some liquids volatilize at high temperature.

Table 1 Mass fraction distribution of sludge pyrolysis under different temperatures

\begin{tabular}{|c|c|c|c|}
\hline Temperature $\left({ }^{\circ} \mathrm{C}\right)$ & Gas & Liquid & Residue \\
\hline 400 & 0.18 & 0.16 & 0.65 \\
\hline 500 & 0.25 & 0.24 & 0.51 \\
\hline 600 & 0.33 & 0.22 & 0.45 \\
\hline 700 & 0.31 & 0.22 & 0.47 \\
\hline 800 & 0.38 & 0.20 & 0.42 \\
\hline
\end{tabular}

\subsection{Chemical constituents of liquid oil}

The microwave heating sludge pyrolysis process was employed to produce $16-24 \mathrm{wt} \%$ of oil based on the dried sludge cake. The average main elemental components of sludge oil were carbon (71-74\%), hydrogen (5.6-8.2\%), nitrogen $(5.5-8.5 \%)$, and sulfur (0.11$0.17 \%$ ) with the pyrolytic temperature at $400-800^{\circ} \mathrm{C}$ (shown as Table 2). Chlorine content was less than $0.01 \%$ in pyrolysis oil. The heat values of liquid oils were $7600-8300 \mathrm{kcal}$ $\mathrm{kg}^{-1}$. High temperature could lead the hydrogen and nitrogen species to volatilize into the gas phase. 
$10^{\text {TH }}$ INTERNATIONAL CONFERENCE ON SUSTAINABLE ENERGY AND ENVIRONMENTAL

Protection (June $27^{\mathrm{TH}}-30^{\mathrm{TH}}, 2017$, BLed, Slovenia), Bioenergy ANd Biofuels

K.-Hsiung Lin, N. Lai, J.-Yan Zeng \& H.-Lung Chiang: Oil Characteristics of

Biosludge Pyrolysis by a Microwave Heating System

Table 2 Major elemental constituents of pyrolysis oil for different temperatures

\begin{tabular}{|c|c|c|c|c|c|}
\hline Elements & 400 & 500 & 600 & 700 & 800 \\
\hline $\mathrm{C}$ & 72.5 & 71.24 & 71.7 & 72.10 & 74.49 \\
\hline $\mathrm{N}$ & 5.54 & 6.36 & 8.52 & 6.68 & 7.90 \\
\hline $\mathrm{H}$ & 5.63 & 7.94 & 8.19 & 8.07 & 7.14 \\
\hline $\mathrm{S}$ & 0.11 & 0.14 & 0.080 & 0.17 & 0.16 \\
\hline
\end{tabular}

\subsection{Organic constituents of sludge oil}

Complex organic compounds with a wide variety of chemical groups present in oils were produced from the microwave heating of sludge pyrolysis. Table 3 shows the detailed oil constituents in terms of the percentage of the gas chromatographic peak area for different compounds. Based on the carbon number fraction of oil products, C9 species account for $11-27 \%, \mathrm{C} 10$ for $14-21 \%, \mathrm{C} 11$ for $8.5-11 \%, \mathrm{C} 12$ for $5.7-8.0 \%$ and $\mathrm{C} 15$ for $2.8-6.9 \%$. The peak area fraction of $\mathrm{C} 13$ was $2.2-5.4 \%, \mathrm{C} 14$ was $0.65-2.2 \%$, and $\mathrm{C} 16$ was in trace amounts in this work. At high temperature, the organic molecules could crack and reformulate, which may be the reason for the variation of the composition fraction of liquid biofuel.

Table 3 Carbon number of sludge-derived oil under different temperatures

\begin{tabular}{|c|c|c|c|c|c|}
\hline $\begin{array}{c}\text { Carbon } \\
\text { number }\end{array}$ & 400 & 500 & 600 & 700 & 800 \\
\hline C7 & 9.25 & 2.67 & 5.14 & 5.17 & 5.06 \\
\hline C8 & 4.99 & 2.74 & 4.44 & 5.83 & 4.89 \\
\hline C9 & 26.97 & 11.07 & 23.35 & 26.14 & 22.8 \\
\hline C10 & 20.41 & 13.66 & 20.51 & 20.7 & 18.97 \\
\hline C11 & 9.62 & 8.43 & 11.17 & 10.63 & 9.76 \\
\hline C12 & 5.74 & 5.72 & 5.94 & 7.89 & 7.98 \\
\hline C13-16 & 8.14 & 15.77 & 7.23 & 7.49 & 7.01 \\
\hline Sum & 85.12 & 60.06 & 77.78 & 83.85 & 76.47 \\
\hline
\end{tabular}

\section{Conclusions}

Sludge from a chemical industry was used to produce oil by a microwave heating reactor. At temperatures from $400-800 \mathrm{oC}$, the fraction of pyrolysis products was $18-38 \%$ in the gas phase, $16-24 \%$ in the liquid phase, and $42-65 \%$ in solid residue. The heat values of liquid oils were $7600-8300 \mathrm{kcal} \mathrm{kg}-1$.

\section{References}

[1] A.J. Ragauskas, C.K. Williams, B.H. Davison, G. Britovsek, J. Cairney, C.A. Eckert, W.J. Jr. Frederick, J.P. Hallett, D.J. Leak, C.L. Liotta, J.R. Mielenz, R. Murphy, R. Templer, and T. Tschaplinski, "The path forward for biofuels and biomaterials," Science, vol. 311, pp. 484-489. 2006. 
$10^{\mathrm{TH}}$ InTERNATIONAL CONFERENCE ON Sustainable ENERGy AND ENVIRONMENTAL Protection (June 27 ${ }^{\mathrm{TH}}-30^{\mathrm{TH}}, 2017$, BLED, SLOVENiA), Bioenergy AND Biofuels K.-Hsiung Lin, N. Lai, J.-Yan Zeng \& H.-Lung Chiang: Oil Characteristics of Biosludge Pyrolysis by a Microwave Heating System

[2] S.W. Park, and C.H. Jang, "Characteristics of carbonized sludge for co-combustion in pulverized coal power plants," Waste Management, vol. 31, pp. 523-529. 2011.

[3] A. Bridgwater, "Renewable fuels and chemicals by thermal processing of biomass," Chemical Engineering Journal, vol. 91, pp. 87-102. 2003.

[4] E. Pokorna, N. Postelmans, P. Jenicek, S. Schreurs, R. Carleer, and J. Yperman,"Study of bio-oils and solids from flash pyrolysis of sewage sludges," Fuel, vol.88, pp.1344-1350. 2009.

[5] G. Tchobanoglous, F.L. Burton, and H.D. Stensel, "Wastewater engineering: Treatment and reuse, fourth ed," Metcalf \& Eddy Inc., McGraw-Hill Higher Education, New York. 2003.

[6] A. Domínguez, J.A. Menendez, M. Inguanzo, and J.J. Pis,"Production of bio-fuels by high temperature pyrolysis of sewage sludge using conventional and microwave heating," Bioresource Technology, vol.97, pp. 1185-1193. 2006.

[7] E.S. Park, B.S. Kang, and J.S. Kim, "Recovery of oils with high caloric value and low contaminant content by pyrolysis of digested and dried sewage sludge containing polymer flocculants,” Energy Fuels, vol.22, pp.1335-1340. 2008.

[8] P. Manara, and A. Zabaniotou," Towards sewage sludge based biofuels via thermochemical conversion - A review," Renewable and Sustainable Energy Reviews, vol. 16, pp. 25662582. 2012.

[9] V.K. Tyagi, and S.L. Lo," Microwave irradiation: a sustainable way for sludge treatment," Renewable and Sustainable Energy Reviews, vol.18, pp. 288-305. 2013.

[10] J.L. Campos, L. Otero, A. Franco, A. Mosquera-Corral, and E. Roca, "Ozonation strategies to reduce sludge production of a seafood industry WWTP," Bioresource Technology, vol. 100, pp. 1069-1073. 2009.

[11] P. Romero, M.D. Coello, J.M. Quiroga, and C.A. Aragon, "Overview of sewage sludge minimisation: techniques based on cell lysis-cryptic growth Desalin," Water Treatment, Vol. 51, pp. 5918-5933. 2013.

[12] C.G. Gasco Blanco, F. Guerrero, and A.M. Mendez Lazaro,"The influence of organic matter on sewage sludge pyrolysis," Journal of Analytical and Applied Pyrolysis, Vol. 74, pp. 413-420. 2005.

[13] J.A. Menéndez, M. Inguanzo, and J.J. Pís, "Microwave-induced pyrolysis of sewage sludge," Water Research ,vol. 36,pp. 3261-3264. 2002.

[14] A. Domínguez, Y. Fernández, B. Fidalgo, and J.J. Pís, J.A. Menéndez, "Biosyngasproduction with low concentrations of $\mathrm{CO} 2$ and $\mathrm{CH} 4$ from microwave-induced pyrolysis of wet and dried sewage sludge," Chemosphere, vol. 70, pp. 70397-70403. 2008.

[15] Q. Lin, G. Chen, and Y. Liu, "Scale-up of microwave heating process for the production of bio-oil from sewage sludge,". Journal of Analytical and Applied Pyrolysis, vol. 94, pp. 114-119. 2012.

[16] Y. Yu, J. Yu, B. Sun, and Z. Yan, "Influence of catalyst types on the microwave-induced pyrolysis of sewage sludge,". Journal of Analytical and Applied Pyrolysis, vol.106, pp. 8691, 2014.

[17] H.L. Chiang, K.H. Lin, N. Lai, and Z.X. Shieh, "Element and PAH constituents in the residues and liquid oil from biosludge pyrolysis in an electrical thermal furnace". Science of the Total Environment, vol. 481, pp.533-541. 2014. 
$10^{\mathrm{TH}}$ InTERnational CONFERENCE ON Sustainable ENERgy AND Environmental Protection (June $27^{\mathrm{TH}}-30^{\mathrm{TH}}$, 2017, Bled, SLOVENIA), BIOENERGY AND BIOFUELS

J. Krope, A.Ghani Olabi, D. Goričanec \& S. Božičnik

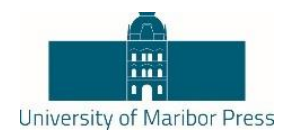

\title{
Fast Pyrolysis of Brown Alga Saccharina Japonica in a Bubbling Fluidized-Bed Reactor: Effects of Anaerobic Fermentaion Pretreatment
}

\author{
JAe Hyung Choi, HeE Chul WoO, Jinsoo Kim \& Seung-Soo Kim
}

\begin{abstract}
Pyrolysis characteristics of anaerobic fermented Saccharina japonica (AFSJ) were investigated using a thermogravimetric analyzer, and fast pyrolysis carried out that of sample pyrolyzed in a bubbling fluidizedbed reactor. The pretreated S. japonica samples (AFSJ-1d, AFSJ-2d, AFSJ$4 \mathrm{~d}$ and AFSJ-6d) were prepared by anaerobic fermentation for 1-6 days. The differential thermo-gravimetric analysis (DTG) curves of the AFSJ samples have three extensive peaks between 75 and $355^{\circ} \mathrm{C}$. The second peak intensity related to fermentable carbohydrates of AFSJ-4d and AFSJ$6 \mathrm{~d}$ decreased compared to AFSJ-1d and AFSJ-2d. This result implies that the anaerobic fermentation for volatile fatty acid (VFA) production is completed for 4 day. The yields of pyrolysis product such as bio-oil, biochar, and gas were significantly influenced in the conditions of different fermentation period. The yield of bio-oil from AFSJ-6d sample was maximal $40.12 \mathrm{wt} \%$ at $375^{\circ} \mathrm{C}$ and $4.0 \mathrm{Umf}$ in a bubbling fluidized-bed reactor. The chemical composition of the bio-oils from AFSJ-1d and AFSJ$2 \mathrm{~d}$ exhibited abundant dianhydromannitol as carbohydrate derivatives compared to one of AFSJ-4d and AFSJ-6d. It is attributed to the presence of unfermented carboxylates for 2 fermentation day.
\end{abstract}

Keywords: • Bubbling fluidized-bed pyrolysis • Anaerobic fermentation • Saccharina japonica $\bullet$ Bio-oil $\bullet$ Pyrolysis characteristics •

Correspondence Address: Seung-Soo Kim, Ph.D., Professor, Kangwon National University, Department of Chemical Engineering, Samcheok, Gangwon-do, Korea, e-mail: sskim2008@kangwon.ac.kr. Jae Hyung Choi, Ph.D., Pukyong National University, Institute of Cleaner Production Technology, Busan 48513, Korea, e-mail: jhchoe@ pknu.ac.kr. Hee Chul Woo, Ph.D., Pukyong National University, Department of Chemical Engineering, Busan 48513, Korea, e-mail: woohc@pknu.ac.kr. Jinsoo Kim, Ph.D., Professor, Kyung Hee University, Department of Chemical Engineering, Yongin-si, Gyeonggi-do 17104, Korea, e-mail: jkim21@khu.ac.kr.

https://doi.org/10.18690/978-961-286-048-6.15

ISBN 978-961-286-048-6

(C) 2017 University of Maribor Press

Available at: http://press.um.si. 
154 10 $10^{\mathrm{TH}}$ InTERnAtional CONFERENCE ON Sustainable ENERGy AND ENVIRONMENTAL Protection (June $27^{\mathrm{TH}}-30^{\mathrm{TH}}, 2017$, BLed, Slovenia), Bioenergy AND Biofuels

J. Hyung Choi, H. Chul Woo, J. Kim \& S.-Soo Kim: Fast Pyrolysis of Brown Alga Saccharina Japonica in a Bubbling Fluidized-Bed Reactor: Effects of Anaerobic Fermentaion Pretreatment

Many researchers have investigated the thermochemical process of fast pyrolysis for biooil and bio-char production [1-4]. The pyrolysis process offers a flexible and attractive way of converting organic matter to liquid products (also known as bio-oil), a solid residue (also known as bio-char), and several light gaseous compounds (i.e., carbon dioxide, carbon monoxide, hydrogen, and light hydrocarbons) [3, 4]. The fast pyrolysis of raw Saccharina japonica (i.e., untreated) has been carried out in a micro-tubing reactor [5], packed tube reactor [6], fixed-bed reactor [4], and bubbling fluidized-bed reactor [3, 7].

For large-scale pyrolysis oil production, the fluidized bed reactor system is regarded as the one with the greatest potential for commercialization. However, during long-term operation of the bubbling fluidized-bed pyrolysis using raw S. japonica, ash fouling and segregation by fluidizing char and mineral particles in the fluidized-bed reactor, may be caused by gelation and/or carbonization of sticky organic polysaccharides (e.g., alginate, fucoidan, laminarin, mannitol) with inorganic minerals, and it is difficult to operate the process continuously [8]. Thus, a pretreatment of anaerobic fermentation with volatile fatty acid (VFA) by-product can be considered as one potential solution to reduce minerals and sticky polysaccharides in the S. japonica biomass $[2,9]$.

In this study, the fast pyrolysis of anaerobic fermented S. japonica (AFSJ) for different fermentation period was investigated using a bubbling fluidized-bed reactor.

\section{$2 \quad$ Experimental}

\subsection{Anaerobic fermentation pretreatment}

The aquacultured $S$. japonica by high-density production method was obtained from Institute of Cleaner Production Technology of Pukyong National University in South Korea [7, 10], and was collected in August 2015 near Cheong-San Island, between Wando and Jeju Islands. After collection, the wet $S$. japonica biomass was directly crushed into particles in the size range of 1-3 cm, using a twin-screw shredder on site. The pretreatment of anaerobic fermentation was performed by the addition of nutrient medium and sewage sludge into the wet $S$. japonica with $100 \mathrm{~L}$ working volume $[9,11]$. Tap water was also added to adjust the substrate concentration. The concentration of macroalgae substrate ( $\mathrm{g}$ of dried alga/L) was $75 \mathrm{~g} / \mathrm{L}$. Iodoform $(0.2 \mathrm{~g} / \mathrm{L}$ ) was used as methanogen inhibitor. $\mathrm{NaOH}$ solution was added to control the $\mathrm{pH}$ between 6.5 and 7.0. The pretreated S. japonica samples (AFSJ-1d, AFSJ-2d, AFSJ-4d and AFSJ-6d) were prepared by anaerobic fermentation for 1-6 days. 
$10^{\text {TH }}$ INTERNATIONAL CONFERENCE ON SUSTAINABLE ENERGY AND ENVIRONMENTAL Protection (June $27^{\mathrm{TH}}-30^{\mathrm{TH}}, 2017$, Bled, Slovenia), Bioenergy AND Biofuels J. Hyung Choi, H. Chul Woo, J. Kim \& S.-Soo Kim: Fast Pyrolysis of Brown Alga Saccharina Japonica in a Bubbling Fluidized-Bed Reactor: Effects of Anaerobic Fermentaion Pretreatment

\subsection{Bubbling fluidized-bed pyrolysis}

The fast pyrolysis of the fermented S. japonica samples was carried out in a bubbling fluidized-bed reactor. A schematic diagram of the experimental equipment is shown in Fig. 1. The reactor consisted of a $3.3-\mathrm{cm}$-schedule stainless steel pipe that was $55 \mathrm{~cm}$ high (including a $10-\mathrm{cm}$ pre-heating zone below the gas distribution plate) and was equipped with a $100-\mu \mathrm{m}$ porous metal gas distributor. The system used silica sand (particle size $180-250 \mu \mathrm{m})$ as the fluidizing bed material and nitrogen as the fluidizing carrier gas. The reactor was externally heated with a three-zone electric furnace. The connecting tubes from the reactor to a cyclone and condensers were maintained at $300{ }^{\circ} \mathrm{C}$ using heating tape to avoid vapor condensation of the product bio-oil within the tubes. The particles of the biomass sample (average size $400 \mu \mathrm{m}$ ) were loaded into a feed hopper (batch-wise) and conveyed into the reactor by a screw feeder. The temperature of the fluidized bed reactor was controlled by measuring the temperature in the sand bed and in the reactor using K-type thermocouples. The bed material was weighed before each reaction and then fed into the reactor. After the fast pyrolysis reaction, the solid product (char and bed material) was collected from the cyclone and the reactor. The weight of char product was calculated by the weight difference. The condensable vapors exiting from the reactor and the cyclone were collected in a series of two condensers that were cooled to a temperature of $-20{ }^{\circ} \mathrm{C}$ using a circulator with ethylene glycol as the cooling solvent. The noncondensable vapors passing through the condensation system were collected in an electrostatic precipitation unit. After reaction, the solid, liquid, and gas products were analyzed to determine their composition.

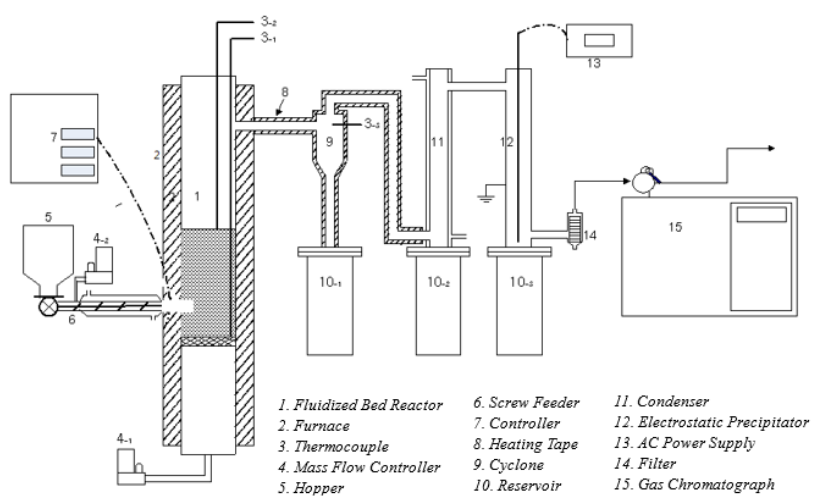

Figure 1. Schematic diagram of a bubbling fluidized-bed reactor

Under all of the reaction conditions, the experiment and analysis were conducted at least twice and the average value was used. The product yields of liquid, char, and gas were determined using the mass balances of reactant and products according to the following equations: 
$156 \quad 10^{\mathrm{TH}}$ International Conference on Sustainable Energy and Environmental Protection (June $27^{\mathrm{TH}}-30^{\mathrm{TH}}, 2017$, BLed, Slovenia), Bioenergy AND Biofuels

J. Hyung Choi, H. Chul Woo, J. Kim \& S.-Soo Kim: Fast Pyrolysis of Brown Alga Saccharina Japonica in a Bubbling Fluidized-Bed Reactor: Effects of Anaerobic Fermentaion Pretreatment

Char yield $(\mathrm{wt} \%)=\frac{\mathrm{m}_{\text {char }}}{\mathrm{m}_{\text {feed }}} \times 100$

Liquid yield $(\mathrm{wt} \%)=\frac{\mathrm{m}_{\text {liquid }}}{\mathrm{m}_{\text {feed }}} \times 100$

Gas yield $(\mathrm{wt} \%)=100-$ Char yield-Liquid yield

where $m_{\text {feed }}$ is the mass of the biomass, and $m_{\text {char }}$ and $m_{\text {liq }}$ are the masses of the solid and liquid products, respectively, after fast pyrolysis.

The compositions of the gas products (e.g., $\mathrm{H}_{2}, \mathrm{CO}, \mathrm{CO}_{2}$, and hydrocarbon gases $\mathrm{C}_{1}-\mathrm{C}_{4}$ ) was analyzed by using gas chromatography (YL 6500 GC) equipped with TCD (Molecular sieve $13 \times$ column) and FID (Porapak N column) detectors. The YL 6500 GC was equipped with a methanizer (packed with $\mathrm{Ni}$ catalyst) which allows to detect low concentrations of $\mathrm{CO}$ and $\mathrm{CO}_{2}$ by the FID detector. The $\mathrm{GC}$ was operated under the following conditions: the TCD detector was set up at $150{ }^{\circ} \mathrm{C}$, using high-purity argon $(99.999 \%)$ as a carrier gas with flow rate of $20 \mathrm{~mL} / \mathrm{min}$. The FID detector was set up at $250{ }^{\circ} \mathrm{C}$, using high-purity nitrogen $(99.999 \%)$ as a carrier gas with flow rate of 20 $\mathrm{mL} / \mathrm{min}$, and a mixture of hydrogen-air to keep the flame lit. The flow rate was 30 $\mathrm{mL} / \mathrm{min}$ for hydrogen and $300 \mathrm{~mL} / \mathrm{min}$ for air.

The moisture and ash content of the biomass and bio-char products were determined using ASTM E 1756 and ASTM E 1755, respectively. The C, H, and N contents of the biomass and bio-char were determined using an elemental analyzer (Flasg EA1112, CE Instrument) and the $\mathrm{O}$ content was given by difference. Thermogravimetric (TG) analysis of anaerobic fermented $S$. japonica samples was carried out using a TGA (TA Instrument, Q50). A sample mass of $20.0 \pm 1.0 \mathrm{mg}$ from each experiment was used for thermogravimetric analysis. Nitrogen was used as a carrier gas at a flow rate of 25 $\mathrm{mL} / \mathrm{min}$. The heating rate was controlled at $10{ }^{\circ} \mathrm{C} / \mathrm{min}$, and from 30 to $800{ }^{\circ} \mathrm{C}$.

The ${ }^{1} \mathrm{H}$ Fourier Transform Nuclear Magnetic Resonance Spectrometer (FT-NMR) spectra for organic phases of bio-oils were determined using a JEOL JMS ECP-400 spectrometer at $400 \mathrm{MHz}$ by dissolving $0.1 \mathrm{~g}$ of bio-oil in $1.0 \mathrm{~mL}$ of dimethyl sulfoxide- $\mathrm{d}_{6}$ (DMSO$\left.\mathrm{d}_{6}\right)$.

\section{$3 \quad$ Results}

Figure 2 shows thermogravimetric analysis results of different fermentation period from $S$. japonica in nitrogen atmosphere at a heating rate of $10^{\circ} \mathrm{C} / \mathrm{min}$. Thermogravimetric 
$10^{\mathrm{TH}}$ INTERNATIONAL CONFERENCE ON SUSTAINABLE ENERGY AND ENVIRONMENTAL Protection (June $27^{\mathrm{TH}}-30^{\mathrm{TH}}, 2017$, BLED, SLOVEniA), Bioenergy AND Biofuels J. Hyung Choi, H. Chul Woo, J. Kim \& S.-Soo Kim: Fast Pyrolysis of Brown Alga Saccharina Japonica in a Bubbling Fluidized-Bed Reactor: Effects of Anaerobic Fermentaion Pretreatment

analysis results of the biomass can be expressed as a function of the conversion $\mathrm{X}$, which is defined as follows:

$$
X=\frac{W_{0}-W}{W_{0}-W_{\infty}}
$$

where $\mathrm{W}_{0}$ is initial mass of the biomass sample, $\mathrm{W}$ is mass of the pyrolyzed sample, and $\mathrm{W}_{\infty}$ is final residual mass. Differential thermo-gravimetric analysis (DTG) data of the biomass sample at a heating rate of $10^{\circ} \mathrm{C} / \mathrm{min}$ were obtained from the differential rate of conversion, $\mathrm{d} X / \mathrm{d} t$. The DTG curves of the AFSJ samples have three extensive peaks between 75 and $355{ }^{\circ} \mathrm{C}$. The first broad peaks in the temperature range of 75 to $220{ }^{\circ} \mathrm{C}$ were attributed to moisture reduction adsorbed on the sample surface. The second peaks of thermal decomposition were observed in the range between 225 and $295^{\circ} \mathrm{C}$, and were mainly attributed to decomposition of alginate and fucoidan, while the third peaks between 395 and $355^{\circ} \mathrm{C}$ mainly corresponded to the decomposition of laminaran, mannitol and protein [4-8]. The slow decomposed peaks over a wide temperature range from 355 to $600{ }^{\circ} \mathrm{C}$ are related to lipid and remaining char, which were structurally complex and more difficult to break down [10]. The patterns of the AFSJ samples showed different trends of second and third peaks. The second peak intensity of AFSJ-4d and AFSJ-6d decreased compared to AFSJ-1d and AFSJ-2d. This result exhibits that the anaerobic fermentation for VFA production is completed for 4 day $[9,11]$.

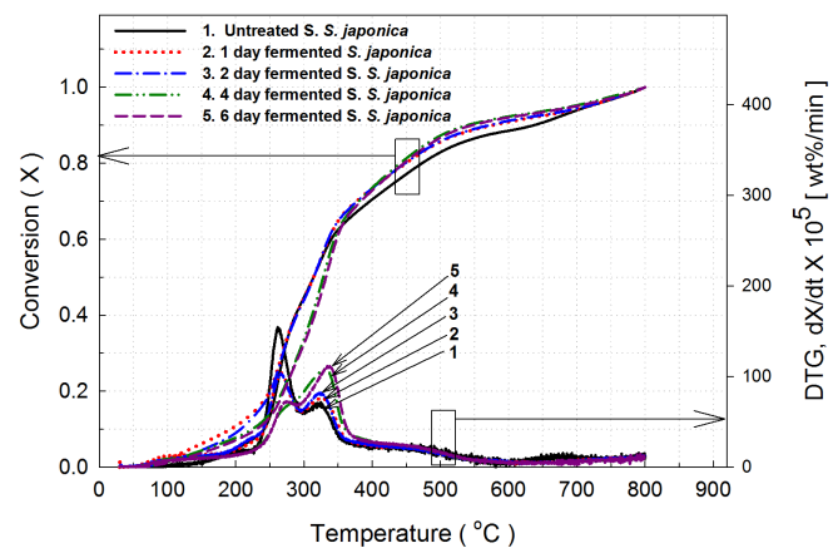

Figure 2. TG conversion and DTG curves illustrating results for fermented $S$. japonica samples at heating rates of $10 \square \mathrm{C} / \mathrm{min}$.

Fast pyrolysis temperature for the AFSJ samples in a bubbling fluidized-bed reactor was determined at $375{ }^{\circ} \mathrm{C}$ based on the TG and DTG data (Figure 2). The effect of 
$10^{\mathrm{TH}}$ InTERNATIONAL CONFERENCE ON Sustainable ENERGY AND ENVIRONMENTAL Protection (June $27^{\mathrm{TH}}-30^{\mathrm{TH}}, 2017$, Bled, Slovenia), Bioenergy AND BIOFuels J. Hyung Choi, H. Chul Woo, J. Kim \& S.-Soo Kim: Fast Pyrolysis of Brown Alga Saccharina Japonica in a Bubbling Fluidized-Bed Reactor: Effects of Anaerobic Fermentaion Pretreatment

fermentation days on product distribution was shown in Figure 3 (a). When the fermentation days increased from 1 to 6 days, the char and gas yield decreased, while the bio-oil yield increased from 31.89 to $40.12 \mathrm{wt} \%$. As discussed for the TG curves, this was attributed to the thermal decomposition of carbohydrate, protein and lipid at between 230 and $375{ }^{\circ} \mathrm{C}$ [4-8]. The increased bio-oil yields during increased fermentation days were attributed to decreased ash content in fermented biomass. Choi et al [7] reported that the pyrolysis of the brown alga $S$. japonica at a higher decomposition temperature exhibited an exothermic reaction by minerals in biomass. Li et al. [12] and Ross et al. [13] mentioned that the macroalgae of L. japonica and S. pallidum at above $400{ }^{\circ} \mathrm{C}$ appeared the charring decomposition of inorganic materials to metal carbonate with exothermic effect. The high bio-oil yields (31.04-31.27 wt\%) of 4-6 days fermented $S$. japonica at $375{ }^{\circ} \mathrm{C}$ were high in comparison with the results from raw S. japonica pyrolysis reported in other studies $[3,4,6]$. The yield of bio-oils from AFSJ-1d and AFSJ$2 \mathrm{~d}$ at pyrolysis temperature $375^{\circ} \mathrm{C}$ was lower than for bio-char, whereas the yield of biooils from AFSJ-4d and AFSJ-6d was higher than for char and gas. The high char formation is attributable to the ash remaining after pyrolysis of $S$. japonica, due to minerals fixed within the structural components [13]. As described in Figure 2, the different chemical compositions of fermentation pretreated biomass may lead to different product distributions as well as to different product compositions.

The main components of the pyrolysis gas from fermented $S$. japonica were $\mathrm{CO}, \mathrm{CO}_{2}$, $\mathrm{H}_{2}$, and hydrocarbon gases $\left(\mathrm{C}_{1}-\mathrm{C}_{4}\right)[3,4,6,7]$. The mole percent of $\mathrm{CO}_{2}$ in the gas products decreased with increasing fermentation days, while that of $\mathrm{CO}, \mathrm{H}_{2}$ and $\mathrm{C}_{1}-\mathrm{C}_{4}$ increased (Figure 3 (b)). The $\mathrm{CO}_{2}$ composition was attributed to the reduced decarboxylation from a decrease of fermentable carbon sources $[3,7]$. 
$10^{\text {TH }}$ INTERNATIONAL CONFERENCE ON SUSTAINABLE ENERGY AND ENVIRONMENTAL Protection (June $27^{\mathrm{TH}}-30^{\mathrm{TH}}, 2017$, Bled, Slovenia), Bioenergy ANd Biofuels

J. Hyung Choi, H. Chul Woo, J. Kim \& S.-Soo Kim: Fast Pyrolysis of Brown Alga Saccharina Japonica in a Bubbling Fluidized-Bed Reactor: Effects of Anaerobic Fermentaion Pretreatment
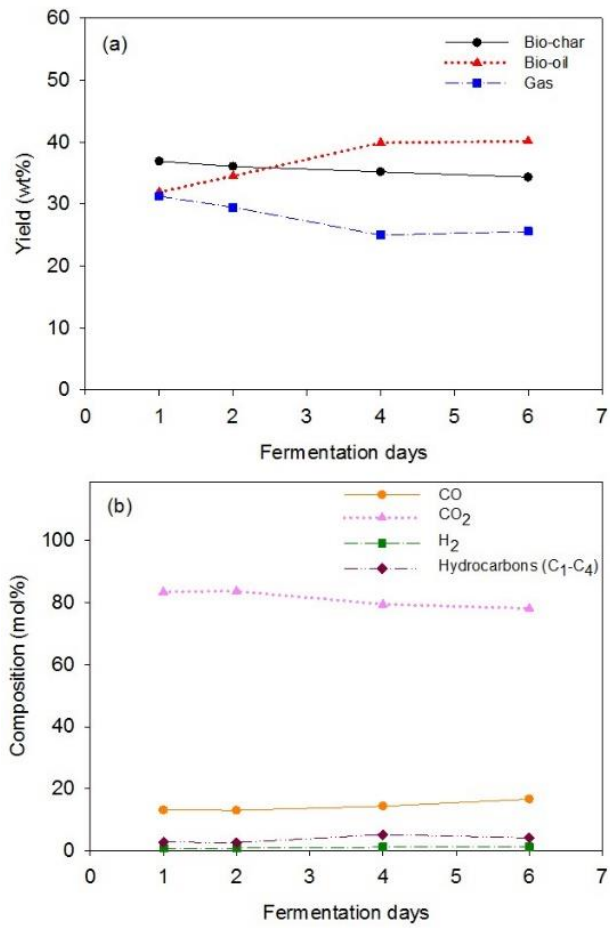

Figure 3. Effect of fermentation days from S. japonica on (a) Product yields and (b) Gas composition in a bubbling fluidized-bed reactor with feeding rate $100 \mathrm{~g} / \mathrm{h}$ and nitrogen flow rate $4 \mathrm{U}_{\mathrm{mf}}$.

The chemical functional groups of bio-oil product were analyzed by ${ }^{1} \mathrm{H}$ NMR. Figure 4 shows the ${ }^{1} \mathrm{H}$ NMR spectra of the bio-oils from fermented $S$. japonica samples at $375^{\circ} \mathrm{C}$. Among the main functional groups in bio-oils, alkanes, aliphatics, anhydrosugars, phenols, and aromatics were identified [3, 7]. The protons on alkane and aliphatic carbon atoms related to heteroatoms or unsaturated groups, were detected in the range 0.5-3.0 ppm from all of fermented $S$. japonica samples. The proton region between 3.0 and 4.5 ppm was assigned to hydroxyl and methoxy groups on anhydrosugars or alcohols [3, 7], the source of which was attributed to carbohydrate derivatives (e.g., dianhydromannitol). This spectral range was quite different depending on the fermentation days of biomass, exhibiting the high intensity on AFSJ-1d and AFSJ-2d. The peak is attributed to unfermented carbohydrates for two fermentation days [9, 11]. The peaks between 4.5 and $6.0 \mathrm{ppm}$ represent hydrogen bonding in phenolic $-\mathrm{OH}$ and non-conjugated olefin groups $[3,7,14]$, and showed the lowest intensity in the entire proton region. Unlike the lignocellulosic biomass, macroalgae do not contain lignin, and have very few phenolic compounds in their bio-oils. Mullen et al. [14] reported that most of the lignin-derived molecules in bio-oil were phenolic compounds, showing high peaks at $4.5-6.0 \mathrm{ppm}$. The 
$160 \quad 10^{\mathrm{TH}}$ InTERNATIONAL CONFERENCE ON SUSTAINABLE ENERGY AND ENVIRONMENTAL Protection (June 27 $7^{\mathrm{TH}}-30^{\mathrm{TH}}, 2017$, Bled, SLOVENiA), BioENERGy AND Biofuels

J. Hyung Choi, H. Chul Woo, J. Kim \& S.-Soo Kim: Fast Pyrolysis of Brown Alga Saccharina Japonica in a Bubbling Fluidized-Bed Reactor: Effects of Anaerobic Fermentaion Pretreatment

proton peaks between 6.0 and $8.5 \mathrm{ppm}$ represent the hydrogen atoms in benzenoids and heteroaromatics containing $\mathrm{O}$ and $\mathrm{N}$ components. Ly et al [3] and Choi et al [7] reported that the nitrogen-containing heteroaromatics (pyridinone, indole, and amines) on the pyrolysis bio-oils of macroalgae were mainly derived from the decomposition of proteins.

\section{$4 \quad$ Conclusions}

Pyrolysis characteristics of AFSJ samples for different fermentation period were investigated in a bubbling fluidized-bed reactor. In the DTG curves of AFSJ-1d, AFSJ$2 \mathrm{~d}, \mathrm{AFSJ}-4 \mathrm{~d}$ and AFSJ-6d, the amount of fermentable carbohydrates from AFSJ-4d and AFSJ-6d decreased by the anaerobic fermentation for VFA production. The yields of pyrolysis product such as bio-oil, bio-char, and gas were significantly influenced in the conditions of different fermentation period. The maximum yield of bio-oil from AFSJ-6d at $375{ }^{\circ} \mathrm{C}$ was considered with reducing ash content in biomass. The chemical composition of the bio-oils from AFSJ-1d and AFSJ-2d exhibited abundant dianhydromannitol as carbohydrate derivatives compared to one of AFSJ-4d and AFSJ$6 \mathrm{~d}$. It is attributed to the presence of unfermented carboxylates for two fermentation day. 
Protection (June $27^{\mathrm{TH}}-30^{\mathrm{TH}}, 2017$, Bled, SLOVEniA), Bioenergy AND Biofuels

J. Hyung Choi, H. Chul Woo, J. Kim \& S.-Soo Kim: Fast Pyrolysis of Brown Alga Saccharina Japonica in a Bubbling Fluidized-Bed Reactor: Effects of Anaerobic

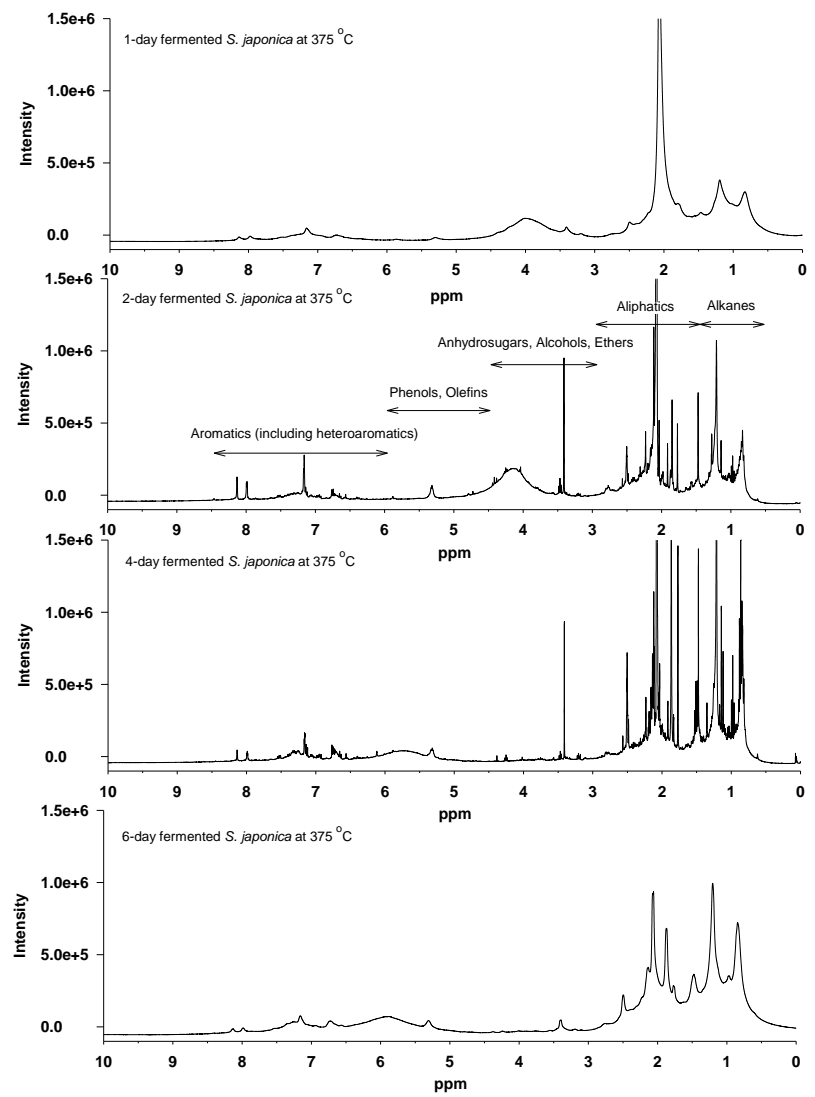

Figure 4. ${ }^{1} \mathrm{H}$ NMR spectra of bio-oils derived from different-day fermented $S$. japonica.

\section{Acknowledgements}

This work was financially supported by the Ministry of Oceans and Fisheries of the Republic of Korea (Project No. 20140559)

\section{References}

[1] A.V. Bridgwater, "Review of fast pyrolysis of biomass and product upgrading," Biomass Bioenergy, vol.38, pp.68-94, 2012.

[2] M. Song, H.D. Pham, J. Seon, H.C. Woo, "Marine brown algae: A conundrum answer for sustainable biofuels production," Renew Sust Energ Rev, vol.50, pp.782-792, 2015.

[3] H.V. Ly, S.S. Kim, H.C. Woo, J.H. Choi, D.J. Suh, J. Kim, "Fast pyrolysis of macroalga Saccharina japonica in a bubbling fluidized-bed reactor for bio-oil production," Energy, vol.93, pp.1436-1446, 2015. 
$10^{\mathrm{TH}}$ InTERNATIONAL CONFERENCE ON Sustainable ENERGy AND ENVIRONMENTAL Protection (June $27^{\mathrm{TH}}-30^{\mathrm{TH}}, 2017$, BLed, Slovenia), Bioenergy AND Biofuels J. Hyung Choi, H. Chul Woo, J. Kim \& S.-Soo Kim: Fast Pyrolysis of Brown Alga Saccharina Japonica in a Bubbling Fluidized-Bed Reactor: Effects of Anaerobic Fermentaion Pretreatment

[4] J.H. Choi, S.S. Kim, D.J. Suh, E.J. Jang, K.I. Min, H.C. Woo, "Characterization of the biooil and bio-char produced by fixed bed pyrolysis of the brown alga Saccharina japonica," Korean J Chem Eng, vol.33, pp.2691-2698, 2016.

[5] S.S. Kim, H.V. Ly, G. Choi, J. Kim, and H.C. Woo, "Pyrolysis characteristics and kinetics of the alga Saccharina japonica," Bioresour Technol, vol.123, pp.445-451, 2012.

[6] Y.J. Bae, C. Ryu, J.K. Jeon, J. Park, D.J. Suh, Y.W. Suh, D. Chang, Y.K. Park, "The characteristics of bio-oil produced from the pyrolysis of three marine macroalgae," Bioresour Technol, vol.102, pp.3512-3520, 2011.

[7] J.H. Choi, S.-S. Kim, H.V. Ly, J Kim, and H.C. Woo, "Effects of water-washing Saccharina japonica on fast pyrolysis in a bubbling fluidized-bed," Biomass Bioenergy, vol.98, pp.112-123, 2017.

[8] J. Choi, J.W. Choi, D.J. Suh, J.M. Ha, J.W. Hwang, H.W. Jung, K.Y. Lee, H.-C. Woo, "Production of brown algae pyrolysis oils for liquid biofuels depending on the chemical pretreatment methods," Energy Convers Manage, vol.86, pp.371-378, 2014.

[9] M. Song, H.D. Pham, J. Seon, H.C. Woo, "Marine brown algae: a conundrum answer for sustainable biofuels production,” Renew Sustain Energy Rev, vol.50, pp.782-792, 2015.

[10] J.H. Choi, S.-S. Kim, H.V. Ly, J Kim, and H.C. Woo, "Thermogravimetric characteristics and pyrolysis kinetics of high-density-aquacultured Saccharina Japonica: Effects of waterwashing," Fuel, vol.193, pp.159-167, 2017.

[11] T.N. Pham, W.J. Nam, Y.J. Jeon, H.H. Yoon, "Volatile fatty acids production from marine macroalgae by anaerobic fermentation," vol.124, pp.500-503, 2013.

[12] D. Li, L. Chen, X. Yi, X. Zhang, and N. Ye, "Pyrolytic characteristics and kinetics of two brown algae and sodium alginate," Bioresour Technol, vol.101, pp.7131-7136, 2010.

[13] A.B. Ross, K. Anastasakis, M. Kubacki, and J.M. Jones, "Investigation of the pyrolysis behaviour of brown algae before and after pre-treatment using PY-GC/MS and TGA," J Anal Appl Pyrolysis, vol.85, pp.3-10, 2009.

[14] C.A. Mullen, G.D. Strahan, A.A. Boateng, Characterization of various fast-pyrolysis biooils by NMR spectroscopy, Energy Fuels 23 (2009) 2707-2718. 
$10^{\mathrm{TH}}$ InTERnational CONFERENCE ON Sustainable ENERgy AND ENVIRONMENTAL Protection (June $27^{\mathrm{TH}}-30^{\mathrm{TH}}$, 2017, Bled, SLOVENIA), BIOENERGY AND BIOFUELS

J. Krope, A.Ghani Olabi, D. Goričanec \& S. Božičnik

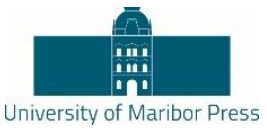

\title{
Effect of Dolomite Catalyst on Bio-Oil Production During Pyrolysis of Tulip Tree (Liriodendron) in Fluidized-Bed Reactor
}

\author{
SEUNG-SOO KIM, JinSOO KIM \& HOANG VU LY
}

\begin{abstract}
In this study, the fast and catalytic pyrolysis of tulip tree was performed in bubbling fluidized-bed reactor under various reaction conditions (pyrolysis temperature, gas flow rate of fluidizing medium, biomass particle size) to investigate the effect of these parameters on the product yields and the qualities of bio-oil. The results showed that the highest yield of bio-oil was obtained at pyrolysis temperature of $450 \mathrm{oC}$ with gas flow rate of $2 \times \mathrm{Umf}$, feeding rate of $100 \mathrm{~g} / \mathrm{hr}$, and biomass particle size of $1.0 \mathrm{~mm}$. The gas compositions were determined by GC with FID and TCD detector. The bio-oil was characterized EA and the compositions of bio-oil was identified by GC-MS.
\end{abstract}

Keywords: • Bubbling fluidized bed $\bullet$ Fast pyrolysis $\bullet$ Catalytic pyrolysis

- Dolomite • Tulip tree•

CorRespondence AdDress: Seung-Soo Kim, Ph.D., Professor, Kangwon National University, Department of Chemical Engineering, Samcheok, Gangwon, Korea, e-mail: sskim2008@kangwon.ac.kr. Jinsoo Kim, Ph.D., Professor, Kyung Hee University, Department of Chemical Engineering, Yongin, Gyeonggi, Korea, e-mail: jkim21@khu.ac.kr. Hoang Vu Ly, Ph.D., Post-doc researcher, Kangwon National University, Department of Chemical Engineering, Samcheok, Gangwon, Korea, e-mail: lyhoangvu87@gmail.com. 
$10^{\mathrm{TH}}$ InTERNATIONAL CONFERENCE ON Sustainable ENERGY AND ENVIRONMENTAL Protection (June $27^{\mathrm{TH}}-30^{\mathrm{TH}}, 2017$, BLed, Slovenia), Bioenergy AND Biofuels S.-Soo Kim, J. Kim \& H. Vu Ly: Effect of Dolomite Catalyst on Bio-Oil Production During Pyrolysis of Tulip Tree (Liriodendron) in Fluidized-Bed Reactor

\section{1}

\section{Introduction}

As lignocellulose biomass, tulip tree (Liriodendron) composed of hemicellulose, cellulose, and lignin, which can be converted into fuels by pyrolysis.

Fast pyrolysis is a thermal conversion process at high temperature $\left(400 \sim 600{ }^{\circ} \mathrm{C}\right)$ in the absence of oxygen, and at short vapor residence time [1]. Fractional catalytic fast pyrolysis is an updated pyrolysis method in which the biomass can be converted into higher quality bio-oil by upgrading the pyrolysis vapor before its condensation via a series of reaction at atmosphere pressure $[2,3]$.

In this study, the fast and catalytic pyrolysis of tulip tree was performed in bubbling fluidized-bed reactor under various reaction conditions using silica sand and dolomite as fluidization material to investigate the effect of these parameters on the product yields and the qualities of bio-oil.

\section{$2 \quad$ Experimental}

\subsection{Woody biomass}

The woody biomass sample, tulip tree (Liriodendron), was used in this study. Before pyrolysis, this sample was ground with a knife mill and sieved to the average particle size of $100 \mu \mathrm{m}$ for experiment. The contents of $\mathrm{C}, \mathrm{H}, \mathrm{O}$, and $\mathrm{N}$ in the biomass were determined by an elemental analyzer (Flash EA1112, CE Instruments) and the moisture and ash contents were determined according to ASTM E 1756 and ASTM E 1755, respectively [1].

Dolomite catalyst was used in this study in order to determine the effects of catalyst species on fast pyrolysis of biomass. The natural dolomite (Seungshin Corp., Korea) with particle size of $50-80$ mesh were activated at $900^{\circ} \mathrm{C}$ for 3 hours.

\subsection{Fluidized bed reactor}

The non-catalytic and catalytic fast pyrolysis of tulip tree were performed in a bubbling fluidized-bed reactor. A schematic diagram of the experimental equipment is shown in Figure 1. The reactor consisted of a $5.5 \mathrm{~cm}$ schedule stainless steel pipe that was $50 \mathrm{~cm}$ high (including a $25 \mathrm{~cm}$ pre-heating zone below the gas distribution plate) and was equipped with a $100 \mu \mathrm{m}$ porous metal gas distributor. The system used silica sand and dolomite (particle of 180 250 $\mu \mathrm{m}$ ) as the fluidizing bed material and nitrogen as the fluidizing medium. Biomass sample $(0.5 \sim 1.5 \mathrm{~mm})$ was loaded into a feed hopper (batchwise) and conveyed into reactor by a screw feeder with a feeding rate of $100 \mathrm{~g} / \mathrm{h}$. The temperature of reactor was ranged from 400 to $550^{\circ} \mathrm{C}$ for the pyrolysis reaction. 


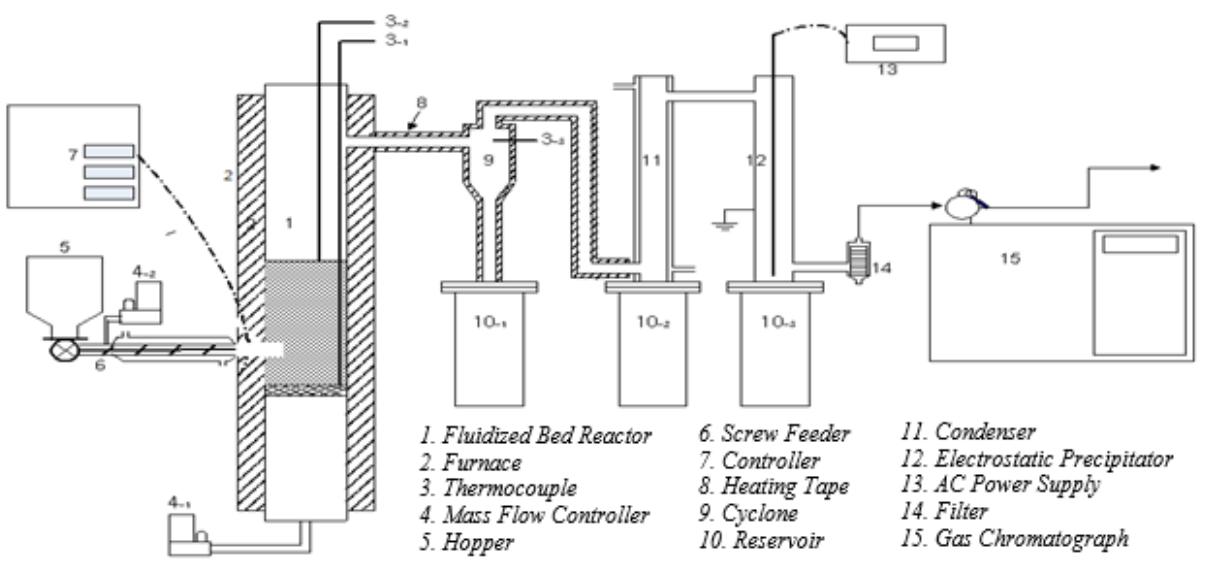

Figure 1. Schematic diagram of the bubbling fluidized-bed reactor

The nitrogen flow rate was controlled to get the residence time of pyrolysis condensable vapour in reactor less than $2 \mathrm{~s}$. The temperature of bed material and reactor were controlled by K-type thermocouples that were inserted into the fluidized bed reactor. After the fast pyrolysis reaction, the solid product included char and bed material (sand and/or dolomite) was collected from the cyclone and the reactor. Most of the liquid products were condensed in a series of ethylene glycol-cooled condensers that were maintained at $-20^{\circ} \mathrm{C}$. The aerosols, which were not condensed in condenser, passing through the condensation system were collected in an electrostatic precipitation unit. The outlet of filter unit was directly connected to the gas chromatography for gases online analysis. The product yields were determined by mass balances of reactants and products by the following equations:

Char yield $(\mathrm{wt} \%)=\frac{\mathrm{m}_{\text {char }}}{\mathrm{m}_{\text {feed }}} \times 100$

Liquid yield $(\mathrm{wt} \%)=\frac{\mathrm{m}_{\text {liquid }}}{\mathrm{m}_{\text {feed }}} \times 100$

Gas yield $(w t \%)=100-$ Char yield - Oil yield

Where $\mathrm{m}_{\text {feed }}$ is the mass of the biomass, and $\mathrm{m}_{\text {char }}$ and $\mathrm{m}_{\mathrm{liq}}$ are the masses of the solid product and the liquid product, respectively. 
166 10 $10^{\mathrm{TH}}$ International Conference on Sustainable Energy and Environmental Protection (June $27^{\mathrm{TH}}-30^{\mathrm{TH}}, 2017$, BLED, SLOVENIA), BioENERGY AND Biofuels S.-Soo Kim, J. Kim \& H. Vu Ly: Effect of Dolomite Catalyst on Bio-Oil Production During Pyrolysis of Tulip Tree (Liriodendron) in Fluidized-Bed Reactor

\section{$3 \quad$ Results and Discussion}

\subsection{Material characterization}

The moisture and the ash contents of tulip tree were $6.56 \mathrm{wt} \%$ and $2.13 \mathrm{wt} \%$, respectively. The elemental analysis showed that the tulip tree biomass consisted of $46.91 \mathrm{wt} \% \mathrm{C}, 7.18$ wt $\% \mathrm{H}, 0.45 \mathrm{wt} \% \mathrm{~N}$ and $45.46 \mathrm{wt} \% \mathrm{O}$ on dry, ash free basis (d.a.f).

The higher heating value (HHV) of biomass can be calculated according to the Demirbas method [4]. It was determined to be $18.87 \mathrm{MJ} / \mathrm{kg}$.

\subsection{Effect of pyrolysis conditions on product distribution}

Temperature is one of the most important factors that affect the product distribution. The product distributions derived from the fast pyrolysis of tulip tree at different temperatures (between $400{ }^{\circ} \mathrm{C}$ and $550{ }^{\circ} \mathrm{C}$ ) are shown in Figure 2a. The highest liquid yield was $49.03 \%$, which was obtained at $450{ }^{\circ} \mathrm{C}$.

The effect of particle size on product yields in pyrolysis of tulip tree was also investigated. This influence is related to heat and mass transfer as well as the extent of secondary reactions inside the particles that affect the product distributions [5]. The experiments were conducted at $450^{\circ} \mathrm{C}$, with different biomass particle size of $0.5,1.0,1.5 \mathrm{~mm}$, respectively, as shown in Figure $2 \mathrm{~b}$. The liquid product reached the highest yield, 49.03 $\mathrm{wt} \%$, using biomass sample size of $1.0 \mathrm{~mm}$. 
$10^{\mathrm{TH}}$ INTERNATIONAL CONFERENCE ON SUSTAINABLE ENERGY AND ENVIRONMENTAL

Protection (June $27^{\mathrm{TH}}-30^{\mathrm{TH}}, 2017$, BLed, Slovenia), Bioenergy ANd Biofuels S.-Soo Kim, J. Kim \& H. Vu Ly: Effect of Dolomite Catalyst on Bio-Oil Production During Pyrolysis of Tulip Tree (Liriodendron) in Fluidized-Bed Reactor

(a)

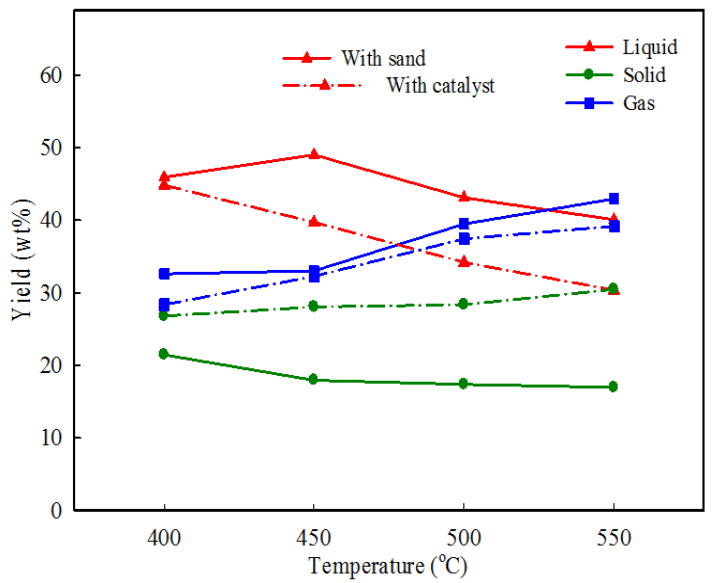

(b)

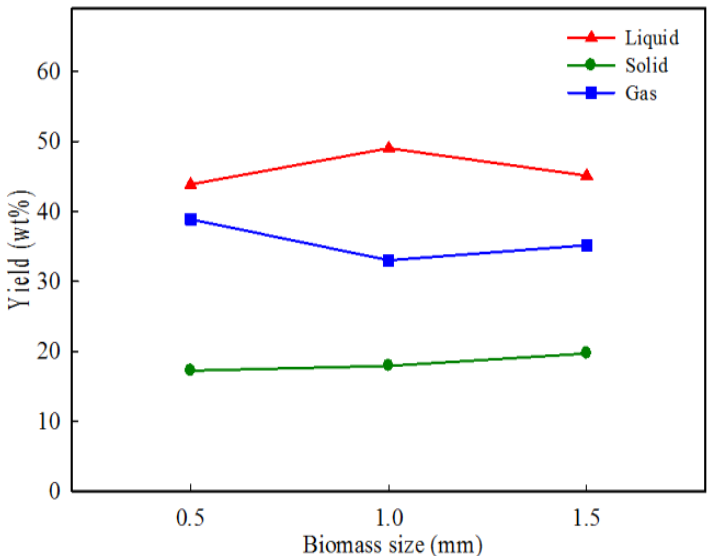

(c)

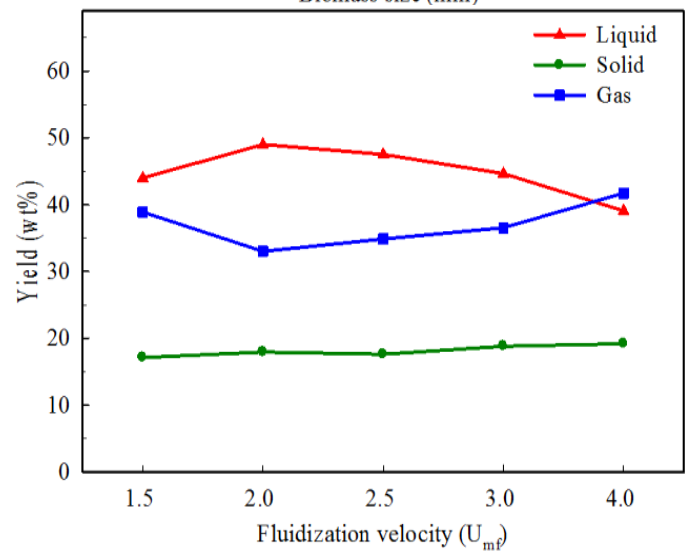

Figure 2. Effect of pyrolysis conditions on product distribution. (a) Effect of temperature. (b) Effect of biomass particle size. (c) Effect of nitrogen gas flow rate. 
$10^{\mathrm{TH}}$ InTERNATIONAL CONFERENCE ON Sustainable ENERGY AND ENVIRONMENTAL Protection (June $27^{\mathrm{TH}}-30^{\mathrm{TH}}, 2017$, BLed, Slovenia), Bioenergy AND Biofuels S.-Soo Kim, J. Kim \& H. Vu Ly: Effect of Dolomite Catalyst on Bio-Oil Production During Pyrolysis of Tulip Tree (Liriodendron) in Fluidized-Bed Reactor

The nitrogen was used as the carrier gas to transport pyrolysis vapours from the hightemperature reaction region to the product-collecting zone $[1,6]$ and it was also used for fluidization of biomass in the reactor. The flow rate of nitrogen (fluidization velocity) is another important factor that affects gas and bio-oil yields. The influence of nitrogen gas flow rate on product distribution of tulip tree pyrolysis was examined and illustrated in Figure 2c. The pyrolysis of tulip tree was conducted at $450{ }^{\circ} \mathrm{C}$ at a fluidization velocity of $1.5 \mathrm{U}_{\mathrm{mf}}, 2.0 \mathrm{U}_{\mathrm{mf}}, 2.5 \mathrm{U}_{\mathrm{mf}}, 3.0 \mathrm{U}_{\mathrm{mf}}$, and/or $4.0 \mathrm{U}_{\mathrm{mf}}$, which corresponded to a residence time of $1.59 \mathrm{~s}, 1.2 \mathrm{~s}, 0.96 \mathrm{~s}, 0.82 \mathrm{~s}$ and/or $0.6 \mathrm{~s}$, respectively. ). The bio-oil yield decreased from $49.03 \mathrm{wt} \%\left(2.0 \mathrm{U}_{\mathrm{mf}}\right)$ to $40.01 \mathrm{wt} \%\left(4.0 \mathrm{U}_{\mathrm{mf}}\right)$.

\subsection{Effect of dolomite on product distribution and properties of bio-oil}

In this study, the dolomite catalyst is used as the fluidizing bed material in reactor. The fast pyrolysis of tulip tree was performed in a bubbling fluidized-bed reactor using dolomite to investigate the catalytic influence on product yield and bio-oil quality. The product distributions derived from the fast pyrolysis of tulip tree under catalytic influence of dolomite at different temperatures (from $400{ }^{\circ} \mathrm{C}$ to $550{ }^{\circ} \mathrm{C}$ ) are shown in Figure 2a. The bio-oil yield was between 30.38 and $44.83 \mathrm{wt} \%$. Compared to silica sand, applying dolomite in fast pyrolysis of tulip tree showed a remarkable decrease in liquid yields at the high temperature.

\subsection{Characterization of gas product}

The compositions of gas products were analyzed by GC with FID and TCD detector. The gas product from the both pyrolysis processes of tulip tree showed similar gas species with different compositions depending on the reaction conditions, as presented in Figure 3. The gaseous products released during the reaction consisted of $\mathrm{CO}, \mathrm{CO}_{2}, \mathrm{H}_{2}$ and hydrocarbon gases $\left(\mathrm{C}_{1}-\mathrm{C}_{4}\right)$.

\subsection{Bio-oil analysis}

The bio-oils obtained from pyrolysis of tulip tree samples were diluted in methanol before GC-MS analysis. Table 1 shows the major compositions in the bio-oils derived from catalytic pyrolysis and pyrolysis of tulip tree samples at reaction temperature of $450^{\circ} \mathrm{C}$ and fluidization velocity of $2 \mathrm{xU}_{\mathrm{mf}}$, respectively. The components in the pyrolysis bio-oil include levogluosan, phenolic compounds and their derivatives. Among these species, levoglucosan was the dominant compound and showed the highest selectivity. 
$10^{\mathrm{TH}}$ INTERNATIONAL CONFERENCE ON SUSTAINABLE ENERGY AND ENVIRONMENTAL

Protection (June $27^{\mathrm{TH}}-30^{\mathrm{TH}}, 2017$, BLed, Slovenia), Bioenergy ANd Biofuels S.-Soo Kim, J. Kim \& H. Vu Ly: Effect of Dolomite Catalyst on Bio-Oil Production During Pyrolysis of Tulip Tree (Liriodendron) in Fluidized-Bed Reactor

(a)

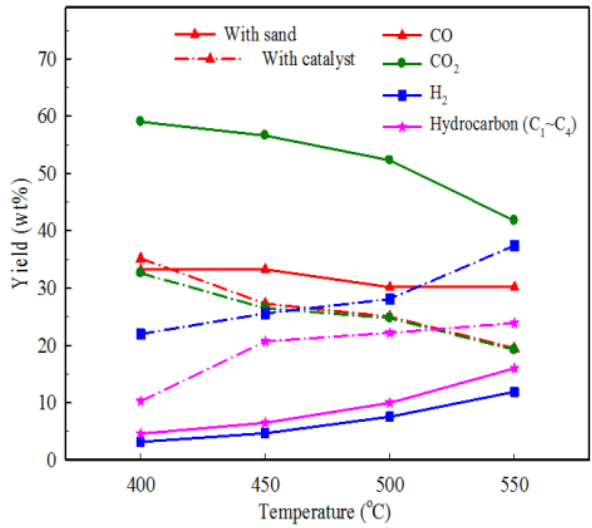

(b)

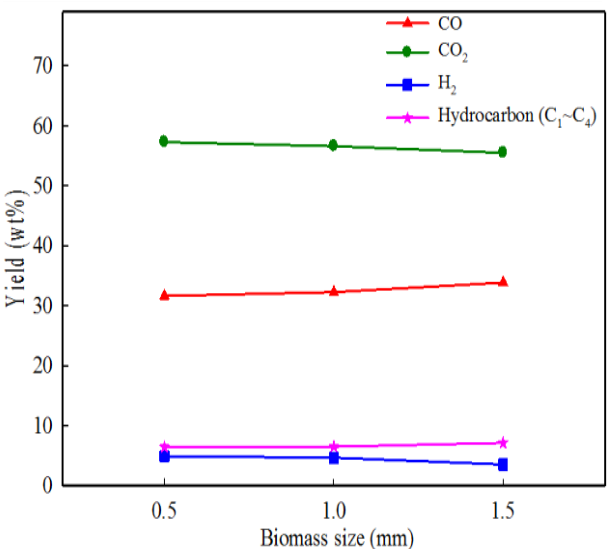

(c)

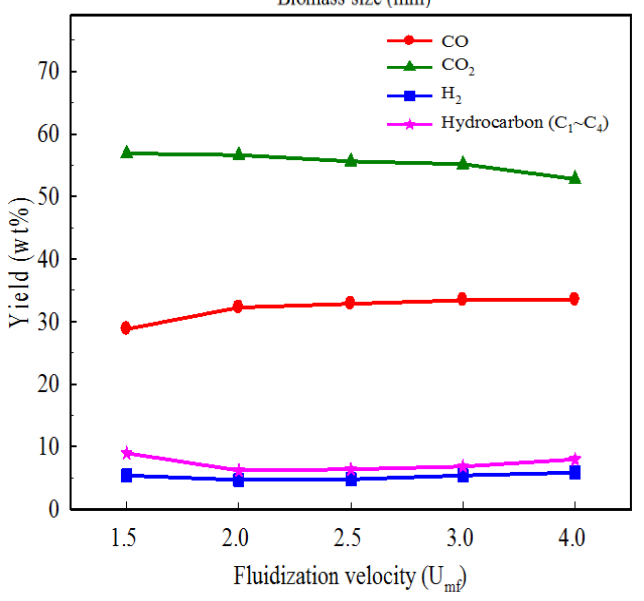

Figure 3. Effect of pyrolysis conditions on gas composition. (a) Effect of temperature. (b) Effect of biomass particle size. (c) Effect of nitrogen gas flow rate. 
$170 \quad 10^{\mathrm{TH}}$ InTERNATIONAL CONFERENCE ON SUSTAINABLE ENERGY AND ENVIRONMENTAL Protection (June $27^{\mathrm{TH}}-30^{\mathrm{TH}}, 2017$, BLed, SLOVEnia), Bioenergy AND Biofuels S.-Soo Kim, J. Kim \& H. Vu Ly: Effect of Dolomite Catalyst on Bio-Oil Production During Pyrolysis of Tulip Tree (Liriodendron) in Fluidized-Bed Reactor

Table 1. Composition of bio-oil produced from fast pyrolysis of tulip tree with and without catalyst, at $450^{\circ} \mathrm{C}$, nitrogen flow rate of $2 \mathrm{xUmf}$, and biomass particle size of 1.0 $\mathrm{mm}$.

\begin{tabular}{|c|c|c|}
\hline \multirow{2}{*}{$\begin{array}{l}\text { Composition of bio-oil from } \\
\text { pyrolysis of tulip tree at } 450^{\circ} \mathrm{C}\end{array}$} & Sand & Dolomite \\
\hline & \multicolumn{2}{|c|}{ Area \% } \\
\hline 2-Butenoic acid & 1.24 & - \\
\hline Furfural & 1.49 & 4.6 \\
\hline 2-Methyl-2-cyclopentenone & - & 1.96 \\
\hline 3-Methyl-2-cyclopentenone & 0.77 & 2.71 \\
\hline Phenol & 0.37 & 2.15 \\
\hline $\begin{array}{l}\text { 2-Hydroxy-3-methyl-2- } \\
\text { cyclopentenone }\end{array}$ & 1.92 & 2.54 \\
\hline 2,3-Dimethyl-2-cyclopentenone & 0.49 & 2.84 \\
\hline 2-Methyl phenol & - & 2.41 \\
\hline 3,5-dimethyl phenol & 0.46 & 2.57 \\
\hline 2-Methoxy-phenol & 1.54 & 2.69 \\
\hline 2-methoxy-4-methyl-phenol & 1.58 & 3.41 \\
\hline 3-methyl-1,2-Benzenediol & 1.4 & 1.82 \\
\hline 2-methoxy-4-ethyl-phenol & 1.14 & 3.35 \\
\hline 2,6-dimethoxy-Phenol & 4.47 & 5.82 \\
\hline $\begin{array}{l}\text { 3-Hydroxy-4-methoxybenzoic acid } \\
\text { (Vanillic acid) }\end{array}$ & 5.12 & 5.59 \\
\hline 2-methoxy-4-(1-propenyl)-Phenol & 3.46 & 5.13 \\
\hline Levoglucosan & 10.76 & - \\
\hline 2,6-Dimethoxy-4-allyl phenol & 9.66 & 8.85 \\
\hline
\end{tabular}

\section{Conclusions}

The fast pyrolysis performance of tulip tree was investigated in a bubbling fluidized-bed reactor at temperature between 400 and $550{ }^{\circ} \mathrm{C}$ and atmospheric pressure using silica sand and dolomite as fluidization materials. The effect of dolomite catalyst on the product yield and the quality of bio-oil were also studied. When the pyrolysis temperature increased from $400^{\circ} \mathrm{C}$ to $550^{\circ} \mathrm{C}$, the bio-oil yield was between 30.38 and $44.83 \mathrm{wt} \%$ with 
dolomite catalyst compare to those of $40.07 \mathrm{wt} \%$ and $49.03 \mathrm{wt} \%$ without catalyst. The HHVs of bio-oil from catalytic pyrolysis were in the range of $21.58-27.15 \mathrm{MJ} / \mathrm{kg}$. Using dolomite catalyst resulted in a reduction in levoglucosan and a formation of aromatic compounds $\left(\mathrm{C}_{5}-\mathrm{C}_{11}\right)$, compared to the fast pyrolysis in the absence of catalyst.

\section{Acknowledgements}

This research was supported by the Basic Science Research Program through the National Research Foundation of Korea (NRF) funded by the Ministry of Education, Science and Technology (NRF2014R1A1A4A01008538).

\section{References}

[1] H. V. Ly, S-S. Kim, J. Kim, J. H. Choi, H. C. Woo, Fast pyrolysis of macroalga Saccharina japonica in a bubbling fluidized-bed reactor for bio-oil production, Energy, vol. 93, 14361446, 2015.

[2] F. A. Agblevor, S. Beis, O. Mante, N. Abdoulmoumine, Fractional Catalytic Pyrolysis of Hybrid Poplar Wood, Ind. Eng. Chem. Res., vol. 49, pp. 3533-3538, 2010.

[3] I. Graça, J. M. Lopes, H. S. Cerqueira, M. F. Ribeiro, Bio-oils upgrading for second generation biofuels, Ind. Eng. Chem. Res. vol. 52, pp. 275-287, 2013.

[4] A. Demirbas, Calculation of higher heating values of biomass fuels, Fuel, vol. 76, pp. 431434, 1997.

[5] S. Yorgun, D. Yildiz, Slow pyrolysis of paulownia wood: Effects of pyrolysis parameters on product yields and bio-oil characterization, J. Anal. App. Pyrolysis, vol. 114, pp. 68-78, 2015.

[6] H. V. Ly, S-S. Kim, J. Kim, J. H. Choi, H. C. Woo, Fast pyrolysis of Saccharina japonica alga in a fixed-bed reactor for bio-oil production. Energ. Convers. Manage., vol. 122, pp. 526-534, 2016. 
172 10 $10^{\mathrm{TH}}$ International CONFERENCE on Sustainable ENERGy AND ENVIRONMENTal Protection (June 27 $7^{\mathrm{TH}}-30^{\mathrm{TH}}, 2017$, BLed, Slovenia), Bioenergy AND Biofuels 
$10^{\mathrm{TH}}$ InTERnational CONFERENCE ON Sustainable ENERgy AND EnVironmental Protection (June $27^{\mathrm{TH}}-30^{\mathrm{TH}}$, 2017, Bled, SLOVENIA), BIOENERGY AND BIOFUELS

J. Krope, A.Ghani Olabi, D. Goričanec \& S. Božičnik

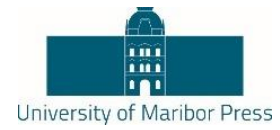

\title{
Advances in Biomass Pretreatment and Cellulosic Bioethanol Production Using Microwave Heating
}

\author{
PRANJALi D. MULEY \& DORIN BOLDOR
}

\begin{abstract}
Utilization of forest and agricultural residue for the production of cellulosic bioethanol is vital to reduce the load from food crops. Since lignocellulosic biomass resists enzymatic hydrolysis, it is crucial to deconstruct biomass to separate cellulose and hemicellulose from lignin for production of cellulosic bioethanol. Various techniques have been developed for economical and efficient biomass pretreatment. Application of reagents such as acids, alkali, ionic liquids, catalysts etc. are some of the emerging techniques that have shown promising results. Microwave heating is a rapid and energy efficient techniques that has been explored in combination with other methods for delignification for bioethanol and biogas production. In this paper we present a comprehensive review describing the application of advanced microwave technology for biomass pretreatment applied to cellulosic bioethanol and biogas production. We discuss the role of microwave chemistry in delignification and attempt to provide insights in to the chemical and physical changes of biomass brought about by microwave irradiation.
\end{abstract}

Keywords: - Microwave processing - Cellulosic bioethanol • Biomass pretreatment $\bullet$ Enzymatic hydrolysis $\bullet$ Biofuels

Correspondence Address: Pranjali D. Muley, Ph.D., Postdoctoral Researcher, Louisiana State University and Agricultural Center, Department of Biological and Agricultural Center, Baton Rouge, Louisiana 70803, USA, e-mail: pmuley1@1su.edu. Dorin Boldor, Ph.D., Charles P. Siess Professor, Louisiana State University and Agricultural Center, Department of Biological and Agricultural Center, Baton Rouge, Louisiana 70803, USA, e-mail: dboldor@agcenter.lsu.edu.

https://doi.org/10.18690/978-961-286-048-6.17

ISBN 978-961-286-048-6

(C) 2017 University of Maribor Press

Available at: http://press.um.si. 
174 10 $10^{\mathrm{TH}}$ International Conference on Sustainable Energy and Environmental Protection (June $27^{\mathrm{TH}}-30^{\mathrm{TH}}, 2017$, BLed, Slovenia), Bioenergy and Biofuels P. D. Muley \& D. Boldor: Advances in Biomass Pretreatment and Cellulosic Bioethanol Production Using Microwave Heating

\section{Introduction}

Blending bioethanol with gasoline has proven to be an effective way to reduce greenhouse gas emissions. First generation bioethanol was mainly produced from sugars derived from food crops such as corn, sugarcane and maize. Bioethanol production from cellulosic biomass has gained popularity due to the fact that it does not compete with food crops. Enzymatic saccharification is a cheaper and effective method of converting cellulose to ethanol. However, one of the main challenges of the process is low cellulose accessibility. This results in high production cost making cellulosic bioethanol less competitive. Biomass pretreatment is a crucial but costly step that involves disruption of crystalline cellulose structure and break down the lignin bonds, making cellulose more accessible for hydrolysis.

Various physical and chemical pretreatment methods have been reported on wide variety of feedstocks. Since biomass pretreament is second most cost intensive process in bioethanol production, costing about $30 \%$ of the total production cost, development of an economic and effective pretreatment method is vital. Major factor that need to be considered during pretreatment includes low chemical toxicity, high cellulose digestibility, better feedstock applicability, and energy efficiency.

Microwave heating has been extensively reported to be effective for biomass pretreatment [1-6]. Microwave process is a physio-chemical pretreatment process due to both thermal and non-thermal effects. Microwave heating has found to increase the cellulose saccharification by up to $30 \%$ compared to conventional techniques [4]. Over the years, microwave processing has been used in combination with other methods to obtain higher yields and energy efficiency. Extensive review of different biomass pretreatment techniques is available in literature. However, most of these reviews briefly cover microwave processing. The purpose of this paper is to review different microwave based pretreatment methods for bioethanol production and to discuss the role of microwave chemistry in delignification and attempt to provide insights in to the chemical and physical changes of biomass brought about by microwave irradiation.

\subsection{Biomass pretreatment mechanism}

Pretreatment of lignocellulosic biomass is a critical step in biofuel production. Cellulose is digested using enzymes and broken down to constituent sugars. These sugars are then fermented to produce bioethanol [5, 7]. However, the accessibility of cellulose for digestion is limited due to various structural, chemical and compositional limitations. Lignocellulosic biomass typically consists of cellulose, lignin and hemicellulose in a tightly bound structure (fig. 1). Deconstruction of these components is an essential step in biofuel production in order to make cellulose more accessible for enzymatic hydrolysis. Pretreatment also ensures reduced cellulose crystallinity, making it easier to breakdown. Various state of the art technologies have demonstrated promising pretreatment pathways. 


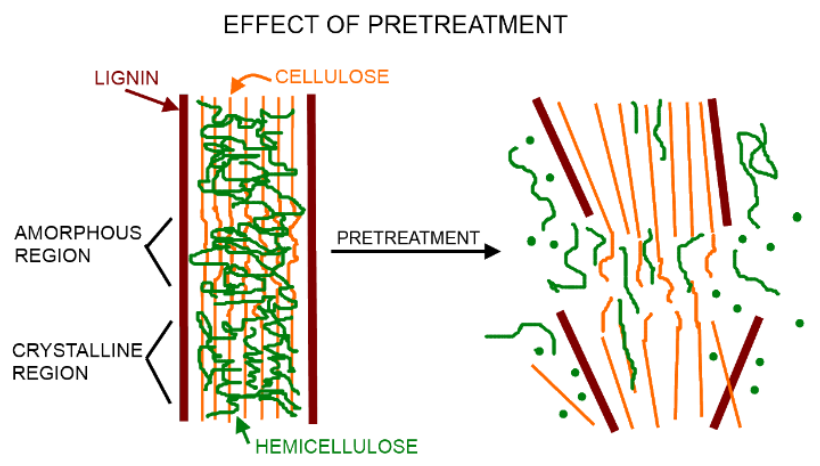

Figure 1. Schematic of pretreatment of lignocellulosic biomass (adapted from [8])

Some of the common pretreatment methods can be categorized as follows: physical pretreatment (grinding, milling), chemical (acid, alkali, solvent) and physio-chemical (steam explosion, wet oxidation, microwave and ultrasound in combination with chemical pretreatment). Physical pretreatment methods are cheaper and less energy intensive, however, the sugar yields and degree of delignification is lower. Chemical methods such as alkali and acid pretreatment have shown to increase cellulose approachability; however, residual acid and alkali could be toxic to enzymes, reducing the overall sugar yields. Milder acid and dilute alkali methods have shown to address this issue.

Microwave heating is a physio-chemical process and is generally used in combination with one of the above physical or chemical processes.

\section{Microwave Heating Mechanism}

Microwaves are electromagnetic waves in the frequency range of $300 \mathrm{MHz}$ to $300 \mathrm{GHz}$. Microwave heating is also known as dielectric heating and is mainly governed by two phenomena namely, dipole rotation and ionic conduction. Polar molecules when irradiated with microwave energy oscillate in the direction of the incident wave. These rotating molecules generate friction between the adjacent molecules, leading to microwave heating. In case of ionic conduction, presence of free ions generates heat. Ionic molecules tend to move in the direction of incident wave and collide with polar molecules on the way thus losing their kinetic energy in the form of heat energy.

Microwave heating depends on various factors such as material properties, power of operation, frequency and mode of operation. Microwave heating offers various advantages over conventional heating mechanism such as faster heating rates, shorter reaction time, volumetric heating at molecular level, high energy efficiency, low heat loss due to direct heating and product selectivity [1]. However, major drawback associated with microwave heating is non-uniform heat profiles which can be controlled with proper system design. 
$176 \quad 10^{\mathrm{TH}}$ InTERNATIONAL CONFERENCE ON SUSTAINABLE ENERGY AND ENVIRONMENTAL Protection (June $27^{\mathrm{TH}}-30^{\mathrm{TH}}, 2017$, Bled, SLOVENiA), Bioenergy AND Biofuels

P. D. Muley \& D. Boldor: Advances in Biomass Pretreatment and Cellulosic Bioethanol

Production Using Microwave Heating

\subsection{Pretreatment Mechanism Using Microwave Heating}

When lignocellulosic biomass is irradiated with microwaves, selective heating of polar molecules is observed due to the dipolar polarization effect. Cellulose molecular chains have polar structures which respond to the imparted electric field. This leads to formation of hotspots within the structure which leads to partial disruption of cell structure. This selective heating also decreases the cellulose crystallinity [1]. In presence of polar solvent, the hot spots generated could lead to rupture or explosion of some of the lignocellulosic structure, giving the solvent better access to cellulose [1].

Presence of moisture within the cell structure could also lead to cell disruption [1]. Moisture is a dielectric material that readily heats in the microwave region. When biomass is imparted with microwaves, the water molecules absorb this energy and expand, generating pressure within the cell structure which leads to the partial disruption of biomass cellular structure.

\subsection{Microwave pretreatment of biomass}

Microwave heating is generally used in combination with other pretreatment methods. Various types of biomass have been studied using microwave pretreatment for bioethanol production (Table 1). Some of the commonly studied biomass types are cellulose based grasses such as switchgrass, coastal Bermuda grass, Sorghum Bagasse, Sugarcane bagasse, Rice straw, Corn stover etc. 
$10^{\mathrm{TH}}$ INTERNATIONAL CONFERENCE ON SUSTAINABLE ENERGY AND ENVIRONMENTAL

Protection (June $27^{\mathrm{TH}}-30^{\mathrm{TH}}, 2017$, BLed, Slovenia), Bioenergy ANd Biofuels

P. D. Muley \& D. Boldor: Advances in Biomass Pretreatment and Cellulosic

Bioethanol Production Using Microwave Heating

Table 1. Pretreatment methods in combination with microwave irradiation

\begin{tabular}{|c|c|c|c|c|c|c|}
\hline $\begin{array}{l}\text { Biomass } \\
\text { type }\end{array}$ & Method & $\begin{array}{l}\text { MW } \\
\text { time } \\
\text { (min) }\end{array}$ & $\begin{array}{l}\text { Power } \\
\text { (W) } \\
\text { Temp } \\
\left({ }^{\circ} \mathrm{C}\right)\end{array}$ & $\begin{array}{l}\text { Sugar } \\
\text { Yield (\%) }\end{array}$ & $\begin{array}{l}\text { Lignin } \\
\text { removal } \\
(\%)\end{array}$ & Ref. \\
\hline \multirow[b]{2}{*}{ Switch grass } & $\begin{array}{l}\text { Dilute } \\
\text { alkali ( } 3 \% \\
\mathrm{NaOH} \text { ) }\end{array}$ & 20 & $250 \mathrm{~W}$ & 82 & 83 & [9] \\
\hline & $\begin{array}{l}\text { Water } \\
\text { goaking }\end{array}$ & - & - & 58.5 & - & [10] \\
\hline $\begin{array}{l}\text { Coastal } \\
\text { Bermudagrass }\end{array}$ & $\begin{array}{l}\text { Dilute } \\
\text { alkali ( } 3 \% \\
\mathrm{NaOH} \text { ) }\end{array}$ & 20 & $250 \mathrm{~W}$ & 87 & 81 & [9] \\
\hline $\begin{array}{l}\text { Oil palm } \\
\text { trunk }\end{array}$ & alkali & 60 & $\begin{array}{l}700 \mathrm{~W} \\
80 \mathrm{C}\end{array}$ & - & 15.33 & [11] \\
\hline $\begin{array}{l}\text { Oil palm } \\
\text { frond }\end{array}$ & alkali & 60 & $\begin{array}{l}700 \mathrm{~W} \\
80 \mathrm{C}\end{array}$ & - & 17.97 & [11] \\
\hline Sorghum & $\begin{array}{l}\text { Dilute } \\
\text { ammonia }\end{array}$ & 60 & $160 \mathrm{C}$ & - & 46 & [3] \\
\hline $\begin{array}{l}\text { Sweet } \\
\text { gorghum } \\
\text { bagasse }\end{array}$ & $\begin{array}{l}\text { lime and } \\
\text { water }\end{array}$ & 4 & $1000 \mathrm{~W}$ & 52.6 & - & {$[7]$} \\
\hline \multirow[b]{3}{*}{ Rice straw } & alkali & 15 & $140 \mathrm{C}$ & $69.3 \mathrm{~g} / \mathrm{g}$ & - & [12] \\
\hline & $\begin{array}{l}\text { Organic } \\
\text { acid }\end{array}$ & 5 & $230 \mathrm{~W}$ & 80.08 & 51.54 & [6] \\
\hline & $\mathrm{FeCl}_{2}$ & 19 & $160 \mathrm{C}$ & $\begin{array}{l}6.62 \mathrm{~g} / \mathrm{L} \\
(2.9 \text { times } \\
\text { higher than } \\
\text { untreated } \\
\text { biomass) }\end{array}$ & - & [13] \\
\hline Beech wood & $\begin{array}{l}\text { ammonium } \\
\text { molybdate } \\
\text { activated } \\
\text { by } \mathrm{H}_{2} \mathrm{O}_{2}\end{array}$ & 30 & $140 \mathrm{C}$ & 59.5 & 68.7 & [14] \\
\hline \multirow{6}{*}{$\begin{array}{l}\text { Sugarcane } \\
\text { bagasse }\end{array}$} & $\begin{array}{l}\text { dilute } \\
\text { sulfuric } \\
\text { acid }\end{array}$ & 5 & $190 \mathrm{C}$ & - & 54.24 & [4] \\
\hline & acid & 4 & $600 \mathrm{~W}$ & $\begin{array}{l}0.091 \mathrm{~g} / \mathrm{g} \\
\text { biomass }\end{array}$ & - & {$[2]$} \\
\hline & alkali & $\begin{array}{l}4 \\
5 \\
\end{array}$ & $\begin{array}{l}600 \mathrm{~W} \\
450 \mathrm{~W}\end{array}$ & $\begin{array}{l}0.665 \mathrm{~g} / \mathrm{g} \\
\text { biomass }\end{array}$ & 96 & [2] \\
\hline & Acid alkali & 4 & $600 \mathrm{~W}$ & $\begin{array}{l}0.83 \mathrm{~g} / \mathrm{g} \\
\text { biomass }\end{array}$ & - & {$[2]$} \\
\hline & $\begin{array}{l}\text { Allkali } \\
\text { goaking }\end{array}$ & 30 & $190 \mathrm{C}$ & 99 & - & [10] \\
\hline & glycerol & 5 & $240 \mathrm{C}$ & 40.2 & 58.8 & [15] \\
\hline \multirow[t]{2}{*}{ Cellulose } & Ionic liquid & $12 \mathrm{~s}$ & $50 \mathrm{~W}$ & $\begin{array}{l}4 \text { times } \\
\text { higher than } \\
\text { conventional }\end{array}$ & - & [16] \\
\hline & Ball milling & 20 & $750 \mathrm{~W}$ & 29.7 & - & [17] \\
\hline Softwood & $\begin{array}{l}\text { aqueous } \\
\text { glycerol }\end{array}$ & 6 & $180 \mathrm{C}$ & 53.1 & - & [18] \\
\hline $\begin{array}{l}\text { Garden } \\
\text { biomass }\end{array}$ & mild acid & 15 & $\begin{array}{l}200 \mathrm{C} \\
700 \mathrm{~W}\end{array}$ & 46.97 & 53.94 & [9] \\
\hline $\begin{array}{l}\text { Cashew apple } \\
\text { bagasse }\end{array}$ & alkali & 15 & $\begin{array}{l}600-900 \\
W\end{array}$ & $\begin{array}{l}355.3 \mathrm{mg} / \mathrm{g} \\
\text { glucan }\end{array}$ & - & [19] \\
\hline Corn Stover & $\begin{array}{l}\text { Steam } \\
\text { explosion }\end{array}$ & 5 & $200 \mathrm{C}$ & 75.2 & - & [20] \\
\hline
\end{tabular}


$10^{\mathrm{TH}}$ InTERNATIONAL CONFERENCE ON Sustainable ENERGy AND ENVIRONMENTAL Protection (June $27^{\mathrm{TH}}-30^{\mathrm{TH}}, 2017$, BLed, Slovenia), Bioenergy AND Biofuels P. D. Muley \& D. Boldor: Advances in Biomass Pretreatment and Cellulosic Bioethanol Production Using Microwave Heating

Microwave assisted alkali pretreatment has been vastly studied mainly due to encouraging results obtained by alkali solvent compared to acid solvent. Lai et al., studied the microwave-alkali (MA) of oil palm trunk and fronds and obtained 15-17\% total lignin removal [11].

Cheng el al., studied the effect of MA pretreatment on Rice straws at $140{ }^{\circ} \mathrm{C}$ with irradiation time of 14 min and obtained total sugar yields of $69.3 \%$ [12]. Rodrigues et al., noted that in combination with $\mathrm{NaOH}$, microwave heating at $600 \mathrm{~W}$ for 15 min resulted in $355 \mathrm{mg} / \mathrm{g}$ of glucan [19].

Dilute alkali pretreatment method has also shown to yield high sugar yields and higher lignin removal when combined with microwave heating. Keshwani et al., showed that with $3 \%$ dilute $\mathrm{NaOH}$, and 20 min irradiation time at $250 \mathrm{~W}$, total lignin removal obtained was $83 \%$ and $81 \%$ for Switchgrass and coastal Bermudagrass respectively [9]. Dilute ammonia with microwave was also tested by Chen et al., with $46 \%$ total lignin removal. These numbers are 2 folds higher than conventional heating techniques [3].

Pretreatment with acid is another highly effective method for biomass deconstruction. Acid in combination with microwave heating yields higher lignin removal. Gong et al., noted that the use of organic acid is equally effective in lignin removal. They tested the effect of acetic acid and propanoic acid on rice straw under microwave irradiation for 5 min at $230 \mathrm{~W}$ and obtained 51.54\% lignin removal [6]. Binod et al., investigated the effect of alkali, acid and alkali-acid combination in presence of microwave on sugarcane bagasse and achieved optimum sugar yields at $600 \mathrm{~W}$ and $4 \mathrm{~min}$ residence time. They also noted that at $450 \mathrm{~W}$ and $5 \mathrm{~min}$ residence time with alkali-microwave treatment, lignin removal was $96 \%$ [2].

Sugarcane bagasse was also studied by alkali soaking and glycerol treatment. With alkali soaking followed by microwave heating, sugar yields achieved were 99\% [10]. While with glycerol treatment, 58.8\% lignin was removed [15].

Some of the recent techniques involving microwave heating are use of ionic liquids for pretreatment. Ionic liquids are dielectric material and readily heat in the microwave environment. Ha et al., studied the dissolution of micro cellulose in ionic liquids in presence of microwave for increased digestibility. They noted that the yields were 4 times higher than conventional heating methods [16]. Some other chemical studied are use of $\mathrm{FeCl} 2$ on rice straw resulted in 3 times higher sugar yields than untreated biomass [13]. Verma et al., studied the use of ammonium molybdate activated by $\mathrm{H}_{2} \mathrm{O}_{2}$ in microwave at $140{ }^{\circ} \mathrm{C}$ for $30 \mathrm{~min}$ that resulted in $68.7 \%$ lignin removal. 


\section{Conclusions}

This review article gives a brief overview of microwave assisted pretreatment methods used for biomass deconstruction for bioethanol production. Microwave heating mechanism and its advantages and disadvantages are also discussed.

\section{Acknowledgements}

The authors would like to thank Candice Ellison, Lesli Sprehe, Daniel Augustine and Jacob Bursavich. The author would also like to extend their thanks to the department of Biological and Agricultural Engineering at the Louisiana State University Agricultural Center, Baton Rouge, LA USA.

\section{References}

[1] A. Aguilar-Reynosa, A. Romaní, R. M. Rodríguez-Jasso, C. N. Aguilar, G. Garrote, and H. A. Ruiz, "Microwave heating processing as alternative of pretreatment in secondgeneration biorefinery: An overview," Energy Conversion and Management, vol. 136, pp. 50-65, 2017.

[2] P. Binod, K. Satyanagalakshmi, R. Sindhu, K. U. Janu, R. K. Sukumaran, and A. Pandey, "Short duration microwave assisted pretreatment enhances the enzymatic saccharification and fermentable sugar yield from sugarcane bagasse," Renewable Energy, vol. 37, pp. 109-116, 2012.

[3] C. Chen, D. Boldor, G. Aita, and M. Walker, "Ethanol production from sorghum by a microwave-assisted dilute ammonia pretreatment," Bioresource technology, vol. 110, pp. 190-197, 2012.

[4] W.-H. Chen, Y.-J. Tu, and H.-K. Sheen, "Disruption of sugarcane bagasse lignocellulosic structure by means of dilute sulfuric acid pretreatment with microwave-assisted heating," Applied Energy, vol. 88, pp. 2726-2734, 2011.

[5] J. Gabhane, S. P. William, A. N. Vaidya, K. Mahapatra, and T. Chakrabarti, "Influence of heating source on the efficacy of lignocellulosic pretreatment-a cellulosic ethanol perspective," Biomass and bioenergy, vol. 35, pp. 96-102, 2011.

[6] G. Gong, D. Liu, and Y. Huang, "Microwave-assisted organic acid pretreatment for enzymatic hydrolysis of rice straw," Biosystems Engineering, vol. 107, pp. 67-73, 10// 2010.

[7] R. Choudhary, A. L. Umagiliyage, Y. Liang, T. Siddaramu, J. Haddock, and G. Markevicius, "Microwave pretreatment for enzymatic saccharification of sweet sorghum bagasse," Biomass and Bioenergy, vol. 39, pp. 218-226, 4// 2012.

[8] N. Mosier, C. Wyman, B. Dale, R. Elander, Y. Y. Lee, M. Holtzapple, et al., "Features of promising technologies for pretreatment of lignocellulosic biomass," Bioresource Technology, vol. 96, pp. 673-686, 4// 2005.

[9] D. R. Keshwani and J. J. Cheng, "Microwave-based alkali pretreatment of switchgrass and coastal bermudagrass for bioethanol production," Biotechnology progress, vol. 26, pp. 644-652, 2010.

[10] Z. Hu and Z. Wen, "Enhancing enzymatic digestibility of switchgrass by microwaveassisted alkali pretreatment," Biochemical Engineering Journal, vol. 38, pp. 369-378, 3/15/ 2008. 
$180 \quad 10^{\mathrm{TH}}$ InTERNATIONAL CONFERENCE ON SUSTAINABLE ENERGY AND ENVIRONMENTAL Protection (June $27^{\mathrm{TH}}-30^{\mathrm{TH}}, 2017$, BLed, Slovenia), Bioenergy AND Biofuels P. D. Muley \& D. Boldor: Advances in Biomass Pretreatment and Cellulosic Bioethanol Production Using Microwave Heating

[11] L.-W. Lai and A. Idris, "Disruption of oil palm trunks and fronds by microwave-alkali pretreatment," BioResources, vol. 8, pp. 2792-2804, 2013.

[12] J. Cheng, H. Su, J. Zhou, W. Song, and K. Cen, "Microwave-assisted alkali pretreatment of rice straw to promote enzymatic hydrolysis and hydrogen production in dark- and photo-fermentation," International Journal of Hydrogen Energy, vol. 36, pp. 2093-2101, 2// 2011.

[13] J. Lü and P. Zhou, "Optimization of microwave-assisted $\mathrm{FeCl} 3$ pretreatment conditions of rice straw and utilization of Trichoderma viride and Bacillus pumilus for production of reducing sugars," Bioresource Technology, vol. 102, pp. 6966-6971, 7// 2011.

[14] P. Verma, T. Watanabe, Y. Honda, and T. Watanabe, "Microwave-assisted pretreatment of woody biomass with ammonium molybdate activated by $\mathrm{H} 2 \mathrm{O} 2$," Bioresource technology, vol. 102, pp. 3941-3945, 2011.

[15] M. M. d. S. Moretti, D. A. Bocchini-Martins, C. d. C. C. Nunes, M. A. Villena, O. M. Perrone, R. d. Silva, et al., "Pretreatment of sugarcane bagasse with microwaves irradiation and its effects on the structure and on enzymatic hydrolysis," Applied Energy, vol. 122, pp. 189-195, 6/1/ 2014.

[16] S. H. Ha, N. L. Mai, G. An, and Y.-M. Koo, "Microwave-assisted pretreatment of cellulose in ionic liquid for accelerated enzymatic hydrolysis," Bioresource Technology, vol. 102, pp. 1214-1219, 1// 2011.

[17] H. Peng, H. Li, H. Luo, and J. Xu, "A novel combined pretreatment of ball milling and microwave irradiation for enhancing enzymatic hydrolysis of microcrystalline cellulose," Bioresource Technology, vol. 130, pp. 81-87, 2// 2013.

[18] J. Liu, R. Takada, S. Karita, T. Watanabe, Y. Honda, and T. Watanabe, "Microwaveassisted pretreatment of recalcitrant softwood in aqueous glycerol," Bioresource Technology, vol. 101, pp. 9355-9360, 12// 2010.

[19] T. H. S. Rodrigues, M. V. P. Rocha, G. R. de Macedo, and L. R. B. Gonçalves, "Ethanol Production from Cashew Apple Bagasse: Improvement of Enzymatic Hydrolysis by Microwave-Assisted Alkali Pretreatment," Applied Biochemistry and Biotechnology, vol. 164, pp. 929-943, 2011.

[20] F. Pang, S. Xue, S. Yu, C. Zhang, B. Li, and Y. Kang, "Effects of combination of steam explosion and microwave irradiation (SE-MI) pretreatment on enzymatic hydrolysis, sugar yields and structural properties of corn stover," Industrial Crops and Products, vol. 42, pp. 402-408, 3// 2013. 
$10^{\mathrm{TH}}$ InTERnational CONFERENCE ON Sustainable ENERgy AND ENVIRONMENTAL Protection (June $27^{\mathrm{TH}}-30^{\mathrm{TH}}$, 2017, Bled, SLOVENIA), BIOENERGY AND BIOFUELS

J. Krope, A.Ghani Olabi, D. Goričanec \& S. Božičnik

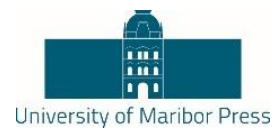

\title{
Optimization of the Biohydrogen Production by Anaerobic Granular Sludge Using Mixtures of Wheat Straw Hydrolysate and Cheese Whey as Substrates
}

\author{
ANGEl Mario LOPEZ-Hidalgo, ZaZIL DonaXi Alvarado-Cuevas, Jose TOMAS \\ ORNELAS SALAS \& ANTONIO DE LEON-RODRIGUEZ
}

\begin{abstract}
Cheese whey $(\mathrm{CW})$ and wheat straw hydrolysate (WSH) were used to produce biohydrogen by anaerobic co-digestion of multiple substrates. Response surface methodology (RSM) was used to evaluate the individual and interactive effects of $\mathrm{pH}$, temperature, $\mathrm{CW}$ concentration and WSH concentration in the fermentation. Optimal operational conditions obtained by RMS were $5 \mathrm{~g} \mathrm{~L}-1 \mathrm{WSH}, 25 \mathrm{~g} \mathrm{~L}-1 \mathrm{CW}, 26.6^{\circ} \mathrm{C}$ and $\mathrm{pH}$ 7.25. With these conditions was expected $5724.5 \mathrm{~mL} \mathrm{H} 2 \mathrm{~L}-1$. When optimal conditions were tested using 0.11 -L anaerobic serological bottles the result obtained for biohydrogen production was $4554.5 \pm 105 \mathrm{~mL} \mathrm{H} 2$ L-1. Results demonstrate that it is possible to use WSH and CW, both individually or in combination, as a substrate for the production of biohydrogen.
\end{abstract}

Keywords: • Biohydrogen $•$ Co-digestion $・$ Dark fermentation $・$ Cheese whey $\bullet$ Wheat straw hydrolysate $\bullet$

CoRRESPONDENCE AdDRESS: Angel Mario Lopez-Hidalgo, MSc, PhD student, Institute for Scientific and Technological Research of San Luis Potosi, Department of Molecular Biology, San Luis Potosi, Mexico, email: angel.lopez@ipicyt.edu.mx. Zazil Donaxi Alvarado-Cuevas, MSc, $\mathrm{PhD}$ student, Institute for Scientific and Technological Research of San Luis Potosi, Department of Molecular Biology, San Luis Potosi, Mexico, email: zazil.alvarado@ipicyt.edu.mx. Jose Tomas Ornelas-Salas, MSc, Professor, Autonomous University of Guadalajara, Science Faculty, Zapopan, Jalisco, Mexico, email: tornelas@uag.mx. Antonio De Leon-Rodriguez, PhD, Professor, Institute for Scientific and Technological Research of San Luis Potosi, Department of Molecular Biology, San Luis Potosi, Mexico, email: aleonr@ipicyt.edu.mx, aleonr@me.com.

https://doi.org/10.18690/978-961-286-048-6.18

ISBN 978-961-286-048-6

(C) 2017 University of Maribor Press

Available at: http://press.um.si. 
182 10 $10^{\mathrm{TH}}$ International Conference on Sustainable Energy and EnVironmental Protection (June $27^{\mathrm{TH}}-30^{\mathrm{TH}}, 2017$, BLED, SLOVENIA), BioENERGY AND Biofuels A. Mario Lopez-Hidalgo, Z. Donaxi Alvarado-Cuevas, J. Tomas Ornelas Salas \& A. De Leon-Rodriguez: Optimization of the Biohydrogen Production by Anaerobic Granular Sludge Using Mixtures of Wheat Straw Hydrolysate and Cheese Whey as Substrates $t$

Exhaustion of fossil fuel resources and environmental damages due to petroleum production and consumption, highlight the importance of a shift to renewable sources for fuels. Biohydrogen is a sustainable form of energy as it can be produced from organic wastes through fermentation processes such as dark fermentation. This process also produces fermented by-products (fatty acids and solvents), thus there is an opportunity for further combination with other processes that yield more bioenergy [1]. Organic wastes are abundant sources of renewable and low cost substrate that can be efficiently fermented by microorganisms. The main criteria for the selection of waste materials to be used in biohydrogen production are the availability, cost, carbohydrate content and biodegradability. Simple sugars such as glucose, sucrose and lactose are readily biodegradable and preferred substrates for hydrogen production. However, pure carbohydrate sources are expensive raw materials for hydrogen production [2]. The advantages of using organic wastes for biohydrogen are: reduction of $\mathrm{CO}_{2}$ and other pollutants emissions, value added agricultural waste, partial substitution of fossil fuels with sustainable biomass fuel, and reduction of environmental and economic costs for diverging the disposition of municipal solid wastes [1]. The production of renewable energy, a reduction of waste and prevention of environmental pollution promote the industrial application of anaerobic co-digestion for the treatment of agro-industrial organic wastes. Co-digestion is defined as the anaerobic treatment of a mixture of at least two different waste types with the aim of improving the efficiency of the anaerobic digestion process [3].

\section{$2 \quad$ Material and Methods}

\subsection{Substrates and inoculum}

CW was purchased from Land O'Lakes Inc. (Arden Hills, Minnesota) and WSH was obtained from CUCBA (University of Guadalajara, Jalisco, Mex). The lactose content of CW solution was $6.9 \mathrm{~g} \mathrm{~L}^{-1}$. WSH contained $21,1.54,13.96$ and $1.93 \mathrm{~g} \mathrm{~L}^{-1}$ of reducing sugars, glucose, xylose and arabinose, respectively. Anaerobic granular sludge was obtained from a wastewater treatment plant in San Luis Potosi, Mexico. The granular sludge was washed with three volumes of tap water and then boiled for $40 \mathrm{~min}$ to inactivate methanogenic microflora and stored at $4^{\circ} \mathrm{C}$ before use.

\subsection{Experimental design}

A Central Composite experimental design with six central points (Table 1) was used to find the optimal conditions for biohydrogen production using mixtures of CW and WSH as substrate. The independent variables were $\mathrm{pH}$, temperature and concentration of $\mathrm{CW}$ and WSH. Three levels for each variable were included and 2 star points. The response variable was biohydrogen production $\left(\mathrm{H}_{2}\right)$. The experiments were performed in $120 \mathrm{~mL}$ anaerobic serological bottles with a working volume of $110 \mathrm{~mL}$, all bottles containing 
medium B [4], $2.75 \mathrm{~g} \mathrm{~L}^{-1}$ yeast extract, and $\mathrm{CW}$ and $\mathrm{WSH}$ at the determined concentrations of experimental design. The cultures were shaken at $175 \mathrm{rpm}$ during the period of experiment. Consequently, the data was analyzed by the response surface methodology (RSM). Analysis of variance (ANOVA), RSM and the optimum conditions were performed using Design-Expert ${ }^{\circledR}$ software (version 7.0 Stat-Ease, Inc.). ANOVA $F$ test was used to assess the adjusted models. The significance of each coefficient was determined with the $t$ test with a $p$-value less than 0.05 . Hierarchical clustering analysis (HCA) was performed using Origin ${ }^{\circledR}$ 9. The results of the HCA are presented in the form of dendrogram to identify the similarity measure between experiments of the Central Composite experimental design.

\subsection{Analytical methods}

The gas production was measured by $1 \mathrm{~N} \mathrm{NaOH}$ displacement in an inverted burette connected to the bioreactor or to serological bottles with rubber tubing and a needle. Hydrogen content in the gas phase was measured using a Gas Chromatograph model 6890N (Agilent Technologies, Wilmington, DE) as described previously [5].

\section{$3 \quad$ Results}

\subsection{Optimization of the Culture Conditions to Improve Biohydrogen Production}

The effect of substrates concentrations, temperature and $\mathrm{pH}$ in biohydrogen production was evaluated with a Central Composite experimental design (Table 1). Central points (experiments $3,10,13,16,18,21$ ) attained a production average of $3592.3 \pm 167.6 \mathrm{~mL}$ $\mathrm{H}_{2} \mathrm{~L}^{-1}$. The highest production was obtained in experiment 11 with $5359.1 \mathrm{~mL} \mathrm{H}_{2} \mathrm{~L}^{-1}$ at $20 \mathrm{~g} \mathrm{~L}^{-1} \mathrm{WSH}, 10 \mathrm{~g} \mathrm{~L}^{-1} \mathrm{CW}$ and $28^{\circ} \mathrm{C}$, with an initial $\mathrm{pH}$ of 7.5. Experiments with $\mathrm{pH} \leq$ 5.5 and temperatures $<28^{\circ} \mathrm{C}$ or $\geq 46^{\circ} \mathrm{C}$, obtained less than $70 \mathrm{~mL} \mathrm{H}_{2} \mathrm{~L}^{-1}$. 
184 10 $10^{\mathrm{TH}}$ InTERnAtional CONFERENCE ON Sustainable ENERGy AND ENVIRONMENTAL Protection (June $27^{\mathrm{TH}}-30^{\mathrm{TH}}, 2017$, BLed, Slovenia), Bioenergy AND Biofuels

A. Mario Lopez-Hidalgo, Z. Donaxi Alvarado-Cuevas, J. Tomas Ornelas Salas \& A. De Leon-Rodriguez: Optimization of the Biohydrogen Production by Anaerobic Granular Sludge Using Mixtures of Wheat Straw Hydrolysate and Cheese Whey as Substrates $t$

Table 2 Central Composite experimental design and corresponding results by anaerobic granular sludge using mixtures of wheat straw hydrolysate and cheese whey as substrate

\begin{tabular}{|c|c|c|c|c|c|}
\hline Experi-ment & $\begin{array}{c}\mathrm{WSH}^{\mathrm{a}}\left(\mathrm{g} \mathrm{L}^{-}\right. \\
\left.{ }^{1}\right)\end{array}$ & $\mathrm{CW}^{\mathrm{b}}\left(\mathrm{g} \mathrm{L}^{-1}\right)$ & $\mathrm{T}\left({ }^{\circ} \mathrm{C}\right)$ & $\mathrm{pH}$ & $\mathrm{H}_{2}{ }^{\mathrm{c}}\left(\mathrm{mL} \mathrm{H}_{2} \mathrm{~L}^{-1}\right)$ \\
\hline 1 & 10 & 20 & 28 & 7.5 & 4963.6 \\
\hline 2 & 10 & 20 & 46 & 7.5 & 4.5 \\
\hline 3 & 15 & 15 & 37 & 6.5 & 3709.1 \\
\hline 4 & 20 & 10 & 28 & 5.5 & 0.0 \\
\hline 5 & 20 & 20 & 28 & 7.5 & 4731.8 \\
\hline 6 & 10 & 10 & 28 & 7.5 & 3425.5 \\
\hline 7 & 20 & 10 & 46 & 7.5 & 0.0 \\
\hline 8 & 20 & 20 & 46 & 7.5 & 0.0 \\
\hline 9 & 15 & 15 & 37 & 4.5 & 9.1 \\
\hline 10 & 15 & 15 & 37 & 6.5 & 3572.7 \\
\hline 11 & 20 & 10 & 28 & 7.5 & 5359.1 \\
\hline 12 & 15 & 15 & 19 & 6.5 & 4.5 \\
\hline 13 & 15 & 15 & 37 & 6.5 & 3718.2 \\
\hline 14 & 20 & 20 & 46 & 5.5 & 4.5 \\
\hline 15 & 5 & 15 & 37 & 6.5 & 2972.7 \\
\hline 16 & 15 & 15 & 37 & 6.5 & 3618.2 \\
\hline 17 & 15 & 15 & 55 & 6.5 & 45.5 \\
\hline 18 & 15 & 15 & 37 & 6.5 & 3666.4 \\
\hline 19 & 10 & 20 & 46 & 5.5 & 36.4 \\
\hline 20 & 20 & 20 & 28 & 5.5 & 63.6 \\
\hline 21 & 15 & 15 & 37 & 6.5 & 3269.1 \\
\hline 22 & 10 & 10 & 28 & 5.5 & 27.3 \\
\hline 23 & 15 & 5 & 37 & 6.5 & 3450.0 \\
\hline 24 & 10 & 20 & 28 & 5.5 & 3750.0 \\
\hline 25 & 15 & 25 & 37 & 6.5 & 4518.2 \\
\hline 26 & 15 & 15 & 37 & 8.5 & 3601.8 \\
\hline 27 & 20 & 10 & 46 & 5.5 & 9.1 \\
\hline 28 & 10 & 10 & 46 & 7.5 & 0.0 \\
\hline 29 & 25 & 15 & 37 & 6.5 & 4559.1 \\
\hline 30 & 10 & 10 & 46 & 5.5 & 0.0 \\
\hline
\end{tabular}

${ }^{a}$ Wheat straw hydrolysate. ${ }^{\mathrm{b}}$ Cheese whey. ${ }^{\mathrm{c}}$ Biohydrogen production. 
A. Mario Lopez-Hidalgo, Z. Donaxi Alvarado-Cuevas, J. Tomas Ornelas Salas \& A.

De Leon-Rodriguez: Optimization of the Biohydrogen Production by Anaerobic Granular Sludge Using Mixtures of Wheat Straw Hydrolysate and Cheese Whey as Substrates
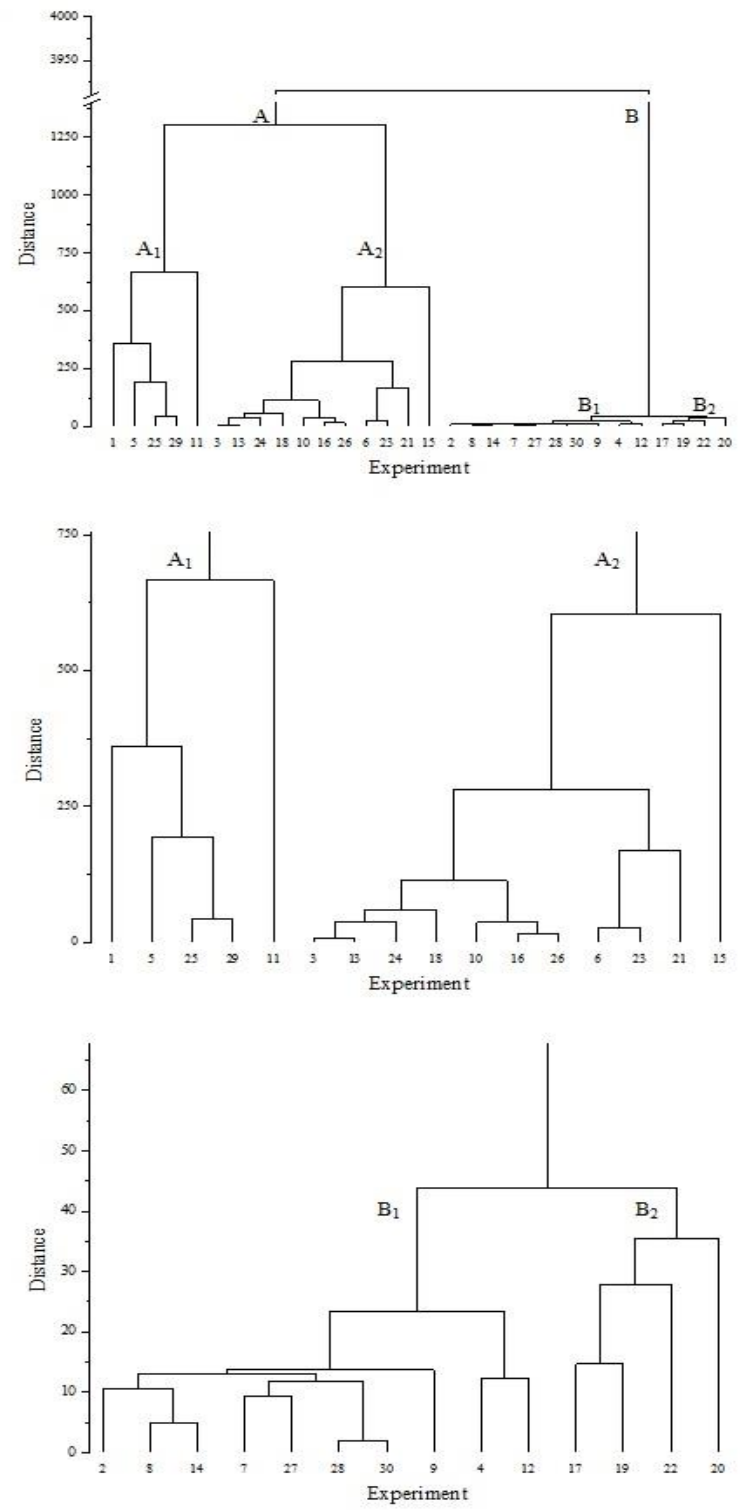

Figure 2 Dendrogram of (a) 30 experiments from the Central Composite experimental design in the space of four measured parameters (listed in Table 1), (b) sub-clusters $A_{1}$ and $\mathrm{A}_{2}$ and (c) sub-clusters $\mathrm{B}_{1}$ and $\mathrm{B}_{2}$ 
$186 \quad 10^{\mathrm{TH}}$ InTERnATIONAL CONFERENCE ON Sustainable ENERGY AND ENVIRONMENTAL Protection (June $27^{\mathrm{TH}}-30^{\mathrm{TH}}, 2017$, BLed, Slovenia), Bioenergy AND Biofuels A. Mario Lopez-Hidalgo, Z. Donaxi Alvarado-Cuevas, J. Tomas Ornelas Salas \& A. De Leon-Rodriguez: Optimization of the Biohydrogen Production by Anaerobic Granular Sludge Using Mixtures of Wheat Straw Hydrolysate and Cheese Whey as Substrates t

The dendrogram presenting the 30 experiments from the Central Composite experimental design in the space of four measured parameters (Figure 1a) revealed two main clusters. Cluster A collected experiments incubated at temperatures lower than $46^{\circ} \mathrm{C}$ but higher than $19^{\circ} \mathrm{C}$ and with biohydrogen production exceeding $2950 \mathrm{ml} \mathrm{H}_{2} \mathrm{~L}^{-1}$. Cluster B grouped experiments with biohydrogen production lower than $70 \mathrm{~mL} \mathrm{H}_{2} \mathrm{~L}^{-1}$.

Furthermore, in cluster A two sub-clusters (Figure 1b) could be distinguished:

- Sub-cluster $\mathrm{A}_{1}$ composed of experiments with initial $\mathrm{pH}$ of 6.5 or 7.5 , and 4500 $\mathrm{mL} \mathrm{H}_{2} \mathrm{~L}^{-1}<\mathrm{H}_{2}<5400 \mathrm{~mL} \mathrm{H}_{2} \mathrm{~L}^{-1}$, and

- Sub-cluster $\mathrm{A}_{2}$ grouping experiments with initial $\mathrm{pH}$ of 5.5, 6.5, 7.5 and 8.5. The biohydrogen production in this sub-cluster is between 2970 and $3750 \mathrm{~mL}$ $\mathrm{H}_{2} \mathrm{~L}^{-1}$.

Also, in cluster B two sub-clusters (Figure 1c) could be observed:

- Sub-cluster $\mathrm{B}_{1}$ including experiments 2, 4, 7, 8, 9, 12, 14, 27, 28 and 30, and

- Sub-cluster $B_{2}$ collecting experiments 17, 19, 22 and 20.

The mathematical model representing the variable response as a function of the evaluated variables in the experimental region are expressed by the Equation (1):

$H_{2}\left(m L H_{2} L^{-1}\right)=-71,174.90531-161.58097 \times \mathrm{WSH}+839.50917 \times \mathrm{CW}+$ $1,586.19349 \times \mathrm{T}+11,918.30972 \times \mathrm{pH}-14.67500 \times \mathrm{WSH} \times \mathrm{CW}+2.75639 \times \mathrm{WSH} \times$ $\mathrm{T}+67.92250 \times \mathrm{WSH} \times \mathrm{pH}-6.47333 \times \mathrm{CW} \times \mathrm{T}-36.28500 \times \mathrm{CW} \times \mathrm{pH}-101.97639 \times$ $\mathrm{T} \times \mathrm{pH}-5.07733 \times \mathrm{WSH}^{2}-2.89233 \times \mathrm{CW}^{2}-13.11214 \times \mathrm{T}^{2}-591.97083 \times \mathrm{pH}^{2}(1)$

With the ANOVA it was established that $\mathrm{H}_{2}$ was affected significantly $(p<0.05)$ by $\mathrm{T}$, $\mathrm{pH}, \mathrm{T} \cdot \mathrm{pH}, \mathrm{T}^{2}$ and $\mathrm{pH}^{2}$ (Table 2). Maximum biohydrogen production of $5724.5 \mathrm{~mL} \mathrm{H}_{2} \mathrm{~L}^{-}$ ${ }^{1}$ can be attained at WSH $5 \mathrm{~g}^{\mathrm{TRS} \mathrm{L}}{ }^{-1}, \mathrm{CW} 25 \mathrm{~g} \mathrm{~L}^{-1} \mathrm{CW}, 26.6^{\circ} \mathrm{C}$ and initial $\mathrm{pH}$ 8.5. To verify the predicted results, additional experiments were performed by triplicate using these optimized conditions and the biohydrogen production attained was $4554.55 \pm 10.9$ $\mathrm{mL} \mathrm{H}_{2} \mathrm{~L}^{-1}$ (Figure 2). The optimization of operational conditions using RSM was successful because the result obtained is within the confidence interval. 
$10^{\mathrm{TH}}$ INTERNATIONAL CONFERENCE ON SUSTAINABLE ENERGY AND ENVIRONMENTAL Protection (June $27^{\mathrm{TH}}-30^{\mathrm{TH}}, 2017$, BLed, Slovenia), Bioenergy and Biofuels

A. Mario Lopez-Hidalgo, Z. Donaxi Alvarado-Cuevas, J. Tomas Ornelas Salas \& A.

De Leon-Rodriguez: Optimization of the Biohydrogen Production by Anaerobic Granular Sludge Using Mixtures of Wheat Straw Hydrolysate and Cheese Whey as

Substrates

Table $3 \mathrm{~F}$-value and $p$-value for biohydrogen production

\begin{tabular}{ccc}
\hline Source & F-value & $p$-value \\
\hline Model & 4.77 & 0.0024 \\
$\mathrm{WSH}$ & 0.036 & 0.8521 \\
$\mathrm{CW}$ & 1.32 & 0.2687 \\
$\mathrm{~T}$ & 13.76 & 0.0021 \\
$\mathrm{pH}$ & 13.75 & 0.0021 \\
$\mathrm{WSH} \cdot \mathrm{CW}$ & 1.44 & 0.2480 \\
$\mathrm{WSH} \cdot \mathrm{T}$ & 0.17 & 0.6902 \\
$\mathrm{WSH} \cdot \mathrm{pH}$ & 1.24 & 0.2834 \\
$\mathrm{CW} \cdot \mathrm{T}$ & 0.91 & 0.3550 \\
$\mathrm{CW} \cdot \mathrm{pH}$ & 0.35 & 0.5611 \\
$\mathrm{~T} \bullet \mathrm{pH}$ & 9.04 & 0.0088 \\
$\mathrm{WSH}$ & 0.5941 \\
$\mathrm{CW}$ & 0.30 & 0.7607 \\
$\mathrm{~T}^{2}$ & 0.096 & 0.0004 \\
$\mathrm{pH}$ & 20.76 & 0.0227 \\
\hline
\end{tabular}
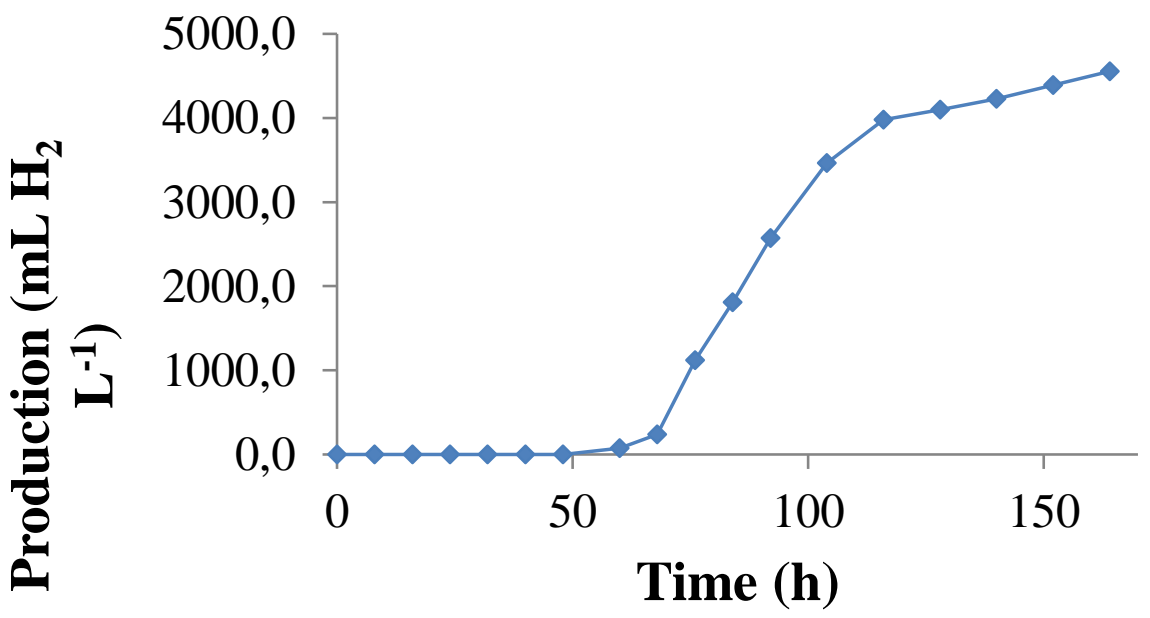

Figure 3 Biohydrogen production in batch culture of anaerobic sludge at optimal conditions $\left(5 \mathrm{~g} \mathrm{~L}^{-1} \mathrm{WSH}, 25 \mathrm{~g} \mathrm{~L}^{-1} \mathrm{CW}, 26.6^{\circ} \mathrm{C}\right.$ and $\left.\mathrm{pH} 7.25\right)$ in $0.11-\mathrm{L}$ Serological Bottles 
$10^{\mathrm{TH}}$ InTERnATIONAL CONFERENCE ON Sustainable ENERGy AND ENVIRONMENTAL Protection (June $27^{\mathrm{TH}}-30^{\mathrm{TH}}, 2017$, Bled, Slovenia), Bioenergy AND Biofuels A. Mario Lopez-Hidalgo, Z. Donaxi Alvarado-Cuevas, J. Tomas Ornelas Salas \& A. De Leon-Rodriguez: Optimization of the Biohydrogen Production by Anaerobic Granular Sludge Using Mixtures of Wheat Straw Hydrolysate and Cheese Whey as Substrates $t$

\section{Conclusion}

Biohydrogen production using the co-digestion of two different sources of carbohydrates by anaerobic granular sludge was successful. Through ANOVA analysis we observe that temperature and $\mathrm{pH}$ are the most important variables in the biohydrogen production. Also the proposed mathematical model proved to be valuable for optimizing the biohydrogen production with the optimal conditions of $5 \mathrm{~g} \mathrm{~L}^{-1} \mathrm{WSH} 25 \mathrm{~g} \mathrm{~L}^{-1} \mathrm{CW}, 26.6^{\circ} \mathrm{C}$ and $\mathrm{pH} 7.25$.

\section{Acknowledgements}

We thank to partial funding through the CONACyT-Básicas Grant 178988 y Problemas Nacionales Grant 247498. A.M. Lopez-Hidalgo would like to thank CONACYT for his scholarship (26109). We also thank L. Aldana for the English revision.

\section{References}

[1] H. M. Poggi-Varaldo, K. M. Munoz-Paez, C. Escamilla-Alvarado, P. N. Robledo-Narváez, M. T. Ponce-Noyola, G. Calva-Calva, E. Ríos-Leal, J. Galíndez-Mayer, C. EstradaVázquez, A. Ortega-Clemente, and N. F. Rinderknecht-Seijas, "Biohydrogen, biomethane and bioelectricity as crucial components of biorefinery of organic wastes: a review," Waste Manag. Res., vol. 32, no. 5, pp. 353-65, 2014.

[2] I. K. Kapdan and F. Kargi, "Bio-hydrogen production from waste materials," Enzyme Microb. Technol., vol. 38, no. 5, pp. 569-582, 2006.

[3] A. Hublin and B. Zelic, "Modelling of the whey and cow manure co-digestion process," Waste Manag. Res., vol. 31, no. 4, pp. 353-360, 2013.

[4] G. Davila-Vazquez, A. de León-Rodríguez, F. Alatriste-Mondragón, and E. Razo-Flores, "The buffer composition impacts the hydrogen production and the microbial community composition in non-axenic cultures," Biomass and Bioenergy, vol. 35, no. 7, pp. 31743181, 2011.

[5] G. Davila-Vazquez, F. Alatriste-Mondragón, A. de León-Rodríguez, and E. Razo-Flores, "Fermentative hydrogen production in batch experiments using lactose, cheese whey and glucose: Influence of initial substrate concentration and pH," Int. J. Hydrogen Energy, vol. 33, no. 19, pp. 4989-4997, 2008. 
$10^{\mathrm{TH}}$ InTERnational CONFERENCE ON Sustainable ENERgy AND ENVIRONMENTAL Protection (June $27^{\mathrm{TH}}-30^{\mathrm{TH}}$, 2017, Bled, SLOVENIA), BIOENERGY AND BIOFUELS

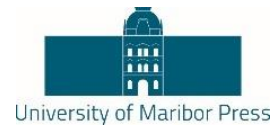

\title{
Bioreactor Study of Using Medicinal Herbs and Edible Flora to Stimulate Microbial Fuel Cells for Electrochemically-Steered Bioremediation
}

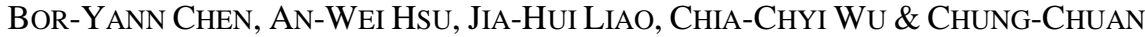 \\ HSUEH
}

\begin{abstract}
Prior studies revealed that biodecolorized intermediates owned capabilities as electron shuttles (ESs) to stimulate reductive decolorization and bioelectricity generation. Recent findings indicated that both antioxidant characteristics and electron-shuttling potential of chemical species are strongly associated. In fact, these properties are also directly proportional to contents of polyphenolics and/or flavonoids. This study quantitatively disclosed such correlations with electrochemical inspections for clarification. Moreover, performance of bioelectricity generation using microbial fuel cells could be significantly augmented via supplementation of extracts of ES-rich medicinal herbs and edible flora. This study also evaluated redox potential profiles $(\mathrm{CV})$ and antioxidant capabilities (DPPH) of herbs or flora for technical feasibility of applications. The finding uncovered that extacts of Syzygium aromaticum, Lonicera japonica and green tea were promising ES-abundant herbs/flora for energy extraction. Due to reversible ES characteristics, wastes of medicinal herbs and edible flora could be reused in electrochemically-steered applications to bioenergy and biorefinery.
\end{abstract}

Keywords: • Medicinal herbs $\bullet$ Edible flora $・$ Electron shuttle $\bullet$ Biofuel cells • Bioenergy recycling •

CoRrespondence AdDRess: Bor-Yann Chen, Ph.D., Professor, National I-Lan University, Department of Chemical and Materials Engineering, I-Lan 26047, Taiwan, e-mail: boryannchen@yahoo.com.tw. An-Wei Hsu, Assistant, National I-Lan University, Department of Chemical and Materials Engineering, I-Lan 26047, Taiwan, e-mail: kimk@kimo.com. Jia-Hui Liao, Assistant, National I-Lan University, Faculty of Chemical and Materials Engineering, I-Lan 26047, Taiwan, email: lisa22684047@gmail.com. Chia-Chyi Wu, Ph.D., Associate Professor, National I-Lan University, Department of Horticulture, I-Lan 26047, Taiwan, email: angwu@niu.edu.tw. Chung-Chuan Hsueh, Ph.D., Professor, National I-Lan University, Department of Chemical and Materials Engineering, I-Lan 26047, Taiwan; email: cchsueh@niu.edu.tw. 
$190 \quad 10^{\mathrm{TH}}$ International Conference on Sustainable Energy and Environmental Protection (June $27^{\mathrm{TH}}-30^{\mathrm{TH}}, 2017$, BLED, SLOVENIA), BioENERGY AND Biofuels B.-Yann Chen, A.-Wei Hsu, J.-Hui Liao, C.-Chyi Wu \& C.-Chuan Hsueh: Bioreactor Study of Using Medicinal Herbs and Edible Flora to Stimulate Microbial Fuel Cells for Electrochemically-Steered Bioremediation

For sustainable development, exploration of abundant biodiversity in densely populated and resource-deficient Taiwan is of great importance. In particular, seeking sources of renewable energy to guarantee energy security becomes top-priority issue without dispute. Thus, for energy-saving decontamination, natural bioremediation of organic pollutants via electron transfer (ET)-stimulated redox reactions was first to be implemented with consideration of environmental friendliness. Apparently, using microbial fuel cells (MFCs) as operation strategy to effectively enhance ET capability for biodegradation seemed to be more economically-appropriate due to favourable characteristics of such electrochemically-steered stimulation. For system optimization, prior quantitative findings [1][2] also revealed that augmentation of electron shuttles (ESs) [3][4] from natural bioresource was the most cost-effective and energy-promising for such bioelectrochemically catalysed biodegradation. From chemical-structure aspect, when hydroxyl $(-\mathrm{OH})$ substituents are present on the benzene ring of compounds (e.g., 2-, 4-aminophenol, hydroquinone), such chemicals could act as redox-mediators to significantly stimulate electron-shuttling capabilities for dye decolorization as well as bioelectricity generation [5]. Prior studies [1][2] revealed that biodecolorized intermediates with amino and/or hydroxyl substiuent(s) showed synergistic capabilities as more promising ESs to stimulate reductive decolorization and bioelectricity generation. However, for practices with environmental friendliness, using natural materials in place of artifically synthesized chemicals would be top priority consideration in public domain. Recent findings [6][7] indicated that both antioxidant characteristics and electron-shuttling potential of chemical species are strongly bioelectrochemically associated. Considering such hydroxyl substituent(s)-abundant bioresource, edible flora and medicinal herbs contained significant contents of polyphenols (e.g., antioxidant-rich chemicals: flavanol, catechin, anthocyanidines; [8][9]) and will be biocompatible ESs for diverse sustainable uses. That is, the presence of such - $\mathrm{OH}$ substituents could considerably enhance ET capabilities of the chemicals to exhibit strong electrochemical activities as either antioxidants or ESs for effective energy extraction [5][10]. Thus, with appropriate augmentation of antioxidant-rich edible flora, electron-shuttling characteristics should be optimally expressed for applications in energy biotechnology. This study first selected the most electrochemically feasible species of edible flora via electrochemical inspections (e.g., cyclic voltammetry) for treatability assessment. Due to strong association upon electrochemical characteristics of antioxidant and ES of tea extract, using edible flora as supplements for optimal electrochemically-steered reactions (e.g., bioremediation and biorefinery) would be cost-effective and energy-saving for sustainable development in energy biotechnology. 
$10^{\mathrm{TH}}$ INTERNATIONAL CONFERENCE ON SUSTAINABLE ENERGY AND ENVIRONMENTAL

Protection (June $27^{\mathrm{TH}}-30^{\mathrm{TH}}, 2017$, Bled, Slovenia), Bioenergy AND Biofuels

B.-Yann Chen, A.-Wei Hsu, J.-Hui Liao, C.-Chyi Wu \& C.-Chuan Hsueh: Bioreactor

Study of Using Medicinal Herbs and Edible Flora to Stimulate Microbial Fuel Cells for Electrochemically-Steered Bioremediation

\section{$2 \quad$ Materials and Methods}

\subsection{Preparation of edible herbs}

This study selected extracts of some medicinal herbs (e.g., Pueraria montana, Eriobotrya japonica, Syzygium aromaticum, Ephedra sinica, Zingiber officinale, Polygonatum odoratum, Citrus reticulata, Lonicera japonica) and tea at different degrees of fermentation (e.g., Camellia sinensis) as sources for inspection. Regarding extraction of medicinal herbs, at ca. $2.5 \mathrm{~g}$ were ground to be powder and then dissolved in $50 \mathrm{~mL}$ $50 \%(\mathrm{v} / \mathrm{v})$ ethanol water for $30 \mathrm{~min}$ concentration via rotary vacuum evaporator to obtain model extracts. For preparation of tea extract, similar procedures were implemented with water extraction at $50 \mathrm{~mL} 100^{\circ} \mathrm{C}$ for $10 \mathrm{~min}$. Then, mixtures of plant extracts were centrifuged at $13,000 \mathrm{rpm}, 25^{\circ} \mathrm{C} 10 \mathrm{~min}$ and filtered to obtain supernatant.

\subsection{Antioxidant activity assay}

Regarding antioxidant activity by radical scavenging DPPH assay, ca. $666 \mu \mathrm{L}$ samples of $1 \mathrm{mM}$ DPPH (2,2-diphenyl-1-picryl-hydrazyl-hydrate) were mixed with $333 \mu \mathrm{L}$ different tea extract at different doses for spectrophotometric measurement at $515 \mathrm{~nm}$ $\left(\mathrm{OD}_{515}\right)$ [11]. Scavenging activity percentage was determined as follows:

DPPH radical scavenging $=\left[1-\frac{\left(\mathrm{Abs}_{\text {sample }}-\mathrm{Abs}_{\text {blank }}\right)}{A b s_{\text {control }}}\right] \times 100$,

where $\mathrm{Abs}_{\text {sample }}, \mathrm{Abs}_{\text {blank }}, \mathrm{Abs}_{\text {control }}$ denoted $\mathrm{OD}_{515}$ after 30 min reaction of $\mathrm{DPPH}+$ tea extract, of ethanol+extract and ethanol+DPPH, respectively. Dose-response analysis for "antioxidant" capability via probit transformation was described elsewhere [12][13]. Note that $\mathrm{P}=1-\mathrm{DPPH} / \mathrm{DPPH}_{0}$ was defined as performance index for comparison $(\mathrm{P}=0$ and $100 \%$ denoted no and complete expression of activity, respectively).

\subsection{Electrochemical measurements}

For power generation measurement, cell voltage was automatically measured using a data acquisition system (DAS 5020; Jiehan Technology Corporation) through external resistance $R_{\text {out }}=1 \mathrm{~K} \Omega$. The power densities $(\mathrm{P})$ and current densities (I) of MFCs were determined using linear sweep voltammetry (LSV) measurement and the corresponding voltages were recorded using a multimeter. Note that all MFCs were operated in model of membrane-less single chamber at $25^{\circ} \mathrm{C}$ as described elsewhere [1][2][5]. 
192 10 $10^{\mathrm{TH}}$ InTERNATIONAL CONFERENCE ON SUSTAINABLE ENERGY AND ENVIRONMENTAL Protection (June $27^{\mathrm{TH}}-30^{\mathrm{TH}}, 2017$, BLed, SLOVEnia), Bioenergy AND Biofuels

B.-Yann Chen, A.-Wei Hsu, J.-Hui Liao, C.-Chyi Wu \& C.-Chuan Hsueh: Bioreactor Study of Using Medicinal Herbs and Edible Flora to Stimulate Microbial Fuel Cells for Electrochemically-Steered Bioremediation

\section{$3 \quad$ Results and Discussion}

\subsection{Assessment upon plant extracts}

To explore electron-shuttling characteristics of naturally-occurring herbs as ESs, different sources of medicinal herb and tea extracts were chosen for CV treatability analysis. As Fig. 1 (redox peaks circled) clearly revealed, several intact herb extracts apparently owned both reduction and oxidation potential peaks of different current levels in CV profiles as candidate ESs (i.e., P. montana, E. japonica, S. aromaticum, E. sinica, $Z$. officinale, $P$. odoratum, $C$. reticulate, $L$. japonica; only part of data shown in Fig. 1) possibly due to active contents of antioxidants (e.g., anthocyanidins, betalain, catechin and polyphenols). In fact, as herbs contained diverse compositions of chemical species, of course several scan cycle- $\mathrm{CV}$ profiles of herb extracts showed gradual attenuation of reduction and oxidation potential peaks (i.e., circled portions in Fig. 2). However, after ca. 80 cycles of scan, such decay seemed to be asymptotically stabilized to an "electrochemically steady-state" level. This suggested that some of herb compositions (e.g., S. aromaticum, L. japonica) might be irreversibly to be utilized as antioxidant via CV redox process and residual compositions were very likely to be feasible as reversible ESs for sustainable uses. However, compared to other herbs and flora, peak cathodic $\left(i_{\mathrm{pc}}\right)$ and anodic $\left(i_{\mathrm{pa}}\right)$ currents of tea extracts were all significantly larger than other herbs (e.g., ca. 10 fold increase in Fig. 1 and 2) [6]. This implied that tea extract very likely contained the most abundant compositions of polyphenolics as ES species for energy extraction. Thus, extracts of teas at different degrees of fermentation were chosen herein for comparative studies afterwards.

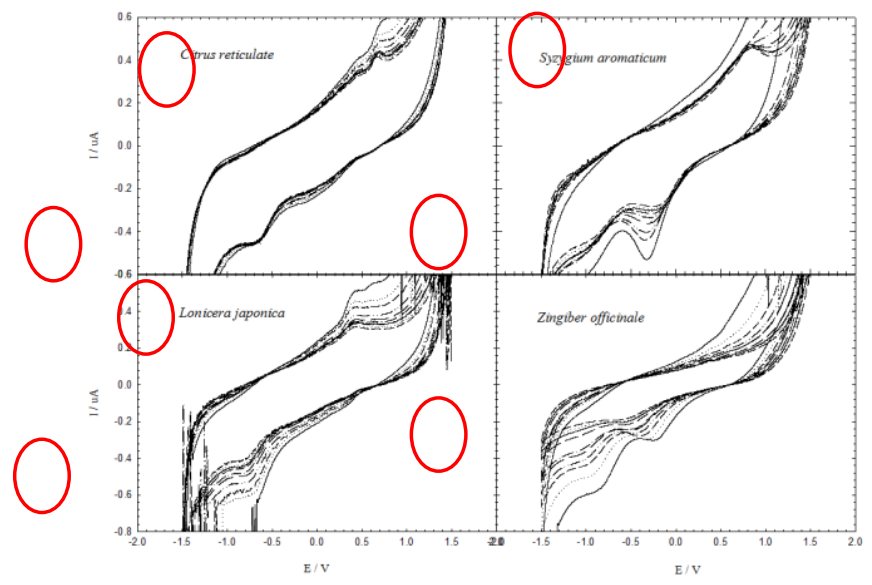

Fig. 1 Cyclic voltammograms for redox processes of some medicinal herbs in distilled deionized water (scan rate $\left.=10 \mathrm{mV} \mathrm{s}^{-1}\right)$ for 100 cycle scan $(\mathrm{CV}$ profiles were gradually attenuated and asymptotically stabilized at constant levels after ca. 80 scan cycles; circles denoted redox potential peaks) 
$10^{\mathrm{TH}}$ INTERNATIONAL CONFERENCE ON SUSTAINABLE ENERGY AND ENVIRONMENTAL

Protection (June $27^{\mathrm{TH}}-30^{\mathrm{TH}}, 2017$, Bled, Slovenia), Bioenergy ANd Biofuels

B.-Yann Chen, A.-Wei Hsu, J.-Hui Liao, C.-Chyi Wu \& C.-Chuan Hsueh: Bioreactor Study of Using Medicinal Herbs and Edible Flora to Stimulate Microbial Fuel Cells for Electrochemically-Steered Bioremediation

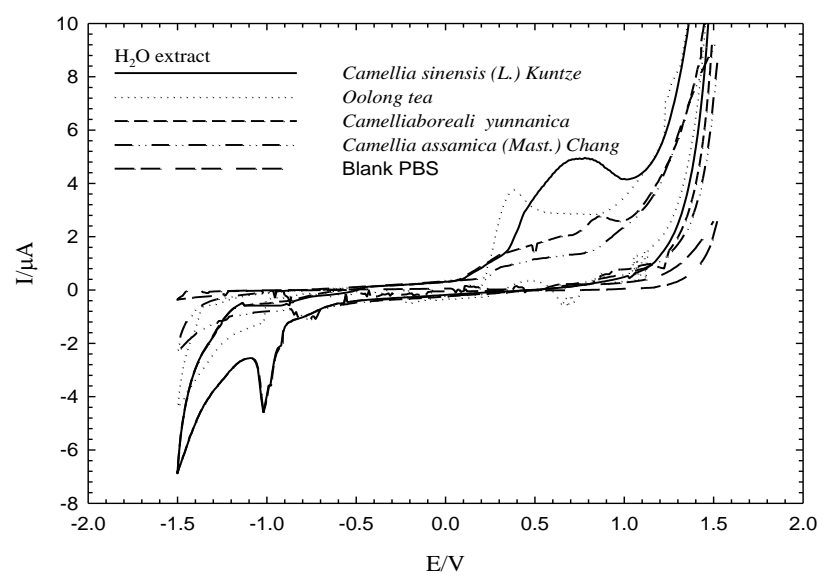

Fig. 2 Comparison of cyclic voltammograms for redox processes of extracts of different tea extracts (e.g., C. sinensis (L.) Kuntze (green tea) and C.-yunnanica (black tea))

\subsection{DPPH antioxidant assay}

As aforementioned, antioxidant capabilities could be positively associated with electronshuttling characteristics [5][6]. Therefore, exploring DPPH scavenging activities of different tea extracts would be crucial to quantitatively evaluate ET capability for bioenergy applications. Furthermore, to obtain correlation of antioxidant activity with respect to the degree of tea fermentation, different concentrations of Camellia sinensis (L.) Kuntze (green tea), oolong tea, C. boreali-yunnanica (black tea) and C. assamica (Mast.) Chang (black tea) were used for comparative study. As Fig. 3 revealed, evidently increased concentration of tea extract would augment antioxidant capability to react free radicals due to higher content of antioxidant polyphenolics [9]. In addition, doseresponse curves indicated that the ranking of DPPH scavenging capabilities of tea extracts was (e.g. $\left.\mathrm{EC}_{50}\right)$ C. sinensis (L.) Kuntze (green tea) $\left(0.195 \mathrm{~g} \mathrm{~L}^{-1}\right)<$ oolong tea $\left(0.363 \mathrm{~g} \mathrm{~L}^{-1}\right)$ $<$ C. boreali-yunnanica (black tea) $\left(0.584 \mathrm{~g} \mathrm{~L}^{-1}\right)<C$. assamica (Mast.) Chang (black tea) $\left(0.740 \mathrm{~g} \mathrm{~L}^{-1}\right)$ (Fig. 4 and Table 1). Comparison of all $E C_{\mathrm{x}}$ values of different fermented tea species clearly suggested that higher degree of tea fermentation would significantly deplete contents of electrochemically associated antioxidant compositions (e.g., detectable effect level $\left(\mathrm{EC}_{0}\right)$ at $0.016 \mathrm{~g} \mathrm{~L}^{-1}$ (green tea) and 0.078-0.094 $\mathrm{g} \mathrm{L}^{-1}$ (black tea)). In addition, slope factors $B$ values of all tea extracts were greater than unity (i.e., slope factor $\mathrm{B}=2.21-3.11$ ), suggesting steeper curves to exhibit promising antioxidant characteristics among various tea extracts [11][12]. These all clearly pointed out electrochemically-available characteristics of different tea extracts. Apparently, unfermented green tea (Fig. 2, 3) expressed the most promising scavenging capability (i.e., far left curve in Fig. 4). As known, higher degree of tea fermentation would significantly decrease antioxidant contents- flavonols and/or catechins-related 
194 10 $10^{\mathrm{TH}}$ International Conference on Sustainable ENERgy and Environmental Protection (June $27^{\mathrm{TH}}-30^{\mathrm{TH}}, 2017$, BLed, SLOVENiA), Bioenergy and Biofuels B.-Yann Chen, A.-Wei Hsu, J.-Hui Liao, C.-Chyi Wu \& C.-Chuan Hsueh: Bioreactor Study of Using Medicinal Herbs and Edible Flora to Stimulate Microbial Fuel Cells for Electrochemically-Steered Bioremediation

polyphenolics in tea extracts [9], leading to less content available for electrochemically functioning chemical species to be functioned as ESs. However, to consider sustainable applicability of various tea extracts, reusability inspection on tea extracts was also implemented. As shown in Fig. 5, evidently DPPH scavenging activity of green tea still stably maintained at ca. $47 \%$ even after 5 times of recycling/reuses. However, after 3 cycles for reuse, antioxidant activity of oolong tea and black tea significantly decreased to ca. $<10 \%$ due to partial and nearly complete fermentation of tea, respectively. That is, the most appropriate tea extracts as antioxidants as well as electron shuttles for biomass energy recycling/reuses would be green tea (i.e., unfermented tea). Of course, intact compositions of polyphenolics as antioxidants or/and ESs could be maximally maintained for lack of tea fermentation for treatment.

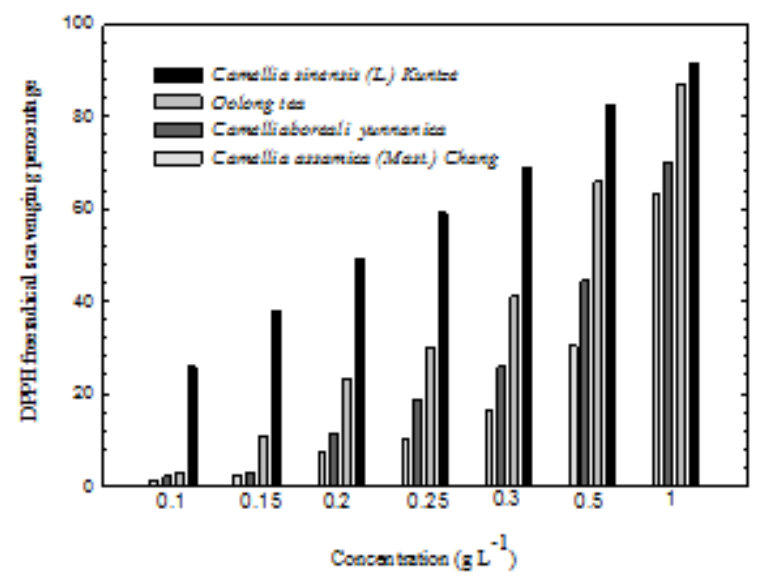

Fig. 3 The effect of different doses upon antioxidant activity of various tea extracts (response variable defined as DPPH/DPPH $\mathrm{H}_{0}$ ).

Table 1 Effective concentrations and dose-reponse analysis of "antioxidant" activity predicted from probit model (unit: $\mathrm{g} \mathrm{L}^{-1}$ )

\begin{tabular}{|l|l|l|l|l|}
\hline & $\mathrm{EC}_{0}$ & $\mathrm{EC}_{20}$ & $\mathrm{EC}_{50}$ & $Y=A+B \log Z$ \\
\hline $\begin{array}{l}\text { Camellia sinensis } \\
\text { (L.) Kuntze }\end{array}$ & 0.016 & 0.081 & 0.195 & $\begin{array}{l}6.57+2.21 \\
\log Z\end{array}$ \\
\hline oolong tea & 0.061 & 0.195 & 0.363 & $\begin{array}{l}6.37+3.11 \\
\log Z\end{array}$ \\
\hline $\begin{array}{l}\text { Camelliaboreali } \\
\text { yunnanica }\end{array}$ & 0.078 & 0.288 & 0.584 & $\begin{array}{l}5.64+2.74 \\
\log Z\end{array}$ \\
\hline $\begin{array}{l}\text { Camellia } \\
\text { assamica (Mast.) } \\
\text { Chang }\end{array}$ & 0.094 & 0.360 & 0.740 & $\begin{array}{l}5.35+2.68 \\
\log Z\end{array}$ \\
\hline
\end{tabular}

${ }^{a}$ Refer to [11] for evaluation of probit transformation. 
$10^{\mathrm{TH}}$ INTERNATIONAL CONFERENCE ON SUSTAINABLE ENERGY AND ENVIRONMENTAL

Protection (June $27^{\mathrm{TH}}-30^{\mathrm{TH}}, 2017$, Bled, SLOVENiA), Bioenergy AND Biofuels

B.-Yann Chen, A.-Wei Hsu, J.-Hui Liao, C.-Chyi Wu \& C.-Chuan Hsueh: Bioreactor Study of Using Medicinal Herbs and Edible Flora to Stimulate Microbial Fuel Cells for Electrochemically-Steered Bioremediation

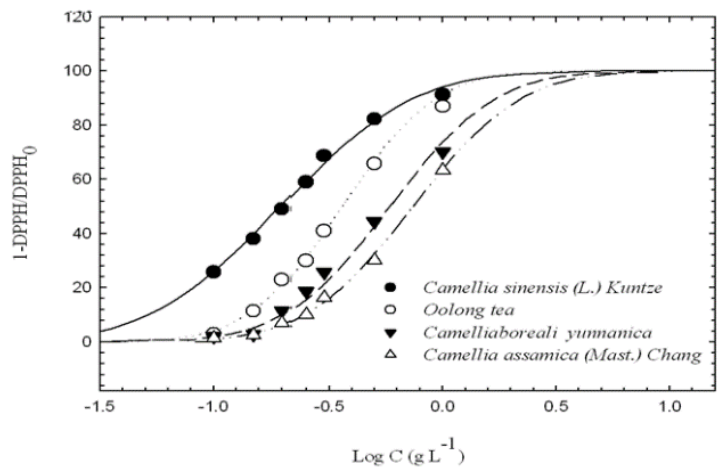

Fig. 4 Dose-response curves of antioxidant activity of various tea extracts (response variable defined as $1-\mathrm{DPPH} / \mathrm{DPPH}_{0}$ ).

\subsection{Power density analysis}

To confirm such significant electron-transfer capabilities of these tea extracts, power density analysis using Shewanella sp. WLP72-inoculated microbial fuel cells as test bioreactor modules were also carried out. As shown in Fig. 6, after acclimatization of WLP72 cells the ranking of maximal power density (MPD) of MFCs for different tea extracts were $C$. sinensis (L.) Kuntze (green tea) $\left(30.51 \mathrm{~mW} \mathrm{~m}^{-2}\right)>$ oolong tea $(21.10 \mathrm{~mW}$ $\left.\mathrm{m}^{-2}\right)>$ C. yunnanica (black tea) $\left(17.31 \mathrm{~mW} \mathrm{~m}^{-2}\right)>$ C. assamica (Mast.) Chang (black tea) $\left(16.57 \mathrm{~mW} \mathrm{~m}^{-2}\right)>$ Blank $\left(11.40 \mathrm{~mW} \mathrm{~m}^{-2}\right)$. In contrast, without prior acclimatization, the ranking of MPD was $C$. sinensis (L.) Kuntze (green tea) $\left(19.24 \mathrm{~mW} \mathrm{~m}^{-2}\right)>C$. assamica (Mast.) Chang) (black tea) $\left(16.57 \mathrm{~mW} \mathrm{~m}^{-2}\right)>$ Blank $\left(11.40 \mathrm{~mW} \mathrm{~m}^{-2}\right)$ (data not shown). Inevitably, stable acclimatization in series of identical conditions for fully expressed ETcapabilities of MFCs would be microbially appropriate and evolutionarily required. In addition, degree of tea fermentation considerably decreased not only polyphenolics content but also electrochemical activities as ESs or antioxidants. Moreover, the performance of water extract was significantly larger than ethanol extract for ET capability to be expressed (e.g., $30.51 \mathrm{~mW} \mathrm{~m}^{-2}\left(\mathrm{H}_{2} \mathrm{O}\right.$ extract) vs. $22.91 \mathrm{~mW} \mathrm{~m}^{-2}$ (EtOH extract); ca. $33 \%$ increase). 
$196 \quad 10^{\mathrm{TH}}$ InTERNATIONAL CONFERENCE ON SUSTAINABLE ENERGY AND ENVIRONMENTAL Protection (June $27^{\mathrm{TH}}-30^{\mathrm{TH}}, 2017$, BLed, Slovenia), Bioenergy AND Biofuels

B.-Yann Chen, A.-Wei Hsu, J.-Hui Liao, C.-Chyi Wu \& C.-Chuan Hsueh: Bioreactor Study of Using Medicinal Herbs and Edible Flora to Stimulate Microbial Fuel Cells for Electrochemically-Steered Bioremediation

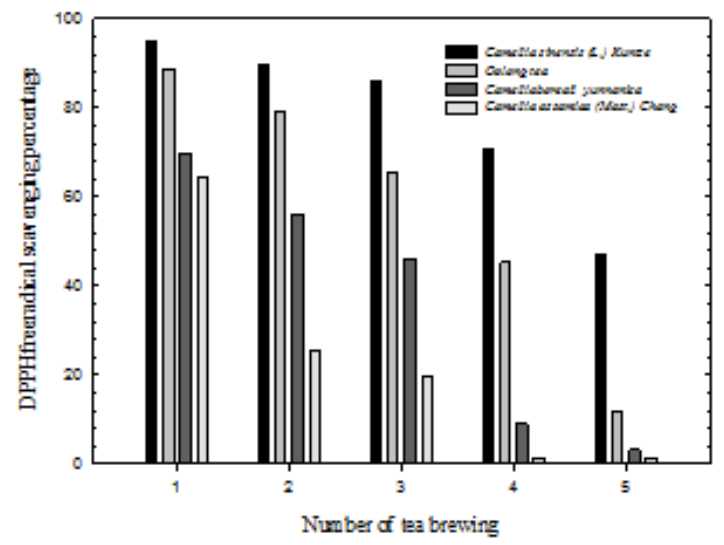

Fig. 5 DPPH radical scavenging activities of various tea extracts with different numbers of tea brewing $\left(1 \mathrm{~g} \mathrm{~L}^{-1}\right.$ tea extract as reference for comparison)

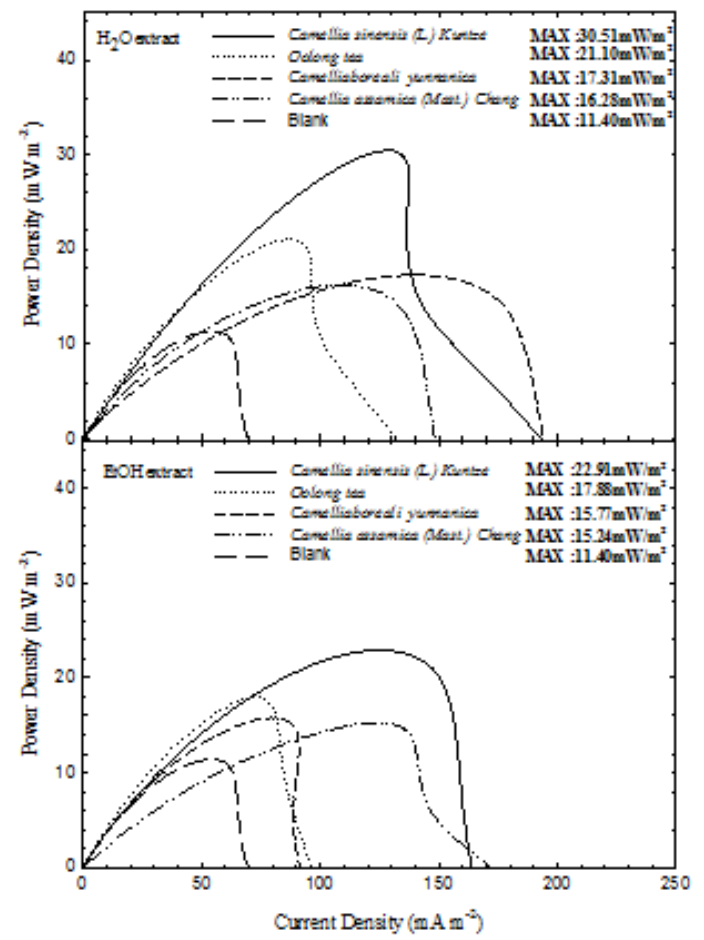

Fig. 6 Comparative curves of power density of Shewanella sp. WLP72-dominant mixed culture microbial fuel cells (MFCs) with supplementation of different teas of water $\left(\mathrm{H}_{2} \mathrm{O}\right)$ and ethanol $(\mathrm{EtOH})$ extracts where MFCs were acclimatized in prior conditions for maximum power-density comparison. 
$10^{\mathrm{TH}}$ INTERNATIONAL CONFERENCE ON SUSTAINABLE ENERGY AND ENVIRONMENTAL

Protection (June $27^{\mathrm{TH}}-30^{\mathrm{TH}}, 2017$, Bled, Slovenia), Bioenergy ANd Biofuels

B.-Yann Chen, A.-Wei Hsu, J.-Hui Liao, C.-Chyi Wu \& C.-Chuan Hsueh: Bioreactor Study of Using Medicinal Herbs and Edible Flora to Stimulate Microbial Fuel Cells for Electrochemically-Steered Bioremediation

\subsection{Electron-shuttling mechanisms}

Although ES-associated characteristics of tea extract were revealed as previously revealed, the presence of such polyphenolics species still needed to be confirmed as proposed (Fig. 7) for clarification. Thus, analysis using tandem mass spectrometry (MSMS or $\mathrm{MS}^{2}$ ) upon samples (e.g., water extracted, $50 \%$ ethanol extracted green tea; Table 2) with standards of vital compositions in green tea extracts (e.g., epigallocatechin (EGCG), gallocatechol (GC), gallic acid (GA)) was conducted. Apparently, the results apparently supported the presence of these compositions in green tea extracts as ESs (e.g., EGCG, GC and GA; Table 2) via identifications of Tandem fragments (detailed data not shown). The findings confirmed that edible flora or herbs might act not only as antioxidants, but also as ESs for myriads of biorefinery applications due to promising electrochemical activities of polyphenolics (i.e., ES mechanisms in Fig. 7). Follow-up studies will be focused on optimal ES-supplementation strategy for maximal stimulation of bioenergy extraction to applications in biorefinery and bioremediation.
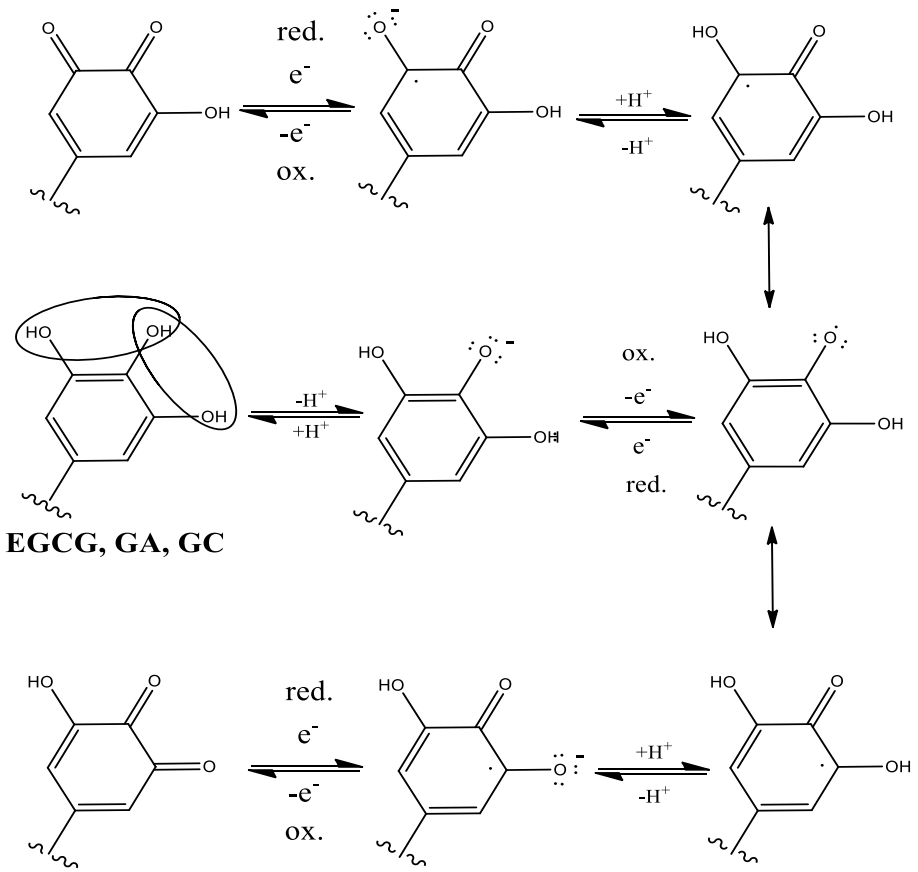

Fig. 7 Proposed redox-mediating mechanisms of functional substituents in ES compositions epigallocatechin (EGCG), gallic acid (GA), GC in tea extracts (EGCG), gallocatechol (GC), (GA)

Table 2 List of Tandem MS-MS fragment spectra of positive ion mode (+) and negative 
$10^{\mathrm{TH}}$ International Conference on Sustainable EnERgy and Environmental Protection (June $27^{\mathrm{TH}}-30^{\mathrm{TH}}, 2017$, BLed, Slovenia), Bioenergy AND Biofuels B.-Yann Chen, A.-Wei Hsu, J.-Hui Liao, C.-Chyi Wu \& C.-Chuan Hsueh: Bioreactor Study of Using Medicinal Herbs and Edible Flora to Stimulate Microbial Fuel Cells for Electrochemically-Steered Bioremediation

ion mode (-)

\begin{tabular}{|c|c|c|c|}
\hline $\mathrm{m} / \mathrm{z}$ & $3 \mathrm{~TB}^{\mathrm{a}}$ & $4 \mathrm{TWB}^{\mathrm{b}}$ & $\begin{array}{c}\text { Molecular } \\
\text { formula }\end{array}$ \\
\hline$(+) 459.09$ & + & + & $\mathrm{C}_{22} \mathrm{H}_{18} \mathrm{O}_{11}$ \\
\hline$(+) 307.08$ & + & + & $\mathrm{C}_{15} \mathrm{H}_{14} \mathrm{O}_{7}$ \\
\hline$(+) 289.07$ & + & + & $\mathrm{C}_{15} \mathrm{H}_{13} \mathrm{O}_{6}$ \\
\hline$(+) 151.01$ & + & + & $\mathrm{C}_{8} \mathrm{H}_{7} \mathrm{O}_{3}$ \\
\hline$(+) 139.04$ & + & $\mathrm{ND}$ & $\mathrm{C}_{7} \mathrm{H}_{7} \mathrm{O}_{3}$ \\
\hline$(-) 457.08$ & + & + & $\mathrm{C}_{22} \mathrm{H}_{18} \mathrm{O}_{11}$ \\
\hline$(-) 305.16$ & + & + & $\mathrm{C}_{15} \mathrm{H}_{14} \mathrm{O}_{7}$ \\
\hline$(-) 169.01$ & + & + & $\mathrm{C}_{7} \mathrm{H}_{6} \mathrm{O}_{5}$ \\
\hline$(-) 125.02$ & + & + & $\mathrm{C}_{6} \mathrm{H}_{6} \mathrm{O}_{3}$ \\
\hline
\end{tabular}

ND: not detected

a3TB: 50\% Ethanol extracted-green tea

b4TWB: Water extracted-green tea

${ }^{\mathrm{d}}$ MS-MS data confirmed with standards not shown

\section{Acknowledgements}

The authors sincerely appreciate financial supports (MOST 102-2221-E-197-016-MY3, MOST 104-2622-E-197-006-CC3 and MOST 105-2221-E-197-022) from Taiwan's Ministry of Science and Technology for the study. This study is also dedicated to the memory of Dolloff F. Bishop and Henry Tabak, as most of novel concepts were initiated while prime author- B.Y. Chen worked in National Risk Management Research Laboratory, US EPA, Cincinnati, Ohio, U.S.A. under their mentorships.

\section{References}

[1] L. J. Qin, K. Han, P. L. Yueh, C. C. Hsueh, B. Y. Chen, "Interactive influences of decolorized metabolites on electron-transfer characteristics of microbial fuel cells," Biochemical Engineering Journal, vol. 109, pp. 297-304, May 2016.

[2] B. Y. Chen, C. M. Ma, K. Han, P. L. Yueh, L. J. Qin, C. C. Hsueh, "Influence of textile dye and decolorized metabolites on microbial fuel cell-assisted bioremediation," Bioresource Technology, vol. 200, pp. 1033-1038, January 2016.

[3] F. P. Van der Zee, F. J. Cervantes, "Impact and application of electron shuttles on the redox (bio)transformation of contaminants: a review, "Biotechnology Advances, vol. 27, pp. 256277, May-June 2009.

[4] K. Watanabe, M. Manefield, M. Lee, A. Kouzuma, "Electron shuttles in biotechnology," Current Opinion in Biotechnology, vol. 20, pp. 633-641, December 2009.

[5] B. Y. Chen, C. C. Hsueh, S. Q. Liu, J. Y. Hung, Y. Qiao, P. L. Yueh, Y. M. Wang, "Unveiling characteristics of dye-bearing microbial fuel cells for energy and materials recycling: Redox mediators," International Journal of Hydrogen Energy, vol. 38, pp. 15598-15605, November 2013.

[6] B. Y. Chen, C. C. Hsueh, "Deciphering Electron Shuttles for Bioremediation and Beyond," American Journal of Chemical Engineering, vol. 4, pp. 114-121, September 2016. 
$10^{\mathrm{TH}}$ INTERNATIONAL CONFERENCE ON SUSTAINABLE ENERGY AND ENVIRONMENTAL

Protection (June $27^{\mathrm{TH}}-30^{\mathrm{TH}}, 2017$, Bled, SLOVENiA), Bioenergy AND Biofuels

B.-Yann Chen, A.-Wei Hsu, J.-Hui Liao, C.-Chyi Wu \& C.-Chuan Hsueh: Bioreactor

Study of Using Medicinal Herbs and Edible Flora to Stimulate Microbial Fuel Cells for

Electrochemically-Steered Bioremediation

[7] B. Y. Chen, A. W. Hsu, C. C. Wu, C. C. Hsueh, "Feasibility study on biostimulation of dye decolorization and bioelectricity generation by using decolorized metabolites of edible flora-extracts," Journal of the Taiwan Institute of Chemical Engineers, In press, March 2017.

[8] M. Przygodzka, D. Zielińska, Z. Ciesarová, K. Kukurová, H. Zieliński, “Comparison of methods for evaluation of the antioxidant capacity and phenolic compounds in common spices," LWT - Food Science and Technology, vol. 58, pp. 321-326, October 2014.

[9] P. A. Kilmartin, C. F. Hsu, "Characterisation of polyphenols in green, oolong, and black teas, and in coffee, using cyclic voltammetry," Food Chemistry, vol. 82, pp.501-512, September 2003.

[10] P. Janeiro, A. M. O. Brett, "Catechin electrochemical oxidation mechanisms," Analytica Chimica Acta, vol.518, pp.109-115, August 2004.

[11] K. F. Gracy, F. Oliveir, T. Tormin, M. F. Raquel Sous, A. de Oliveir, S. A. L. de Morais, E. M. Richter, R.A.A. Munoz, "Batch-injection analysis with amperometric detection of the DPPH radical for evaluation of antioxidant capacity," Food Chemistry, vol. 192, pp. 691-697, February 2016.

[12] B. Y. Chen, H. L. Liu, Y. W. Chen, Y. C. Cheng, "Dose-response assessment of metal toxicity upon indigenous Thiobacillus thiooxidans BC1," Process Biochemistry, vol. 39, pp. 737-748, February 2004.

[13] B. Y. Chen, C. H. Wu, J. S. Chang, "An assessment of the toxicity of metals to Pseudomonas aeruginosa PU21 (Rip64)," Bioresource Technology, vol. 97, pp. 18801886, October 2006. 
$200 \mid 10^{\text {TH }}$ International CONFERENCE ON Sustainable ENERgy AND ENVIRONMENTAL Protection (June $27^{\mathrm{TH}}-30^{\mathrm{TH}}, 2017$, BLed, Slovenia), Bioenergy AND Biofuels 
$10^{\mathrm{TH}}$ InTERnational CONFEREnCE ON Sustainable ENERgy AND

ENVIRONMENTAL Protection (June $27^{\mathrm{TH}}-30^{\mathrm{TH}}$, 2017, Bled, SLOVENIA), BIOENERGY AND BIOFUELS

J. Krope, A.Ghani Olabi, D. Goričanec \& S. Božičnik

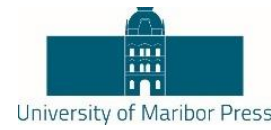

\title{
Bioethanol Production Power Plants from Sugarcane: First and Second Generation
}

\author{
MARCUS Vinicius RonCARI MARI, JOAO MARCOS RONCARCI MARI, MAYKON CESAR \\ SPOlti FerReIRA, W.A.dos S. CONCEIÇÃo \& Cid MARCOS GONCALVES ANDRADE
}

\begin{abstract}
The demand for renewable energy sources has been increasing around the world, due to depletion of fossil fuels and climate change derived their use. Bioethanol production plants are one of the most important industries to Brazilian economy, therefore, this work aims to do a brief review of bioethanol production, first and second generation, as an attempt to indicate what the best option is. First generation plants produce bioethanol from sugarcane juice, while sugarcane bagasse and trash are used to generate steam and electricity to supply energy consumption, besides the surplus energy can be sold to electricity companies. On the other hand, second generation plants use bagasse as feedstock for bioethanol production, which is a lignocellulosic material cheaper than sugarcane. Several researches have shown that second generation provides a global efficiency better than first generation, although there are some contradictions because new stages in production process increase losses and irreversibilities.
\end{abstract}

Keywords: • Biofuel $\bullet$ Sugarcane $・$ Bagasse $・$ Electricity $\bullet$ Cogeneration $\bullet$

CORRESPONDENCE AdDRESS: Marcus Vinicius Roncari Mari, Master's Degree Student, State University of Maringá, Department of Mechanical Engineering, Av. Colombo, 5790 - Zona 7, Maringá - PR, 87020-900, Brazil, email: vinicius_roncari@hotmail.com. Joao Marcos Roncarci Mari, Master's Degree Student, State University of Maringá, Department of Mechanical Engineering, Av. Colombo, 5790 - Zona 7, Maringá - PR, 87020-900, Brazil, email: joao_roncari@hotmail.com. Maykon Cesar Spolti Ferreira, Master's Degree Student, State University of Maringá, Department of Mechanical Engineering, Av. Colombo, 5790 - Zona 7, Maringá - PR, 87020-900, Brazil, email: spolti.maykon@gmail.com. W.A.dos S. Conceição, Professor, State University of Maringá, Department of Mechanical Engineering, Av. Colombo, 5790 - Zona 7, Maringá - PR, 87020-900, Brazil; email: wasconceicao@ gmail.com. Cid Marcos Goncalves Andrade, Professor, State University of Maringá, Department of Chemical Engineering, Av. Colombo, 5790 - Zona 7, Maringá - PR, 87020-900, Brazil; email: cid@ deq.uem.br.

https://doi.org/10.18690/978-961-286-048-6.20

ISBN 978-961-286-048-6

(C) 2017 University of Maribor Press

Available at: http://press.um.si. 
$10^{\mathrm{TH}}$ InTERNATIONAL CONFERENCE ON Sustainable ENERGY AND ENVIRONMENTAL Protection (June $27^{\mathrm{TH}}-30^{\mathrm{TH}}, 2017$, BLed, Slovenia), Bioenergy AND Biofuels M.V.R. Mari, J.M.R. Mari, M.C.S. Ferreira, W.A.dos S. Conceição \& C.M.G. Andrade: Bioethanol Production Power Plants from Sugarcane: First and Second Generation

Exaggerated use of non-renewable fuels has been causing irreversible problems to environmental since industrial revolution until nowadays. Concern about depletion of sources fossil fuels, polluting gases emission to atmosphere and political instability of the biggest producer petrol countries have been motivating the search by renewable fuels, such as bioethanol [1], which probably has the greater potential to replace fossil fuels [2]. In 1975 Brazilian government created a program called Programa Nacional do Álcool (ProÁlcool), as a response the petrol crisis installed in 1970s and also due to sugar price fluctuation at international market [3]. This program consisted in a lot of incentives that made bioethanol economically, socially and environmentally feasible as an alternative fuel [4]. ProÁlcool has decreased fossil fuels dependency through addition of $25 \%$ of ethanol to gasoline and also contributing to reduction of $\mathrm{CO}_{2}$ emissions [3]. In 1980 Brazilian vehicles industry started producing alcohol-fueled cars, where $90 \%$ of total sales of cars at that time was alcohol-fueled [4]. In 2003 appeared flex cars, which are driven by ethanol and gasoline, which allowed the driver to choose the best fuel option [3]. The main products generated from sugarcane are bioethanol, sugar and electricity comes from burning of sugarcane bagasse and trash in cogeneration systems. [5]. Brazil is the biggest world producer of sugarcane and sugar and the second biggest producer of ethanol [6]. Sugarcane production in 2015 achieved 660.5 million tons, where sugar production was 34.2 million tons and more than 30 billion liters of ethanol [7]. Biomass represents $9 \%$ of the installed capacity of the Brazilian electricity grid, whose sugarcane is responsible for $76 \%$. In 2016 bioelectricity production from sugarcane was $36 \mathrm{TWh}$ [6]. This work aims to show the processes of first and second generation bioethanol production in order to know the differences and similarities between each one and to evaluate who produces better results.

\section{First Generation Bioethanol Production}

First generation bioethanol production plants have been producing ethanol in large scale for more than 30 years in Brazil due to ProÁlcool [3]. This process consists at sugarcane juice extraction in mills to be converted in ethanol, where bagasse and trash collected from the canefield are used as fuels in boilers, generating steam, which move turbines, producing electricity to supply the process demand and also is possible to sell the electricity surplus to the grid [8]. Figure 1 shows a first generation plant typical configuration. 


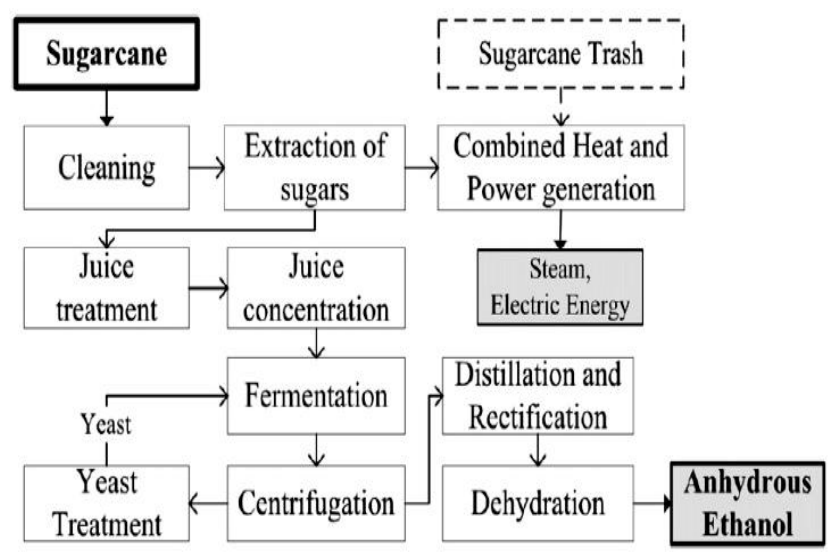

Figure 1. Block Flow Diagram of the First Generation

After extraction of sugars is carried out juice treatment, followed by concentration, fermentation, where yeast is treated and fermented again, coming back to centrifugation. At the end of these processes occur distillation, rectification and dehydration, producing anhydrous ethanol [8]. In most cases juice treatment consists of the steps: sorting, heating, liming, decantation and mud filtration, as shown in $[8,9,10]$. The juice concentration is carried out by a multi-effects evaporation system, which allow to reduce steam consumption in the process $[8,9,10,11]$. Fermentation stage happens at $28^{\circ} \mathrm{C}$ allowing wine production with high ethanol content and consequently decreasing sugar and ethanol losses, as well as vinasse generation [10]. At the end of fermentation the wine is centrifuged and the most of yeast is recovered [9]. Distillation and rectification stages are performed by a double-effect process, which permits a reduction of steam consumption and water refrigeration $[8,10]$. Finally, anhydrous ethanol is obtained after dehydration that is an extractive distillation process with monoethylene glycol $[9,10]$.

\subsection{Cogeneration systems}

The most common cogeneration systems used by Brazilian sugarcane plants are based on Rankine Cycle. These plants used to operate with low levels of steam pressure and temperature, about 20 bar and $350{ }^{\circ} \mathrm{C}$ respectively, and backpressure turbines, which causes low efficiency and high sugarcane bagasse consumption, therefore is produced just a little electricity surplus [10]. In 2001 a big electricity crisis motivated new sugarcane plants projects with cogeneration systems more efficiency, through the uses of steam at high pressures and temperatures and condensing turbines. These changes have been permitting significant increases in electricity generation [10]. 
$204 \quad 10^{\text {TH }}$ INTERNATIONAL CONFERENCE ON SUSTAINABLE ENERGY AND ENVIRONMENTAL Protection (June $27^{\mathrm{TH}}-30^{\mathrm{TH}}, 2017$, Bled, Slovenia), BioENERGy AND Biofuels M.V.R. Mari, J.M.R. Mari, M.C.S. Ferreira, W.A.dos S. Conceição \& C.M.G. Andrade: Bioethanol Production Power Plants from Sugarcane: First and Second Generation

\subsection{Evaluation of first generation}

Several studies have been evaluating first generation ethanol and electricity production plants. A standard distillery with low cogeneration system efficiency, steam pressure and temperature of 22 bar and $300{ }^{\circ} \mathrm{C}$, respectively, it has produced 81.8 Lethanol/Tsugarcane, almost nothing surplus electricity and $3.7 \%$ of surplus lignocellulosic material. On the other hand, a plant using optimized processes and focused to produce the maximum electricity that is possible, because all bagasse is burnt, steam pressure and temperature of 90 bar and $520{ }^{\circ} \mathrm{C}$, respectively, it has produced 83.2 Lethanol/Tsugarcane and $173.2 \mathrm{kWh} /$ Tsugarcane of surplus electricity [8]. Similar results are shown in $[2,12]$, where a plant with steam pressure and temperature of 65 bar and $485^{\circ} \mathrm{C}$, respectively, it has achieved a production of 83 Lethanol/Tsugarcane and surplus electricity of $170 \mathrm{kWh} /$ Tsugarcane [12]. Whereas in study of [2], the production has been 82.3 Lethanol/Tsugarcane and $199 \mathrm{kWh} /$ Tsugarcane of surplus electricity, whose plant has a cogeneration system of 82 bar and $520^{\circ} \mathrm{C}$.

\section{Second Generation Bioethanol Production}

Bioethanol production from lignocellulosic material that is found in sugarcane bagasse is known as second generation and consists in five main steps: biomass pretreatment, cellulose hydrolysis, hexose fermentation, separation and effluent treatment. Moreover, detoxification and fermentation of pentoses released during the preatment step can be performed [13]. Figure 2 shows the process steps.

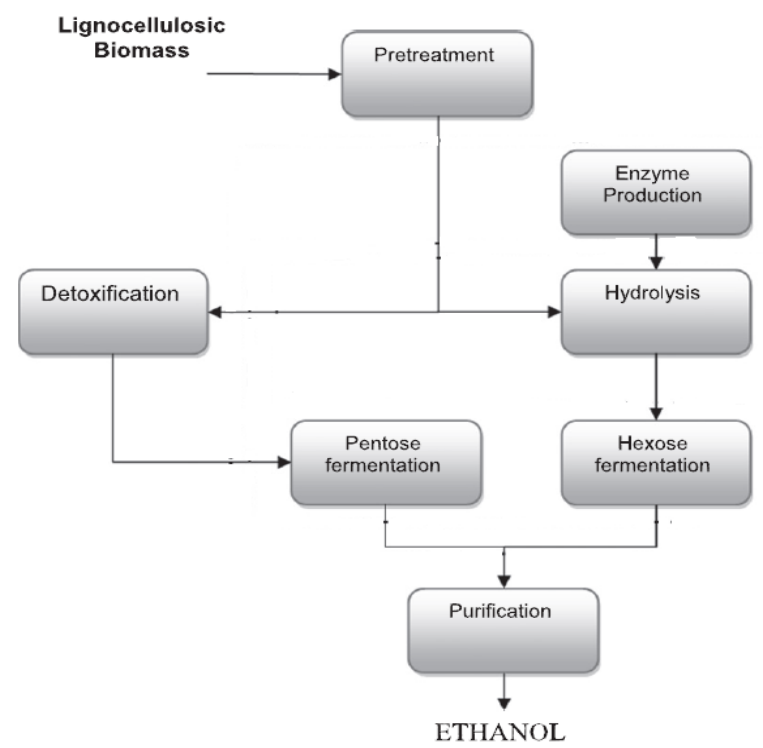

Figure 2. Block Flow Diagram of the Second Generation 
$10^{\text {TH }}$ INTERNATIONAL CONFERENCE ON SUSTAINABLE ENERGY AND ENVIRONMENTAL

Protection (June $27^{\mathrm{TH}}-30^{\mathrm{TH}}, 2017$, BLed, Slovenia), Bioenergy AND Biofuels

M.V.R. Mari, J.M.R. Mari, M.C.S. Ferreira, W.A.dos S. Conceição \& C.M.G.

Andrade: Bioethanol Production Power Plants from Sugarcane: First and Second

Generation

Currently the pretreatment is one of the most expensive step in bioethanol second generation, however, it is essential to achieve good yields. Cellulose hydrolysis yield without pretreatment is usually less than $20 \%$, whereas with addition this step the yield can achieve more than $90 \%$ [14].

\subsection{Biomass pretreatment}

Pretreatment is a key stage for successful conversion of lignocellulosic material into ethanol due to close association existent among the three main components of plant cell wall (cellulose, hemicelluloses and lignin), which is the most determinant factor for low accessibility of plant carbohydrates [3]. Therefore, the main goal of this step is to decrease the interaction existent among plant components and become them susceptible to enzymatic hydrolysis and fermentation [15]. Another important function is to avoid creating compounds that are inhibitors of next steps [3]. Several studies have been analyzing the main pretreatment methods, which are: alkaline washing, lime, alkaline hydrogen peroxide, dilute acid hydrolysis, ammonia fiber explosion, wet oxidation and steam explosion [3]. Steam explosion has been one of the most used methods as can be seen in $[8,12,16,17]$. This process consists in exposing biomass to high steam pressure under controlled conditions, followed by extinction of reactor contents to a pressure vessel by adiabatic expansion [18].

\subsection{Cellulose hydrolysis}

In this process cellulose is converted to sugar glucose by means of a catalyst, which might be dilute acid, concentrated acid or enzymes [14]. Enzymatic cellulose hydrolysis has been one of the most used processes, as can be seen in $[2,8,9,12,16,17,19,20]$. This process can be carried out separately from alcoholic fermentation, as known as Separate Hydrolysis Fermentation (SHF) or it may happens together, called as Simultaneous Saccharification and Fermentation (SSF) [3]. In the SHF process hydrolysis can be performed at temperatures as high as $50{ }^{\circ} \mathrm{C}$, which allows taking advantage of enzymes stability at this temperature, reducing bacterial contamination. Furthermore, it is also possible easier separation of sugar syrup from hydrophobic lignin that can be used as solid fuel [3]. On the other hand, in the SSF process the ethanol production is faster and cheaper, because the created glucose is simultaneous fermented to ethanol. In addition, contamination risk is lower due to the presence of ethanol, anaerobic conditions and continuous withdrawal of glucose. The main difficulty of this process refers to the different temperatures between enzymatic hydrolysis $\left(45-50^{\circ} \mathrm{C}\right)$ and alcoholic fermentation $\left(28-35^{\circ} \mathrm{C}\right)[3]$.

\section{$4 \quad$ Integrated First and Second Generation Processes}

Integrated second generation plant with first generation is basically the junction of both processes. Sugarcane bagasse and trash are used as fuels for cogeneration, whereas the amount of bagasse that exceeds what is required to supply thermal energy demand of the 
206 1 $10^{\mathrm{TH}}$ InTERNATIONAL CONFERENCE ON Sustainable ENERGY AND ENVIRONMENTAL Protection (June $27^{\mathrm{TH}}-30^{\mathrm{TH}}, 2017$, Bled, Slovenia), BioENERGy AND Biofuels M.V.R. Mari, J.M.R. Mari, M.C.S. Ferreira, W.A.dos S. Conceição \& C.M.G. Andrade: Bioethanol Production Power Plants from Sugarcane: First and Second Generation

plant is used as feedstock to produce ethanol [12]. Moreover, it is not only bagasse and trash that can be utilized as fuels in boilers, but it also possible to use some residues, such as unreacted cellulose, lignin and biogas produced from pentoses biodigestion [8]. Figure 3 shows the integrated processes.

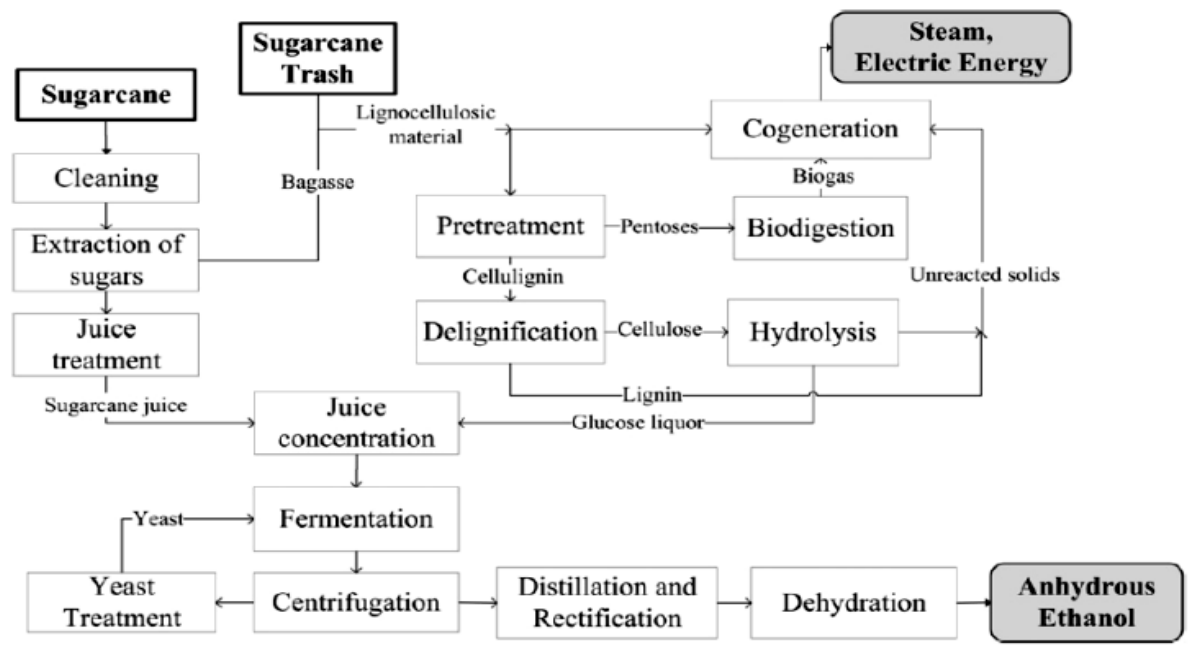

Figure 3. Block Flow Diagram of the Integrated Processes

Joining second generation process with conventional first generation may improve the ethanol production viability from second generation, since if it will be compared with a second generation plant only, the integrated process will require less investments, because some steps such as concentration, fermentation, distillation and cogeneration could be shared between both plants [17].

\subsection{Evaluation of integrated processes}

There are some researches that have been analyzing results from integrated first and second generation bioethanol production. An integrated plant with a cogeneration system of $90 \mathrm{bar}$ and $520^{\circ} \mathrm{C}$ has produced $110.1 \mathrm{Lethanol} /$ Tsugarcane and $66.7 \mathrm{kWh} /$ Tsugarcane of surplus electricity [8]. Another plant with steam pressure and temperature of 65 bar and $485^{\circ} \mathrm{C}$, respectively, it has achieved a production of 115 Lethanol/Tsugarcane and surplus electricity of $70 \mathrm{kWh} /$ Tsugarcane [12]. Similar results are shown in [2], the production has been 105.8 Lethanol/Tsugarcane and $89.5 \mathrm{kWh} /$ Tsugarcane of surplus electricity, whose plant has a cogeneration system of 82 bar and $520{ }^{\circ} \mathrm{C}$. 


\section{$5 \quad$ Conclusions}

There are a lot of variables which may influence in how to choose the best destination to sugarcane bagasse, for example when ethanol price is worthier than electricity price, it might be more feasible use it at second generation, and vice versa. Furthermore, it must be evaluated energetic consumptions, efficiencies and investments in each process, because the conversion of biomass to biofuel adds steps to the production, which increase losses and costs. As shown in the studies of [2, 8, 12], integrated first and second generation process has achieved bigger ethanol production than first generation plants, however surplus electricity has been smaller.

\section{Acknowledgements}

This work has been realized with support of Coordenação de Aperfeiçoamento de Pessoal de Nível Superior (CAPES) - Brazil

\section{References}

[1] L. Luo, E. V. D. Voet, and G. Huppes, "An energy analysis of ethanol from cellulosic feedstock - corn stover," Renew. Sustain. Energy Rev., vol. 13, no. 8, pp. 2003-2011, Oct. 2009.

[2] M. O. S. Dias et al, "Cogeneration in integrated first and second generation ethanol from sugarcane," Chem. Eng. Res. Des., vol. 91, no. 8, pp. 1411-1417, Aug. 2013.

[3] C. R. Soccol et al. "Bioethanol from lignocelluloses: status and perspectives in Brazil," Bioresour. Technol., vol. 101, no. 13, pp. 4820-4825, July. 2010.

[4] J. A. P. de Oliveira, "The policymaking process for creating competitive assets for the use of biomass energy: The Brazilian Alcohol programme," Renew. Sustain. Energy Rev., vol. 6, pp. 129-140, Jun. 2002.

[5] A. V. Ensinas et al, "Reduction of irreversibility generation in sugar and ethanol production from sugarcane," Energy, vol. 34, no. 5, pp. 680-688, May. 2009.

[6] União da Indústria da Cana-de-Açúcar, Boletim: a bioeletricidade da cana em números, Mar. 2017. [Online]. Available: http://www.unica.com.br/documentos/documentos/.htm [Accessed: 5 Mar. 2017].

[7] Empresa de Pesquisa Energética, Balanço energético nacional 2016. [Online]. Available: https://ben.epe.gov.br/downloads/Relatorio_Final_BEN_2016.pdf [Accessed: 5 Jun. 2017].

[8] M. O. S. Dias et al, "Improving second generation ethanol production through optimization of first generation production process from sugarcane," Energy, vol. 43, no. 1, pp. 246-252, July. 2012.

[9] R. Palacios-Bereche et al, "Exergetic analysis of the integrated first- and second-generation ethanol production from sugarcane," Energy, vol. 62, no. 1, pp. 46-61, Dec. 2013.

[10] M. O. S. Dias et al, "Improving bioethanol production from sugarcane: evaluation of distillation, thermal integration and cogeneration systems," Energy, vol. 36, no. 6, pp. 36913703, Jun. 2011. 
208 10 $10^{\mathrm{TH}}$ InTERnAtional CONFERENCE ON Sustainable ENERGy AND ENVIRONMENTAL Protection (June $27^{\mathrm{TH}}-30^{\mathrm{TH}}, 2017$, BLed, Slovenia), Bioenergy AND Biofuels

M.V.R. Mari, J.M.R. Mari, M.C.S. Ferreira, W.A.dos S. Conceição \& C.M.G. Andrade:

Bioethanol Production Power Plants from Sugarcane: First and Second Generation

[11] L. F. Pellegrini, and S. de O. Junior, "Combined production of sugar, ethanol and electricity: Thermoeconomic and environmental analysis and optimization," Energy, vol. 36, no. 6, pp. 3704-3715, Jun. 2011.

[12] M. O. S. Dias et al, "Evaluation of process configurations for second generation integrated with first generation bioethanol production from sugarcane," Fuel Process. Technol., vol. 109, pp. 84-89, May. 2013.

[13] C. A. Cardona, and O. J. Sánchez, "Fuel ethanol production: process design trends and integration opportunities," Bioresour. Technol., vol. 98, no. 12, pp. 2415-2457, Sept. 2007.

[14] C. N. Hamelinck, G. V. Hooijdonk, and A. PC. Faaij, "Ethanol from lignocellulosic biomass: techno-economic performance in short-, middle- and long-term," Biomass Bioenerg., vol. 28, no. 4, pp. 384-410, Apr. 2005.

[15] S. Gámez et al, "Study of the hydrolysis of sugar cane bagasse using phosphoric acid," $J$. Food Eng., vol. 74, pp. 78-88, May. 2006.

[16] K. Ojeda, E. Sánchez, and V. Kafarov, "Sustainable ethanol production from lignocellulosic biomass - Application of exergy analysis," Energy, vol. 36, no. 4, pp. 2119 2128, Apr. 2011.

[17] M. O. S. Dias et al, "Integrated versus stand-alone second generation ethanol production from sugarcane bagasse and trash," Bioresour. Technol., vol. 103, pp. 152-161, Jan. 2012.

[18] M. Balat, H. Balat, and O. Z. Cahide, "Progress in bioethanol processing," Prog. Energy Combust. Sci., vol. 34, pp. 551-573, Oct. 2008.

[19] C. M. Oliveira, A. J. G. Cruz, and C. B. B. Costa, "Improving second generation bioethanol production in sugarcane biorefineries through energy integration," Appl. Therm. Eng., vol. 109, pp. 819-827, Oct. 2016.

[20] M. O. S. Dias et al, "Biorefineries for the production of first and second generation ethanol and electricity from sugarcane," Appl. Energy, vol. 109, pp. 72-78, Sept. 2013. 
$10^{\mathrm{TH}}$ InTERnational CONFERENCE ON Sustainable ENERgy AND

EnVironmental Protection (June $27^{\mathrm{TH}}-30^{\mathrm{TH}}$, 2017, Bled, SLOVENIA), BIOENERGY AND BIOFUELS

J. Krope, A.Ghani Olabi, D. Goričanec \& S. Božičnik

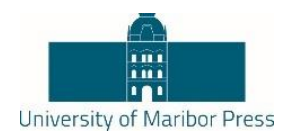

\title{
Optimization of in-Silico Ethanol Production Using a Hybrid Evolutionary Algorithm
}

\author{
HANNIEL FERREIRA SARMENTo Freitas, Jose EdUARdo OliVo \& Cid MARCoS \\ GONCALVES ANDRADE
}

\begin{abstract}
Due to the worldwide crescent demand for energetic sources of the industrialized society and the environmental impacts of the fossil fuels, the adoption of alternative sources became an important research subject. Among those alternative sources, the bioethanol, produced through the anaerobic fermentation of substrate, stands out as an important biofuel. However, this product is obtained through the biological activity of a micro-organism, what implies in several intrinsic characteristic such as complex non-linear growth behaviour, occurrence of substrate and product inhibition, among others. In this sense, the stochastic optimization algorithms exhibit several advantages for handling biotechnological process. The present work aims to perform an optimization study of insilico bioethanol production, using a hybrid evolutionary algorithm, mixing the advantages of two different tools, comparing its performance against classical meta-heuristic routines. The results indicate that the hybrid algorithm exhibits advantages against the classical routines, and the amount of product could be maximized in terms of the in-silico production.
\end{abstract}

Keywords: • Optimization $\bullet$ Silico ethanol $\bullet$ Hybrid evolutionary algorithm

- Biotechnological process $\bullet$ Fossil fuels •

CORRESPONDENCE AdDRESS: Hanniel Ferreira Sarmento Freitas., State University of Maringá, Federal Institute of Education, Science and Technology of Rio Grande do Norte, Chemical Engineering Postgraduate Program Av. Colombo, 5790 - Zona 7, Maringá - PR, 87020-900, Brazil, email: hanniel.freitas@ifrn.edu.br. Jose Eduardo Olivo, State University of Maringá, Chemical Engineering Department, State University of Maringá, Av. Colombo, 5790 - Zona 7, Maringá - PR, 87020-900, Brazil, Paraná, email: jeolivo@uem.br. Cid Marcos Goncalves Andrade, State University of Maringá, Chemical Engineering Department, State University of Maringá, Av. Colombo, 5790 - Zona 7, Maringá - PR, 87020-900, Brazil, Paraná, email: cidmga@yahoo.com.br.

https://doi.org/10.18690/978-961-286-048-6.21

ISBN 978-961-286-048-6

(C) 2017 University of Maribor Press

Available at: http://press.um.si. 
$210 \mid 10^{\text {TH }}$ INTERNATIONAL CONFERENCE ON SUSTAINABLE ENERGY AND ENVIRONMENTAL Protection (June $27^{\mathrm{TH}}-30^{\mathrm{TH}}, 2017$, BLed, Slovenia), BioENERGy AND Biofuels

H. F. S. Freitas, J. E. Olivo \& C. M. G. Andrade: Optimization of in-Silico Ethanol

Production Using a Hybrid Evolutionary Algorithm

The development of the modern society is have been noticed by a continuous worldwide increase of the energy demand. In this context, the fossil fuels stand out as the kernel of the energy matrix, and a common raw material for the production processes of many items used daily. In this sense, it is clear the importance of research on the subject of renewable energy sources [1]. Among them, the biofuels stands out as important alternatives, especially due to their environmental-friendly aspect [2].

In this sense, the ethanol consists in an important energy source, due to the availability of raw materials for its production, and the high energy power of this fuel, among other advantages [3]. The biotechnological processes used for ethanol production, as well as other bioprocesses, are now subjected to extensive studies of process control and optimization, with the aim to provide a more reliable productive process, enhancing its yield and productivity $[4,5]$.

Those bioprocess frequently exhibit characteristics that make the process control and optimization a challenging task, such as the complex non-linear growth profile of the working micro-organisms, inhibition due to substrate and/or the target metabolite, among many others. Under a mathematical point of view, those processes can be described by sets of non-linear differential and algebraic equations, usually subjected to constraints in the state and control variables [6]. In this sense, the meta-heuristic optimization techniques, such as the evolutionary algorithms, stands out as important numerical tools for tackling with bioprocess related problems, as the analytical techniques usually are prohibitively complex, especially for cases with high numbers of state and control variables. In this sense, the stochastic meta-heuristic methods, such as those belonging to the evolutionary computation subclass, usually obtain good solutions with relatively modest computation times, although global optimally could not be guaranteed $[7,8]$.

In the present work, a hybrid evolutionary algorithm, called Swarm Algorithm with Differential Evolution (SADIFFE), is presented. This routine combines the strengths of the Particle Swarm Optimization (PSO) and Differential Evolution (DE) algorithms, such as the good local exploration of the first, and the exploitation capabilities of the later. With this aim, the work is divided as follow: after the present introductory section, the theoretical referential is presented in the second section, followed by the methodology in the third section, in which the SADIFFE implementation and optimization studies are described, and its comparison against the results obtained with classical PSO and DE algorithms. In the fourth section, the results are presented, and in the fifth section, the conclusions of the work are outlined. In the section six, the references employed in the present work are listed. 


\section{Theoretical Referential}

\subsection{Particle swarm optimization}

The Particle Swarm Optimization (PSO) is an stochastic algorithm, firstly presented in the work of Erbehart and Kennedy (1995) [9], referred as population-based, that models the behaviour of animal swarms, such as bird flocks. In this sense, the particle positions are initialized in the search space $\left[x_{i_{\min }} ; x_{i_{\max }}\right]$, according to the Equation (1), using a uniform distribution.

$$
x_{i}=U\left(x_{i_{\min }} ; x_{i_{\max }}\right)
$$

The new positions of the particles $x^{k+1}$ are updated for each iteration, according to the Equation (2).

$$
x^{k+1}=x^{k}+v^{k}, v^{k} \subset\left[v_{\min } ; v_{\max }\right]
$$

In the aforementioned equation, the term $v^{k}$ represents the particle velocity, which is bounded between $\left[v_{\min } ; v_{\max }\right]$. The particle velocity is evaluated using the Equation (3).

$$
v^{k}=\omega x^{k}+\phi_{L} \Delta_{L}{ }^{k} U(0 ; 1)+\phi_{G} \Delta_{G}{ }^{k} U(0 ; 1)
$$

In the Equation (3), the term $U(0 ; 1)$ represent an uniform random number in the inverval $[0 ; 1]$. The terms $\omega, \phi_{L}, \phi_{G}$ represent the inertia factor and the local and global acceleration coefficients, respectively. The terms $\Delta_{L}^{k}, \Delta_{G}^{k}$ represent the local and global displacement for the particle, defined in the Equations (4) and (5).

$$
\begin{aligned}
& \Delta_{L}{ }^{k}=\left(x^{k}-x_{L B}{ }^{k}\right) \\
& \Delta_{G}{ }^{k}=\left(x^{k}-x_{G B}{ }^{k}\right)
\end{aligned}
$$

In the aforementioned equations, the terms $x_{L B}^{k}, x_{G B}^{k}$ represent the current best position of the particle (local best), and the best position among the whole swarm (global best), respectively.

Some authors point out that the structure of the PSO as a non-greedy algorithm makes the routine generally better in exploration of local minima and somewhat deficient in exploitation to global minima $[10,11]$. Several works proposed modified versions of the 
212 10 $10^{\mathrm{TH}}$ InTERnAtional CONFERENCE ON Sustainable ENERGy AND ENVIRONMENTAL Protection (June $27^{\mathrm{TH}}-30^{\mathrm{TH}}, 2017$, BLED, Slovenia), Bioenergy AND Biofuels

H. F. S. Freitas, J. E. Olivo \& C. M. G. Andrade: Optimization of in-Silico Ethanol Production Using a Hybrid Evolutionary Algorithm

PSO, and the discussion of its variants it's beyond the scope of the present work, as it was employed the presented standard algorithm in this study.

\subsection{Differential evolution}

The Differential Evolution (DE) is an evolutionary algorithm, which was presented in the work of Storn \& Price (1995) and Price et al. (2005) [12,13]. The DE shares characteristics of other evolutionary algorithms, employing a crossover as mutation operator, although it distinguishes itself for employing the concept of direction in the search space to guide the optimization process. The vectors are initialized using an equivalent to the Equation (1). For each iteration, a mutant vector $m^{k+1}$ is generated using the difference randomly chosen vectors $r_{i}^{k}$, weighted by a scale factor, as shown in the Equation (6)

$$
m^{k+1}=r_{1}^{k}+S_{f}\left(r_{2}^{k}-r_{3}^{k}\right)
$$

After the generation of the mutant vectors, for each vector, a recombination process occurs. A randomly selected parameter $k$ of the vector is chosen to not suffer mutation. For each parameter of the vector, a random number $j \in U(0 ; 1)$ is evaluated. If $j<p_{c}$, in which the second term represent the crossover probability, the parameter from the mutated vector is selected. Otherwise, the information from the original vector is kept. After the recombination process, the fitness of the new vectors is evaluated, and if there is improvement, the new vectors replace the originals. There are several variations for the mutation process - Equation (6) -, and the discussion of them is beyond of the scope of the present work.

\section{3}

Methodology

In the present section, the methodology employed in the work development will be outlined. First, the development of the hybrid meta-heuristic optimization algorithms, combining the classical routines of PSO and DE. Secondly, open-loop optimization studies for in-silico ethanol production maximization were performed using the hybrid algorithm.

\subsection{Development of the hybrid optimization algorithm}

The hybrid meta-heuristic algorithm combines the advantages of two classical heuristics, the Particle Swarm Optimization (PSO), and the Differential Evolution (DE). The resultant heuristic, Swarm Algorithm with Differential Evolution (SADIFFE) combines both heuristics as explained below.

Initially, for a constrained optimization problem, each parameter of the candidate vectors $\left(x_{1}, x_{2}, \cdots, x_{n}\right)$ is initialized in the $R^{n}$ search-space through the utilization of the Equation (1). After the initialization of the parameters for each dimension of the candidate vectors, 
the parameters are subsequently modified with the aim to find a new search-space, towards a superior fitness value region. In this sense, the SADIFFE algorithm balances between the referred exploration capabilities of PSO, and the exploitation capabilities of the DE. Thus, for each iteration, an percentage $p_{s}$ of the candidate vectors, randomly selected among the whole population, are modified under the swarm approach, accordingly to the Equations (2-5). Similarly, a percentage $p_{d}$ of the candidates are subjected to the differential evolution operator, according to the Equations (6). The percentages are determined through the utilization of the Equations (7) and (8).

$$
\begin{aligned}
& p_{d}=\frac{\bar{f}-f_{\min }}{f_{\max }-f_{\min }} \\
& p_{s}=1-p_{d}
\end{aligned}
$$

In the equations above, the terms $\bar{f}, f_{\min }$ and $f_{\text {max }}$ represent the mean, minimum and maximum fitness value from the candidate vectors. For stagnant populations, which the variability among the fitness value is low, an expressive percentage of the population will be subjected to the differential evolution operator, exploiting new solutions from old candidate vectors. On the other hand, for populations in which there are substantial variability in the fitness value, the new candidate vectors are generated towards the best solution, using the particle swarm approach, as presented in the Equations (2-5). The algorithm for the SADIFFE is depicted in the Figure (1).

lthough the differential evolution algorithm is employed in SADIFFE to avoid the stagnation of the candidate vectors in local minima, the particle swarm approach can be benefited by the dynamical adjustment of the inertia weight [14]. In this sense, for each application of the particle swarm operator in the SADIFFE the inertia weight is randomly updated, accordingly to the Equation (9), that is a modified version of the rule presented in Eberhart et al. (2001) [15]. In the same way, the acceleration coefficients are also updated dynamically, as shown in the Equations (10) and (11).

$$
\begin{aligned}
& \omega=0.5+\frac{U(0 ; 1)}{2 N+1} \\
& \phi_{G}=0.005+N * E-4 \\
& \phi_{L}=2-\phi_{L}
\end{aligned}
$$

With the dynamical rules to update the coefficients presented in the Equations (9-11), the SADIFFE algorithm needs only two parameters: the scale factor $\left(S_{f}\right)$ and the crossover probability $\left(p_{c}\right)$. Although the fine tuning of those parameters are important for the 
214 10 $10^{\mathrm{TH}}$ InTERnational CONFERENCE ON Sustainable ENERGy AND ENVIRONMENTAL Protection (June $27^{\mathrm{TH}}-30^{\mathrm{TH}}, 2017$, BLed, SLOVENiA), Bioenergy AND Biofuels

H. F. S. Freitas, J. E. Olivo \& C. M. G. Andrade: Optimization of in-Silico Ethanol Production Using a Hybrid Evolutionary Algorithm

obtention of good results, in general they exhibit and diminute effect on the final optimization results $[16,17]$.

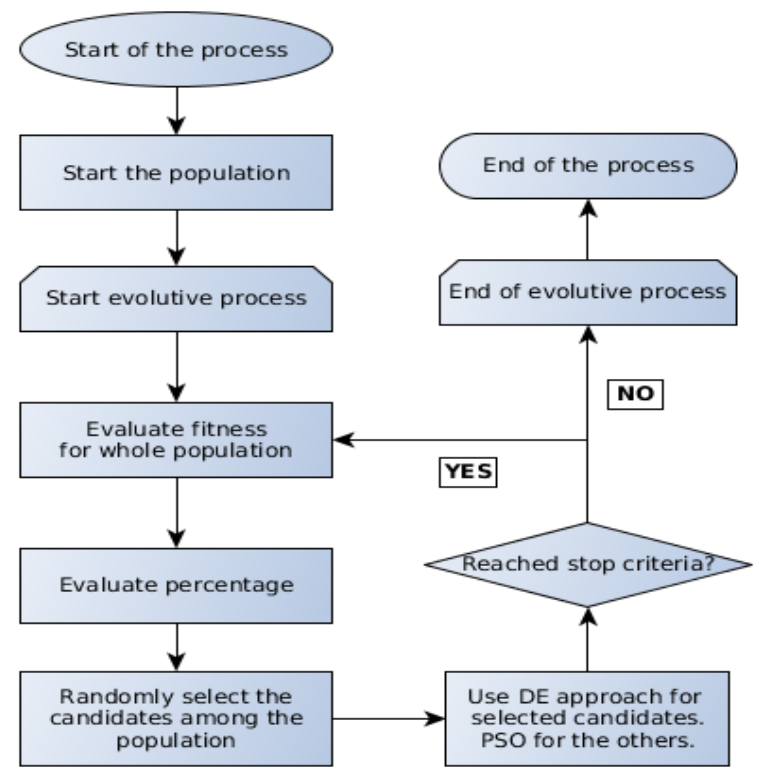

Figure 1 - Working principle of the SADIFFE algorithm.

\subsection{Open-loop optimization studies}

In order to evaluate the performance of SADIFFE algorithm, compared to classical PSO and DE approach, open-loop optimization studies were performed through an classical model for fed-batch ethanol production benchmarking [18], for which the feed rate is the manipulated variable. The referred model is presented in the Equations (12-17).

$$
\begin{aligned}
& \frac{d X}{d t}=g_{1} X-F\left(\frac{X}{V}\right) \\
& \frac{d S}{d t}=-10 g_{1} X+F\left(\frac{150-S}{V}\right) \\
& \frac{d P}{d t}=g_{2} X-F\left(\frac{P}{V}\right) \\
& \frac{d V}{d t}=F
\end{aligned}
$$


$g_{1}=\left(\frac{0.408}{1+0.0625 P}\right)\left(\frac{s}{0.22+s}\right)$

$$
g_{2}=\left(\frac{1}{1+0.0014 P}\right)\left(\frac{s}{0.44+S}\right)
$$

In the aforementioned equations, the terms $\mathrm{X}, \mathrm{S}, \mathrm{P}, \mathrm{V}$ and $\mathrm{F}$ represent the biomass, substrate and ethanol concentration $(\mathrm{g} / \mathrm{L})$, liquid volume in the fermenter $(\mathrm{L})$ and feed rate $(\mathrm{L} / \mathrm{h})$, respectively. For the optimization studies, the feed rate is parameterized, and the parameters for the parameterized expression constitute the optimized variables for the optimization algorithm. In this sense, several parameterization functions are available, and in the present work, a cosinoidal function was chosen, due to its remarkable characteristics, such as smooth profile and higher ethanol production yield [19]. The functional form of the feed rate expression is defined in the Equation (17), and the parameters to be determined are $\mathrm{a}_{0} \ldots \mathrm{a}_{6}$.

$$
\begin{aligned}
F= & a_{0}+a_{1} \cos \left(a_{2}\left(\frac{t-t_{0}}{t_{f}-t_{0}}\right)+a_{3}\right) \\
& +a_{4} \cos \left(a_{5}\left(\frac{t-t_{0}}{t_{f}-t_{0}}\right)+a_{6}\right)
\end{aligned}
$$

The objective function to be maximized by the optimization algorithms corresponds to the ethanol productivity ( $g$ ethanol) at the end of the batch time $\left(\mathrm{t}_{\mathrm{f}}\right)$, defined in the Equation (19).

$$
\Phi(F, t)=P\left(t=t_{f}\right) V\left(t=t_{f}\right)
$$

In the optimization studies, to minimize the influence of the stochastic nature of the algorithms employed, the tests were run 3 times, and the presented results are obtained as the mean values of those. The configurations employed in the algorithms are presented in the Table (1). The stop criteria employed for the tests was the number of function evaluations, and three different scenarios were analysed in order to monitor the convergence for each algorithms, corresponding to 3,10,50 and 100 thousands of function evaluations. 
216 10 $10^{\mathrm{TH}}$ InTERnAtional CONFERENCE ON Sustainable ENERGy AND ENVIRONMENTAL Protection (June $27^{\mathrm{TH}}-30^{\mathrm{TH}}, 2017$, Bled, SLOVENIA), BioENERGy AND Biofuels

H. F. S. Freitas, J. E. Olivo \& C. M. G. Andrade: Optimization of in-Silico Ethanol Production Using a Hybrid Evolutionary Algorithm

Table 1 - Configurations employed in the optimization studies.

\begin{tabular}{c|c|c|c}
\hline Parameter & PSO & DE & SADIFFE \\
\hline $\begin{array}{c}\text { Inertia factor } \\
(\omega)\end{array}$ & -0.05 & - & Equation (9) \\
\hline $\begin{array}{c}\text { Social coefficient } \\
\left(\phi_{L}\right)\end{array}$ & 0.05 & - & Equation (11) \\
\hline $\begin{array}{c}\text { Global coefficient } \\
\left(\phi_{G}\right)\end{array}$ & 0.025 & - & Equation $(10)$ \\
\hline $\begin{array}{c}\text { Crossover probability } \\
\left(p_{c}\right)\end{array}$ & - & 0.6 & 0.6 \\
\hline $\begin{array}{c}\text { Scale factor } \\
\left(S_{f}\right)\end{array}$ & - & 0.5 & 0.5 \\
\hline $\begin{array}{c}\text { Number of particles or } \\
\text { candidate vectors }\end{array}$ & 50 & 50 & 50 \\
\hline$\quad$
\end{tabular}

4

Results

The results obtained in terms of ethanol production are presented in the Table 2, for the SADIFFE algorithm, and the classical PSO and DE routines as well. The studies we conducted for the scenarios of maximum number of function evaluations (FE) corresponding to $3,10,50$ and 100 thousands $(3,10,50 \mathrm{kFE})$ of function evaluations 
$10^{\mathrm{TH}}$ INTERNATIONAL CONFERENCE ON SUSTAINABLE ENERGY AND ENVIRONMENTAL Protection (June $27^{\mathrm{TH}}-30^{\mathrm{TH}}, 2017$, Bled, SLOVENiA), BioENERGY AND Biofuels H. F. S. Freitas, J. E. Olivo \& C. M. G. Andrade: Optimization of in-Silico Ethanol Production Using a Hybrid Evolutionary Algorithm

Table 2 - Productivity results for each algorithm employed in this work.

\begin{tabular}{|c|c|c|c|c|c|}
\hline & \multirow[b]{2}{*}{ Value } & \multicolumn{4}{|c|}{ Ethanol productivity (kg) } \\
\hline & & $\begin{array}{c}3 \\
\text { kFE }\end{array}$ & $\begin{array}{c}10 \\
k F E\end{array}$ & $\begin{array}{c}50 \\
\text { kFE }\end{array}$ & $\begin{array}{c}100 \\
\text { kFE }\end{array}$ \\
\hline \multirow{3}{*}{ ஜ } & $\begin{array}{l}\text { Std. } \\
\text { dev }\end{array}$ & $2.8 \mathrm{E}-3$ & $9 \mathrm{E}-4$ & $2 \mathrm{E}-4$ & $1.8 \mathrm{E}-3$ \\
\hline & Mean & 14.453 & 14.459 & 14.462 & 14.464 \\
\hline & Max & 14.457 & 14.461 & 14.463 & 14.467 \\
\hline \multirow{3}{*}{ 㕿 } & $\begin{array}{l}\text { Std. } \\
\text { dev }\end{array}$ & $2.2 \mathrm{E}-3$ & $2.3 \mathrm{E}-3$ & $9.8 \mathrm{E}-5$ & $4.5 \mathrm{E}-4$ \\
\hline & Mean & 14.453 & 14.458 & 14.462 & 14.460 \\
\hline & Max & 14.457 & 14.461 & 14.462 & 14.461 \\
\hline \multirow{3}{*}{$\frac{\sqrt{1}}{\mathbf{2}}$} & $\begin{array}{l}\text { Std. } \\
\text { dev }\end{array}$ & $1 E-2$ & $2.8 E-2$ & $4.3 E-3$ & $1.9 \mathrm{E}-2$ \\
\hline & Mean & 14.406 & 14.425 & 14.425 & 14.417 \\
\hline & Max & 14.457 & 14.460 & 14.462 & 14.462 \\
\hline
\end{tabular}

In the present work, a hybrid algorithm combining the PSO and DE was presented, named SADIFFE. According to the results depicted in the Table 2, it is possible to observe that the performance of the hybrid algorithm is somewhat similar to its original counterparts. However, it is important to mention that the SADIFFE algorithm is almost free of adjustable parameters, and thus, standing out as a robust alternative for meta-heuristic algorithms that are most sensitive to parameter configurations.

\section{References}

[1] L. Caspeta; N. A. A. Buijis and J. Nielsen, "The role of biofuels in the future energy supply”. Energy \& Environmental Science, vol. 6, n. 4, p. 1077-1082, 2013.

[2] W. Dai, D. P. Word, and J. Hahn, "Modeling and dynamic optimization of fuel-grade ethanol fermentation using fed-batch process," Control Engineering Practice, vol. 22, pp. 231-241, 2014.

[3] R. E. Sims, W. Mabee, J. N. Saddler and M. Taylor, "An overview of second generation biofuel technologies”, Bioresource technology, 101(6), 1570-1580, 2010.

[4] M. S. Croughan, K. B. Konstantinov, and C. Cooney, "The future of industrial bioprocessing: Batch or continuous?", Biotechnology and bioengineering, vol. 112, n. 4, pp. $648-651,2015$. 
218 10 $10^{\mathrm{TH}}$ International Conference on Sustainable Energy and ENVIRONMENTal Protection (June $27^{\mathrm{TH}}-30^{\mathrm{TH}}, 2017$, BLed, Slovenia), Bioenergy AND Biofuels

H. F. S. Freitas, J. E. Olivo \& C. M. G. Andrade: Optimization of in-Silico Ethanol Production Using a Hybrid Evolutionary Algorithm

[5] G. D. Najafpour, Biochemical Engineering and Biotechnology. Amsterdam: Elsevier, 2007.

[6] J. R. Banga, E. Balsa-Canto, C. G. Moles and A. A. Alonso, "Dynamic optimization of bioprocesses: Efficient and robust numerical strategies", Journal of Biotechnology, vol. 117, n. 4, pp. 407-419, 2005.

[7] M. Rocha, R. Mendes, O. Rocha, I. Rocha and E. C. Ferreira, "Optimization of fed-batch fermentation processes with bio-inspired algorithms", Expert Systems with Applications, vol. 41, n. 5, pp. 2186-2195, 2014.

[8] C. Liu, Z. Gong, B. Shen, and E. Feng, "Modelling and optimal control for a fed-batch fermentation process," Applied Mathematical Modelling, vol. 37, n. 3, pp. 695-706, 2013.

[9] R.C. Eberhart and J. Kennedy. "A New Optimizer using Particle Swarm Theory”, presented at the $6^{\text {th }}$ International Symposium on Micromachine and Human Science, Nagoya, pp. 3943, 1995.

[10] J. B. Park, Y. W. Jeong, J. R. Shin, and K. Y. Lee, "An improved particle swarm optimization for nonconvex economic dispatch problems", IEEE Transactions on Power Systems, vol. 25, n. 1, pp. 156-166, 2010.

[11] D. P. Rini, S. M. Shamsuddin and S. S. Yuhaniz, "Particle swarm optimization: technique, system and challenges", International Journal of Computer Applications, vol. 14, n. 1, 1926, 2011.

[12] R. Storn and K. Price, "Differential evolution - A Simple and efficient adaptive scheme for global optimization over continuous spaces", Technical Report TR-95-012, International Computer Science Institute, 1995.

[13] K.V. Price, R.M. Storn, and J.A. Lampinen. Differential Evolution: A Practical Approach to Global Optimization. Springer, 2005.

[14] J. C. Bansal, P. K. Singh, M. Saraswat, A. Verma, S. S. Jadon and A. Abraham, "Inertia weight strategies in particle swarm optimization" presented at the $3^{\text {rd }}$ World Congress on Nature and Biologically Inspired Computing (NaBIC), Salamanca, pp. 633-640, 2011.

[15] R. C. Eberhart and Y. Shi, "Tracking and optimizing dynamic systems with particle swarms", presented at the IEEE Congress on Evolutionary Computation, Seoul, vol. 1, pp. 94-100, 2001.

[16] A.K. Qin and P.N. Suganthan, "Self-adaptive differential evolution algorithm for numerical optimization", presented at the IEEE Congress on Evolutionary Computation, Edinburgh, v. 2, pp. 1785-1791, 2005.

[17] M. G. Omran, A. P. Engelbrecht and A. Salman, "Differential evolution based particle swarm optimization", presented at the IEEE Swarm Intelligence Symposium, Honolulu, pp. 112-119, 2007.

[18] C.-T. Chen, C. Hwang, "Optimal control computation for differential-algebraic process systems with general constraints", Chemical Engineering Communications, v. 97, n. 1, pp. 9-26, 1990.

[19] S. Ochoa, "A new approach for finding smooth optimal feeding profiles in fed-batch fermentations”, Biochemical Engineering Journal, v. 105, pp. 177-188, 2016. 
$10^{\mathrm{TH}}$ InTERnational CONFERENCE ON Sustainable ENERgy AND

ENVIRONMENTAL Protection (June $27^{\mathrm{TH}}-30^{\mathrm{TH}}$, 2017, Bled,

SLOVENIA), BIOENERGY AND BIOFUELS

J. Krope, A.Ghani Olabi, D. Goričanec \& S. Božičnik

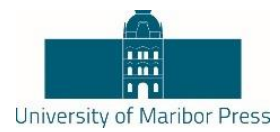

\title{
Modeling the Production Process of Bioethanol in Free Software Using Metabolic Pathways
}

\author{
MATHEUS Yuri GRITZENCO De GIOVANNi, RENAM LuIS ACORSI, IGOR ROSSI FERMO, \\ Cid MARCos GONÇALVES ANDRADE \& José EdUARDO Olivo
}

\begin{abstract}
Alternative sources of renewable energy to replace the use of fossil fuels have been studied. Among them, the production of ethanol from fermentative processes of carbon-based renewable raw materials has attracted attention because it is a clean and more viable option. These fermentative processes can and should be continuously optimized and there are several forms of modeling them. One of the most useful ways to analyze processes is the development of mathematical models of processes. In view of this, the present work seeks to implement a basic metabolic model for the fermentation process of bioethanol production using Saccharomyces cerevisiae as microorganism, since this is the main microorganism used for the production of bioethanol. The development of a model based on metabolism generates a deeper understanding of the fermentation process, as well as assist in the development of genetic modifications that will further enhance the industrial productivity of bioethanol. The implementation and development of the model will be done using the free software COPASI, whose results have been satisfactory according to the literature.
\end{abstract}

Keywords: • COPASI • Free software • Renewable energy • Ethanol • Metabolic pathway •

CORRESPONDENCE ADDRESS: Matheus Yuri Gritzenco De Giovanni, M.Sc, Universidade Estadual de Maringá, Chemical Engineering Department, Av. Colombo, 5790 - Vila Esperanca, Maringá Paraná, Brasil, email: matheusdegiovanni@gmail.com. Renam Luis Acorsi, Ph.D, Universidade Estadual de Maringá, Chemical Engineering Department, Av. Colombo, 5790 - Vila Esperanca, Maringá - Paraná, Brasil, email:rnmacorsi@gmail.com. Igor Rossi Fermo, M.Sc, Universidade Estadual de Maringá, Chemical Engineering Department, Av. Colombo, 5790 - Vila Esperanca, Maringá - Paraná, Brasil, email: igor_fermo@ hotmail.com. Cid Marcos Gonçalves Andrade, Ph.D, Universidade Estadual de Maringá, Chemical Engineering Department, Av. Colombo, 5790 - Vila Esperanca, Maringá - Paraná, Brasil, email: cid@deq.uem.br. José Eduardo Olivo, Ph.D, Universidade Estadual de Maringá Chemical Engineering Department, Av. Colombo, 5790 - Vila Esperanca, Maringá - Paraná, Brasil, email:olivo@gmail.com.

https://doi.org/10.18690/978-961-286-048-6.22

ISBN 978-961-286-048-6

(C) 2017 University of Maribor Press

Available at: http://press.um.si. 
$10^{\mathrm{TH}}$ InTERNATIONAL CONFERENCE ON Sustainable ENERGY AND ENVIRONMENTAL Protection (June $27^{\mathrm{TH}}-30^{\mathrm{TH}}, 2017$, BLed, Slovenia), Bioenergy AND Biofuels M. Yuri Gritzenco De Giovanni, R. Luis Acorsi, I. Rossi Fermo, C. Marcos Gonçalves Andrade \& J. Eduardo Olivo: Modeling the Production Process of Bioethanol in Free Software Using Metabolic Pathways

Problems caused by the use of fossil resources induces the development of sustainable bioprocesses [1]. The use of fuels derived from petroleum results in a great emission of $\mathrm{CO}_{2}$, which represents a major contribution to the total greenhouse gas (GHG) emissions [2]. Currently, bioethanol is the dominant biofuel, with the majority being produced in USA and Brazil, with the feedstocks being corn and sugarcane, respectively [2,3]. The costs of feedstock, especially corn costs, production and the reduction in GHG emissions leads to continuum debate about the use of biofuels [4]. In Brazil, there is no doubt that the dependency from petroleum derived fuels decreased due the development and the continuous improvement of the sugar and alcohol industry, which besides ethanol, produces also bioelectricity, polymers and even food to human and animal consumption $[5,6]$.

A way to improve bioprocesses is by studying the transforming agent used, like the microorganisms used in fermentation [1]. Microorganisms can be seen as tiny factories, controlled by its metabolism, a well-regulated network of reactions, which almost never overproduces the desired substance [7]. Then, improving the performance of an microorganism can be achieved either by optimization and better comprehension of its metabolic network or the introduction of new metabolic pathway by genetic modifications, a method that needs a great knowledge of genetics and metabolism [1,2]. There is where systems biology comes: systems biology aims to unravel the molecular mechanisms underlying the phenotype of biological systems and to predict cellular behavior through the combination of high-throughput technologies and computational methods [8].

In bioethanol production, the most used microorganism is the yeast Saccharomyces cerevisiae, one of the most studied fungus. Among the characteristics that make this yeast an excellent choice for the sugar and alcohol industry, we can highlight its rapid growth, high fermentation capacity and metabolization of sugars, tolerance to high concentrations of ethanol and low levels of oxygen, tolerance to large variations of temperature and activity over a wide $\mathrm{pH}$ range [9]. S. cerevisiae is also a particularly suitable organism because: it is well-characterized genetically, and it can be grown under conditions of continuous culture in which its metabolism can adopt a steady state. These conditions allow multiple proteome and metabolome samples to be acquired, and ensure a high reproducibility of measurements and hence fidelity of the final results [10].

In S. cerevisiae, there is main metabolic pathway of glucose consumption and ethanol production in anaerobic condition, also known as glycolysis. That pathway is, perhaps, the most important in the metabolism of many living cells, because consuming glucose, produces free energy in the form of ATP and reducing equivalents in the form of NADH as other precursors used in different metabolic pathways. The glycolysis describes the conversion of glucose and other hexoses to pyruvate, which is then reduced to ethanol in anaerobic conditions. Being glucoses the substrate, the ideal mass fraction of products 
$10^{\text {TH }}$ INTERNATIONAL CONFERENCE ON SUSTAINABLE ENERGY AND ENVIRONMENTAL

Protection (June $27^{\mathrm{TH}}-30^{\mathrm{TH}}, 2017$, Bled, Slovenia), Bioenergy AND Biofuels

M. Yuri Gritzenco De Giovanni, R. Luis Acorsi, I. Rossi Fermo, C. Marcos Gonçalves

Andrade \& J. Eduardo Olivo: Modeling the Production Process of Bioethanol in Free Software Using Metabolic Pathways

will be 0,511 of ethanol $[11,12,13]$. Glycolysis represents an excellent test-case, being a metabolic pathway found in all three domains of life, Archaea, Bacteria and Eukarya, although this pathway show some differences between organisms [10].

Mathematical models can simulate the complex and dynamic behavior of cell metabolism. Metabolic pathway models consist of enzymatic reactions described by their stoichiometry, the enzymatic rate laws, and their kinetic constants (some of the kinetic constants needed for a model could be collected from literature, but they are often incomplete, incompatible, or simply not available) [14]. This way, the majority of mathematical models of biochemical pathways have been developed based on data collected from different sources $[10,14]$. It is worth to say that the enzyme kinetic data used in such models have usually been measured at each enzyme's optimal $\mathrm{pH}$; however the optimal $\mathrm{pH}$ of each enzyme in a pathway is normally different and the physiological $\mathrm{pH}$ and other conditions would not match the optimal conditions for each enzyme [15]. This approach may result in a distorted view, i.e., one not fully representative of the system under study. Any unknown parameters of the model are estimated through the finding of a best fit to an available set of experimental data and the more we know about these quantities, the more reliably we can simulate the metabolic dynamics [10,14].

This way, seeking to begin a better understand and improve the bioethanol production through fermentation by Saccharomyces cerevisiae, a kinetic model of the glycolysis pathway described in [16] will be proposed, using data taken from literature to run the model in the software COPASI, a stand-alone program that can be used through a graphical user interface [17].

A generalized version of the reversible Michaelis-Menten rate law, which is suitable for any reaction stoichiometry and accounting for various types of allosteric regulation, will be used to model enzymatic kinetics. Once a metabolic network and enzymatic rate laws have been chosen, we need numerical values for the kinetic constants, something that can be a challenge, especially for large networks [14]. Note that the model here developed doesn't aim to fit any experimental data yet, we just seek to propose a basic model to glycolysis. With this initial and basic model running in the free software proposed, a more complex and precise model can be formulated and validated with experimental data, helping to comprehend deeply this kind of fermentation.

\section{$2 \quad$ Method}

A metabolic pathway is a complex network of reactions occurring simultaneously. To exemplify this, the schematic model of branched glycolysis that will be used in this model consists of 19 reactions. Aiming to simplify the visualization and working with all the species involved, there will be used some specific abbreviations to refer to the enzymes and substances used in that model, as shown in Table 1. 
222 10 $10^{\mathrm{TH}}$ InTERNATIONAL CONFERENCE ON Sustainable ENERGY AND ENVIRONMENTAL Protection (June $27^{\mathrm{TH}}-30^{\mathrm{TH}}, 2017$, BLed, Slovenia), Bioenergy AND Biofuels

M. Yuri Gritzenco De Giovanni, R. Luis Acorsi, I. Rossi Fermo, C. Marcos Gonçalves Andrade \& J. Eduardo Olivo: Modeling the Production Process of Bioethanol in Free Software Using Metabolic Pathways

Table 1. Abbreviation of Isoenzymes and Substances

\begin{tabular}{|c|c|}
\hline Abreviation & Isoenzyme/Substance \\
\hline HXT & Hexose Transporters \\
\hline HK & Hexokinase \\
\hline PGI & Phosphogluco Isomerase \\
\hline PFK & Phosphofructokinase \\
\hline Alda & Fructose-1,6-Bisphosphate Aldolase \\
\hline PGM & Phosphoglycerate Mutase \\
\hline ENO & Enolase \\
\hline PYK & Pyruvate Kinase \\
\hline PDC & Pyruvate Decarboxylase \\
\hline $\mathrm{ADH}$ & Alcohol Dehydrogenase \\
\hline Acald & Acetaldehyde \\
\hline ADP & Adenosine Diphosphate \\
\hline AMP & Adenosine Monophosphate \\
\hline ATP & Adenosine Triphosphate \\
\hline $\mathrm{BPG}$ & Bisphosphoglycerate \\
\hline Glycerol & Glycerol \\
\hline $\mathrm{CO} 2$ & Carbon Dioxide \\
\hline DHAP & Dihydroxyacetone phosphate \\
\hline $\mathrm{EtOH}$ & Ethanol \\
\hline F16bP & fructose-1,6-bisphosphate \\
\hline F26bP & fructose 2,6-bisphosphate \\
\hline F6P & fructose 6-phosphate \\
\hline G6P & glucose 6-phosphate \\
\hline GAP & Glyceraldehyde 3-phosphate \\
\hline GLCi & Glycosis In \\
\hline GLCo & Glycosys Out \\
\hline Glycogen & Glycogen \\
\hline NAD & Nicotinamide adenine dinucleotide \\
\hline $\mathrm{NADH}$ & $\begin{array}{l}\text { Nicotinamide adenine dinucleotide } \\
\text { (reduced form) }\end{array}$ \\
\hline $\mathrm{P} 2 \mathrm{G}$ & Glycerate \\
\hline $\mathrm{P} 3 \mathrm{G}$ & Phosphates \\
\hline PEP & Phosphoenol-pyruvate \\
\hline PYR & Pyruvate \\
\hline Succinate & Succinate \\
\hline Trehalose & Trehalose \\
\hline
\end{tabular}

So, with these abbreviations, the chosen model for glycolysis is presented in Fig. 1. This glycolysis pathway model were proposed by Teusink et al. [16], being used later in the 
$10^{\mathrm{TH}}$ INTERNATIONAL CONFERENCE ON SUSTAINABLE ENERGY AND ENVIRONMENTAL 223

Protection (June $27^{\mathrm{TH}}-30^{\mathrm{TH}}, 2017$, Bled, Slovenia), Bioenergy AND Biofuels M. Yuri Gritzenco De Giovanni, R. Luis Acorsi, I. Rossi Fermo, C. Marcos Gonçalves Andrade \& J. Eduardo Olivo: Modeling the Production Process of Bioethanol in Free Software Using Metabolic Pathways

works of Pritchard and Kell [13] and Smallbone et al. [10]. The kinetic parameters to be used in this model simulation were taken from [10].

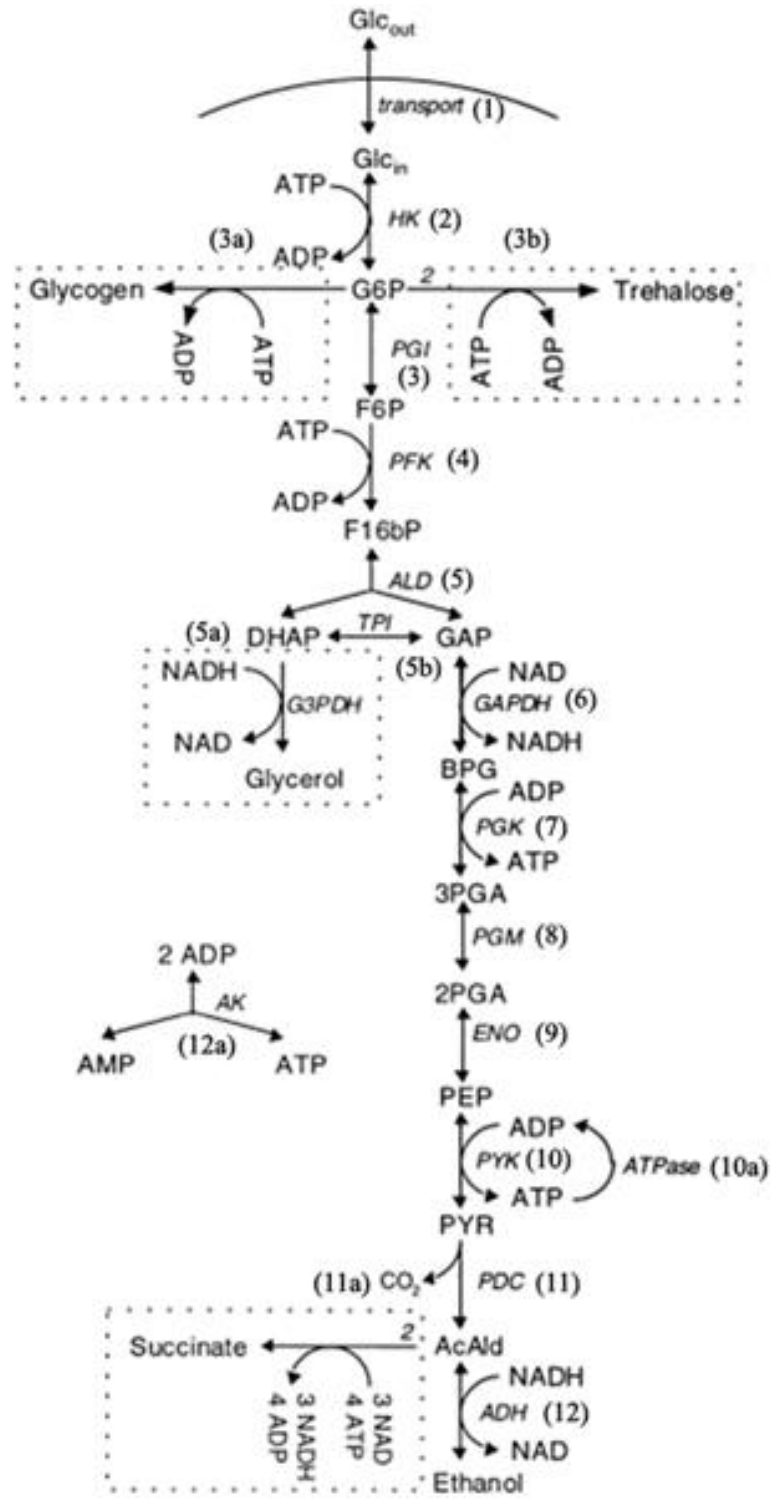

Figure 1. Schematic of the model yeast glycolytic pathway of Teusink [16] 
224 10 $10^{\text {TH }}$ InTERnAtional CONFERENCE ON Sustainable ENERGy AND ENVIRONMENTAL Protection (June $27^{\mathrm{TH}}-30^{\mathrm{TH}}, 2017$, Bled, Slovenia), BioENERGY AND Biofuels

M. Yuri Gritzenco De Giovanni, R. Luis Acorsi, I. Rossi Fermo, C. Marcos Gonçalves Andrade \& J. Eduardo Olivo: Modeling the Production Process of Bioethanol in Free Software Using Metabolic Pathways

The reactions describing the kinetic model were directly inserted in COPASI software. The kinetics reactions used were:

HXT:

$G L C O=G L C i$

HK:

$G L C i+A T P=G 6 P+A D P$

Glycogen:

G6P $+A T P \rightarrow A D P+$ Glycogen

Trehalose:

$2 G 6 P+A T P \rightarrow A D P+$ Trehalose

PGI:

$G 6 P=F 6 P$

PFK:

$F 6 P+A T P \rightarrow F 16 b P+A D P$

ALD:

$F 16 b P=D H A P+G A P$

Glycerol Branch:

DHAP $+N A D H \rightarrow$ Glycerol $+N A D$

TPI:

$D H A P=G A P$

GAPDH:

$G A P+N A D=B P G+N A D H$

PGK:

$B P G+A D P=P 3 G+A T P$ 
PGM:

$P 3 G=P 2 G$

ENO:

$P 2 G=P E P$

PYK:

$P E P+A D P=P Y R+A T P$

ATPase:

$A T P \rightarrow A D P$

PDC:

$P Y R \rightarrow$ AcAld $+\mathrm{CO}_{2}$

Succinate:

2 AcAld $+3 N A D \rightarrow$ Succinate $+3 N A D H$

ADH:

AcAld $+N A D H=E t O H+N A D$

AK:

$2 A D P=A T P+A M P$

\section{$3 \quad$ Results and Discussion}

Setting initial concentration of the metabolic intermediates in zero, letting just a tiny amount of AMP, ADP, ATP, NAD and NADH existing inside the cell, in way to emulate cells without any metabolic reaction happening before the start of simulation, the following profiles shown in Figures 4 to 7 were generated: 
226 10 $10^{\text {TH }}$ InTERnAtional CONFERENCE ON Sustainable ENERGy AND ENVIRONMENTAL Protection (June $27^{\mathrm{TH}}-30^{\mathrm{TH}}, 2017$, Bled, SLOVENiA), BioENERGY AND Biofuels

M. Yuri Gritzenco De Giovanni, R. Luis Acorsi, I. Rossi Fermo, C. Marcos Gonçalves Andrade \& J. Eduardo Olivo: Modeling the Production Process of Bioethanol in Free Software Using Metabolic Pathways

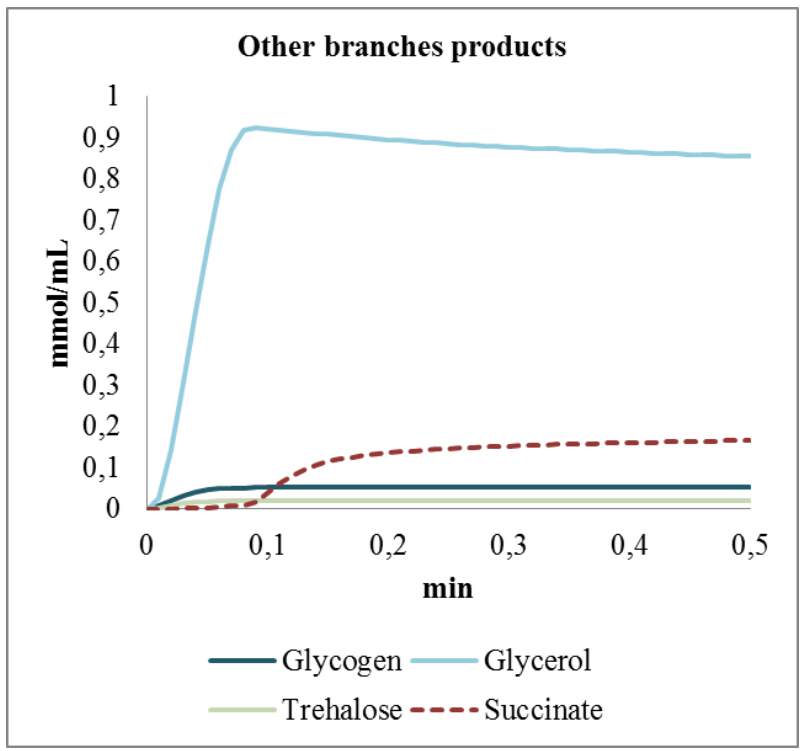

Figure 4. Other branches products

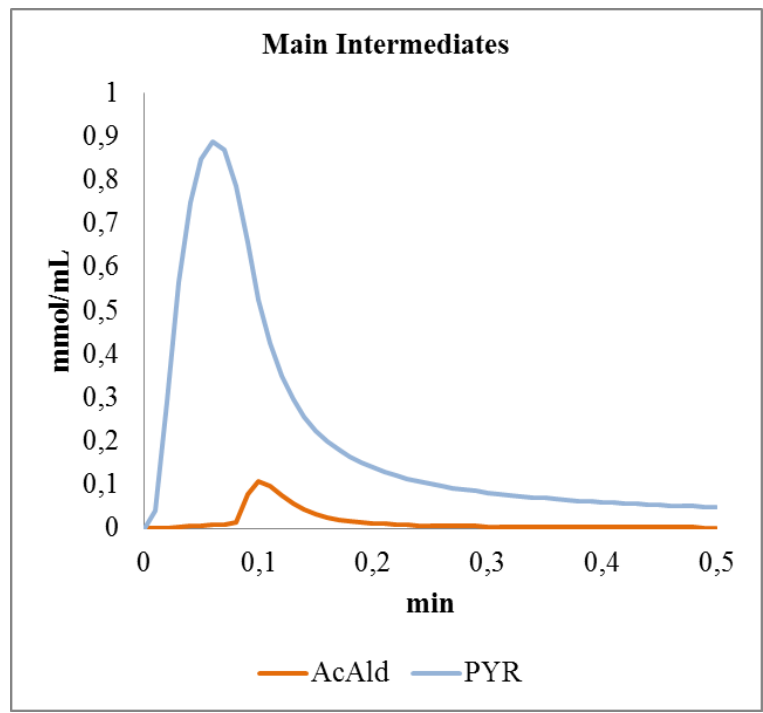

Figure 5. Main intermediates 
$10^{\text {TH }}$ INTERNATIONAL CONFERENCE ON SUSTAINABLE ENERGY AND ENVIRONMENTAL

Protection (June $27^{\mathrm{TH}}-30^{\mathrm{TH}}, 2017$, Bled, Slovenia), Bioenergy and Biofuels M. Yuri Gritzenco De Giovanni, R. Luis Acorsi, I. Rossi Fermo, C. Marcos Gonçalves Andrade \& J. Eduardo Olivo: Modeling the Production Process of Bioethanol in Free Software Using Metabolic Pathways

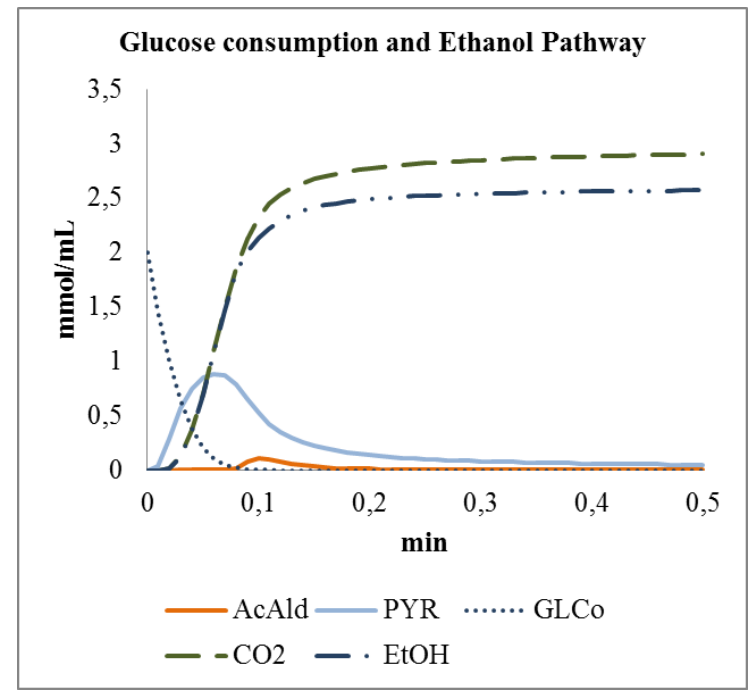

Figure 6. Ethanol pathway

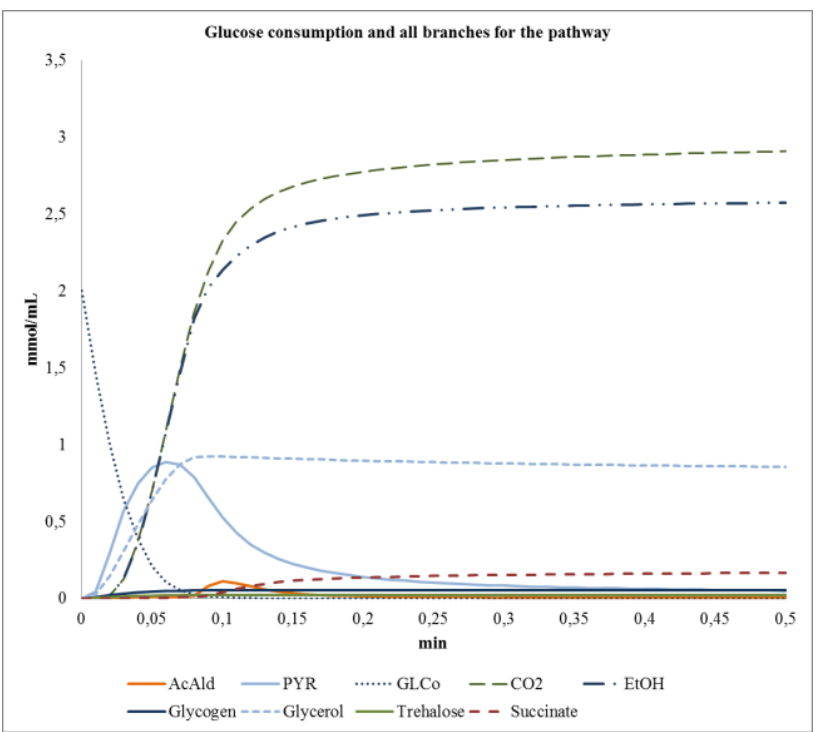

Figure 7. Glucose consumption and products from all branches

Before starting the analysis, we must consider where the used data came from: literature kinetics values used to create Figures 5 to 8 were measured experimentally under a standardized set of conditions and the data were integrated into an approximate mathematical model to predict a new set of metabolite concentrations and reevaluate the control properties [10]. Kinetics parameters of most glycolytic enzymes and initial 
$10^{\mathrm{TH}}$ InTERNATIONAL CONFERENCE ON Sustainable ENERGY AND ENVIRONMENTAL Protection (June $27^{\mathrm{TH}}-30^{\mathrm{TH}}, 2017$, Bled, SLOVENiA), BioENERGy AND Biofuels

M. Yuri Gritzenco De Giovanni, R. Luis Acorsi, I. Rossi Fermo, C. Marcos Gonçalves Andrade \& J. Eduardo Olivo: Modeling the Production Process of Bioethanol in Free Software Using Metabolic Pathways

concentration inside cell were first calculated at the known Teusink model [16], which studied in vivo behavior of yeast glycolysis, and reevaluated by Pritchard and Kell [13] using parameter scanning with three flux-control, two by hexose transport and one by phosphofructokinase.

In this model were set initial concentration of the metabolic intermediates as zero, keeping only AMP, ADP, ATP, NAD and NADH. At literature we found that F26bP works as an inhibitor for PFK reaction tough it is not created inside the metabolic path, for this reason we kept its value fixed. Ethanol production on ADH reaction was in reversible form due to experimental facility to calculate kinetics parameters.

At first, branch reactions were ignored. In this way the model failed to reach the stable steady state that was observed in appropriate literature. Introduction of branches towards trehalose, glycogen, glycerol and succinate did allow such a steady state. This shows that these kinetics parameters and equations are only reliable if using the whole pathway, since it considers all products and intermediates interactions. It is a full model but really sensitive to changes.

The predictions of this branched model were compared with the literature. The ratio of Ethanol and Carbon Dioxide should be around 0,51-0,49 but we found 0,47-0,53 using this model. Stoichiometry should be 1:2 but is around 1:1,3. Analyzing these profiles, we found that it is according to stoichiometric desired, with both carbon dioxide and ethanol under $4 \mathrm{mmol} / \mathrm{ml}$. This maximum value would only be found if all the glucose found outside the cell is converted to carbon dioxide and ethanol, without other substances, like glycogen, trehalose, succinate and, as we observed in this model, glycerol.

The intention of this work was fully accomplished, since a mathematic model for ethanol production pathway (glycolysis) with profiles as expected from the literature were obtained. This model can be improved further, with insertion of new metabolic pathways and more data, specially experimental data. Since it is modelled at COPASI, which is a free software and full of tools, it is a dynamic model where we can set any initial concentration (fixating it or making it reactionary) as well as any kinetic parameter or equation. This model can be defined as one step for future works we intend to do, especially on kinetic parameters and equation refinement and ethanol production enhancement.

\section{Acknowledgements}

The Authors would like to thank in advance the Conference Responsible for the opportunity to present our work, our co-authors and professor adviser for all the time and effort demanded in this job and to Chemical Engineering Department together with CAPES and CNPq for supporting our researches. 
$10^{\text {TH }}$ INTERNATIONAL CONFERENCE ON SUSTAINABLE ENERGY AND ENVIRONMENTAL

Protection (June $27^{\mathrm{TH}}-30^{\mathrm{TH}}, 2017$, Bled, Slovenia), Bioenergy ANd Biofuels

M. Yuri Gritzenco De Giovanni, R. Luis Acorsi, I. Rossi Fermo, C. Marcos Gonçalves

Andrade \& J. Eduardo Olivo: Modeling the Production Process of Bioethanol in Free Software Using Metabolic Pathways

\section{References}

[1] Dai, Z. and Nielsen, J. (2015) Advancing metabolic engineering through systems biology of industrial microorganisms. Current Opinion in Biotechnology. 36, 8-15.

[2] Nielsen, J., Larsson, C., Van Maris, A. and Pronk, J. (2013) Metabolic engineering of yeast for production of fuels and chemicals. Current Opinion in Biotechnology. 24, 398-404.

[3] Chen, B. and Saghsian, S. (2015) The relationship among ethanol, sugar and oil prices in Brazil: cointegration analysis with structural breaks. Selected Paper prepared for presentation at the Southern Agricultural Economics Association's 2015.

[4] Caspeta, L., Buijs, N.A.A., Nielsen, J. (2013) The role of biofuels in the future energy supply. Energy \& Environmental Science. 6, 1077-1082.

[5] Filoso, S., do Carmo, J.B., Mardegan, S.F., Lins, S.R.M., Gomes, T.F. and Martinelli, L.A. (2015) Reassessing the environmental impacts of sugarcane ethanol production in Brazil to help meet sustainability goals. Renewable and Sustainable Energy Reviews. 52, 1847-1856.

[6] Lapola, D.M., Schaldach, R., Alcamo, J., Bondeau, A., Koch, J., Koelking, C., et al. (2010) Indirect land-use changes can overcome carbon savings from biofuels in Brazil. Proceedings of the National Academy of Sciences. 107, 3388-3393.

[7] Demain, A.L. (2000) Microbial technology. Trends in Biotechnology. 18, 26-31.

[8] Nielsen, J., Jewett, M.C. (2008) Impact of systems biology on metabolic engineering of Saccharomyces cerevisiae. FEMS Yeast Res. 8, 122-131.

[9] Andrietta, M.G.S., Andrietta, S.R., Steckelberg, C. and Stupiello, E.N.A. (2007) Bioethanol - 30 years of Proálcool. International Sugar Journal. 109, 195-200.

[10] Smallbone, K., Messiha, H.L., Carroll, K.M., Winder, C.L., Malys, N., Dunn, W.B., Murabito, E., Swainston, N., Dada, J.O., Khan, F. et al.. (2013) A model of yeast glycolysis based on a consistent kinetic characterisation of all its enzymes. FEBS Letters. 587, 17:2832-2841.

[11] Madigan, M.T., Martinko, J.M. and Parker, J. (2000) Brock Biology of Microbiology. 9th Edition. New Jersey: Prentice-Hall.

[12] Bai, F.W., Anderson, W.A. and Moo-Young, M. (2008) Ethanol fermentation technologies from sugar and starch feedstocks. Biotechnology Advances. 26, 89-105.

[13] Pritchard, L. and Kell, D.B. (2002) Schemes of flux control in a model of Saccharomyces cerevisiae glycolysis. European Journal of Biochemistry. 269, 3894-3904.

[14] Lubitz, T., Schulz, M., Klipp, E. and Liebermeister, W. (2010) Parameter balancing in kinetic models of cell metabolism. The Journal of Physical Chemistry. B 114, 1629816303.

[15] Garcia-Contreras, R., Vos, P., Westerhoff, H.V. and Boogerd, F.C. (2012) Why in vivo may not equal in vitro - new effectors revealed by measurement of enzymatic activities under the same in vivo-like assay conditions. FEBS Journal. 279, 4145-4159.

[16] Teusink, B., Passarge, J., Reijenga, C.A., Esgalhado, E., van der Weijden, C.C., Schepper, M., Walsh, M.C., Bakker, B.M., van Dam, K., Westerhoff, H.V. \& Snoep, J.L. (2000) Can yeast glycolysis be understood in terms of in vitro kinetics of the constituent enzymes? Testing Biochemistry. European Journal of Biochemistry. 267, 5313-5329.

[17] Hoops, S., Sahle, S., Gauges, R. et al. (2006) COPASI - a COmplex PAthway Simulator. Bioinformatics. 24, 3067-3074. 
$230 \mid 10^{\mathrm{TH}}$ International CONFERENCE ON Sustainable ENERGy AND ENVIRONMENTAL Protection (June $27^{\mathrm{TH}}-30^{\mathrm{TH}}, 2017$, BLed, Slovenia), Bioenergy AND Biofuels 
$10^{\mathrm{TH}}$ InTERnational CONFEREnCE ON Sustainable ENERgy AND ENVIRONMENTAL Protection (June $27^{\mathrm{TH}}-30^{\mathrm{TH}}$, 2017, Bled, SLOVENIA), BIOENERGY AND BIOFUELS

J. Krope, A.Ghani Olabi, D. Goričanec \& S. Božičnik

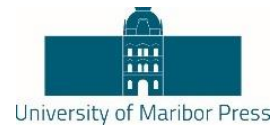

\title{
Preliminary Exergy Analysis of Biodiesel Production Routes: A Brief Review
}

\author{
JOAO MARCOS RONCARCI MARI, MARCUS VINICIUS RONCARI MARI, MAYKON CESAR \\ SPOLTI FERREIRA, EUGENIA LEANDRO ALMEIDA, W.A.DOS S. CONCEIÇÃO \& CID \\ MARCOS GONCALVES ANDRADE
}

\begin{abstract}
Fossil fuels have been being the basis of world energy matrix since the industrial revolution to nowadays, although the increasing request and the exorbitant consumption, it has become a challenge for society not to compromise the available resources to future generations. In this scene, an alternative could be biofuels, as biodiesel. Whereas Brazil is the second largest producer of soybeans worldwide, there is a big potential for developing renewable energy sources. This work aims to review the concepts of preliminary exergy analysis, for this, it will be shown the stages of assessment process, starting at energy and exergy balances up to energy and exergy efficiencies. Furthermore, feedstock to produce biodiesel and transesterification process. Researchers claim the exergy analysis is a powerful tool to identify losses, locate inefficiency sources and make accounts the wastage of energy conversion. Hence, it will be discussed the biodiesel as a potential substitute of non-renewable sources.
\end{abstract}

Keywords: • Biofuel • Biodiesel • Renewable • Transesterification • Exergy analysis $\bullet$

CoRReSPONDENCE AdDRESS: Joao Marcos Roncarci Mari, Master's Degree Student, State University of Maringá, Department of Mechanical Engineering, Av. Colombo, 5790 - Zona 7, Maringá - PR, 87020-900, Brazil, email: joao_roncari@ hotmail.com. Marcus Vinicius Roncari Mari, Master's Degree Student, State University of Maringá, Department of Mechanical Engineering, Av. Colombo, 5790 - Zona 7, Maringá - PR, 87020-900, Brazil, email, vinicius_roncari@hotmail.com. Maykon Cesar Spolti Ferreira, Master's Degree Student, State University of Maringá, Department of Mechanical Engineering, Av. Colombo, 5790 - Zona 7, Maringá - PR, 87020-900, Brazil, email: spolti.maykon@gmail.com. Eugenia Leandro Almeida, Master's Degree Student, Department of Chemical Engineering, State University of Maringá, Department of Mechanical Engineering, Av. Colombo, 5790 - Zona 7, Maringá - PR, 87020-900, Brazil, email: eugenia-almeida@hotmail.com. W.A.dos S. Conceição, Professor, State University of Maringá, Department of Mechanical Engineering, Av. Colombo, 5790 - Zona 7, Maringá - PR, 87020-900, Brazil. email: wasconceicao@gmail.com. Cid Marcos Goncalves Andrade, Professor, State University of Maringá, Department of Chemical Engineering, Av. Colombo, 5790 - Zona 7, Maringá - PR, 87020-900, Brazil, email: cid@ deq.uem.br.

https://doi.org/10.18690/978-961-286-048-6.23

ISBN 978-961-286-048-6

(C) 2017 University of Maribor Press

Available at: http://press.um.si. 
$23210^{\mathrm{TH}}$ INTERNATIONAL CONFERENCE ON SUSTAINABLE ENERGY AND ENVIRONMENTAL Protection (June $27^{\mathrm{TH}}-30^{\mathrm{TH}}, 2017$, BLED, SLOVENIA), BioENERGY AND Biofuels J.M.R. Mari, M.V.R. MARI, M.C.S. Ferreira, E.L. Almeida, W.A.dos S. Conceição \& C.M.G. Andrade: Preliminary Exergy Analysis of Biodiesel Production Routes: A Brief Review

With the oil crisis started at 70's decade, when it was discovered that this fuel was not renewable associate with global concern on decreases the burning of fossil fuels that cause the greenhouse effect and consequently global warming, alternative fuels have been sought increasingly, which are biodegradable and have low emission of pollutants. Thus, biofuels such as ethanol, biomass, biogas and biodiesel have become important on world stage [1]. Due to biodiesel is a renewable source of energy from vegetable oils or animal fat, researches consider this source as promising to achieve a sustainable future [2]. Soybean oil is the most used feedstock for biodiesel production in America, moreover Brazil is the second largest world producer of grain, 95.631 million tons was produced in 2015/2016 crop [3], therefore there is a big potential of development in the country. Researchers discuss the utilization of edible oils for fuel production such as a negative aspect, because social problems, as hunger, however, in Brazil there is an extensive area of cultivation, then it is possible to produce soybean for food and biodiesel production as well. Exergetic analysis is used to evaluate judiciously the performance of production plants, because this tool combines The First and Second Law of Thermodynamic in order to quantify inefficiencies within energy process [4]. In this context the work aims to review concepts of preliminary exergy analysis, showing how this method can be utilized to evaluate biodiesel production process. Moreover, it intends to show which are feedstock used, the transesterification process and lastly to discuss results that have been obtained by researchers of area.

\section{Description of Biodiesel Production Process}

The idea of utilization vegetal oils such as fuel is so old as diesel engine, because there is reports that the scientist Rudolf Diesel, in the year 1900, used peanut oil to run an engine for several hours at the World Exposition in Paris [5]. However, a long term, the utilization of raw oil induced engine breakdowns, as hole obstruction, carbon deposits and coke formation. The reason for the damages has been identified as high viscosity, low volatility and reactivity of hydrocarbon chains found at vegetal oils [6]. Just in the beginning of 90 's, scientists discovered ways to reduce the high viscosity of vegetal oils, among some ways, it was highlighted pyrolysis and transesterification [6]. The pyrolysis was characterized to be an expensive process and that generated undesirable products [7], thus, the transesterification process was widely studied and one of its products was called biodiesel. Technologies for biodiesel production are differentiated as to choice of feedstock and as to way of obtaining, it could be chemical or enzymatic [8]. The chemical way includes transesterification, acidic and alkaline, thermal cracking, as known as pyrolysis, and supercritical fluid. On the other hand, the enzymatic process uses enzymes, in this case, lipases [8]. Currently, the most used process for biodiesel production is the transesterification, because there are some advantages such as low temperatures and the possibility of utilization several catalysts. The most common are: sodium hydroxide and potassium hydroxide. Other advantage of this process are transesterifying agents, which are common alcohols, as ethanol and methanol. Therefore, there is a decreasing of 
$10^{\mathrm{TH}}$ INTERNATIONAL CONFERENCE ON SUSTAINABLE ENERGY AND ENVIRONMENTAL

Protection (June $27^{\mathrm{TH}}-30^{\mathrm{TH}}, 2017$, Bled, Slovenia), Bioenergy AND Biofuels

J.M.R. Mari, M.V.R. MARI, M.C.S. Ferreira, E.L. Almeida, W.A.dos S. Conceição \& C.M.G. Andrade: Preliminary Exergy Analysis of Biodiesel Production Routes: A Brief

Review

production costs and consequently viability of process [9]. Veillette et al. [10] have proposed the production of biodiesel from oil extracted from ScenedesmusObliquus microalgae. The basic catalysts used were potassium hydroxide and strontium oxide. The experimental parameters used were: proportion of methanol with respect to lipid mass $31.4 \%$ and mass of catalyst with respect to oil mass $2.48 \%$, reaction time and temperature of $22.2 \mathrm{~min}$ and $60{ }^{\circ} \mathrm{C}$. The results demonstrate that potassium hydroxide presented higher yield compared to strontium oxide. Although it presented a lower yield, the strontium oxide proved to be an effective catalyst, since it presented a yield of $76 \%$. On the other hand, Barbosa et al. [11] have proposed the production of biodiesel from vegetable oil extracted from the almond of the amazon tucumã Astrocaryum aculeatum. The authors have used homogeneous acid and basic catalysis. In the acid catalysis the catalysts used were hydrochloric acid $(\mathrm{HCl})$ and sulfuric acid ( $\mathrm{H} 2 \mathrm{SO} 4)$. The experimental parameters were: concentration of catalysts 0.0625 and $1.0 \mathrm{M}$, molar ratio oil per ethyl alcohol hydrate $1: 6$, reaction time of $24 \mathrm{~h}$ and temperature of $90{ }^{\circ} \mathrm{C}$. According to the authors, the acid catalysts with concentration of $1.0 \mathrm{M}$ have presented yields higher than $90 \%$.

\subsection{Main feedstock}

There are more than 300 feedstock globally identified as potential crops for biodiesel production [12]. However, a sustainable production needs to have a low cost of feedstock and be available in enough amounts for commercialization, this factors depend fundamentally on geographic localization, weather, soil conditions and agricultural practices used [13]. Feedstock alone represents $75 \%$ of overall biodiesel production costs, consequently, a correct choice will define a process viability. [13]. In general, feedstock for biodiesel production can be divide into three main categories [12], as shown as Table 1.

Table 1. Feedstock Categories

\begin{tabular}{|c|c|c|}
\hline $\begin{array}{l}\text { First Generation } \\
\text { (Edible Oils) }\end{array}$ & $\begin{array}{l}\text { Second Generation } \\
\text { (Non-Edible Oils* } \\
\text { and Fat Animals**) }\end{array}$ & Third Generation \\
\hline $\begin{array}{l}\text { Rapeseed } \\
\text { Canola Soybean } \\
\text { Sunflower Palm } \\
\text { Peanut Coconut }\end{array}$ & $\begin{array}{l}\text { Jatropha* } \\
\text { Neem* } \\
\text { Pongamia* } \\
\text { Cooking oil* } \\
\text { Tallow** } \\
\text { Yellow fat** } \\
\text { Chicken fat** } \\
\text { Fish oil*** }\end{array}$ & $\begin{array}{l}\text { Microalgae oil } \\
\text { Fungus oil }\end{array}$ \\
\hline
\end{tabular}

Soybean oil is the most used in United States, on the other hand in Europe is rapeseed oil, in Malaysia is palm oil and in India is jatropha oil [14]. In Brazil, Figure 1 shows the percentage of feedstock utilized for biodiesel production on December 2016. 
234 10 $10^{\mathrm{TH}}$ InTERnational CONFERENCE ON Sustainable ENERGy AND ENVIRONMENTAL Protection (June $27^{\mathrm{TH}}-30^{\mathrm{TH}}, 2017$, BLED, SLOVENIA), BioENERGY AND Biofuels J.M.R. Mari, M.V.R. MARI, M.C.S. Ferreira, E.L. Almeida, W.A.dos S. Conceição \& C.M.G. Andrade: Preliminary Exergy Analysis of Biodiesel Production Routes: A Brief Review

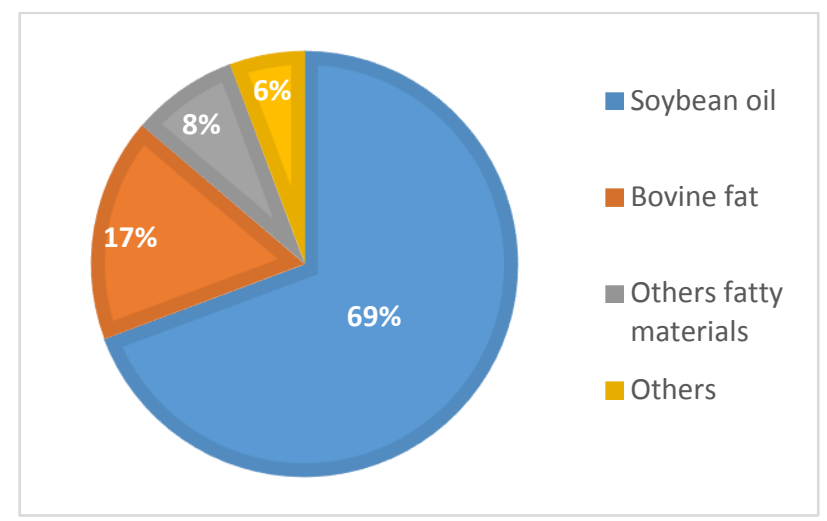

Figure 1. Predominant feedstock in Brazil

The $6 \%$ include cotton oil, cooking oil, pork fat, chicken fat, palm oil and canola oil.

\subsection{Transesterification}

Transesterification consists of a chemical reaction between animal fat or vegetable oil and excess alcohol at presence of a catalyst, in order to form ester and glycerol [15]. Usually is used methyl or ethyl alcohol, then, it is produced methyl or ethyl ester, respectively [12]. The Figure 2 exemplifies this reaction.

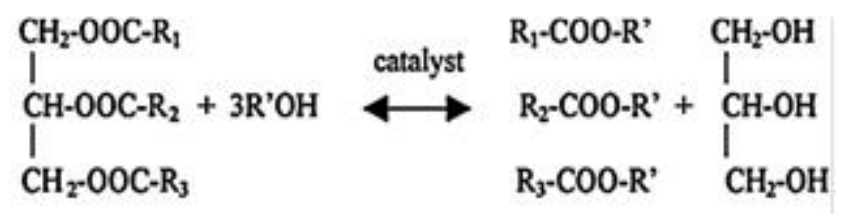

Glyceride Alcohol Esters Glycerol

Figure 2. Transesterification Reaction

The Figure 3 shows in a detailed form the biodiesel production process by means of transesterification. 


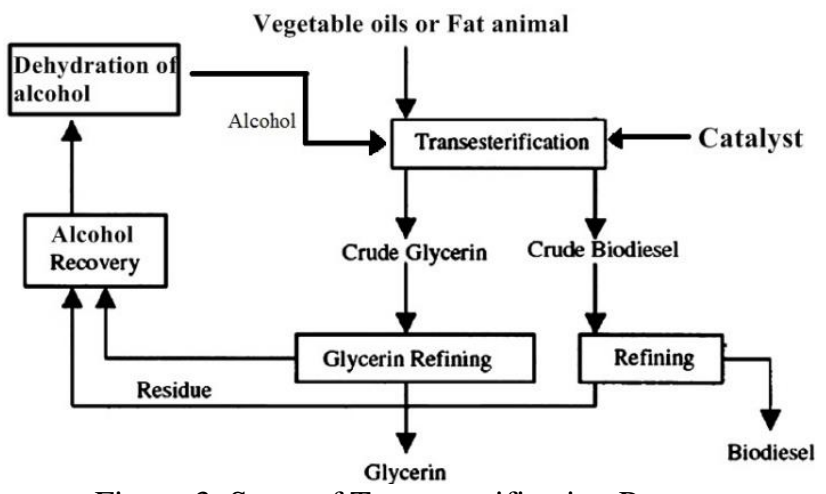

Figure 3. Steps of Transesterification Process

The transesterification reaction will depend on amount/type of alcohol and catalyst, temperature and reaction time, besides the moisture content and the amount of free fatty acids in feedstock [12]. After the reaction, it is obtained a product constituted of two phases, which can be separated by decantation and/or centrifugation. The dense phase represents raw glycerine, whereas the light phase esters or raw biodiesel. This products are impregnated with excess alcohol and impurities, for this reason, it is called raw [16]. The steps of alcohol recovery from glycerine and esters happen at the same way, by means of an evaporation process, followed by a liquefaction in an appropriate condenser, it is recovered excess alcohol. After a dehydration, through distillation, it is possible to reuse at transesterification reaction [16]. Lastly, esters must be purified, through centrifugation and after dehumidified, in order to obtain biodiesel. On the other hand is realized a vacuum distillation from glycerine, then it is obtained distilled glycerine [16].

\section{Steps of Exergetic Assessment Process}

The First Law of Thermodynamics deals with amount and claims that energy can not be created neither destroyed. Whereas The Second Law of Thermodynamics deals with way of process and its irreversibilities. Combining both laws, it results in a thermodynamic measure as known as exergy. [9]. The exergy of a system can be defined as the maximum theoretical useful work obtained when a system comes from a certain state to equilibrium with reference environment [17]. Thus, exergy is just conserved when process that happen into a system and its environment are reversible. On the other hand, it is always destroyed when there are irreversibilities in the process [18]. When the exergetic analysis is realized in an energy generation plant or chemical process, thermodynamic imperfections can be quantified such as exergy destruction, which means, waste of energy quality or waste of useful work [18]. 
$10^{\text {Th }}$ International Conference on Sustainable Energy and Environmental Protection (June 27 $7^{\mathrm{TH}}-30^{\mathrm{TH}}, 2017$, Bled, SLOVENIA), BioENERGY AND Biofuels J.M.R. Mari, M.V.R. MARI, M.C.S. Ferreira, E.L. Almeida, W.A.dos S. Conceição \& C.M.G. Andrade: Preliminary Exergy Analysis of Biodiesel Production Routes: A Brief

Review

\subsection{Mass and Energy Balances}

The mass balance equation for a control volume, Equation (1), can be expressed as,

$\frac{d m}{d t}=\sum_{\text {in }} \dot{m}_{\text {in }}-\sum_{\text {out }} \dot{m}_{\text {out }}$

where $\dot{m}$ represents mass flow, $t$ time and subscripts in and out, input and output, respectively [19]. While The First Law of Thermodynamics for a control volume is shown by Equation (2),

$$
\begin{aligned}
& \frac{d E_{V C}}{d t}=\dot{Q}-\dot{W}+\sum_{\text {in }}\left[\dot{m}_{\text {in }}\left(h_{\text {in }}+\frac{V_{\text {in }}^{2}}{2}+g z_{\text {in }}\right)\right]-\sum_{\text {out }}\left[\dot { m } _ { \text { out } } \left(h_{\text {out }}+\frac{V_{\text {out }}{ }^{2}}{2}+\right.\right. \\
& \left.\left.g z_{\text {out }}\right)\right]
\end{aligned}
$$

where $\dot{Q}, \dot{W}, h, V, g$ e $z$ represent, heat, work, enthalpy, velocity, gravity and height, respectively [19].

\subsection{Types of exergy}

Exergy can be divided in 4 parts: kinetic, potential, physical and chemical [18]. Some researchers classify the kinetic, potential and physical exergy only as thermomechanical exergy. [19]. The Equation (3) includes the specific kinetic exergy, potential and physical.

$e=h-h_{0}-T_{0}\left(s-s_{0}\right)+\frac{V^{2}}{2}+g z$

Where $T$ and $s$ represents temperature and entropy, respectively, whereas the subscript 0 refers to dead state or reference environment. On the other hand, the determination of chemical exergy is not so easy, because industrial fuels are compounds of several chemical components. Thus, Szargut [20] has proposed that the ratio of chemical exergy with the net calorific value for industrial solid and liquid is the same as pure chemical substances, having the same elements ratio. The Equation (4) represents this ratio.

$\varphi=\frac{b^{o}}{(N C V)^{0}}$

Where $b^{o}$ is the chemical exergy and $(N C V)^{0}$ the net calorific value. There are some correlations of $\varphi$ for solid and liquid fuels, for liquid biomass substances such as biodiesel, glycerin and free fatty acids the Equation (5) can be used.

$\varphi=1.0374+0.0159 \frac{h^{\prime}}{c^{\prime}}+0.0567 \frac{o^{\prime}}{c^{\prime}}$

Where $h^{\prime}, c^{\prime}$ and $o^{\prime}$ are mass fraction of hydrogen, carbon and oxygen, respectively [20]. 
$10^{\mathrm{TH}}$ INTERNATIONAL CONFERENCE ON SUSTAINABLE ENERGY AND ENVIRONMENTAL

Protection (June $27^{\mathrm{TH}}-30^{\mathrm{TH}}, 2017$, Bled, Slovenia), Bioenergy AND Biofuels

J.M.R. Mari, M.V.R. MARI, M.C.S. Ferreira, E.L. Almeida, W.A.dos S. Conceição \&

C.M.G. Andrade: Preliminary Exergy Analysis of Biodiesel Production Routes: A Brief

Review

\subsection{Exergy balance}

After it has been defined the types of exergy, it is possible to apply the exergy balance for a control volume by means of Equation (6),

$\frac{d E_{x}}{d t}=\sum\left(1-\frac{T_{o}}{T_{b}}\right) \dot{Q}-\left(\dot{W}-P_{0} \frac{d v}{d t}\right)+\sum_{\text {in }}\left(\dot{m} e_{x}\right)_{\text {in }}-\sum_{\text {out }}\left(\dot{m} e_{x}\right)_{\text {out }}-T_{0} \dot{\sigma}(6)$

where $E_{x}, P, v, e_{x}$ and $\dot{\sigma}$ represent the whole exergy of system, pressure, volume, whole specific exergy and entropy generation, respectively. Whereas the subscript $b$ is the boundary of system [19]. Appling this balance is possible to calculate the exergy destruction in each component of system, and then to identify where is the biggest source of process inefficiency.

\subsection{Energetic and exergetic efficiencies}

Efficiencies are used to measure the performance of equipment and process. The Equations (7) and (8) show ways to calculate the energetic and exergetic efficiency, respectively.

$$
\begin{aligned}
& \eta=\frac{\text { Energy output in product }}{\text { Energy input }} \\
& \varepsilon=\frac{\text { Exergy output in product }}{\text { Exergy input }}
\end{aligned}
$$

Where product could refer to shaft work, electricity, heat transfer, flows or mixing of some of these [18].

\subsection{Analysis of some researches}

At research of Marigorta, Medina and Castellano [4] the authors have realized an exergetic analysis of biodiesel production from jatropha, where they have obtained $63 \%$ of global exergetic efficiency of system. The authors have pointed the transesterification reactor such as the biggest inefficiency component, because it has represented almost $95 \%$ of fuel exergy destruction. Therefore, it is evidenced that chemical reactions are the reason of the biggest process irreversibilities. Demir et al [2] have done an exergetic analysis applied to biodiesel production through canola oil. In this case the authors has obtained $96.50 \%$ of global energetic efficiency of process and $75.60 \%$ of global exergetic efficiency. Whereas the biggest waste of exergy have been glycerin (18\%) and water (2.5\%). At research of Coronado et al [21] rapeseed oil has been used as feedstock to biodiesel production and the main objective of study has been to identify ideal parameters to transesterification reaction. Through to molar ratio of 6:1 (methanol:oil) and reaction temperature of $60^{\circ} \mathrm{C}$, it was achieved the lowest irreversibilities of production plant. As 
$10^{\mathrm{TH}}$ InTERNATIONAL CONFERENCE ON Sustainable ENERGy AND ENVIRONMENTAL Protection (June $27^{\mathrm{TH}}-30^{\mathrm{TH}}, 2017$, Bled, SLOVENiA), BioENERGY AND Biofuels

J.M.R. Mari, M.V.R. MARI, M.C.S. Ferreira, E.L. Almeida, W.A.dos S. Conceição \& C.M.G. Andrade: Preliminary Exergy Analysis of Biodiesel Production Routes: A Brief Review

conclusion of this study the authors have pointed the transesterification tank such as the main responsible of exergy destruction, as well as [4].

\section{Conclusion}

The exergetic analysis has shown such as a valuable tool to design and evaluate the performance of industrial plants, because it is possible to locate inefficiency sources and quantify losses. Several researchers have been using this methodology and have obtained excellent results, such as the studies above, where it was evidenced the transesterification reaction as the main cause of process irreversibilities. However, the biodiesel production has presented exergetically feasible, because it has been obtained efficiencies above $63 \%$. Taking account environment aspects, biodiesel is a promising source of energy, because it is renewable and biodegradable, furthermore having an extensive variety of possible feedstock. This advantage makes Brazil such as a potential producer, because in this country there is extensive cultivation area and variety of grain production.

\section{Acknowledgements}

This work has been realized with support of Coordenação de Aperfeiçoamento de Pessoal de Nível Superior (CAPES) - Brazil.

\section{References}

[1] A. K. Akella, R. P. Saini, and M. P. Sharma, "Social, economical and environmental impacts of renewable energy systems," Renew. Energy, vol. 34, no. 2, pp. 390-396, 2009.

[2] B. Demir et al, "Exergy assessment of biodiesel production process: application," J. Energy Inst., vol. 84, no. 4, pp. 236-245, Nov. 2011.

[3] Embrapa. (2016). Soja em números. [Online]. Available: https://www.embrapa.br/soja/cultivos/soja1/dados-economicos [Accessed: 5 Mar. 2017].

[4] A. M. B. Marigorta, J. S. Medina, and A. V. Castellano, "Exergetic analysis of a biodiesnel production process from Jatropha curcas," Appl. Energy, vol. 101, pp. 218-225, 2013.

[5] B. Orchard, J. Denis and J. Cousins, "Developments in biofuel processing technologies," World Pumps, vol. 2007, no. 487, pp. 24-28, 2007.

[6] B. Bharathiraja et al, "Biodiesel pruduction using chemical and biological methods - A review of process, catalyst, acyl acceptor, source and process variables," Renew. Sustain. Energy Rev., vol. 38, pp. 368-382, Oct. 2014.

[7] A. E. Bailey, D. Swern and M. W. Formo, Bailey's industrial oil and fat products. New York: John Wiley \& Sons, 1979.

[8] P. S. M. Abreu, "Análise econômica dos processos de produção do biodiesel de soja: rota química x rota enzimática", Ph.D. dissertation, School of Chemical, Universidade Federal do Rio de Janeiro, Rio de Janeiro, Brazil, 2013.

[9] M. E. M. Ferreira, "Análise exergoeconômica da produção de biodiesel de babaçu obtido por via metílica e etílica," M.S. thesis, Setor de Ciências Agrárias, Universidade Federal do Paraná, Curitiba, Brazil, 2014.

[10] V. Marc et al., "A biodiesel production process catalyzed by the leaching of alcaline metal Earths in metano," J. Chem. Technol. Biotechnol. pp. 1-10. 2016. 
$10^{\mathrm{TH}}$ INTERNATIONAL CONFERENCE ON SUSTAINABLE ENERGY AND ENVIRONMENTAL 239

Protection (June $27^{\mathrm{TH}}-30^{\mathrm{TH}}, 2017$, Bled, Slovenia), Bioenergy AND Biofuels

J.M.R. Mari, M.V.R. MARI, M.C.S. Ferreira, E.L. Almeida, W.A.dos S. Conceição \&

C.M.G. Andrade: Preliminary Exergy Analysis of Biodiesel Production Routes: A Brief

Review

[11] B. S. Barbosa et al., " The use of tucumã of amazonas kernel oil in the biodiesel production," Acta Amazonia. vol. 90, no. 2, pp. 1-10. 2010.

[12] E. M. Shahid and Y. Jamal, "Production of biodiesel: A technical review," Renew. Sustain. Energy Rev., vol. 15, no. 9, pp. 4732-4745, Dec. 2011.

[13] M. Kumar and M. P. Sharma, "Assessment of potencial of oils for biodiesel production," Renew. Sustain. Energy Rev., vol. 44, pp. 814-823, Apr. 2015.

[14] Y. C. Sharma, B. Singh and S. N. Upadhyay, "Advancements in development and characterization of biodiesel: a review," Fuel, vol. 87, no. 12, pp. 2355-2373, 2008.

[15] F. Ma and M. A. Hanna, "Biodiesel production: a review," Bioresour. Technol., vol. 70, no. 1, pp. 1-15, Oct. 1999.

[16] E. J. S. Parente, Biodiesel: uma aventura tecnológica num país engraçado. Fortaleza: Tecbio, 2003.

[17] A. Bejan, G. Tsatsaronis and M. Moran, Thermal design \& optimization. New York: WileyInterscience, 1996.

[18] I. Dincer and M. A. Rosen, Exergy: energy, environment and sustainable development. London: Elsevier, 2013.

[19] M. J. Moran and H. N. Shapiro, Princípios de Termodinâmica para Engenharia. Rio de Janeiro: LTC, 2009.

[20] J. Szargut, D. R. Morris and F. R. Steward, Exergy analysis of thermal, chemical and metallurgical process. New York: Hemisphere, 1988.

[21] C. R. Coronado et al, "Development of a thermoeconomic methodology for the optimization of biodiesel production - Part I: Biodiesel plant and thermoeconomic function diagram," Renew. Sustain. Energy Rev., vol. 23, pp. 138-146, Jul. 2013. 
$240 \mid 10^{\text {TH }}$ International CONFERENCE ON Sustainable ENERGy AND ENVIRONMENTAL Protection (June $27^{\mathrm{TH}}-30^{\mathrm{TH}}, 2017$, BLed, Slovenia), Bioenergy AND Biofuels 
$10^{\mathrm{TH}}$ INTERNATIONAL CONFERENCE ON Sustainable ENERgy AND ENVIRONMENTAL Protection (June $27^{\mathrm{TH}}-30^{\mathrm{TH}}$, 2017, Bled, SLOVENIA), BIOENERGY AND BIOFUELS

J. Krope, A.Ghani Olabi, D. Goričanec \& S. Božičnik

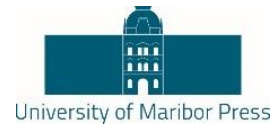

\title{
Sorption Enhanced Reforming of Different Fuel Types for the Production of a Hydrogen-Rich Reduction Gas
}

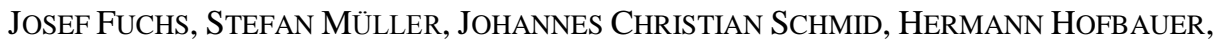 \\ Hugo StOCKER, NinA KIEBERGER \& THOMAS BÜRGLER
}

\begin{abstract}
A dual fluidized bed reactor system allows the production of a nitrogen-free product gas with a high reduction potential for steel industry. By using calcite as bed material in-situ removal of carbon dioxide out of the product gas is possible. Hence, a hydrogen-rich product gas can be generated. This so called "sorption enhanced reforming" process has already been proven for wood as fuel, but since the costs for biomass like wood increased significantly during the last years, cheaper renewable fuels are of interest. Thus, experimental results for cheap biogenic residues such as rice husk or bark in a $100 \mathrm{~kW}$ pilot plant at TU Wien are presented. Additionally, a comparison with results from an experiment with the fuel type lignite is part of the paper. Major differences of the investigated fuels regarding process control as well as process limitations, are discussed.
\end{abstract}

Keywords: • Dual fluidized bed $\bullet$ Sorption enhanced reforming $\bullet$ Volatile matter $\bullet$ Calcite $\bullet$ Biogenic fuels $\bullet$

CORRESPONDENCE AdDRESS: Josef Fuchs, DI, Assistant, TU Wien, Faculty of Technical Chemistry, Getreidemarkt 9/166, 1060 Vienna, Austria, e-mail: josef.fuchs@tuwien.ac.at. Stefan Müller, Dr, Assistant, TU Wien, Faculty of Technical Chemistry, Getreidemarkt 9/166, 1060 Vienna, Austria, e-mail: stefan.müller@tuwien.ac.at. Johannes Christian Schmid, Dr, Assistant, TU Wien, Faculty of Technical Chemistry, Getreidemarkt 9/166, 1060 Vienna, Austria, e-mail: johannes.schmid@tuwien.ac.at. Hermann Hofbauer, Dr, Professor, TU Wien, Faculty of Technical Chemistry, Getreidemarkt 9/166, 1060 Vienna, Austria, e-mail: hermann.hofbauer@tuwien.ac.at. Hugo Stocker, DI, Key Researcher, voestalpine Stahl Donawitz GmbH, Kerpelystraße 199, 8700 Leoben, Austria, e-mail: hugo.stocker@voestalpine.com. Nina Kieberger, DI, Key Researcher, voestalpine Stahl GmbH, voestalpine-Straße 3, 4020 Linz, Austria, e-mail: nina.kieberger@voestalpine.com. Thomas Bürgler, DI, Head of R\&D Ironmaking, voestalpine Stahl GmbH, voestalpine-Straße 3, 4020 Linz, Austria, e-mail: thomas.buergler@voestalpine.com.

https://doi.org/10.18690/978-961-286-048-6.24

ISBN 978-961-286-048-6

(C) 2017 University of Maribor Press

Available at: http://press.um.si. 
242 10 $10^{\mathrm{TH}}$ InTERNATIONAL CONFERENCE ON Sustainable ENERGY AND ENVIRONMENTAL Protection (June $27^{\mathrm{TH}}-30^{\mathrm{TH}}, 2017$, BLED, SLOVENiA), Bioenergy AND Biofuels

J. Fuchs, S. Müller, J. Christian Schmid, H. Hofbauer, H. Stocker, N. Kieberger \& T. Bürgler: Sorption Enhanced Reforming of Different Fuel Types for the Production of a Hydrogen-Rich Reduction Gas

\section{Introduction}

The substitution of fossil fuels is one of the major challenges for reducing greenhouse gas emissions. Biomass as renewable source releases the same amount of carbon dioxide as it aggregates during its growth. Therefore, gasification of biomass is a reliable technology for the reduction of greenhouse gas emissions and for gaining a valuable product gas for the production of heat, electric power, syngas and also for the usage as a reducing agent in the iron and steel industry. The utilization of cheap alternative biomass sources becomes important, since the increasing use of high-grade biomass (like wood chips) leads to increasing fuel costs as well. Due to challenging characteristics of alternative fuels (accompanying undesired chemical substances, high ash content, low ash deformation temperature, high tar and dust contents in the product gas, etc.) further development of existing technologies towards biogenic residues is of great relevance. Further, for the utilization of the product gas in steel industry a high reduction potential of the product gas is required. To meet the mentioned requirements the dual fluidized bed (DFB) steam gasification is a suitable process for the thermochemical conversion of biomass into a nitrogen-free product gas, which mainly consists of hydrogen $\left(\mathrm{H}_{2}\right)$, carbon monoxide $(\mathrm{CO})$, methane $\left(\mathrm{CH}_{4}\right)$, and carbon dioxide $\left(\mathrm{CO}_{2}\right)$. A steam blown gasification reactor and an air blown combustion reactor are the main parts. The combustion reactor provides the necessary heat for the overall endothermic steam gasification via combustion of residual char from gasification. Furthermore, if char is not sufficient for the heat balance, fuel can be fed to the combustion reactor as well. The produced heat is transferred into the gasification reactor via a so called bed material, which is typical for fluidized beds. Usually silica sand or olivine is used for conventional gasification applications as bed material. Besides these well-known bed materials, beneficial effects like the selective in-situ removal of $\mathrm{CO}_{2}$ in the gasification reactor can be achieved by the usage of a calcium based bed material $\left(\mathrm{CaO} / \mathrm{CaCO}_{3}\right)$.

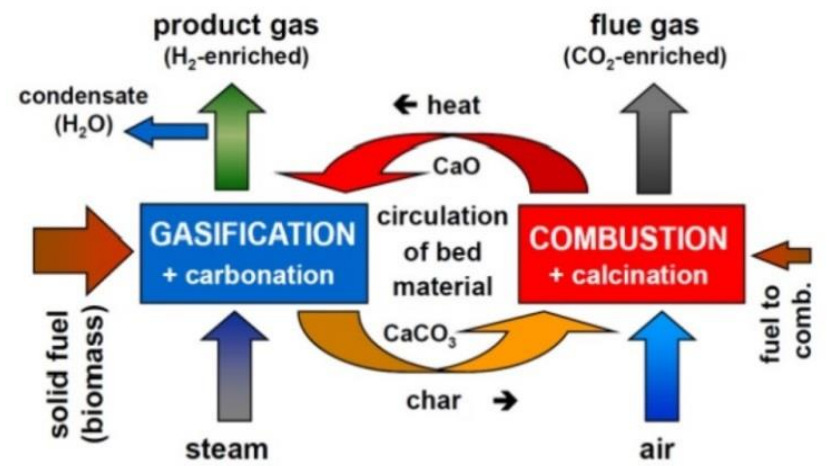

Figure 1. Principle of Gasification with $\mathrm{CO}_{2}$ Capture (SER) 
$10^{\mathrm{TH}}$ INTERNATIONAL CONFERENCE ON SUSTAINABLE ENERGY AND ENVIRONMENTAL

Protection (June $27^{\mathrm{TH}}-30^{\mathrm{TH}}, 2017$, Bled, Slovenia), Bioenergy AND Biofuels

J. Fuchs, S. Müller, J. Christian Schmid, H. Hofbauer, H. Stocker, N. Kieberger \& T. Bürgler: Sorption Enhanced Reforming of Different Fuel Types for the Production of a Hydrogen-Rich Reduction Gas

\section{$2 \quad$ Materials and methods}

\subsection{Sorption enhanced reforming}

The circulating bed material plays a crucial role for the basic operation of the DFB gasification system as transport medium of char from the gasification reactor into the combustion reactor and as transport medium for heat vice versa (from the combustion reactor into the gasification reactor). Furthermore, the bed material can also act as a catalyst and therefore contributes to tar reduction in the product gas. Another possible function of the bed material is the capture of gaseous components from the product gas (Figure 1): The sorption enhanced reforming (SER) process uses limestone/calcite $\left(\mathrm{CaCO}_{3}\right)$ as bed material. By operating both reactors in a suitable temperature range insitu $\mathrm{CO}_{2}$ capture in the gasification reactor according to Equation (1) and its release in the combustion reactor is possible (reverse of Equation (1)). The decreased $\mathrm{CO}_{2}$ concentration leads to a more intensive reaction of water/steam $\left(\mathrm{H}_{2} \mathrm{O}\right)$ with carbon monoxide (CO). Thus, the water-gas shift reaction (Equation (2)) enhances the production of $\mathrm{H}_{2}$ in the gasification reactor. Müller et al. [1] showed that the SER process produces a hydrogen-based reducing agent with a higher reduction potential than the gas produced from the conventional gasification process with olivine as bed material.

$$
\begin{aligned}
& \mathrm{CaO}+\mathrm{CO}_{2} \rightarrow \mathrm{CaCO}_{3} \quad \Delta H_{R}^{650}=-170 \mathrm{~kJ} / \mathrm{mol} \\
& \mathrm{CO}+\mathrm{H}_{2} \mathrm{O} \leftrightarrow \mathrm{CO}_{2}+\mathrm{H}_{2} \quad \Delta H_{R}^{650}=-36 \mathrm{~kJ} / \mathrm{mol}
\end{aligned}
$$

The suitable temperature range for gasification and combustion reactor during SER depends on the equilibrium partial pressure of $\mathrm{CO}_{2}$ in Equation (1). The equilibrium curve is reproduced in Figure 2, where operational conditions of the investigated test runs for gasification reactor and combustion reactor are outlined as well. Typical temperatures in the gasification reactor are between 600 and $700{ }^{\circ} \mathrm{C}$., whereas in the combustion reactor the bed material is heated up above $820^{\circ} \mathrm{C}$. There a suitable residence time ensures the full calcination to calcium oxide $(\mathrm{CaO})$. 
244 10 $10^{\text {TH }}$ InTERnAtional CONFERENCE ON Sustainable ENERGy AND ENVIRONMENTAL Protection (June 27 $7^{\mathrm{TH}}-30^{\mathrm{TH}}, 2017$, Bled, Slovenia), BioENERGy AND Biofuels

J. Fuchs, S. Müller, J. Christian Schmid, H. Hofbauer, H. Stocker, N. Kieberger \& T. Bürgler: Sorption Enhanced Reforming of Different Fuel Types for the Production of a Hydrogen-Rich Reduction Gas

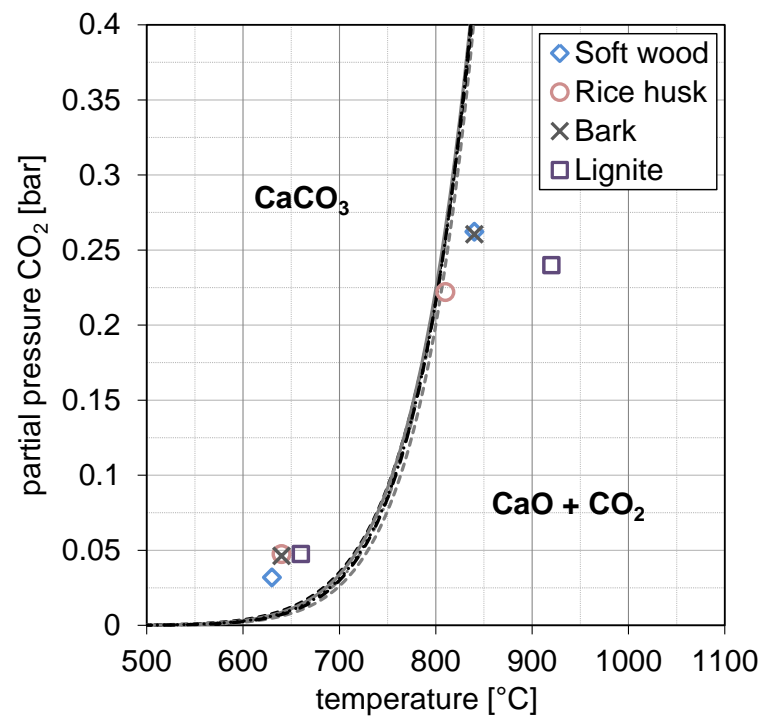

Figure 2. Equilibrium Partial Pressure of $\mathrm{CO}_{2}$ for the System $\mathrm{CaCO}_{3} / \mathrm{CaO}$

\section{$2.2 \quad$ Advanced $100 \mathrm{~kW}_{\text {th }}$ DFB test plant}

TU Wien has designed a novel dual fluidized bed test plant for the gasification of various fuels. A sketch of the plant is shown in Figure 3. 


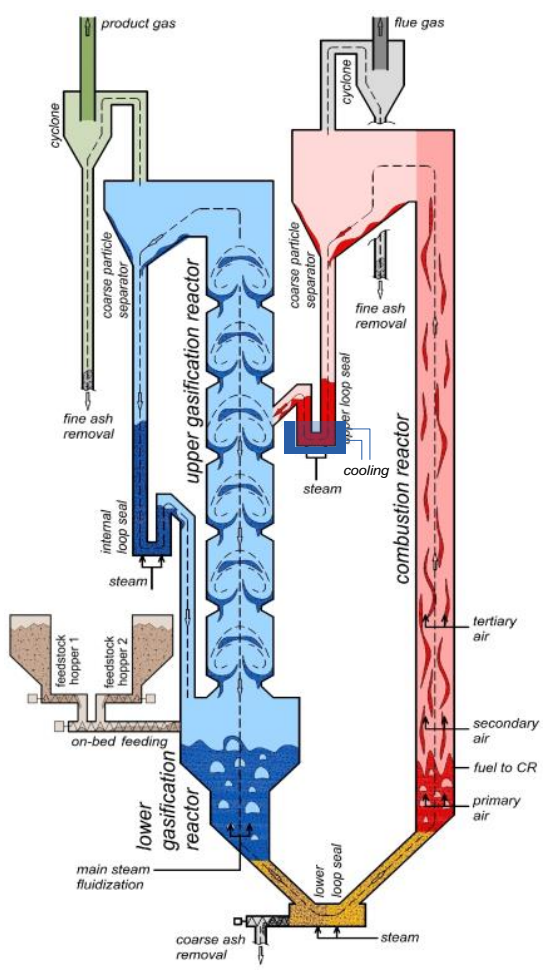

Figure 3. Advanced $100 \mathrm{~kW}_{\text {th }}$ Test Plant at TU Wien

The advanced reactor design enhances the gas-solid contact by a new countercurrentcolumn, which is placed subsequent to the lower bubbling bed of the gasification reactor. The geometrical modifications in this upper part of the gasification reactor lead to an improved bed material hold-up [2] and enlarge the range of applicable fuels because of higher tar and char conversion rates compared to other DFB systems. Further, gravity separators with gentle separation characteristics instead of cyclones support the usage of soft bed materials such as calcite/limestone. The new system prohibits high velocities of gas and particles and minimizes attrition effects. Additionally, a bed material cooling in the upper loop seal enables the defined setting of temperature differences between the gasification and combustion reactor for SER.

\section{$3 \quad$ Experimental}

SER of four different fuels was investigated and the main results are presented within this paper. Three of them originate from renewable organic sources - soft wood, rice husk, and bark. Lignite, the fourth presented fuel is used for reasons of comparison and to point out the fuel flexibility of the presented system. The detailed chemical analysis of the mentioned fuels is given in Table 2. All fuels were gasified with the same type of bed 
$10^{\mathrm{TH}}$ International Conference on Sustainable EnERgy and Environmental Protection (June $27^{\mathrm{TH}}-30^{\mathrm{TH}}, 2017$, Bled, SLOVENIA), BioENERGY AND Biofuels

J. Fuchs, S. Müller, J. Christian Schmid, H. Hofbauer, H. Stocker, N. Kieberger \& T. Bürgler: Sorption Enhanced Reforming of Different Fuel Types for the Production of a Hydrogen-Rich Reduction Gas

material (limestone/calcite, Table 1), which mainly forms $\mathrm{CaO}$ during the calcination process with high temperature in the combustion reactor. During the test runs, main product gas components like $\mathrm{H}_{2}, \mathrm{CO}, \mathrm{CO}_{2}$ and $\mathrm{CH}_{4}$ were analyzed by Rosemount NGA2000 measurement equipment. Higher gaseous hydrocarbons $\left(\mathrm{C}_{\mathrm{x}} \mathrm{H}_{\mathrm{y}}\right)$ were analyzed by a gas chromatograph (Perkin Elmer ARNEL - Clarus 500). A large number of temperature and pressure sensors and an extensive measurement equipment for mass and volume flows of the input and output streams guarantee an effective process control. A standardized arrangement of sampling equipment was used to analyze the content of dust, water, char and tar in the product gas stream. Detailed information about the sampling equipment can be found in [3], [4]. Furthermore, all measured values are validated by mass and energy balances carried out with a sophisticated model of the software IPSEpro. This approach guarantees accuracy and reliability of the presented values.

Table 1. Chemical Composition of Bed Material Particles Limestone/Calcite

\begin{tabular}{l|c|c|}
\hline Parameter/name & \multicolumn{1}{l}{ Unit } & Value \\
\hline $\mathrm{CaCO}_{3}$ & \multicolumn{1}{c}{ wt.-\% } & 97 \\
\hline $\mathrm{MgCO}_{3}$ & wt.-\% & 1.5 \\
\hline $\mathrm{SiO}_{2}$ & wt.-\% & 0.5 \\
\hline $\mathrm{Al}_{2} \mathrm{O}_{3}$ & wt.-\% & 0.3 \\
\hline $\mathrm{Fe}_{2} \mathrm{O}_{3}$ & wt.-\% & 0.2 \\
\hline $\begin{array}{l}\text { Loss of mass after } \\
\text { calcination }\end{array}$ & wt.-\% & 44 \\
\hline Sauter diameter $\left(\mathrm{d}_{\text {sv }}\right)$ & $\mu \mathrm{m}$ & 483 \\
\hline
\end{tabular}

\section{$4 \quad$ Results and Discussion}

The results of all test runs confirm that the necessary conditions for the SER process in both reactors (gasification and combustion) were fulfilled (Figure 2 and Table 3). In general, the gasification reactor has to work on the left side of the equilibrium curve of the system $\mathrm{CaCO}_{3} / \mathrm{CaO}$ to capture $\mathrm{CO}_{2}$ and for the formation of $\mathrm{CaCO}_{3}$. 
$10^{\mathrm{TH}}$ INTERNATIONAL CONFERENCE ON SUSTAINABLE ENERGY AND ENVIRONMENTAL

Protection (June $27^{\mathrm{TH}}-30^{\mathrm{TH}}, 2017$, Bled, SLOVENiA), BioENERGY AND Biofuels

J. Fuchs, S. Müller, J. Christian Schmid, H. Hofbauer, H. Stocker, N. Kieberger \& T.

Bürgler: Sorption Enhanced Reforming of Different Fuel Types for the Production of a Hydrogen-Rich Reduction Gas

Table 2. Chemical Composition of the Investigated Fuels

\begin{tabular}{|c|c|c|c|c|c|}
\hline Parameter/name & Unit & Soft wood & Rice husk & Bark & Lignite \\
\hline Water content & wt.- $\%$ & 7.2 & $\overline{5.8}$ & 7.7 & 13.0 \\
\hline Volatiles & wt.- $\%_{\text {daf }}$ & 86 & 81 & 78 & 54 \\
\hline LHV (moist) & $\mathrm{kJ} / \mathrm{kg}$ & 17060 & 14740 & 16480 & 20320 \\
\hline Ash content & wt. $-\%_{\mathrm{db}}$ & 0.2 & 15.2 & 7.0 & 4.2 \\
\hline Carbon (C) & wt.- $\%_{\text {daf }}$ & 50.8 & 51.2 & 52.3 & 68.4 \\
\hline Hydrogen $(\mathrm{H})$ & wt.- $\%_{\text {daf }}$ & 5.9 & 6.1 & 6.0 & 3.9 \\
\hline Oxygen $(\mathrm{O})$ & wt. $-\%_{\text {daf }}$ & 43.1 & 42.0 & 41.3 & 26.3 \\
\hline Nitrogen $(\mathrm{N})$ & wt.- $\%_{\text {daf }}$ & 0.21 & 0.55 & 0.34 & 0.88 \\
\hline Sulphur (S) & wt.- $\%_{\text {daf }}$ & 0.005 & 0.071 & 0.053 & 0.397 \\
\hline Chlorine $(\mathrm{Cl})$ & wt.- $\%_{\text {daf }}$ & 0.005 & 0.106 & 0.053 & 0.052 \\
\hline
\end{tabular}

(A)

\begin{tabular}{|l|l|l|l|l|l|}
\hline Ash flow temp. (D) & ${ }^{\circ} \mathrm{C}$ & 1440 & $>1500$ & 1210 & $>1500$ \\
\hline
\end{tabular}

Table 3. Operational Parameter and Results of Gasification Experiments

\begin{tabular}{|c|c|c|c|c|c|}
\hline Parameter/name & Unit & Soft wood & $\begin{array}{l}\text { Rice } \\
\text { husk }\end{array}$ & Bark & Lignite \\
\hline $\begin{array}{l}\text { Gasification } \\
\text { temperature } \\
\text { (in the lower GR) }\end{array}$ & ${ }^{\circ} \mathrm{C}$ & 630 & 640 & 640 & 660 \\
\hline $\begin{array}{l}\text { Max. temperature in } \\
\text { CR }\end{array}$ & ${ }^{\circ} \mathrm{C}$ & 840 & 810 & 840 & 920 \\
\hline Fuel to GR & $\mathrm{kW}$ & 110 & 105 & 102 & 100 \\
\hline Additional fuel to CR & $\mathrm{kW}$ & 4 & 29 & 6 & 0 \\
\hline Chem. energy in PG & $\mathrm{kW}$ & 81 & 76 & 77 & 45 \\
\hline $\mathrm{H}_{2}$ & vol.- $\%_{\mathrm{db}} *$ & 69.5 & 55.5 & 66.9 & 75.7 \\
\hline $\mathrm{CO}$ & vol.- $\%_{\mathrm{db}} *$ & 8.6 & 13.5 & 6.4 & 4.4 \\
\hline $\mathrm{CO}_{2}$ & vol.- $\%_{\mathrm{db}} *$ & 5.6 & 11.6 & 9.1 & 9.8 \\
\hline $\mathrm{CH}_{4}$ & vol.- $\%_{\mathrm{db}} *$ & 14.0 & 15.8 & 14.4 & 8.4 \\
\hline $\mathrm{C}_{\mathrm{x}} \mathrm{H}_{\mathrm{y}}$ & vol.- $\% \mathrm{db}_{\mathrm{db}} *$ & 2.3 & 3.6 & 3.2 & 1.7 \\
\hline PG yield & $\mathrm{Nm}_{\mathrm{db}}^{3} / \mathrm{kg}_{\text {fuel,daf }}$ & 0.9 & 0.9 & 1 & 0.9 \\
\hline $\mathrm{CO}_{2}$ in flue gas & vol.- $\%_{\mathrm{db}}$ & 28.9 & 23.7 & 27.8 & 25.6 \\
\hline Gravimetric tar & $\mathrm{g} / \mathrm{Nm}_{\mathrm{db}}^{3}$ & $1.26^{* *}$ & 17.8 & n.m. & n.m. \\
\hline GCMS tar & $\mathrm{g} / \mathrm{Nm}_{\mathrm{db}}^{3}$ & $5.67 * *$ & 29.4 & n.m. & n.m. \\
\hline $\mathrm{S} / \mathrm{F}$ & $\mathrm{kg}_{\mathrm{H} 2 \mathrm{O}} / \mathrm{kg}_{\text {fuel, daf }}$ & 0.8 & 1.2 & 1.0 & 1.1 \\
\hline $\mathrm{S} / \mathrm{C}$ & $\mathrm{kg} / \mathrm{kg}_{\mathrm{C}}$ & 1.6 & 2.3 & 1.9 & 1.6 \\
\hline
\end{tabular}

*PG composition without $\mathrm{N}_{2}$ and other minor impurities; **average of four similar test runs, n.m.: not measured 
248 10 $10^{\mathrm{TH}}$ InTERnAtional CONFERENCE ON Sustainable ENERGy AND ENVIRONMENTAL Protection (June $27^{\mathrm{TH}}-30^{\mathrm{TH}}, 2017$, BLed, Slovenia), Bioenergy AND Biofuels

J. Fuchs, S. Müller, J. Christian Schmid, H. Hofbauer, H. Stocker, N. Kieberger \& T. Bürgler: Sorption Enhanced Reforming of Different Fuel Types for the Production of a Hydrogen-Rich Reduction Gas
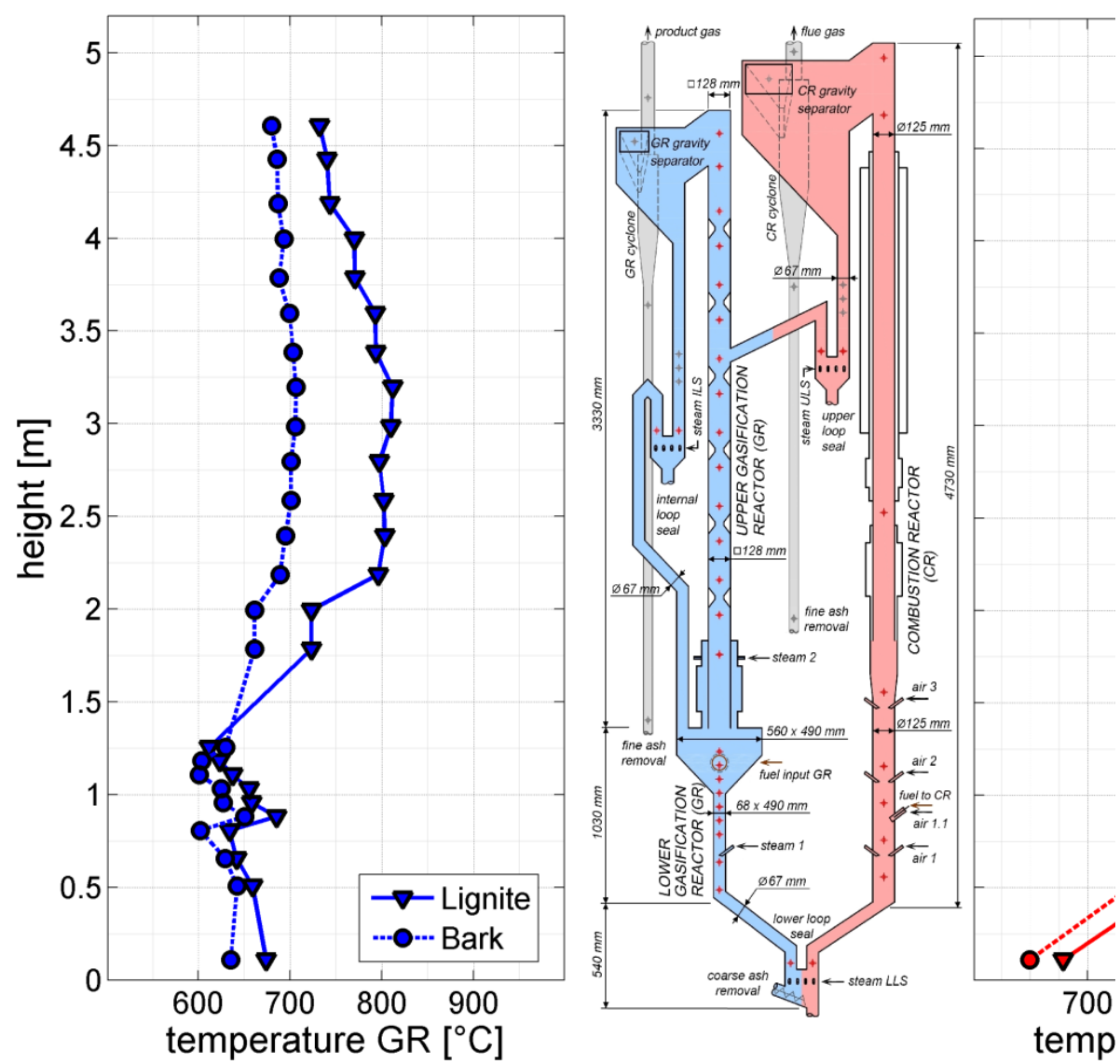

Figure 4. Temperature Profile of the Gasification Reactor (left) and the Combustion Reactor (right) for SER Gasification of Lignite and Bark 
$10^{\mathrm{TH}}$ INTERNATIONAL CONFERENCE ON SUSTAINABLE ENERGY AND ENVIRONMENTAL

Protection (June $27^{\mathrm{TH}}-30^{\mathrm{TH}}, 2017$, Bled, SLOVENiA), BioENERGY AND Biofuels

J. Fuchs, S. Müller, J. Christian Schmid, H. Hofbauer, H. Stocker, N. Kieberger \& T. Bürgler: Sorption Enhanced Reforming of Different Fuel Types for the Production of a Hydrogen-Rich Reduction Gas

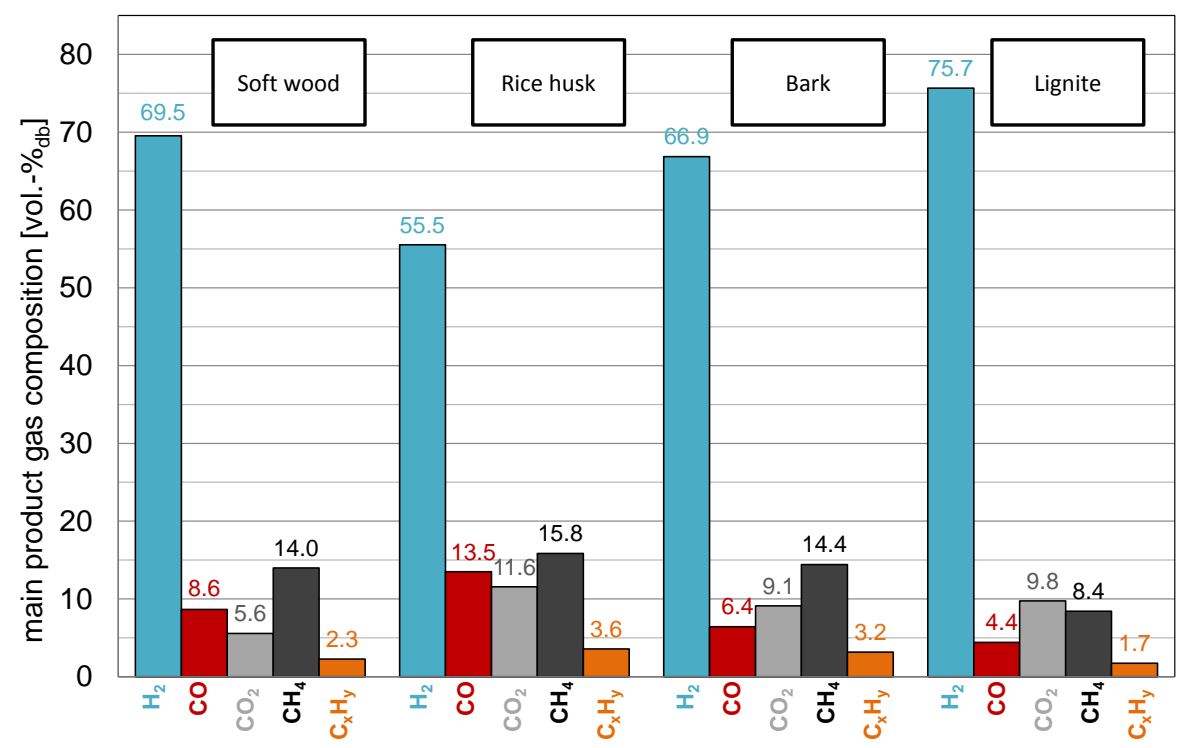

Figure 5. Main Product Gas Composition

Vice versa, the combustion reactor must be operated on the right side of the equilibrium curve to release $\mathrm{CO}_{2}$ and calcine $\mathrm{CaCO}_{3}$ to $\mathrm{CaO}$. Investigating Figure 2 in more detail shows that the operation points of the gasification reactor for the different experiments are in a narrow range, whereas the operation points for the combustion reactor are spread more widely. The reason for this behavior can be explained by the following considerations: First, the most important operational parameter is the gasification temperature to guarantee an optimized $\mathrm{CO}_{2}$-sorption parallel to the thermochemical conversion of the fuel. It has been shown in previous works that these two requirements are fulfilled at a temperature around $650{ }^{\circ} \mathrm{C}$ [5], [6]. Therefore, the most important control parameter is to keep this temperature in the lower part of the gasification reactor (close to the fuel input). Second, the temperature level in the combustion reactor is strongly dependent on the chemical composition of the fuel. For SER of lignite a significantly higher maximum combustion temperature was achieved. The reason for this behavior is the low content of volatile matter in the fuel lignite (Table 2). This means, that a high amount of char (residual from gasification of the fuel) is transported to the combustion reactor. This assumption is supported by the temperature profiles of the reactors in Figure 4. During the gasification of lignite, the temperature profile in the combustion reactor increased with height. This results from the high amount of char, which burns along the reactor height with the fluidizing air. The temperature of the bed material at the exit of the combustion reactor leads to higher temperatures in the countercurrent-column for gasification of lignite, which is advantageous for the reduction of the tar content in the product gas [3]. A comparably smaller amount of char reaches the combustion reactor in case of gasification of bark - the char is already combusted in the lower part of the 
$250 \quad 10^{\mathrm{TH}}$ InTERNATIONAL CONFERENCE ON SUSTAINABLE ENERGY AND ENVIRONMENTAL Protection (June $27^{\mathrm{TH}}-30^{\mathrm{TH}}, 2017$, BLED, SLOVENiA), Bioenergy AND Biofuels

J. Fuchs, S. Müller, J. Christian Schmid, H. Hofbauer, H. Stocker, N. Kieberger \& T. Bürgler: Sorption Enhanced Reforming of Different Fuel Types for the Production of a Hydrogen-Rich Reduction Gas

combustion reactor. The temperature decreased slightly with the height of the reactor. Additionally, a slight fuel input directly into the combustion reactor supports the calcination of bed material during the SER experiments with wood, rice husk and bark. The described differences for lignite and bark are illustrative results for fuels with high volatile matter and low volatile matter in general. Comparing the product gas composition for the SER gasification of the investigated fuels in Figure 5 shows that for soft wood, bark and lignite, $\mathrm{H}_{2}$ contents of about 70 vol.- $\%_{\mathrm{db}}$ were reached. Only the gasification of rice husk led to a significantly lower $\mathrm{H}_{2}$ content in the product gas. Two reasons can be identified for this behavior: First, the SER experimental phase of rice husk took place after conventional gasification with maximum temperatures of over $1050{ }^{\circ} \mathrm{C}$ in the combustion reactor. These high temperatures probably led to sintering effects of the original porous $\mathrm{CaO}$ bed material particles and, therefore, a decrease of the specific surface area. Thus, $\mathrm{CO}_{2}$ sorption capacity decreases as well [7]. Second, the comparably low maximum temperature (for SER gasification) in the combustion reactor leads to an operation close to the equilibrium curve of the chemical system $\mathrm{CaCO}_{3} / \mathrm{CaO}$ (Figure 2). It is assumed, that complete calcination of the bed material was not ensured, which may have impeded the effective $\mathrm{CO}_{2}$ sorption in the gasification reactor. Consequently, a comparatively lower $\mathrm{H}_{2}$ content in the product gas was observed for SER with rice husk. The reason for the lower system temperatures is the behavior of the rice husk ash: Fluidization problems were encountered during conventional gasification with gasification temperatures about $750{ }^{\circ} \mathrm{C}$ to $800{ }^{\circ} \mathrm{C}$ and high combustion temperatures of $1050^{\circ} \mathrm{C}$. To avoid limitations because of agglomeration effects of bed material particles, SER system temperatures were kept as low as possible. Thus, a more smooth operation regarding fluid dynamics of the dual fluidized bed was found for SER of rice husk.

Especially, the gasification of wood, bark and lignite led to preferable operational conditions without any limitations regarding the temperature range. With the correct adjustment of the bed material circulation rate, high $\mathrm{H}_{2}$ and low $\mathrm{CO}_{2}$ contents in the product gas are reachable. Thus, a high reduction potential of the produced gas stream is achievable for the utilization in the iron and steel industry.

5

\section{Conclusion}

Steam gasification of four different fuels, operating the so-called sorption enhanced reforming (SER) process for the production of a hydrogen-rich reduction gas, is investigated in this paper. It has been shown that the amount of volatiles in a fuel exerts a great influence on the operation conditions of the two interconnected reactors of a dual fluidized bed gasification system. Moreover, for SER the appropriate operation conditions are of crucial importance to ensure optimized $\mathrm{CO}_{2}$ sorption in the gasification reactor for production of a product gas with high reduction potential. Further, operation conditions, more precisely temperature levels, influence the ash behavior: High temperatures may lead to a breakdown of the fluidized bed due to critical ash melting behavior for some fuels. SER is operated on a lower temperature level in general and thus may be preferable for fuels with critical ash melting behavior. As a conclusion, problem- 
free operation conditions for the SER process with four different fuel types were demonstrated.

\section{Acknowledgements}

The present work is part of the research project ERBA II in cooperation with voestalpine Stahl $\mathrm{GmbH}$ and voestalpine Stahl Donawitz GmbH. ERBA II receives financial support by the research program "Energieforschung" funded by the "Austrian Climate and Energy Fund".

$\begin{array}{ll}\text { Abbreviations } & \\ \text { CR } & \text { combustion reactor } \\ \text { daf } & \text { dry and ash free } \\ \text { db } & \text { dry basis } \\ \text { DFB } & \text { dual fluidized bed } \\ \text { GR } & \text { gasification reactor } \\ \text { GCMS } & \text { gas chromatograph mass spectroscopy } \\ \text { max. } & \text { maximum } \\ \text { n.m. } & \text { not measured } \\ \text { PG } & \text { product gas } \\ \text { S/C } & \text { steam to carbon ratio } \\ \text { S/F } & \text { steam to fuel } \\ \text { (daf) ratio } \\ \text { SER } & \text { sorption enhanced reforming }\end{array}$

\section{References}

[1] S. Müller, S. Koppatz, M. Fuchs, T. Pröll, and H. Hofbauer, "Hydrogen Production Based on Conventional Dual Fluid Gasification versus Sorption Enhanced Reforming," in International Conference on Polygeneration Strategies, 2013.

[2] J. Schmid, T. Pröll, H. Kitzler, C. Pfeifer, and H. Hofbauer, "Cold flow model investigations of the countercurrent flow of a dual circulating fluidized bed gasifier," Biomass Convers. Biorefinery, vol. 2, no. 3, pp. 229-244, 2012.

[3] U. Wolfesberger-Schwabl, I. Aigner, and H. Hofbauer, "Mechanism of Tar Generation during Fluidized Bed Gasification and Low Temperature Pyrolysis," Ind. Eng. Chem. Res., vol. 51, no. 40, pp. 13001-13007, Oct. 2012.

[4] “CEN/TS 15439:2006," 2006.

[5] N. Poboß, "Experimentelle Untersuchung der sorptionsunterstützten Reformierung," Universität Stuttgart, $\mathrm{PhD}, 2016$.

[6] G. Soukup, "Der AER - Prozess , Weiterentwicklung in einer Technikumsanlage und Demonstration an einer Großanlage," TU Wien, PhD, 2009.

[7] G. Grasa and J. Abanades, "CO2 capture capacity of $\mathrm{CaO}$ in long series of carbonation/calcination cycles," Ind. Eng. Chem. Res., 2006. 
252 10 $10^{\mathrm{TH}}$ InTERnational CONFERENCE ON Sustainable ENERGy AND ENVIRONMENTAL Protection (June $27^{\mathrm{TH}}-30^{\mathrm{TH}}, 2017$, Bled, Slovenia), Bioenergy AND Biofuels 
$10^{\mathrm{TH}}$ InTERnational CONFEREnCE ON Sustainable ENERgy AND EnVironmental Protection (June $27^{\mathrm{TH}}-30^{\mathrm{TH}}$, 2017, Bled, SLOVENIA), BIOENERGY AND BIOFUELS

J. Krope, A.Ghani Olabi, D. Goričanec \& S. Božičnik

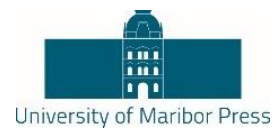

\title{
Mixtures of Silica Sand and Calcite as Bed Material for Dual Fluidized Bed Steam Gasification
}

\author{
AnNa Magdalena MaUerhofer, Florian BENEDIKT, JOHANNES CHRISTIAN SCHMID \\ $\&$ HERMANN HOFBAUER
}

\begin{abstract}
Results of the dual fluidized bed steam gasification with mixtures of silica sand and calcite with mass ratios of 100/0, 90/10, 50/50 and 0/100 used as bed material are presented. At high process temperatures, calcite is calcined to calcium oxide, which acts as catalytic active bed material and enhances in-situ tar, char and water conversion. Silica sand shows nearly no catalytic activity, but the advantages of this bed material are a good attrition resistance and preferable heat transfer. Both bed material types are cheap and easily available worldwide. The influence of different mixtures of the two bed materials on the product gas composition, the contents of gravimetrical tar and tar analyzed by gas chromatography coupled with mass spectrometry, the tar dew points and the char and dust contents are presented. Important key figures of the gasification process, like water conversion, cold gas efficiency and product gas yield were calculated.
\end{abstract}

Keywords: • Pilot plant $\bullet$ Soft $\operatorname{wood} \bullet$ Bed material $\bullet$ Catalytic activity $\bullet$ tar reduction $\bullet$

CORRESPONDENCE ADDRESS: Anna Magdalena Mauerhofer, MSc, Assistant, TU Wien, Faculty of Technical Chemistry, Getreidemarkt 9/166, 1060 Vienna, Austria, e-mail: anna.mauerhofer@tuwien.ac.at. Florian Benedikt, MSc, Assistant, TU Wien, Faculty of Technical Chemistry, Getreidemarkt 9/166, 1060 Vienna, Austria, e-mail: florian.benedikt@ tuwien.ac.at. Johannes Christian Schmid, Ph.D., Assistant, TU Wien, Faculty of Technical Chemistry, Getreidemarkt 9/166, 1060 Vienna, Austria, e-mail: johannes.schmid@ tuwien.ac.at. Hermann Hofbauer, Ph.D., Professor, TU Wien, Faculty of Technical Chemistry, Getreidemarkt 9/166, 1060 Vienna, Austria, e-mail: hermann.hofbauer@ tuwien.ac.at.

https://doi.org/10.18690/978-961-286-048-6.25

ISBN 978-961-286-048-6

(C) 2017 University of Maribor Press

Available at: http://press.um.si. 
$10^{\mathrm{TH}}$ InTERNATIONAL CONFERENCE ON Sustainable ENERGy AND ENVIRONMENTAL Protection (June $27^{\mathrm{TH}}-30^{\mathrm{TH}}, 2017$, Bled, Slovenia), Bioenergy AND BIOFuels A. Magdalena Mauerhofer, F. Benedikt, J. Christian Schmid \& H. Hofbauer: Mixtures of Silica Sand and Calcite as Bed Material for Dual Fluidized Bed Steam Gasification

Relating to the worldwide supply of electricity, heat and fuels, the thermo-chemical conversion of biogenic feedstock is a promising alternative to promote sustainable and eco-friendly production in the future. Dual fluidized bed (DFB) steam gasification is an important field of research at TU Wien. The principle of the DFB gasification process is presented in

Figure 4.

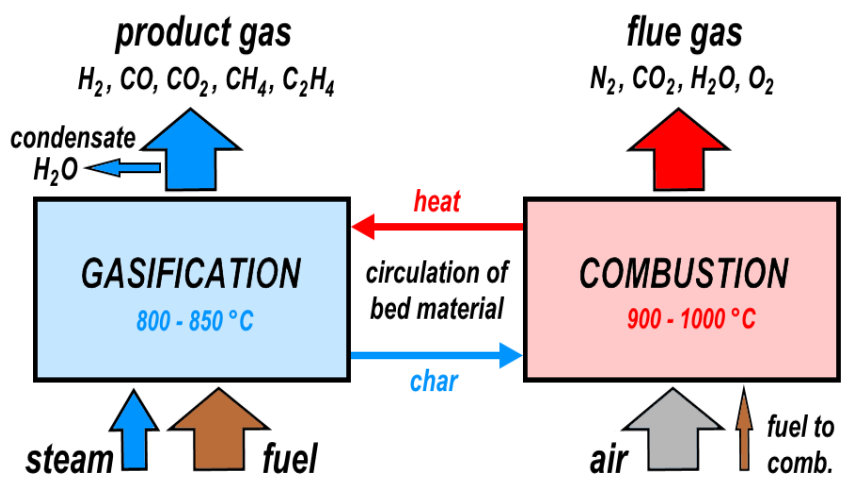

Figure 4. Basic principle of DFB steam gasification

This process consists of a gasification reactor (GR) and a combustion reactor (CR) and generates a nitrogen-free product gas based on solid fuels. The combustion reactor and the gasification reactor are connected by a circulating bed material, which transports the excess heat of the combustion reactor to the gasification reactor to enable the endothermic gasification. The technology was successfully realized at industrial scale as well, e.g. in Güssing, Austria ( $8 \mathrm{MW}_{\text {th }}$ fuel power) [1] or Gothenburg, Sweden (33 $\mathrm{MW}_{\mathrm{th}}$ ) [2].

\section{$2 \quad$ Material and Methods}

\subsection{Conventional and advanced DFB steam gasification}

Figure 5 shows the conventional (conv) design, which is typically applied at industrial plants, as well as advanced (adv) DFB design. The conventional design consists of a bubbling fluidized bed as gasification reactor and a fast fluidized bed as combustion reactor. The reactors are connected by one loop seal or a chute in the lower part and another loop seal in the upper part of the reactors. The bed material, which leaves the combustion reactor, enters a cyclone, where it is separated from the flue gas and further reinserted into the freeboard of the gasification reactor. To improve the gas-solid contact between the hot bed material and the product gas in the gasification reactor, an advanced concept was designed. The focus of the improvements refers mainly to the design of the gasification reactor, which is composed of two parts: While the lower part with the fuel 
input is performed as bubbling bed, the upper part is realized as counter-current column with turbulent fluidized bed zones. This adaption of the reactor enables an extended residence time and gas-solid interaction of catalytic active bed material with the product gas. Additionally, the higher temperatures which prevail in the counter-current column have a positive influence on tar reduction [3]. Another advantage of the novel design appeared in the use of pure calcite or limestone $\left(\mathrm{CaCO}_{3}\right)$ as bed material. Calcite is transformed to calcium oxide $(\mathrm{CaO})$ during the experiments discussed in this paper due to the high temperatures in the DFB gasifier. To balance the low abrasion resistances of calcite, two gravity separators were installed on top of the reactors, which allowed for a smoother separation of calcite than with cyclones. Fines after the gravity separators are removed via cyclones.

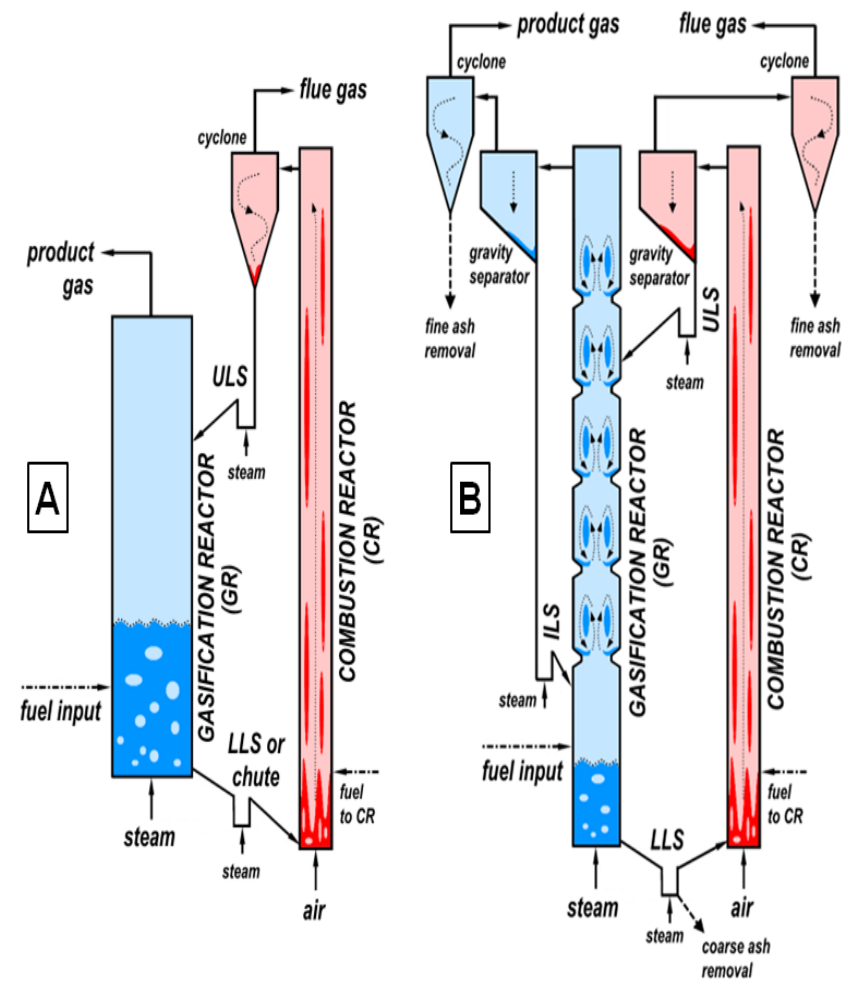

Figure 5. Conventional (A) and advanced (B) design of the DFB gasification pilot plant at TU Wien 
$10^{\text {Th }}$ International Conference on Sustainable Energy and Environmental Protection (June $27^{\mathrm{TH}}-30^{\mathrm{TH}}, 2017$, BLED, Slovenia), Bioenergy AND Biofuels

A. Magdalena Mauerhofer, F. Benedikt, J. Christian Schmid \& H. Hofbauer: Mixtures of Silica Sand and Calcite as Bed Material for Dual Fluidized Bed Steam Gasification

\section{2-2 Materials}

\section{Bed materials}

For the experiments, calcite and silica sand were used as bed materials. Calcite provided the catalytic activity for the ongoing chemical reactions during the gasification process, but had a low abrasion resistance as well as a small heat capacity. For these reasons, experiments with mixtures of calcite and silica sand were performed. Silica sand not merely compensated the bad heat transfer properties, but also showed good abrasion characteristics. The supplementing properties of these two materials fulfilled the desired requirements for the gasification process.

\section{Feedstock}

Soft wood pellets were used as fuel for all presented experiments.

Table 4 presents the mean proximate and ultimate analysis of soft wood.

Table 4. Proximate and ultimate analysis of soft wood for the experiments at the DFB steam gasification pilot plant

\begin{tabular}{|c|c|c|c|}
\hline Parameter & Unit & \multicolumn{2}{|c|}{ Soft wood } \\
\hline Water content & wt.- $\%$ & 6.7 & $+/-0.6$ \\
\hline Ash content & wt. $-\%_{\mathrm{db}}$ & 0.3 & $+/-0.1$ \\
\hline Carbon (C) & wt. $-\%_{\text {daf }}$ & 50.5 & $+/-0.2$ \\
\hline Hydrogen $(\mathrm{H})$ & wt. $-\%_{\text {daf }}$ & 6.0 & $+/-0.1$ \\
\hline Nitrogen $(\mathrm{N})$ & wt. $-\%_{\text {daf }}$ & 0.2 & $+/-0.1$ \\
\hline Sulphur (S) & wt. $-\%_{\text {daf }}$ & 0.005 & $+/-0.0$ \\
\hline Chlorine $(\mathrm{Cl})$ & wt. $-\%_{\text {daf }}$ & 0.004 & $+/-0.0$ \\
\hline Oxygen & wt. $-\%_{\text {daf }}$ & 43.3 & $+/-0.2$ \\
\hline $\begin{array}{l}\text { Volatile } \\
\text { compounds }\end{array}$ & wt.- $\%_{d b}$ & 86.0 & $+/-0.5$ \\
\hline Fixed C & wt. $-\%_{\mathrm{db}}$ & 14.0 & $+/-0.4$ \\
\hline $\begin{array}{l}\text { Lower heating } \\
\text { value }(\mathrm{LHV})_{\text {moist }}\end{array}$ & $\mathrm{MJ} / \mathrm{kg}$ & 17.4 & $+/-0.1$ \\
\hline
\end{tabular}

\section{Experimental setup}

Table 5 shows the mixtures of bed materials for presented experiments within this paper. The experiment with $100 \%$ silica sand as bed material was carried out in the conventional DFB steam gasification pilot plant [2]. All other experiments were performed in the advanced DFB pilot plant. In Table 5, abbreviations in terms of numbers for the four different experiments are named and are used subsequently. The experimental setup of experiment 1 is described in detail by Koppatz et al. [2] 
$10^{\mathrm{TH}}$ INTERNATIONAL CONFERENCE ON SUSTAINABLE ENERGY AND ENVIRONMENTAL Protection (June $27^{\mathrm{TH}}-30^{\mathrm{TH}}, 2017$, Bled, Slovenia), Bioenergy ANd Biofuels A. Magdalena Mauerhofer, F. Benedikt, J. Christian Schmid \& H. Hofbauer: Mixtures of Silica Sand and Calcite as Bed Material for Dual Fluidized Bed Steam Gasification

Table 5. Presented experiments with bed material compositions and experiment

\begin{tabular}{|c|c|c|c|c|c|}
\hline \multicolumn{6}{|c|}{ abbreviations } \\
\hline & & Expe & ment & & \\
\hline Material & Unit & 1 & 2 & 3 & 4 \\
\hline Pilot plant & - & $\begin{array}{l}\text { conv } \\
\text { (A) }\end{array}$ & $\begin{array}{l}\mathrm{adv} \\
\text { (B) }\end{array}$ & $\begin{array}{l}\mathrm{adv} \\
\text { (B) }\end{array}$ & $\begin{array}{l}\mathrm{adv} \\
\text { (B) }\end{array}$ \\
\hline Silica Sand & wt. $-\%$ & 100 & 90 & 50 & 0 \\
\hline Calcite & wt.- $\%$ & 0 & 10 & 50 & 100 \\
\hline
\end{tabular}

The controlling of the advanced pilot plant was carried out via a programmable logic controller (PLC), which continuously measured and recorded the data of all important flow rates, temperatures, pressures and gas compositions (Rosemount NGA2000). $\mathrm{C}_{2} \mathrm{H}_{4}$ was analyzed with a gas chromatograph (Perkin Elmer ARNEL - Clarus 500) every 15 minutes. The setup and measurement devices are reported in detail by Kolbitsch [4]. The gravimetric tar content is determined and the single tar components are measured by gas chromatography coupled with mass spectrometry. Char, dust and water contents were analyzed using an appropriate standardized sampling equipment [5]. At the DFB pilot plant, toluene was used as solvent due to the higher solubility for tar in toluene and the opportunity to measure the water content in the product gas at the same time. The use of toluene as solvent excludes the detection of it and the recording of benzene and xylene is difficult within this setup. Thus, all tar contents are presented without benzene, toluene and xylene (BTX).

\section{Validation for process data with IPSEpro}

The process simulation software IPSEpro enables the user to calculate mass and energy balances of the process data, which are recorded during the test runs. Further, the validation of measured data with IPSEpro depicts results in a very valuable and representative way. For calculations with IPSEpro, a detailed model library which was developed at TU Wien was used [6].

\section{Key parameters for the gasification}

The following parameters were selected to describe important key figures of the gasification process. As steam is used for the gasification of carbon feedstocks and to have the possibility to compare gasification experiments with different fuels, the steam to carbon ratio $\varphi_{S C}$ is used and showed in Equation (1).

$$
\varphi_{\mathrm{SC}}=\frac{\dot{\mathrm{m}}_{\text {steam,GR }}+\dot{\mathrm{m}}_{\mathrm{H} 2 \mathrm{O}, \mathrm{GR}, \text { fuel }}}{\dot{\mathrm{m}}_{\mathrm{C}, \mathrm{GR}, \text { fuel }}}
$$


$10^{\text {TH }}$ International Conference on Sustainable Energy and Environmental Protection (June $27^{\mathrm{TH}}-30^{\mathrm{TH}}, 2017$, Bled, Slovenia), Bioenergy AND BIOFuels

A. Magdalena Mauerhofer, F. Benedikt, J. Christian Schmid \& H. Hofbauer: Mixtures of Silica Sand and Calcite as Bed Material for Dual Fluidized Bed Steam Gasification

The steam-related water conversion $\mathrm{X}_{\mathrm{H}_{2} \mathrm{O}}$ presents the relation of water consumed for hydrogen production and the sum of water introduced into the GR, see Equation (2)

$$
\mathrm{X}_{\mathrm{H} 2 \mathrm{O}}=\frac{\dot{\mathrm{m}}_{\text {steam }, \mathrm{GR}}+\dot{\mathrm{m}}_{\mathrm{H} 2 \mathrm{O}, \mathrm{GR}, \text { fuel }^{-}} \dot{\mathrm{m}}_{\mathrm{H} 2 \mathrm{O}, \mathrm{PG}}}{\dot{\mathrm{m}}_{\text {steam }, \mathrm{GR}}+\dot{\mathrm{m}}_{\mathrm{H} 2 \mathrm{O}, \mathrm{GR}, \text { fuel }}}
$$

The product gas yield PGY is presented in Equation (3) and gives the ratio between dry PG to dry and ash-free fuel introduced into the GR.

$$
\mathrm{PGY}=\frac{\dot{\mathrm{V}}_{\mathrm{PG}}}{\dot{\mathrm{m}}_{\mathrm{GR}, \text { fuel,daf }}}
$$

The cold gas efficiency $\eta_{\mathrm{CG}}$ is defined as the chemical energy content of gaseous components in the product gas (tar- \& char-free) in relation to the chemical energy in the fuel introduced into the GR, all based on the LHV, see Equation (4).

$$
\eta_{\mathrm{CG}}=\frac{\dot{\mathrm{V}}_{\mathrm{PG}} \cdot \mathrm{LHV}_{\mathrm{PG}}}{\dot{\mathrm{m}}_{\mathrm{GR}, \text { fuel }} \cdot \mathrm{LHV}_{\mathrm{GR}, \text { fuel }}} \cdot 100
$$

The quantity of chemical energy in the product gas referring to the chemical energy in the fuel, which is introduced into the gasification and combustion reactor based on the LHV minus appearing heat losses, is defined as the overall cold gas efficiency $\eta_{\mathrm{CG}, \mathrm{o}}$ (Equation (5))

$$
\eta_{\mathrm{CG}, \mathrm{o}}=\frac{\dot{\mathrm{V}}_{\mathrm{PG}} \cdot \mathrm{LHV}_{\mathrm{PG}}}{\dot{\mathrm{m}}_{\mathrm{GR}, \text { fuel }} \cdot \mathrm{LHV}_{\mathrm{GR}, \text { fuel }}+\dot{\mathrm{m}}_{\mathrm{CR}, \text { fuel }} \cdot \mathrm{LHV}_{\mathrm{CR}, \text { fuel }}-\dot{\mathrm{Q}}_{\text {loss }}} \cdot 100
$$

With regard to the product gas composition, the water gas shift (WGS) reaction is the most important heterogeneous catalysed gas-gas reaction that occurs in the generated product gas, see Equation (6).

$$
\mathrm{CO}+\mathrm{H}_{2} \mathrm{O} \rightleftharpoons \mathrm{CO}_{2}+\mathrm{H}_{2}
$$

Additionally, the steam reforming of hydrocarbons is shown here to discuss tar decomposition later on (Equation (7))

$$
\mathrm{C}_{\mathrm{a}} \mathrm{H}_{\mathrm{b}}+\mathrm{a} \mathrm{H}_{2} \mathrm{O} \rightleftharpoons \mathrm{a} \mathrm{CO}+\left(\mathrm{a}+\frac{\mathrm{b}}{2}\right) \mathrm{H}_{2}
$$


$10^{\mathrm{TH}}$ INTERNATIONAL CONFERENCE ON SUSTAINABLE ENERGY AND ENVIRONMENTAL

Protection (June $27^{\mathrm{TH}}-30^{\mathrm{TH}}, 2017$, BLed, Slovenia), Bioenergy and Biofuels A. Magdalena Mauerhofer, F. Benedikt, J. Christian Schmid \& H. Hofbauer: Mixtures of Silica Sand and Calcite as Bed Material for Dual Fluidized Bed Steam Gasification

\section{$3 \quad$ Results and Discussion}

In Table 6, the main operation parameters for the experiments 1 to 4 are shown. Temperatures in the GR and CR are provided by Koppatz et al. [2] and additional data from the detailed documentation of the experiment at TU Wien is used. For experiment 2 to 4 , the following definitions were used: The mean temperature in the lower section of the gasification reactor $\left(\mathrm{T}_{\text {mean }}\right.$ in $\left.\mathrm{GR}_{\text {lower }}\right)$ corresponded to the temperature in the bubbling bed, whereas the temperature in the upper section of the gasification reactor ( $T$ in $\left.\mathrm{GR}_{\mathrm{upper}}\right)$ was equivalent to the temperature of hot bed material re-entering the gasification reactor from the upper loop seal (ULS) (see Figure 5).

Table 6. Main operation parameters for the gasification experiments 1 to 4

\begin{tabular}{|l|l|l|l|l|l|}
\hline \multirow{2}{*}{ Value } & \multirow{2}{*}{ Unit } & \multicolumn{4}{|l|}{ Experiment } \\
\cline { 3 - 6 } & $\mathbf{1}$ & $\mathbf{2}$ & $\mathbf{3}$ & $\mathbf{4}$ \\
\hline $\begin{array}{l}\text { Fuel }_{\text {in }} \\
\text { into GR }\end{array}$ & $\mathrm{kW}$ & 97 & 101 & 101 & 101 \\
\hline $\begin{array}{l}\text { Fuel } \\
\text { into }\end{array}$ & $\mathrm{kW}$ & 31 & 65 & 56 & 52 \\
\hline$\dot{\mathrm{Q}}_{\text {loss }}$ & $\mathrm{kW}$ & $13^{\mathrm{a}}$ & 30 & 26 & 32 \\
\hline$\varphi_{\mathrm{SC}}$ & $\begin{array}{l}\mathrm{kg}_{\mathrm{H} 2 \mathrm{O}} \\
/ \mathrm{kg}_{\mathrm{C}}\end{array}$ & 1.6 & 1.7 & 1.5 & 1.4 \\
\hline $\begin{array}{l}\mathrm{T}_{\text {mean }}{ }^{\mathrm{b}} \text { in } \\
\mathrm{GR}_{\text {lower }}\end{array}$ & ${ }^{\circ} \mathrm{C}$ & 851 & 790 & 813 & 769 \\
\hline $\begin{array}{l}\mathrm{T}_{\text {in }} \\
\mathrm{GR}_{\text {upper }}\end{array}$ & ${ }^{\circ} \mathrm{C}$ & $799^{\mathrm{c}}$ & 947 & 967 & 991 \\
\hline $\begin{array}{l}\mathrm{T}_{\text {at }} \\
\mathrm{CR}_{\text {outlet }}\end{array}$ & ${ }^{\circ} \mathrm{C}$ & 867 & 948 & 974 & 1010 \\
\hline
\end{tabular}

${ }^{\mathrm{a}}$ calculated with data from internal documentation of TU

Wien

${ }^{\mathrm{b}}$ temperature in the GR at fuel feeding position

${ }^{\mathrm{c}}$ freeboard temperature at the product gas outlet

Figure 6 presents the main product gas compositions of experiments 1 to 4 , which were conducted with the DFB steam gasification pilot plants at TU Wien. 
$10^{\mathrm{TH}}$ International Conference on Sustainable EnERgy and Environmental Protection (June $27^{\mathrm{TH}}-30^{\mathrm{TH}}, 2017$, Bled, Slovenia), Bioenergy AND Biofuels

A. Magdalena Mauerhofer, F. Benedikt, J. Christian Schmid \& H. Hofbauer: Mixtures of Silica Sand and Calcite as Bed Material for Dual Fluidized Bed Steam Gasification

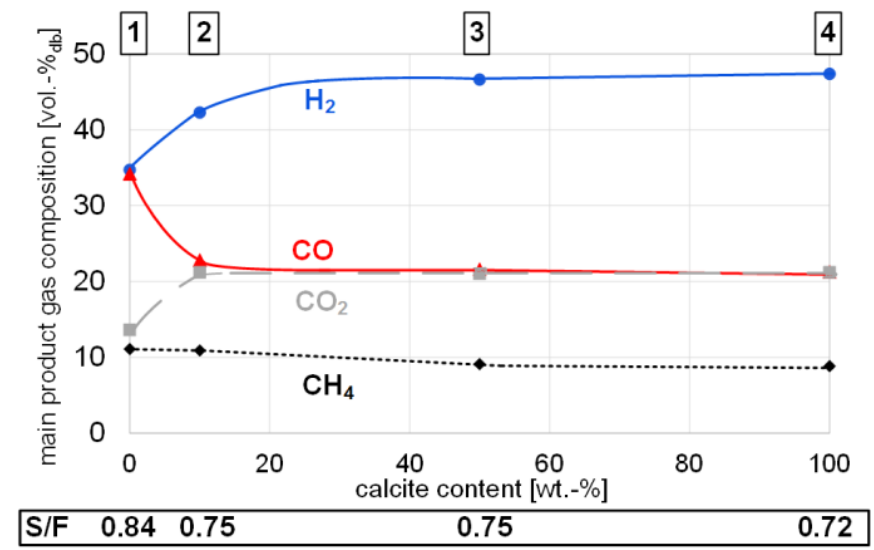

Figure 6. Main product gas composition and steam to fuel ratio

Regarding experiment 1 with $100 \%$ silica sand as bed material, it was obvious that the gas-solid contact between the bed material and the product gas as well as the low catalytic activity of silica sand had great impact on the product gas composition. Due to the inert characteristics of silica sand, it might have been that the WGS reaction (Equation (6))) was limited. Thus, the $\mathrm{CO}$ concentration was considerably higher than in experiments 2 to 4 . With an increasing content of calcite, the $\mathrm{H}_{2}$ content rose to a maximum of 47.4 vol.$\%_{\mathrm{db}}$ in experiment 4 . At the same time, $\mathrm{CO}$ contents decreased, which both can be explained by enhanced WGS reaction due to the catalytic active calcium oxide $\mathrm{CaO}$. For the experiments 2 to 4 , the development of $\mathrm{CO}_{2}$ remained widely stable, whereas $\mathrm{CH}_{4}$ showed a dropping trend justified by the steam-reforming reaction (Equation (7)), which is enhanced by the catalytic activity of $\mathrm{CaO}$ for this reaction as well.

In Figure 7, the gravimetric and GC/MS tars and $\mathrm{C}_{2} \mathrm{H}_{4}$ of the four gasification experiments are shown. Furthermore, the tar dew points (TDP) of the detected GC/MS tar compounds were calculated via the calculation tool from the Energy Research Centre of the Netherlands (ECN) [8]. The high tar values of experiment 1 could be traced back to the conventional design of the DFB pilot plant, which was explained by Kern et al [7] and low catalytic activity of silica sand in terms of steam reforming of hydrocarbons (see Equation (7)). The tar dew points, which are an important indicator for formation of deposits in the product gas line, decreased from $181^{\circ} \mathrm{C}(90 \%$ silica sand $)$ to $87^{\circ} \mathrm{C}(100 \%$ calcium oxide) with the experiments carried out in the advanced design. 

A. Magdalena Mauerhofer, F. Benedikt, J. Christian Schmid \& H. Hofbauer: Mixtures of Silica Sand and Calcite as Bed Material for Dual Fluidized Bed Steam Gasification

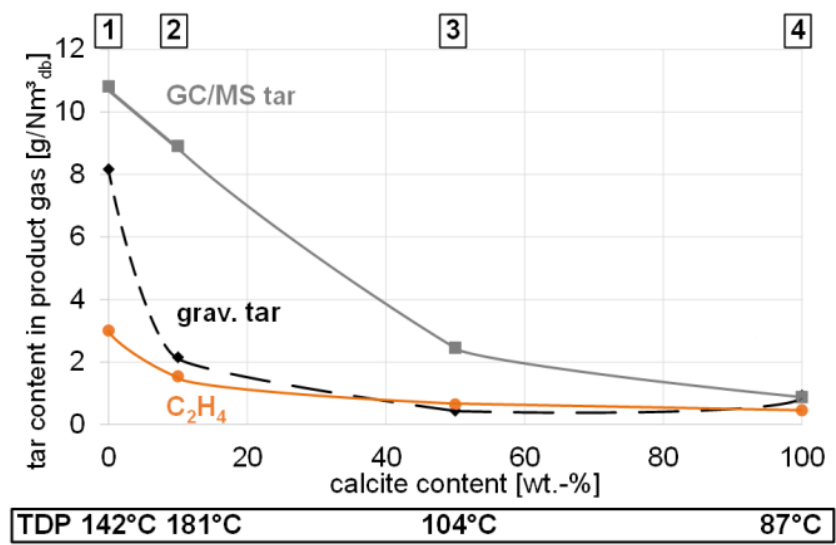

Figure 7. Tar and $\mathrm{C}_{2} \mathrm{H}_{4}$ contents and calculated tar dew points of the product gas

Figure 8 demonstrates the dust contents of the gasification experiments 1 to 4 . It is evident that the level of dust grew with an increasing amount of the bed material calcite. The low abrasion resistance of $\mathrm{CaCO}_{3} / \mathrm{CaO}$ affected the dust content in the product gas negatively, whereas the lowest value of dust of $2.8 \mathrm{~g} / \mathrm{Nm}_{\mathrm{db}}^{3}$ accounted for good attrition characteristics of silica sand.

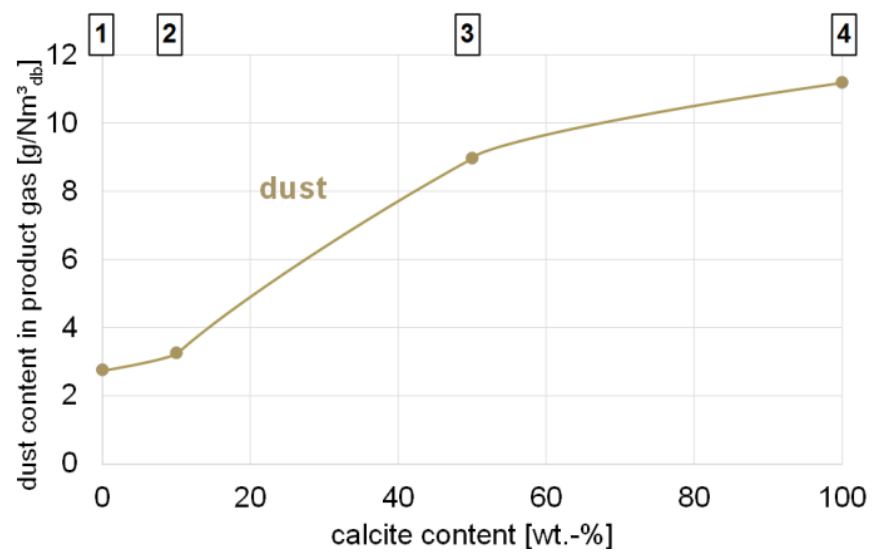

Figure 8. Dust content of the product gas

Figure 9 depicts the contents of char in the product gas for the four gasification experiments. In the advanced design of the pilot plant, char particles exhibited a longer residence time in the counter-current column of the gasification reactor, which affected the char content in the product gas favourably. In addition, the product gas cyclone may lead to lower fly-char contents. This can be seen in low values of product gas char contents for experiment 2 to 4 . However, the conventional gasifier was not equipped with a counter-current regime and consequently, the residence time of char particles and the advantageous gas-particle interaction was much lower. 
$10^{\mathrm{TH}}$ International Conference on Sustainable EnERgy and Environmental Protection (JunE $27^{\mathrm{TH}}-30^{\mathrm{TH}}, 2017$, BLED, SLOVENIA), BioENERGY AND BIOFUELS

A. Magdalena Mauerhofer, F. Benedikt, J. Christian Schmid \& H. Hofbauer: Mixtures of Silica Sand and Calcite as Bed Material for Dual Fluidized Bed Steam Gasification

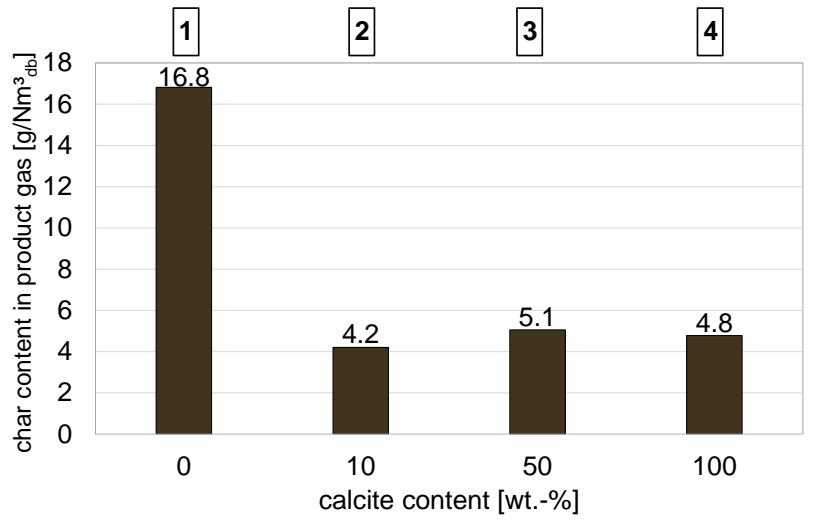

Figure 9. Char content of the product gas of the gasification experiments 1 to 4

Table 7 gives important key figures for the gasification experiments, described in section 0 . The results of experiments 2 to 4 , which were conducted in the advanced pilot plant, show a similar character. The remarkably higher product gas yields of experiments 2 to 4 could be justified by longer residence times of char particles in the advanced DFB pilot plant and higher water conversions. The rising steam-related water conversion might have been positively influenced by more intense and longer contact times between gas and particles and a higher catalytic activity of the bed material. The cold gas efficiency also showed superior values with the advanced design than with the conventional design. Referring to the experiments 2 and 3, the higher cold gas efficiencies compared to experiment 4 are caused by two effects, which are related to a high share of silica sand in the bed material: (i) higher heat capacity of silica sand than calcium oxide and (ii) a higher density compared to calcium oxide. These characteristics allow preferable heat transfer properties and therefore have a positive influence on the cold gas efficiencies of experiment 2 and 3, compared to experiment 4.

Table 7. Key figures of the gasification experiments 1 to 4

\begin{tabular}{|l|l|l|l|l|l|}
\hline \multirow{2}{*}{ Value } & \multirow{2}{*}{ Unit } & \multicolumn{4}{|l|}{ Experiment } \\
\cline { 3 - 6 } $\mathrm{X}_{\mathrm{H} 2 \mathrm{O}}$ & $\begin{array}{l}\mathrm{kg}_{\mathrm{H} 2 \mathrm{O}} / \\
\mathrm{kg}_{\text {steam }}\end{array}$ & 0.05 & 0.31 & 0.37 & 0.36 \\
\hline$\eta_{\mathrm{CG}}$ & $\%$ & 77 & 94 & 93 & 88 \\
\hline$\eta_{\mathrm{CG}, \mathrm{o}}$ & $\%$ & $65^{\mathrm{a}}$ & 71 & 71 & 73 \\
\hline PGY & $\begin{array}{l}\mathrm{Nm}_{\mathrm{db}} / \\
\mathrm{kg}_{\text {fuel,daf }}\end{array}$ & 0.99 & 1.41 & 1.49 & 1.43 \\
\hline
\end{tabular}

\footnotetext{
a calculated with data from internal documentation of TU Wien
} 


\section{$4 \quad$ Conclusion and Outlook}

To sum up, the results of the DFB steam gasification of soft wood with two different bed materials, silica sand and calcite, were presented within this work. The catalytic active bed material calcite shifted the product gas composition towards high $\mathrm{H}_{2}$ contents, low tar and char values, but higher dust values due to attrition effects. However, the low attrition characteristics as well as the high heat capacity of silica sand supplemented the missing properties of calcite. Thus, silica sand and calcite as bed materials mixtures and the advanced DFB gasifier offer a promising alternative to commercially used bed materials like olivine to produce a highly valuable product gas.

\section{List of abbreviations}

$\begin{array}{ll}\text { Adv } & \text { advanced } \\ \text { BTX } & \text { benzene, toluene, xylene } \\ \text { conv } & \text { conventional } \\ \text { CR } & \text { combustion reactor } \\ \text { DFB } & \text { dual fluidized bed } \\ \text { ECN } & \text { Energy Research Centre of the Netherlands } \\ \text { GC/MS } & \text { gas chromatography coupled with mass spectrometry } \\ \text { GR } & \text { gasification reactor } \\ \text { LHV } & \text { lower heating value } \\ \text { PGY } & \text { product gas yield } \\ \text { S/F } & \text { steam to fuel ratio } \\ \text { T } & \text { temperature } \\ \text { TDP } & \text { tar dew point } \\ \text { ULS } & \text { upper loop seal } \\ \text { vol.- } \% & \text { volumetric percent } \\ \text { WGS } & \text { water gas shift } \\ \text { wt.- } \% & \text { weight percent }\end{array}$

\section{List Of Subscripts}

$\begin{array}{ll}\text { C } & \text { Carbon } \\ \text { Daf } & \text { Dry And Ash-Free } \\ \mathrm{Db} & \text { Dry Basis } \\ \mathrm{H}_{2} \mathrm{O} & \text { Water } \\ \mathrm{Pg} & \text { Product Gas } \\ \mathrm{Th} & \text { Thermal }\end{array}$

\section{List of symbols}

$\begin{array}{lll}\mathrm{LHV}_{\mathrm{CR}, \text { fuel }} & \begin{array}{l}\text { lower heating value of } \\ \text { fuel into the combustion } \\ \text { reactor }\end{array} & \mathrm{MJ} / \mathrm{kg} \\ \mathrm{LHV}_{\mathrm{GR}, \text { fuel }} & \begin{array}{l}\text { lower heating value of } \\ \text { fuel into the gasification }\end{array} & \mathrm{MJ} / \mathrm{kg}\end{array}$


$10^{\mathrm{TH}}$ International Conference on Sustainable Energy and Environmental Protection (June $27^{\mathrm{TH}}-30^{\mathrm{TH}}, 2017$, Bled, Slovenia), Bioenergy AND BIOFuels

A. Magdalena Mauerhofer, F. Benedikt, J. Christian Schmid \& H. Hofbauer: Mixtures of Silica Sand and Calcite as Bed Material for Dual Fluidized Bed Steam Gasification

\begin{tabular}{|c|c|c|}
\hline & reactor & \\
\hline $\mathrm{LHV}_{\mathrm{PG}}$ & $\begin{array}{l}\text { lower heating value of PG } \\
\text { on dry basis }\end{array}$ & $\begin{array}{l}\mathrm{MJ} / \mathrm{m}^{3}(25 \mathrm{C}, \\
\text { lbar })\end{array}$ \\
\hline$\dot{\mathrm{m}}_{\mathrm{C}, \mathrm{GR}, \text { fuel }}$ & $\begin{array}{l}\text { Mass flow of carbon in } \\
\text { the fuel into the } \\
\text { gasification reactor }\end{array}$ & $\mathrm{kg} / \mathrm{h}$ \\
\hline$\dot{\mathrm{m}}_{\mathrm{CR} \text {,fuel }}$ & $\begin{array}{l}\text { Mass flow of fuel into the } \\
\text { combustion reactor }\end{array}$ & $\mathrm{kg} / \mathrm{h}$ \\
\hline$\dot{\mathrm{m}}_{\mathrm{GR}, \text { fuel }}$ & $\begin{array}{l}\text { Mass flow of fuel into the } \\
\text { gasification reactor }\end{array}$ & $\mathrm{kg} / \mathrm{h}$ \\
\hline$\dot{\mathrm{m}}_{\mathrm{GR}, \text { fuel,daf }}$ & $\begin{array}{l}\text { dry and ash free mass } \\
\text { flow of fuel into the } \\
\text { gasification reactor }\end{array}$ & \\
\hline$\dot{\mathrm{m}} \mathrm{H} 2 \mathrm{O}, \mathrm{GR}$, fuel & $\begin{array}{l}\text { Mass flow of water in the } \\
\text { fuel into the gasification } \\
\text { reactor }\end{array}$ & $\mathrm{kg} / \mathrm{h}$ \\
\hline$\dot{\mathrm{m}} \mathrm{H} 2 \mathrm{O}, \mathrm{PG}$ & $\begin{array}{l}\text { Mass flow of water in the } \\
\text { product gas }\end{array}$ & $\mathrm{kg} / \mathrm{h}$ \\
\hline$\dot{m}_{\text {steam,GR }}$ & $\begin{array}{l}\text { Mass flow of fluidization } \\
\text { steam into the gasification } \\
\text { reactor }\end{array}$ & $\mathrm{kg} / \mathrm{h}$ \\
\hline$\dot{\mathrm{Q}}_{\text {loss }}$ & $\begin{array}{l}\text { heat losses of the } \\
\text { gasification and } \\
\text { combustion reactor }\end{array}$ & $\mathrm{MJ} / \mathrm{h}($ or $\mathrm{kW})$ \\
\hline$\dot{\mathrm{V}}_{\mathrm{PG}}$ & $\begin{array}{l}\text { volume flow of product } \\
\text { gas on dry basis }\end{array}$ & $\mathrm{m}^{3} / \mathrm{h}(25 \mathrm{C}, 1 \mathrm{bar})$ \\
\hline $\mathrm{X}_{\mathrm{H}_{2} \mathrm{O}}$ & $\begin{array}{l}\text { steam-related water } \\
\text { conversion }\end{array}$ & $\mathrm{kg}_{\mathrm{H} 2 \mathrm{O}} / \mathrm{kg}_{\mathrm{H} 2 \mathrm{O}}$ \\
\hline$\eta_{\mathrm{CG}}$ & cold gas efficiency & $\%$ \\
\hline$\eta_{\mathrm{CG}, \mathrm{o}}$ & overall cold gas efficiency & $\%$ \\
\hline$\varphi_{\mathrm{SC}}$ & steam to carbon ratio & $\mathrm{kg}_{\mathrm{H} 2 \mathrm{O}} / \mathrm{kg}_{\mathrm{C}}$ \\
\hline
\end{tabular}

\section{References}

[1] H. Hofbauer, R. Rauch, K. Bosch, R. Koch, and C. Aichernig, "Biomass CHP Plant Güssing - A Success Story,” Expert Meet. Pyrolysis Gasif. Biomass Waste, 2002.

[2] S. Koppatz, C. Pfeifer, and H. Hofbauer, "Comparison of the performance behaviour of silica sand and olivine in a dual fluidised bed reactor system for steam gasification of biomass at pilot plant scale," Chem. Eng. J., vol. 175, no. 1, pp. 468-483, 2011.

[3] U. Wolfesberger-Schwabl, I. Aigner, and H. Hofbauer, "Mechanism of tar generation during fluidized bed gasification and low temperature pyrolysis," Ind. Eng. Chem. Res., vol. 51, no. 40, pp. 13001-13007, 2012.

[4] M. Kolbitsch, First Fuel Tests at a Novel $100 \mathrm{kWth}$ Dual Fliuidized Bed Steam Gasification Pilot Plant. 2016.

[5] D. I. N. Cen and D. F. Cen, “Cen/Ts 15439:2006," Norm, no. August, 2006.

[6] T. Pröll and H. Hofbauer, "Development and Application of a Simulation Tool for Biomass Gasification Based Processe Development and Application of a Simulation Tool for Biomass Gasification Based Processes *," Int. J. Chem. React. Eng., vol. 6, p. Article A89, 2008. 
$10^{\mathrm{TH}}$ INTERNATIONAL CONFERENCE ON SUSTAINABLE ENERGY AND ENVIRONMENTAL

Protection (June $27^{\mathrm{TH}}-30^{\mathrm{TH}}, 2017$, Bled, Slovenia), Bioenergy ANd Biofuels

A. Magdalena Mauerhofer, F. Benedikt, J. Christian Schmid \& H. Hofbauer: Mixtures of Silica Sand and Calcite as Bed Material for Dual Fluidized Bed Steam Gasification

[7] S. Kern, "Gasification and Co-gasification of Coal, Biomass and Plastics in a Dual Fluidized Bed System,” 2013.

[8] Energy and Research Centre of the Netherlands, http://www.thersites.nl, (accessed: February 12, 2017) 
266 10 $10^{\mathrm{TH}}$ InTERnational CONFERENCE ON Sustainable ENERGy AND ENVIRONMENTAL Protection (June $27^{\mathrm{TH}}-30^{\mathrm{RD}}, 2017$, Bled, Slovenia), Bioenergy ANd Biofuels 
$10^{\mathrm{TH}}$ InTERnational CONFERENCE ON Sustainable ENERgy AND ENVIRONMENTAL Protection (June $27^{\mathrm{TH}}-30^{\mathrm{TH}}$, 2017, Bled, SLOVENIA), BIOENERGY AND BIOFUELS

J. Krope, A.Ghani Olabi, D. Goričanec \& S. Božičnik

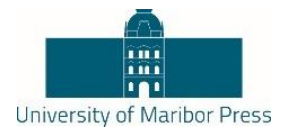

\title{
Continuous Hydrocarbon Production by Hydrodeoxygenation of Liquid Phase Pyrolysis Oil
}

\author{
Klara Treusch, NikOlaus SchWaiger, Klaus Schlackl, Roland NAGL, Peter \\ PUCHER \& MATTHÄUS SIEBENHOFER
}

\begin{abstract}
In this paper continuous hydrodeoxygenation (HDO) of liquid phase pyrolysis (LPP) oil in labscale is discussed. Pyrolysis oil is derived from the bioCRACK pilot plant at the OMV refinery in Vienna/ Schwechat. Three hydrodeoxygenation temperature set points at $350^{\circ} \mathrm{C}, 375^{\circ} \mathrm{C}$ and $400^{\circ} \mathrm{C}$ were investigated. Liquid hourly space velocity (LHSV) was $0.5 \mathrm{~h}$ 1. Hydrodeoxygenation was performed with an in situ sulfided metal oxide catalyst. During HDO, three product phases were collected. A gaseous phase, an aqueous phase and a hydrocarbon phase. Experiment duration was 36 hours per temperature set point in steady state operation mode. Water content of the hydrocarbon phase was reduced to below $0.05 \mathrm{wt} . \%$. The water content of the aqueous phase was between 96.9 wt.\% and 99.9 wt. $\%$, indicating effective hydrodeoxygenation. The most promising results, concerning the rate of hydrodeoxygenation, were achieved at $400^{\circ} \mathrm{C}$. After 36 hours of experiment, catalyst deactivation was observed.
\end{abstract}

Keywords: • Hydrodeoxygenation $\bullet$ Liquid phase pyrolysis $\bullet$ Pyrolysis oil

- Temperature variation $\bullet$ 2nd generation biofuels •

CoRReSPONDENCE AdDRESS: Klara Treusch, MSc., Junior Researcher BtL, BDI - BioEnergy International AG, Parkring 18, 8074 Raaba-Grambach, klara.treusch@bdi-bioenergy.com. Nikolaus Schwaiger, Ph.D., Senior Researcher BtL, Graz, University of Technology, Institute of Chemical Engineering and Environmental Technology, Inffeldgasse 25c, 8010 Graz, nikolaus.schwaiger@tugraz.at. Klaus Schlackl, MSc., Master Student, Graz, University of Technology, Institute of Chemical Engineering and Environmental Technology, Inffeldgasse 25c, 8010 Graz, klaus_schlackl@gmx.at. Roland Nagl, BSc., Master Student, Graz, University of Technology, Institute of Chemical Engineering and Environmental Technology, Inffeldgasse 25c, 8010 Graz, roland.nagl@student.tugraz.at. Peter Pucher, Ph.D., Head of R\&D BtL, BDI BioEnergy International AG, Parkring 18, 8074 Raaba-Grambach, peter.pucher@bdibioenergy.com. Matthäus Siebenhofer, Ph.D.,Professor, Graz, University of Technology, Institute of Chemical Engineering and Environmental Technology, Inffeldgasse 25c, 8010 Graz, m.siebenhofer@tugraz.at. 
$10^{\mathrm{TH}}$ InTERNATIONAL CONFERENCE ON Sustainable ENERGY AND ENVIRONMENTAL Protection (June $27^{\mathrm{TH}}-30^{\mathrm{TH}}, 2017$, Bled, SLOVENIA), BioENERGY AND Biofuels

K. Treusch, N. Schwaiger, K. Schlackl, R. Nagl, P. Pucher \& M. Siebenhofer: Continuous Hydrocarbon Production by Hydrodeoxygenation of Liquid Phase Pyrolysis Oil

\section{$1 \quad$ Introduction}

Biomass pyrolysis is a suitable pathway for the production of second generation biofuels. [1] During pyrolysis, one of the major products is pyrolysis oil. Due to its high water content, high corrosivity and other negative properties, according to Table 8, pyrolysis oil needs intensive upgrading prior to usage as fuel for combustion engines. To achieve gasoline quality standards, an upgrading step is necessary. Hydrodeoxygenation is a high potential upgrading technology.

Hydrodeoxygenation of pyrolysis oil is performed in a two-step process. In a first step pyrolysis oil gets stabilized [2] through mild hydrotreatment at low temperature. In a second step the final hydrodeoxygenation takes place. Hydrotreatment temperatures are between $140^{\circ} \mathrm{C}$ and $375^{\circ} \mathrm{C}$, at liquid hourly space velocities between $0.28 \mathrm{~h}^{-1}$ and $0.5 \mathrm{~h}^{-1}$. The hydrocracking step is performed at temperatures of about $400^{\circ} \mathrm{C}$ and liquid hourly space velocities of $0.1 \mathrm{~h}^{-1}$ to $0.4 \mathrm{~h}^{-1}$. [3],[4] In this study LPP oil was upgraded in one hydrodeoxygenation step at temperatures between $350^{\circ} \mathrm{C}$ and $400^{\circ} \mathrm{C}$ and a liquid hourly space velocitiy of $0.5 \mathrm{~h}^{-1}$.

\subsection{Liquid phase pyrolysis}

In liquid phase pyrolysis, biomass gets pyrolysed in a liquid heat carrier. [5],[6] During this conversion, a part of the biomass dissolves in the heat carrier, while a second liquid phase, a non-polar hydrocarbon phase, is generated. [7] In the bioCRACK process [8] LPP was operated with the heat carrier vacuum gas oil to enable integration in an oil refinery. From 2012 to 2014 a pilot plant was operated by BDI - BioEnergy International $\mathrm{AG}$ at the OMV refinery in Vienna/Schwechat.

The LPP oil was derived from the bioCRACK pilot plant. It was produced by LPP of spruce wood. The composition of LPP oil is shown in Table 8.

Table 8. Properties and composition of LPP oil

\begin{tabular}{lcc} 
Property & Unit & LPP Oil \\
\hline Water content & {$[\mathrm{wt} \%]$} & 57.0 \\
Lower heating value & {$[\mathrm{MJ} / \mathrm{kg}]$} & 7.4 \\
Density & {$\left[\mathrm{kg} / \mathrm{m}^{3}\right]$} & 1092 \\
Viscosity & {$[\mathrm{mPa} \cdot \mathrm{s}]$} & 3.5 \\
Carbon content & {$[\mathrm{wt} \%]$} & 22.3 \\
Hydrogen content & {$[\mathrm{wt} \%]$} & 9.4 \\
Oxygen content (balance) & {$[\mathrm{wt} \%]$} & 67.8 \\
Nitrogen content & {$[\mathrm{wt} \%]$} & $<1$ \\
\hline
\end{tabular}


$10^{\text {TH }}$ INTERNATIONAL CONFERENCE ON SUSTAINABLE ENERGY AND ENVIRONMENTAL

Protection (June $27^{\mathrm{TH}}-30^{\mathrm{TH}}, 2017$, Bled, Slovenia), Bioenergy ANd Biofuels

K. Treusch, N. Schwaiger, K. Schlackl, R. Nagl, P. Pucher \& M. Siebenhofer:

Continuous Hydrocarbon Production by Hydrodeoxygenation of Liquid Phase

Pyrolysis Oil

\section{Experimental}

Experiments were carried out in a plug flow reactor with an inner diameter of $3 / 8$ inches and a heated zone of about $30 \mathrm{~cm}$, made by Parr Instrument Company. It was designed for a maximum pressure of 220 bar and a maximum temperature of $550^{\circ} \mathrm{C}$. The temperature was detected by an inner thermowell with a thermocouple with three measuring points. Heat was provided by a single zone external electric heater. In the temperature range between $350^{\circ} \mathrm{C}$ and $400^{\circ} \mathrm{C}$ three operation points were tested: $350^{\circ} \mathrm{C}$, $375^{\circ} \mathrm{C}$ and $400^{\circ} \mathrm{C}$. Hydrogen pressure was kept constant at 121.5 bar for all experiments. After having achieved steady state, duration of each experiment was $36 \mathrm{~h}$.

\subsection{Experimental procedure}

For each experiment the reactor was filled with fresh $\mathrm{CoMo} / \mathrm{Al}_{2} \mathrm{O}_{3}$ catalyst of Alfa Aesar and inertised with nitrogen. Afterwards the reactor was flushed with hydrogen. Then a flow rate of hydrogen of $0.5 \mathrm{l} / \mathrm{h}$ was adjusted.

\section{Sulfidation}

For the activation of the catalyst a sulfidation step preceded the HDO experiments. Thus, 35 wt.\% di-tert-butyldisulfide (DTBDS) in decane was pumped through the reactor during heating up. Sulfidation was continued for five hours at $400^{\circ} \mathrm{C}$. After sulfidation the temperature was reduced to the requested temperature for HDO procedure.

\section{Hydrodeoxygenation}

After sulfidation, five hours of HDO of LPP oil were performed in the unsteady state operation mode. Afterwards 36 hours of HDO were performed, with liquid product sampling every 12 hours. The gas phase composition was monitored every 4 hours.

\subsection{Results}

The temperature had a decisive impact on the product formation and the product quality.

\section{Temperature profile in the reactor}

The temperature profile, shown in Figure 10, was similar for all experiments. Due to the fact, that the pyrolysis oil was not pre-heated, the feed temperature was lower than the temperature in the middle of the reactor. The temperature maximum was obtained in the middle of the reactor, this temperature was the set point temperature for all HDO experiments. At the exit of the reactor, the temperature dropped significantly due to external cooling effects. From the temperature profile it was concluded, that the exothermal HDO reaction was completed after about $2 / 3$ of the reactor. 
$10^{\mathrm{TH}}$ International Conference on Sustainable EnERgy and Environmental Protection (June $27^{\mathrm{TH}}-30^{\mathrm{TH}}, 2017$, Bled, SLOVENIA), BioENERGY AND Biofuels

K. Treusch, N. Schwaiger, K. Schlackl, R. Nagl, P. Pucher \& M. Siebenhofer: Continuous Hydrocarbon Production by Hydrodeoxygenation of Liquid Phase Pyrolysis Oil

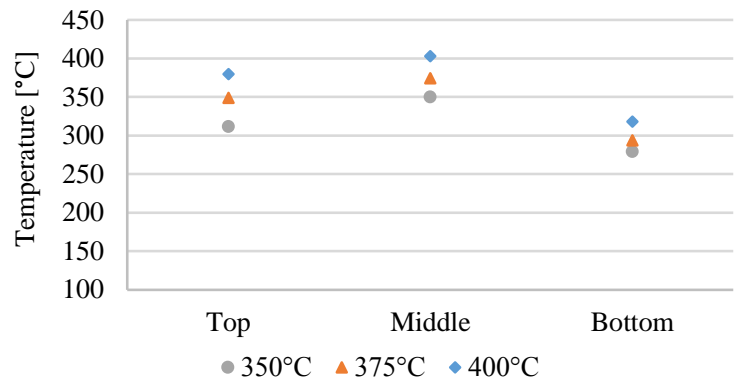

Figure 10. Temperature profile in the reactor

\section{Mass balance}

During HDO three product phases were formed. A hydrocarbon phase, the target product, an aqueous phase and a gaseous phase. In Table 9 the mass balance based on LPP oil and $\mathrm{H}_{2}$ is shown. In general, the difference concerning the product distribution between hydrocarbon product and aqueous phase is quite small. Table 9 shows, that the yield of aqueous phase decreased with temperature, whereas the gas yield was rising.

Table 9. Mass balance based on $\mathrm{PYO}$ and $\mathrm{H}_{2}$ feed

\begin{tabular}{lccc} 
Temperature & $\mathbf{3 5 0}^{\circ} \mathbf{C}$ & $\mathbf{3 7 5}^{\circ} \mathbf{C}$ & $\mathbf{4 0 0}^{\circ} \mathbf{C}$ \\
\hline PYO [wt.\%] & 79.13 & 79.32 & 80.47 \\
$\mathrm{H}_{2}$ [wt.\%] & 20.87 & 20.68 & 19.53 \\
\hline Aqueous [wt.\%] & 59.96 & 58.94 & 58.62 \\
Hydrocarbon [wt.\%] & 7.68 & 7.76 & 7.79 \\
Gaseous [wt.\%] & 26.82 & 27.55 & 28.37 \\
\hline
\end{tabular}

The yield of the hydrocarbon product phase based on the LPP oil in the feed is shown in Figure 11 . At $350^{\circ} \mathrm{C}$ and $375^{\circ} \mathrm{C}$ it increased continuously until the end of experiment. At $400^{\circ} \mathrm{C}$ the hydrocarbon product yield was constant. 


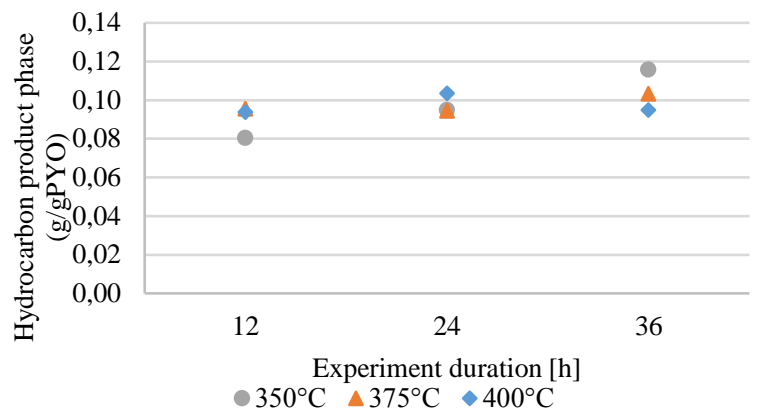

Figure 11. Yield of hydrocarbon product phase

\section{Rate of HDO}

As shown in Table 8, LPP oil contains a high amount of water. Yield, based on the LPP oil feed, was therefore low too. Referring to the carbon content of LPP oil, a carbon transfer into the hydrocarbon product phase up to $46 \mathrm{wt}$.\% was obtained. Scattered carbon transfer was observed at $350^{\circ} \mathrm{C}$ hydrodeoxygenation temperature. After 12 hours operation, it was only about $30 \mathrm{wt} \%$ and increased to $46 \mathrm{wt} \%$ after 36 hours. This observation goes along with the yield of hydrocarbon products and is partly caused by a higher oxygen content. This leads to the conclusion, that more polar compounds dissolved in the hydrocarbon product phase. Due to the lower gas yield one can also assume, that less cracking reactions occured due to deactivation of the catalyst at low temperature. The carbon transfer increased slightly at $375^{\circ} \mathrm{C}$ and was nearly constant at $400^{\circ} \mathrm{C}$.

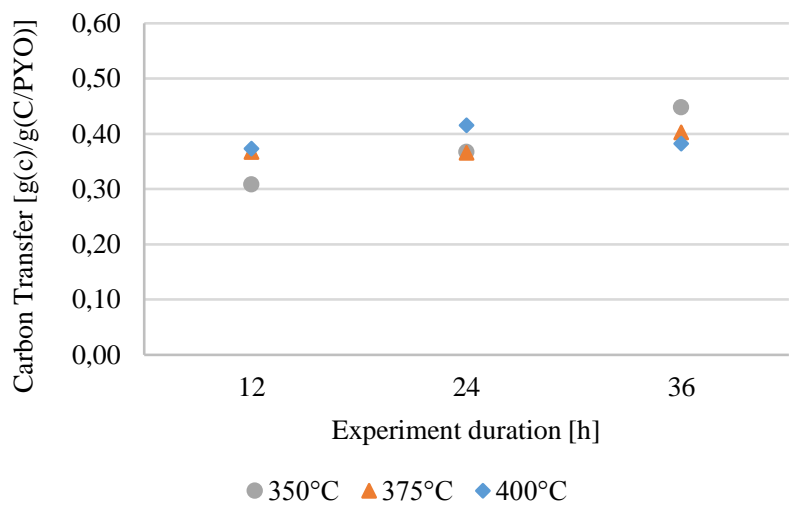

Figure 12. Carbon transfer into the hydrocarbon product phase 
$27210^{\text {TH }}$ INTERNATIONAL CONFERENCE ON SUSTAINABLE ENERGY AND ENVIRONMENTAL Protection (June $27^{\mathrm{TH}}-30^{\mathrm{TH}}, 2017$, BLED, Slovenia), Bioenergy AND Biofuels

K. Treusch, N. Schwaiger, K. Schlackl, R. Nagl, P. Pucher \& M. Siebenhofer: Continuous Hydrocarbon Production by Hydrodeoxygenation of Liquid Phase Pyrolysis Oil

The $\mathrm{H} / \mathrm{C}$ ratio is a very significant indicator for characterizing the degree of hydrogenation. In combination with the oxygen content, it quantifies the degree of hydrodeoxygenation. The oxygen content was derived from the balance of the ultimate analysis. According to Table 10, the oxygen content was below the detection limit for all experiments over the whole time range, except for the experiment at $350^{\circ} \mathrm{C}$ after 36 hours operation. It's obvious that at this temperature the activity of the catalyst depleted during the experiment. Therefore, the $\mathrm{H} / \mathrm{C}$ ratio can be considered as main quality criterion for the degree of hydrodeoxygenation for all other data points.

Table 10. Oxygen (determined by balance of the ultimate analysis)

\begin{tabular}{llcc} 
Oxygen [wt. \%] & $\mathbf{1 2} \mathbf{~ h}$ & $\mathbf{2 4} \mathbf{~ h}$ & $\mathbf{3 6 ~ h}$ \\
\hline $350^{\circ} \mathrm{C}$ & 0.00 & 0.00 & 1.11 \\
$375^{\circ} \mathrm{C}$ & 0.00 & 0.00 & 0.00 \\
$400^{\circ} \mathrm{C}$ & 0.00 & 0.00 & 0.00 \\
\hline
\end{tabular}

As shown in Figure 13, the water content of the hydrocarbon product phase correlates with the oxygen content. Except the experiment at $\mathrm{T}=350^{\circ} \mathrm{C}$, the water content of the hydrocarbon product phase was $0.02 \mathrm{wt} . \%$ to $0.05 \mathrm{wt} \%$.

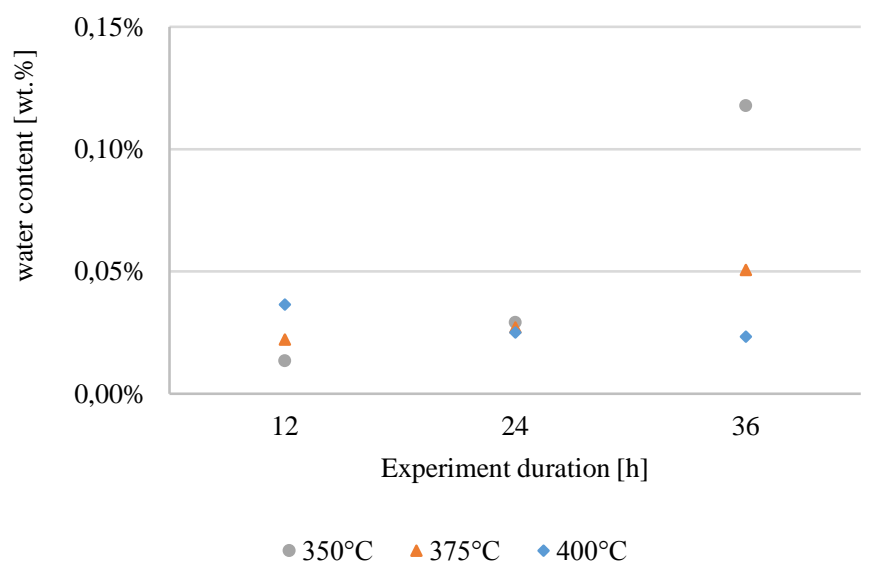

Figure 13. Water content of the hydrocarbon product phase

The carbon content of the aqueous phase is a complementary quality parameter for the HDO performance. High carbon content of the aqueous phase correlates with high oxygen content of the hydrocarbon product phase. At $350^{\circ} \mathrm{C}$, the carbon content of the aqueous phase increased during the experiment with a maximum of about $2.1 \mathrm{wt} . \%$. The opposite happened at $375^{\circ} \mathrm{C}$, where the carbon content was highest in the first period of 
the experiment. At $400^{\circ} \mathrm{C}$ the carbon content, indicating a carbon loss into the aqueous phase, was below 0.5 wt.\% over the whole experiment and didn't show a trend.

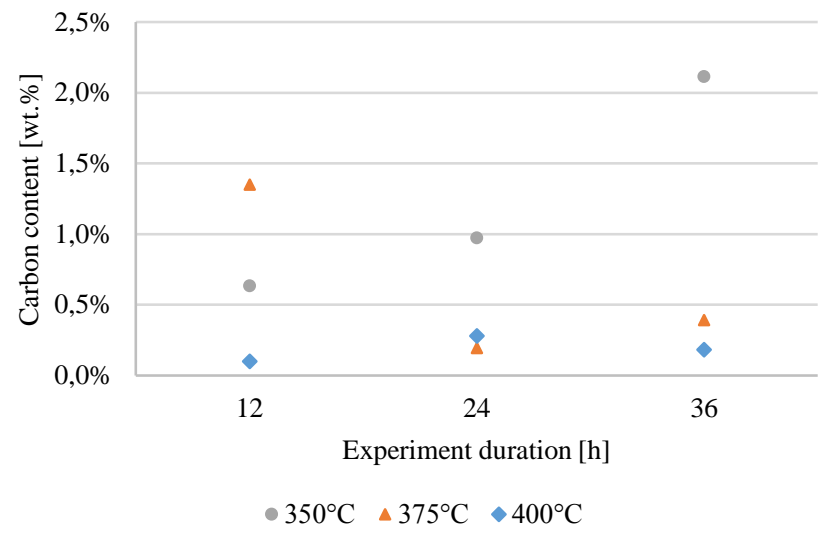

Figure 14. carbon content of the aqueous phase

The water content of the aqueous phase was between 96.9 wt.\% and 99.9 wt.\% in all cases, as shown in Table 11. This result confirms the low carbon loss and high effectiveness of hydrodeoxygenation.

Table 11. water content of the aqueous phase

\begin{tabular}{llll}
\hline Water [wt.\%] & $\mathbf{1 2} \mathbf{~}$ & $\mathbf{2 4} \mathbf{~ h}$ & $\mathbf{3 6} \mathbf{~ h}$ \\
\hline $350^{\circ} \mathrm{C}$ & 99.9 & 99.7 & 97.8 \\
$375^{\circ} \mathrm{C}$ & 97.0 & 97.6 & 96.9 \\
$400^{\circ} \mathrm{C}$ & 98.5 & 97.6 & 98.1 \\
\hline
\end{tabular}

Figure 15 shows the $\mathrm{H} / \mathrm{C}$ ratio of the hydrocarbon product phase compared to diesel and gasoline. For comparison, the H/C ratio of diesel was compared with hydrotreated vegetable oil (HVO) additives and gasoline without biogenic additives. The H/C ratio decreased over the time span of the experiment and increased with the temperature. The highest $\mathrm{H} / \mathrm{C}$ ratio was observed at $400^{\circ} \mathrm{C}$ in the first period of the experiment. Afterwards deactivation of the catalyst became detectable, although the $\mathrm{H} / \mathrm{C}$ ratio was still in the range of diesel and gasoline. The results of the experiment at $350^{\circ} \mathrm{C}$ again confirmed a significant oxygen content, indicating insufficient hydrodeoxygenation. 
274 10 $10^{\text {TH }}$ InTERnAtional CONFERENCE ON Sustainable ENERGy AND ENVIRONMENTAL Protection (June $27^{\mathrm{TH}}-30^{\mathrm{TH}}, 2017$, Bled, Slovenia), BioENERGy AND Biofuels

K. Treusch, N. Schwaiger, K. Schlackl, R. Nagl, P. Pucher \& M. Siebenhofer: Continuous Hydrocarbon Production by Hydrodeoxygenation of Liquid Phase Pyrolysis Oil

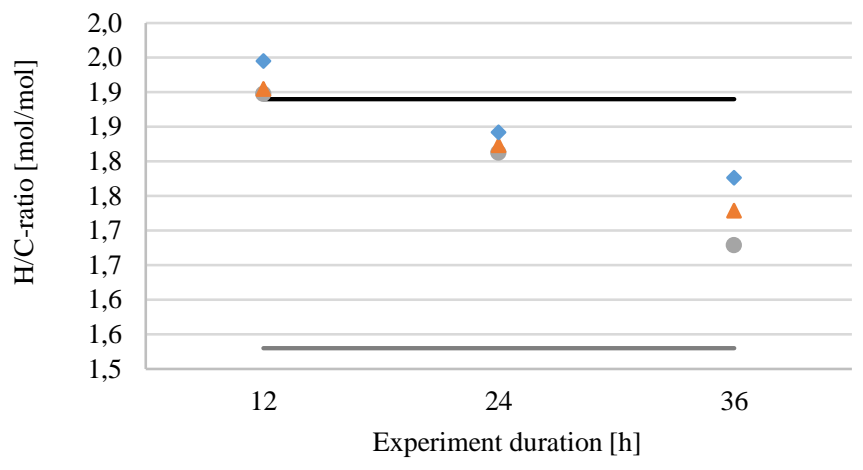

- $350^{\circ} \mathrm{C} \triangle 375^{\circ} \mathrm{C} \diamond 400^{\circ} \mathrm{C} \longrightarrow$ Diesel Gasoline

Figure 15: H/C ratio of the hydrocarbon product phase

\section{Product characterization}

In Table 12 the properties of the hydrocarbon product phase, depending on the HDO temperature, are listed and compared to the specification of diesel and gasoline.

Table 12. Hydrocarbon product characterization after $24 \mathrm{~h}$ of experiment compared to diesel and gasoline

\begin{tabular}{|c|c|c|c|c|c|c|}
\hline Compound & Unit & $\begin{array}{c}\text { HDO } \\
350^{\circ} \mathrm{C}\end{array}$ & $\begin{array}{c}\text { HDO } \\
375^{\circ} \mathrm{C}\end{array}$ & $\begin{array}{c}\text { HDO } \\
400^{\circ} \mathrm{C}\end{array}$ & Diesel & Gasoline \\
\hline Water content & [wt.\%] & 0.03 & 0.03 & 0.03 & $<0.02$ [9] & n.a. \\
\hline $\begin{array}{l}\text { Lower heating } \\
\text { value } \\
\text { (Boie }[10] \text { ) }\end{array}$ & {$[\mathrm{MJ} / \mathrm{kg}]$} & 42.68 & 42.73 & 42.72 & 43.2 & 41.8 \\
\hline Density & {$\left[\mathrm{kg} / \mathrm{m}^{3}\right]$} & 829 & 823 & 805 & $820-845$ [9] & $720-775[11]$ \\
\hline Viscosity & {$[\mathrm{mPa} \cdot \mathrm{s}]$} & 1.56 & 1.45 & 1.07 & $2.0-4.5[9]$ & n.a. \\
\hline Boiling at $150^{\circ} \mathrm{C}$ & [V.\%] & 32.6 & 31.0 & 20.7 & n.a. & $\geq 75[11]$ \\
\hline Boiling at $350^{\circ} \mathrm{C}$ & [V.\%] & 96.6 & 97.2 & 98.5 & $\geq 85[9]$ & n.a. \\
\hline Carbon transfer & [\%] & 36.7 & 36.6 & 41.5 & - & - \\
\hline Carbon content & [wt.\%] & 86.37 & 86.35 & 86.03 & 86.3 & 88.7 \\
\hline Hydrogen content & [wt.\%] & 13.17 & 13.24 & 13.33 & 13.7 & 11.4 \\
\hline $\begin{array}{l}\text { Balance } \\
\text { (Oxygen content) }\end{array}$ & [wt.\%] & 0.00 & 0.00 & 0.00 & 0.0 & 0.0 \\
\hline Nitrogen content & [wt.\%] & $<1$ & $<1$ & $<1$ & $<1$ & $<1$ \\
\hline
\end{tabular}


The ultimate analysis is compared with gasoline without biogenic additives and diesel with $\mathrm{HVO}$ additives. The lower heating value was calculated with the algorithm of Boie [10] (equation 1).

$$
L H V=35 \cdot c+94,3 \cdot h-10,8 \cdot o+10,4 \cdot s+6,3 \cdot n-2,44 \cdot w
$$

with, $c, h, o, s, n$ and $w$ representing the amount of carbon, hydrogen, oxygen, sulphur, nitrogen and water in wt.\%, respectively.

Water content, density, viscosity and boiling cut points of diesel and gasoline are derived from the standard of diesel (EN 590 [9]) and gasoline (EN 228 [11]).

\section{$3 \quad$ Summary}

HDO has been performed successfully in a single step process. The water content of LPP oil could be decreased to below $0.05 \mathrm{wt} . \%$. The carbon loss into the aqueous product phase was very low, with carbon contents of 0.5 wt. $\%$ at $400^{\circ} \mathrm{C}$. Decreasing HDO rate at $\mathrm{T}=350^{\circ} \mathrm{C}$ indicates fast deactivation of the catalyst. The carbon transfer and from LPP oil into the hydrocarbon product phase yield were highest at $400^{\circ} \mathrm{C}$. Also the $\mathrm{H} / \mathrm{C}$ ratio, an indicator for the degree and effectiveness of hydrodeoxygenation, was highest at this temperature.

\section{Acknowledgements}

This work was funded by the Austrian Research Promotion Agency (FFG) under the scope of the Austrian Climate and Energy Fund.

\section{References}

[1] A. Demirbas, "Competitive liquid biofuels from biomass," Appl. Energy, vol. 88, no. 1, pp. 17-28, 2011.

[2] H. Pucher, N. Schwaiger, R. Feiner, P. Pucher, L. Ellmaier, and M. Siebenhofer, "Catalytic hydrodeoxygenation of dehydrated liquid phase pyrolysis oil," Energy Res., vol. 31, no. April 2014, p. 3205, 2014.

[3] M. V. Olarte et al., "Stabilization of Softwood-Derived Pyrolysis Oils for Continuous Biooil Hydroprocessing," Top. Catal., vol. 59, no. 1, pp. 55-64, 2016.

[4] D. C. Elliott, T. R. Hart, G. N. G., L. J. Rotness, and A. H. Zacher, "Catalytic Hydroprocessing of Biomass Fast Pyrolysis Bio-oil to Produce Hydrocarbon Products," Environ. Sci. Technol., vol. 28, no. 3, pp. 441-449, 2009.

[5] N. Schwaiger et al., "Liquid and Solid Products from Liquid-Phase Pyrolysis of Softwood," Bioenergy Res., vol. 4, no. 4, pp. 294-302, 2011.

[6] N. Schwaiger et al., "Formation of liquid and solid products from liquid phase pyrolysis," Bioresour. Technol., vol. 124, pp. 90-94, 2012.

[7] N. Schwaiger, R. Feiner, H. Pucher, and L. Ellmaier, "BiomassPyrolysisRefinery Herstellung von nachhaltigen Treibstoffen,” no. 6, pp. 1-8, 2015. 
276 10 $10^{\text {TH }}$ InTERnAtional CONFERENCE ON Sustainable ENERGy AND ENVIRONMENTAL Protection (June $27^{\mathrm{TH}}-30^{\mathrm{TH}}, 2017$, Bled, SLOVENIA), BioENERGy AND Biofuels

K. Treusch, N. Schwaiger, K. Schlackl, R. Nagl, P. Pucher \& M. Siebenhofer: Continuous Hydrocarbon Production by Hydrodeoxygenation of Liquid Phase Pyrolysis Oil

[8] J. Ritzberger, P. Pucher, N. Schwaiger, and M. Siebenhofer, "The BioCRACK Process-A Refinery Integrated Biomass-to-Liquid Concept to Produce Diesel from Biogenic Feedstock," Chem. Eng. Trans., vol. 39, no. 2010, pp. 1189-1194, 2014.

[9] EN 590.2004.

[10] K.-H. Grote and J. Feldhusen, Dubbel Taschenbuch für Maschinenbau, 22nd ed. Springer, 2007.

[11] EN 228. 2004. 
$10^{\mathrm{TH}}$ InTERnational CONFERENCE ON Sustainable ENERgy AND ENVIRONMENTAL Protection (June $27^{\mathrm{TH}}-30^{\mathrm{TH}}$, 2017, Bled, SLOVENIA), BIOENERGY AND BIOFUELS

J. Krope, A.Ghani Olabi, D. Goričanec \& S. Božičnik

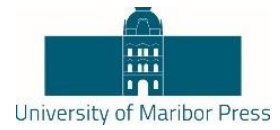

\title{
2,5 DMF Production from Biomass Using Heterogenous Catalysts
}

\author{
Nerea Viar, Jesus ReQuiEs, ION AgIRRE, \& PEDRo Luis ARIAS
}

\begin{abstract}
The biorefinery can be a good alternative to cover the current needs of energy, fine chemicals and unconventional fuels. 5hydroxymethylfurfural (HMF) can be obtained directly from biomass, and it is considered as the most promising intermediate for the 2,5dimethylfuran (DMF) synthesis. DMF is particularly attractive due to its similar characteristics to gasoline. Recent publications [1-2] show that this biofuel/bioadditive can be produced in autoclave type reactors by heterogeneous catalysis using non-noble and noble metal catalysts. In this work DMF has been obtained from biomass via HMF using a continuous fixed bed catalytic reactor. For this purpose, different monometallic $\mathrm{Cu} / \mathrm{ZrO} 2, \mathrm{Cu}-\mathrm{Ru} / \mathrm{ZrO} 2$ and different $\mathrm{Cu}$ and $\mathrm{Ru}-\mathrm{Cu} / \mathrm{ZrO} 2-\mathrm{CeO} 2$ catalysts were tested. In addition, different textural properties are also analyzed to establish a relationship among the DMF yield and the catalyst characteristics.
\end{abstract}

Keywords: • 2,5-Dimethylfuran • 5-Hidroxymethylfurfural • Hydrogenation • Copper • Zirconium •

CorRespondence AdDRess: Nerea Viar, Peter Trop, Ph.D Engineering Faculty of Bilbao, University of Basque Country (UPV/EHU), C/ Alameda Urquijo s/n, 48013 Bilbao, Spain, e-mail: nerea.viar@ehu.eus, Jesus Requies, Associate Professor, Engineering Faculty of Bilbao, University of Basque Country (UPV/EHU), C/ Alameda Urquijo s/n, 48013 Bilbao, Spain, e-mail :jesus.requies@ehu.eus, Ion Agirre, Associate Professor, Engineering Faculty of Bilbao, University of Basque Country (UPV/EHU), C/ Alameda Urquijo s/n, 48013 Bilbao, Spain, email:ion.agirre@ehu.eus, Pedro Luis Arias, Full professor Engineering Faculty of Bilbao, University of Basque Country (UPV/EHU), C/ Alameda Urquijo s/n, 48013 Bilbao, Spain, e-mail: pedroluis.arias@ehu.es 
$10^{\mathrm{TH}}$ InTERNATIONAL CONFERENCE ON Sustainable ENERGY AND ENVIRONMENTAL Protection (June $27^{\mathrm{TH}}-30^{\mathrm{TH}}, 2017$, BLed, Slovenia), Bioenergy AND Biofuels

N. Viar, J. Requies, I. Agirre \& P.L. Arias: 2,5 DMF Production from Biomass Using Heterogenous Catalysts

\section{Introduction}

The biorefinery can be a good alternative to cover the current needs of energy, fine chemicals and unconventional fuels. Moreover, due to the drawbacks presented by this first generation biofuels in their use in transportation motors, the efforts are leading to the development of second generation biofuels and bioadditives [1,3], which can be produced from lignocellulosic biomass (sugars).

According to the literature [4], top 7 chemical building blocks can be produced from sugars using chemical routes. These chemicals are levulinic acid, glucaric acid, sorbitol, arabitol, furfural and 5-hydroxymethylfurfural (HMF). Among the mentioned chemicals HMF can be obtained directly from the sugar raw material and moreover, it is considered to be the most promising intermediate for the 2,5-dimethylfuran (DMF) synthesis and other fine chemical molecules like levulinic acid, 2,5-furandicarboxilic acid, ethyl levulinate [1].

DMF is particularly attractive because its characteristics are similar to the gasoline ones, i.e. its low solubility in water and high capacity to blend with other transportation fuels. Therefore, DMF can be used as biofuel or as bioadditive.

As it is indicated, a previous synthesis of HMF as an intermediate is required for the production of DMF. Nowadays, the most extended process to produce HMF is the catalytic dehydration of carbohydrates (glucose, fructose, sucrose). Additionally, DMF can be produced from hydrogenolysis, also called selective hydrogenation, of HMF by heterogeneous catalysis by means of both non-noble and noble metal catalysts $[5,6]$.

The main objective of this work is the use of the different bifunctional catalysts in the 2,5 DMF production process analyzing the influence of the support and the different metals in the 2,5 DMF yield.

\section{Experimental}

Synthetic HMF (Sigma-Aldrich, 99\%) diluted in 1-butanol was used as the feed to a continuous fix bed reactor in order to produce DMF. For these experiments $\mathrm{Cu}$ and $\mathrm{Ru}$ $\mathrm{Cu}$ catalysts supported on $\mathrm{ZrO}_{2}$ were prepared by the incipient wetness impregnation method. The monometallic $\mathrm{Cu}$ catalysts, designed as $15 \mathrm{CuZr}, 30 \mathrm{CuZr}, 45 \mathrm{CuZr}$, in which the numerical factor belong to nominal wt $\%$ of copper, were prepared by a single step impregnation. Conversely the bimetallic catalyst, designed as $1 \mathrm{RuXCuZr}$ (also in nominal weight), and $\mathrm{Cu} / \mathrm{ZrCe}$ were carried out by impregnation of the $15 \mathrm{CuZr}, 30 \mathrm{CuZ}$ and $45 \mathrm{CuZrr}$ catalysts with a ruthenium precursor solution. The $30 \mathrm{Cu} / \mathrm{Zr}-\mathrm{XCe}$ and $15 \mathrm{Cu} / \mathrm{Zr}-\mathrm{XCe}$ were also developed in two sequential impregnation steps. After impregnation and drying, the samples were calcined in air at $523 \mathrm{~K}$ for $2 \mathrm{~h}$. 
The catalysts were characterized by several physicochemical techniques such as; temperature programmed reduction (TPR), and temperature programmed desorption with ammonia (TPD) in order to measure the acidity of the different catalysts.

\subsection{Results and discussion}

DMF production through HMF hydrogenolysis was studied using $\mathrm{CuZr}, \mathrm{Ru}-\mathrm{Cu} / \mathrm{Zr}$, and $\mathrm{Cu} / \mathrm{Zr}$-Ce catalysts in a continuous fixed bed reactor under different temperature and pressure conditions: $200-275^{\circ} \mathrm{C}$ and $15-20$ bar of $\mathrm{H}_{2}$.

The temperature affects the DMF yield but not the HMF conversion (Table 1). At any temperature a total HMF conversion was reached. However, at higher temperatures higher DMF yield was obtained.

The variation of $\mathrm{H}_{2}$ pressure had any effect neither in the DMF yield nor in the HMF conversion. Moreover, the catalyst reduction prior to the activity tests had also any effect in the activity parameters. The reducing atmosphere during the activity test is enough for copper reduction, producing the same activity results that with the reduced catalysts. Therefore, after this initial catalytic screening, there were fixes the following operating conditions were fixed for the upcoming experiments: $\mathrm{T}=275^{\circ} \mathrm{C}, \mathrm{P}=15$ bar and no catalyst reductions.

Table 1- CuZr screening catalysts

\begin{tabular}{|c|c|c|c|c|c|c|}
\hline Catalyst & Reduced & P (bar) & $\mathrm{T}(\mathrm{O} C)$ & Time (h) & Yield & Conversion \\
\hline $15 \mathrm{CuZr}$ & No & 15 & 200 & 6 & 2.79 & 100 \\
\hline $15 \mathrm{CuZr}$ & Yes & 15 & 200 & 6 & 5.3 & 100 \\
\hline $15 \mathrm{CuZr}$ & No & 15 & 275 & 10 & 28.39 & 100 \\
\hline 1Ru15CuZr & Yes & 15 & 200 & 6 & 9.05 & 100 \\
\hline 1Ru15CuZr & Yes & 15 & 250 & 6 & 21.34 & 100 \\
\hline 1Ru15CuZr & Yes & 15 & 275 & 6 & 22.04 & 100 \\
\hline 1Ru15CuZr & No & 15 & 275 & 10 & 25.12 & 100 \\
\hline $30 \mathrm{CuZr}$ & Yes & 15 & 275 & 6 & 25.92 & 100 \\
\hline $30 \mathrm{CuZr}$ & Yes & 20 & 275 & 6 & 25.94 & 100 \\
\hline $30 \mathrm{CuZr}$ & No & 15 & 275 & 6 & 26.29 & 100 \\
\hline $30 \mathrm{CuZr}$ & No & 15 & 275 & 10 & 16.08 & 100 \\
\hline 1Ru30CuZr & Yes & 15 & 275 & 6 & 21.29 & 100 \\
\hline 1Ru30CuZr & No & 15 & 275 & 6 & 21.65 & 100 \\
\hline $45 \mathrm{CuZr}$ & No & 15 & 275 & 6 & 3.49 & 100 \\
\hline 1Ru45CuZr & No & 15 & 275 & 6 & 0.06 & 95.015 \\
\hline
\end{tabular}

After fixing the operation conditions, the studied parameter was the copper loading. In Figure 1, it can be observed that the best result was reached for the $30 \mathrm{CuZr}$ catalyst with $20 \%$ yield to DMF after 6 hours on stream. The catalyst with a $15 \%$ of copper reached a $15 \%$ yield of DMF, and the worst result was reached by the catalyst with the highest copper amount, $45 \mathrm{CuZr}$, that reached a DMF yield lower than $10 \%$. With the best two catalysts different tests with longer times on stream were carried out in order to analyze the catalyst stability (Figure 1). 
In Figure 1 it can be observed that for the 30CuZr the maximum DMF yield was reached at 6 hours and after this time on stream the DMF yield decreased a little bit. This behaviour was not repeated with the $15 \mathrm{CuZr}$, therefore it seems that the stability of the $15 \mathrm{CuZr}$ is better than $30 \mathrm{CuZr}$, being this decrease a consequence of the formation of new by-products and the coke formation. Probably this behaviour is related to the $\mathrm{Cu}$ particle size. It is expected that higher amount of $\mathrm{Cu}$ higher particle size, and higher particle size usually presents higher coke formation tendency. These results agree with the TPR results (Figure 2).

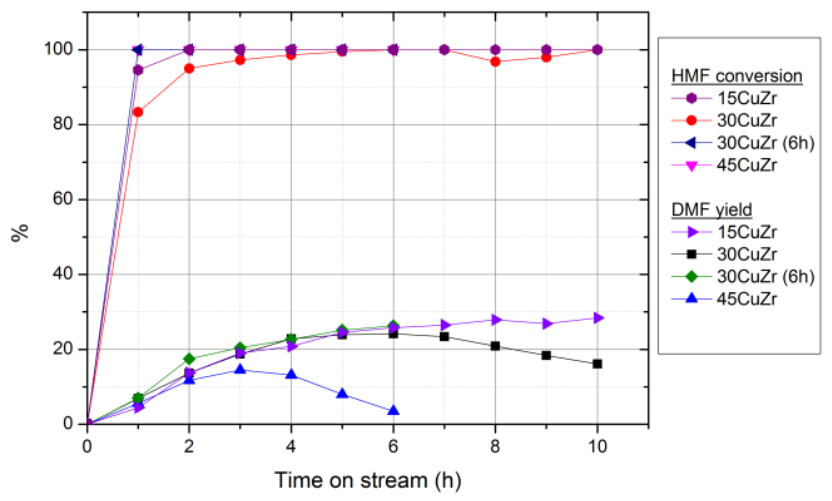

Figure 1 Activity results of the $\mathrm{Cu} / \mathrm{Zr}$ catalysts

The TPR profiles of the catalysts are shown in Figure 2. In the case of $\mathrm{Cu} / \mathrm{Zr}, \mathrm{Ru}-\mathrm{Cu} / \mathrm{Zr}$, and $\mathrm{Cu}-\mathrm{Ce} / \mathrm{Zr}$ two-three peaks of reduction were detected. In the case of catalysts prepared by wetness impregnation, the literature reports three reduction peaks: two overlapping peaks at temperature below $200{ }^{\circ} \mathrm{C}$ are assigned to highly dispersed $\mathrm{Cu}$ species and the third peak at higher temperatures (around $300{ }^{\circ} \mathrm{C}$ ) is associated with bulk $\mathrm{CuO}[7,8]$.

In the case of the $\mathrm{Cu} / \mathrm{Zr}$ catalysts, the reductions of the dispersed $\mathrm{CuO}$ species are observed with the three catalysts. The third peak related to bulk $\mathrm{CuO}$ does not appear clearly in any catalysts' TPR results. In the case of the $45 \mathrm{CuZr}$ the reduction peaks are shifted up to lower temperatures, probably due to the lower dispersion of the copper. This could explain the lower DMF yield obtained for this catalyst due to large particle size favors coke formation deactivating the catalyst.

In this $\mathrm{Cu} / \mathrm{Zr}$ catalyst there is a relationship between the amount of copper and the copper reduction. At higher $\mathrm{Cu}$ amount higher copper reduction.

The presence of ruthenium changes completely the reduction profile. The amount of $\mathrm{Cu}$ highly dispersed is shifted up to lower temperatures, favoring the copper reduction. This 
effect is very notorious in the $1 \mathrm{Ru} 30 \mathrm{CuZr}$ and in the $1 \mathrm{Ru} 45 \mathrm{CuZr}$. Therefore, it seems that the presence of ruthenium improves the $\mathrm{Cu}$ reduction capacity. Using $\mathrm{RuCl}_{3}$ as the precursor salt with the $\mathrm{Cu}$, an interaction is generated between the support and the metallic salts [9]. From this interaction among the different salt it can be inferred that the shifts in reduction temperature may be caused by inter-phase hydrogen adsorption, which favors $\mathrm{Cu}$ reduction [9]. This is corroborated in this work in Figure 3.

The presence of small amount of $\mathrm{Ce}$ on the catalysts did not affect to the catalysts reduction, while the presence of large $\mathrm{Ce}$ amount shifts up to lower temperatures the reduction peaks.

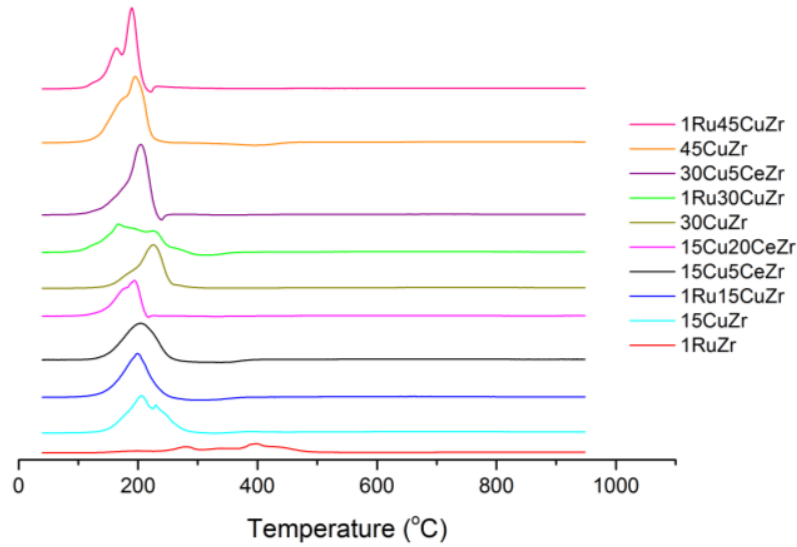

Figure 3 TPR results of the different catalysts

In order to improve the yield towards DMF using $30 \mathrm{CuZr}$ and $15 \mathrm{CuZr}$ catalysts, it was decided to add $1 \%$ of Ru in the catalyst. As it is shown in Table 1, the presence of a low amount of $\mathrm{Ru}$ did not improve the DMF yield for $30 \mathrm{CuZr}$, neither for the $15 \mathrm{CuZr}$. The $\mathrm{Ru}$ has higher hydrogenation capacity than $\mathrm{Cu}$, and in this case the $\mathrm{Ru}$ presence was not favorable in the DMF yield. The presence of other over hydrogenated products as 2,5dimethyltetrahydrofuran (DMTF) could be the explanation of this worse DMF yield. To view the effect of the $\mathrm{Ru}$ in this reaction, the $1 \mathrm{RuZr}$ was also tested under the same operating conditions. This last catalyst presented a total HMF conversion but no DMF yield. That means, that ruthenium and zirconia did not favoured the $\mathrm{C}-\mathrm{O}$ bond cleavage, and this is why there is not any DMF yield. In this case, the presence of HMF hydrogenation products is favoured.

The acidity is also an important factor in the DMF yield. The support's acidity favours the $\mathrm{C}-\mathrm{C}$ bond scissions decreasing the DMF selectivity, while the presence of $\mathrm{Cu}$ decreases the acidity of the support and favours the $\mathrm{C}-\mathrm{O}$ bond cleavage increasing the 2,5 DMF yield. The RuZr catalyst does not present any selectivity to DMF. The problem is that the ruthenium and zirconia do not present a significant capacity to $\mathrm{C}-\mathrm{O}$ bond scission, 
282 10 $10^{\mathrm{TH}}$ International Conference on Sustainable Energy and Environmental Protection (June $27^{\mathrm{TH}}-30^{\mathrm{TH}}, 2017$, Bled, SLOVENiA), Bioenergy AND BIofuels

N. Viar, J. Requies, I. Agirre \& P.L. Arias: 2,5 DMF Production from Biomass Using Heterogenous Catalysts

favouring hydrogenation products. In the Table 2 the total acidity strength of these catalysts is summarized. It seems that the presence of $\mathrm{Ru}$ and $\mathrm{Cu}$ enhance the acidity strength, specially the ruthenium. This could explain the low DMF yield obtained for these catalysts, because the presence of higher acidity centre could favour the C-C scissions opening the HMF ring and producing different undesirable by-products.

Table 2 Acidity of the different catalysts

\begin{tabular}{|c|c|c|}
\hline Catalyst & $\mathrm{mmol} \mathrm{NH}_{3} / \mathrm{g}$ cat & Peak Temperature (ㅇ) \\
\hline $\mathrm{Zr}$ & 42.4 & 308 \\
\hline $1 \mathrm{RuZr}$ & 63.3 & 425 \\
\hline $15 \mathrm{CuZr}$ & 38.2 & 375 \\
\hline $30 \mathrm{CuZr}$ & 50.8 & 383 \\
\hline $45 \mathrm{CuZr}$ & 64 & 360 \\
\hline 1 Ru30CuZr & 41 & 390 \\
\hline 1 Ru45CuZr & 70.2 & 370 \\
\hline $15 \mathrm{Cu} 20 \mathrm{CeZr}$ & 59.9 & 380 \\
\hline
\end{tabular}

The presence of cerium on the catalysts hardly improves the selectivity of DMF, but increases the stability of the catalysts. This can be observed in the Figure 4. The conversion was total and the DMF yield is also maintained during 10 hours on stream. Mixing $\mathrm{ZrO}_{2}$ and $\mathrm{CeO}_{2}$ has been found to improve the thermal stability, catalytic activity and oxygen storage capacity. The latter refers to the ability to deliver oxygen from the lattice to the gas phase or to solid (adsorbed) carbon [10,11]. This effect can be related to a better stability of the catalysts supported on ceria.

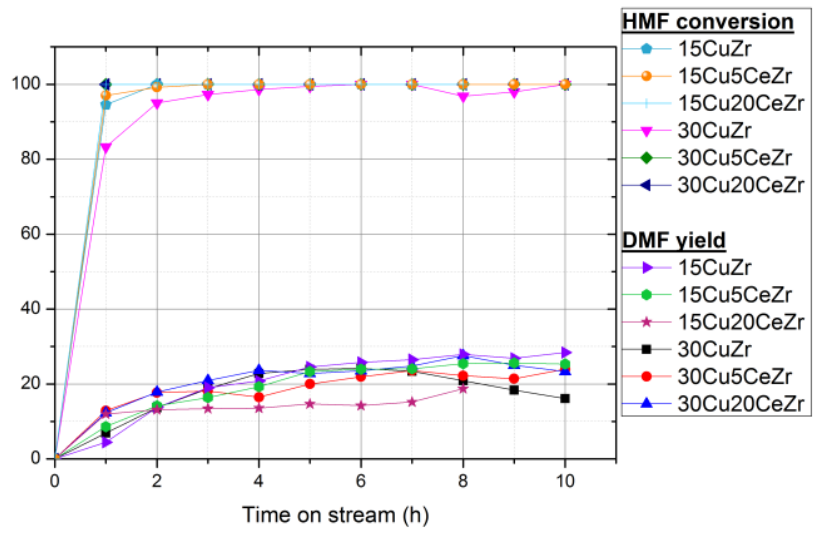

Figure 4 Activity results of the $\mathrm{Cu} / \mathrm{Ce}-\mathrm{Zr}$ catalysts 


\section{$3 \quad$ Conclusions}

The main conclusions of this work are stated below:

High temperatures favour the DMF yield, obtaining the best values of DMF yield for $\mathrm{CuZr}$ catalysts at $275^{\circ} \mathrm{C}$.

The increment of $\mathrm{H}_{2}$ pressure from 15 to 20 bar has not any influence on the DMF yield.

The presence of ruthenium has not a positive effect in the $\mathrm{CuZr}$ catalysts for the DMF selectivity, due to the over hydrogenation of the DMF.

The cerium presence in the $\mathrm{CuZr}$ catalysts improves their stability, because ceria is able to eliminate the formed carbon.

\section{Acknowledgments}

This work was supported by funds from University of the Basque Country (UPV/EHU), Spanish Ministry of Economy and Innovation (Projects: CTQ2015-64226-C3-2-R), and Basque Country Government (Project: IT993-16).

\section{References}

[1] S. Nishimura, N. Ikeda, K. Ebitani, Catal. Today 232 (2014) 89-98.

[2] Y. Zu, P. Yang, J. Wang, X. Liu, J. Ren, G. Lu, Y. Wang, Appl. Catal. B Environ. 146 (2014) 244-248.

[3] International Energy Agency, World Energy Outlook 2015, Paris, 2015.

[4] International Energy Agency, Key Oil Trends, 2016.

[5] M. Zhang, X. Tong, R. Ma, Y. Li, Catal. Today 264 (2016) 131-135.

[6] P. Yang, Q. Cui, Y. Zu, X. Liu, G. Lu, Y. Wang, Catal. Commun. 66 (2015) 55-59.

[7] G. Aguila, A. Valenzuela, S. Guerrero, P. Araya, Cat.Commun. 39 (2013) 82-85.

[8] G. Agila, F. Gracia, J. Cortes, P. Araya, Appl. Cat. B:Environmental 77 (2008) 325-338.

[9] A. V.H. Soares, J.B. Salazar, D. D. Falcone, F. A. Vasconcellos, R.J. Davis, F. B. Passos. Journal of Molecular Catalysis A: Chemical 415 (2016) 27-36

[10] J. Chen, Q. Wu, J. Zhang, J. Zhang. Fuel, 87 (2008), pp. 2901-2907

[11] A.Wolfbeisser, O. Sophiphun, J. Bernardi, J. Wittayakun, K. Föttinger, G. Rupprechter, Catalysis Today, 277, 15, 2016, 234-245. 
284 10 $10^{\text {TH }}$ InTERnAtional CONFERENCE ON Sustainable ENERGy AND ENVIRONMENTAL Protection (June $27^{\mathrm{TH}}-30^{\mathrm{TH}}, 2017$, BLed, Slovenia), Bioenergy AND Biofuels 
$10^{\mathrm{TH}}$ InTERnAtional CONFERENCE ON Sustainable ENERgy AND EnVironmental Protection (June $27^{\mathrm{TH}}-30^{\mathrm{TH}}$, 2017, Bled, SLOVENIA), BIOENERGY AND BIOFUELS

J. Krope, A.Ghani Olabi, D. Goričanec \& S. Božičnik

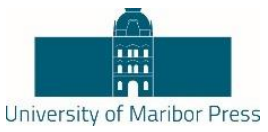

\title{
Can Various Bioenergy Technologies Add Value to Each Other?
}

\author{
KATRIN HEINSOO \& KADRI TALI
}

\begin{abstract}
Bioenergy is sustainable and sufficient only if both the production technology and coproduct utilisation are environmentally friendly. Hence, we suggest the establishment of small-scale willow Short Rotation Coppice close to biogas plants to solve the digestate utilisation problems and to promote woodchip production without mineral fertilisers.

Our greenhouse experiment with young Salix plants revealed that application of biogas digestate increased the plant biomass production. However, the overdose of additional chemicals can be harmful and cause plant dieback. The impact of digestate on plants in our experiment was similar to the impact of the original slurry that was used for anaerobic digestion. Furthermore, the biomass growth of plants that were fertilised with slurry or digestate was similar to the plants that received liquid mineral fertiliser instead. Therefore we conclude that anaerobic fermentation did not change the chemical composition of traditional organic fertiliser and digestate can replace mineral fertilisers in non-food crops.
\end{abstract}

Keywords: • Bioenergy $\bullet$ Fertilisation $・$ Salix $・$ Short rotation coppice • Sustainability $\bullet$

Correspondence Address: Katrin Heinsoo, Ph.D., Senior Researcher, Estonian University of Life Sciences, Institute of Agricultural and Environmental Sciences, Kreutzwaldi 5D, 51014 Tartu, Estonia, e-mail: Katrin.Heinsoo@emu.ee. Kadri Tali, Ph.D., Senior Researcher, Estonian University of Life Sciences, Institute of Agricultural and Environmental Sciences, Kreutzwaldi 5D, 51014 Tartu, Estonia, e-mail: Kadri.Tali@emu.ee. 
Bioenergy production from agricultural areas is an alternative practice to traditional farm management options that has an important role to meet the European targets for renewable energy. Usage of dedicated energy crops for this purpose enables to increase the yield of energy production from area and to reduce the green-house emission. Shortrotation Coppice (SRC) is a perennial dedicated energy crop that can offer several ecosystem services beside bioenergy production [1]. A SRC with willow (Salix) plants can perform stable annual wood production for 20 years which supports carbon sequestration to the agricultural soil. Furthermore, biomass harvesting only once in $3 \ldots 4$ years creates ecosystem that is proved to be a useful habitat for different plant and animal species and to increase the biodiversity in the area.

On the other hand, long-term harvesting cycles and large investments that are needed for SRC establishment (planting material, weed control during the establishment year) makes SRC management risky and special instruments are welcome to convince the farmers shifting their land use from typical annual crops towards SRC. One key issue here is to create calculation tools that enable to predict the expenses and incomes during SRC management. According to such tools crop fertilisation is the most costly activity in SRC after the establishment year [2]. However, reasonable wood production yield throughout several harvests can be achieved only by means of additional nutrient application. Therefore it would be necessary to find cheaper and more environmental-friendly solutions to replace the traditional mineral fertilisers.

Anaerobic fermentation is another bioenergy production option, which has recently raised a lot of interest in Europe and enables to increase the share of renewables both on electricity and transport fuel market. The main problem here is the large amount of residues in the form of nitrogen(N)-rich digestate [3]. On the other hand, it can be an useful nutrient resource in organic farming to promote plant growth [4]. There are controversial data available in the literature about the uptake of $\mathrm{N}$ from the digestate [5] , but most of the studies agree that the $\mathrm{pH}$ of the material increases during fermentation process [6]. Hence the utilisation of the digestate without negative environmental impact on the plant and soil microorganism communities is complicated. Using the digestate for fertilisation of perennial highly-productive woody plants with well-developed root rhizospheres can be a reasonable option in order to get both economically feasible biomass for renewable energy production and to support the biogas production via more sustainable ways for residue utilisation. Before suggesting such methodology to farmers, however, it was reasonable to control the hypotheses in small-scale. We created a greenhouse-type experiment to understand:

-does biogas digestate increase willow growth?

-is there any differences in the impact of digestate and original organic material application?

-do different willow clones react on the fertilisation in the same way?

-what is the optimal load of digestate that can be applied to young plants without complications? 
$10^{\text {TH }}$ INTERNATIONAL CONFERENCE ON SUSTAINABLE ENERGY AND ENVIRONMENTAL

Protection (June $27^{\mathrm{TH}}-30^{\mathrm{TH}}, 2017$, Bled, Slovenia), Bioenergy AND Biofuels

K. Heinsoo \& K. Tali: Can Various Bioenergy Technologies Add Value to Each Other?

\section{$2 \quad$ Material and Methodology}

The experiment was carried out during two consecutive growing periods of 2012 and 2013. In May $16^{\text {th }}, 2012$ we planted 86 cuttings of $20 \mathrm{~cm}$ long and $11 \ldots 16 \mathrm{~mm}$ upper diameter sliced from one-year old shoots vertically into specially designed pots with outer vessel performing as additional water reservoir, water being available for the cuttings through textile wicks. The upper diameters of all cuttings were measured and recorded. Additional slices of the shoot were weighted and dried at $85^{\circ} \mathrm{C}$ for three days to measure their moisture content.

Before planting the pots were filled with gravy substrate. This material was used in order to diminish the natural availability of plant nutrients in growing environment and to enable the collection of all fine roots of the plants according to the experiment scheme. During both growing periods the pots with plants were in garden area exposed to full sunshine and protected from wind. Between the growing periods the inner vessels of the pots that were not harvested in 2012 were partly buried into the ground, the substrate level remaining $1 \ldots 2 \mathrm{~cm}$ above the ground level. With this treatment we simulated the natural growing conditions of plant roots during winter period. Throughout the growing periods we added water to the outer vessel at least twice a week and assumed therefore that the plants had sufficient water supply during the experiment.

Half of the planted cuttings originated from Salix viminalis clone 78183 (according to Swedish clone numbering system and further abbreviated "83") and the rest from hybrid Salix schwerinii $x$ S. viminalis (clone "Tora"). All cuttings sprouted within two weeks from the planting, however, from both clones three plants with slowest growth during the first month were excluded from the further experiment.

The organic fertilisers originated from different biogas production facilities. In 2012 we got both slurry and digestate from the pigs and in 2013 from the neat husbandry where slurry was the only (2012) or dominating (2013) biogas substrate. For all collected liquids the chemical composition was studied and the application load was calculated according to the amount of total Nitrogen $(\mathrm{N})$ (Table 1). The used mineral fertiliser was a liquid that contained the most alike $\mathrm{N} / \mathrm{P}$ (phosphorus)/K(potassium) ratio with that of digestate in 2012 in order to keep also the availability of other nutrients beside treatments as similar as possible. The supplement of nutrients started in the June, $25^{\text {th }}$ in both years. We diluted the weekly dosage of the fertiliser at least in 0.51 of water before application and poured the solution to the pots gradually throughout the week taking into account the natural precipitation. If we were not able to utilise to total amount of solutions during the week we skipped the next week new application. Hence our experiment took longer than ten weeks and ended in late September in both years. 
$10^{\mathrm{TH}}$ InTERNATIONAL CONFERENCE ON Sustainable ENERGY AND ENVIRONMENTAL Protection (June $27^{\mathrm{TH}}-30^{\mathrm{TH}}, 2017$, BLED, SLOVENIA), BioENERGY AND Biofuels

K. Heinsoo \& K. Tali: Can Various Bioenergy Technologies Add Value to Each Other?

Table 1. Scheme of nutrient application in different treatments

\begin{tabular}{|l|l|c|c|}
\hline treatment & origin of nutrients & $\begin{array}{c}\text { total N } \\
\text { per week } \\
(\mathrm{g})\end{array}$ & $\begin{array}{c}\text { N during } \\
\text { growing } \\
\text { period (g) }\end{array}$ \\
\hline $0.5 \mathrm{~S}$ & slurry & 0.5 & 5 \\
\hline $0.5 \mathrm{D}$ & digestate & 0.5 & 5 \\
\hline MIN & liquid mineral ferliser & 0.5 & 5 \\
\hline $1 \mathrm{D}$ & digestate & 1 & 10 \\
\hline $\mathrm{C}$ & none & 0 & 0 \\
\hline
\end{tabular}

From August to October the plants were covered with thin textile nest in order to collect all the falling leaves. All leaves, fallen and remaining ones were collected in the end of October. In 2012 after collecting leaves half of the pots from both clones and all treatments were fixed for plant harvesting. For each plant we removed all shoots with sharp scissors near the surface of initial cutting and chopped the shoots for packing into paper bags. The inner vessels of the pots were emptied into a large bowl and the root system was carefully removed from the substrate. Both the root system and growth substrate were washed with standing water in order to collect the pieces of fine roots and to separate the particles of the substrate. All the paper bags with leaves, shoots, stems and fine roots were labelled with treatment and plant index and dried at $85{ }^{\circ} \mathrm{C}$ for 5 days to measure dry weight. A year later we repeated the same procedures with the remaining plants. In all cases the biomass production of the cutting was calculated as the difference between the dry weights of the harvested and planted cuttings. The latter was modelled from its weight and the moisture content of sample slices of the same clone.

For statistical analyses SAS 9.4 software package (SAS Institute Inc., Cary, NC, USA) was applied. For analysing the influence of cutting diameter, harvest year and treatment SAS GLM MANOVA procedure was used. Multiple comparison of biomass and its allocation by treatments were carried out with the Ryan-Einot-Gabriel-Welsch Multiple Range (REGWQ) test. The confidence level of all analyses was set at $95 \%$.

3

Results

From the methodological aspect it was crucial to understand the relations between the cutting diameter and its biomass production. Application of multivariate analysis MANOVA did not reveal any significance of cutting diameter on its biomass production either at the end of the first or second growing season (Fig 1). Hence we were able to analyse the impact of other experiment factors on biomass production without any restrictions or normalisation of collected data.

The average biomass of studied plants varied significantly by experiment years and treatments. The factor "clone" was not significant in the general MANOVA model and hence we amalgamated the data of both clones for further analysis. As expected, the biomass of both roots and shoots increased significantly during the second growing year. 
The biomass of leaves, however, was not different in one-year-old and two-year-old plants.

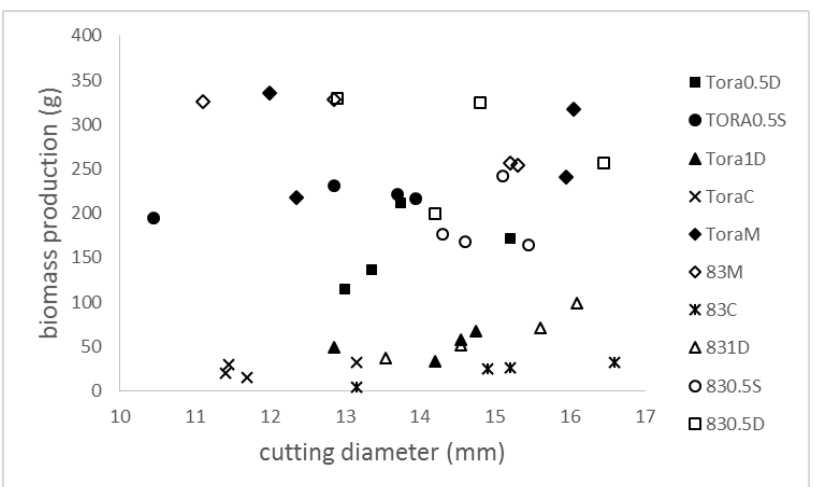

Figure 1. Relations between original diameter of the cutting and its biomass production at the end of the second growing period. Various clones and treatments are labelled with miscellaneous symbols.

Different treatments had a severe impact on biomass growth. Plants that periodically received liquid mineral fertiliser performed the largest biomass production in both years. Both slurry and digestate application also increased the production significantly compared to the control plants, during the second experiment year the impact of these two organic fertilisers was not significantly different from each other anymore (Table 2 ).

Table 2. Differences between treatments in the biomass production of various willow parts by years according to SAS GLM REGWQ test

\begin{tabular}{|c|c|c|c|c|c|c|c|c|}
\hline \multirow{2}{*}{ treatment } & \multicolumn{2}{|c|}{ roots } & \multicolumn{2}{c|}{ shoots } & \multicolumn{2}{c|}{ leaves } & \multicolumn{2}{c|}{ total biomass } \\
\cline { 2 - 9 } & 2012 & 2013 & 2012 & 2013 & 2012 & 2013 & 2012 & 2013 \\
\hline M & A & A & A & A & A & A & A & A \\
\hline O.5D & B & A & B & B & B & B & B & B \\
\hline 0.5S & B & A & C & C & C & B & C & B \\
\hline C & C & B & D & E & D & C & D & C \\
\hline D & C & B & D & D & D & B & D & C \\
\hline
\end{tabular}

Larger dosage of digestate did not promote plants growth further and the production of these plants remained similar to the control plants, the allocation of photosynthesis products to different plant parts was drastically different between these two groups. The control plants invested more material to their roots and the plants that received large amounts of digestate had the biggest ratio of biomass in their aboveground parts (Fig. 2). 
$10^{\mathrm{TH}}$ International CONFERENCE on Sustainable EnERgy and EnVIRONMENTAL Protection (June $27^{\mathrm{TH}}-30^{\mathrm{TH}}, 2017$, BLED, SLOVENIA), BioENERGY AND Biofuels

K. Heinsoo \& K. Tali: Can Various Bioenergy Technologies Add Value to Each Other?

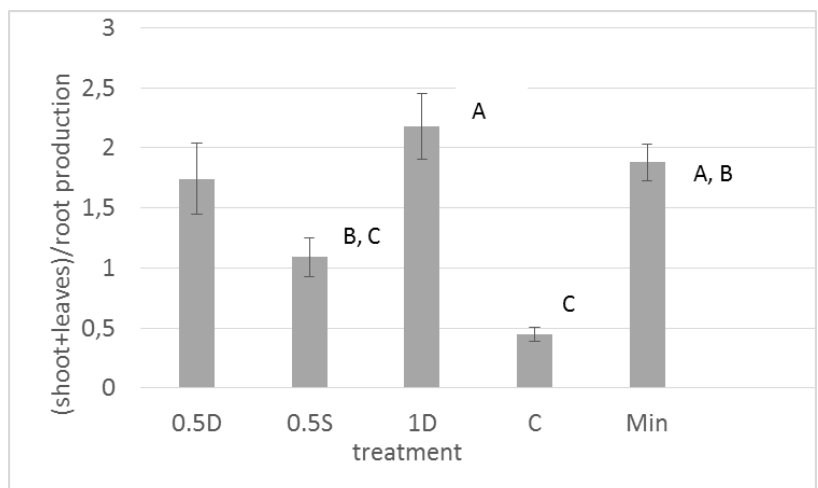

Figure 2. The ratio between above- and belowground biomass production of plants with various fertilisation treatments at the end of the second growing period

4

Discussion

Application of different fertilisers to one or two-years-old willow plants revealed that all applied chemicals can be used as additional sources of nutrients for the plants. The predicted optimal load of $5 \mathrm{~g}$ of nitrogen per plant per year is reasonable for young plants. However, this value cannot be extrapolated for the mature SRC where at least twice as much $\mathrm{N}$ can be used with positive impact on the wood yield [7]. In our previous experiment larger amounts of digestate have caused dieback of young plants during winter.

With the other analysis in our study we revealed that in the range of $11 \ldots .16 \mathrm{~mm}$ the cutting growth potential was similar and there was no need for data normalisation to further statistics. It has been demonstrated that the cutting diameter can be a significant predictor of the plant production and therefore equal-size cuttings usage is suggested to avoid competition and dieback of smaller plants in the SRC with high plant density [8]. It is not clear if such differences in results are caused by different cutting diameter ranges or by longer growing period of the plants in the current experiment. Therefore further dedicated analyses are required.

We did not detect any significant differences in the total biomass production by clones. It was an unexpected result as clone "Tora" is specially bred for bioenergy purposes and demonstrated higher wood yield compared with clone "83" at SRC level [9]. It is not clear if such a result was caused by smaller number of studied plants in our experiment or can be explained by the unlimited water and nutrient availability that hindered the natural differences in the physiological processes in studied willow clones.

Our main hypothesis proved correct and the studied organic fertilisers showed positive impact on willow growth. Both slurry and digestate application increased significantly the biomass production of all studied parts of the plants. It remains disputable if nutrients from the digestate were better available for the plants than that from slurry, as the 
differences in biomass production in the first year were not confirmed by the second year data. The latter was similar with the results from our previous study, where also no significant differences on biomass yield between these two potential fertilisers were found [10] and do not confirm the assumption about digestate benefits compared with slurry application [11] Informed preference of one or other fertiliser should incorporate also information about the impact of fertiliser on the soil microorganisms community.

Comparison of the studied organic nutrient resources with the mineral fertilisers is always a disputable issue. In our previous experiment, where we used solid mineral fertiliser with the similar N/P/K ratio with digestate, we demonstrated that both slurry and digestate application promoted biomass growth compared to mineral fertiliser. In the current experiment the liquid fertiliser promoted production significantly compared with slurry or digestate with the same amount of N. Most likely this was caused by the fact that in this specific liquid fertilizer for houseplants the micronutrients and $\mathrm{N}$ were in forms that were taken up by the plants easier than the common agricultural fertilisers. Therefore we prefer to mix mineral fertilisers commonly used in agriculture for a reasonable $\mathrm{N}, \mathrm{P}$ and $\mathrm{K}$ load for fertiliser comparison studies in the future. The plants that received overloads of digestate in our experiment had similar total biomass production with the control plants that were growing on the nutrient-poor gravel only. However, the allocation of biomass to different parts of the plant was totally different. During the first year of the experiment the shoot and leaf production of $1 \mathrm{D}$ and $\mathrm{C}$ plants was similar, but a year later more resources were allocated to these plant parts by $1 \mathrm{D}$ plants. Hence the ratio between the above- and belowground parts of 1D was even higher than that of MIN plants even if the reasons for such pattern were totally different. Most probably MIN plants preferred to allocate their biomass to aboveground parts as light capture was more growth limiting than minerals. Poor total growth but high aboveground biomass ratio of $1 \mathrm{D}$ plants indicate unfavourable root growth conditions due to changes in $\mathrm{pH}$ or microorganism community and/or any overloaded chemical element in the experiment.

To conclude we state that:

- Biogas digestate is a reasonable fertiliser in SRC, its application increases biomass production of willows

- The impact of digestate application is similar to that of slurry but may be smaller than that of liquid mineral fertilisers

- Without water or nutrient limitation the growth potential of different clones is similar

- $\quad 5 \mathrm{~g}$ of $\mathrm{N}$ per willow plant is reasonable nutrient application without damaging the root system. 


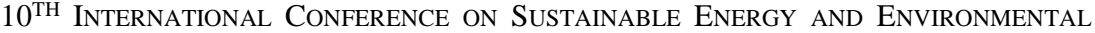
Protection (June $27^{\mathrm{TH}}-30^{\mathrm{TH}}, 2017$, Bled, Slovenia), BioENERGY AND Biofuels

K. Heinsoo \& K. Tali: Can Various Bioenergy Technologies Add Value to Each Other?

\section{Acknowledgements}

The financial support to the experiment was provided by Estonian Science Foundation (grant ETF9375). The study and conference participation were supported by Estonian Ministry of Education and Science (IUT 21-1 and PUT1463).

\section{References}

[1] A. Karp and. I. Shield, "Bioenergy from plants and the sustainable yield challenge," New Phytologist, vol. 179, pp. 15-32, Jan. 2008.

[2] H. Rosenqvist and M. Dawson, "Economics of using wastewater irrigation of willow in Northern Ireland," Biomass and Bioenergy, vol. 29, pp. 83-92, Feb. 2005.

[3] T. Rehl and J. Müller, "Life cycle assessment of biogas digestate processing technologies," Resources, Conservation and Recycling, vol. 56, pp. 92-104., Jan. 2011.

[4] A. Gunnarsson, B. Linden, U. Gertsson, A. A. F. Gunnarsson, B. Linden and U. Gertsson, "Biodigestion of Plant Material Can Improve Nitrogen Use Efficiency in a Red Beet Crop Sequence," Hortscience, vol. 46, pp. 765-775, May, 2011.

[5] K. Möller and T. Müller, "Effects of anaerobic digestion on digestate nutrient availability and crop growth: A review," Engineering in Life Sciences, vol. 12, pp. 242-257, March, 2012.

[6] P. Frost and S. Gilkinson, "27 months performance summary for anaerobic digestion of dairy cow slorry at AFBI Hillsborough," Hillsborough: AFBI, 2011.

[7] K. Heinsoo, E. Sild and A. Koppel, "Estimation of shoot biomass productivity in Estonian Salix plantations," Forest Ecology and Management, vol. 170, pp. 67-74, 2002.

[8] T. Verwijst, A. Lundkvist, S. Edelfeldt, J. Forkman and N.-E. Nordh, "Effects of clone and cutting traits on shoot emergence and early growth of willow," Biomass Bioenergy, vol. 37, pp. 257-264. 2012.

[9] K. Aasamaa, K. Heinsoo and B. Holm, "Biomass production, water use and photosynthesis of Salix clones grown in a wastewater purification system," Biomass and Bioenergy, vol. 34. pp. 897-905., June, 2010.

[10] B. Holm and K. Heinsoo, "Biogas digestate sustainability for the fertilisation of young Salix plants,” Baltic Forestry, vol. 20, pp. 263-271, Feb. 2014.

[11] G. Kocar, "Anaerobic digesters: From waste to energy crops as an alternative energy source," Energy Sources, Part A: Recovery, Utilization and Environmental Effects, vol. 30, pp. 660-669, July 2008. 
$10^{\mathrm{TH}}$ InTERnational CONFEREnCE ON Sustainable ENERgy AND ENVIRONMENTAL Protection (June $27^{\mathrm{TH}}-30^{\mathrm{TH}}$, 2017, Bled, SLOVENIA), BIOENERGY AND BIOFUELS

J. Krope, A.Ghani Olabi, D. Goričanec \& S. Božičnik

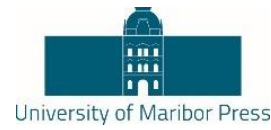

\title{
Operational Experience of Biomass Combustion Using Chemical Looping Processes
}

\author{
Francisco García-Labiano, Alberto Abad, Teresa Mendiara, María Teresa \\ IZQUIERDO, PILAR GAYÁN, LUIS FRANCISCO DE DIEGO \& JUAN ADÁNEZ
}

\begin{abstract}
The Paris Agreement proposed the reduction of $\mathrm{CO} 2$ emissions this century in order to limit the increase in the global average temperature to $2{ }^{\circ} \mathrm{C}$ or below. To achieve this objective, bio-energy with carbon capture and storage (BECCS) technologies represent an interesting option because they are able to achieve even negative $\mathrm{CO} 2$ emissions. Chemical looping (CL) is recognized as one of the most innovative of $\mathrm{CO} 2$ capture technologies because of its low energy penalty. CL processes allow combustion/gasification of renewable solid fuels in a nitrogen-free atmosphere because the oxygen is supplied by solid oxygen carriers. Therefore, CL includes both combustion for heat/electricity production and syngas/H2 generation. $\mathrm{CO} 2$ capture is possible in both cases. The present work presents an overview of the main results obtained at the Instituto de Carboquímica (ICB-CSIC) with the use of biomass in CL processes. This includes tests in a 1.5-kW CLC unit, different oxygen carriers and biomass types.
\end{abstract}

Keywords: $\bullet \mathrm{CO}_{2}$ capture $\cdot \mathrm{BECCS} \cdot$ Chemical looping combustion • Chemical looping gasification • Biomass •

Correspondence AdDress: Francisco García-Labiano, Ph.D., Tenured Scientist, Instituto de Carboquímica (ICB-CSIC), Miguel Luesma Castán 4, 50018 Zaragoza, Spain, e-mail: glabiano@icb.csic.es. Alberto Abad, Ph.D., Tenured Scientist, Instituto de Carboquímica (ICBCSIC), Miguel Luesma Castán 4, 50018 Zaragoza, Spain, e-mail: abad@icb.csic.es. Teresa Mendiara, Ph.D., "Ramón y Cajal" Postdoctoral Researcher, Instituto de Carboquímica (ICBCSIC), Miguel Luesma Castán 4, 50018 Zaragoza, Spain, e-mail: tmendiara@icb.csic.es. María Teresa Izquierdo, Ph.D., Tenured Scientist, Instituto de Carboquímica (ICB-CSIC), Miguel Luesma Castán 4, 50018 Zaragoza, Spain, e-mail: mizq@icb.csic.es. Pilar Gayán, Ph.D., Tenured Scientist, Instituto de Carboquímica (ICB-CSIC), Miguel Luesma Castán 4, 50018 Zaragoza, Spain, e-mail: pgayan @icb.csic.es. Luis Francisco de Diego, Ph.D., Tenured Scientist, Instituto de Carboquímica (ICB-CSIC), Miguel Luesma Castán 4, 50018 Zaragoza, Spain, e-mail: ldediego@icb.csic.es. Juan Adánez, Ph.D., Research Professor, Instituto de Carboquímica (ICBCSIC), Miguel Luesma Castán 4, 50018 Zaragoza, Spain, e-mail: jadanez@icb.csic.es.

https://doi.org/10.18690/978-961-286-048-6.29

ISBN 978-961-286-048-6

(C) 2017 University of Maribor Press

Available at: http://press.um.si. 
$10^{\text {Th }}$ International Conference on Sustainable Energy and Environmental Protection (June $27^{\mathrm{TH}}-30^{\mathrm{TH}}, 2017$, BLed, Slovenia), Bioenergy AND Biofuels F. García-Labiano, A. Abad, T. Mendiara, M. Teresa Izquierdo, P. Gayán, L. Francisco de Diego \& J. Adánez: Operational Experience of Biomass Combustion Using Chemical Looping Processes

\section{$1 \quad$ Introduction}

At the Paris Climate Conference (COP21) held in December 2015, 195 countries adopted the first-ever universal, legally binding global climate deal. The agreement set out a global action plan to hold the increase in global average temperature to well below $2{ }^{\circ} \mathrm{C}$ over pre-industrial levels and pursues efforts to limit the temperature increase to $1.5^{\circ} \mathrm{C}$.

According to the IPCC predictions, in order to meet that objective, $\mathrm{CO}_{2}$ emissions should start to decrease by 2020 and be negative by the end of the century [1]. Among the different options available with which to meet this goal, most low-carbon scenarios rely on the use of bio-energy with carbon capture and storage (BECCS) [2].

For this purpose, the use of renewable fuels is needed, and biomass is one of the preferred options. Biomass is a $\mathrm{CO}_{2}$-neutral fuel, i.e. the carbon dioxide released during biomass combustion has been previously removed from the atmosphere during biomass growth. Therefore, negative emissions are achieved if the $\mathrm{CO}_{2}$ captured is safely stored [3-5].

$\mathrm{CO}_{2}$ capture technologies have been intensively developed over the last 20 years, currently reaching the status of technical readiness level (TRL) 6, with scale-up likely in the short-medium term [6, 7]. All these technologies are intended to produce a concentrated $\mathrm{CO}_{2}$ stream during the fuel combustion process, which can be captured and safely sequestrated, and therefore preventing $\mathrm{CO}_{2}$ emission into the atmosphere. In this sense, chemical looping combustion (CLC) is one of the most promising technologies for $\mathrm{CO}_{2}$ capture considering both economic and energy aspects [8]. Figure 1 shows a scheme of the CLC process.

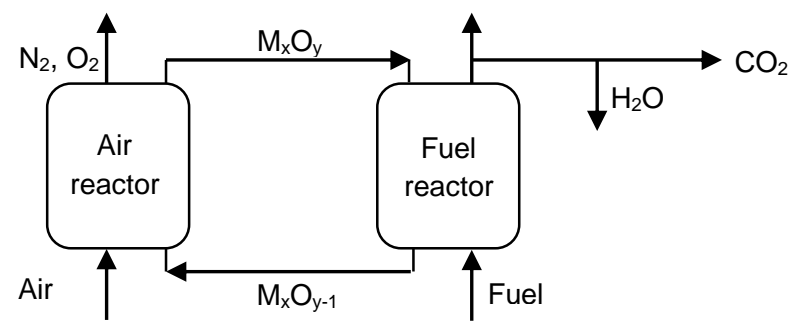

Figure 1. Scheme of the chemical looping process. 
$10^{\text {TH }}$ INTERNATIONAL CONFERENCE ON SUSTAINABLE ENERGY AND ENVIRONMENTAL

Protection (June $27^{\mathrm{TH}}-30^{\mathrm{TH}}, 2017$, BLED, Slovenia), Bioenergy AND Biofuels

F. García-Labiano, A. Abad, T. Mendiara, M. Teresa Izquierdo, P. Gayán, L. Francisco de Diego \& J. Adánez: Operational Experience of Biomass Combustion Using

Chemical Looping Processes

Table 1. Summary of processes involving biomass and chemical looping.

\begin{tabular}{|c|c|c|c|c|}
\hline Aim & & Process & $\mathrm{CO}_{2}$ capture & Main features \\
\hline \multirow{4}{*}{ 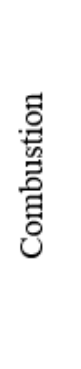 } & $\begin{array}{l}\text { Ex- } \\
\text { situ }\end{array}$ & $\begin{array}{l}\text { Syngas- } \\
\text { CLC }\end{array}$ & Inherent & $\begin{array}{l}\text { - Previous gasification of solid fuel } \\
\text { - Oxygen requirement for gasification }\end{array}$ \\
\hline & In-situ & iG-CLC & Inherent & $\begin{array}{l}\text { - Gasification of the solid fuel inside the fuel reactor } \\
\text { - Low cost oxygen carriers are desirable }\end{array}$ \\
\hline & In-situ & CLOU & Inherent & $\begin{array}{l}\text { - Use of oxygen carriers with gaseous } \mathrm{O}_{2} \text { release properties } \\
\text { - Rapid conversion of the solid fuel }\end{array}$ \\
\hline & In-situ & OCAC & $\begin{array}{l}\text { Post- } \\
\text { combustion }\end{array}$ & $\begin{array}{l}\text { - Redox cycles at different locations inside the boiler } \\
\text { - Low cost oxygen carriers } \\
\text { - Test of oxygen carrier behaviour at high scale }\end{array}$ \\
\hline \multirow{2}{*}{ 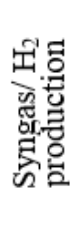 } & $\begin{array}{l}\text { Ex- } \\
\text { situ }\end{array}$ & $\begin{array}{l}\text { Syngas- } \\
\text { CLR }\end{array}$ & $\begin{array}{l}\text { Pre- } \\
\text { combustion }\end{array}$ & $\begin{array}{l}\text { - Previous gasification of solid fuel with } \mathrm{O}_{2} \\
\text { - Oxygen carriers with catalytic activity are desirable }\end{array}$ \\
\hline & In-situ & CLG & $\begin{array}{l}\text { Pre- } \\
\text { combustion }\end{array}$ & $\begin{array}{l}\text { - Partial oxidation of solid fuel with oxygen carriers instead } \\
\text { of gaseous } \mathrm{O}_{2} \\
\text { - Process can be fit to produce a pure } \mathrm{N}_{2} \text { stream and the } \\
\text { desired } \mathrm{CO} / \mathrm{H}_{2} \text { ratio }\end{array}$ \\
\hline
\end{tabular}

In this technology, the oxygen needed for combustion is supplied by a solid oxygen carrier, normally a metal oxide $\left(\mathrm{M}_{\mathrm{x}} \mathrm{O}_{\mathrm{y}}\right)$. The oxygen carrier is reduced inside the fuel reactor while the solid fuel is burnt to $\mathrm{CO}_{2}$ and $\mathrm{H}_{2} \mathrm{O} . \mathrm{H}_{2} \mathrm{O}$ condensation produces an almost pure $\mathrm{CO}_{2}$ stream. The reduced oxygen carrier is regenerated in the air reactor by taking oxygen from air.

One of the main advantages of chemical looping (CL) technology is its great versatility by allowing a large degree of combination between fuels (gaseous, liquid and solids), processes (combustion, reforming, etc.) and final products (heat, electricity, syngas or $\mathrm{H}_{2}$ ) [9]. All these options include the possibility of $\mathrm{CO}_{2}$ capture.

Table 1 provides a summary of the chemical looping processes involving the use of biomass. The main division is produced between processes generating heat/electricity by combustion and those intended for $\mathrm{H}_{2}$ /syngas production. Considering the experience gained in CL processes using gaseous fuels, there is a possibility to transform the biomass into a syngas by means of prior gasification/pyrolysis, and to use it for combustion (syngas-CLC) or reforming (syngas-CLR). However, these ex-situ processes require a previous step with pure $\mathrm{O}_{2}$ or $\mathrm{N}_{2}$ that would increase their cost.

Among in-situ processes for biomass combustion are in-situ gasification integrated with chemical looping combustion (iG-CLC), where biomass is gasified inside the reactor and the gaseous products react with the oxygen carrier, and chemical looping with oxygen uncoupling (CLOU), where biomass reacts with the gaseous oxygen released by the oxygen carrier. CL technology with solid fuels, mainly coal, has benefited from great 
$296 \quad 10^{\text {TH }}$ INTERNATIONAL CONFERENCE ON SUSTAINABLE ENERGY AND ENVIRONMENTAL Protection (June $27^{\mathrm{TH}}-30^{\mathrm{TH}}, 2017$, BLed, Slovenia), Bioenergy AND Biofuels

F. García-Labiano, A. Abad, T. Mendiara, M. Teresa Izquierdo, P. Gayán, L. Francisco de Diego \& J. Adánez: Operational Experience of Biomass Combustion Using Chemical Looping Processes

advances in the last 10 years with pilot plants ranging from $10 \mathrm{~kW}$ to $3 \mathrm{MW}$ [10]. However, the the process is not currently expected to be scaled up in the short term. In the meantime, it is necessary to continue with the testing and evaluation of oxygen carriers, with particular regard given to the evaluation of lifetime at large scale, in the MW range. In this sense, the oxygen carrier aided combustion (OCAC) process uses oxygen carriers in existing boilers and the redox cycles take place at different locations within the fluidized bed [11].

Among in-situ processes for $\mathrm{H}_{2}$ production is chemical looping gasification (CLG), where biomass is partially oxidized with the oxygen carrier to produce syngas [12].

All the above processes involving the use of biomass include the possibility to capture the $\mathrm{CO}_{2}$ produced in the process. In some cases, $\mathrm{CO}_{2}$ capture is inherent to the process, i.e. an almost pure $\mathrm{CO}_{2}$ stream is obtained. In other cases, a separation step is required, using chemical or physical absorbents for post- or pre-combustion capture systems. When the possibility of $\mathrm{CO}_{2}$ storage is considered, the use of biomass or other renewable solid fuels in the above processes would lead to the achievement of negative emissions [3-5].

The objective of this work is to summarize the research conducted by the Instituto de Carboquímica (ICB-CSIC) on the use of biomass in combustion processes, mainly under iG-CLC and CLOU modes. The use of the same types of biomass in the same CLC unit enabled the comparison of both operating modes to be made. CLC performance was evaluated considering relevant parameters such as $\mathrm{CO}_{2}$ capture efficiency and combustion efficiency.

\section{Experimental}

For this work we selected two promising oxygen carriers for the iG-CLC and CLOU processes. An iron ore from a haematite mine in Tierga, Spain, was used for the iG-CLC tests. After calcination, it contained about $76 \% \mathrm{Fe}_{2} \mathrm{O}_{3}$, with $\mathrm{SiO}_{2}, \mathrm{Al}_{2} \mathrm{O}_{3}, \mathrm{CaO}$ and $\mathrm{MgO}$ as impurities. The preparation and characterization of the material can be found elsewhere [13]. In contrast, a synthetic $\mathrm{Cu}$-based material prepared by spray drying and containing $60 \% \mathrm{CuO}$ supported on $\mathrm{MgAl}_{2} \mathrm{O}_{4}$ was selected for combustion in CLOU mode. Its properties has been described elsewhere [14]. This material is known as Cu60MgAl.

Three biomass residues produced in Spain were selected as renewable fuels. One forest residue, pine (Pinus sylvestris) sawdust, was chosen as a reference material. Olive (Olea europaea) stones and almond (Prunus dulcis) shells were selected as they are agricultural residues with high annual production. 
$10^{\mathrm{TH}}$ INTERNATIONAL CONFERENCE ON SUSTAINABLE ENERGY AND ENVIRONMENTAL

Protection (June $27^{\mathrm{TH}}-30^{\mathrm{TH}}, 2017$, Bled, Slovenia), Bioenergy and Biofuels

F. García-Labiano, A. Abad, T. Mendiara, M. Teresa Izquierdo, P. Gayán, L. Francisco de Diego \& J. Adánez: Operational Experience of Biomass Combustion Using

Chemical Looping Processes

Table 1. Biomass composition.

\begin{tabular}{lccc}
\hline & Pine sawdust & Olive stones & $\begin{array}{c}\text { Almond } \\
\text { shells }\end{array}$ \\
\hline Moisture & 4.2 & 9.4 & 2.3 \\
Ash & 0.4 & 0.8 & 1.1 \\
$\mathrm{C}$ & 51.3 & 46.5 & 50.2 \\
$\mathrm{H}$ & 6.0 & 4.8 & 5.7 \\
$\mathrm{~N}$ & 0.3 & 0.2 & 0.2 \\
$\mathrm{~S}$ & 0.0 & 0.0 & 0.0 \\
$\mathrm{O}$ & 37.8 & 38.3 & 40.5 \\
$\mathrm{LHV}(\mathrm{kJ} / \mathrm{kg})$ & 19158 & 16807 & 18071 \\
\hline
\end{tabular}

Combustion experiments were performed in the ICB-CSIC-s1 unit with nominal power of $1.5 \mathrm{~kW}_{\text {th. }}$. This facility comprises two interconnected fluidized-bed reactors, a riser for solid transport, a solid valve to control the solids fed to the FR, a loop seal and a cyclone. A relevant characteristic of this design is the possibility to control the solid circulation flow rate between both reactors. A further description of this CLC prototype and the experimental procedure followed in biomass experiments is present elsewhere [15].

\section{$3 \quad$ Results}

\subsection{Experiments under iG-CLC mode}

In the experiments carried out at ICB-CSIC under iG-CLC mode, three different types of biomass were used: pine sawdust (as reference), olive stones and almond shells.

The effect of different operating variables on CLC performance was evaluated in the course of about $80 \mathrm{~h}$ of combustion with biomass. Figure 2 shows the effect of the fuel reactor temperature on $\mathrm{CO}_{2}$ capture efficiency, $\square_{\mathrm{CC}}$, i.e. how much of the carbon introduced was captured in gaseous fuel at the fuel reactor outlet. An increase in temperature was observed to lead to an increase in $\mathrm{CO}_{2}$ capture efficiency in all cases. This was because as the temperature increased, so did the char gasification rate, therefore allowing less unburnt char to reach the air reactor, resulting in better $\mathrm{CO}_{2}$ capture efficiency values being achieved. It is also significant that it was possible to reach $100 \%$ $\mathrm{CO}_{2}$ capture efficiency at about $950{ }^{\circ} \mathrm{C}$ for all the biomass types tested. Even more significant is the fact that no carbon stripper was available between the fuel and air reactors in these experiments. 
$10^{\text {Th }}$ International Conference on Sustainable Energy and Environmental Protection (June $27^{\mathrm{TH}}-30^{\mathrm{TH}}, 2017$, Bled, Slovenia), Bioenergy AND Biofuels F. García-Labiano, A. Abad, T. Mendiara, M. Teresa Izquierdo, P. Gayán, L. Francisco de Diego \& J. Adánez: Operational Experience of Biomass Combustion Using Chemical Looping Processes

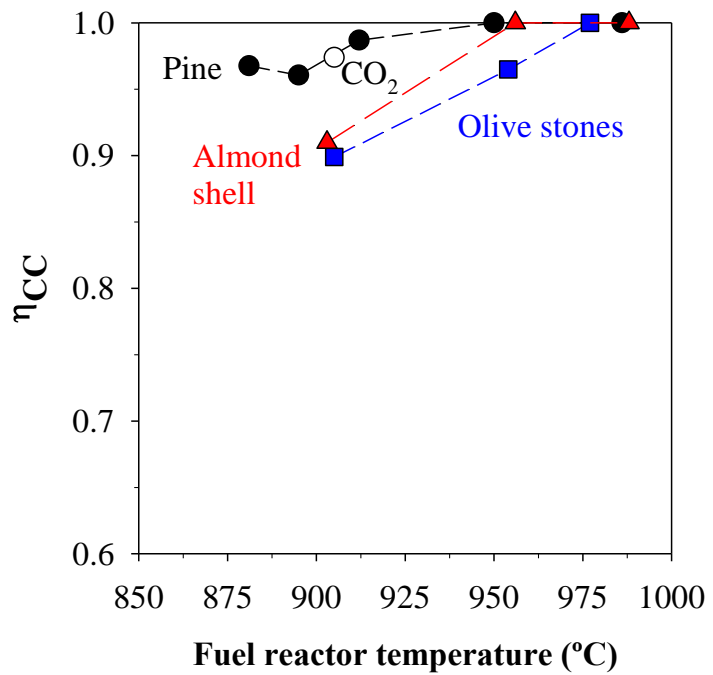

Figure 2. Effect of fuel reactor temperature on $\mathrm{CO}_{2}$ capture efficiency for different biomass types using steam or $\mathrm{CO}_{2}$ as gasifying agents (iG-CLC mode).

This type of carbon separation system allows unburnt char leaving the fuel reactor to be returned to it for further conversion, and is usually required when coal is used as the fuel, in order to reach high $\mathrm{CO}_{2}$ capture efficiencies. The results shown in Figure 2 indicate that the carbon stripper is not as necessary in the case of biomass as it is in the case of coal, a consequence of the lower amount of char produced during biomass processing and its higher reactivity.

In order to analyse the behaviour of the three biomass types in the iG-CLC process, combustion efficiency in the fuel reactor, $\square$ comb,FR, was also considered, see Figure 3. This parameter is a measure of the gas conversion obtained in the fuel reactor.

At temperatures higher than $900{ }^{\circ} \mathrm{C}$, combustion efficiency values did not show a clear trend. They were about $70 \%$ for all the biomass types evaluated. In the case of pine sawdust, higher values were obtained at lower temperatures. However, it should be noted that those values were obtained with the use of higher specific solids inventories in the fuel reactor than for the rest of the results presented. A higher amount of solids represent higher oxygen availability, which would favour higher combustion efficiencies.

The effect of the fluidizing/gasifying agent was also assessed in experiments with pine sawdust. 


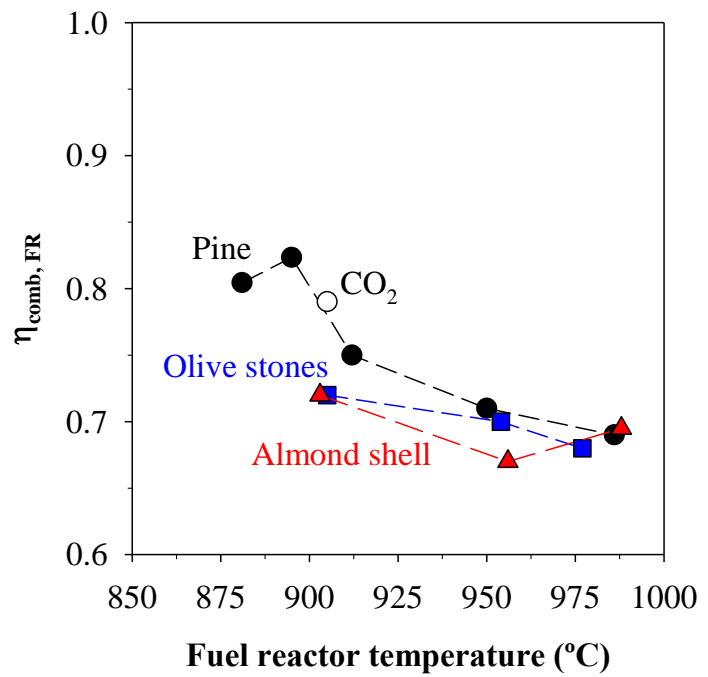

Figure 3. Effect of fuel reactor temperature on the combustion efficiency in the fuel reactor for different biomass types using steam or $\mathrm{CO}_{2}$ as gasifying agents (iG-CLC mode).

Figures 2 and 3 both show that $\mathrm{CO}_{2}$ capture and combustion efficiency values did not change significantly at $900{ }^{\circ} \mathrm{C}$ when the steam was replaced by $\mathrm{CO}_{2}$ as the gasifying agent. According to these results, we conclude that it would be possible to use recirculated $\mathrm{CO}_{2}$ as the gasifying agent in the iG-CLC process with energy savings corresponding to steam generation.

Another important aspect to be considered during biomass utilization under iG-CLC mode was the possible formation of tar from biomass gasification. In this work, tar at the outlet of the fuel reactor was measured and quantified. The tar concentration measured at $950{ }^{\circ} \mathrm{C}$ varied between 3 and $4.3 \mathrm{~g} / \mathrm{Nm}^{3}$. As an example, Figure 4 shows the composition obtained at $950^{\circ} \mathrm{C}$. As can be seen, the major compound was naphthalene, followed by acenaphthylene and phenanthrene. These compounds accounted for $\approx 80 \%$ of all the tar mass measured. Despite this high value, no fouling problems at the fuel reactor outlet can be expected since these compounds will be burnt in the oxygen polishing step after the fuel reactor. Calculations showed that their contribution to the final oxygen demand in this polishing step would be about 1 percentage point. 
$10^{\mathrm{TH}}$ InTERNATIONAL CONFERENCE ON Sustainable ENERGY AND ENVIRONMENTAL Protection (June $27^{\mathrm{TH}}-30^{\mathrm{TH}}, 2017$, Bled, Slovenia), Bioenergy AND Biofuels

F. García-Labiano, A. Abad, T. Mendiara, M. Teresa Izquierdo, P. Gayán, L. Francisco de Diego \& J. Adánez: Operational Experience of Biomass Combustion Using Chemical Looping Processes

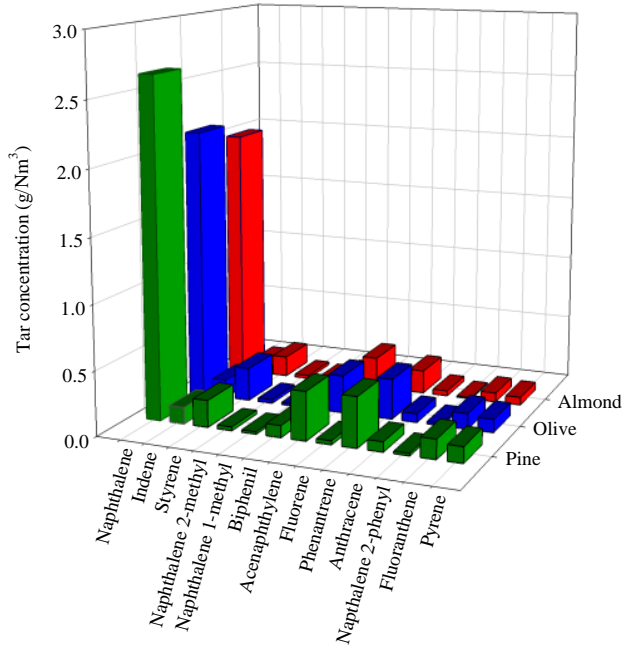

Figure 4. Tar composition at the fuel reactor outlet for different biomasses at $950{ }^{\circ} \mathrm{C}$ (iG-CLC mode).

Finally, the effect of biomass ashes on the iron ore oxygen carrier used in iG-CLC experiments was studied [15]. No interaction between biomass ashes and the oxygen carrier was observed using SEM-EDX on an oxygen carrier sample extracted from the continuous unit after operation.

\subsection{Experiments under CLOU mode}

The first experiments under CLOU mode burning biomass were performed at ICB-CSIC using pine sawdust as fuel [14]. These experiments constituted the proof of concept of CLOU technology with biomass. These tests, evaluated the effect of the fuel reactor temperature on $\mathrm{CO}_{2}$ capture and combustion efficiencies. Figure 5 shows the results obtained. Worthy of note is the high $\mathrm{CO}_{2}$ capture efficiency achieved, with $\square$ cC values above $97 \%$ even at temperatures as low as $900^{\circ} \mathrm{C}$. It should be remembered that this CLC unit did not include a carbon stripper. This degree of efficiency was a consequence of the combination of good combustion made possible by the oxygen released inside the fuel reactor and the high reactivity of the biomass char.

In addition, $100 \%$ combustion efficiency in the fuel reactor, $\square$ comb,FR, was obtained in the temperature range $900-935^{\circ} \mathrm{C}$. These results represent a clear advantage over those obtained under iG-CLC mode, and is attributed to the more efficient combustion induced by the gaseous oxygen released from the oxygen carrier. In line with these results, no tars were detected at the fuel reactor outlet. 


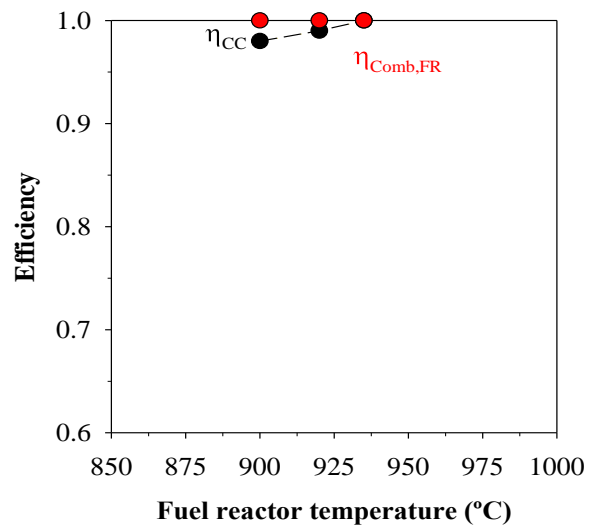

Figure 5. Effect of fuel reactor temperature on $\mathrm{CO}_{2}$ capture and combustion efficiencies in the fuel reactor for pine sawdust (CLOU mode).

\section{$4 \quad$ Conclusions}

Biomass combustion experiments were performed in a $1.5-\mathrm{kW}_{\text {th }}$ CLC unit operating under both iG-CLC and CLOU modes.

Considering the results obtained with the reference biomass (pine), the CLOU process presents relevant advantages in comparison to iG-CLC, mainly owing to the absence of unburnt products by an improved combustion mechanism inside the fuel reactor. In contrast, the oxygen carrier used in the iG-CLC mode is cheaper and more readily available than the synthetic CLOU oxygen carrier.

In any case, high $\mathrm{CO}_{2}$ capture efficiency, even $100 \%$, can be achieved in both combustion modes. This demonstrated that both CLC processes using biomass as fuel (bio-CLC) represent a promising BECCS technology option to achieve negative emissions.

\section{Acknowledgements}

The authors thank the Spanish Ministry of Economy and Competitiveness (MINECO project ENE2014-56857-R) and the European Regional Development Fund (ERDF) for their financial support. T. Mendiara is grateful for the "Ramón y Cajal" post-doctoral contract awarded by the Spanish Ministry of Economy and Competitiveness.

\section{References}

[1] IPCC, "Climate Change 2014: Synthesis Report. Contribution of Working Groups I, II and III to the Fifth Assessment Report of the Intergovernmental Panel on Climate Change," Geneva (Switzerland).2014. 
$10^{\mathrm{TH}}$ International CONFerence on Sustainable EnERgy and EnVIRONMENTAL Protection (June $27^{\mathrm{TH}}-30^{\mathrm{TH}}, 2017$, Bled, Slovenia), Bioenergy AND Biofuels F. García-Labiano, A. Abad, T. Mendiara, M. Teresa Izquierdo, P. Gayán, L. Francisco de Diego \& J. Adánez: Operational Experience of Biomass Combustion Using Chemical Looping Processes

[2] T. Gasser, C. Guivarch, K. Tachiiri, C. D. Jones, and P. Ciais, "Negative emissions physically needed to keep global warming below $2{ }^{\circ} \mathrm{C}$," Nature Communications, vol. 6 , 2015.

[3] S. Fuss, J. G. Canadell, G. P. Peters, M. Tavoni, R. M. Andrew, P. Ciais, et al., "Betting on negative emissions," Nature Climate Change, vol. 4, pp. 850-853, 2014.

[4] F. Creutzig, N. H. Ravindranath, G. Berndes, S. Bolwig, R. Bright, F. Cherubini, et al., "Bioenergy and climate change mitigation: An assessment," GCB Bioenergy, vol. 7, pp. 916-944, 2015.

[5] K. Tokimatsu, R. Yasuoka, and M. Nishio, "Global zero emissions scenarios: The role of biomass energy with carbon capture and storage by forested land use," Applied Energy, vol. 185, pp. 1899-1906, 2017.

[6] J. C. Abanades, B. Arias, A. Lyngfelt, T. Mattisson, D. E. Wiley, H. Li, et al., "Emerging $\mathrm{CO}_{2}$ capture systems," International Journal of Greenhouse Gas Control, 2015.

[7] L. S. Fan, Chemical Looping Systems for Fossil Energy Conversion: John Wiley \& Sons, 2010.

[8] H. R. Kerr, "Capture and separation technology gaps and priority research needs," in Carbon dioxide capture for storage in deep geologic formationse results from the $\mathrm{CO}_{2}$ capture project. vol. 1, D. C. Thomas and S. M. Benson, Eds., ed Oxford, UK: Elsevier, 2005.

[9] J. Adanez, A. Abad, F. Garcia-Labiano, P. Gayan, and L. F. De Diego, "Progress in chemical-looping combustion and reforming technologies," Progress in Energy and Combustion Science, vol. 38, pp. 215-282, 2012.

[10] A. Lyngfelt, "Chemical-looping combustion of solid fuels - Status of development," Applied Energy, vol. 113, pp. 1869-1873, 2014.

[11] M. Rydén, M. Hanning, A. Corcoran, and F. Lind, "Oxygen Carrier Aided Combustion (OCAC) of Wood Chips in a Semi-Commercial Circulating Fluidized Bed Boiler Using Manganese Ore as Bed Material," Applied Science vol. 6, p. 347, 2016.

[12] S. Huseyin, G. Q. Wei, H. B. Li, F. He, and Z. Huang, "Chemical-looping gasification of biomass in a $10 \mathrm{~kW}$ th interconnected fluidized bed reactor using $\mathrm{Fe}_{2} \mathrm{O}_{3} / \mathrm{Al}_{2} \mathrm{O}_{3}$ oxygen carrier," Ranliao Huaxue Xuebao/Journal of Fuel Chemistry and Technology, vol. 42, pp. 922-931, 2014.

[13] T. Mendiara, L. F. De Diego, F. García-Labiano, P. Gayán, A. Abad, and J. Adánez, "On the use of a highly reactive iron ore in Chemical Looping Combustion of different coals," Fuel, vol. 126, pp. 239-249, 2014.

[14] I. Adánez-Rubio, A. Abad, P. Gayán, L. F. De Diego, F. García-Labiano, and J. Adánez, "Biomass combustion with $\mathrm{CO}_{2}$ capture by chemical looping with oxygen uncoupling (CLOU)," Fuel Processing Technology, vol. 124, pp. 104-114, 2014.

[15] T. Mendiara, A. Abad, L. F. de Diego, F. García-Labiano, P. Gayán, and J. Adánez, "Biomass combustion in a CLC system using an iron ore as an oxygen carrier," International Journal of Greenhouse Gas Control, vol. 19, pp. 322-330, 2013. 
$10^{\mathrm{TH}}$ InTERnational CONFEREnCE ON Sustainable ENERgy AND ENVIRONMENTAL Protection (June $27^{\mathrm{TH}}-30^{\mathrm{TH}}$, 2017, Bled, SLOVENIA), BIOENERGY AND BIOFUELS

J. Krope, A.Ghani Olabi, D. Goričanec \& S. Božičnik

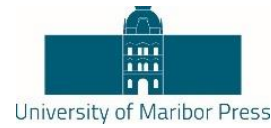

\title{
Comparison on Compositions of Bio-Oil Derived from Mulberry Bark Hydrothermal Liquefaction in Sub/Critical-Water and Ethanol-Water Co-Solvents
}

\author{
Conguin Chen, JingXian Zhu, ShuAng JiA, Zhangfa Tong, ZhiXia Li \& Mingfei Li
}

\begin{abstract}
The bio-oil was derived from mulberry bark catalytic hydrothermal liquefaction in sub/critical- ethanol-water co-solvents(S/C$\mathrm{E}-\mathrm{W}$ ) and sub/critical-water(S/C-W), the compositions of bio-oil were analyzed by GC-MS analysis methods. The results shows that: The liquefaction conversion rate in S/C-E-W and S/C-W were $95.72 \%$ and $87.5 \%$, the yield of the heavy oil(HO) were $26.16 \%$ and $26.25 \%$, and the yield of the light oil(LO) were $2.56 \%$ and $4.16 \%$. The components of biooils were complex, mainly contained phenols, aromatic, alkanes, ketone, esters, furans, olefin compounds, etc. Phenols in LO mainly are 1,2Benzenediol, 1,2-Benzenediol,3-methoxy-, Phenol,2,6-dimethoxy-, Phenol,3-methoxy-, 1,4-Benzenediol,2-methyl-, 1,3-Benzenediol,4,5dimethyl-, Phenol,3-propyl-, 1,3-Benzenediol,4-propyl-, etc, accounting for about $35 \%$ (derived in S/C-W) and 25\% (derived in S/C-E-W). Phenols in HO mainly are phenol, 2-methoxy-, phenol, 4-ethyl-2-methoxy-, phenol, 2-methoxy-4-propyl-, phenol, 2-methoxy-4-methyl-, phenol, 2,6dimethoxy-, Phenol, 3-methoxy-,etc. accounting for about $28.55 \%$ (derived in S/C-W) and $2.49 \%$ (derived in S/C-E-W).
\end{abstract}

Keywords: $\bullet$ Composition analysis $\bullet$ Hydrothermal liquefaction $\bullet$ Ethanol-water cosolvents • Bio-oil • GC-MS・

\begin{abstract}
CORRESPONDENCE ADDRESS: Congjin Chen, Guangxi Colleges and Universities Key Laboratory of New Technology and Application in Resource Chemical Engineering, School of Chemistry and Chemical Engineering, Guangxi University, Nanning 530004 China, email: zhftong@ sina.com. Jingxian Zhu, Guangxi Key Laboratory of Petrochemical Resource Processing and Process Intensification Technology, School of Chemistry and Chemical Engineering, Guangxi University, Nanning 530004 China; email:gxdxccj@163.com. chencongjin@gxu.edu.cn. Shuang Jia, Guangxi Key Laboratory of Petrochemical Resource Processing and Process Intensification Technology, School of Chemistry and Chemical Engineering, Guangxi University, Nanning 530004 China, email:gxdxccj@163.com. chencongjin@gxu.edu.cn. Zhangfa Tong, Guangxi Key Laboratory of Petrochemical Resource Processing and Process Intensification Technology, School of Chemistry and Chemical Engineering, Guangxi University, Nanning 530004 China; email:gxdxccj@163.com. chencongjin@gxu.edu.cn. Zhixia Li, Guangxi Key Laboratory of Petrochemical Resource Processing and Process Intensification Technology, School of Chemistry and Chemical Engineering, Guangxi University, Nanning 530004 China, email:gxdxccj@163.com. chencongjin@gxu.edu.cn. Mingfei Li, Beijing Key Laboratory of Lignocellulosic Chemistry, Beijing Forestry University, Beijing 100083 China; email: 280998510@qq.com.
\end{abstract}


$304 \quad 10^{\mathrm{TH}}$ InTERNATIONAL CONFERENCE ON Sustainable ENERGY AND ENVIRONMENTAL Protection (June $27^{\mathrm{TH}}-30^{\mathrm{TH}}, 2017$, BLED, Slovenia), Bioenergy AND Biofuels C. Chen, J. Zhu, S. Jia, Z. Tong, Z. Li \& M. Li: Comparison on Compositions of BioOil Derived from Mulberry Bark Hydrothermal Liquefaction in Sub/Critical-Water and Ethanol-Water Co-Solvents

Mulberry, as the groundwork of silk civilization, also called Morus alba L., belong to Moraceae, and had once been cultivated in central region of China, and now, cultivated all over China[1]. Mulberry branches are one of the by-products of mulberry planting and mulberry processing waste, mulberry branches are consisting of xylem and bark. At present, the research about mulberry branches is very limited, except for study on the related active components and activities[2-11], most mulberry branches was burn directly, the utilization efficiency was very low, mulberry branches biomass resources did not been fully utilized, and cause environmental pollution. Currently, chemicals and energy are mainly derived from fossil fuels, which are challenged by the rapidly declined reserves and fluctuating prices of crude oil, and research into alternative sources for chemical and fuel production has attracted a great deal of attention and become hot spot of current research[12]. Mulberry branches are an excellent reproducible biomass resource [1,13-18]. If mulberry branches can be converted into liquid products, not only can make up for the shortage of crude oil resources, but also further develop more chemical products.

In the present work, the mulberry bark was used as raw materials, $\mathrm{K}_{2} \mathrm{CO}_{3}$ was used as catalyst, water or ethanol-water co-solvents was used as medium to prepare bio-oil, the compositions of bio-oil were analyzed by gas chromatography-mass spectrometry (GCMS) analysis methods. The results might reveal the effect of ethanol on biomass liquefaction in solvents, while being useful to develop efficient biomass utilization processes.

\section{$2 \quad$ Material and Methods}

\subsection{Materials}

Mulberry was collected from Guangxi sericulture science research institute in the city of Nanning, located in southern China. Mulberry branches and barks was separated, airdried, crushed, screened, and the sample with particle size of $100 \sim 120$ mesh was collected, dried at $110{ }^{\circ} \mathrm{C}$ for $24 \mathrm{~h}$, kept in desiccators at room temperature. All chemicals were analytical reagent grade and used as received.

\subsection{Liquefaction procedure and the bio-oil separation}

Liquefaction procedure and the bio-oil separation was performed according to method mentioned in the literature [19], and modified a little. The mass ratio of Mulberry bark/catalyst /solvent (mass: mas: volume, g:g:ml) was maintained at 1:0.1:10, and the volume ratio of ethanol /water was maintained at 1:1 in ethanol-water co-solvents. In a typical liquefaction reaction, $24 \mathrm{~g}$ of Mulberry bark, $2.4 \mathrm{~g}$ of potassium carbonate and $240 \mathrm{~g}$ of solvent (ethanol-water co-solvents) were loaded in the autoclave and liquefied for $60 \mathrm{~min}$ at $300^{\circ} \mathrm{C}$. The liquid and solid products were collected, filtered. The insoluble 
$10^{\mathrm{TH}}$ INTERNATIONAL CONFERENCE ON SUSTAINABLE ENERGY AND ENVIRONMENTAL

Protection (June $27^{\mathrm{TH}}-30^{\mathrm{TH}}, 2017$, Bled, Slovenia), Bioenergy AND Biofuels

C. Chen, J. Zhu, S. Jia, Z. Tong, Z. Li \& M. Li: Comparison on Compositions of Bio-

Oil Derived from Mulberry Bark Hydrothermal Liquefaction in Sub/Critical-Water and

Ethanol-Water Co-Solvents

material and the reactor were further washed with solvent (ethanol-water co-solvents), the resulting liquid was heated to $60^{\circ} \mathrm{C}$ to evaporate ethanol and then heated to $75^{\circ} \mathrm{C}$ to evaporate water in a rotary evaporator, the light bio-oil (LO) obtained, weighed and denoted as $\mathrm{B}_{1}$, the residual insoluble solids material was further washed with acetone until the washing solution became colourless. The collected washing solution was heated to $45^{\circ} \mathrm{C}$ to evaporate acetone and then heated to $75^{\circ} \mathrm{C}$ to evaporate residual solvents. After removal of the solvents, the obtained fraction heavy oil (HO) was weighed and marked as $\mathrm{C}_{1}$. The insoluble material was rinsed with water and dried at $110^{\circ} \mathrm{C}$ for $24 \mathrm{~h}$, then was weighed and designated as solid residue (SR).

In addition, to study the effect of the solvent on the bio-oil, the experiments were carried out with $240 \mathrm{~g}$ of water instead of ethanol-water co-solvents, and the obtained light biooil denoted as $\mathrm{B}_{2}$, heavy oil (HO) denoted as $\mathrm{C}_{2}$.

The results obtained in this study are reported using the parameters defined as:

Conversion $\omega \%=\left(W_{0}-W_{S R}\right) / W_{0}$

Bio-oil yield $\alpha \%=W_{B O} / W_{0}$

where $W_{0}$ is the weight of starting mulberry barks (dry, g), $W_{S R}$ is the weight of solid residue (dry, g), and $W_{B O}$ is the weight of the bio-oil( light oil or heavy oil, dry, g).

\subsection{GC-MS analyses of the bio-oil}

The compositions of bio-oil were analyzed by GC-MS analysis methods[20], and GCMS analyses were performed according to details mentioned in the literature[21]. The compounds were identified by a comparison with the NIST Mass Spectral Database and analysis after consulting correlation literature. An FID was used for quantification of the constituents in the bio-oil. Quantification was expressed as the percentage contribution of each compound to the total amount of material detected after peak area normalization[21]

\section{$3 \quad$ Results and Discussion}

\subsection{The percent conversion and bio-oil yield}

The percent conversion and bio-oil yield are shown in Table 1. The light oil yield is very low, may be some crude oil was degraded and converted into gas components in long time reaction. The heavy oil yield in ethanol-water co-solvents is slightly less than that of in water, presumably because ethanol as solvent not only played the role of heat and mass transfer, but also germination the degradation reaction with biomass to produce 
$306 \quad 10^{\mathrm{TH}}$ InTERnAtional CONFERENCE ON Sustainable ENERGy AND ENVIRONMENTAL Protection (June $27^{\mathrm{TH}}-30^{\mathrm{TH}}, 2017$, BLED, SLOVENiA), Bioenergy AND Biofuels

C. Chen, J. Zhu, S. Jia, Z. Tong, Z. Li \& M. Li: Comparison on Compositions of BioOil Derived from Mulberry Bark Hydrothermal Liquefaction in Sub/Critical-Water and Ethanol-Water Co-Solvents

small molecular gas products, resulting in the conversion is higher but the bio-oil yield is lower.

Table 1 The conversion and bio-oil yield in sub/critical water and ethanol-water cosolvents

\begin{tabular}{lllllll}
\hline items & conversion $/ \%$ & & light oil yield $/ \%$ & & heavy oil yield $/ \%$ & \\
\hline medium & ethanol-water & water & ethanol-water $\left(\mathrm{B}_{1}\right)$ & water $\left(\mathrm{B}_{2}\right)$ & ethanol-water $\left(\mathrm{C}_{1}\right)$ & water $\left(\mathrm{C}_{2}\right)$ \\
\hline barks & 95.72 & 87.5 & 2.56 & 4.16 & 26.16 & 26.25 \\
\hline
\end{tabular}

\subsection{The compositions of bio-oil}

A total of 141 and 131 kinds of compounds were identified in the light bio-oils, 43 and 50 kinds of compounds were identified in the heavy bio-oils derived from mulberry barks hydrothermal liquefaction in sub/critical ethanol-water co-solvents and sub/critical water in order of their experimental retention time and retention indices, all accounting for $100 \%$ (relative mass fraction). The main components identified are listed in Table 2 (light bio-oil) and Table 3 (heavy bio-oil).

Table 2 The main compositions in the light bio-oil

\begin{tabular}{llcccc}
\hline \multirow{2}{*}{ No. } & Compounds & M.F. & $\begin{array}{l}\text { R.T. } \\
\text { (min) }\end{array}$ & \multicolumn{2}{l}{ R.M.F $(\%)$} \\
\cline { 5 - 7 } & & $\mathrm{B}_{1}$ & $\mathrm{~B}_{2}$ \\
\hline 1 & Phenol & $\mathrm{C}_{6} \mathrm{H}_{6} \mathrm{O}$ & 4.456 & 0.225 & 0.028 \\
2 & 3-Phenylbut-1-ene & $\mathrm{C}_{10} \mathrm{H}_{12}$ & 4.579 & 0.376 & 0.339 \\
3 & Hexanoic acid, hexyl ester & $\mathrm{C}_{12} \mathrm{H}_{24} \mathrm{O}_{2}$ & 4.692 & 0.335 & \\
4 & 3-Ethoxy-1,2-propanediol & $\mathrm{C}_{5} \mathrm{H}_{12} \mathrm{O}_{3}$ & 5.133 & 0.803 & 1.120 \\
5 & 2(3H)-Furanone, dihydro-4-methyl- & $\mathrm{C}_{5} \mathrm{H}_{8} \mathrm{O}_{2}$ & 5.923 & 0.196 & 0.126 \\
6 & 2-Cyclopenten-1-one, 2,3-dimethyl- & $\mathrm{C}_{7} \mathrm{H}_{10} \mathrm{O}$ & 6.466 & 2.563 & 1.158 \\
7 & 4-Pyridinol & $\mathrm{C}_{5} \mathrm{H}_{5} \mathrm{NO}$ & 7.943 & 3.819 & 3.791 \\
8 & 2-Furancarboxylic acid, dodecyl ester & $\mathrm{C}_{17} \mathrm{H}_{28} \mathrm{O}_{3}$ & 8.384 & 0.534 & \\
9 & 4(1H)-Pyridone & $\mathrm{C}_{5} \mathrm{H}_{5} \mathrm{NO}$ & 8.518 & & 3.673 \\
10 & Phenol, 4-ethyl- & $\mathrm{C}_{8} \mathrm{H}_{10} \mathrm{O}$ & 8.569 & 0.345 & \\
11 & 3-Pyridinol, 2,6-dimethyl- & $\mathrm{C}_{7} \mathrm{H}_{9} \mathrm{NO}$ & 9.297 & 1.751 & \\
12 & 3-Pyridinol, 6-methyl- & $\mathrm{C}_{6} \mathrm{H}_{7} \mathrm{NO}$ & 9.533 & & 1.234 \\
13 & 1,2-Benzenediol & $\mathrm{C}_{6} \mathrm{H}_{6} \mathrm{O}_{2}$ & 9.677 & 8.122 & 11.48 \\
14 & Phenol, 3-amino- & $\mathrm{C}_{6} \mathrm{H}_{7} \mathrm{NO}$ & 10.661 & & 1.007 \\
15 & Phenol, 3-(dimethylamino)- & $\mathrm{C}_{8} \mathrm{H}_{11} \mathrm{NO}$ & 10.723 & 1.242 & \\
16 & Ethanone, 1-(2,4-dimethyl-1H- & $\mathrm{C}_{8} \mathrm{H}_{11} \mathrm{NO}$ & 10.989 & 1.601 & \\
17 & pyrrol-3-yl)- & $\mathrm{C}_{7} \mathrm{H}_{8} \mathrm{O}_{3}$ & 11.02 & & 7.443 \\
18 & Cyclopenta[c]pyrazol-3-amine, & $\mathrm{C}_{7} \mathrm{H}_{11} \mathrm{~N}_{3}$ & 11.143 & 0.961 & \\
19 & 2,4,5,6-tetrahydro-2-methyl- & $\mathrm{C}_{7} \mathrm{H}_{8} \mathrm{O}$ & 11.246 & 1.453 & \\
20 & Bhenol, 3-methoxy- & $\mathrm{C}_{7} \mathrm{H}_{8} \mathrm{SO}$ & 11.307 & & 1.869 \\
21 & Hydrone, (methylsulfinyl)- & $\mathrm{C}_{6} \mathrm{H}_{6} \mathrm{O}_{2}$ & 12.015 & & 5.409 \\
22 & Benzaldehyde, 2-fluoro- & $\mathrm{C}_{7} \mathrm{H}_{5} \mathrm{FO}$ & 12.077 & 0.6 & \\
23 & 1,2-Benzenediol, 4-methyl- & $\mathrm{C}_{7} \mathrm{H}_{8} \mathrm{O}_{2}$ & 12.261 & 1.114 & \\
24 & 2-Benzothiazolamine & $\mathrm{C}_{7} \mathrm{H}_{6} \mathrm{~N}_{2} \mathrm{~S}$ & 12.405 & 0.983 & \\
25 & Dihydro iso-jasmone & $\mathrm{C}_{11} \mathrm{H}_{18} \mathrm{O}$ & 12.579 & 2.264 & \\
& (2-hexylcyclopent-2-en-1-one) & & & &
\end{tabular}


Protection (June $27^{\mathrm{TH}}-30^{\mathrm{TH}}, 2017$, Bled, Slovenia), Bioenergy AND Biofuels

C. Chen, J. Zhu, S. Jia, Z. Tong, Z. Li \& M. Li: Comparison on Compositions of Bio-

Oil Derived from Mulberry Bark Hydrothermal Liquefaction in Sub/Critical-Water and

Ethanol-Water Co-Solvents

\begin{tabular}{|c|c|c|c|c|c|}
\hline 26 & 3-Isobutyldihydropyrazin-2-one & $\begin{array}{c}\mathrm{C}_{8} \mathrm{H}_{13} \mathrm{~N}_{2} \\
\mathrm{O}\end{array}$ & 12.682 & & 1.904 \\
\hline 27 & 5-Ethyl-2-furaldehyde & $\mathrm{C}_{7} \mathrm{H}_{8} \mathrm{O}_{2}$ & 12.907 & 0.424 & \\
\hline 28 & 1,3-Benzenediol, 2-methyl- & $\mathrm{C}_{7} \mathrm{H}_{8} \mathrm{O}_{2}$ & 13.01 & & 0.689 \\
\hline 29 & Phenol, 2,6-dimethoxy- & $\mathrm{C}_{8} \mathrm{H}_{10} \mathrm{O}_{3}$ & 13.256 & 7.794 & 5.866 \\
\hline 30 & $\begin{array}{l}\text { Cyclohexene, 1,5,5- } \\
\text { trimethyl-6-acetylmethyl- }\end{array}$ & $\mathrm{C}_{12} \mathrm{H}_{20} \mathrm{O}_{2}$ & 13.451 & 1.004 & \\
\hline 31 & 1,4-Benzenediol, 2-methyl- & $\mathrm{C}_{7} \mathrm{H}_{8} \mathrm{O}_{2}$ & 13.656 & & 2.928 \\
\hline 32 & 1,4-Benzenediol, 2,6-dimethyl- & $\mathrm{C}_{8} \mathrm{H}_{10} \mathrm{O}_{2}$ & 13.882 & 0.425 & \\
\hline 33 & Pyridine, 2-butyl-, 1-oxide & $\mathrm{C}_{9} \mathrm{H}_{13} \mathrm{NO}$ & 13.995 & 1.009 & \\
\hline 34 & Benzene, 1,4-dimethoxy- & $\mathrm{C}_{8} \mathrm{H}_{10} \mathrm{O}_{2}$ & 14.005 & & 0.28 \\
\hline 35 & 2-Furancarboxaldehyde, 5-methyl- & $\mathrm{C}_{6} \mathrm{H}_{6} \mathrm{O}_{2}$ & 14.087 & & 0.453 \\
\hline 36 & 2-Methoxybenzyl alcohol & $\mathrm{C}_{8} \mathrm{H}_{10} \mathrm{O}_{2}$ & 14.22 & 0.793 & 0.508 \\
\hline 37 & Furan, 2-(1,1-dimethylethyl)-4-methyl- & $\mathrm{C}_{8} \mathrm{H}_{12} \mathrm{O}$ & 14.282 & 0.633 & 0.798 \\
\hline 38 & 1,3-Benzenediol, 4-ethyl- & $\mathrm{C}_{8} \mathrm{H}_{10} \mathrm{O}_{2}$ & 14.466 & 1.093 & \\
\hline 39 & Benzaldehyde, 4-fluoro- & $\mathrm{C}_{8} \mathrm{H}_{5} \mathrm{FO}$ & 14.692 & 1.476 & \\
\hline 40 & Ethanone, 1-(3-hydroxyphenyl)- & $\mathrm{C}_{8} \mathrm{H}_{8} \mathrm{O}_{2}$ & 14.723 & & 1.103 \\
\hline 41 & Benzene, 2-fluoro-1,3,5-trimethyl- & $\mathrm{C}_{9} \mathrm{H}_{11} \mathrm{~F}$ & 14.877 & 0.254 & \\
\hline 42 & Pyridine, 4-(1-pyrrolidinyl)- & $\mathrm{C}_{9} \mathrm{H}_{12} \mathrm{~N}_{2}$ & 14.989 & 1.334 & \\
\hline 43 & 2-Methyl-5-hydroxybenzofuran & $\mathrm{C}_{9} \mathrm{H}_{8} \mathrm{O}_{2}$ & 15.00 & & 0.779 \\
\hline 44 & 2,3-Dimethylhydroquinone & $\mathrm{C}_{8} \mathrm{H}_{10} \mathrm{O}_{2}$ & 15.133 & 1.291 & 0.297 \\
\hline 45 & 1,3-Benzenediol, 4,5-dimethyl- & $\mathrm{C}_{8} \mathrm{H}_{10} \mathrm{O}_{2}$ & 15.461 & 1.124 & 1.205 \\
\hline 46 & Benzenamine, 4-methoxy-2-nitro- & $\begin{array}{c}\mathrm{C}_{7} \mathrm{H}_{8} \mathrm{~N}_{2} \mathrm{O} \\
3\end{array}$ & 15.594 & & 1.352 \\
\hline 47 & 1,2,4-Trimethoxybenzene & $\mathrm{C}_{9} \mathrm{H}_{12} \mathrm{O}_{3}$ & 15.595 & 2.846 & \\
\hline 48 & Phenol, 2-methoxy-4-methyl- & $\mathrm{C}_{8} \mathrm{H}_{10} \mathrm{O}_{2}$ & 15.687 & & 0.88 \\
\hline 49 & Benzeneethanol, 2-hydroxy- & $\mathrm{C}_{8} \mathrm{H}_{10} \mathrm{O}_{2}$ & 15.913 & 0.854 & \\
\hline 50 & 4-Butylbenzyl alcohol & $\mathrm{C}_{11} \mathrm{H}_{16} \mathrm{O}$ & 15.954 & 0.736 & \\
\hline 51 & Phenol, 3-propyl- & $\mathrm{C}_{9} \mathrm{H}_{12} \mathrm{O}$ & 15.964 & & 1.223 \\
\hline 52 & 1,3-Benzenediol, 4-propyl- & $\mathrm{C}_{9} \mathrm{H}_{12} \mathrm{O}_{2}$ & 16.118 & 1.285 & \\
\hline 53 & 2-Furancarboxaldehyde, 5-methyl- & $\mathrm{C}_{6} \mathrm{H}_{6} \mathrm{O}_{2}$ & 16.436 & & 0.433 \\
\hline 54 & 1,4-Benzenediol, 2,5-dimethyl- & $\mathrm{C}_{8} \mathrm{H}_{10} \mathrm{O}_{2}$ & 16.456 & 0.563 & \\
\hline 55 & 1,4-Benzenediol, 2,3,5-trimethyl- & $\mathrm{C}_{9} \mathrm{H}_{12} \mathrm{O}_{2}$ & 16.569 & 0.269 & 0.194 \\
\hline 56 & 2-Furanacetaldehyde, .alpha.-isopropyl- & $\mathrm{C}_{9} \mathrm{H}_{12} \mathrm{O}_{2}$ & 16.671 & 0.547 & \\
\hline 57 & 1,4-Benzenediol, 2-(1,1-dimethylethyl)- & $\mathrm{C}_{10} \mathrm{H}_{14} \mathrm{O}_{2}$ & 16.682 & & 0.712 \\
\hline 58 & Benzenemethanol, 4-methoxy- & $\mathrm{C}_{8} \mathrm{H}_{10} \mathrm{O}_{2}$ & 16.784 & 1.296 & \\
\hline 59 & $\begin{array}{l}\text { Benzene, 1,2,3-trimethoxy-5-methyl- } \\
\text { 2-Propanone, 1-(4-hydroxy- }\end{array}$ & $\mathrm{C}_{10} \mathrm{H}_{14} \mathrm{O}_{3}$ & 17.502 & 2.024 & 1.249 \\
\hline 60 & 3-methoxyphenyl)- & $\mathrm{C}_{10} \mathrm{H}_{12} \mathrm{O}_{3}$ & 17.707 & & 1.021 \\
\hline 61 & Furan, 2,5-dimethyl- & $\mathrm{C}_{6} \mathrm{H}_{8} \mathrm{O}$ & 18.815 & & 0.23 \\
\hline 62 & Phenol, 2,6-dimethyl-4-nitro- & $\mathrm{C}_{8} \mathrm{H}_{9} \mathrm{NO}_{3}$ & 19.441 & & 0.467 \\
\hline 63 & Xanthone & $\mathrm{C}_{13} \mathrm{H}_{8} \mathrm{O}_{2}$ & 19.451 & 2.011 & \\
\hline 64 & $\begin{array}{l}\text { Pyrrolo[1,2-a]pyrazine-1,4-dione, } \\
\text { hexahydro-3-(2-methylpropyl)- }\end{array}$ & $\begin{array}{c}\mathrm{C}_{10} \mathrm{H}_{16} \mathrm{~N}_{2} \\
\mathrm{O}_{2}\end{array}$ & 24.641 & & 1.244 \\
\hline 65 & Phenol, 3,5-dimethoxy- & $\mathrm{C}_{8} \mathrm{H}_{10} \mathrm{O}_{3}$ & 25.933 & 0.676 & 1.36 \\
\hline
\end{tabular}

$\mathrm{B}_{1}$ and $\mathrm{B}_{2}$ are the light bio-oil derived from mulberry bark hydrothermal liquefaction in sub/critical ethanol-water co-solvents and sub/critical- water. M.F. is molecular formula, R.T. is retention time, and R.M.F. is relative mass fraction. 
$10^{\mathrm{TH}}$ InTERNATIONAL CONFERENCE ON Sustainable ENERGY AND ENVIRONMENTAL Protection (June $27^{\mathrm{TH}}-30^{\mathrm{TH}}, 2017$, BLed, Slovenia), Bioenergy AND Biofuels C. Chen, J. Zhu, S. Jia, Z. Tong, Z. Li \& M. Li: Comparison on Compositions of BioOil Derived from Mulberry Bark Hydrothermal Liquefaction in Sub/Critical-Water and Ethanol-Water Co-Solvents

Table 3 The main compositions in the heavy bio-oil

\begin{tabular}{|c|c|c|c|c|c|}
\hline \multirow{2}{*}{ No. } & \multirow{2}{*}{ Compounds } & \multirow{2}{*}{ M.F. } & \multirow{2}{*}{$\begin{array}{l}\text { R.T. } \\
(\min )\end{array}$} & \multicolumn{2}{|c|}{ R.M.F. (\%) } \\
\hline & & & & $\mathrm{C}_{1}$ & $\mathrm{C}_{2}$ \\
\hline 1 & 2-Cyclopenten-1-one, 2,3-dimethyl- & $\mathrm{C}_{7} \mathrm{H}_{10} \mathrm{O}$ & 5.625 & & 4.274 \\
\hline 2 & Phenol, 2-methoxy- & $\mathrm{C}_{7} \mathrm{H}_{8} \mathrm{O}_{2}$ & 6.702 & 0.263 & 8.981 \\
\hline 3 & Phenol, 3-methoxy- & $\mathrm{C}_{7} \mathrm{H}_{8} \mathrm{O}_{2}$ & 7.687 & & 1.262 \\
\hline 4 & Naphthalene, 1,2,3,4-tetrahydro- & $\mathrm{C}_{10} \mathrm{H}_{12}$ & 8.405 & 10.256 & 4.622 \\
\hline 5 & Phenol, 2-methoxy-4-methyl- & $\mathrm{C}_{8} \mathrm{H}_{10} \mathrm{O}_{2}$ & 9.164 & & 4.47 \\
\hline 6 & Spiro[2.4]heptane, 4-methylene- & $\mathrm{C}_{8} \mathrm{H}_{12}$ & 10.948 & & 1.951 \\
\hline 7 & Phenol, 4-ethyl-2-methoxy- & $\mathrm{C}_{9} \mathrm{H}_{12} \mathrm{O}_{2}$ & 11.348 & 0.982 & 6.561 \\
\hline 8 & Phenol, 2,6-dimethoxy- & $\mathrm{C}_{8} \mathrm{H}_{10} \mathrm{O}_{3}$ & 13.287 & & 2.45 \\
\hline 9 & Phenol, 2-methoxy-4-propyl- & $\mathrm{C}_{10} \mathrm{H}_{14} \mathrm{O}_{2}$ & 13.584 & 1.247 & 4.806 \\
\hline 10 & $\begin{array}{l}\text { Ethanol, } \quad 2-(3,3 \text {-dimethylbicyclo[2.2.1]hept-2 } \\
\text { ylidene)- }\end{array}$ & $\mathrm{C}_{11} \mathrm{H}_{18} \mathrm{O}$ & 13.728 & & 1.648 \\
\hline 11 & 1,2,3-Trimethoxybenzene & $\mathrm{C}_{9} \mathrm{H}_{12} \mathrm{O}_{3}$ & 15.594 & & 2.007 \\
\hline 12 & 3-Allyl-6-methoxyphenol & $\mathrm{C}_{10} \mathrm{H}_{12} \mathrm{O}_{2}$ & 16.117 & & 1.77 \\
\hline 13 & 1H-Indole, 2,5-dimethyl- & $\mathrm{C}_{10} \mathrm{H}_{11} \mathrm{~N}$ & 16.682 & & 1.424 \\
\hline 14 & 5-tert-Butylpyrogallol & $\mathrm{C}_{10} \mathrm{H}_{14} \mathrm{O}_{3}$ & 17.492 & 0.55 & 2.793 \\
\hline 15 & 4-Propyl-1,1'-diphenyl & $\mathrm{C}_{15} \mathrm{H}_{16}$ & 19.441 & 0.983 & 4.829 \\
\hline 16 & 2-Acetyl-1-tetralone & $\mathrm{C}_{12} \mathrm{H}_{12} \mathrm{O}_{2}$ & 23.01 & & 2.07 \\
\hline 17 & 1,4-Naphthoquinone, 5-ethoxy- & $\mathrm{C}_{12} \mathrm{H}_{10} \mathrm{O}_{3}$ & 26.015 & & 1.122 \\
\hline 18 & Tridecanoic acid & $\mathrm{C}_{13} \mathrm{H}_{26} \mathrm{O}_{2}$ & 26.702 & & 3.13 \\
\hline 19 & Hexadecanoic acid, ethyl ester & $\mathrm{C}_{18} \mathrm{H}_{36} \mathrm{O}_{2}$ & 27.328 & 5.07 & \\
\hline 20 & Dibenzo[a,i]pyrene & $\mathrm{C}_{24} \mathrm{H}_{14}$ & 29.871 & & 1.162 \\
\hline 21 & Ethyl Oleate & $\mathrm{C}_{20} \mathrm{H}_{38} \mathrm{O}_{2}$ & 30.517 & 1.719 & \\
\hline 22 & Octadecanoic acid, ethyl ester & $\mathrm{C}_{20} \mathrm{H}_{40} \mathrm{O}_{2}$ & 30.979 & 1.167 & \\
\hline 23 & Hexanedioic acid, dicyclohexyl ester & $\mathrm{C}_{18} \mathrm{H}_{30} \mathrm{O}_{4}$ & 32.907 & & 1.277 \\
\hline 24 & 4-Ethoxy-3-methoxyphenethyl alcohol & $\mathrm{C}_{11} \mathrm{H}_{16} \mathrm{O}_{3}$ & 33.389 & & 1.769 \\
\hline 25 & Nonadecanoic acid, ethyl ester & $\mathrm{C}_{21} \mathrm{H}_{42} \mathrm{O}_{2}$ & 37.44 & 1.324 & 0.551 \\
\hline 26 & 1-Hexacosene & $\mathrm{C}_{26} \mathrm{H}_{52}$ & 38.928 & 1.384 & \\
\hline 27 & Ethyl tetracosanoate & $\mathrm{C}_{26} \mathrm{H}_{52} \mathrm{O}_{2}$ & 40.333 & 3.403 & \\
\hline 58 & Phenol, 6-methyl-2-[(4-morpholinyl)methyl]- & $\mathrm{C}_{12} \mathrm{H}_{17} \mathrm{NO}_{2}$ & 41.656 & 1.759 & 1.435 \\
\hline 29 & 9-Tricosene, $(Z)-$ & $\mathrm{C}_{23} \mathrm{H}_{46}$ & 41.758 & 3.381 & \\
\hline 30 & Anthracene, 9,10-dihydro-9,9,10-trimethyl- & $\mathrm{C}_{17} \mathrm{H}_{18}$ & 42.025 & 2.696 & \\
\hline 31 & $\begin{array}{l}\text { A-Neooleana-3(5),12-diene } \quad(5 \mathrm{a}, 5 \mathrm{~b}, 7 \mathrm{a}, 10,10,13 \mathrm{~b} \\
\text { Hexamethyl-3-(1-methylethylidene)- } \\
\text { 2,3,3a,4,5,5a,5b,6,7,7a,8,9,10,11,11a,13,13a,13b- } \\
\text { octadecahydro-1H-cyclopenta[a]chrysene) }\end{array}$ & $\mathrm{C}_{30} \mathrm{H}_{48}$ & 42.189 & 4.016 & 2.712 \\
\hline
\end{tabular}


$10^{\text {TH }}$ INTERNATIONAL CONFERENCE ON SUSTAINABLE ENERGY AND ENVIRONMENTAL

Protection (June $27^{\mathrm{TH}}-30^{\mathrm{TH}}, 2017$, Bled, SLOvenia), Bioenergy AND Biofuels

C. Chen, J. Zhu, S. Jia, Z. Tong, Z. Li \& M. Li: Comparison on Compositions of Bio-

Oil Derived from Mulberry Bark Hydrothermal Liquefaction in Sub/Critical-Water and

Ethanol-Water Co-Solvents

\begin{tabular}{|c|c|c|c|c|c|}
\hline 32 & $\begin{array}{l}\text { 10-Ethoxy-1,2,9-trimethoxy-7H- } \\
\text { dibenzo[de,g]quinolin-7-one }\end{array}$ & $\mathrm{C}_{22} \mathrm{H}_{25} \mathrm{NO}_{6}$ & 42.271 & 1.683 & \\
\hline 33 & $\begin{array}{l}\text { 6-Methoxy-4-methyl-8-nitro-5-[[4'- } \\
\text { phenoxy]phenoxy]quinoline }\end{array}$ & $\mathrm{C}_{19} \mathrm{H}_{18} \mathrm{~N}_{2} \mathrm{O}_{5}$ & 42.446 & 2.035 & \\
\hline 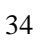 & Tetracosanoic acid, 2,4,6-trimethyl-, methyl ester & $\mathrm{C}_{28} \mathrm{H}_{56} \mathrm{O}_{2}$ & 43.112 & 4.274 & \\
\hline & 2-Ethylacridine & $\mathrm{C}_{15} \mathrm{H}_{13} \mathrm{~N}$ & 43.266 & 1.594 & \\
\hline 36 & $\begin{array}{l}\text { 5(1H)-Azulenone, } \quad 2,4,6,7,8,8 \mathrm{a}-\text { hexahydro-3, }, \\
\text { dimethyl-4-(1-methylethylidene)-, (8S-cis)- }\end{array}$ & $\mathrm{C}_{15} \mathrm{H}_{22} \mathrm{O}$ & 43.697 & 1.8 & \\
\hline 37 & Anthracene, 9,10-dihydro-9,9,10-trimethyl- & $\mathrm{C}_{17} \mathrm{H}_{18}$ & 43.81 & 4.282 & 1.423 \\
\hline 38 & $\begin{array}{l}\mathrm{N} \text {-[(E)-(6-Nitro-1,3-benzodioxol-5-yl)methylidene]- } \\
\text { 2-phenylethanamine }\end{array}$ & $\mathrm{C}_{16} \mathrm{H}_{14} \mathrm{~N}_{2} \mathrm{O}_{4}$ & 44.005 & 2.428 & \\
\hline 39 & Coumarin, 7-hydroxy-4-methyl-3-propyl- & $\mathrm{C}_{13} \mathrm{H}_{15} \mathrm{O}_{3}$ & 44.425 & 5.808 & 1.247 \\
\hline 40 & 2-Methyl-7-phenylindole & $\mathrm{C}_{15} \mathrm{H}_{13} \mathrm{~N}$ & 44.548 & 1.223 & \\
\hline 41 & 5-Acetamido-4,7-dioxo-4,7-dihydrobenzofurazan & $\mathrm{C}_{8} \mathrm{H}_{5} \mathrm{~N}_{3} \mathrm{O}_{4}$ & 44.969 & 2.58 & \\
\hline 42 & $\begin{array}{l}\text { 2-(Acetoxymethyl)-3- } \\
\text { (methoxycarbonyl)biphenylene }\end{array}$ & $\mathrm{C}_{17} \mathrm{H}_{14} \mathrm{O}_{4}$ & 45.861 & 4.554 & \\
\hline 43 & $\begin{array}{l}\text { Hexacosanoic acid, 2,4,6-trimethyl-, methyl estes } \\
(2 \mathrm{R}, 4 \mathrm{~S}, 6 \mathrm{R})-(-)-\end{array}$ & $\mathrm{C}_{30} \mathrm{H}_{60} \mathrm{O}_{2}$ & 46.712 & 1.695 & \\
\hline . & Benzo[h]quinoline, 2,4-dimethyl- & $\mathrm{C}_{15} \mathrm{H}_{13} \mathrm{~N}$ & 49.225 & 0.875 & 3.157 \\
\hline 45 & 1H-Indole, 1-methyl-2-phenyl- & $\mathrm{C}_{15} \mathrm{H}_{13} \mathrm{~N}$ & 49.235 & 2.28 & \\
\hline 46 & Olean-12-ene & $\mathrm{C}_{30} \mathrm{H}_{50}$ & 49.81 & 2.358 & \\
\hline 47 & $\begin{array}{l}\text { 4,4,6a,6b,8a,11,11,14b-Octamethyl- } \\
\text { 1,4,4a,5,6,6a,6b,7,8,8a,9,10,11,12,12a,14,14a,14b- } \\
\text { octadecahydro-2H-picen-3-one }\end{array}$ & $\mathrm{C}_{29} \mathrm{H}_{47} \mathrm{O}$ & 50.158 & 1.959 & 5.345 \\
\hline 48 & Benzo[b]naphtho[2,3-d]furan & $\mathrm{C}_{6} \mathrm{H}_{10} \mathrm{O}$ & 50.158 & 4.572 & \\
\hline 49 & $\begin{array}{l}\text { 9,10-Methanoanthracen-11-ol, 9,10-dihydro-9,10,11 } \\
\text { trimethyl- }\end{array}$ & $\mathrm{C}_{18} \mathrm{H}_{18} \mathrm{O}$ & 50.292 & 1.141 & \\
\hline 50 & alpha-Amyrin & $\mathrm{C}_{30} \mathrm{H}_{50} \mathrm{O}$ & 50.61 & 8.392 & 3.328 \\
\hline 51 & 5-Methyl-2-phenylindolizine & $\mathrm{C}_{15} \mathrm{H}_{13} \mathrm{~N}$ & 51.563 & 1.039 & 1.482 \\
\hline
\end{tabular}

$\mathrm{C}_{1}$ and $\mathrm{C}_{2}$ are the heavy bio-oil derived from mulberry bark hydrothermal liquefaction in sub/critical ethanol-water co-solvents and sub/critical- water. M. F. is molecular formula, R.T. is retention time, and R.M.F. is relative mass fraction.

\section{Conclusions}

Hydrothermal liquefaction of mulberry bark in sub/critical-water and ethanol-water cosolvents was investigated using a batch reactor. The conversion rate in sub/criticalethanol-water co-solvents and sub/critical- water medium were $95.72 \%$ and $87.5 \%$, the yield of the heavy oil were $26.16 \%$ and $26.25 \%$, and the yield of the light oil were $2.56 \%$ and $4.16 \%$ at $300{ }^{\circ} \mathrm{C}$. The components of bio-oils were complex, mainly contained phenols, aromatic, alkanes, ketone, esters, furans, olefin compounds, etc. The content of phenols in the bio-oil derived from mulberry bark hydrothermal liquefaction in $\mathrm{sub} /$ critical water is more than that liquefaction in sub/critical- ethanol-water co-solvents. 
$310 \quad 10^{\mathrm{TH}}$ International Conference on Sustainable Energy and ENVIRONMENTal Protection (June $27^{\mathrm{TH}}-30^{\mathrm{TH}}, 2017$, BLED, SLOVENiA), Bioenergy AND Biofuels C. Chen, J. Zhu, S. Jia, Z. Tong, Z. Li \& M. Li: Comparison on Compositions of BioOil Derived from Mulberry Bark Hydrothermal Liquefaction in Sub/Critical-Water and Ethanol-Water Co-Solvents

\section{Acknowledgments}

The authors are grateful for the financial support from the National Natural Science Foundation of China for the key projects (No. 31430092, No. 31110103902). This project was also supported by the Guangxi Natural Science Foundation (No. 2015GXNSFAA139023), the Dean Project of Guangxi Key Laboratory of Petrochemical Resource Processing and Process Intensification Technology of China (No. 2014K006).

\section{References}

[1] Y. Tang, Q. Liu and F. Chen, "Preparation and characterization of activated carbon from waste ramulus mori," Chemical Engineering Journal, vol. 203, pp. 19-24, 2012.

[2] F. Qiu, T. He and Y. Zhang, "The isolation and the characterization of two polysaccharides from the branch bark of mulberry (Morus alba L.)," Archives of Pharmacal Research, vol. 39, pp. 887-896, 2016.

[3] S. Sun, R. Chen and D. Yu, "Structures of Two New Benzofuran Derivatives from the Bark of Mulberry," Journal of Asian Natural Products Research, vol. 3, pp. 253-259, 2001.

[4] S. Wang, M. Fang, Y. Ma, and Y. Zhang, "Preparation of the Branch Bark Ethanol Extract in Mulberry Morus alba, Its Antioxidation, and Antihyperglycemic Activity In Vivo," Evidence-Based Complementary and Alternative Medicine, pp. 1-7, 2014.

[5] C. Rivière, S. Krisa, L. Péchamat, M. Nassra, J. Delaunay, A. Marchal, A. Badoc, P. WaffoTéguo, and J. Mérillon, "Polyphenols from the stems of Morus alba and their inhibitory activity against nitric oxide production by lipopolysaccharide-activated microglia," Fitoterapia, vol. 97, pp. 253-260, 2014.

[6] I. Thabti, W. Elfalleh, N. Tlili, M. Ziadi, M. G. Campos, and A. Ferchichi, "Phenols, Flavonoids, and Antioxidant and Antibacterial Activity of Leaves and Stem Bark of Morus Species," International Journal of Food Properties, vol. 17, pp. 842-854, 2014.

[7] K. M. Meselhy, L. N. Hammad and N. Farag, "Novel Antisickling, Antioxidant and Cytotoxic Prenylated Flavonoids from the Bark of Morus alba L," Life Science Journal, vol. 9, pp. 830-841, 2012.

[8] H. Liu, M. Fang and Y. Zhang, "In Vivo Hypoglycaemic Effect and Inhibitory Mechanism of the Branch Bark Extract of the Mulberry on STZ-Induced Diabetic Mice," The Scientific World Journal, vol. 2014, pp. 1-11, 2014.

[9] D. Biao, L. Yi and Z. Yu-Qing, "Anti-tumor effect of morusin from the branch bark of cultivated mulberry in Bel-7402 cells via the MAPK pathway," RSC Advances, pp. 1739617404, 2016.

[10] S. Wang, X. Liu, J. Zhang, and Y. Zhang, "An Efficient Preparation of Mulberroside A from the Branch Bark of Mulberry and Its Effect on the Inhibition of Tyrosinase Activity," Plos One, vol. 9, pp. 781-790, 2014.

[11] G. M. Abbas, B. F. Abdel, H. N. Baraka, A. A. Gohar, and M. F. Lahloub, "A new antioxidant stilbene and other constituents from the stem bark of Morus nigra L," Nat Prod Res, vol. 28, pp. 952-9, 2014-01-20 2014.

[12] S. Feng, S. Cheng, Z. Yuan, M. Leitch, and C. C. Xu, "Valorization of bark for chemicals and materials: A review," Renewable and Sustainable Energy Reviews, vol. 26, pp. 560578, 2013.

[13] B. Velázquez-Martí, M. Sajdak, I. López-Cortés, and A. J. Callejón-Ferre, "Wood characterization for energy application proceeding from pruning Morus alba L., Platanus hispanica Münchh. and Sophora japonica L. in urban areas," Renewable Energy, vol. 62, pp. $478-483,2014$. 
$10^{\mathrm{TH}}$ INTERNATIONAL CONFERENCE ON SUSTAINABLE ENERGY AND ENVIRONMENTAL Protection (June $27^{\mathrm{TH}}-30^{\mathrm{TH}}, 2017$, Bled, Slovenia), Bioenergy AND Biofuels

C. Chen, J. Zhu, S. Jia, Z. Tong, Z. Li \& M. Li: Comparison on Compositions of Bio-

Oil Derived from Mulberry Bark Hydrothermal Liquefaction in Sub/Critical-Water and Ethanol-Water Co-Solvents

[14] M. Takasaki, M. Yamasaki, H. Nakanishi, H. Morikawa, and H. Konishi, "Preparation, Structure and Properties of Paper Sheets fromMulberry Bark," Fiber, vol. 68, pp. 304-307, 2012.

[15] C. Qu, S. Wang, K. Wang, and Q. Ma, "Preparation and antibacterial property of the mulberry based textiles," Fibers and Polymers, vol. 15, pp. 498-503, 2014.

[16] T. Shu, P. Lu and N. He, "Mercury adsorption of modified mulberry twig chars in a simulated flue gas," Bioresource Technology, vol. 136, pp. 182-187, 2013.

[17] H. Serencam, D. Ozdes, C. Duran, and M. Tufekci, "Biosorption properties of Morus alba L. for Cd (II) ions removal from aqueous solutions," Environmental Monitoring and Assessment, vol. 185, pp. 6003-6011, 2013.

[18] L. Liu, T. Jiang and J. Yao, "A Two-Step Chemical Process for the Extraction of Cellulose Fiber and Pectin from Mulberry Branch Bark Efficiently," Journal of Polymers and the Environment, vol. 19, pp. 568-573, 2011.

[19] Z. Li, J. Cao, K. Huang, Y. Hong, C. Li, X. Zhou, N. Xie, F. Lai, F. Shen, and C. Chen, "Alkaline pretreatment and the synergic effect of water and tetralin enhances the liquefaction efficiency of bagasse," Bioresource Technology, vol. 177, pp. 159-168, 2015.

[20] P. K. Kanaujia, Y. K. Sharma, U. C. Agrawal, and M. O. Garg, "Analytical approaches to characterizing pyrolysis oil from biomass," Trends in Analytical Chemistry, vol. 42, pp. 125-136, 2013.

[21] C. Chen, Z. Tong, D. Liao, Y. Li, G. Yang, and M. Li, "Chemical Composition and Antimicrobial and DPPH Scavenging Activity of Essential Oil of Toona sinensis (A. Juss.) Roem from China," BioResources, vol. 9, pp. 5262-5278, 2014. 
312 10 $10^{\mathrm{TH}}$ InTERnational CONFERENCE ON Sustainable ENERGy AND ENVIRONMENTAL Protection (June $27^{\mathrm{TH}}-30^{\mathrm{TH}}, 2017$, Bled, Slovenia), Bioenergy AND Biofuels 
$10^{\mathrm{TH}}$ InTERnational CONFERENCE ON Sustainable ENERgy AND EnVironmental Protection (June $27^{\mathrm{TH}}-30^{\mathrm{TH}}$, 2017, Bled, SLOVENIA), BIOENERGY AND BIOFUELS

J. Krope, A.Ghani Olabi, D. Goričanec \& S. Božičnik

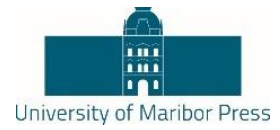

\title{
Biodiesel Production. A Brief Review
}

\author{
EugÊNia LEANdro Almeida, Cid Marcos GonçAlves Andrade \& OnÉlia \\ APARECIDA ANDREO DOS SANTOS
}

\begin{abstract}
Diesel plays a significant role in the economy of a country, being used in industrial machines, electric generators, locomotives, trucks, buses, etc. Currently, there is a worldwide concern with the depletion of nonrenewable energy sources, also with the emission of gases from its burning, which contribute to the worsening of the greenhouse effect. Studies have been developed in search of alternatives for partial or total replacement of petroleum diesel. These alternatives must be technically feasible, economically competitive and do not harm the environment. Biodiesel is a possible substitute. Biodiesel is a renewable fuel, which can be obtained from different raw materials such as vegetable oil, animal fat and oil / waste fat. Biodiesel can be produced by various processes, including enzymatic catalysis, basic or acid catalysis. The objective of this work was to carry out a review of the different biodiesel production methods, regarding raw materials and chemical production routes.
\end{abstract}

Keywords: - Biodiesel - Biofuel • Biodiesel production - Renewable energy $\bullet$ Catalysis $\bullet$

CORRESPONDENCE AdDRESs: Eugenia Leandro Almeida, M.Sc, Universidade Estadual de Maringá, Chemical Engineering Department, Av. Colombo, 5790 - Vila Esperança, Maringá - Paraná, Brasil, email: eugenia-almeida@hotmail.com Cid Marcos Gonçalves Andrade, Ph.D, Universidade Estadual de Maringá, Chemical Engineering Department, Av. Colombo, 5790 - Vila Esperanca, Maringá - Paraná, Brasil,email: cid@deq.uem.br. Onélia Aparecida Andreo dos Santos, Ph.D, Universidade Estadual de Maringá, Chemical Engineering Department, Av. Colombo, 5790 - Vila Esperanca, Maringá - Paraná, Brasil,email: onelia@deq.uem.br.

https://doi.org/10.18690/978-961-286-048-6.31

ISBN 978-961-286-048-6

(C) 2017 University of Maribor Press

Available at: http://press.um.si. 
314 10 $10^{\mathrm{TH}}$ InTERnAtional CONFERENCE ON Sustainable ENERGy AND ENVIRONMENTAL Protection (June $27^{\mathrm{TH}}-30^{\mathrm{TH}}, 2017$, BLed, SLOVENiA), Bioenergy AND Biofuels

E.L. Almeida, C.M.G. Andrade \& O.A.A. Santos: Biodiesel Production. A Brief Review

Diesel consumption represents a significant part of a country's economy, since it is used in several economic sectors. One of the sectors with the highest demand for diesel, derived from petroleum, is the road sector [1]. In Brazil the road sector is the main transportation system in the country. According to the National Department of Land Transport, linked to the Ministry of Transportation, there are 119,936 kilometers of federal highways in the country. Studies show that the consumption of diesel oil in the Brazilian market tends to increase between 2014 and 2023 [2].

However, with the increase in the demand for fossil fuels, in the case in particular diesel, there is in parallel a concern regarding the amount of gases emitted from the burning of this fuel, being this concern not only national but also worldwide. These gases from the combustion process of diesel contribute directly to the worsening of the greenhouse effect [3]. In this context, studies have been carried out with the objective of developing sustainable and renewable alternatives for partial or total replacement of diesel obtained from petroleum fractionation [4] [5]. A possible successor to diesel is biodiesel.

Biodiesel, as well as diesel, can be used in cycle engines, such as trucks, buses, etc. And in stationary motors, such as electric power generators [6]. One of the advantages of using biodiesel when compared to diesel, non-renewable fossil fuel is the fact that biodiesel is a renewable fuel [7] [8].

Biodiesel can be used pure or mixed with diesel. When mixed, it receives the designation B2, $\mathrm{B} 5$, or B20, etc., referring to the percentage of biodiesel present in diesel, respectively, $2 \%, 5 \%$ and $20 \%$, etc. It can also be called B100, representing pure biodiesel. In Brazil the biodiesel blend in diesel started in 2004, through the National Program for the Production and Use of Biodiesel (PNPB), launched by the federal government. In 2004 the $2 \%$ blend was experimental only. Between 2005 and 2007 the mixture of $2 \%$ became optional. And in 2008 the $2 \%$ mix became mandatory throughout the national territory. This percentage gradually increased. Currently, in 2017 the percentage of biodiesel in diesel is 7\% [9].

Due to the demand for biodiesel in the current scenario, studies have been carried out with the purpose of proposing biodiesel production routes that present higher conversions without causing damage to the environment and that are at the same time economically viable. In this way, the work aims to present a literature review highlighting the main methods of obtaining biodiesel and the main raw materials used.

\section{Raw Material}

Biodiesel is a fuel obtained from the chemical reaction of compounds present in vegetable oils, animal fats or waste oils and fats, reacting with alcohol, usually methanol or ethanol, in the presence of a catalyst [10].

Methanol when compared to ethanol has higher reactivity. It exhibits greater efficiency in both the speed and yield of the reaction. The use of methanol in the reaction to obtain biodiesel makes 
$10^{\mathrm{TH}}$ INTERNATIONAL CONFERENCE ON SUSTAINABLE ENERGY AND ENVIRONMENTAL

the separation of glycerine from biodiesel in the biodiesel purification process easier and more efficient. Low economic cost is one of the most relevant factors for your choice. However, the use of methanol has some drawbacks, such as its high toxicity. Methanol in Brazil is produced from natural gas. The fact of producing one of the reagents from a non-renewable source causes biodiesel to partially escape the concept of green fuel. There are methods where methanol can be produced from biomass. However, in Brazil it is still not economically feasible when compared to the low cost of the product obtained from natural gas [11].

Ethanol produced in Brazil is predominantly of vegetable origin. Unlike methanol, ethanol has no toxicity. However, the limited use of ethanol is due to a number of factors, including the fact that ethanol is less reactive than methanol. In this way, demanding greater product surplus, higher temperature and longer reaction time, consequently, causes a significant increase in the operational cost. Ethanol also favours the formation of an emulsion, making it difficult to separate the product, thus contributing to an increase in operating costs. Therefore, in the current context, it only economically compensates to produce biodiesel from the ethanol route when ethanol presents a significantly lower price than that of methanol [11].

Other reagents used in the biodiesel production process are vegetable oils and / or animal fats, formed basically by triglycerides and fatty acids.

One of the main raw materials used in the production of biodiesel is vegetable oils. Brazil is a country mostly agricultural and has a wide array of fertile lands and a climate conducive to the cultivation of different oil crops. This makes biodiesel production from vegetable oil larger when compared to other raw materials. Among the oil seeds used in the biodiesel production process we can highlight soybean, palm, cottonseed, colza, babaçu, sunflower seed and castor bean. Soybean is currently the most used oilseed in the process of obtaining biodiesel in Brazil [12].

To obtain the vegetable oil the raw material undergoes an extraction process. Prior to the extraction process, regardless of the method or crop to be used as feedstock, the oilseed normally undergoes a preparation process, which basically includes cleaning, for removal of bark and impurities, crushing, rolling and baking . Vegetable oil can be extracted by two methods, mechanical pressing and mixed pressing, also called chemical extraction. In the mixed press, besides the use of the mechanical press, the use of an organic solvent, usually hexane, is attributed. In the mechanical pressing there is a loss of approximately $6 \%$ of oil in the remaining pie, already in the chemical extraction, this loss is reduced to $1 \%$ [13].

Other sources of raw materials that can be employed in the process of obtaining biodiesel are animal fats. Among them are bovine tallow, fish oils, pork fat, etc. Being the most used bovine tallow. Bovine tallow is a by-product from the meat market [3]. It consists basically of fatty acids of saturated chain, presenting a structure similar to the vegetable oil. The fact that it has a saturated chain causes the clogging to occur at higher temperatures, at approximately $19{ }^{\circ} \mathrm{C}$, which is the maximum clogging temperature allowed by the National Agency for Petroleum, Natural Gas and Biofuels (Brazil). One way to decrease the clogging point is to mix the bovine tallow with vegetable oil with a decrease of approximately $10{ }^{\circ} \mathrm{C}$. When comparing bovine 
tallow with soybean oil, we have the advantage of not competing with the food market, there is no risk of crop failure and it presents lower cost [14][15][16].

Finally, we have that the residual oils can also be used as raw material for biodiesel production. The residual oils are rich in triglycerides, however, they also present significant amount of fatty acids, which depending on the methodology applied for the biodiesel production process requires a pre-treatment of the raw material [17]. Residual oils can be collected in snack bars, industrial, commercial and domestic kitchens. The use of the residual oil promotes the correct disposal and less aggressive to the environment.

\section{$3 \quad$ Biodiesel Production Processes}

Biodiesel appears in the world context from the interest in replacing diesel of non-renewable fossil origin with a fuel that is sustainable and renewable. Therefore, several studies have been and are being developed with the objective of producing biodiesel from renewable sources or alternative sources that have high energy potential, as in the case of oils and residual fats. And, at the same time, develop routes that use reagents less aggressive to the environment and provide satisfactory yields. Finally, to enable large-scale production [18][19] [20].

Biodiesel can be obtained from the esterification or transesterification reaction. The esterification reaction is also known as Fischer's reaction (1895). The reaction is characterized by forming a specific ester, from the reaction of a carboxylic acid with an alcohol, usually methanol or ethanol. It is a slow reaction at room temperature $\left(25^{\circ} \mathrm{C}\right)$. Thus, heating and / or use of catalyst is required [21]. The esterification reaction is usually used to treat the raw material for biodiesel production, in order to reduce the concentration of free fatty acids.

In the transesterification reaction, the ester is always obtained from another ester. In the case of biodiesel the precursor ester is a triglyceride, receiving this connotation because it has three groups of esters [21]. In the production of biodiesel by transesterification reaction, the triglyceride reacts with alcohol, methanol or ethanol, in the presence of a catalyst, forming biodiesel and glycerin [22].

Biodiesel can be obtained from different routes: basic catalysis, acid or enzymatic. The catalysts are used in the production process with the aim of modifying the kinetics of the reaction, increasing the reaction rate and selectivity in relation to the desired product [23]. The following will be presenting the main methodologies used in its production.

\subsection{Process of biodiesel production via alkaline catalysis}

Among the biodiesel production methods we can highlight the transesterification via basic catalysis. This production route can be divided into two groups, basic homogeneous catalysis and basic heterogeneous catalysis. The most common homogeneous basic catalysts are sodium hydroxide $(\mathrm{NaOH})$, potassium hydroxide $(\mathrm{KOH})$, sodium methoxide $(\mathrm{NaOCH} 3)$ and sodium ethoxide ( $\mathrm{NaOCH} 2 \mathrm{CH} 3)$. According to the literature, the most heterogeneous basic catalysts used are calcium hydroxide $(\mathrm{Ca}(\mathrm{OH})$ 2) and oxides of magnesium $(\mathrm{MgO})$, calcium $(\mathrm{CaO})$, strontium $(\mathrm{SrO})$, barium $(\mathrm{BaO})$ and zinc $\mathrm{ZnO})[24]$. 
$10^{\mathrm{TH}}$ INTERNATIONAL CONFERENCE ON SUSTAINABLE ENERGY AND ENVIRONMENTAL

Protection (June $27^{\mathrm{TH}}-30^{\mathrm{TH}}, 2017$, Bled, Slovenia), Bioenergy AND Biofuels

E.L. Almeida, C.M.G. Andrade \& O.A.A. Santos: Biodiesel Production. A Brief

Review

Industrially, basic homogeneous catalysis is the most employed. The most homogeneous basic catalysts used in large scale production are sodium hydroxide $(\mathrm{NaOH})$ and potassium hydroxide $(\mathrm{KOH})$. This is due to the low economic cost of the catalysts and the fact that they have high conversion rates [25]. To obtain the maximum yield, anhydrous alcohol is used and preferably raw materials with low concentrations of free fatty acids. The high moisture content in the reaction medium causes the hydrolysis of triglycerides to occur, this hydrolysis favours the formation of fatty acids. High concentrations of fatty acids in contact with basic catalysts provide the production of soap. Soap formation, in turn, makes it difficult to purify biodiesel during the washing process [26].

The work developed by Lee et al. (2016) aimed to investigate the catalytic activity of mixed metal oxides in biodiesel production using as raw material jatropha oil via the methyl route. The catalysts used were: $\mathrm{CaO}-\mathrm{MgO}, \mathrm{CaO}-\mathrm{ZnO}, \mathrm{CaO}-\mathrm{La} 2 \mathrm{O} 3$ and $\mathrm{MgO}-\mathrm{ZnO}$. The results show that the catalysts of mixed metal oxides presented higher catalytic activity than the pure metal oxides. According to the authors, the catalysts of mixed metal oxides present high density and strong basicity, being excellent properties for transesterification reaction. The mixed catalysts based on $\mathrm{CaO}$ showed higher catalytic activity, good reuse and low leaching. Among them, the $\mathrm{CaO}-\mathrm{ZnO}$ catalyst was the one that favoured greater biodiesel conversion [27].

Veillette et al. (2016) proposed the production of biodiesel from oil extracted from Scenedesmus obliquus microalgae. The basic catalysts used were potassium hydroxide and strontium oxide. The experimental parameters used were: proportion of methanol with respect to lipid mass $31.4 \%$ and mass of catalyst with respect to oil mass $2.48 \%$, reaction time and temperature of $22.2 \mathrm{~min}$ and $60^{\circ} \mathrm{C}$. The results demonstrate that potassium hydroxide presented higher yield compared to strontium oxide. Although it presented a lower yield, the strontium oxide proved to be an effective catalyst, since it presented a yield of $76 \%$. However, the authors caution that the use of alkaline earth metals, such as strontium oxide, should be avoided due to leaching of the catalyst in the reaction medium. They conclude that the leaching occurs due to the presence of free fatty acids and moisture. Thus, the use of basic heterogeneous catalysts requires that the raw material be free of free fatty acids and moisture [28].

\subsection{Process of biodiesel production via acid catalysis}

One of the problems related to the use of conventional catalysis is the formation of soaps due to the reaction of the basic catalyst with the free fatty acids. In this way, studies have been developed with the objective of finding alternatives technically, environmentally and economically feasible. Acid catalysis has been studied as a possible partial or complete substitute biodiesel production route of the conventional route. Acid catalysis has the advantage of obtaining biodiesel both through the esterification reaction of fatty acids and transesterification of triglycerides. Thus, acid catalysis makes it possible to use raw materials with a significant content of fatty acids, which in turn is economically more viable. It also eliminates, even partially, the pre-treatment step of the raw material present in the traditional process.

Vieira et al. (2013) evaluated the use of heterogeneous acid catalysts in biodiesel production. The catalysts used were: La2O3, SO42- / La2O3, HZSM-5 (zeolite) and SO42- / La2O3 / HZSM-5 (SOL / HZSM-5). The experimental parameters evaluated were: molar ratio of oleic 
oil per methyl alcohol, percentage of catalyst with respect to oleic oil mass and reaction temperature. According to the authors, temperature was the parameter that most influenced the catalytic process. The results show that the SOL / HZSM-5 catalyst showed the highest conversion. The best results were obtained at the temperature $100^{\circ} \mathrm{C}$ and molar ratio of 1: 5 , with the exception of the HZSM-5 catalyst which was $1: 2$. The authors conclude that the results presented a good performance by the catalysts and can be used in the biodiesel production process [29].

The work performed by Peres et al. (2016) had as objective to evaluate the performance of the metallic oxides catalysts spinel type in the biodiesel production. These catalysts are characterized by being bifunctional, presenting acidic and basic sites. It can act on esterification of fatty acids and transesterification of triglycerides. The catalysts used were zinc aluminate $(\mathrm{ZnAl} 2 \mathrm{O} 4)$ and cobalt aluminate ( $\mathrm{CoAl} 2 \mathrm{O} 4)$. The parameters evaluated were: catalyst concentration, alcohol / oil molar ratio and temperature on yield. Using as raw material oils and residual fats. The results showed that at concentrations above $7 \%$ the $\mathrm{ZnAl} 2 \mathrm{O} 4$ catalyst yields higher than $80 \%$ yield regardless of the temperature and alcohol / oil molar ratio. In the case of CoAl.sub.2 O.sub.4 to obtain yields of greater than $80 \%$ at $7 \%$ concentration it is necessary to work at a temperature of $140{ }^{\circ} \mathrm{C}$ and an alcohol / oil molar ratio of 1: 6 or $100{ }^{\circ} \mathrm{C}$ and alcohol / oil molar ratio of 1: 9 . According to PERES et. $\mathrm{Al}$ (2016) the process of transesterification using the zinc and cobalt aluminate catalysts may be an alternative for the production of biodiesel from waste oils and fats [30].

\subsection{Process of biodiesel production via enzymatic catalysis}

Another route of biodiesel production is enzymatic catalysis. Enzymes are organic polymers formed by amino acids. They have in their structure active sites that can act as biological catalysts with high specificity [31][32]. In the literature the enzyme lipase stands out in the biodiesel production process. The enzyme can be obtained from Aspergillus niger (lipase A), Mucor javanicus (lipase M), Burkholderia cepacia (lipase PS), Pseudomonas fluorescens (lipase AK), among other microorganisms [33]. The lipase enzyme is classified as hydrolase by acting on the ester bond of various compounds. The enzymes are generally immobilized in order to obtain biocatalysts with higher catalytic activity and also with higher thermal and chemical stability. One of the disadvantages of using lipase is due to its financial cost. The immobilization of the lipase allows to recover the biocatalyst and reuse again in the process, reducing the cost of production. The most frequent immobilization techniques are adsorption, ionic and covalent bonding [31].

Souza et al. (2016) studied the production of biodiesel using Jatropha (Jatropha curcas L.) oil as raw material via enzymatic ethyl ester transesterification. Commercial lipases immobilized by covalent attachment on epoxy-SiO2-PVA were used. The immobilized lipases of Pseudomonas fluorescens (lipase AK) and Burkholderia cepacia (lipase PS) showed better yield of ethyl ester, being 91.1 and $98.3 \%$ in 72 hours of reaction. The reactions that occurred under microwave irradiation presented higher yield and productivity when compared to the conventional heating method. According to the authors the biocatalysts have shown satisfactory results and that the same can be applied in the production of biodiesel. The authors emphasize that the use of biocatalysts requires a solvent-free medium [34]. 
$10^{\text {TH }}$ INTERNATIONAL CONFERENCE ON SUSTAINABLE ENERGY AND ENVIRONMENTAL

The work developed by Nordblad et al. (2016) proposed a pre-treatment of rapeseed oil that will be used as raw material in the biodiesel production process, via basic catalysis. Pretreatment was performed through enzymatic catalysis using the enzyme lipase B (Novozym 435), focusing on the initial concentration of free fatty acids and methanol, in order to obtain the best experimental parameters. The authors found that using $5 \%$ of catalyst and $4 \%$ of methanol at $35{ }^{\circ} \mathrm{C}$, the concentration of $15 \%$ of fatty acids present in the raw material could be reduced to $0.5 \%$ in one hour of reaction. The authors conclude that the suggested pretreatment process is an efficient method to reduce the concentration of fatty acids. It can be used in raw materials with a concentration of up to $20 \%$ of fatty acids [35].

\section{Conclusion}

Biodiesel has characteristics similar to diesel from petroleum, being a possible substitute. Studies show great interest in production in biodiesel production, since, compared to conventional diesel, biodiesel has the advantage of being renewable and less aggressive to the environment. Biodiesel can be produced from different raw materials. However, it is possible to conclude that the main raw material is vegetable oils, because it can produce biodiesel from various oilseeds.

Several biodiesel production routes were presented. However, the production of biodiesel through the basic catalysis was to the route that showed the best results regarding conversion, reaction time and economic cost. Acid catalysis, in turn, has proved to be a possible route to be used as pre-treatment of raw materials with high levels of fatty acids. Finally, enzymatic catalysis despite having many advantages, such as its high specificity, is not yet economically feasible.

\section{Acknowledgements}

The authors would like to thank Coordenação de Aperfeiçoamento de Pessoal de Nível Superior (CAPES) for the financial support.

\section{References}

[1] International Energy Administration. CO2 Emissions fron Fuel Combustion. Accessed: 23/10/ 2015. http://www.iea.org/stats/.

[2] N. Rodrigues and L. Losekann, Demand analysis for diesel oil in Brazi. 5th Latin American Energy Economics Meeting, Medellin, 2015. pp. 1-8.

[3] I. L. Sauer et al., Energias renováveis: ações e perpectivas na Petrobrás. Bahia Análises e Dados. Vol. 16, pp. 9-22, 2006.

[4] L. L. N. Guarieiro et al., Determination of biodiesel percentage in biodiesel:diesel mixtures using mid-infrared spectroscopy. Química Nova. Vol. 31, pp. 421-426, 2008.

[5] A.P.B. Santos and A.C Pinto, Biodiesel: An alternative of the clean fue, Química Nova, Vol. 31, pp. 58-62, 2009.

[6] F.C.C. Oliveira et a., Biodiesel: possibilites and challenges, Química nova na Escola, Vol. 28, pp. 2-8, 2008.

[7] M. Meira et al., Determination of the oxidation stability of biodiesel and by spectrofluorimetry and multivariate calibration, Talanta, Vol. 85, pp. 430-434, 2011. 
$320 \quad 10^{\mathrm{TH}}$ International Conference on Sustainable Energy and Environmental Protection (June $27^{\mathrm{TH}}-30^{\mathrm{TH}}, 2017$, BLED, SLOVENiA), Bioenergy AND Biofuels E.L. Almeida, C.M.G. Andrade \& O.A.A. Santos: Biodiesel Production. A Brief Review

[8] N. N. A. N Yusuf, S. K kamarudin and Z. Yaakub, Overview on the current trends in biodiesel production. Energy Conversion and Management. Vol. 52, pp. 2741-2751, 2011.

[9] ANP. Agência Nacional do Petróleo, Gás Natural e Biocombustíveis. http://www.anp.gov.br/wwwanp/biocombustiveis/biodiesel. Accessed: 02/02/2017

[10] A. Abbaszaadeh et al., Current biodiesel production technologies: A comparative review. Energy Conversion and Management, Vol. 63, pp. 138-148, 2012.

[11] P.A. Z. Suarez. Metanol ou Etanol: algumas considerações. biodieselbr. https://www.biodieselbr.com/noticias/colunistas/suarez/metanol-ou-etanol-consideracoes-20-0208.htm. Accessed: 15/12/2016

[12] ANP. Agência Nacional do Petróleo, Gás Natural e Biocombustíveis. http://www.anp.gov.br/wwwanp/biocombustiveis/biodiesel. Access: 12/03/2017

[13] M.A. Sartori et al., Análise de arranjos para extração de óleos vegetais e suprimento de usina de biodiesel. Revista de Economia e Sociologia Rural - RESR, Vol. 37, pp. 419-434, 2009.

[14] M.S.A. Moraes et al., Tallow Biodiesel: Properties Evaluation and Consumption Tests in a Diesel Engine. Energy \& Fue, Vol. 22, pp. 1949-1954, 2008.

[15] M. E. Cunha et al., Beef tallow biodiesel produced in a pilot scale. Fuel Processing Technology, Vol. 90, pp. 1949-1954. 2009

[16] B.B. Milli, et al. Study of the biodiesel production from tallow veal with mixed vegetable oil. Enciclopédia Biosfera, Vol. 7, pp. 1-26, 2011.

[17] J.M. Marchetti et al., Heterogeneous esterification of oil with high amount of free fatty acids, Fuel, Vol. 86, pp. 906-910, 2007.

[18] N. Gaurav et al., Utilization of bioresources for sustainable biofuels: A Review. Renewable and Sustainable Energy Reviews, Vol. 73, pp. 205-214, 2017.

[19] S.K. Ghosh, Biomass \& Bio-waste Supply Chain Sustainability for Bio-energy and Bio-fuel Production. Procedia Environmental Sciences., Vol. 31, pp. 31 - 39, 2016.

[20] Y. Weldemichael and G. Assefa. Assessing the energy production and GHG (greenhouse gas) emissions mitigation potential of biomass resources for Alberta. Journal of Cleaner Production., Vol. 112, pp 4257 - 4264. 2016

[21] G. Solomons et al., Organic chemistry. Rio de Janeiro : LTC, 2002

[22] J.K. Raman et al.,Life cycle assessment of biodiesel production using alkali, soluble and immobilized enzyme catalyst processes, Biomass Bioenergy, Vol. 35, pp. 4221-4229, 2011.

[23] H.S.Fogler, Elements of chemical reaction engineering. Rio de Janeiro : LTC - Livros Técnicos e científicos, 2012.

[24] Z. Helwani et al., Solid heterogeneous catalysts for transesterification of triglycerides with methanol: A review. Applied Catalysis A: General, Vol. 363, pp. 1-10, 2009.

[25] D.Y. Leung and M. Leung, A review on biodiesel production using catalyzed, Appl. Energy, Vol. 87, pp. 1083-1095, 2010

[26] R. Luque et al., Biodiesel as feasible petrol fuel replacement: A multidisciplinary overview, Energy Environ, Vol. 3, pp. 1706-1721. 2010

[27] H. Lee, Environment-Friendly Heterogeneous Alkaline-Based Mixed Metal Oxide Catalysts for Biodiesel Production. Energies, Vol. 9, pp. 1-12, 2016.

[28] M. Veillette et al., A biodiesel production process catalyzed by the leaching of alcaline metal Earths in metano. JChemTechnolBiotechnol,Vol. 92, pp. 1094 - 1103, 2017.

[29] B.S.Barbosa et al., The use of tucumã of amazonas kernel oil in the biodiesel production. Acta amazonia, 39, pp. $371-376,2010$

[30] S.S. Vieira et al. Biodiesel production by free fatty acid esterification using lanthanum $\left(\mathrm{La}_{3}^{+}\right)$and HZSM-5 based catalysts. Bioresource Technology, Vol. 133, pp. 248-255, 2013.

[31] R.S. Peres et al., Óxidos Metálicos tipo espinélio como catalisadores na produção de Biodiesel a partir de óleo e gordura residual. Acta Scientiae et Technicae, Vol. 4, pp. 1-16,2016

[32] P. Adlercreutz, Immobilisation and application of lipases in organic media. Chemical Society Reviews, Vol. 33, pp. 6406-6436, 2013. 
$10^{\mathrm{TH}}$ INTERNATIONAL CONFERENCE ON SUSTAINABLE ENERGY AND ENVIRONMENTAL

Protection (June $27^{\mathrm{TH}}-30^{\mathrm{TH}}, 2017$, Bled, Slovenia), Bioenergy AND Biofuels

E.L. Almeida, C.M.G. Andrade \& O.A.A. Santos: Biodiesel Production. A Brief

Review

[34] J. K. Poppe et al., Enzymatic reactors for biodiesel synthesis: present status and future prospects. Biotechnology Advances, Vol. 33, pp. 511-525, 2015.

[33] T.M. Mata et al. Biodiesel Production from Corn Oil via Enzymatic Catalysis with Ethanol. Energy Fuels, Vol. 26, p. 3034-3041,2012.

[34] L.T.A. Souza et al., Selection of Lipases for the Synthesis of Biodiesel from Jatropha Oil and the Potential of Microwave Irradiation to Enhance the Reaction Rate. BioMed Research International, pp. 1-13, 2016.

[35] M. Nordblad et al., Enzymatic Pretreatment of Low-Grade Oils for Biodiesel Production. Biotechnology and Bioengineering., Vol. 113, pp. 754-760, 2016. 
322 10 $10^{\mathrm{TH}}$ International CONFERENCE on Sustainable ENERGy AND ENVIRONMENTAL Protection (June $27^{\mathrm{TH}}-30^{\mathrm{TH}}, 2017$, Bled, Slovenia), Bioenergy AND Biofuels 
$10^{\mathrm{TH}}$ INTERNATIONAL CONFERENCE ON Sustainable ENERgy AND EnVironmental Protection (June $27^{\mathrm{TH}}-30^{\mathrm{TH}}$, 2017, BLed, SLOVENIA), BIOENERGY AND BIOFUELS

J. Krope, A.Ghani Olabi, D. Goričanec \& S. Božičnik

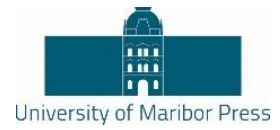

\title{
Biodiesel Production Process Versus Bioethanol Production Process. Preliminary Analysis
}

\author{
EugÊnia LEANdro Almeida, SÉRgio InÁCIO Gomes, Cid Marcos GonÇAlves \\ ANDRADE \& ONÉLIA APARECIDA ANDREO DOS SANTOS
}

\begin{abstract}
Biofuels are sustainable and renewable alternatives for partial or total replacement of fossil fuels. Among the biofuels, two stand out: biodiesel and bioethanol. In Brazil, biodiesel is produced, mainly, from soybean oil, via basic homogeneous catalysis. Bioethanol is produced from sugarcane via fermentation process. In this way, the objective of the work was to carry out a preliminary analysis of the energy content that can be extracted from a particular cultivable area. Evaluating two situations: First, the amount of energy stored in soybeans grown in an area of $10000 \mathrm{~m}^{2}$ and the conversion of this energy into biodiesel and its co-products. Second, the amount of energy stored in sugarcane cultivated in the same area of 10 $000 \mathrm{~m}^{2}$ and to analyse the conversion of this energy into bioethanol and its co-products. Finally, compare which of the two situations has the highest energy potential.
\end{abstract}

Keywords: $\bullet$ Biodiesel $\bullet$ Biofuel $\bullet$ Bioethanol $\bullet$ Renewable energy $\bullet$ Energy

CORRESPONDENCE ADDRESS: Eugenia Leandro Almeida, M.Sc, Universidade Estadual de Maringá, Chemical Engineering Department, Av. Colombo, 5790 - Vila Esperança, Maringá - Paraná, Brasil, email: eugenia-almeida@hotmail.com. Sérgio Inácio Gomes, Ph.D, Universidade Estadual de Maringá, Chemical Engineering Department, Av. Colombo, 5790 - Vila Esperanca, Maringá Paraná, Brasil,email: sigomes2@uem.br. Cid Marcos Gonçalves Andrade, Ph.D, Universidade Estadual de Maringá, Chemical Engineering Department, Av. Colombo, 5790 - Vila Esperanca, Maringá - Paraná, Brasil,email: cid@deq.uem.br. Onélia Aparecida Andreo dos Santos, Ph.D, Universidade Estadual de Maringá, Chemical Engineering Department, Av. Colombo, 5790 - Vila Esperanca, Maringá - Paraná, Brasil,email: onelia@deq.uem.br.

https://doi.org/10.18690/978-961-286-048-6.32

ISBN 978-961-286-048-6

(C) 2017 University of Maribor Press

Available at: http://press.um.si. 
$10^{\mathrm{TH}}$ InTERNATIONAL CONFERENCE ON Sustainable ENERGY AND ENVIRONMENTAL Protection (June $27^{\mathrm{TH}}-30^{\mathrm{TH}}, 2017$, BLed, Slovenia), Bioenergy AND Biofuels E.L. Almeida, S.I. Gomes C.M.G. Andrade \& O.A.A. Santos: Biodiesel Production Process Versus Bioethanol Production Process. Preliminary Analysis

Technological advances, both in the industrial area and in people's daily lives, have significantly increased the demand for fossil fuels from petroleum. At present, the use of these fuels has been sought to reduce the emission of gases that contribute to the worsening of the greenhouse effect [1]. Studies have been developed to propose sustainable and renewable alternatives to fully or partially meet the demand for fossil fuels [2]. Biofuels appear as sustainable and renewable alternatives, presenting numerous advantages, such as lower pollution rate with their burning, their raw materials can be cultivated, therefore renewable, biodegradable, etc. [3, 4]. Among biofuels, biodiesel and bioethanol can be highlighted [5].

Biodiesel is a potential substitute for conventional diesel obtained from the petroleum fractionation process [6]. Biodiesel is an ester, usually obtained by the transesterification reaction of triglycerides with alcohol, in the presence of a catalyst, forming as product glycerine and biodiesel [7]. In general, the alcohols used are methanol or ethanol, being the methanol most used because of its high reactivity and to facilitate the process of separation of biodiesel from other products and reagents [8]. The transesterification reaction is a reversible reaction, and it is convenient to use excess alcohol, in order to displace the reaction equilibrium in the product formation direction. The catalytic processes frequently used in biodiesel production are: basic, acid and enzymatic catalysis [9]. Vegetable oil, animal fat and oil/waste fat are possible raw materials used in the biodiesel production process $[10,11,12]$. In commercial scale the process of biodiesel production is carried out by homogeneous basic catalysis via the methyl route [12]. The catalysts frequently used are potassium hydroxide $(\mathrm{KOH})$ and sodium hydroxide $(\mathrm{NaOH})$. In Brazil, the most important raw material in biodiesel production is soybean oil. According to the National Agency of Petroleum, Natural Gas and Biofuels $72 \%$ of the biodiesel produced comes from soybean oil [13].

Bioethanol, also known as ethyl alcohol, is a possible successor to petroleum gasoline. Bioethanol presents some advantages when compared to gasoline, such as the fact that it is a biodegradable and renewable fuel, has low toxicity and presents a lower emission of pollutants in the atmosphere [14]. Bioethanol can be used pure, as alcohol hydrated or mixed with gasoline, as anhydrous alcohol [15]. It can be produced from several raw materials, receiving three denominations with respect to the type of raw material used in its procurement process. First-generation bioethanol is that derived from sugars and starches, such as sugarcane, beet, potato and cassava. Second-generation bioethanol is that derived from lignocellulose biomass, such as wood, straw and fibbers, for example, sugarcane bagasse. Finally, the third generation bioethanol from aquatic biomass, micro algae or macro algae [16]. Bioethanol is produced by means of a fermentation process. The microorganisms frequently used in fermentation are Sccharomyces cerevisiae yeasts. These yeasts present higher productivity of bioethanol, high tolerance to bioethanol and ability to ferment various substrates [17]. In Brazil, bioethanol is obtained from sugarcane. The use of sugarcane in the production of bioethanol is favourable, since the country has a vast territorial extension and a favourable climate for the development of 
this culture. The production of bioethanol from sugarcane presents a lower cost when compared to bioethanol produced from other raw materials [18].

This work aimed to perform a preliminary analysis of a particular area of soybean plantation, and calculate from mass and energy balances how much biodiesel is produced, consequently, analyse the amount of energy in the form of biodiesel is generated with respect to the area. Carry out the same analysis for bioethanol, using the same area, but for planting sugarcane. Check which of the two biofuels has the highest energy potential, considering the same area and its respective raw materials. It is important to emphasize that in this preliminary work several parameters were not taken into account in order to calculate only the ratio of the area to the amount of energy stored in the raw materials that will later be converted into biofuels. Another work is being developed considering such variables that includes an exergética analysis that of all the productive stages of the process, from the planting of the cultures until the obtaining of the final products.

\section{$2 \quad$ Materials and Methods}

For a preliminary, comparative analysis, which relates a certain area for biodiesel production and bioethanol production, in order to calculate its energy potentials, some considerations were made, such as:

- The energy expended with the agricultural inputs used in both cases was not considered.

- The necessary energy for the planting of both crops, as well as the harvests and transportation of the raw materials, were not considered.

- The energy supplied to the equipment used during the production processes to obtain biofuels was not considered. Therefore, energy balances (or exergéticos, which are more adequate) in the process plants were not performed.

- Losses were not considered during the processes for obtaining biofuels.

- It was found that in both procedures the conversion of the reactants into products was $100 \%$.

- An area of one hectare, equivalent to $10,000 \mathrm{~m}^{2}$, was considered as the basis of calculation.

- The same crop cycle was considered for both crops.

- It was first considered only the energy stored in the raw materials during the cultivation process and then the conversion of this energy into biofuels.

- It was considered the sale of by-products with the highest highlights of each situation and the amount collected used to buy the fuels produced in each situation, as a form of energy conversion. 
$10^{\text {Th }}$ International Conference on Sustainable Energy and Environmental Protection (JunE $27^{\mathrm{TH}}-30^{\mathrm{TH}}, 2017$, Bled, Slovenia), BioENERGY AND Biofuels E.L. Almeida, S.I. Gomes C.M.G. Andrade \& O.A.A. Santos: Biodiesel Production Process Versus Bioethanol Production Process. Preliminary Analysis

\subsection{Biodiesel production process}

For the development of the work, there was considered the production of biodiesel using soybean oil and ethyl alcohol as raw materials. The reaction of transesterification, via homogeneous alkaline catalysis using $\mathrm{NaOH}$ as catalyst. The overall transesterification reaction is shown in figure 1 .

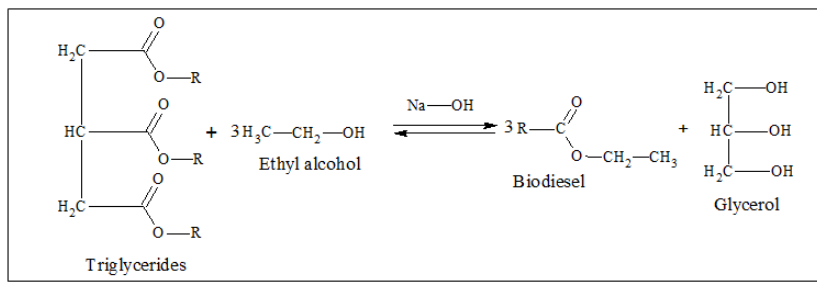

Figure 1: Basic homogeneous transesterification reaction. $\mathrm{R}$ represents the fatty acid carbon chains

As it is intended to evaluate the amount of energy stored in soybeans grown per hectare and later converted to biodiesel, the analysis was started with the soybean oil extraction process. Figure 2 shows the flowchart of a soybean oil extraction process.

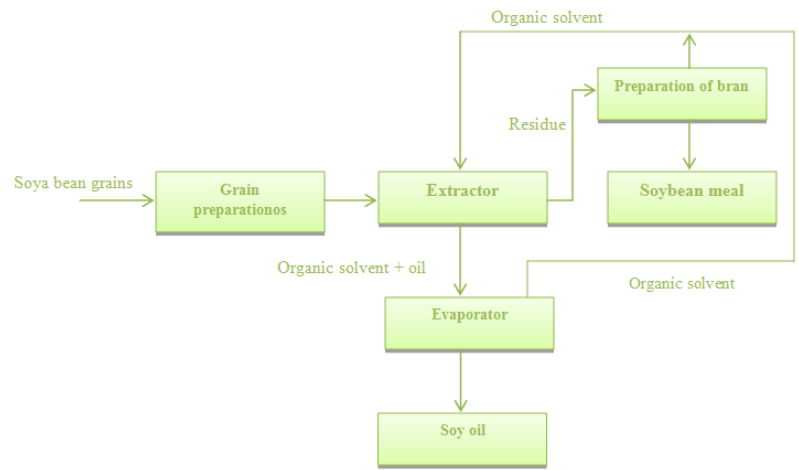

Figure 2: Flow diagram of the soybean oil extraction process

The average compositions of soybean grains are: $40.3 \%$ protein, $21 \%$ oil and $38.8 \%$ carbohydrates on dry basis [18]. The calorific power of soybean oil is on average 9.421 (kcal / kg) [19]. And its molar mass of soybean oil $873.36 \mathrm{~g} / \mathrm{mol}$ [[20]. Soybean oil usually has a content of 1 to $5 \%$ of free fatty acids. Therefore, a quantitative analysis of the fatty acid content present in this oil is necessary since the production process of the conventional biodiesel is via alkaline transesterification. Figure 3 shows a generic flowchart of biodiesel production via alkaline transesterification. 


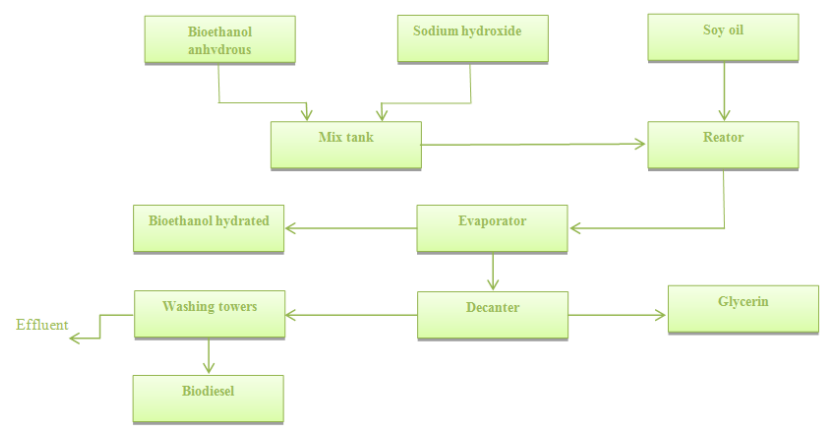

Figure 3: Flow diagram of biodiesel production process

According to the Brazilian Agricultural Research Corporation, the average yield of Brazilian soybean is $3,000.00 \mathrm{~kg}$ per hectare [21]. The soybean cultivation cycle is approximately 120 days.

\subsection{Process of production of bioethanol}

In the bioethanol production process, sugarcane was considered as the raw material. The conversion of sugars into bioethanol was carried out via alcoholic fermentation using Sccharomyces Cerevisiae yeast. Figure 4 shows the overall reaction of the ethanol produced by the fermentation process.

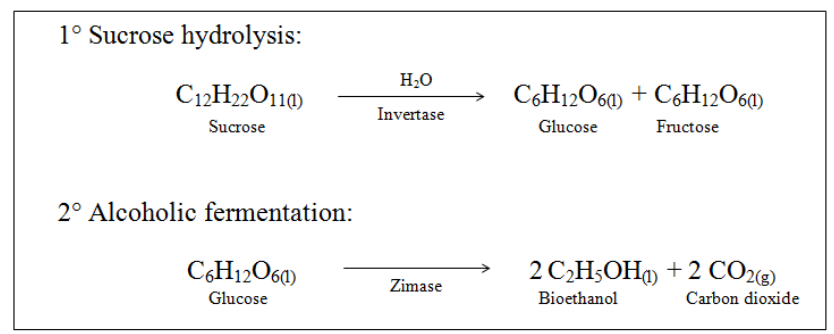

Figure 4: Global reaction of bioethanol production

The bioethanol production process begins with the preparation of the raw material. Firstly, the sugarcane passes through an electromagnet to remove metallic objects. Then, the sugar cane goes through a washing process, this step is only carried out when the sugar cane harvest is done manually. Subsequently the sugarcane goes through chopping and shredding. Once the sugarcane has been prepared, it is then moved to the mills, with the objective of extracting the sugarcane juice. This broth goes into a process of treatment and concentration, following to the fermentation tanks together with the yeasts. At the end of the alcoholic conversion, the yeast is separated from the fermented wine. The yeasts are treated in the vats and the wine goes to distillation, thus obtaining the bioethanol. Figure 5 shows the generalized flowchart of the production process. 
$10^{\mathrm{TH}}$ International Conference on Sustainable EnERgy and Environmental Protection (June $27^{\mathrm{TH}}-30^{\mathrm{TH}}, 2017$, BLed, Slovenia), Bioenergy AND Biofuels E.L. Almeida, S.I. Gomes C.M.G. Andrade \& O.A.A. Santos: Biodiesel Production Process Versus Bioethanol Production Process. Preliminary Analysis

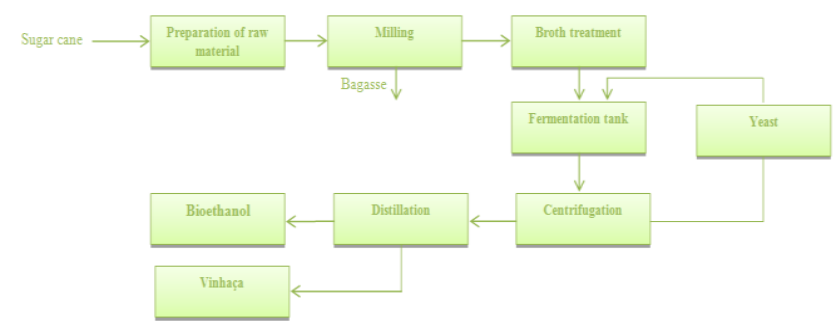

Figure 5: Flow diagram of the bioethanol production process

The average production of sugarcane is 73.225 tons per hectare. The cultivation cycle of sugarcane is 18 months [22].

\section{$3 \quad$ Results}

\subsection{Biodiesel production process}

It has been that the cycle of cultivation of soybeans is of months frame and the cycle of cultivation of the sugar cane is of 18 months. Thus, to analyze the same available area and consequently the amount of energy stored in these raw materials during their cultivations, the same time interval was considered. Therefore, if in a period of 4.0 months produces $3,000.00 \mathrm{~kg}$ of soybean per hectare, in 18 months $13,500 \mathrm{~kg}$ of soybean per hectare is obtained. The amount of soybean hulls is equivalent to $2 \%$ of the soybean mass entering the extraction process, according to Zambom et al. (2001) the amount is minimal that can be processed in order to increase the protein value of the bran [23]. Table 1 presents the specific considerations made in the biodiesel production process.

Table 1: Considerations made in the biodiesel production process

\begin{tabular}{|l|r|}
\hline Variables & Values \\
\hline Concentration of oil in soybean & $21.0 \%$ \\
\hline Protein concentration in soybean grain & $40.3 \%$ \\
\hline Concentration of carbohydrates in soybean & $38.8 \%$ \\
\hline Concentration of free fatty acids & $1.0 \%$ \\
\hline Concentration of catalyst & $5 \%$ \\
\hline Molar ratio oil/alcohol & $1: 6$ \\
\hline
\end{tabular}

The molar mass of the triglycerides was considered the same as the oil since a percentage of $1 \%$ of fatty acids was considered. By using a relatively low concentration one can consider the same molar mass and also, it was possible to disregard the process of treatment of the raw material. Table 2 shows the results obtained. 
$10^{\mathrm{TH}}$ INTERNATIONAL CONFERENCE ON SUSTAINABLE ENERGY AND ENVIRONMENTAL Protection (June $27^{\mathrm{TH}}-30^{\mathrm{TH}}, 2017$, BLed, Slovenia), Bioenergy ANd Biofuels E.L. Almeida, S.I. Gomes C.M.G. Andrade \& O.A.A. Santos: Biodiesel Production Process Versus Bioethanol Production Process. Preliminary Analysis

Table 2: Results of the biodiesel production process by area

\begin{tabular}{|l|r|}
\hline Variables & Results \\
\hline Mass of soya & $13,500.00\left(\mathrm{~kg} / \mathrm{m}^{2}\right)$ \\
\hline Mass of oil & $2,835.00\left(\mathrm{~kg} / \mathrm{m}^{2}\right)$ \\
\hline Mass of soybean & $10,665.00\left(\mathrm{~kg} / \mathrm{m}^{2}\right)$ \\
\hline Mass of catalyst & $141.75(\mathrm{~kg})$ \\
\hline Mass of bioethanol & $897.09(\mathrm{~kg})$ \\
\hline Mass of Triglycerides & $2,806.65\left(\mathrm{~kg} / \mathrm{m}^{2}\right)$ \\
\hline Mass of biodiesel & $2,954.48\left(\mathrm{~kg} / \mathrm{m}^{2}\right)$ \\
\hline Mass of glycerin & $295.97\left(\mathrm{~kg} / \mathrm{m}^{2}\right)$ \\
\hline
\end{tabular}

Analysing table 2 it is possible to note the considerable amount of bran produced. Soybean meal is one of the most important co-products of biodiesel production, since bran is rich in protein. Therefore, a way of quantifying the energy obtained from the meal, was considered its sale and the amount collected used to buy biodiesel. The price of soybean meal - Chicago Stock Exchange, closing April 24, 2017 [24] was 316 US\$/ton. The price of the dollar on 04/26/2016 was R \$3.1821. According to the National Agency of Petroleum, Natural Gas and Biofuels (54th Biodiesel Auction held in February 2017) the average biodiesel price is $2,126.85 \mathrm{R} \$ / \mathrm{m}^{3}$. The density of ethyl biodiesel at $20^{\circ} \mathrm{C}$ is $880\left(\mathrm{~kg} / \mathrm{m}^{3}\right)$ [25] and the calorific capacity of soybean biodiesel is $37.20(\mathrm{MJ} / \mathrm{kg})$. The mass of biodiesel purchased from the sale of the bran is $\left(4,437.18 \mathrm{~kg} / \mathrm{m}^{2}\right)$. The results are shown in Table 3.

Table 3: Amount of energy converted per hectare of soybean

\begin{tabular}{|l|r|}
\hline Variables & Energy \\
\hline $\begin{array}{l}\text { Biodiesel obtained during the } \\
\text { process }\end{array}$ & $109,906.53\left(\mathrm{MJ} / \mathrm{m}^{2}\right)$ \\
\hline $\begin{array}{l}\text { Biodiesel obtained from the sale } \\
\text { of soybean meal }\end{array}$ & $165,063.10\left(\mathrm{MJ} / \mathrm{m}^{2}\right)$ \\
\hline Total energy & $274,969.63\left(\mathrm{MJ} / \mathrm{m}^{2}\right)$ \\
\hline
\end{tabular}

\subsection{Production of bioethanol}

The cultivation cycle of sugarcane is 180 days producing on average 73,225 tons by area. Table 4 presents the considerations for the bioethanol production process and Table 5 shows the results obtained. 
$330 \quad 10^{\mathrm{TH}}$ InTERNATIONAL CONFERENCE ON SUSTAINABLE ENERGY AND ENVIRONMENTAL Protection (June $27^{\mathrm{TH}}-30^{\mathrm{TH}}, 2017$, BLed, SloveniA), Bioenergy AND Biofuels E.L. Almeida, S.I. Gomes C.M.G. Andrade \& O.A.A. Santos: Biodiesel Production Process Versus Bioethanol Production Process. Preliminary Analysis

Table 4: Considerations made in the bioethanol production process

\begin{tabular}{|l|r|}
\hline Variables & Values \\
\hline Mass fraction of sucrose in sugarcane & $14 \%$ \\
\hline Mass fraction of solids soluble in sugarcane & $7 \%$ \\
\hline Mass fraction of sugarcane bagasse & $30 \%$ \\
\hline Mass fraction of water in sugarcane & $49 \%$ \\
\hline Mass fraction of bioethanol & $96 \%$ \\
\hline
\end{tabular}

Table 5: Results obtained from the bioethanol production process by area.

\begin{tabular}{|l|r|}
\hline Variables & Results \\
\hline Amount of sugarcane & $73,225.00\left(\mathrm{~kg} / \mathrm{m}^{2}\right)$ \\
\hline Sugarcane bagasse & $21,967.50\left(\mathrm{~kg} / \mathrm{m}^{2}\right)$ \\
\hline Mass of bioethanol & $1,372.11\left(\mathrm{~kg} / \mathrm{m}^{2}\right)$ \\
\hline Mass of carbon dioxide & $1,259.96\left(\mathrm{~kg} / \mathrm{m}^{2}\right)$ \\
\hline
\end{tabular}

In the bioethanol production process one of the by-products generated is sugarcane bagasse. Due to its high calorific bagasse it is used as biomass for electricity generation. Therefore, the sale of this by-product was considered. The value hypothetically collected from the sale of bagasse was used to purchase hydrated ethanol. In Brazil, the price of the ton of sugarcane bagasse on average is $\$ 85.00$ [26] this data was published on December 13, 2016. The price of the bioethanol plant is on average $\mathrm{R} \$ 1,566$ per litter [27]. This data was published on 04 March 2017. Density of bioethanol $20^{\circ} \mathrm{C}$ is 0.789 $\left(\mathrm{g} / \mathrm{m}^{3}\right)$. Mass of ethanol purchased from the sale of bagasse is $940,772.92\left(\mathrm{~kg} / \mathrm{m}^{2}\right)$. The calorific value of bioethanol is $25.56(\mathrm{MJ} / \mathrm{kg})$.

Table 6: Amount of energy converted by area of sugarcane

\begin{tabular}{|c|c|}
\hline Variables & Energy \\
\hline $\begin{array}{l}\text { Bioethanol produced during the } \\
\text { process }\end{array}$ & $\begin{array}{r}35,071.13 \\
\left(\mathrm{MJ} / \mathrm{m}^{2}\right)\end{array}$ \\
\hline $\begin{array}{l}\text { Bioethanol purchased from the sale } \\
\text { of bagasse }\end{array}$ & $\begin{array}{r}24,046,155.75 \\
\left(\mathrm{MJ} / \mathrm{m}^{2}\right)\end{array}$ \\
\hline Total energy & $\begin{array}{r}24,081,226.88 \\
\left(\mathrm{MJ} / \mathrm{m}^{2}\right)\end{array}$ \\
\hline
\end{tabular}

\section{Discussion}

The preliminary analysis carried out with the objective of quantifying energy stored in soybean and sugarcane crops that were later converted to biodiesel and bioethanol in an area of 10,000 square meters showed that bioethanol is the biofuel that has the highest potential Energy. Bioethanol had an energy potential of 24,081,226.88 $\left(\mathrm{MJ} / \mathrm{m}^{2}\right)$ while biodiesel $274,969.63$ $\left(\mathrm{MJ} / \mathrm{m}^{2}\right)$.

However, it is important to note that in both processes several parameters were not considered, one of them being the amount of energy required during the processes, which in turn interferes 
directly with the final results, since each process plant has energy consumptions Different. Another important variable is the conversion of the raw material into product, because each process has its own conversion. One process may have greater conversion than the other.

Another important point is the losses during the processes. In the case of bioethanol in particular, significant losses occur during the production process, including the various unit operations involved in the process and the alcoholic fermentation itself.

Therefore, although preliminary analysis shows that bioethanol has a higher energy potential than biodiesel. Studies are being developed in order to carry out a more complex and detailed analysis. Taking into account the application of an exergetic balance in both processes, since this balance provides more realistic data of the losses of energies (destruction of exergy).

\section{5}

\section{Conclusion}

It is concluded that in this preliminary analysis (with simplifying hypotheses) bioethanol is the fuel that presented the highest energy potential per cultivated area of the crops considered (soybean and sugarcane).

\section{Acknowledgements}

The authors would like to thank Coordenação de Aperfeiçoamento de Pessoal de Nível Superior (CAPES) for the financial support.

\section{References}

[1] Kiran, B. et al., Perspectives of microalgal biofuels as a renewable source of energy. Energy Conversion and Management, Vol. 88, pp. 1228-1244, 2014.

[2] Weldemichael, Y. and Assefa, G., Assessing the energy production and GHG (greenhouse gas) emissions mitigation potential of biomass resources for Alberta. Journal of Cleaner Production, Vol. 112, pp. 3597-4900, 2016

[3] Gaurav, N., et al., Utilization of bioresources for sustainable biofuels: A Review. Renewable and Sustainable Energy Reviews, Vol. 73, pp. 205-214, 2017.

[4] Ghosh, S.K., Biomass \& Bio-waste Supply Chain Sustainability for Bio-energy and Bio-fuel Production. Procedia Environmental Sciences, Vol. 31, pp. 31 - 39, 2016

[5] Hassan, M.H. and Kalam, M. A., An overview of biofuel as a renewable energy source: development and challenges. Procedia Engineering, Vol. 56, pp. 39-53, 2013.

[6] Kapor, N.Z.A., et al., Palm fatty acid distillate as a potential source for biodiesel production - a review. Journal of Cleaner Production, Vol. 143, pp. 1-9. 2017

[7] Evangelista, J. P., et al., Alumina-supported potassium compounds as heterogeneous catalysts for biodiesel production: A review. Renewable and Sustainable Energy Reviews, Vol. 59, pp. 887894, 2016.

[8] Zabeti, M., et al., Activity of solid catalysts for biodiesel production: A review. Fuel Processing Technology, Vol. 90, pp. 770-777, 2009.

[9] Helwani, Z., et al., Solid heterogeneous catalysts for transesterification of triglycerides with methanol: A review. Applied Catalysis A: General, Vol. 363, pp. 1-10, 2009 
332 10 $10^{\mathrm{TH}}$ International Conference on Sustainable Energy and Environmental Protection (June $27^{\mathrm{TH}}-30^{\mathrm{TH}}, 2017$, BLed, Slovenia), Bioenergy AND Biofuels

E.L. Almeida, S.I. Gomes C.M.G. Andrade \& O.A.A. Santos: Biodiesel Production

Process Versus Bioethanol Production Process. Preliminary Analysis

[10] Ilkılıç, C., et al., Biodiesel from safflower oil and its application in a diesel engine. Fuel Processing Technology, Vol. 92, pp. 356-362, 2011.

[11] Dias, J.M., et al., Selection of heterogeneous catalysts for biodiesel production from animal fat. Fuel, Vol. 94, pp. 418-425, 2012.

[12] Srilathaa, K., et al., et al. Biodiesel production from used cooking oil by two-step heterogeneous catalyzed process. Bioresource Technology, Vol. 119, pp. 306-311, 2012

[13] ANP. Boletins ANP. Agência Nacional do Petróleo, Gás Natural e Biocombustíveis. http://www.anp.gov.br/wwwanp/biocombustiveis/biodiesel. Accessed: 20/02/2017

[14] Johna, R.P., et al., Micro and macroalgal biomass: A renewable source for bioethanol. Bioresource Technology, Vol. 102, pp. 186-193, 2011.

[15] Staniszewskia, et al., Ethanol production from whey in bioreactor withco-immobilized enzyme and yeast cells followed bypervaporative recovery of product - Kinetic model predictions. Journal of Food Engineering, Vol. 82, pp. 618-625. 2007

[16] Nigama, P.S and Singhb, A., Production of liquid biofuels from renewable resources. Progress in Energy and Combustion Science, Vol. 37, pp. 52-68, 2011.

[17] Azhara, S.H.M., et al., Yeasts in sustainable bioethanol production: A review. Biochemistry and Biophysics Reports, Vol. 10, pp. 52-61, 2017

[18] EMBRAPA. Empresa Brasileira de Pesquisa Agropecuária. http://www.agencia.cnptia.embrapa.br/gestor/cana-de-acucar. Accessed: 02/02/2017.

[19] Costa, P.R. e Rossi, L.F.S. The utilization of used frying oil for the production of biodiesel. Quimica Nova, Vol. 23, pp. 531-537, 2000.

[20] Pighinelli, A.L., et al., Optimization of sunflower grain pressing and its characterization. Revista Brasileira de Engenharia Agrícola e Ambiental. 2009, Vol. 13, pp. 63-67.

[21] EMBRAPA. Empresa Brasileira de Pesquisa Agropecuária. https://www.embrapa.br/soja/cultivos/soja1. Accessed: 03:/2/2017

[22] Companhia Nacional de Abastecimento, Acompanhamento da safra brasileira de cana-de-açúcar, Vol. 2, pp. 1-70, 2016.

[23] Zambom, M.A., et al., Nutritional value of soybean hulls, soybean meal, ground corn and wheat meal for cattle. Acta Scientiarum, Vol. 23, pp. 937-943, 2001.

[24] CME Group. Soybean Meal Futures http://www.cmegroup.com/trading/agricultural/grain-and-oilseed/soybean-meal.html. Acessed: 25/04/2017.

[25] Froehner, S., et al,. Transesterification of vegetable oils: characterization by thin-layer cromatography and density. Química Nova, Vol. 30, pp. 2016-2019, 2007.

[26] Cana Online. www.canaonline.com.br. Accessed: 27/04/2017

[27] Nova Cana. https://www.novacana.com/etanol. Accessed: 27/04/2017. 
$10^{\mathrm{TH}}$ InTERnational CONFERENCE ON Sustainable ENERGy AND EnVironmental Protection (June $27^{\mathrm{TH}}-30^{\mathrm{TH}}$, 2017, BLed, SLOVENIA), BIOENERGY AND BIOFUELS

J. Krope, A.Ghani Olabi, D. Goričanec \& S. Božičnik

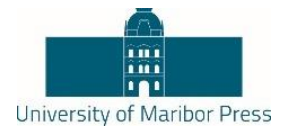

\title{
Comparative Study of Steam- and Nitrogen Explosion Pretreatment Methods
}

\author{
MERlin RAud, Klaus KRENNHUBER, AlEXANDER JÄGER \& Timo KIKAS
}

\begin{abstract}
The aim of this paper was to investigate chemical and physical changes in biomass during N2 explosive decompression pretreatment and compare it with steam explosion pretreatment. The methods are economically and environmentally attractive since only pressure and water/steam are used to break down the biomass structure. Two pretreatment methods were used at different temperatures and samples from all process steps were analysed. The results were used to assess the pretreatment effect and the chemical changes in biomass and, finally, the mass balances of the bioethanol process at different process steps. Results show that the highest glucose and ethanol yields were obtained with the steam explosion pretreatment method at $200{ }^{\circ} \mathrm{C}(24.29 \mathrm{~g}$ and $12.72 \mathrm{~g}$ per $100 \mathrm{~g}$ biomass, respectively). At lower temperatures, the nitrogen explosion treatment produced better yields.
\end{abstract}

Keywords: • Biomass $・$ Lignocellulose $\cdot$ Bioethanol $\cdot$ Steam explosion pretreatment $\bullet$ Nitrogen explosive decompression pretreatment •

Correspondence AdDress: Merlin Raud, PhD, Research Scientist, Estonian University of Life Sciences, Institute of Technology, Kreutzwaldi 56, Tartu, Estonia, e-mail: merlin.raud@emu.ee. Klaus Krennhuber, Dipl.ing, Teaching Assistant, University of Applied Sciences Upper Austria, Faculty of Engineering, Department of Bio \& Environmental Technology, Stelzhamerstr. 23 , 4600 Wels, Austria, e-mail: K.krennhuber@fh-wels.at. Alexander Jäger, PhD, Professor, University of Applied Sciences Upper Austria, Faculty of Engineering, Department of Bio \& Environmental Technology, Stelzhamerstr. 23 , 4600 Wels, Austria, e-mail: a.jaeger@fh-wels.at. Timo Kikas, $\mathrm{PhD}$, Professor, Estonian University of Life Sciences, Institute of Technology, Kreutzwaldi 56, Tartu, Estonia, e-mail: timo.kikas@emu.ee. 
$10^{\mathrm{TH}}$ InTERNATIONAL CONFERENCE ON Sustainable ENERGY AND ENVIRONMENTAL Protection (June $27^{\mathrm{TH}}-30^{\mathrm{TH}}, 2017$, BLed, Slovenia), Bioenergy AND Biofuels

M. Raud, K. Krennhuber, A. Jäger \& T. Kikas: Comparative Study of Steam- and Nitrogen Explosion Pretreatment Methods

\section{Introduction}

Lignocellulosic ethanol has attracted attention as an alternative to fossil fuels. Lignocellulosic biomass is defined as either non-edible residues from food crop production or non-edible whole plant biomass [1]. Different kinds of biomass can be used in bioethanol production, such as by-products (straw, sugar cane bagasse, forest residues), waste materials (organic components of municipal solid waste), and dedicated feedstocks (purpose-grown vegetative grasses, short-rotation wood, etc.) [2-4].

The traditional bioethanol production process consists of three steps - pretreatment, hydrolysis and fermentation. The pretreatment step is used to open the biomass structure and make the cellulose accessible for enzymatic hydrolysis. In the enzymatic hydrolysis, cellulose polymer is degraded into glucose monomers. Hydrolysis is followed by fermentation, where glucose is fermented into ethanol.

Out of the three main components of the lignocellulosic biomass, cellulose, hemicellulose and lignin, only cellulose can be converted into ethanol. However, cellulose is wrapped inside the hemicellulose and lignin matrix, which makes it difficult to access. In order to gain access to cellulose, effective pretreatment is paramount. The goal of the pretreatment is to alter the biomass structure in a way that breaks down the cellulosic structure of the biomass and opens it for further enzymatic hydrolysis [5].

Different methods for biomass pretreatment have been proposed. They can be divided into chemical, physical, and combined pretreatment methods. Physical methods are mainly based on size reduction [6] and not widely used due to high energy input and low efficiency. However, it is often combined with chemical or physio-chemical methods [7]. Chemical methods use acids, bases, solvents, etc. to dissolve some components of the biomass, thereby gaining access to the cellulose. These methods are effective, however, cost of the chemicals raises the total cost of the process and, subsequently, the price of the ethanol produced, which in turn impedes competition with fossil fuels.

Of the combined methods, steam explosion (SE) and its variations - ammonia fiber explosion (AFEX), $\mathrm{CO}_{2}$ or $\mathrm{SO}_{2}$ explosions are most common. In SE, biomass is treated with saturated steam at high pressure, [8] where temperatures of $180-220{ }^{\circ} \mathrm{C}$ are commonly used, and after a retention time of 2-10 minutes [5], the pressure is suddenly decreased. During the process, hemicellulose is hydrolyzed through the action of steam and this reaction is further catalyzed by the presence of the organic acids formed during treatment [9]. The AFEX process and also $\mathrm{CO}_{2}$ or $\mathrm{SO}_{2}$ explosions are variations of steam explosion methods, where ammonia, $\mathrm{CO}_{2}$ or $\mathrm{SO}_{2}$ are added to enhance the effect of pretreatment [10]. These methods are very effective at dissolving and removing hemicellulose, however, organic acids and furfural are formed during the pretreatment, which act as inhibitors.

In addition to SE, $\mathrm{N}_{2}$ explosive decompression (NED) pretreatment of biomass was recently proposed $[1,11]$. In NED pretreatment, the biomass is mixed with water and 
placed into a pressure reactor. The reactor is then heated and pressure is applied to the biomass mixture by adding $\mathrm{N}_{2}$ gas. The nitrogen molecules, which are smaller than the water molecules or gas molecules used in other pretreatment methods $\left(\mathrm{CO}_{2}\right.$ and $\left.\mathrm{SO}_{2}\right)$, can more effectively penetrate into the cells of the biomass. The subsequent explosive release of pressure causes the dissolved nitrogen gas to expand. This opens the cellulosic structure of the biomass and increases the accessible surface area for enzymatic hydrolysis. The NED pretreatment method is economically and environmentally attractive since neither catalysts nor chemicals are added in these processes $[1,11]$. However, the working principle and the processes that occur during the pretreatment still need further research.

The aim of this paper was to investigate the chemical and physical changes in biomass during the NED pretreatment and compare the results with those of SE pretreatment method. The two pretreatment methods were used at different temperatures and samples from various process steps were analyzed with different methods. Results were used to assess the pretreatment effect and the chemical and physical changes in biomass and finally, a mass balances of the bioethanol process in different process steps was compiled [1].

\section{$2 \quad$ Materials and Methods}

\subsection{Biomass}

Barley straw (Hordeum vulgare) was used as a biomass in all experiments. The samples were dried to moisture content less than $100 \mathrm{~g} \mathrm{~kg}^{-1}$ and ground with Cutting Mill SM 100 (Retsch $\mathrm{GmbH}$ ) and then with Cutting Mill ZM 200 (Retsch $\mathrm{GmbH}$ ) to a particle-size 3 mm or less.

\subsection{NED pretreatment}

The instrumentation and working principles of NED pretreatment method are described in detail in previous publications $[1,11,12]$. In NED pretreatment, $650 \mathrm{ml}$ of distilled water was added to $100 \mathrm{~g}$ of dried and milled biomass. Samples were mixed thoroughly and heated to temperatures between $100-175 \pm 3^{\circ} \mathrm{C}$ and the pressure of 30 bar was applied using compressed nitrogen gas. After reaching the target temperature, the mixture was cooled below the boiling point and pressure was released in an explosive manner. After the explosion, samples were cooled to a temperature below $50^{\circ} \mathrm{C}$ and used in the enzymatic hydrolysis step.

\subsection{Steam explosion pretreatment}

SE pretreatment method and instrumentation described by Tutt et al [11] was used in this work. Sample of $900 \mathrm{~g}$ pre-dried and milled hay was soaked in $900 \mathrm{~g}$ of distilled water. SE was performed in a laboratory scale SE system at the University of Applied Sciences Upper Austria. SE was carried out at temperatures $150-200{ }^{\circ} \mathrm{C}$ and incubation time of 
$10^{\mathrm{TH}}$ International Conference on Sustainable EnERgy and Environmental Protection (June $27^{\mathrm{TH}}-30^{\mathrm{TH}}, 2017$, Bled, SLOVENiA), Bioenergy AND Biofuels M. Raud, K. Krennhuber, A. Jäger \& T. Kikas: Comparative Study of Steam- and Nitrogen Explosion Pretreatment Methods

30 minutes. Pretreated material was then dried at $40{ }^{\circ} \mathrm{C}$ to a dry matter content of $95 \%$ or more.

\subsection{Enzymatic hydrolysis and fermentation}

Pretreated biomass was used to prepare suspensions with dry matter content of $10 \%$ in citrate buffer (5 mmol L-1, $\mathrm{pH} 5.0$ ) in case of SE pretreatment. In case of NED pretreatment, distilled water and enzyme was added to the pretreated biomass in order to gain the volume of the mixture $1000 \mathrm{ml}$. Enzyme mixture was added to biomass suspension at a ratio of $0.3 \mathrm{ml}$ per $\mathrm{g}$ of biomass. Enzyme complex Accellerase 1500 from Genencor ${ }^{\circledR} ; 30 \mathrm{FPU} \mathrm{g}^{-1}$ cellulose) was used in all experiments. Hydrolysis lasted for 72 hours at a temperature of $50^{\circ} \mathrm{C}$ under constant stirring in rotating shaker/incubator $(100$ $\left.\min ^{-1}\right)$.

After enzymatic hydrolysis the liquid phase of the suspension was separated from solid phase by vacuum filtration. Yeast Saccharomyces cerevisiae was added to the liquid phase gained after filtration to start the fermentation process. Fermentation lasted 7 days at the temperature of at a temperature of $30^{\circ} \mathrm{C}$.

\subsection{Chemical analysis}

The biomass samples were taken for analysis before and after pretreatment and after enzymatic hydrolysis. The solid and liquid parts of the biomass mixture were weighed before and after pretreatment and after enzymatic hydrolysis. The solid biomass gained after pretreatment and enzymatic hydrolysis was dried and milled for analysis.

Dry matter content was analysed with a moisture analyser Ohaus MB 45. The fibre analysis (cellulose, hemicellulose and lignin) was performed using an ANKOM 2000 analyzer.

\subsection{Data analysis}

All the weights of the liquid and solid phases from all process stages, glucose and ethanol concentrations were measured after hydrolysis and fermentation stages, fiber analysis results of all solid residues were conducted.

The hydrolysis efficiency was calculated based on a formula 1:

$E_{H Y}=\frac{m_{g l c}}{m_{c e l} \cdot 1,11} \cdot 100 \%$

Where $m_{\text {glc }}$ is measured amount of glucose in sample; $m_{\text {cel }}$ is measured amount of cellulose in sample and 1.11 is cellulose to glucose conversion factor based on stoichiometric biochemistry of hydrolysis [13]. The fermentation efficiency was calculated based on 
$E_{F}=\frac{c_{e t h}}{c_{g l c} \cdot 0,51} \cdot 100 \%$

Where $c_{\text {glc }}$ is concentration of glucose in sample; $c_{\text {eth }}$ is concentration of ethanol in sample and 0.51 is glucose to ethanol conversion factor based on stoichiometric biochemistry of fermentation [13].

The mass balance was calculated based on the masses of the solid and liquid phases and the calculated masses of the components of biomass and liquid.

Averaged results of at least three parallel measurements are used. Data were analyzed using MS Excel software.

\section{$3 \quad$ Results and discussion}

\subsection{Biomass characterization}

Biomass can be characterised based on its composition - relative proportion of cellulose, hemicellulose, and lignin. Previous research has shown that energy crops for bioethanol production should be selected based on their cellulose content. Bioethanol is produced from glucose, which is formed during cellulose degradation and therefore, the most important property of biomass for bioethanol production is high cellulose content [14]. In addition, a low lignin and hemicellulose content is preferred. The hemicellulose-lignin matrix makes cellulose that is packed into this matrix, inaccessible to enzymes. Furthermore, the degradation products of lignin and hemicellulose inhibit the hydrolysis of cellulose to sugars and therefore, the low lignin content biomasses are preferred [15].

Table 1 shows that barley straw, used in these experiments as a sample biomass, had a relatively high cellulose content of $41.56 \%$ while the hemicellulose and lignin contents were lower, $32.9 \%$ and $5.35 \%$, respectively. Relatively high cellulose content makes it a suitable biomass for bioethanol production since high ethanol yields can be obtained.

Table 1. Composition of biomass used in the experiments

\begin{tabular}{|l|l|}
\hline Component & Content (\%) \\
\hline Hemicellulose & 32.9 \\
\hline Cellulose & 41.6 \\
\hline Lignin & 5.4 \\
\hline
\end{tabular}


338 10 $10^{\mathrm{TH}}$ INTERNATIONAL CONFERENCE ON SUSTAINABLE ENERGY AND ENVIRONMENTAL Protection (June $27^{\mathrm{TH}}-30^{\mathrm{TH}}, 2017$, BLed, Slovenia), Bioenergy AND Biofuels M. Raud, K. Krennhuber, A. Jäger \& T. Kikas: Comparative Study of Steam- and Nitrogen Explosion Pretreatment Methods

\subsection{Effect of pretreatment to biomass}

Two different methods- NED and SE were used for biomass pretreatment. Biomass was pretreated at different temperatures, at constant pressure, and pretreatment duration. After the pretreatment, fiber analysis was performed to investigate the change in the biomass due to pretreatment. Since no chemicals are used in either of pretreatments, the methods require high temperatures and/or high pressures to effectively dissolve hemicellulose and expose cellulose fibres to enzyme molecules in the following hydrolysis process [11]. In addition, the heating step in both methods is followed by a swift release of pressure causing the steam or $\mathrm{N}_{2}$ gas to expand within the lignocellulosic matrix. During the explosion, the plant biomass particles are shattered into small pieces, the fibres of the plant biomass are separated, and the ordered structure of the plant biomass is significantly disrupted [16]. The results of fiber analysis from pretreated biomass are shown in table 2. The results show that both pretreatment methods decrease the concentration of hemicellulose in the biomass (to not detectable level at $190{ }^{\circ} \mathrm{C}$ with SE pretreatment or to $7.3 \%$ at $175{ }^{\circ} \mathrm{C}$ with NED pretreatment).

Table 2. The composition of biomass after pretreatment with NED or SE pretreatment method at different temperatures

\begin{tabular}{|l|l|l|l|l|}
\hline $\begin{array}{l}\text { Temperature } \\
\left({ }^{\circ} \mathbf{C}\right)\end{array}$ & $\begin{array}{l}\text { Hemicellulose } \\
(\boldsymbol{\%})\end{array}$ & $\begin{array}{l}\text { Cellulose } \\
(\boldsymbol{\%})\end{array}$ & Lignin (\%) & Ash (\%) \\
\hline \multicolumn{5}{|l|}{ Steam explosion pretreatment } \\
\hline 150 & 26.7 & 42.1 & 8.7 & 3.59 \\
\hline 160 & 14.0 & 38.4 & 8.7 & 4.23 \\
\hline 170 & 11.2 & 35.3 & 10.8 & 3.81 \\
\hline 180 & 0.8 & 33.0 & 12.8 & 4.74 \\
\hline 190 & ND $^{*}$ & 38.4 & 14.1 & 4.55 \\
\hline 200 & ND $^{*}$ & 39.5 & 13.9 & 4.01 \\
\hline $\mathbf{N}_{2}$ explosive pretreatment & \multicolumn{5}{|l|}{} \\
\hline 100 & 28.3 & 44.2 & 2.3 & 4.00 \\
\hline 125 & 27.1 & 44.1 & 3.3 & 3.50 \\
\hline 150 & 24.1 & 40.8 & 4.6 & 3.89 \\
\hline 175 & 7.3 & 36.8 & 8.9 & 4.27 \\
\hline
\end{tabular}

Both pretreatment methods decrease the hemicellulose content in biomass by dissolving the hemicellulose at high temperature, which increases substantially the availability of the cellulosic fraction of the material [15]. This also enables to improve the hydrolysis yields of cellulosic fraction in the further steps of process since the cellulose is more accessible to enzymes [15].

At the same time the cellulose proportion varies between $42.1 \%$ and $33.0 \%$ with SE pretreatment and decreases only slightly to $36.8 \%$ with NED pretreatment. This shows 
that there is a loss in cellulose content however, compared to dissolution of hemicellulose the cellulose losses are negligible

\subsection{Hydrolysis and fermentation of the pretreated biomass}

The pretreated biomass was used in a traditional three-step bioethanol production process, where enzymatic hydrolysis and fermentation followed pretreatment. After these steps, the glucose and ethanol concentrations were measured and hydrolysis and fermentation efficiencies were calculated (figure 1) to assess the effect of pretreatment.

From the figure 1 it can be seen that the higher hydrolysis efficiency was gained using NED method at temperatures up to $175{ }^{\circ} \mathrm{C}$ where $52.6 \%$ hydrolysis efficiency was gained. At lower temperatures, at $100{ }^{\circ} \mathrm{C}$, the hydrolysis efficiency was $26.0 \%$ but increased steadily to maximum values at $175^{\circ} \mathrm{C}$, where glucose yield of $15.2 \mathrm{~g}$ of glucose from $100 \mathrm{~g}$ of biomass was gained. Higher temperatures were not tested with NED pretreatment method because we already demstrated that the glucose yield reaches a plateau or decreases at temperatures higher that $175^{\circ} \mathrm{C}[1,11]$.

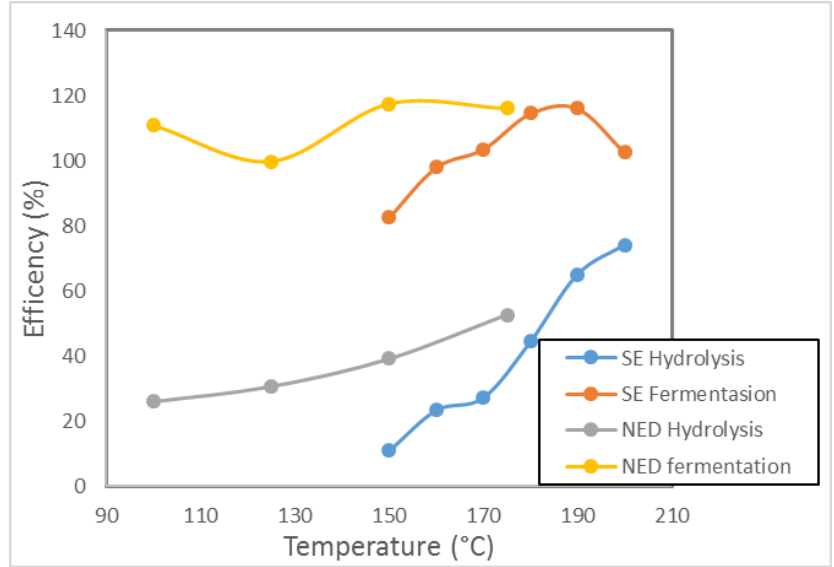

Figure 1. The hydrolysis and fermentation efficiencies when steam explosion pretreatment (SE) and explosive decompression pretreatment (NED) was used at different temperatures.

Similarly to NED, with SE the lowest glucose yield was gained at lower temperatures at $150{ }^{\circ} \mathrm{C}$. However as the pretreatment temperature was increased, the hydrolysis efficiency increased steeply up to $66.7 \%$ and exceeded the highest efficiency gained with NED method, which was $52.7 \%$. In comparison, in temperature range of $150-175^{\circ} \mathrm{C}$, where both methods were applied the NED method enabled to gain $72-53 \%$ more glucose than SE pretreatment method. However, at higher temperature the SE method was more efficient. Fermentation efficiency was higher when NED pretreatment was used and it varied between $99 \%$ to $117 \%$. With SE pretreatment, the fermentation efficiency increased from $82 \%$ at $150{ }^{\circ} \mathrm{C}$ to $116 \%$ at $190{ }^{\circ} \mathrm{C}$ and then decreased to $102 \%$. In the 
$340 \quad 10^{\mathrm{TH}}$ InTERNATIONAL CONFERENCE ON SUSTAINABLE ENERGY AND ENVIRONMENTAL Protection (June $27^{\mathrm{TH}}-30^{\mathrm{TH}}, 2017$, BLED, SloveniA), Bioenergy AND Biofuels

M. Raud, K. Krennhuber, A. Jäger \& T. Kikas: Comparative Study of Steam- and Nitrogen Explosion Pretreatment Methods

temperature range of $150-175^{\circ} \mathrm{C}$, NED method enabled to gain higher fermentation efficiencies.

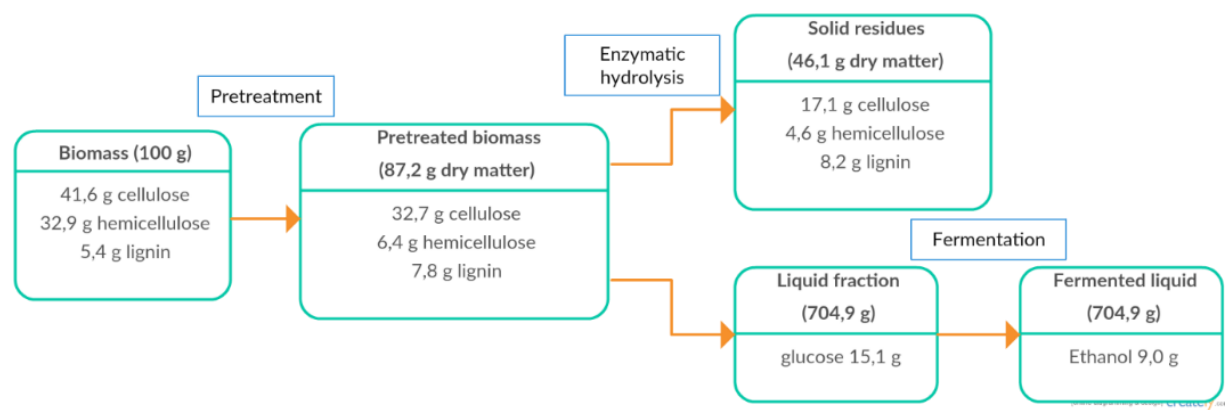

Figure 2. Mass balance of bioethanol production with NED pretreatment at $175^{\circ} \mathrm{C}$

The fermentation efficiencies exceeding $100 \%$ indicate that during fermentation more sugars were available than measured after enzymatic hydrolysis. After enzymatic hydrolysis, the liquid fraction was separated from solid fraction and glucose concentration was measured. However, the liquid fraction also contained dissolved sugar oligomers that remained undetected when glucose was measured but were hydrolyzed into glucose during fermentation, which increased the concentration of available sugars and enabled to gain fermentation efficiencies over $100 \%$.

\subsection{Mass balance of processes}

Mass balance was calculated based on the weight of liquid and solid phases from each process stage, fiber content of those solid residues, and glucose and ethanol concentrations, measured after hydrolysis and fermentation stages, respectively. Mass flow charts were prepared from ethanol production processes using different pretreatments at $175{ }^{\circ} \mathrm{C}$ and at $180{ }^{\circ} \mathrm{C}$ with $\mathrm{NED}$ and $\mathrm{SE}$ pretreatment methods, respectively.

Bioethanol production process started with $100 \mathrm{~g}$ on biomass, which contained $41.6 \%$ of cellulose. After pretreatment, the dry matter content of biomass decreased to $87.2 \mathrm{~g}$ and $83.2 \mathrm{~g}$ with NED and SE pretreatment methods, respectively. Main effect on both pretreatment methods is the dissolution of hemicellulose, which decreased in biomass $80.5 \%$ and $97.3 \%$ in case of NED and SE pretreatments, respectively. At the same time, decrease for cellulose is negligible and lignin mass increases slightly.

After the pretreatment and the enzymatic hydrolysis, solid and liquid phases were separated by filtration. The weight of solid residue was $46.1 \mathrm{~g}$ in case of NED pretreatment and $34.5 \mathrm{~g}$ with SE pretreatment, with the polymeric cellulose part $17.1 \mathrm{~g}$ and $12.7 \mathrm{~g}$, respectively. These results show that SE is more effective in hemicellulose dissolution. Additionally, the method enables to gain more effective cellulose usage since less cellulose remains intact after hydrolysis, which results in higher glucose yield. 
In hydrolysis and fermentation steps both pretreatment methods under similar conditions result in similar glucose and ethanol yields. Although, NED method enabled to gain more of liquid fraction, almost equal amount of glucose was produced with both pretreatments. However, SE pretreatment was also used at $200{ }^{\circ} \mathrm{C}$ and there $24.3 \mathrm{~g}$ of glucose was produced in comparison to $15.4 \mathrm{~g}$ at $180^{\circ} \mathrm{C}$. Furthermore, equal amounts of ethanol $(9 \mathrm{~g})$ were measured in the fermentation broth with both methods. Similarly to hydrolysis step, more ethanol was produced with SE method at $200{ }^{\circ} \mathrm{C}$ where $36 \%$ more ethanol was gained from the same amount of initial biomass.

\section{$4 \quad$ Conclusions}

Two pretreatment methods were used in three-step bioethanol production process to investigate the effect of pretreatment to chemical and physical changes in biomass. Biomass was pretreated at different temperatures, samples from various process stages were analyzed and finally, mass balances of the bioethanol process in different process steps were compiled.

The results show that both pretreatment methods are effective in hemicellulose removal, while decrease in cellulose content is negligible. After pretreatment, hydrolysis efficiencies exceeded $58 \%$ and $74 \%$ for NED and SE pretreatments, respectively. Fermentation efficiencies reached over $100 \%$, which shows that fermentation inhibiting compounds did not form during pretreatment. Mass analysis of the process shows that at similar pretreatment temperatures the methods gave similar results in terms of glucose and ethanol yields. However, SE is more effective in hemicellulose removal and after fermentation, less cellulose remained unused in the solid residue. Higher temperature enables to gain higher yields and efficiencies and thereby, the highest glucose and ethanol yields, $24.3 \mathrm{~g}$ and $12.7 \mathrm{~g}$ from $100 \mathrm{~g}$ of biomass, respectively, were gained with SE pretreatment at $200^{\circ} \mathrm{C}$.

\section{Acknowledgements}

We gratefully acknowledge the financial support of the European Regional Development Fund via the Mobilitas Pluss (project MOBERA1) of the Estonian Research Council and base financed project of EULS P170025 TIPT.

\section{References}

[1] M. Raud, J. Olt, and T. Kikas, " $\mathrm{N}_{2}$ explosive decompression pretreatment of biomass for lignocellulosic ethanol production," Biomass and Bioenergy, vol. 90, pp. 1-6, 7// 2016.

[2] R. E. H. Sims, W. Mabee, J. N. Saddler, and M. Taylor, "An overview of second generation biofuel technologies," Bioresource Technology, vol. 101, pp. 1570-1580, 2010.

[3] P. Phitsuwan, K. Sakka, and K. Ratanakhanokchai, "Improvement of lignocellulosic biomass in planta: A review of feedstocks, biomass recalcitrance, and strategic 
$10^{\mathrm{TH}}$ InTERNATIONAL CONFERENCE ON Sustainable ENERGy AND ENVIRONMENTAL Protection (June $27^{\mathrm{TH}}-30^{\mathrm{TH}}, 2017$, BLed, Slovenia), Bioenergy AND Biofuels

M. Raud, K. Krennhuber, A. Jäger \& T. Kikas: Comparative Study of Steam- and Nitrogen Explosion Pretreatment Methods

manipulation of ideal plants designed for ethanol production and processability," Biomass and Bioenergy, vol. 58, pp. 390-405, 2013.

[4] Raud, M., Mitt, M., Oja, T., Olt, J., Orupõld, K., and Kikas, T. "The Utilisation Potential of Urban Greening Waste: Tartu Case Study” Urban Forestry \& Urban Greening vol. 21, pp. 96-101, 2017.

[5] D. Chiaramonti, M. Prussi, S. Ferrero, L. Oriani, P. Ottonello, P. Torre, et al., "Review of pretreatment processes for lignocellulosic ethanol production, and development of an innovative method," Biomass and Bioenergy, vol. 46, pp. 25-35, 2012.

[6] E. Shirkavand, S. Baroutian, D. J. Gapes, and B. R. Young, "Combination of fungal and physicochemical processes for lignocellulosic biomass pretreatment - A review," Renewable and Sustainable Energy Reviews, vol. 54, pp. 217-234, 2// 2016.

[7] A. Barakat, S. Chuetor, F. Monlau, A. Solhy, and X. Rouau, "Eco-friendly dry chemomechanical pretreatments of lignocellulosic biomass: Impact on energy and yield of the enzymatic hydrolysis," Applied Energy, vol. 113, pp. 97-105, 2014.

[8] C. Conde-Mejía, A. Jiménez-Gutiérrez, and M. El-Halwagi, "A comparison of pretreatment methods for bioethanol production from lignocellulosic materials," Process Safety and Environmental Protection, vol. 90, pp. 189-202, 5// 2012.

[9] L. Perez-Cantu, A. Schreiber, F. Schütt, B. Saake, C. Kirsch, and I. Smirnova, "Comparison of pretreatment methods for rye straw in the second generation biorefinery: Effect on cellulose, hemicellulose and lignin recovery," Bioresource Technology, vol. 142, pp. 428$435,8 / / 2013$.

[10] Y. Sun and J. Cheng, "Hydrolysis of lignocellulosic materials for ethanol production: a review," Bioresource Technology, vol. 83, pp. 1-11, 2002.

[11] M. Tutt, M. Raud, H. Kahr, M. Pointner, J. Olt, and T. Kikas, "Nitrogen explosion pretreatment of lignocellulosic material for bioethanol production," Energy Sources, Part A: Recovery, Utilization and Environmental Effects, vol. 38, pp. 1785-1789, 2016.

[12] M. Raud, V. Rooni, and T. Kikas, "Explosive decompression pretreatment: Nitrogen vs. compressed air," Agronomy Research, vol. 14, pp. 569-578, 2016.

[13] J. Lu, X. Li, J. Zhao, and Y. Qu, "Enzymatic Saccharification and Ethanol Fermentation of Reed Pretreated with Liquid Hot Water," Journal of Biomedicine and Biotechnology, vol. 2012, p. 9, 2012.

[14] Kikas, T., Tutt, M., Raud, M., Alaru, M., Lauk, R., and Olt, J. "Basis of Energy Crop Selection for Biofuel Production: Cellulose vs. Lignin.” International Journal of Green Energy, vol. 13(1), pp. 49-54, 2017.

[15] M. Raud, M. Tutt, J. Olt, and T. Kikas, "Dependence of the hydrolysis efficiency on the lignin content in lignocellulosic material," International Journal of Hydrogen Energy, 2016.

[16] Tutt, M., Kikas, T., Kahr, H., Pointner, M., Kuttner, P., Olt, J. "Using steam explosion pretreatment method for bioethanol production from floodplain meadow hay." Agronomy Research, vol. 12(2), pp. 417-424. 2014. 
$10^{\mathrm{TH}}$ InTERnational CONFERENCE ON Sustainable ENERgy AND ENVIRONMENTAL Protection (June $27^{\mathrm{TH}}-30^{\mathrm{TH}}$, 2017, Bled, SLOVENIA), BIOENERGY AND BIOFUELS

J. Krope, A.Ghani Olabi, D. Goričanec \& S. Božičnik

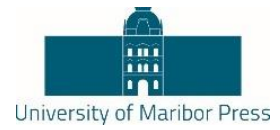

\title{
Direct Conversion of Ethanol Into Linear $\alpha$ - Alcohols in the Supercritical Regime Over Au-Cu and Au-Ni Catalysts
}

\author{
Andrey V. Chistyakov, Sergey A. Nikolaev, Polina A. Zharova, Mark V. \\ TSODIKOV \& FLAVIO MANENTI
}

\begin{abstract}
In this paper, novel $\mathrm{CuO}_{\mathrm{x}} / \mathrm{Au} / \mathrm{Al}_{2} \mathrm{O}_{3}$ and $\mathrm{NiO} \mathrm{x}_{\mathrm{x}} / \mathrm{Au} / \mathrm{Al}_{2} \mathrm{O}_{3}$ catalysts with different metal loadings and monometallic analogues $\left(\mathrm{Au} / \mathrm{Al}_{2} \mathrm{O}_{3}\right.$, $\mathrm{NiO}_{\mathrm{x}} / \mathrm{Al}_{2} \mathrm{O}_{3}, \mathrm{CuO}_{\mathrm{x}} / \mathrm{Al}_{2} \mathrm{O}_{3}$ ) were applied for the direct ethanol conversion into linear $\alpha$-alcohols in the supercritical regime. $\mathrm{CuO}_{\mathrm{x}} / \mathrm{Au} / \mathrm{Al}_{2} \mathrm{O}_{3}$ catalyst was found to provide ethanol conversion into 1-butanol, 1-hexanol and 1octanol with $77.6 \%$ selectivity of 1-butanol or total selectivity of linear $\alpha$ alcohols of 99.8 at $45 \%$ conversion of ethanol. The supercritical conditions allow to increase catalysts productivity in comparison with subcritical regime. The high activity and selectivity of $\mathrm{Au}-\mathrm{Cu}$ and $\mathrm{Au}-\mathrm{Ni}$ catalysts presumably is a result of its specific surface and higher concentration of $\mathrm{Au}^{+}$cations comparative with monometallic $\mathrm{Au}$-containing catalysts.
\end{abstract}

Keywords: • ethanol $\bullet$ butanol-1 $\bullet$ supercritical conditions $\bullet$ heterogeneous catalysis $\bullet \mathrm{Au}-\mathrm{Cu} \bullet$

CORRESPONDENCE AdDRESS: Andrey V. Chistyakov, Ph.D., Leading Researcher, Topchiev Institute of Petrochemical Synthesis RAS, Leninsky prospekt, 29, Moscow, Russia, e-mail: chistyakov@ips.ac.ru. Sergey A. Nikolaev, Ph.D., Senior Researcher, Moscow State University, Leninskie Gory 1, Moscow 119991, Russia, e-mail: serge2000@ rambler.ru. Polina A. Zharova, $\mathrm{Ph} . D$. student, Junior researcher, Topchiev Institute of Petrochemical Synthesis RAS, Leninsky prospekt, 29, Moscow, Russia, e-mail: zharova@ips.ac.ru. Mark V. Tsodikov, Ph.D., Head of the laboratory, Topchiev Institute of Petrochemical Synthesis RAS, Leninsky prospekt, 29, Moscow, Russia, e-mail: tsodikov@ips.ac.ru. Flavio Manenti Professor of Chemical Engineering, Politecnico di Milano, Dipartimento di Chimica, Materiali e Ingegneria Chimica "Giulio Natta", Piazza Leonardo da Vinci, 32, 20133 Milano, Italy, e-mail: flavio.manenti@ polimi.it.

https://doi.org/10.18690/978-961-286-048-6.34

ISBN 978-961-286-048-6

(C) 2017 University of Maribor Press

Available at: http://press.um.si. 
344 10 $10^{\mathrm{TH}}$ International Conference on Sustainable Energy and Environmental Protection (June $27^{\mathrm{TH}}-30^{\mathrm{TH}}, 2017$, BLED, Slovenia), Bioenergy AND Biofuels

A. V. Chistyakov, S. A. Nikolaev, P. A. Zharova, M. V. Tsodikov \& F. Manenti: Direct Conversion of Ethanol Into Linear A- Alcohols in the Supercritical Regime Over Au$\mathrm{Cu}$ and $\mathrm{Au}-\mathrm{Ni}$ Catalysts

\section{$1 \quad$ Introduction}

1-Butanol is a crucial bulk chemical with a wide range of industrial uses. 1-Butanol is a commodity chemical used as a solvent and for the production of various esters and ethers, some of which are important monomers for the polymer industry. It is also well known that butanol can be used as a fuel, having some advantages over ethanol such as a higher energy density (29.2 MJL-1vs. 19.6 MJL-1), lower corrosiveness, and being more suitable for distribution through existing pipelines [1].

In the petrochemical industry 1-butanol is generally produced by using the oxo synthesis, also known as hydroformylation, (Scheme 1), which consists of propylene hydroformylation followed by butyraldehyde hydrogenation to yield 1butanol.

The oxo synthesis uses harmful carbon monoxide as a raw material at high pressure of approximately $30 \mathrm{MPa}$ in addition to propylene and is a complicated process, resulting in high cost and low profitability. Also requires two different catalysts (cobalt or rhodium in the first step and nickel in the second step). Furthermore, because it is based on a homogeneous catalyst, the process suffers from drawbacks such as difficult separation of the desired compound, costly catalyst preparation, and environmental issues that can be attributed to the limited lifetime of the transition-metal complexes used[2].
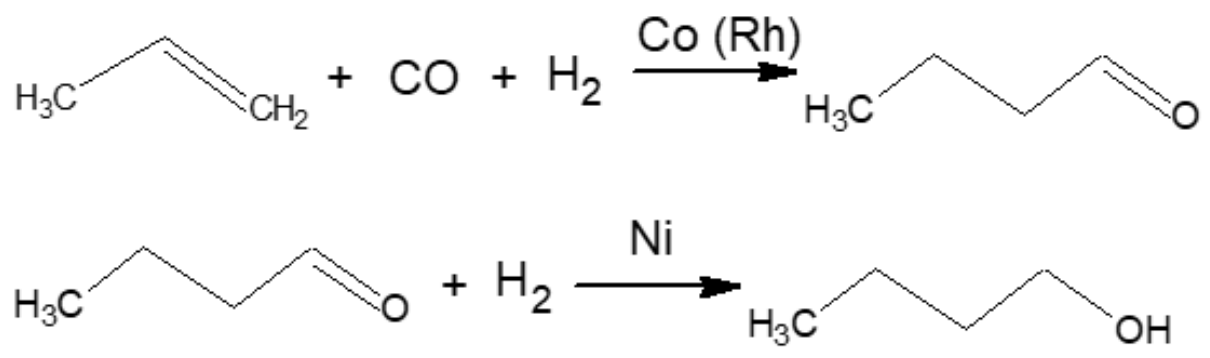

Scheme 1. The oxo process for the production of 1-butanol.

Alternative to the fossil-feedstock-based process is the ABE fermentation process in which mixtures of acetone, butanol, and ethanol are produced by the use of strains of the bacterium Clostridium acetobutylicum has been possible since the 1919 [3]. But currently the bulk synthesis of butanol from biosustainable feedstock remains a challenge, with much recent interest still focused on revisiting of butanol producing via ABE fermentation [4]. To date, the best reported selectivity with this process is approximately $60-70 \%$ (by weight) with a yield of about $16 \%$ per kilogram of feedstock [5]. 
One more approach aimed to the catalytic valorization of readily available ethanol into more advanced products e.g. biofuel. Since this process is clean, it theoretically fits the "green chemistry" requirements of the 21 st century. Ethanol, a renewable chemical, can be converted to higher molecular weight alcohols, socalled Guerbet alcohols [6-7], to be used, for instance, in the production of highadded value linear $\alpha$-alcohols, e.g. 1-butanol. The traditional (partlyhomogeneous) synthesis of Guerbet alcohols is known to proceed via several consecutive steps [8-9] (Scheme 2).

It is clear that a purely heterogeneous process would present many advantages over the hybrid homogeneous-heterogeneous system aforementioned. The conversion of ethanol into butanol over purely heterogeneous catalysts has been reported in several publications and patents [7, 10-19]. Generally the reaction temperatures vary from $200{ }^{\circ} \mathrm{C}$ up to $450{ }^{\circ} \mathrm{C}$, with a relatively low conversion (10-20\%) and selectivity approaching $70 \%$. Hydroxyapatites were shown to be the most active and selective to higher alcohols $[11,12]$.

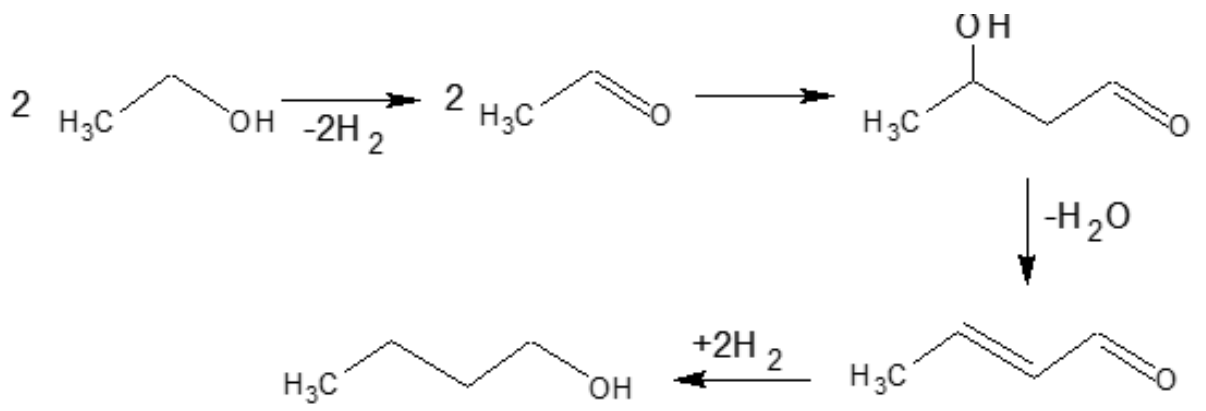

Scheme 2. Ethanol condensation mechanism based on Guerbet reaction.

The highest selectivity to n-butanol ever reported is $76.3 \%$ at $14.7 \%$ conversion of ethanol [12] and $81.2 \%$ at $7.6 \%$ conversion of ethanol [11]. These described technologies suggest a two-phase process where ethanol vapor is passed through a solid catalyst loaded in a fixed bed. The study of a liquid-phase process for ethanol to 1-butanol conversion over $\gamma$-alumina supported catalysts modified with a large number of metals showed $20 \% \mathrm{Ni} / \mathrm{Al}_{2} \mathrm{O}_{3}$ (manufactured by Crossfield) possess the highest selectivity equal to $62 \%$ at $5 \%$ conversion of ethanol [20].

Gold had long been regarded as a very stable and catalytically inert metal until Haruta et al. found the surprisingly high activity of gold nanoparticles for the lowtemperature $\mathrm{CO}$ oxidation [21]. The recent progress in heterogeneous catalysis by gold resulted in remarkable investigations that showed the high activity of 3-10 nm gold particles in water gas shift reaction [22, 23], hydrogenation [24, 25], isomerization [26, 27], and hydrodechlorination of organic molecules [28, 29]. 
346 10 $10^{\mathrm{TH}}$ International Conference on Sustainable Energy and Environmental Protection (June $27^{\mathrm{TH}}-30^{\mathrm{TH}}, 2017$, BLED, Slovenia), Bioenergy AND Biofuels

A. V. Chistyakov, S. A. Nikolaev, P. A. Zharova, M. V. Tsodikov \& F. Manenti: Direct Conversion of Ethanol Into Linear A- Alcohols in the Supercritical Regime Over Au$\mathrm{Cu}$ and $\mathrm{Au}-\mathrm{Ni}$ Catalysts

Recently, we found that decoration of gold nanoparticles with $\mathrm{NiO}_{x}$ or $\mathrm{CuO}_{x}$ clusters results in stabilization of small gold clusters deposited on $\mathrm{Al}_{2} \mathrm{O}_{3}$. According to XPS, XAS and IR studies the electron transfer from Au0 to NiOx $(\mathrm{CuOx})$ took place that resulted in formation of extremely active $\mathrm{Au}^{\delta+}$ sites. Bimetallic catalysts based on $\mathrm{NiO}_{x} / \mathrm{Au}$ or $\mathrm{CuO}_{\mathrm{x}} / \mathrm{Au}$ nanoparticles showed high activity in $\mathrm{CO}$ oxidation [30, 31], ethanol conversion into $\mathrm{C}_{3+}$ hydrocarbons [32] and allylic isomerization of allylbenzene [33]. It should be pointed that allylic isomerization proceeds via "dehydrogenation-hydrogenation" steps. According to Scheme 2, both high dehydrogenation and hydrogenation catalytic activity is necessary to achieve the high yield of Guerbet alcohols. Thus $\mathrm{CuO}_{\mathrm{x}} / \mathrm{Au}$ and $\mathrm{NiO}_{\mathrm{x}} / \mathrm{Au}$ nanoparticles seem to be suitable for ethanol conversion into linear $\alpha$ alcohols.

In this paper, novel $\mathrm{CuO}_{\mathrm{x}} / \mathrm{Au} / \mathrm{Al}_{2} \mathrm{O}_{3}$ and $\mathrm{NiO}_{\mathrm{x}} / \mathrm{Au} / \mathrm{Al}_{2} \mathrm{O}_{3}$ catalysts with different metal loadings and monometallic analogues $\left(\mathrm{Au} / \mathrm{Al}_{2} \mathrm{O}_{3}, \mathrm{NiO}_{\mathrm{x}} / \mathrm{Al}_{2} \mathrm{O}_{3}, \mathrm{CuO}_{\mathrm{x}} / \mathrm{Al}_{2} \mathrm{O}_{3}\right)$ were produced by impregnation and/or deposition-precipitation techniques (See experimental for details). The electronic and morphological features of catalysts are presented in Table 1.

\section{Experimental}

Gamma alumina was used as a support for the mono- and bimetallic nanoparticles; $\mathrm{Cu}\left(\mathrm{NO}_{3}\right)_{2}, \mathrm{Ni}\left(\mathrm{NO}_{3}\right)_{2}$ and $\mathrm{HAuCl}_{4}$ (Sigma-Aldrich, $98-99 \%$ pure) were used as metal precursors. $\mathrm{CuO}_{\mathrm{x}} / \mathrm{Al}_{2} \mathrm{O}_{3}$ catalysts with 0.07 and 0.32 wt. $\%$ of $\mathrm{Cu}$ were prepared by impregnation [31] and denoted as $0.07 \mathrm{Cu}$ and $0.32 \mathrm{Cu}$, consequently. $\mathrm{NiO}_{\mathrm{x}} / \mathrm{Al}_{2} \mathrm{O}_{3}$ catalyst with 0.06 wt. \% of $\mathrm{Ni}$ was prepared by impregnation [33] and denoted as $0.06 \mathrm{Ni}$. $\mathrm{Au} / \mathrm{Al}_{2} \mathrm{O}_{3}$ catalysts with 0.2 and $0.5 \mathrm{wt}$. \% of Au were prepared by deposition-precipitation [31-33] and denoted as $0.2 \mathrm{Au}$ and $0.5 \mathrm{Au}$, consequently. Bimetallic $\mathrm{CuO}_{\mathrm{x}} / \mathrm{Au} / \mathrm{Al}_{2} \mathrm{O}_{3}$ catalysts were produced by impregnating of the $0.2 \mathrm{Au}(0.5 \mathrm{Au})$ sample with $0.07(0.32) \mathrm{wt} . \%$ of $\mathrm{Cu}[31]$ and denoted as $0.07 \mathrm{Cu} / 0.2 \mathrm{Au}$ and $0.32 \mathrm{Cu} / 0.5 \mathrm{Au}$, consequently. Bimetallic $\mathrm{NiO}_{\mathrm{x}} / \mathrm{Au} / \mathrm{Al}_{2} \mathrm{O}_{3}$ catalyst was produced by impregnating of the $0.2 \mathrm{Au}$ with 0.06 wt.\% of $\mathrm{Ni}[33]$ and denoted as $0.06 \mathrm{Ni} / 0.2 \mathrm{Au}$.

The metal content of the catalysts was determined by atomic absorption on a Thermo iCE 3000 AA spectrometer. TEM and EDX analysis of catalysts were carried out on a JEOL JEM 2100F/UHR microscope with 0.1-nm resolution and a JED-2300 X-ray spectrometer, respectively.

Analytical grade ethanol (96\%) was used without further purification. Catalytic experiments were carried out in a $45 \mathrm{~mL}$ high pressure Parr autoclave equipped with magnetic stirring. The reactor was loaded with the catalyst (typically $4.5 \mathrm{~g}$ ). The catalyst testing procedure was as follows: the reactor with catalyst was loaded with ethanol, closed and flushed with inert gas (Ar). The reactor was heated with 
a heating rate of $20^{\circ} \mathrm{C} / \mathrm{min}$. The reaction was allowed to proceed for $3 \mathrm{~h}$. After reaction, the reactor was cooled down in atmosphere.

Qualitative and quantitative analyses of the $\mathrm{C}_{1}-\mathrm{C}_{5}, \mathrm{CO}, \mathrm{CO}_{2}$ and $\mathrm{H}_{2}$ hydrocarbon gases were performed by GC. The qualitative composition of the liquid products were identified by GLC-MS. The quantitative content of the organic compounds was determined by GLC. Calibration of the GLC was carried out with commercial standards using method [21].

\section{$3 \quad$ Results and discussion}

The results of ethanol conversion over bimetallic $0.07 \mathrm{Cu} / 0.2 \mathrm{Au}$ and $0.06 \mathrm{Ni} / 0.2 \mathrm{Au}$ catalysts in supercritical regime indicates that ethanol conversion and selectivity to 1-butanol, 1hexanol and 1-octanol considerably increases in comparison with sub-critical conditions (Table 2).

The effect of temperature on selectivity of ethanol conversion into linear $\alpha$-alcohols has extremum. The maximum selectivity of 95.2 and $85.2 \%$ was obtained at $275^{\circ} \mathrm{C}$ over $0.07 \mathrm{Cu} / 0.2 \mathrm{Au}$ and $0.06 \mathrm{Ni} / 0.2 \mathrm{Au}$ catalysts, respectively. Should be noticed that $0.06 \mathrm{Ni} / 0.2 \mathrm{Au}$ catalyzed ethanol processing with conversion rate approximately twice higher than one observed over $0.07 \mathrm{Cu} / 0.2 \mathrm{Au}$ catalyst. Such high activity of $\mathrm{Ni} / \mathrm{Au}$ clusters may be explained with morphological peculiarities. Table 1 indicates that the mean size of $\mathrm{Ni} / \mathrm{Au}$ clusters is smaller than one of $\mathrm{Cu} / \mathrm{Au}$ clusters. Since the supported metals quantity in both cases was equal $\mathrm{Ni} / \mathrm{Au}$ particles may be suggested to have larger surface accessible for ethanol molecules.

Table 1 The electronic and morphological features of $\mathrm{M} / \mathrm{Al}_{2} \mathrm{O}_{3}$ catalysts

\begin{tabular}{|c|c|c|c|c|c|}
\hline \multirow{2}{*}{ Catalyst (abbreviation) } & \multicolumn{3}{|c|}{ Metal loading, wt.\% } & \multirow{2}{*}{$\begin{array}{l}\text { Mean particle } \\
\text { size, nm }\end{array}$} & \multirow{2}{*}{$\begin{array}{l}\text { Surface } \\
\text { species, at.\% }\end{array}$} \\
\hline & $\mathrm{Au}$ & $\mathrm{Cu}$ & $\mathrm{Ni}$ & & \\
\hline $\mathrm{CuO}_{\mathrm{x}} / \mathrm{Al}_{2} \mathrm{O}_{3} 0.07 \mathrm{Cu}$ & 0 & 0.07 & 0 & 3 & \multirow{2}{*}{$\begin{array}{l}\mathrm{Cu}^{2+} / \mathrm{Cu}^{+} \\
90 / 10[32]\end{array}$} \\
\hline $\mathrm{CuO}_{\mathrm{x}} / \mathrm{Al}_{2} \mathrm{O}_{3} 0.32 \mathrm{Cu}$ & 0 & 0.32 & 0 & 4 & \\
\hline $\mathrm{NiO}_{\mathrm{x}} / \mathrm{Al}_{2} \mathrm{O}_{3} 0.06 \mathrm{Ni}$ & 0 & 0 & 0.06 & 3 & $\begin{array}{l}\mathrm{Ni}^{2+}=100 \\
{[33,34]}\end{array}$ \\
\hline $\mathrm{Au} / \mathrm{Al}_{2} \mathrm{O}_{3} 0.2 \mathrm{Au}$ & 0.2 & 0 & 0 & 7 & \multirow{2}{*}{$\begin{array}{l}\mathrm{Au}^{0}=100 \\
{[32-34]}\end{array}$} \\
\hline $\mathrm{Au} / \mathrm{Al}_{2} \mathrm{O}_{3}(0.5 \mathrm{Au})$ & 0.5 & 0 & 0 & 10 & \\
\hline $\begin{array}{r}\mathrm{CuO}_{\mathrm{x}} / \mathrm{Au} / \mathrm{Al}_{2} \mathrm{O}_{3} \\
0.07 \mathrm{Cu} / 0.2 \mathrm{Au} \\
\end{array}$ & 0.2 & 0.07 & 0 & 5 & \multirow{2}{*}{$\begin{array}{l}\mathrm{Cu}^{2+} / \\
\mathrm{Cu}^{+}=63 / 37 ; \\
\mathrm{Au}^{0} / \mathrm{Au}^{+} \\
53 / 47[32]\end{array}$} \\
\hline $\begin{array}{r}\mathrm{CuO}_{\mathrm{x}} / \mathrm{Au} / \mathrm{Al}_{2} \mathrm{O}_{3} \\
0.32 \mathrm{Cu} / 0.5 \mathrm{Au}\end{array}$ & 0.5 & 0.32 & 0 & 7 & \\
\hline $\begin{array}{r}\mathrm{NiO}_{\mathrm{x}} / \mathrm{Au} / \mathrm{Al}_{2} \mathrm{O}_{3} \\
0.06 \mathrm{Ni} / 0.2 \mathrm{Au}\end{array}$ & 0.2 & 0 & 0.06 & 4 & $\begin{array}{l}\mathrm{Ni}^{2+}=100 \\
\mathrm{Au}^{0} / \mathrm{Au}^{+}= \\
81 / 19[33,34]\end{array}$ \\
\hline
\end{tabular}

An increase in reaction temperature from 275 up to $295^{\circ} \mathrm{C}$ leads to a slight ethanol conversion increase over considered catalysts. In the same time the selectivity of 1-butanol decreases from 74.4 down to $57.2 \%$ over $0.07 \mathrm{Cu} / 0.2 \mathrm{Au}$ catalyst (Table 2). The 1-butanol selectivity decrease is caused by diethyl ether and hydrocarbons 
348 10 $10^{\mathrm{TH}}$ International Conference on Sustainable Energy and Environmental Protection (June $27^{\mathrm{TH}}-30^{\mathrm{TH}}, 2017$, BLED, Slovenia), Bioenergy AND Biofuels

A. V. Chistyakov, S. A. Nikolaev, P. A. Zharova, M. V. Tsodikov \& F. Manenti: Direct Conversion of Ethanol Into Linear A- Alcohols in the Supercritical Regime Over Au$\mathrm{Cu}$ and $\mathrm{Au}-\mathrm{Ni}$ Catalysts

$\mathrm{C}_{2}$ (ethane, ethylene) and $\mathrm{C}_{4}$ (butane, butenes) formation suggesting dehydration reaction intensification over acidic centers of alumina. The effect of reaction temperature increase on yields of various alcohols from ethanol over $0.06 \mathrm{Ni} / 0.2 \mathrm{Au}$ showed that 1-butanol selectivity increases to $71.7 \%$ but total linear $\alpha$-alcohols selectivity decreases to $81.4 \%$.

A decrease in reaction temperature down to $245^{\circ} \mathrm{C}$ leads to a sharp decline of ethanol conversion and selectivity of $\alpha$-alcohols over both considered catalysts. Probably, at low temperature ethanol dehydrogenation reaction slows down that negatively effect on ethanol condensation (Scheme 1) suggesting butanol-1 yield decrease.

Table 2 Results obtained with alumina supported bimetallic $0.06 \mathrm{Ni} / 0.2 \mathrm{Au}$ and $0.07 \mathrm{Cu} / 0.2 \mathrm{Au}$ catalysts.

\begin{tabular}{|l|c|c|c|c|}
\hline $0.07 \mathrm{Cu} / 0.2 \mathrm{Au}$ catalyst \\
\hline $\mathrm{T},{ }^{\circ} \mathrm{C}$ & 295 & 275 & 245 & $275^{[\mathrm{a}]}$ \\
\hline conversion & 35.1 & 33.4 & 4.6 & 15.1 \\
\hline $\begin{array}{l}\text { selectivity of } \\
\text { butanol-1 }\end{array}$ & 57.2 & 74.4 & 57.9 & 25.30 \\
\hline $\begin{array}{l}\text { selectivity of } \\
\text { hexanol-1 }\end{array}$ & 6.4 & 17.8 & 3.0 & 7.20 \\
\hline \multicolumn{5}{|c|}{$0.06 \mathrm{Ni} / 0.2 \mathrm{Au}$ catalyst } \\
\hline conversion & 71.7 & 63.5 & 6.9 & 33.5 \\
\hline $\begin{array}{l}\text { selectivity of } \\
\text { butanol-1 }\end{array}$ & 64.9 & 58.4 & 25.7 & 25.9 \\
\hline $\begin{array}{l}\text { selectivity of } \\
\text { hexanol-1 }\end{array}$ & 16.0 & 21.2 & 0 & 3.8 \\
\hline $\begin{array}{l}\text { selectivity of } \\
\text { octanol-1 }\end{array}$ & 0.5 & 5.6 & 0 & 0 \\
\hline
\end{tabular}

${ }^{[a]}$ subcritical pressure of ethanol $(50 \mathrm{~atm})$.

For the next step, we studied whether super-critical conditions could be advantageous in the investigated reaction. The critical point of ethanol is $241{ }^{\circ} \mathrm{C}$ and $61 \mathrm{~atm}$. [34]. Under subcritical pressure 50 atm catalysts activity significantly changes in ethanol conversion at $275{ }^{\circ} \mathrm{C}$ (Table 2). Over $0.06 \mathrm{Ni} / 0.2 \mathrm{Au}$ catalyst ethanol conversion and selectivity of 1-butanol decreases from 71.7 to 33.5 and from 64.9 to $25.9 \%$, respectively. Over $0.07 \mathrm{Cu} / 0.2 \mathrm{Au}$ also was observed halving of catalytic activity. The selectivity of 1-butanol decrease is caused by hydrocarbons $\left(\mathrm{C}_{2}, \mathrm{C}_{4}, \mathrm{C}_{6}\right)$, diethyl ether and ethyl butyl ester formation. In the work [20] over Au- and Ni-containing catalysts the effect of sub- vs. supercritical conditions was studied and no beneficial effects related to super-critical conditions were found. The absence of any effect in the work [20] may be explained with the fact that authors compared results obtained at $250{ }^{\circ} \mathrm{C}$ and at temperatures below $241{ }^{\circ} \mathrm{C}$. Our study demonstrates that $250{ }^{\circ} \mathrm{C}$ is too low to reach high catalytic 
$10^{\mathrm{TH}}$ INTERNATIONAL CONFERENCE ON SUSTAINABLE ENERGY AND ENVIRONMENTAL Protection (June $27^{\mathrm{TH}}-30^{\mathrm{TH}}, 2017$, BLed, Slovenia), Bioenergy AND Biofuels

A. V. Chistyakov, S. A. Nikolaev, P. A. Zharova, M. V. Tsodikov \& F. Manenti:

Direct Conversion of Ethanol Into Linear A- Alcohols in the Supercritical Regime Over $\mathrm{Au}-\mathrm{Cu}$ and $\mathrm{Au}-\mathrm{Ni}$ Catalysts

efficiency, moreover we compared sub- and supercritical conditions by pressure varying at optimal temperature $275^{\circ} \mathrm{C}$.

The reason of observed in our work beneficial catalytic activity increase under supercritical conditions may be caused by several factors: the decrease of hydrogen bonds of ethanol, diffusion barrier lowering and $\mathrm{O}-\mathrm{H}$ bonds acidity increase [3537].

Table 3 Catalytic conversions of ethanol over alumina supported monometallic Au, $\mathrm{CuO}_{\mathrm{x}}, \mathrm{NiO}_{\mathrm{x}}$ and bimetallic $\mathrm{CuO}_{\mathrm{x}} / \mathrm{Au}$ catalysts $\left(\mathrm{T}=275^{\circ} \mathrm{C}, \mathrm{P}_{\mathrm{EtOH}}=100 \mathrm{~atm}\right.$, time $\left.=5 \mathrm{~h}\right)$.

\begin{tabular}{|l|l|l|l|l|}
\hline Catalyst & $\mathrm{X}, \%$ & $\begin{array}{l}\mathrm{S} \text { butanol- } \\
1, \%\end{array}$ & $\begin{array}{l}\mathrm{S} \text { hexanol- } \\
1, \%\end{array}$ & $\begin{array}{l}\mathrm{S} \text { octanol- } \\
1, \%\end{array}$ \\
\hline $\mathrm{Al}_{2} \mathrm{O}_{3}$ & 25.3 & 0.8 & 0 & 0 \\
\hline $0.06 \mathrm{Ni}$ & 5.8 & 0.3 & 0 & 0 \\
\hline $0.07 \mathrm{Cu}$ & 11.5 & 0.2 & 0 & 0 \\
\hline $0.32 \mathrm{Cu}$ & 13.1 & 0.6 & 0 & 0 \\
\hline $0.2 \mathrm{Au}$ & 34.0 & 15.9 & 0.5 & 0.0 \\
\hline $0.5 \mathrm{Au}$ & 40.6 & 41.9 & 5.5 & 0.0 \\
\hline $0.32 \mathrm{Cu} / 0.5 \mathrm{Au}$ & 44.8 & 77.6 & 17.9 & 2.9 \\
\hline
\end{tabular}

S- selectivity, X-conversion

As mentioned above, the catalytic activities and product selectivities depend on sub- or supercritical conditions but another important factor affecting on reaction is the catalyst composition. Over both the support $\gamma-\mathrm{Al}_{2} \mathrm{O}_{3}$ and monometallic $0.06 \mathrm{Ni}$ and $0.07 \mathrm{Cu}$ catalysts ethanol conversion considerably lower than one over the bimetallic catalysts and butanol-1 selectivity does not exceed 1\% (Table 3). Should be noticed that the monometallic 20 wt. $\%$ Ni/ $/ \mathrm{Al}_{2} \mathrm{O}_{3}$ catalyst converts ethanol into butanol-1 with selectivity about 37-62 \% [20]. We used monometallic $\mathrm{Ni}$ - and $\mathrm{Cu}$-containing catalysts modified with extremely small amounts of metals $0.06-0.32 \mathrm{wt} . \%$ that may suggest its low activity. On the other hand, monometallic Au-containing catalysts showed good activity in butanol-1 producing. As shown in Table 3, Au concentration increases from 0.2 to $0.5 \mathrm{wt}$. \% leads to selectivity of 1-butanol increase from 15.9 up to $41.9 \%$ and also considerable amounts of 1 hexanol were found in the ethanol conversion products.

Diethyl ether and hydrocarbons $\mathrm{C}_{2}$ and $\mathrm{C}_{4}$ were found to be the main co-products of ethanol conversion over $\mathrm{Au} / \mathrm{Al}_{2} \mathrm{O}_{3}$ catalysts. The comparison of activities 
$10^{\mathrm{TH}}$ InTERNATIONAL CONFERENCE ON Sustainable ENERGY AND ENVIRONMENTAL Protection (June $27^{\mathrm{TH}}-30^{\mathrm{TH}}, 2017$, Bled, Slovenia), Bioenergy AND Biofuels

A. V. Chistyakov, S. A. Nikolaev, P. A. Zharova, M. V. Tsodikov \& F. Manenti: Direct Conversion of Ethanol Into Linear A- Alcohols in the Supercritical Regime Over Au$\mathrm{Cu}$ and $\mathrm{Au}-\mathrm{Ni}$ Catalysts

monometallic $0.2 \mathrm{Au}$ and bimetallic $0.07 \mathrm{Cu} / 0.2 \mathrm{Au}$ catalysts showed that $\mathrm{Au}$ promotion with $\mathrm{Cu}$ allows to increase selectivity of 1-butanol from 15.9 up to 74.4 $\%$ by ethanol conversion is constant $34 \%$ (Table 2-3). The same trend was observed during investigations of $0.06 \mathrm{Ni} / 0.2 \mathrm{Au}$ catalyst.

The increase of active components concentration in the bimetallic $\mathrm{Cu} / \mathrm{Au}$ catalyst leads to the activity and selectivity increase similar to monometallic Au-containing catalysts. Ethanol conversion reaches $45 \%$ over $0.32 \mathrm{Cu} / 0.5 \mathrm{Au}$ catalyst versus 33.4 $\%$ conversion over $0.07 \mathrm{Cu} / 0.2 \mathrm{Au}$ catalyst at the optimal temperature $275^{\circ} \mathrm{C}$. Over $0.32 \mathrm{Cu} / 0.5 \mathrm{Au}$ catalyst the selectivity of 1-butanol, 1-hexanol and 1-octanol was $77.6,19.3$ and $2.9 \%$, respectively. Thus the total conversion of linear $\alpha$-alcohols reaches up to $99 \%$ (Table 3 ).

Fig. 1 shows the kinetics studies of ethanol conversion and the selectivity of linear $\alpha$-alcohols over the most effective $0.32 \mathrm{Cu} / 0.5 \mathrm{Au}$ catalyst.

During five hours the conversion of ethanol lineally increases. More longtime experiments 12 and 24 hours do not result in ethanol conversion rate. This result agreed with that of Riitonen et. al. [20]. The selectivity of 1-hexanol and 1-octanol illustrate a stable upward trend. The selectivity of 1-butanol seems to peak in approximately 1 hour and 30 minutes of the reaction followed by a smooth decrease. The same functions of selectivities were observed by Ogo et. al. [38] and Tsuchida et. al. [39]. Observed maximum of 1-butanol selectivity believable is the result of its accumulation in the beginning of the reaction followed by conversion into higher alcohols that selectivities, as mentioned above, lineally increase. Interestingly, the selectivity of butanol-1 as a function of ethanol conversion obtained in present work has some advantages in comparison with ones obtained in the next works $[14,20,38]$. That fact gives us opportunity to consider $0.32 \mathrm{Cu} / 0.5 \mathrm{Au}$ catalyst as the most prospective to the best of our knowledge. 
$10^{\mathrm{TH}}$ INTERNATIONAL CONFERENCE ON SUSTAINABLE ENERGY AND ENVIRONMENTAL Protection (June $27^{\mathrm{TH}}-30^{\mathrm{TH}}, 2017$, BLed, Slovenia), Bioenergy ANd Biofuels

A. V. Chistyakov, S. A. Nikolaev, P. A. Zharova, M. V. Tsodikov \& F. Manenti: Direct Conversion of Ethanol Into Linear A- Alcohols in the Supercritical Regime Over $\mathrm{Au}-\mathrm{Cu}$ and $\mathrm{Au}-\mathrm{Ni}$ Catalysts
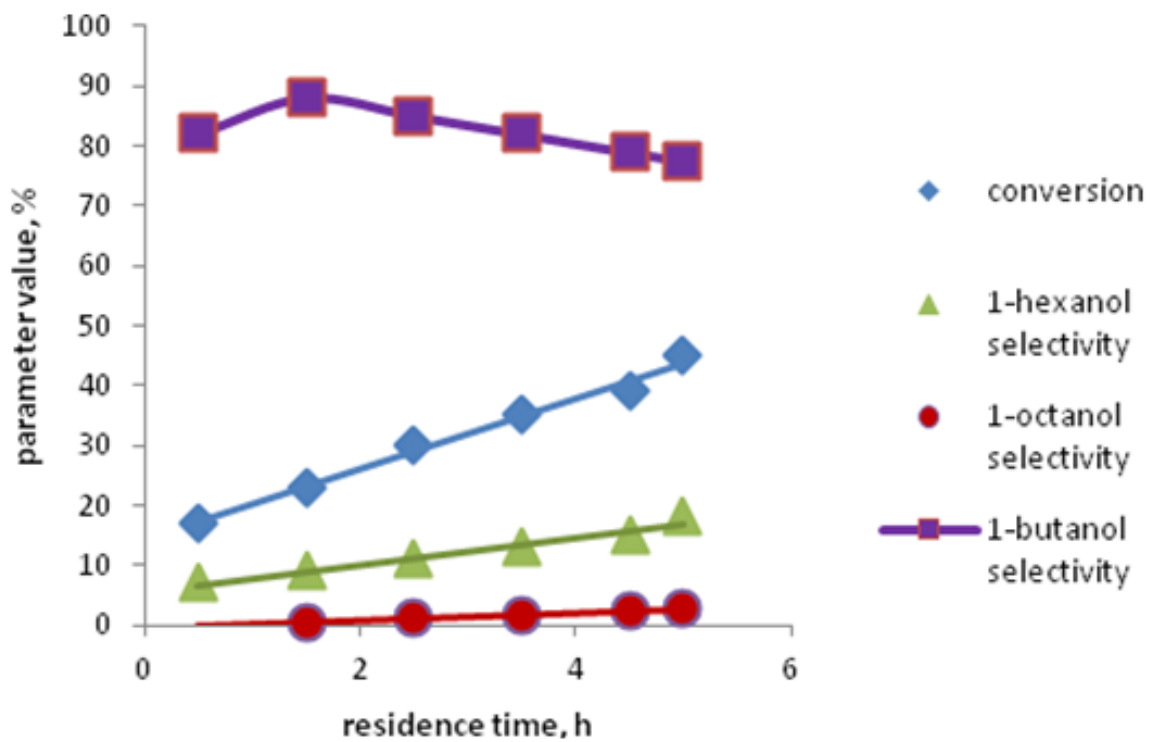

Fig. 1 Ethanol conversion and selectivity of 1-butanol, 1-hexanol and 1-octanol as a function of time $\left(0.32 \mathrm{Cu} / 0.5 \mathrm{Au}, \mathrm{T}=275^{\circ} \mathrm{C}, \mathrm{P}_{\mathrm{EtOH}}=100 \mathrm{~atm}\right)$.

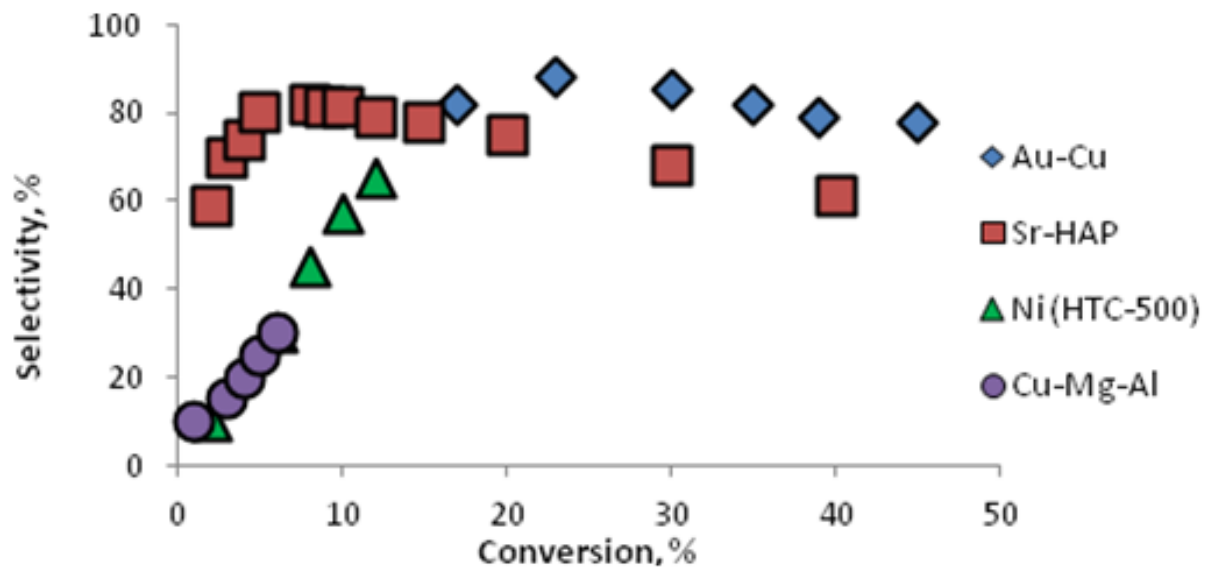

Figure 2 1-Butanol selectivity vs ethanol conversion on $0.32 \mathrm{Cu} / 0.5 \mathrm{Au}$ catalyst of the present study; Cu-Mg-Al catalyst [14]; Ni catalyst [21]; Sr catalyst [39]. 
$10^{\mathrm{TH}}$ InTERNATIONAL CONFERENCE ON Sustainable ENERGy AND ENVIRONMENTAL Protection (June $27^{\mathrm{TH}}-30^{\mathrm{TH}}, 2017$, BLED, Slovenia), Bioenergy AND Biofuels

A. V. Chistyakov, S. A. Nikolaev, P. A. Zharova, M. V. Tsodikov \& F. Manenti: Direct Conversion of Ethanol Into Linear A- Alcohols in the Supercritical Regime Over Au$\mathrm{Cu}$ and $\mathrm{Au}-\mathrm{Ni}$ Catalysts

\section{Acknowledgements}

This study was financially supported by Russian Scientific Foun-dation Grant No. 15-13-30034 and used the equipment of M.V.Lomonosov Moscow State University (Program of MSU Development).

\section{References}

[1] E. Crabbe, C. Nolasco-Hipolito, G. Kobayashi, K. Sonomoto, A. Ishizaki, Process Biochem. 2001, 37, 65- 71.

[2] C. Angelici, B. M. Weckhuysen, P. C. A. Bruijnincx, ChemSusChem 2013, 6, 1595 - 1614.

[3] Charles Weizmann, US1315585 A, 1919.

[4] E. M. Green, Curr. Opin. Biotechnol. 2011, 22, 337 - 343.

[5] C. Jin, M. Yao, H. Liu, C.-F. Lee, J. Ji, Renewable Sustainable Energy Rev. 2011, 15, 4080 -4106 .

[6] M. Guerbet, C. R. Acad. Sci. Paris 1899, 1002-1004.

[7] W. Birky, J.T. Kozlowski, R.J. Davis, J. Catal. 2013, 298, 130-137.

[8] S. Veibel, J.I. Nielsen, Tetrahedron 1967, 23, 1723-1733.

[9] R.E. Miller, G.E. Bennett, Ind. Eng. Chem. 1961, 53, 33-36.

[10] T. Tsuchida, K. Atsumi, S. Sakuma, T. Inui, Patent Assigned to Sangi Co., Ltd., US 6,323,383 (B1), November 27, 2001.

[11] S. Ogo, A. Onda, K. Yanagisawa, Appl. Catal. A: Gen. 2011, 402, 188-195.

[12] T. Tsuchida, J. Kubo, T. Yoshioka, S. Sakuma, T. Takeguchi, W. Ueda, J. Catal. 2008, 259, 183-189.

[13] K.W. Yang, X.Z. Jiang, W.C. Zhang, Chinese Chem. Lett. 2004, 15, 1497-1500.

[14] I.-C. Marcu, D. Tichit, F. Fajula, N. Tanchoux, Catal. Today 2009, 147, 231-238.

[15] V. Nagarajan, Indian J. Technol. 1971, 9, 380-386.

[16] C. Yang, Z. Meng, J. Catal. 1993, 142, 37-44.

[17] A.S. Ndou, N. Plint, N.J. Coville, Appl. Catal. A: Gen. 2003, 251, 337-345.

[18] J.I. Di Cosimo, C.R. Apesteguia, M.J.L. Gines, E. Iglesia, J. Catal. 2000, 190, 261-275.

[19] T.G. Calvarese, R.J. Davis, P.J. Fagan, R. Ozer, Patent Assigned to Du Pont,WO2011031928 (A1), March 17, 2011.

[20] T. Riittonen, E. Toukoniitty, D.K. Madnani, A.-R. Leino, K. Kordas, M. Szabo, A. Sapi, K. Arve, J. Wärnå, J.-P. Mikkola Catalysts 2012, 2(1), 68-84.

[21] M. Haruta, T. Kobayashi, H. Sano, N. Yamada, Chem. Lett. 1987, 16, 405-408.

[22] T. Tabakova, L. Ilieva, I. Ivanov, R. Zanella, J.W. Sobczak, W. Lisowski, Z. Kaszkur, D. Andreeva, Appl. Catal. B: Environ. 2013, 136-137, 70-80.

[23] M.G. Castaño, T.R. Reina, S. Ivanova, M.A. Centeno, J.A. Odriozola, J. Catal. 2014, 314, $1-9$.

[24] S.A. Nikolaev, V.V. Smirnov, A. Yu Vasil'kov, V.L. Podshibikhin, Kinet. Catal. 2010, 51, 375-379.

[25] S.A. Nikolaev, N.A. Permyakov, V.V. Smirnov, A. Yu Vasil'kov, S.N. Lanin, Kinet. Catal. 2010, 51, 288-292.

[26] V.V. Smirnov, S.A. Nikolaev, G.P. Murav'eva, L.A. Tyurina, A. Yu Vasil'kov, Kinet. Catal. 2007, 48, 265-270.

[27] I.L. Simakova, S. Yu. Solkina, B.L. Moroz, O.A. Simakova, S.I. Reshetnikov, I.P. Prosvirin, V.I. Bukhtiyarov, V.N. Parmon, D. Yu. Murzin, Appl. Catal. A 2010, 385, 136143.

[28] S. Gómez-Quero, F. Cárdenas-Lizana, M.A. Keane, J. Catal. 2013, 303, 41-49. 
$10^{\mathrm{TH}}$ INTERNATIONAL CONFERENCE ON SUSTAINABLE ENERGY AND ENVIRONMENTAL 353

Protection (June $27^{\mathrm{TH}}-30^{\mathrm{TH}}, 2017$, Bled, SloveniA), Bioenergy ANd Biofuels

A. V. Chistyakov, S. A. Nikolaev, P. A. Zharova, M. V. Tsodikov \& F. Manenti: Direct Conversion of Ethanol Into Linear A- Alcohols in the Supercritical Regime Over $\mathrm{Au}-\mathrm{Cu}$ and $\mathrm{Au}-\mathrm{Ni}$ Catalysts

[29] F. Cárdenas-Lizana, D. Lamey, N. Perret, S. Gómez-Quero, L. Kiwi-Minsker, M.A. Keane, Catal. Commun. 2012, 21, 46-51.

[30] S.A. Nikolaev, E.V. Golubina, L.M. Kustov, A.L. Tarasov, O.P. Tkachenko, Kinet. Catal. 2014, 55, 311-318.

[31] S.A. Nikolaev, E.V. Golubina, I.N. Krotova, M.I. Shilina, A.V. Chistyakov, V.V. Kriventsov, Appl. Catal. B: Environ. 2015, 168, 303-312

[32] S.A. Nikolaev, A.V. Chistyakov, M.V. Chudakova, V.V. Kriventsov, E.P. Yakimchuk, M. V. Tsodikov, J. Catal. 2013, 297, 296-305.

[33] O.P. Tkachenko, L.M. Kustov, S.A. Nikolaev, V.V. Smirnov, K.V. Klementiev, A.V. Naumkin, I.O. Volkov, A.Yu. Vasil'kov, D.Yu. Murzin, Topics in Catal. 2009, 52, 344350.

[34] R.C. Reid, J.M. Prausnitz and B.E. Poling (1988) The properties of gases and liquids, McGraw-Hill Book Company, 4th ed.

[35] Eckert, C.; Liotta, E.; Boughner, E.; Lu, J., Fluid Phase Equilibria 2002, 198, 37-49. 21.

[36] Yang, J.; Zhang, Y.; Yu, Y.-X.; Li, Y.-G., J. Supercrit. Fluids 2005, 36, 145-153. 22.

[37] Samios, J., Dellis, D.; Chalaris, M., J. Phys. Chem. B 2005, 109, 18575-18590.

[38] S. Ogo, A. Onda, Y. Iwasa, K. Hara, A. Fukuoka, K. Yanagisawa, J. Catal., 2012, 296, 24 30 .

[39] Takashi Tsuchida, Shuji Sakuma, Tatsuya Takeguchi, and Wataru Ueda, Ind. Eng. Chem. Res. 2006, 45, 8634-8642. 


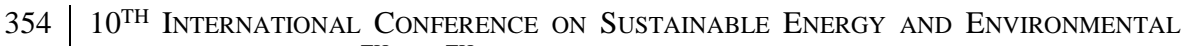
Protection (June $27^{\mathrm{TH}}-30^{\mathrm{TH}}, 2017$, BLed, Slovenia), Bioenergy AND Biofuels 
$10^{\mathrm{TH}}$ InTERNATIONAL CONFERENCE ON Sustainable ENERGy AND Environmental Protection (June 27 $7^{\mathrm{TH}}-30^{\mathrm{TH}}$, 2017, BLed, SLOVENIA), BIOENERGY AND BIOFUELS

J. Krope, A.Ghani Olabi, D. Goričanec \& S. Božičnik

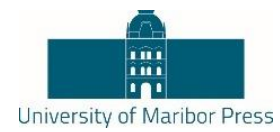

\title{
Original Pt-Sn/ $/ \mathrm{Al}_{2} \mathrm{O}_{3}$ Catalyst for Selective Hydrodeoxygenation of Vegetable Oils
}

\author{
Polina A. Zharova, Andrey V. Chistyakov, Sergey S. Shapovalov, AleXander \\ A. PASYNSKII \& MARK V. TSODIKOV
}

\begin{abstract}
The performance of bimetallic $\mathrm{Pt}-\mathrm{Sn} / \mathrm{Al}_{2} \mathrm{O}_{3}$ catalyst, which is characterized by the $\mathrm{Sn} / \mathrm{Pt}$ molar ratio of $5 / 1$, has been studied in the selective hydrodeoxygenation of esters. The supported catalysts were prepared via impregnation of $\gamma-\mathrm{Al}_{2} \mathrm{O}_{3}$ using the solution of the heterometallic $\left(\mathrm{PPh}_{4}\right) 3\left[\mathrm{Pt}\left(\mathrm{SnCl}_{3}\right) 5\right]$ complex, in which platinum and tin atoms are linked by a metal-metal bond. The reductive deoxygenation of a number of esters has been shown to proceed with a quantative yield of hydrocarbons derived from alkoxy and acyl groups of the starting ester.
\end{abstract}

Keywords: • hydrodeoxygenation $\bullet$ vegetable oil $\bullet$ esters $\bullet$ platinum $\bullet$ tin $\bullet$ heterogeneous catalysis•

Correspondence AdDress: Polina A. Zharova, Ph.D. student, Junior researcher, Topchiev Institute of Petrochemical Synthesis RAS, Leninsky prospekt, 29, Moscow, Russia, e-mail: zharova@ips.ac.ru. Andrey V. Chistyakov, Ph.D., Leading Researcher, Topchiev Institute of Petrochemical Synthesis RAS, Leninsky prospekt, 29, Moscow, Russia, e-mail: chistyakov@ips.ac.ru. Sergey S. Shapovalov, Ph.D., Senior Researcher, Kurnakov Institute of General and Inorganic Chemistry RAS, Leninsky prospekt, 31, Moscow, Russia, e-mail: schss@yandex.ru. Alexander A. Pasynskii, Ph.D., Head of the laboratory, Kurnakov Institute of General and Inorganic Chemistry RAS, Leninsky prospekt, 31, Moscow, Russia, e-mail: pasynskii@igic.ac.ru. Mark V. Tsodikov, Ph.D., Head of the laboratory, Topchiev Institute of Petrochemical Synthesis RAS, Leninsky prospekt, 29, Moscow, Russia, e-mail: tsodikov@ips.ac.ru. 
$10^{\mathrm{TH}}$ InTERNATIONAL CONFERENCE ON Sustainable ENERGY AND ENVIRONMENTAL Protection (June $27^{\mathrm{TH}}-30^{\mathrm{TH}}, 2017$, BLed, SloveniA), Bioenergy AND Biofuels P. A. Zharova, A. V. Chistyakov, S. S. Shapovalov, A. A. Pasynskii \& M. V. Tsodikov: Original Pt-Sn/ $/ \mathrm{Al}_{2} \mathrm{O}_{3}$ Catalyst for Selective Hydrodeoxygenation of Vegetable Oils

Vegetable oils are considered to be promising renewable feedstock for the chemical and polymer industries. Alpha olefins, alcohols, as well as fuel constituents are known to be produced from it [1-4]. Within recent years, the scientific attention has been attracted by the syntheses of novel oil-based polymer materials since some of these polymers exhibit unique shock-absorbing properties and have the "memory effect" [5]. However, much more efforts have been focused on application of vegetable oils as a sustainable energy resource.

Lipids containing fatty acid triglycerides (FATG) are the main components of the vegetable oils commonly used to fabricate biofuels or, precisely, biodiesel $[5,6]$. Depending on the starting source of lipids, three generations of biofuel have been considered. The first generation biodiesel, the most general nowadays, is a mixture of methyl (ethyl) esters of fatty acids obtained via transesterification of fatty acid triglycerides of edible plant oils with monoatomic alcohols (methanol, ethanol, etc.). However, a large amount of glycerin is formed as a by-product in the above mentioned reaction $[3,6]$. In addition, quite poor performance characteristics of the final biodiesel such as cetane number, resistibility to oxidation, as well as carbon deposits on the engine operating elements are to be indicated. These drawbacks promote the development of more effective approaches to the synthesis of hydrocarbons from biomass. Moreover, not the least issue is a need in a highly effective alternative fuel for the aviation or that applied in the northern regions, which are characterized by a low setting point and a high heat value $[3,6]$. Taking this into account, the methods for hydrocarbon production from fatty acids as well as from plant lipids via direct hydrogenation over conventional hydrocracking catalysts are of current interest. The main fuel characteristics of green diesel, namely, high cetane number (75-90), lower setting point, high oxidation stability, excel those of biodiesel synthesized via transesterification and those of petroleum based diesel $[15,16]$. Moreover, non-edible plant oils, agricultural residues or wastes (second generation biofuel), as well as microalgae oils (third generation biofuel) are to be considered as main sources of lipids to decrease an amount of crops being diverted away from the global food market [2,7-13].

Reductive deoxygenation proceeds in the range of temperatures from 300 to $380^{\circ} \mathrm{C}$ and pressures from 30 to $50 \mathrm{~atm}$. There are three general reaction pathways occurs within the process: decarboxylation, decarbonylation, and hydrodeoxygenation. The latter makes it possible to keep valuable carbon-containing mass, but much hydrogen is consumed. Whereas less hydrogen is required in decarboxylation and decarbonylation, but a significant shortcoming of these reactions is lower yield in target products owing to carbon atom loss $[14,15]$. Since low availability of non-eligible sources of triglycerides of fatty acids limits the development of the green diesel manufacture $[3,6]$. Therefore, one of the demands for the biodiesel production technology is to minimize carboncontaining mass loss in the reactions of decarboxylation/decarbonylation (carbon oxide generation) and cracking (methane generation). 
$10^{\mathrm{TH}}$ INTERNATIONAL CONFERENCE ON SUSTAINABLE ENERGY AND ENVIRONMENTAL

Earlier, we showed that bimetallic $\mathrm{Pt}-\mathrm{Sn} / \mathrm{Al}_{2} \mathrm{O}_{3}$ supported catalyst, which was prepared by impregnation of gamma alumina oxide using solution of heterometallic $\left(\mathrm{PPh}_{4}\right)_{3}\left[\mathrm{Pt}\left(\mathrm{SnCl}_{3}\right)_{5}\right]$ complex performed an outstanding selectivity in the reductive deoxygenation of rapeseed oil at $400{ }^{\circ} \mathrm{C}$ and hydrogen pressure of $30 \mathrm{~atm}[16,17]$. No products of cracking $\left(\mathrm{C}_{1}, \mathrm{C}_{2}\right.$ compounds) or products of decarboxylation and decarbonylation were detected in the resulting deoxygenated mixture. Hence the selectivity towards the obtained hydrocarbons reached $99 \%$ and the selectivity towards $\mathrm{C}_{18}$ alkane-olefin fraction, which was calculated with respect to the hydrocarbon chains of the starting FATG, was $84 \%$. When the industrial platinum-alumina catalyst was examined, the content of $\mathrm{C}_{18}$ hydrocarbons fell down to $14 \%$ and the products of cracking, mainly $\mathrm{C}_{17+}$ hydrocarbons, were prevalent. In addition, almost $4 \%$ of methane and carbon oxides were obtained. Tin-containing catalytic system was reported to be hardly active in FATG transformation at given temperature. With increasing $\mathrm{Sn} / \mathrm{Pt}$ ratio (the total amount of the loaded metals remained constant) the selectivity in respect to $\mathrm{C}_{18}$ and $\mathrm{C}_{3}$ increased as well as the yield of $\mathrm{C}_{1}$ compounds. When the heterometallic complex containing Pt$\mathrm{Sn}$ bond in its structure was used as a precursor, $\mathrm{Pt}-\mathrm{Sn} / \mathrm{Al}_{2} \mathrm{O}_{3}$ catalyst appeared to remarkably more selective than the bimetallic catalysts prepared by impregnation from an organic solution of individual platinum- and tin-containing complexes. Transmission electron microscopy and X-ray photoelectron spectroscopy tests established that an increase in $\mathrm{Sn} / \mathrm{Pt}$ ratio from 1 to 5, especially in heterometallic complex on alumina oxide surface, increases the concentration of $\mathrm{PtSn}_{3 \pm \delta}$ alloy nanoparticles as well as of tin oxides $(2+; 4+)[16]$.

Thus, such high selectivity of the platinum-tin supported catalyst, which was synthesized via impregnation using the heterometallic complex as a precursor [17], encouraged us to apply it in hydrodeoxygenation of individual esters. This work is aimed to demonstrate the original experimental data on the reductive deoxygenation of a wide range of esters over bimetallic Pt-Sn/ $/ \mathrm{Al}_{2} \mathrm{O}_{3}$ catalyst.

\section{Experimental}

The feedstock was rapeseed oil manufactured by the Russkie Semena company (fatty acid composition of the oil transesterified with methanol is given in [18]. Nonyl propinoate (reagen grade) and methyl oleate (OA, Alfa Aesar GmbH \& Co, EG-Nr 203992-5) were applied as individual esters. The latter reactant consisted on methyl oleate (93 wt.\%), methyl stearate $(4.8$ wt.\%) methyl gondoinate $(1.8 \%)$, methyl erucate $(0.1$ $\%)$. In addition, ethyl acetate, nonyl propionate, methyl oleate, methyl palmitate, methyl myristate, methyl benzoate and benzyl acetate were used as individual esters with various lengths of alkyl and aryl substitutes.

The conversion of rapeseed oil FATGs was studied on a PID Eng\&Tech microcatalytic unit with a fixed bed flow reactor. 
$10^{\mathrm{TH}}$ InTERNATIONAL CONFERENCE ON Sustainable ENERGy AND ENVIRONMENTAL Protection (June $27^{\mathrm{TH}}-30^{\mathrm{TH}}, 2017$, BLed, Slovenia), Bioenergy AND Biofuels P. A. Zharova, A. V. Chistyakov, S. S. Shapovalov, A. A. Pasynskii \& M. V. Tsodikov: Original Pt-Sn/Al $\mathrm{O}_{3}$ Catalyst for Selective Hydrodeoxygenation of Vegetable Oils

Gaseous reaction products were analyzed by the GC. Liquid organic products in the aqueous and organic phases were analyzed by gas GC-MS, using MSD 6973 (Agilent) and Automass\%150 (Delsi Nermag).

$1 \mathrm{Pt}-5 \mathrm{Sn} / \mathrm{Al}_{2} \mathrm{O}_{3}$ catalyst with the molar ratio of platinum and tin is 1:5 were obtained by impregnated on $\mathrm{Al}_{2} \mathrm{O}_{3}$ support. The platinum loading on the catalysts was $0.4 \mathrm{wt} . \%$. The heterometallic $\mathrm{Pt}-\mathrm{Sn}$ bond-containing complex precursor $\left(\mathrm{PPh}_{4}\right)_{3}\left[\mathrm{Pt}\left(\mathrm{SnCl}_{3}\right)_{5}\right]$ obtained according to a unique procedure, were used as precursors for catalyst preparation [16].

3

\section{Results and discussion}

The composition of the products of rapeseed oil conversion over the catalyst with the various $\mathrm{Sn} / \mathrm{Pt}$ ratios is present in Fig 1. An increase in selectivity towards $\mathrm{C}_{18}$ with increasing $\mathrm{Sn} / \mathrm{Pt}$ ratio is demonstrated.

Table 1 shows the experimental data on the individual ester conversion over the bimetallic Pt-5Sn $/ \mathrm{Al}_{2} \mathrm{O}_{3}$ catalyst at $400^{\circ} \mathrm{C}$.

\begin{tabular}{|c|c|c|c|c|c|}
\hline \multirow[t]{2}{*}{ Substrate } & \multirow[t]{2}{*}{ Income, mmol } & \multicolumn{2}{|c|}{$\begin{array}{c}\text { Outcome, } \\
\text { mmol }\end{array}$} & \multirow[t]{2}{*}{$\mathrm{S}, \% \mathrm{R}_{1} \mathrm{CH}_{3}$} & \multirow{2}{*}{$\begin{array}{l}\mathrm{S}, \% \\
\mathrm{R}_{2}-\mathrm{H}\end{array}$} \\
\hline & & $\mathrm{R}_{1} \mathrm{CH}_{3}$ & $\mathrm{R}_{2}-\mathrm{H}$ & & \\
\hline Ethyl acetate & 404 & \multicolumn{2}{|c|}{798} & \multicolumn{2}{|c|}{98.8} \\
\hline Nonyl propionate & 173 & 168 & 172 & 97.1 & 99.4 \\
\hline Methyl oleate & 94 & 90 & 94 & 95.8 & 100.0 \\
\hline Methyl palmitate & 104 & 100 & 104 & 96.2 & 100.0 \\
\hline Methyl myristate & 116 & 112 & 116 & 96.6 & 100.0 \\
\hline Methyl benzoate & 199 & 190 & 199 & 95.5 & 100.0 \\
\hline Benzyl acetate & 172 & 170 & 170 & 99.2 & 99.2 \\
\hline
\end{tabular}

S-selectivity

As it can be seen, $404 \mathrm{mmol}$ of ethyl acetate give rise to $798 \mathrm{mmol}$ of ethane-ethylene fraction, which corresponds to the total selectivity of the catalyst towards hydrodeoxygenation of $98.8 \%$. However, when only ethyl acetate transformation used as a model reaction, no certain conclusion can be made about the selectivity towards the reactions involving carboxyl fragment or alkyl group derived from alcohol (1). To clarify the contribution from hydrodeoxygenation reaction to the total selectivity, nonyl propionate, the ester containing alkyl substitutes with various carbon atoms, was used as a substrate.

As it follows from the product distribution of nonyl propionate conversion, the alkyl group reacts with the selectivity of $99.4 \%$ and ester acyl fragment turns into the corresponding hydrocarbon with the selectivity of $97.1 \%$ (Table 1). The total yield of $\mathrm{C}_{3}$ and $\mathrm{C}_{9}$ hydrocarbons was ca. $98 \%$. Such results are consistent with those observed for the rapeseed oil (Fig. 1). Therefore, it can be postulated that the catalyst selectivity towards 
$10^{\mathrm{TH}}$ INTERNATIONAL CONFERENCE ON SUSTAINABLE ENERGY AND ENVIRONMENTAL 359 Protection (June $27^{\mathrm{TH}}-30^{\mathrm{TH}}, 2017$, BLED, SLOVENIA), Bioenergy AND Biofuels P. A. Zharova, A. V. Chistyakov, S. S. Shapovalov, A. A. Pasynskii \& M. V. Tsodikov: Original $\mathrm{Pt}-\mathrm{Sn} / \mathrm{Al}_{2} \mathrm{O}_{3}$ Catalyst for Selective Hydrodeoxygenation of Vegetable Oils

the alkane formation from the alkyl fragment derived from alcohol is higher than from the acyl group of the initial ester (2).

Methanolysis has recently become one of the general pathways for processing FATGs [19-21]. An additional scientific interest is focused on the direct extraction of microalgae with methanol under supercritical conditions. The latter method enables to produce fatty acids methyl esters (FAMEs) in one stage [22, 23]. With allowance for this, we endeavored to recycle technical grade methyl oleate. The reaction of this substrate over $1 \mathrm{Pt}-5 \mathrm{Sn} / \mathrm{Al}_{2} \mathrm{O}_{3}$ was found to mainly yield $\mathrm{C}_{18}$ and methane. However, an appreciable amount of propane in the reaction products indicates the presence of mono- and diglycerides of fatty acids in the feedstock; those are able to readily turn into hydrocarbons as well. It is worth noting that significantly less amount of olefins yields from methyl oleate than from the rapeseed oil. This finding may be attributed to the arisen steric hindrance which prevents hydrogenation during conversion FATGs of rapeseed oil.

As a result of conversion of individual methyl esters of oleic $\left(\mathrm{C}_{18}\right)$, palmitin $\left(\mathrm{C}_{16}\right)$, and mistrine $\left(\mathrm{C}_{14}\right)$ acids, which are the main components of majority of vegetarian oils, it was established that alkyl fragment undergoes hydrogenation with the selectivity being close to $100 \%$. The catalyst selectivity towards the reductive deoxygenation of carboxylate moiety has propensity to increase with decreasing length of the carbon chain (3-5).

At reductive deoxygenation of the esters containing aryl substitutes, the catalyst selectivity towards hydrocarbon formation was nearly $100 \%$. However, unlike the results obtained for the above mentioned esters, in the case of methyl benzoate, carbon oxides and methanol were produced. Probably, the change in selectivity at reductive deoxygenation of aliphatic compounds is explained by cracking of the hydrocarbon chain at a greater extent than by the decarbonylation/decarboxylation. $(6,7)$. Herewith, when the esters comprising aryl substitutes are applied as substrates, decrease in selectivity is probably has the greater effect on decarbonylation/decarboxylation.

For the samples obtained from the heterometallic complex at a Sn:Pt ratio of 5 the EDX data show that the quantity of $\mathrm{Sn}$ is higher in comparison with other samples and is close to $\sim 1$ at \% compared to Al. Particles of $\mathrm{Pt}$, as in the previous samples, are present in the form of clusters and small particles (marked with red circles) (Fig. 2). The sample contains only two types of nanoparticles: Pt nanoparticles with a size of 1-2 nm, and ones with dimensions of $\sim 3-5 \mathrm{~nm}$ and of $\mathrm{PtSn}_{3 \pm \delta}$ composition, according to the EDS data. Note that the individual nanoparticles of "pure"tin were not found, as well as in the previous samples. 
$10^{\mathrm{TH}}$ InTERNATIONAL CONFERENCE ON Sustainable ENERGY AND ENVIRONMENTAL Protection (June $27^{\mathrm{TH}}-30^{\mathrm{TH}}, 2017$, BLed, Slovenia), Bioenergy AND Biofuels P. A. Zharova, A. V. Chistyakov, S. S. Shapovalov, A. A. Pasynskii \& M. V. Tsodikov: Original Pt-Sn/Al $\mathrm{O}_{3}$ Catalyst for Selective Hydrodeoxygenation of Vegetable Oils
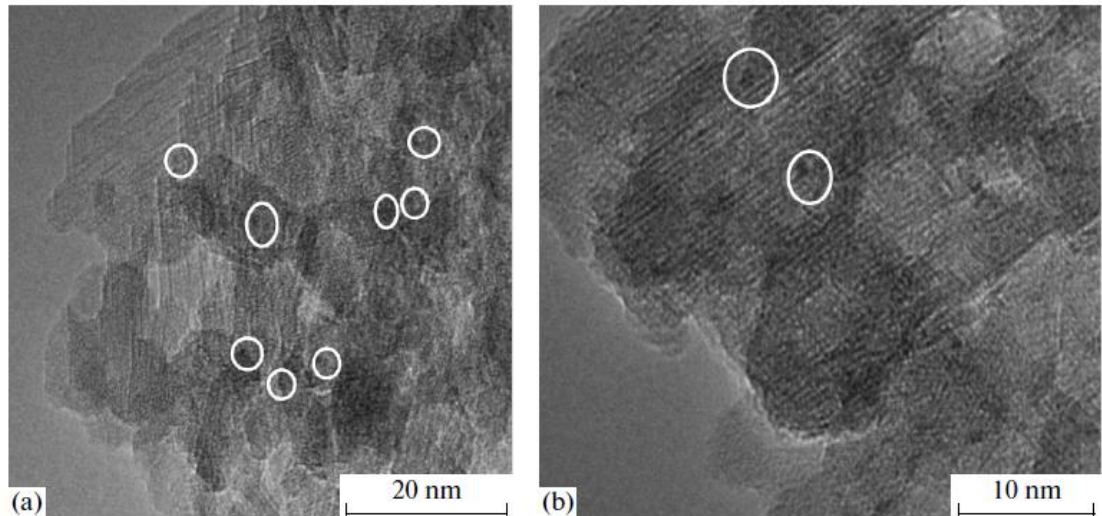

Figure 2. TEM photomicrographs at different magnifications of a sample of the catalyst 1Pt-5Sn, obtained from the heterometallic complex $(\mathrm{a}, \mathrm{b})$.

The $\mathrm{Pt} 4 \mathrm{f}_{7 / 2}$ electron binding energy of $72.9 \mathrm{eV}$ is in the range $72.4-74.6 \mathrm{eV}$ typical of $\mathrm{PtO}$ [24], and the corresponding electron binding energy for $\mathrm{Sn}_{3} \mathrm{~d}_{5 / 2}$ that makes $487.0 \mathrm{eV}$ is close to $486.8 \mathrm{eV}$ measured for $\mathrm{SnO}_{2}$ [25]. With regard to the second state with an electron binding energy of $488.0 \mathrm{eV}$, it, to our knowledge, has no analogs in the literature and should therefore be attributed to differential charging; in this case, it is due to the difference in the interaction of metal atoms with impurity carbon and the carrier, as indicated by the difference in the $\mathrm{C} 1 \mathrm{~s}-\mathrm{Al} 2 \mathrm{~s}$ energy interval (Table 2). An increase in the binding energy and peak broadening, as well as an increase in the surface core level shift reflects the size effects of platinum and tin particles [26].

The results allow us to conclude that in the activated state the active ingredients consisting of superfine $\mathrm{Pt}, \mathrm{Sn}^{2+}, \mathrm{Sn}^{4+}$ particles and particles of $\mathrm{PtSn}_{3 \pm \delta}$ alloy are present on the surface of the catalyst system. Such a high selectivity of the catalyst in the reductive deoxygenation of esters resulting in the quantitative yield of hydrocarbon fragments and water is probably caused by the chemisorption of the oxygen atoms of the carbonyl and ether groups on the ions of tin $\left(2^{+}-4^{+}\right)$.

4

\section{Conclusions}

Thus, in the presence of the $\mathrm{Pt}-\mathrm{Sn} / \mathrm{Al} 2 \mathrm{O} 3$ catalyst prepared by applying the heterometallic complex, highly selective reductive deoxygenation of FATGs is achieved, resulting in the formation of only alkane-alkene hydrocarbons that are the hydrocarbon fragments of FATGs; $\mathrm{C} 1$ byproducts formed as a result of cracking reactions and the removal of carbonyl and carboxyl groups of esters are nearly absent. A high selectivity of the catalyst in the reaction of the reductive decomposition of esters is provided by two important factors: particle size factor and the structure of the precursor of the active ingredients. A small size of tin oxide and intermetallic alloy clusters probably set conditions for their interaction only with ester oxygen atoms as the most active centers 
of the substrate, but the clusters are spatially hindered for the reaction with unsaturated bonds in the carbon chain of the acyl moieties. The heterometallic complex used as a precursor of the active ingredients comprises a direct bond between the platinum and the tin atoms, which probably favors the formation on the surface of adjoining tin-containing and intermetallic centers having the ability for chemisorption of FATGs by oxygen atoms, and for its reduction with hydrogen, and a weakened ability for cracking hydrocarbon fragments. The results do not allow us to estimate the sequence or concerted action of the deoxygenation reaction. To this end, we will conduct the theoretical analysis of the energy and activation parameters of the reactions.

Table 2. Binding energies of photoelectron peaks and the energy intervals between them.

\begin{tabular}{|c|c|c|c|c|c|c|c|}
\hline & $\begin{array}{c}\mathrm{Pt} \\
4 f 7 / 2\end{array}$ & $\begin{array}{c}\mathrm{Sn} \\
3 d_{5 / 2}\end{array}$ & $\mathrm{C} 1 s$ & $\begin{array}{c}\mathrm{C} 1 s- \\
\mathrm{Pt} 4 f_{7 / 2}\end{array}$ & $\begin{array}{c}\mathrm{Sn} 3 d_{5 / 2}- \\
\mathrm{C} 1 s\end{array}$ & $\begin{array}{c}\text { Sn3d5/2- } \\
\mathrm{Pt} 4 f 7 / 2\end{array}$ & $\mathrm{C} 1 s-\mathrm{Al} 2 s$ \\
\hline $\begin{array}{c}1 \mathrm{Pt}-5 \mathrm{Sn} / \mathrm{Al}_{2} \mathrm{O}_{3} \\
\text { initial }\end{array}$ & 72.3 & 485.9 & 284.8 & 212.5 & 201.1 & 413.6 & 165.8 \\
\hline $\begin{array}{c}1 \mathrm{Pt}-5 \mathrm{Sn} / \mathrm{Al}_{2} \mathrm{O}_{3} \\
\text { after activation }\end{array}$ & 71.6 & 486.2 & 284.8 & 213.2 & 201.4 & 414.5 & 165.1 \\
\hline $\begin{array}{c}1 \mathrm{Pt} 5 \mathrm{Sn} / \mathrm{Al}_{2} \mathrm{O}_{3} \\
\text { after catalysis }\end{array}$ & 71.8 & 486.3 & 284.8 & 213.0 & 201.5 & 414.4 & 165.1 \\
\hline $\mathrm{Sn} / \mathrm{Al}_{2} \mathrm{O}_{3}$ & - & 487 & 284.8 & - & 202.2 & - & 164.7 \\
\hline$\left(\mathrm{PPh}_{4}\right)_{3}\left[\mathrm{Pt}_{\left.\left(\mathrm{SnCl}_{3}\right)_{5}\right]}\right.$ & 72.9 & 487.0 & 284.8 & 211.9 & 202.2 & 414.0 & - \\
\hline $\mathrm{Al}_{2} \mathrm{O}_{3}$ & - & - & 284.8 & - & - & - & 165.8 \\
\hline
\end{tabular}

\section{Acknowledgements}

This study was financially supported by Russian Scientific Foundation Grant No. 15-13-30034.

\section{References}

[1] U.S. Energy Information Administration, "Annual energy outlook 2014", http://www.eia.gov/forecasts/aeo/pdf/0383(2014).pdf

[2] A. Demirbas, Biodiesel: A realistic fuel alternative for diesel engines. London: Springer, 2008.

[3] J. Holmgren, C. Gosling, R. Marinangeli, T. Marker, G. Faraci, C. Perego, "A new development in renewable fuels: green diesel," UOP report AM-07-11, 2007.

[4] J. D. Cox, G. Pilcher Thermochemistry of organic and organometallic compounds. London: Acad. Press, 1970.

[5] I. I. Moiseev "Biotechnology is storming the heights of petrochemistry," Kinetics and Catalysis, vol. 57, №4, 2016, pp. 405-421.

[6] A. Vonortas, N. Papayannakos, "WIREs Energy Environment," 2014, 3, pp. 3-23.

[7] S.N. Naik, V. V. Goud, P. K. Rout, A. K. Dalai, "Production of first and second generation biofuels: a comprehensive review," Renewable and Sustainable Energy Rev., 2010, 14, pp. 578-597.

[8] P. D. Patil, V. G. Gude, A. Mannarswamy, S. Deng, P. Cooke, S. Munson-McGee, I. Rhodes, P. Lammers, N. Nirmalakhandan, "Optimization of direct conversion of wet algae 
$362 \quad 10^{\mathrm{TH}}$ International Conference on Sustainable Energy and Environmental Protection (June $27^{\mathrm{TH}}-30^{\mathrm{TH}}, 2017$, BLed, Slovenia), Bioenergy AND Biofuels P. A. Zharova, A. V. Chistyakov, S. S. Shapovalov, A. A. Pasynskii \& M. V. Tsodikov: Original Pt-Sn/Al $\mathrm{O}_{3}$ Catalyst for Selective Hydrodeoxygenation of Vegetable Oils

to biodiesel under supercritical methanol conditions," Biorecourse technol. 2011. 102. P. 118-122.

[9] D. Pimentel, Global Economic and Environmental Aspects of Biofuels, CRC Press Teylor and Francis Group, 2012.

[10] U.S. Energy Information Administration. Annual energy outlook 2014 with projections to 2040, 2014.

[11] J. Holmgren, C. Gosling, R. Marinangeli, T. Marker, G. Faraci, C. Perego, "A new development in renewable fuels: green diesel," UOP report AM-07-11, 2007.

[12] A.S. Berenblyum, T.A. Podoplelova, R.S. Shamsiev, E.A. Katsman, V.Ya. Danyushevsky, V.R. Flid, "Catalytic chemistry of preparation of hydrocarbon fuels from vegetable oils and fats," Catalysis in Industry, 2012, vol. 4, № 3, pp. 209-214.

[13] V.O. Dundich, V.A. Yakovlev, Chemistry for Sustainable Development. 2009. T. 17. C. 521.

[14] V.A. Yakovlev, S.A. Khromova, V.I. Bukhtiyarov, "Heterogeneous catalysts for the transformation of fatty acid triglycerides and their derivatives to fuel hydrocarbons," Russian Chemical Reviews, 2011, vol. 80, № 10, pp. 911-925.

[15] J. Hancsók, M. Krár, Sz. Magyar, L. Boda, A. Holló, D. Kalló. Microporous and Mesoporous Materials, 101, 148 (2007).

[16] S.S. Shapovalov, A.A. Pasynskii, Y.V. Torubaev, I.V. Skabitskii, M. Scheer, M. Bodensteiner, "Stannylene complexes of manganese, iron, and platinum," Russian Journal of Coordination Chemistry, 2014, vol. 40, № 3, pp. 131-137.

[17] A.V. Chistyakov, P.A. Zharova, M.V. Tsodikov, S.S. Shapovalov, A.A. Pasinskiy, V.Yu. Murzin, A.E. Gekhman, I.I. Moiseev, "Highly Selective Conversion of Vegetable Oil into Hydrocarbons," Doklady Chemistry, Vol. 460, Part 1, pp. 26-28, 2015.

[18] M.V. Tsodikov, A.V. Chistyakov, M.A. Gubanov et al., Izv. Akad. Nauk, Ser. Khim., 9, 2062-2068, 2015.

[19] D.Y.C. Leung, X.Wu, M.K.H., “A review on biodiesel production using catalyzed transesterification," Leung. Appl. Energy, vol. 87, p. 1083, 2010.

[20] U. Patel, A. Vaghela, N.M. Patel. Int. J. Res. Information Technol., 1, 4, 17, 2013.

[21] S.N. Naik, V.V. Goud, P.K. Rout, A.K. Dalai. Renewable and Sustainable Energy Rev., $14,578,2010$.

[22] P.D. Patil, V G. Gude, A. Mannarswamy, S. Deng, P. Cooke, S. Munson-McGee, I. Rhodes, P. Lammers, N. Nirmalakhandan. Biorecourse technol., 102, 118, 2011.

[23] D. Pimente, In Global Economic and Environmental Aspects of Biofuels. New York: CRC Press Teylor and Francis Group, 2012.

[24] A.V. Naumkin, A. Kraut-Vass, S.W. Gaarenstroom, C.J. Powell, NIST X-ray Photoelectron Spectroscopy Database. Version 4.1, Gaithersburg, 2012 http://srdata.nist.gov/xps/.

[25] V. Larchev and S. Popova, "New phases in the system Pt-Sn at high-pressure," Inorganic Materials, 20, 693-695, 1984.

[26] A. Ramstad, F. Strisland, S. Raaen, T. Worren, A. Borg, C. Berg, "Growth and alloy formation studied by photoelectron spectroscopy and STM," Surface Science, 425, 57-67, 1999. 
$10^{\mathrm{TH}}$ InTERNATIONAL CONFERENCE ON Sustainable ENERGy AND

Environmental Protection (June 27 $7^{\mathrm{TH}}-30^{\mathrm{TH}}$, 2017, Bled,

SLOVENIA), BIOENERGY AND BIOFUELS

J. Krope, A.Ghani Olabi, D. Goričanec \& S. Božičnik

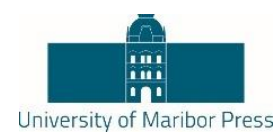

\title{
Modeling of an Biohydrogen Generation Process Using Artificial Neural Networks and Meta-Heuristic Algorithms
}

\author{
HANNIEL FERREIRA SARMENTO DE FREITAS, EUGÊNIA LEANDRO ALMEIDA, José \\ EDUARDO OLIVO \& CID MARCOS GONÇALVES ANDRADE
}

\begin{abstract}
The daily growth in the energy demand for the modern society has driven the urge for the diversification of the energy matrix. The biofuels represent an important alternative, as they exhibit an environmentalfriendly aspect when compared to fossil fuels, as well as figures out as important precursors for the popularization of biotechnological processes in substitution to the current production routes for the products used daily. In this sense, the biohydrogen represent an important research topic, figuring out as an important fuel and raw material. Being a product obtained through the biological activity of working micro-organisms, it is subjected to the complex non-linear growth behavior that is common to biotechnological processes. The present work aims to employ artificial neural networks (ANN) for the modeling of the complex growth profile of biohydrogen generating micro-organism, employing a meta-heuristic algorithm for synaptic weights adjustment. The obtained results that the association of ANN and meta-heuristic algorithms were able to appropriately model the process dynamics and maximize the amount of biohydrogen produced.
\end{abstract}

Keywords: • biohydrogen $\bullet$ artificial neural networks $\bullet$ modelling • optimization • in-silico •

Correspondence Address: Hanniel Ferreira Sarmento de Freitas, Ph.D, Chemical Engineering Department, Universidade Estadual de Maringá, Av. Colombo, 5790 - Vila Esperança, Maringá Paraná, Brasil, e-mail: hanniel.freitas@ifrn.edu.br. Eugênia Leandro Almeida, M.Sc, Chemical Engineering Department, Universidade Estadual de Maringá, Av. Colombo, 5790 - Vila Esperança, Maringá - Paraná, Brasil, e-mail: eugenia-almeida@ hotmail.com. José Eduardo Olivo, Ph.D, Chemical Engineering Department, Universidade Estadual de Maringá, Av. Colombo, 5790 - Vila Esperanca, Maringá - Paraná, Brasil, e-mail: jeolivo@uem.br. Cid Marcos Gonçalves Andrade, Ph.D, Chemical Engineering Department, Universidade Estadual de Maringá, Av. Colombo, 5790 - Vila Esperanca, Maringá - Paraná, Brasil, e-mail: cid@ deq.uem.br. 
364 10 $10^{\mathrm{TH}}$ International Conference on Sustainable Energy and Environmental Protection (June $27^{\mathrm{TH}}-30^{\mathrm{TH}}, 2017$, BLed, SLOVENiA), Bioenergy AND Biofuels

H. Ferreira Sarmento De Freitas, E. Leandro Almeida, J. Eduardo Olivo \& C. Marcos Gonçalves Andrade: Modeling of an Biohydrogen Generation Process Using Artificial Neural Networks and Meta-Heuristic Algorithms

The development of the modern society is have been noticed by a continuous worldwide increase of the energy demand, which is estimated to reach 624 quadrillions of BTU in 2020, and 825 quadrillions in 20140 [1]. The fossil fuels stands out as the kernel of the energy matrix, as well as the production base of much of the products used daily, such as fabric, plastic tools, etc. In this sense, it is clear the importance of research on the subject of renewable energy sources [2]. Among them, the biofuels stands out as important alternatives, especially due to their environmental-friendly aspect [3].

In this sense, the biohydrogen exhibits notable characteristics, such as the fact that the subproduct of their utilization as combustion fuel is the water vapour and the high energy content $(122 \mathrm{~kJ} / \mathrm{g})$ [4]. It is important to emphasize that among the plethora of technological route for hydrogen generation, several authors point out that the utilization biotechnological process stands out as the most sustainable and environmentally efficient, as several residues (agricultural, waste water, among others) can be employed in this intent, and there are virtually no production of greenhouse effect gases $[5,6]$.

The biotechnological processes exhibit frequently distinct characteristics such as a complex non-linear growth profile, and occurrence of substrate inhibition, facts that imply in an inherent difficulty for process control and optimization. For this purpose, the meta-heuristic optimization techniques stands out as important tools for bioprocess related problems, as the analytical techniques usually are prohibitively complex [7]. Similarly, the artificial intelligence (AI) techniques, such as the Artificial Neural Networks (ANN), figures as important tools for modelling complex phenomena, such as microbial growth pattern.

In the present work, an study about the modelling of biohyrogen generation process by natural microbial culture obtained in mangroves, using experimental data and ANN, with a meta-heuristic routine of genetic algorithm (GA) for training the neural network.

\section{Theoretical Referential}

\subsection{Artificial Neural Networks (ANN)}

The Artificial Neural Networks (ANN) consists in adaptive non-linear information processing systems which combine several processing units, or neurons, in a defined interconnected structure [8]. In practical terms, the neurons receives information inputs and, through the utilization of a defined transfer function (or activation function), produce an information output.

Several distinct types of ANN are available, and the discussion of the particular characteristics of each one is beyond the scope of the present work. Among several types of ANN presented in the specialized literature, the multi-layer perceptron networks 
$10^{\mathrm{TH}}$ INTERNATIONAL CONFERENCE ON SUSTAINABLE ENERGY AND ENVIRONMENTAL Protection (June $27^{\mathrm{TH}}-30^{\mathrm{TH}}, 2017$, BLed, Slovenia), Bioenergy ANd Biofuels H. Ferreira Sarmento De Freitas, E. Leandro Almeida, J. Eduardo Olivo \& C. Marcos Gonçalves Andrade: Modeling of an Biohydrogen Generation Process Using Artificial Neural Networks and Meta-Heuristic Algorithms

(MLPN) consists in the association of the neurons in groups or layers. First, an input network receives the information input signal, applying the defined activation function; Then, in the hidden layers (one or two, frequently), the neurons will process the information coming from the previous layers; finally, in the output layer, the neurons will produce the information output for the network. The magnitude of the connection between two different neurons (value which will multiply the corresponding information signal), called as connection weight, represent an important aspect of the ANN, and needs to be adjusted (or trained) to accurately represent the desired process. In a mathematical perspective, the ANN operates as non-linear black-box models [9].

The determination of the number of neurons for each hidden layer of the MLPN, as well as the weight value, is cardinal for the appropriated operation of the ANN [10]. Under a mathematical perspective, the degrees of freedom of the ANN in terms of the number of neurons for each layer are limited to the hidden layers, as the input layer has its number related to the number of information inputs for the ANN, similarly to the number of outputs for the output layer.

\subsection{Genetic Algorithm (GA)}

The Genetic Algorithm (GA) is an evolutionary algorithm, presented in the work of Davis (1991) and Goldberg (1989) [11, 12]. The meta-heuristic algorithm is based in the mechanism of natural selection for the continuous improvement of the candidate selections, which share information between each other, and are also subjected to minor random modifications within its parameters, a process analogous to mutation of the genome of organisms.

Each candidate solution, or individual, carries an solution space $x \in R^{n}$, in which the $n$ represent the dimensionality of the search-space (in other words, the number of dimensions of the problem). Each individual has its fitness evaluated utilizing the fitness function $F(x)$. New individuals are generated through the combination (a process called crossover) of the randomly selected solutions currently present in the population, employing the fitness of the solution (directly or indirectly) as the selection probability, with the aim to emphasize the reproduction of best fitted solutions. During the combination process, each parameter is subjected to random minor modifications in its values (a process called mutation), with the aim to generate diversification between the population. After the crossover and mutation steps, the most fitted candidates of the population are selected to compose the new generation of the population, and the process is restarted.

Several mutation and crossover operators are available, and the presentation of each one, as well as the discussion of its advantages and drawbacks, is beyond the scope of the present work. In this intent, the work of Thakur et al. (2014) and Burke et. al. (2005) [13, 14] present several operators for the genetic algorithms. In the Figure 1, the working principle of the GA is schematically presented. 
366 10 $10^{\text {TH }}$ InTERnAtional CONFERENCE ON Sustainable ENERGy AND ENVIRONMENTAL Protection (June $27^{\mathrm{TH}}-30^{\mathrm{TH}}, 2017$, BLED, Slovenia), Bioenergy AND Biofuels

H. Ferreira Sarmento De Freitas, E. Leandro Almeida, J. Eduardo Olivo \& C. Marcos Gonçalves Andrade: Modeling of an Biohydrogen Generation Process Using Artificial Neural Networks and Meta-Heuristic Algorithms

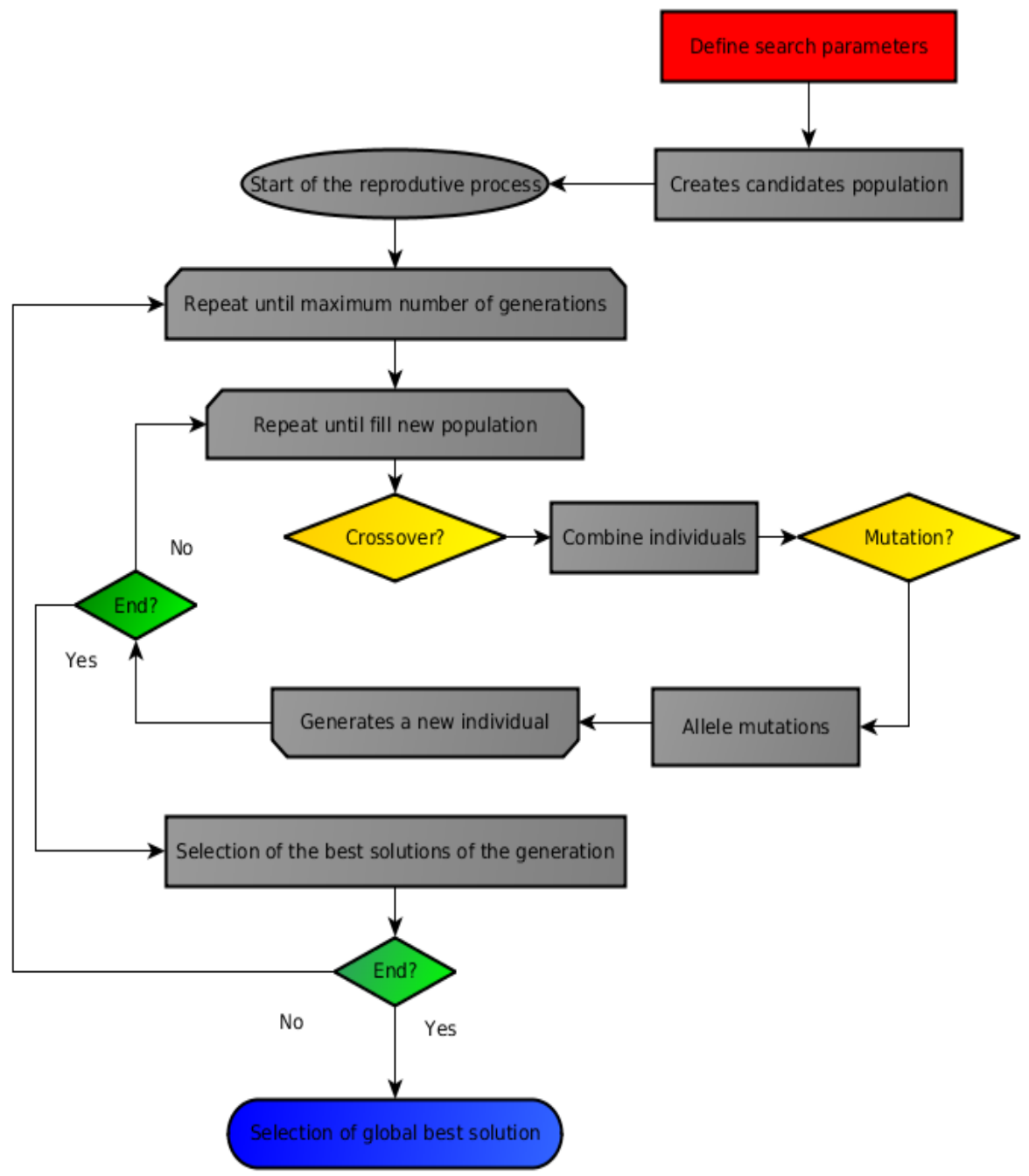

Figure 1: Working principle of the GA 
In the present section, the methodology employed in the work development will be outlined. In this sense, the development of the Artificial Neural Network is discussed, followed by the training of the ANN using the GA meta-heuristic routine.

\subsection{Development of the Artificial Neural Network}

The ANN was developed through an in-house code developed in Python computational language. The network employed in the present work used the sigmoidal activation function as the transfer function for the input and hidden layers, and the linear activation function for the output layer. In terms of the determination of the networks topography, the number of neurons for the hidden layers were determined through an empirical process, as discussed in Massimo et al. (1991) [15], as presented in the next subsection.

\subsection{ANN Training using GA}

The GA employed in the weight adjustment process for the ANN training was a in-house code developed in Python computational language. The experimental data employed for the ANN training were obtained from the work of Mullai et al. (2013) [17], in which the author present several studies for biohydrogen generation through cultures of microorganisms obtained in local mangroves. In the present work, the influence of the $\mathrm{pH}$ and cultivation time $(h)$ in the accumulated biohydrogen production $(m L)$ were modelled through the utilization of ANN. The configurations for the GA employed in the network training are presented in the Table (1).

Table 1: Configurations employed in the optimization studies.

\begin{tabular}{|c|c|}
\hline Parameter & Value \\
\hline Crossover probability & $60 \%$ \\
\hline Mutation probability & $1.5 \%$ \\
\hline Crossover operator & Arithmetic \\
\hline Mutation operator & Gaussian \\
\hline Population size & 100 \\
\hline Stop criterion & Number of generations (5000) \\
\hline
\end{tabular}

In order to establish the adequate number of neurons for the hidden layers, several configurations were evaluated. For each one, the summation of the squared errors between the experimental values were evaluated, according to the Equation (1).

$S S Q E=\sum_{i=1}^{k}\left(y_{i}-\hat{y}_{i}\right)$ 
$10^{\mathrm{TH}}$ InTERNATIONAL CONFERENCE ON Sustainable ENERGY AND ENVIRONMENTAL Protection (June $27^{\mathrm{TH}}-30^{\mathrm{TH}}, 2017$, BLed, Slovenia), Bioenergy AND Biofuels H. Ferreira Sarmento De Freitas, E. Leandro Almeida, J. Eduardo Olivo \& C. Marcos Gonçalves Andrade: Modeling of an Biohydrogen Generation Process Using Artificial Neural Networks and Meta-Heuristic Algorithms

In the Equation (1), the term $k$ represents the number of experimental values, $y_{i}$ the experimental accumulated biohydrogen production, $\hat{Y}_{i}$ the value obtained through the model, and $S S Q E$ the summation of the squared errors. The results in terms of SSQE for several configurations are presented in the Table (2).

Table 2: Analysis of the effect of the number of neurons in the hidden layers in relation with the final SSQE obtained in the end of the ANN synaptic weight optimization.

\begin{tabular}{|c|c|c|}
\hline $\begin{array}{c}\text { Neurons in hidden } \\
\text { layer \#1 }\end{array}$ & $\begin{array}{c}\text { Neurons in hidden } \\
\text { layer \#2 }\end{array}$ & SSQE \\
\hline 2 & 0 & 0.85499 \\
\hline 2 & 2 & 0.57909 \\
\hline 2 & 6 & 0.65158 \\
\hline 2 & 8 & 0.88460 \\
\hline 2 & 10 & 0.85501 \\
\hline 6 & 0 & 0.32920 \\
\hline 6 & 2 & 0.32425 \\
\hline 6 & 6 & 0.36108 \\
\hline 6 & 8 & 0.32338 \\
\hline 6 & 10 & 0.59227 \\
\hline 8 & 0 & 0.38164 \\
\hline 8 & 2 & 0.35836 \\
\hline 8 & 6 & 0.50399 \\
\hline 8 & 8 & 0.42077 \\
\hline 8 & 10 & 0.72430 \\
\hline 10 & 0 & 0.31636 \\
\hline 10 & 2 & 0.45239 \\
\hline 10 & 6 & 0.63280 \\
\hline 10 & 8 & 0.59490 \\
\hline 10 & 10 & 0.78363 \\
\hline
\end{tabular}

As presented in the Table (2), the best configuration for the ANN developed for the present problem has the following number of neurons: 2 neurons in the input layer $(\mathrm{pH}$, cultivation time); 10 neurons in the first hidden layer; 0 neurons in the second hidden layer; one neuron in the output layer (cumulative biogas production).

\section{$4 \quad$ Results}

As the optimal configuration for the ANN in terms of number of neurons for each layer was determined empirically, as described in the previous section, a new weight optimization was realized using the weights obtained for the best configuration as the initial guess. A final value of SSQE corresponding to 0.1891 was obtained. In the Figure (2), a comparison between the 
experimental results and those obtained with the ANN is presented, for a $\mathrm{pH}$ value of 6 , referred by the authors as the optimal value for biohydrogen generation during the experiments.

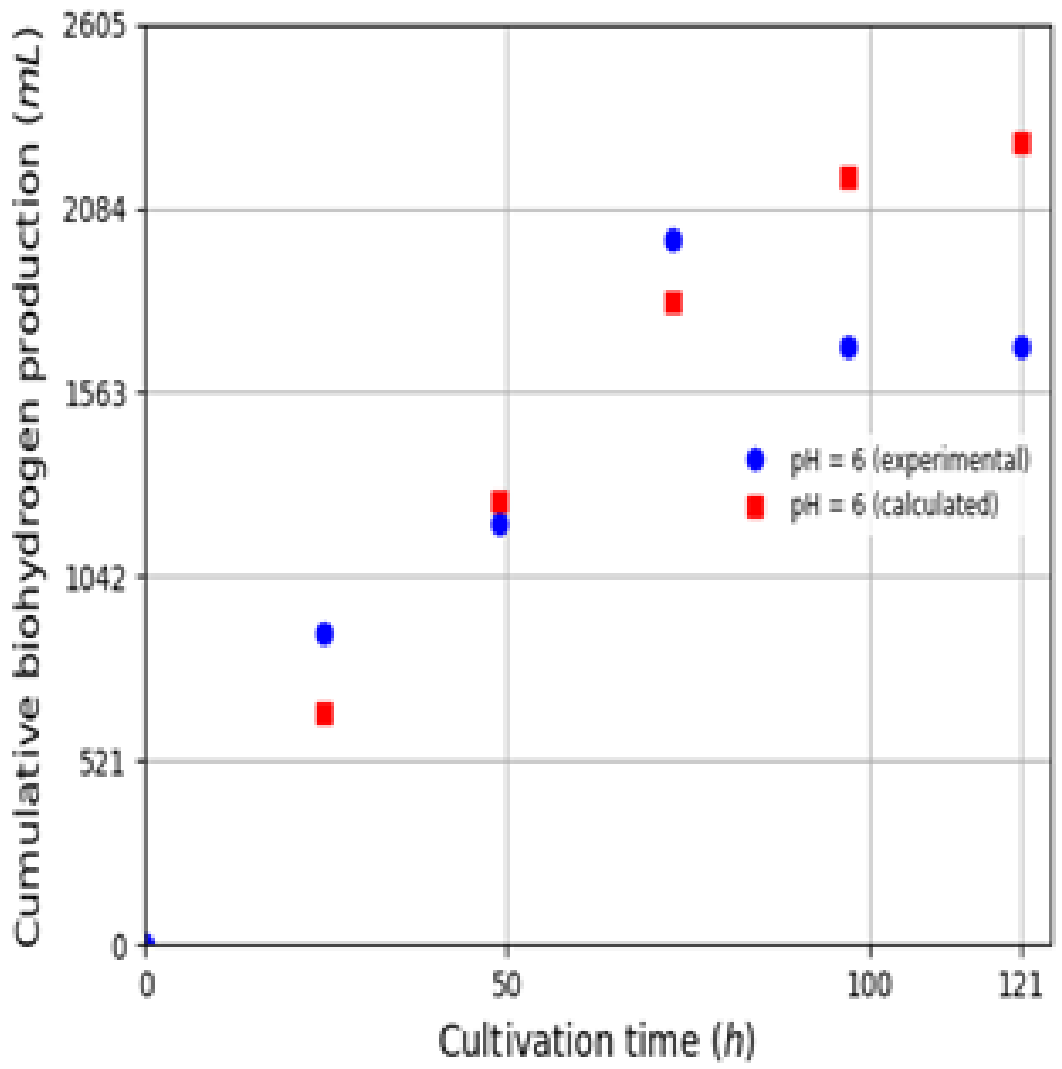

Figure 2: Comparison between the experimental results (blue) and those obtained by the ANN (red) for the accumulated biohydrogen production.

5

\section{Conclusion}

In the present work, the modelling of an biohydrogen production process through microbial cultivation was realized, using the ANN, an artificial intelligence technique, combined with a meta-heuristic routine, the GA, for the network training. The small value corresponding to the SSQE, which represents the squared deviation between the experimental results and the calculated values. This fact is endorsed by the graphical comparison between the experimental values and those obtained with the ANN, as presented in the Figure (2). 
$10^{\mathrm{TH}}$ InTERnATIONAL CONFERENCE ON Sustainable ENERGy AND ENVIRONMENTAL Protection (June $27^{\mathrm{TH}}-30^{\mathrm{TH}}, 2017$, BLed, Slovenia), Bioenergy AND Biofuels H. Ferreira Sarmento De Freitas, E. Leandro Almeida, J. Eduardo Olivo \& C. Marcos Gonçalves Andrade: Modeling of an Biohydrogen Generation Process Using Artificial Neural Networks and Meta-Heuristic Algorithms

In this sense, the importance of the utilization of artificial intelligence techniques and stochastic optimization in conjunction with biotechnological process is notable. The modelling of bioprocesses by these mathematical tools can provide new insights for process control and optimization studies.

\section{Acknowledgements}

The authors would like to thank Coordenação de Aperfeiçoamento de Pessoal de Nivel Superior (CAPES) for the financial support.

\section{References}

[1] EIA, International Energy Outlook 2016 (DOE/EIA-0484). US Energy Information Administration. Available at <https://www.eia.gov/outlooks/ieo/pdf/0484(2016).pdf>. Acesso: Março de 2017.

[2] L. Caspeta; N. A. A. Buijis and J. Nielsen, "The role of biofuels in the future energy supply”. Energy and Environmental Science, 6(4), pp. 1077-1082, 2013.

[3] W. Dai, D. P. Word, and J. Hahn, "Modeling and dynamic optimization of fuel-grade ethanol fermentation using fed-batch process," Control Engineering Practice, 22, pp. 231241, 2014.

[4] T. Tommasi, B. Ruggeri and S. Sanfilippo. "Energy valorisation of residues of dark anaerobic production of hydrogen." Journal Cleaner Production, 34, pp. 91-97, 2013.

[5] S. R. Mohan. "Structure and growth of research on biohydrogen generation using wastewater." International Journal of Hydrogen Energy, 40(46), pp. 16056-16069, 2015.

[6] A. Ghimire, L. Frunzo, F. Pirozzi, E. Trably, R. Escudie, P. N. Lens and G. A. Esposito. "Review on dark fermentative biohydrogen production from organic biomass: process parameters and use of by-products". Applied Energy, 144, pp. 73-95, 2015.

[7] J. R. Banga, E. Balsa-Canto, C. G. Moles and A. A. Alonso, "Dynamic optimization of bioprocesses: Efficient and robust numerical strategies", Journal of Biotechnology, 117(4), pp. 407-419, 2005.

[8] S. Ding, H. Li, C. Su, J. Yu and F. Jin. "Evolutionary artificial neural networks: a review". Artificial Intelligence Review, 29(3), pp. 1-10, 2013.

[9] A. Juditsky, H. Hjalmarsson, A. Benveniste, B. Delyon, L. Ljung, J. Sjöberg and Q. Zhang. "Nonlinear black-box models in system identification: Mathematical foundations". Automatica, 31(12), pp. 1725-1750, 1995.

[10] D. E. Goldberg. Genetic Algorithms in Search Opimization and Machine Learning, Addison-Wesley Professional, 1995.

[11] L. D. Davis. Handbook of Genetic Algorithms, Van Nostrand Rheinhold, 1991.

[12] M. Thakur, S. S. Meghwani and H. Jalota. "A modified real coded genetic algorithm for constrained optimization." Applied Mathematics and Computation, 235, pp. 292-317, 2014.

[13] E. K. Burke and G. Kendall. Search methodologies. Springer, 2005.

[14] K.V. Price, R.M. Storn and J.A. Lampinen. Differential Evolution: A Practical Approach to Global Optimization. Springer, 2005.

[15] C. Massimo, M. J. Willis, G. A. Montague, M. T. Tham and A. J. Morris. "Bioprocess model building using artificial neural networks". Bioprocess and Biosystems Engineering, 7(1), pp. 77-82, 1991. 
$10^{\mathrm{TH}}$ INTERNATIONAL CONFERENCE ON SUSTAINABLE ENERGY AND ENVIRONMENTAL

Protection (June $27^{\mathrm{TH}}-30^{\mathrm{TH}}, 2017$, Bled, Slovenia), Bioenergy ANd Biofuels H. Ferreira Sarmento De Freitas, E. Leandro Almeida, J. Eduardo Olivo \& C. Marcos Gonçalves Andrade: Modeling of an Biohydrogen Generation Process Using Artificial Neural Networks and Meta-Heuristic Algorithms

[16] P. Mullai, E. R. Rene and K, Sridevi. "Biohydrogen production and kinetic modeling using sediment microorganisms of pichavaram mangroves, India" BioMed research international, 2013. 
372 10 $10^{\mathrm{TH}}$ InTERnational CONFERENCE ON Sustainable ENERGy AND ENVIRONMENTAL Protection (June 27 $7^{\mathrm{TH}}-30^{\mathrm{TH}}, 2017$, BLed, Slovenia), Bioenergy AND Biofuels 
$10^{\mathrm{TH}}$ InTERNATIONAL CONFERENCE ON Sustainable ENERGY AND Environmental Protection (June 27 $7^{\mathrm{TH}}-30^{\mathrm{TH}}$, 2017, Bled, SLOVENIA), BIOENERGY AND BIOFUELS

J. Krope, A.Ghani Olabi, D. Goričanec \& S. Božičnik

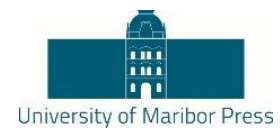

\title{
Heating Value of Torrified Oak Wood and Sewage Sludge Depending on Temperature
}

\author{
MARKo Agrež, DANiJEla URBANCL, SANJA POTRČ \& DARKo GORIČANEC
}

\begin{abstract}
Solid fuel production from different biomass sources become a very challenging area. The paper presents the mild pyrolysis, so called torrification process, where biomass material is converted into solid fuel with higher heating value. The material is processed in inert atmosphere or in the atmosphere with very low oxygen concertation. The study was done for two different materials, oak wood and dehydrated sewage sludge, which were analysed at different temperatures of torrifaction. The results of mass drop, the heating value and chemical composition are performed.
\end{abstract}

Keywords: • solid fuel • pyrolysis • torrifaction • oak wood • biomass •

CoRRESPONDENCE ADDRESS: Marko Agrež, technical manager, Energetika Ljubljana d.o.o., Toplarniška ulica 19, 1000 Ljubljana, Slovenia, e-mail: marko.agrez@energetika-lj.si. Danijela Urbancl, Ph.D., Assistant, University of Maribor, Faculty of Chemistry and Chemical Engineering, Smetanova ulica 17, 2000 Maribor, Slovenia, e-mail: danijela.urbancl@um.si. Sanja Potrč, University of Maribor, Faculty of Chemistry and Chemical Engineering, Smetanova ulica 17, 2000 Maribor, Slovenia, e-mail: sanja.potrc@student.um.si. Darko Goričanec, Ph.D., Associate Professor, University of Maribor, Faculty of Chemistry and Chemical Engineering, Smetanova ulica 17, 2000 Maribor, Slovenia, e-mail: darko.goricanec@um.si. 
$374 \quad 10^{\mathrm{TH}}$ InTERNATIONAL CONFERENCE ON Sustainable ENERGY AND ENVIRONMENTAL Protection (June $27^{\mathrm{TH}}-30^{\mathrm{TH}}, 2017$, BLed, Slovenia), Bioenergy AND Biofuels M. Agrež, D. Urbancl, S. Potrč \& D. Goričanec: Heating Value of Torrified Oak Wood and Sewage Sludge Depending on Temperature

The international framework for RES (renewable energy sources) was presented in the Kyoto protocol, in defending of which the EU played a crucial role, as the EU puts strong emphasis on the development of the renewable energy technologies. The measures specified in the protocol assume a reduction in the consumption of coal, natural gas and oil, and support the use of renewable energy sources [1]-[3].

Biomass is one of the more important sources for the production of energy and synthetic fuels [4], especially in Slovenia being one of the more forested countries in Europe with over 50\% of its area covered by forests. Furthermore, Slovenia is one of a few countries to have a positive increment of wood biomass. The annual increment is approximately 7 million cubic metres, of which about 4.9 million cubic metres are available for energy production. This potential is not fully utilised presently because the properties of biomass restrict its wider uptake by industries. Furthermore, biomass is more expensive than coal but carbon-trading laws are a good motivation for greater usage of biomass. Tenacity of raw biomass is especially challenging, which prevents efficient pulverisation of biomass in order to use it in high temperature gasifiers or in boilers of thermal power plants and heating plants. The torrefaction process (mild pyrolysis) is coming to the fore as a possible thermochemical conversion route that enhances the biomass properties obtaining ecologically acceptable energy source, which has similar properties as coal [5], [6]. Torrefied biomass is hydrophobic, resistant to biodegradation and is suitable for storage. Furthermore, the homogeneity and heating value of torrefied biomass is greater than that of wood. An important advantage of torrefied biomass is also its reduced tenacity, which enables for easier milling and application in industrial equipment.

\section{$2 \quad$ Pyrolysis}

Pyrolysis of wood is used mainly for the energetic exploitation, as the product can replace the fossil fuels [7]. Pyrolysis is a thermal decomposition of organic materials at the inert conditions or at a limited inflow of air. This process leads to a release of volatile substances and the formation of product. Furthermore, waste can be converted to products with high heating value by using the pyrolysis process. It is difficult to achieve an atmosphere totally devoid of oxygen; therefore oxygen is present in small concertation within every pyrolysis system, causing minor oxidation. The process takes place at a controlled concertation of oxygen, consequently careful reaction control is necessary with options for rapid cooling and heating. Wood pyrolysis usually starts at $200^{\circ} \mathrm{C}$ and is carried out to a temperature of $450^{\circ} \mathrm{C}$ or $500^{\circ} \mathrm{C}$, depending on the type of biomass [8]. Reaction products are usually divided into three groups: gases, liquids (bio-oil and tar) and solid residue - Charcoal. The degree of pyrolysis and with it the temperature, pressure and heating rate are the main factors that influence the amount, properties, composition and ratio of products [9]. 
$10^{\mathrm{TH}}$ INTERNATIONAL CONFERENCE ON SUSTAINABLE ENERGY AND ENVIRONMENTAL Protection (June $27^{\mathrm{TH}}-30^{\mathrm{TH}}, 2017$, BLed, Slovenia), Bioenergy and Biofuels M. Agrež, D. Urbancl, S. Potrč \& D. Goričanec: Heating Value of Torrified Oak Wood and Sewage Sludge Depending on Temperature

\subsection{Torrefaction}

Torrefaction is a mild pyrolysis that converts lignocellulosic biomass into a solid product with a higher energy density, lower moisture content compared to raw material. Physical and chemical properties of biomass are changed in this way and the biomass becomes similar to coal. A breakdown of the fibre structure occurs during the torrefaction of wood, while the water contained in the biomass is removed together with volatiles, and the biopolymers partly decompose, giving off various types of volatiles. The remaining solid, dry, blackened material is the final product which is referred to as torrefied biomass or "bio-coal". Biomass typically loses $20 \%$ to $30 \%$ of its mass, while only $10 \%$ of the energy content in the biomass is lost during the torrefaction process. This energy (i.e. the volatiles) can be used as a heating fuel for the torrefaction process. As the torrefied product already loses a high amount of volatiles during the thermochemical conversion, there is less remaining for the following combustion step. The specific heating value $(\mathrm{J} / \mathrm{kg})$ of the torrefied biomass is greatly increased due to the significant mass reduction and relatively small amount of energy wasted during the process. The main purpose is to use torrefied biomass as a fuel, which has similar milling and storing properties as coal.

The torrefaction process can be divided into 5 stages:

- Initial heating: During the first stage biomass is initially heated, then drying occurs, and at the end of this stage the moisture starts to evaporate.

- Pre-drying: Free water evaporates at a constant rate during the second stage. A constant rate of evaporation also means a constant temperature. During this stage the biomass loses from 5 to $10 \%$ of its initial mass, and after that point is reached, the rate of the evaporation decreases, indicating the end of the second phase.

- Post-drying and intermediate heating: An additional amount of physicallybonded water is released during the third stage whilst the biomass is being heated to $200^{\circ} \mathrm{C}$. Some lighter organic compounds could also evaporate during the third stage, which is finished when the temperature exceeds $200{ }^{\circ} \mathrm{C}$

- Torrefaction: This stage is entered as soon as the temperature exceeds $200^{\circ} \mathrm{C}$ and it ends as soon the temperature drops below $200{ }^{\circ} \mathrm{C}$ again. The final (peak) temperature varies between $200-300{ }^{\circ} \mathrm{C}$, and the residence time from 60 to 90 min. This stage consists of both heating and cooling periods. Devolatilisation begins during the heating period. The process of mass loss is continued during the period of constant temperature until during or after the cooling period.

- Solids cooling: the obtained solid product is further cooled from $200{ }^{\circ} \mathrm{C}$ to the desired final temperature. There is no further mass loss during this period. However, some evaporation of adsorbed reaction products may occur.

The largest heat duty is encountered during the drying of the biomass. This, however, depends on the initial moisture content. The second-largest heat duty is encountered during the post-drying and intermediate heating period and the smallest heat duty is 
$10^{\mathrm{TH}}$ InTERNATIONAL CONFERENCE ON Sustainable ENERGY AND ENVIRONMENTAL Protection (June $27^{\mathrm{TH}}-30^{\mathrm{TH}}, 2017$, Bled, SLOVENiA), BioENERGy AND Biofuels M. Agrež, D. Urbancl, S. Potrč \& D. Goričanec: Heating Value of Torrified Oak Wood and Sewage Sludge Depending on Temperature

encountered during the torrefaction itself. The required heat during the period of constant torrefaction temperature reflects the endothermic nature of decomposition reactions. However, it can also be a cooling duty, as torrefaction can be exothermic as well. This depends on the type of biomass and decomposition regime.

The main goal of torrefaction is to enhance the raw biomass and produce solid fuel that is easier to handle with properties similar to fossil coal, which leads to lower costs [10]. The energy density of the biomass is increased by approximately $30 \%$ during the torrefaction process. During the process, the structure of biomass changes, leading to new properties that make the handling of the final product much easier and also offers the possibility to utilise it in existing coal-fired boilers [11]. The grind ability of the biomass is enhanced by torrefaction due to the modification of its molecular structure, so that existing problems arising from untreated biomass in the milling component of a coal power plant are overcome. Usually a significant improvement in grind ability requires quite high torrefaction temperatures in the range of $290^{\circ} \mathrm{C}$ to $300^{\circ} \mathrm{C}$. A reduction of grinding energy consumption by 10 times can be achieved compared to untreated biomass.

Contrary to wood torrefied biomass is hydrophobic, which allows for easier storage and greater resistance to the biologic degradation, self-ignition, and physical decomposition. The fuel is also less sensitive to moisture adsorption and degradation.

Torrefied biomass can be densified, usually into briquettes or pellets using conventional densification equipment, in order to further increase the density of the material. The torrefied wood has an approximate density of $240 \mathrm{~kg} / \mathrm{m}^{3}$, which densifies to $800 \mathrm{~kg} / \mathrm{m}^{3}$ during the pelletisation process. A high quality fuel is obtained by the torrefaction process, which is disclosed with a comparison between properties of solid fuels listed in Table 1 . 
$10^{\text {TH }}$ INTERNATIONAL CONFERENCE ON SUSTAINABLE ENERGY AND ENVIRONMENTAL

Protection (June $27^{\mathrm{TH}}-30^{\mathrm{TH}}, 2017$, Bled, Slovenia), Bioenergy and Biofuels M. Agrež, D. Urbancl, S. Potrč \& D. Goričanec: Heating Value of Torrified Oak Wood and Sewage Sludge Depending on Temperature

Table 1. Solid fuels comparison

\begin{tabular}{|c|c|c|c|c|}
\hline & Wood & Wood pellets & $\begin{array}{c}\text { Torrefied } \\
\text { pellets }\end{array}$ & Charcoal \\
\hline $\begin{array}{l}\text { Moisture content } \\
(\% \mathrm{wt})\end{array}$ & $30-45$ & $7-10$ & $1-5$ & $1-5$ \\
\hline $\begin{array}{l}\text { Lower heating value } \\
(\mathrm{MJ} / \mathrm{kg})\end{array}$ & $9-12$ & $15-18$ & $20-24$ & $30-32$ \\
\hline Volatile matter $(\%)$ & $70-75$ & $70-75$ & $55-65$ & $10-12$ \\
\hline Fixed carbon $(\%)$ & $20-25$ & $20-25$ & $28-35$ & $85-87$ \\
\hline Density (kg/l) (bulk) & $0.2-0.25$ & $0.55-0.75$ & $0.75-0.85$ & $\sim 0.2$ \\
\hline $\begin{array}{l}\text { Energy density } \\
\left(\mathrm{GJ} / \mathrm{m}^{3}\right) \text { (bulk) }\end{array}$ & $2-3$ & $7.5-10.4$ & $15-18.7$ & $6-6.4$ \\
\hline Dust & average & limited & limited & high \\
\hline $\begin{array}{l}\text { Hydroscopic } \\
\text { properties }\end{array}$ & hydrophilic & hydrophilic & hydrophobic & hydrophobic \\
\hline $\begin{array}{l}\text { Biological } \\
\text { degradation }\end{array}$ & yes & yes & no & no \\
\hline Grind ability & poor & poor & good & good \\
\hline Handling & special & special & good & good \\
\hline
\end{tabular}

\section{$3 \quad$ Experiment}

The comparison between two different materials was performed in order to evaluate the influence of temperature on heating value and chemical composition of the torrified biomass.

The first material was oak wood; the calorific value and chemical composition are given in table 2 for raw sample.

The second material was dehydrated sewage sludge from waste water treatment plant; the calorific value and chemical composition are given in table 3 .

Table 2. Properties of raw oak wood

\begin{tabular}{|l|r|}
\hline Parameter & \\
\hline GVC/LHV [kJ/kg] & $19,074 / 17,793$ \\
\hline Analytical moisture [\%] & 10.45 \\
\hline Nitrogen [\%] & 0.34 \\
\hline Volatiles[\%] & 79.12 \\
\hline Carbon [\%] & 48.53 \\
\hline Ash [\%] & 3.24 \\
\hline Hydrogen [\%] & 5.89 \\
\hline Sulfur [\%] & 0.02 \\
\hline
\end{tabular}


$10^{\text {TH }}$ International Conference on Sustainable Energy and Environmental Protection (June $27^{\mathrm{TH}}-30^{\mathrm{TH}}, 2017$, BLed, Slovenia), Bioenergy AND Biofuels M. Agrež, D. Urbancl, S. Potrč \& D. Goričanec: Heating Value of Torrified Oak Wood and Sewage Sludge Depending on Temperature

Table 3. Properties of raw sewage sludge

\begin{tabular}{|l|r|}
\hline Parameter & \\
\hline GVC/LHV [kJ/kg] & $15,520 / 14,421$ \\
\hline Analytical moisture [\%] & 8.5 \\
\hline Nitrogen [\%] & 5.87 \\
\hline Volatiles [\%] & 61.14 \\
\hline Carbon [\%] & 36.59 \\
\hline Ash [\%] & 32.58 \\
\hline Hydrogen [\%] & 5.09 \\
\hline Sulphur [\%] & $0, .8$ \\
\hline
\end{tabular}

The materials were processed in Bosio electric resistance furnace. The process started with warm up stage, which took place for 30 minutes, after that stage sample was torrefied for 2 hours at constant temperature. The process continued with cool down stage for 30 minutes when the temperature of the furnace reached $50^{\circ} \mathrm{C}$. At the end the sample was cool down to the room temperature.

The container was covered with ceramic lid that the inert atmosphere conditions were reached. Ceramic lid was placed in the way that the combustion gasses could discharge.

The samples were weight before and after the process, and a mass drop was evaluated and the analyses of heating value and chemical composition were performed.

\section{$4 \quad$ Results}

The samples of oak wood and sewage sludge were processed at different temperatures and the mas drop was evaluated, table 4.

The chemical analyses were performed for each sample; the results are given in table 5 for torrified oak wood and in table 6 for sewage sludge.

The comparison of higher calorific values (GVC) and low calorific values (LHV) for torrified oak wood and sewage sludge at different temperatures are given on figure 1 and figure 2 . 
$10^{\text {TH }}$ INTERNATIONAL CONFERENCE ON SUSTAINABLE ENERGY AND ENVIRONMENTAL

Protection (June $27^{\mathrm{TH}}-30^{\mathrm{TH}}, 2017$, BLED, Slovenia), Bioenergy ANd Biofuels M. Agrež, D. Urbancl, S. Potrč \& D. Goričanec: Heating Value of Torrified Oak Wood and Sewage Sludge Depending on Temperature

Table 4. The mass drop for torrified oak wood and sewage sludge

\begin{tabular}{|c|c|c|}
\hline \multirow{2}{*}{ Temperature $\left[{ }^{\circ} \mathrm{C}\right]$} & \multicolumn{2}{|c|}{ Mass drop [\%] } \\
\cline { 2 - 3 } & Oak wood & Sewage sludge \\
\hline 220 & 25.9 & 22.0 \\
\hline 240 & 37.8 & 23.3 \\
\hline 260 & 54.4 & 27.3 \\
\hline 280 & 60.4 & 31.9 \\
\hline 300 & 64.3 & 34.3 \\
\hline 320 & 66.8 & 37.5 \\
\hline 340 & 66.8 & 40.1 \\
\hline 400 & 74.3 & 46.6 \\
\hline
\end{tabular}

Table 5. Properties of torrified oak wood depending on temperature

\begin{tabular}{|l|r|r|r|r|r|r|r|r|}
\hline \multirow{2}{*}{ Parameter } & \multicolumn{8}{|c|}{ Temperature $\left[{ }^{\circ} \mathrm{C}\right]$} \\
\cline { 2 - 10 } & 220 & 240 & 260 & 280 & 300 & 320 & 340 & 400 \\
\hline $\begin{array}{l}\text { Analytical } \\
\text { moisture [\%] }\end{array}$ & 1.38 & 2.13 & 1.59 & 2.07 & 2.77 & 3.25 & 3.35 & 3.86 \\
\hline Nitrogen [\%] & 0.34 & 0.39 & 0.42 & 0.54 & 0.53 & 0.55 & 0.6 & 0.71 \\
\hline Volatiles [\%] & 73.59 & 64.44 & 47.94 & 42.96 & 40.23 & 39.38 & 35.96 & 34.1 \\
\hline Carbon [\%] & 52.27 & 56.56 & 65.01 & 65.93 & 68.35 & 67.13 & 68.75 & 72.43 \\
\hline Ash [\%] & 2.9 & 4.67 & 5.03 & 7.56 & 5.63 & 8.02 & 8.25 & 6.22 \\
\hline Hydrogen [\%] & 5.58 & 5.1 & 4.24 & 3.87 & 3.75 & 3.72 & 3.34 & 2.77 \\
\hline Sulphur [\%] & 0.02 & 0.02 & 0.01 & 0.01 & 0.02 & 0.01 & 0.01 & 0.01 \\
\hline
\end{tabular}

Table 6. Properties of torrified sewage sludge depending on temperature

\begin{tabular}{|l|r|r|r|r|r|r|r|r|}
\hline \multirow{2}{*}{ Parameter } & \multicolumn{7}{|c|}{ Temperature $\left[{ }^{\circ} \mathrm{C}\right]$} \\
\cline { 2 - 10 } & 220 & 240 & 260 & 280 & 300 & 320 & 340 & 400 \\
\hline $\begin{array}{l}\text { Analytical } \\
\text { moisture [\%] }\end{array}$ & 1.16 & 0.58 & 0.61 & 0.66 & 1.24 & 0.6 & 1.12 & 0.9 \\
\hline Nitrogen [\%] & 6.31 & 6.36 & 6.26 & 5.94 & 5.81 & 5.63 & 5.38 & 4.92 \\
\hline Volatiles [\%] & 51.15 & 53.06 & 50.75 & 45.09 & 43.16 & 40.74 & 37.2 & 27.98 \\
\hline Carbon [\%] & 39.24 & 39.57 & 39.9 & 39.57 & 39.33 & 38.73 & 37.54 & 33.82 \\
\hline Ash [\%] & 37.94 & 37.5 & 39.61 & 42.85 & 43.99 & 45.89 & 48.58 & 55.32 \\
\hline Hydrogen [\%] & 4.21 & 4.45 & 4.27 & 3.9 & 3.71 & 3.5 & 3.23 & 2.1 \\
\hline Sulphur [\%] & 0.87 & 0.88 & 0.79 & 0.7 & 0.66 & 0.61 & 0.55 & 0.46 \\
\hline
\end{tabular}




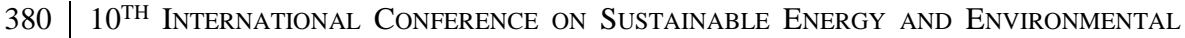
Protection (June $27^{\mathrm{TH}}-30^{\mathrm{TH}}, 2017$, Bled, SLOVENiA), BioENERGY AND Biofuels M. Agrež, D. Urbancl, S. Potrč \& D. Goričanec: Heating Value of Torrified Oak Wood and Sewage Sludge Depending on Temperature

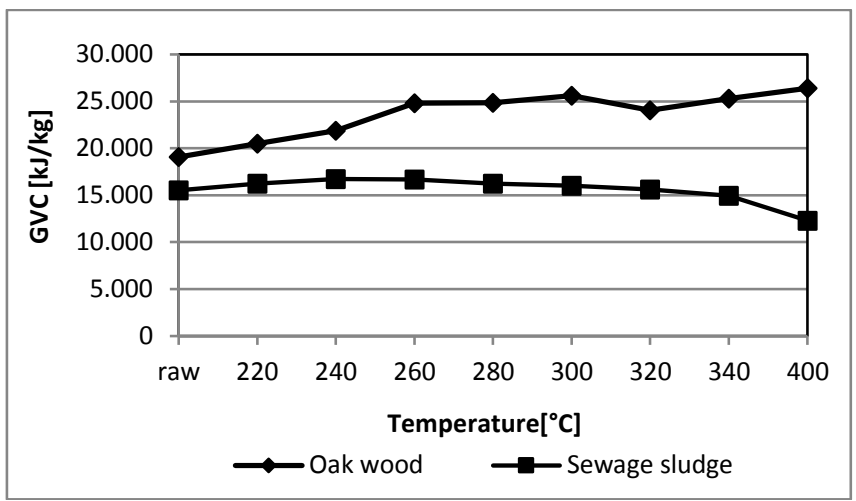

Figure 1. The higher calorific value (GVC) for torrified oak wood and sewage sludge

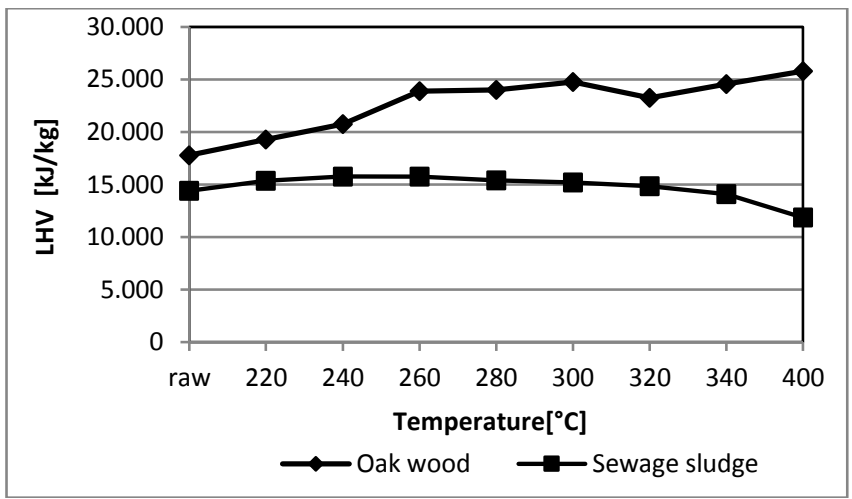

Figure 2. The low calorific value (LHV) for torrified oak wood and sewage sludge

The raw and torrified oak wood at $280^{\circ} \mathrm{C}$ is presented on figure 3 . The raw and torrified sewage sludge at $280^{\circ} \mathrm{C}$ is presented on figure 4 .

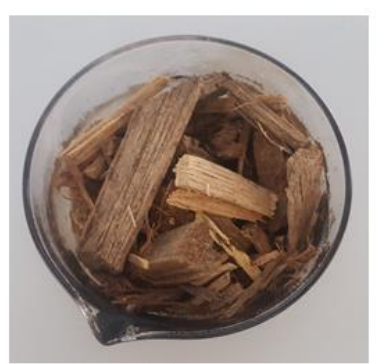

(a)

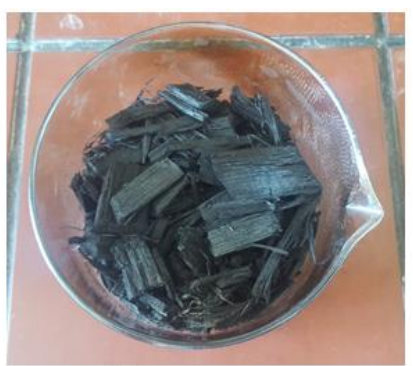

(b)

Figure 3. The oak wood: (a) raw and (b) torrified at $280^{\circ} \mathrm{C}$ 


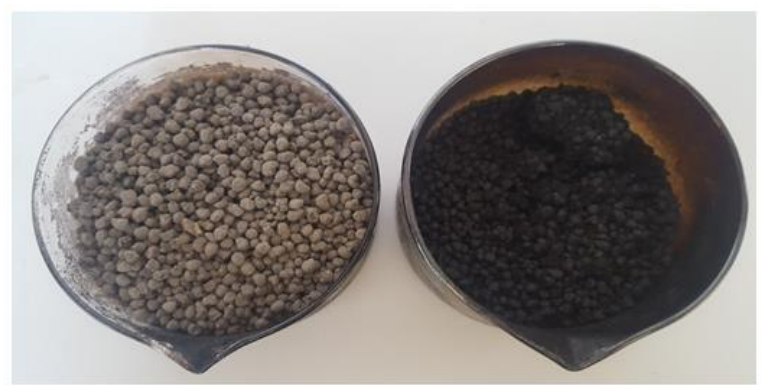

(a)

(b)

Figure 4. The sewage sludge, (a) raw and (b) torrified at $280^{\circ} \mathrm{C}$

Torrefied oak wood samples were more fragile at higher temperatures in comparison to raw or torrified oak wood samples at lower temperatures. At torrefied sewage sludge samples the changes in fragility could not be detected due to pre prepared granulates of sludge.

\section{Conclusion}

Oak wood and dehydrated sewage sludge where processed at different temperatures according to torrification conditions.

It was found out that the heating value of both materials increases with the temperature. The mass drop is larger for oak wood, while the wood has the higher moisture content than sludge. After the torrifaction the material become hydrophobic and the grind ability for the wood was higher.

It could be concluded that with biomass torrifaction the solid fuel could be produced with similar properties as coal.

\section{References}

[1] D. Urbancl, J. Zlak, B. Anicic, P. Trop, and D. Goricanec, "The evaluation of heat production using municipal biomass co-incineration within a thermal power plant," Energy, p. , 2015.

[2] P. Trop, M. Agrez, D. Urbancl, and D. Goricanec, "Co-gasification of torrefied wood biomass and sewage sludge," in Computer Aided Chemical Engineering, vol. 38, 2016, pp. 2229-2234.

[3] D. Urbancl, P. Trop, and D. Goricanec, "Geothermal heat potential - the source for heating greenhouses in Southestern Europe," Therm. Sci., vol. 20, no. 4, pp. 1061-1071, 2016.

[4] A. G. Olabi, "State of the art on renewable and sustainable energy," Energy, vol. 61, pp. 2-5, Nov. 2013.

[5] R. Correia, M. Gonçalves, C. Nobre, and B. Mendes, "Impact of torrefaction and lowtemperature carbonization on the properties of biomass wastes from Arundo donax L. and Phoenix canariensis," Bioresour. Technol., vol. 223, pp. 210-218, 2017. 
$10^{\text {Th }}$ International Conference on Sustainable Energy and Environmental Protection (June 27 $7^{\mathrm{TH}}-30^{\mathrm{TH}}, 2017$, Bled, Slovenia), Bioenergy AND Biofuels M. Agrež, D. Urbancl, S. Potrč \& D. Goričanec: Heating Value of Torrified Oak Wood and Sewage Sludge Depending on Temperature

[6] P. Trop, B. Anicic, and D. Goricanec, "Production of methanol from a mixture of torrefied biomass and coal," Energy, vol. 77, pp. 125-132, 2014.

[7] M. J. C. van der Stelt, H. Gerhauser, J. H. A. Kiel, and K. J. Ptasinski, "Biomass upgrading by torrefaction for the production of biofuels: A review," Biomass and Bioenergy, vol. 35, no. 9, pp. 3748-3762, 2011.

[8] Y. Yue, H. Singh, B. Singh, and S. Mani, "Torrefaction of sorghum biomass to improve fuel properties," Bioresour. Technol., vol. 232, pp. 372-379, 2017.

[9] D. A. Granados, F. Chejne, and P. Basu, "A two dimensional model for torrefaction of large biomass particles,” J. Anal. Appl. Pyrolysis, vol. 120, pp. 1-14, 2016.

[10] S. Proskurina, J. Heinimö, F. Schipfer, and E. Vakkilainen, "Biomass for industrial applications: the role of torrefaction," Renew. Energy, 2017.

[11] B. Batidzirai, A. P. R. Mignot, W. B. Schakel, H. M. Junginger, and A. P. C. Faaij, "Biomass torrefaction technology: Techno-economic status and future prospects," Energy, vol. 62, pp. 196-214, 2013. 
$10^{\text {TH }}$ InTERnAtional CONFERENCE ON Sustainable ENERGy AND

Environmental Protection (June 27 $7^{\mathrm{TH}}-30^{\mathrm{TH}}$, 2017, Bled,

SLOVENIA), BIOENERGY AND BIOFUELS

J. Krope, A.Ghani Olabi, D. Goričanec \& S. Božičnik

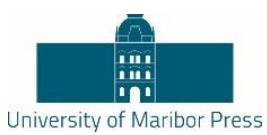

\title{
Managing Soil Sustainability Indicators for Sustainable Bioenergy Production
}

\author{
SHEIKH ADIL EDRISI \& PURUSHOTHAMAN CHIRAKKUZHYIL ABHILASH
}

\begin{abstract}
The current era of global warming and its subsequent impact on the changing climate mooted the expansion of bioenergy resources at the global level. The range of global average annual growth rate of biomass exploration for bioenergy production is around $5-8 \%$ that has been expected to double in the near future. The availability and the management of the bioenergy production should be assured especially from the marginal and degraded lands to further extend and maintain its viability and feasibility. Therefore, it is necessary to understand and monitor the complex inter-connected supportive systems that are significantly providing nourishment to the plants. More particularly the study is emphasized on the management of belowground sustainability indicators that are basically required for the production of bioenergy crops. Herein, the study discuss and propose the key soil sustainability indicators viz. bulk density (BD), moisture content (MC), available nitrogen (AN), available potassium (AK) and microbial biomass carbon (MBC) are important at the fundamental levels at the studied area. Also it has been considered that the biochemical indicators such as the activity of key enzymes like dehydrogenase and urease are playing vital role in the growth of bioenergy crops like Dalbergia sissoo Roxb. This represents the interrelation of the bioenergy crops in maintaining the soil sustainability indicators itself. Hence, the study conclude that the adoption of integrative indigenous technologies with the management of self-supportive processes would help to maintain the viability of lands meant for the long term sustainable bioenergy production system.
\end{abstract}

Keywords: • Energy security • Marginal lands • Sustainability indicators • Sustainable practices $\bullet$ Bioenergy production $\bullet$

CorresPondence Address: Sheikh Adil Edrisi, PhD Student, Banaras Hindu University, Institute of Environment and Sustainable Development, Varanasi-221005, U.P. India, e-mail: sheikhadiledrisi@gmail.com. Purushothaman Chirakkuzhyil Abhilash, Assistant Professor, Development, Banaras Hindu University, Institute of Environment and Sustainable, Varanasi221005, U.P. India, e-mail: pcabhilash@ hotmail.com. 
$10^{\mathrm{TH}}$ InTERnATIONAL CONFERENCE ON Sustainable ENERGy AND ENVIRONMENTAL Protection (June $27^{\mathrm{TH}}-30^{\mathrm{TH}}, 2017$, BLed, Slovenia), Bioenergy AND Biofuels

S. Adil Edrisi \& P. Chirakkuzhyil Abhilash: Managing Soil Sustainability Indicators for Sustainable Bioenergy Production

Currently the bioenergy exploration has been widely promoted due to the emerging issues of global warming and its subsequent climate change effects. The range of global average annual growth rate of biomass exploration for bioenergy production is around 5-8\% that has been expected to be double in the near future [1]. As a result, the terrestrial biomass production has now been mooted in the present scenario of bioenergy production. There has been a burgeoning debate for the production of this type of biomass vis-à-vis bioenergy production as it utilizes the viable lands that are meant for agricultural productions $[2,3]$. Therefore, the importance of marginal lands, partially degraded lands, degraded or contaminated lands is now been emerged as an additional avenue for biomass/bioenergy production $[4,5]$. Hence, it is the need of the hour to enhance and maintain the viability and feasibility of the marginal and other partially degraded lands. So it is necessary to explore the key soil supportive systems to suggest the modest proposal for the development of soil system models or the profiling of the soil systems for these land types. Furthermore, the management of these supportive systems is an essential requirement for the continued production of feedstock for bioenergy development. Soil supportive systems could be one of the complex and organized systems that help in the fundamental regulation of the nutrients that depicts the soil health. Naturally, the system can be comprised of different indicators that help to assess the condition of concerned environment and monitor trends over the time period $[6,7]$. However, the majority of the soil system models also tries to include some limited variables of the soil supportive systems such as above and belowground plant biomass, soil microbial biomass, microbial nutrient content, soil $\mathrm{C}$ and $\mathrm{N}$ ratio and its mobilization, immobilization, mineralization rates, etc. [8]. Still it lacks the consideration of microbial physiology [9] that can be accounted as one of the key indicators of the soil supportive systems.

Therefore, the present work was aimed to explore, study and categorize the soil sustainability indicators and tried to articulate the concepts regarding their development. Furthermore, we also analyze the impact of these indicators from the soil samples collected from the rhizosphere of already grown bioenergy plant Dalbergia sisso Roxb. The fuelwood characteristics has also been studied for this plant found in the Aravally mountain region [10]. The calorific value, wood density, ash percent, biomass-ash ratio, moisture percent, fuelwood value index of the plant was found to be $25.01 \pm 0.09 \mathrm{KJ} / \mathrm{g}$ dry weight, $0.931 \pm 0.04 \mathrm{~g} / \mathrm{m}^{3}, 1.94 \pm 0.25(\%), 35.01 \pm 12.32,32.20 \pm 11.79(\%), 1202.91 \pm 26.72$ respectively [11]. D. sissoo is a prominent tree legume that has potential to grow in the arid, semi-arid soils and harsh environmental conditions. Since the plant is exposed to extreme climatic and stress conditions, it affect the population dynamics of microorganisms and their spatio-temporal relationships in natural ecosystems [12]. Therefore, it has been observed that the tree itself play a vital role in restoring and maintaining the soil sustainability indicators. Researchers has observed that the plant has potential for the rehabilitation of degraded sodic lands [13]. It was found that the physicochemical and biological properties were improved along with the age of the plants. The tree species stimulated microbial activity significantly due to the organic matter 
accumulation by the incorporation of litter mass and root decay [12]. Furthermore, the biomass production and carbon sequestration potential of $D$. sissoo has also been analyzed in the Tarai region of Central Himalaya [13]. The total biomass of the tree of 10 years was found around $94.8 \mathrm{Mg} \mathrm{ha}^{-1}$ and the carbon stocks was found around 43.39 $\mathrm{Mg} \mathrm{ha}^{-1}[13]$. Therefore, $D$. sissoo was suggested a highly potential plant species for the carbon sequestration both in above-ground and below-ground parts i.e., 145.2 and 42.12 $\mathrm{t} \mathrm{ha}{ }^{-1}$ respectively and has the $\mathrm{CO}_{2}$ mitigation rate of around $28.6 \mathrm{t} \mathrm{CO}_{2} \mathrm{ha}^{-1} \mathrm{yr}^{-1}$ [14]. The tree has also ameliorated the other soil sustainability indicators like nitrogen, phosphorus and potassium by $137.4,35.4,99.8 \mathrm{~kg} \mathrm{ha}^{-1}$ respectively and hence resulting in the higher biomass content [14]. Different approaches have been made to analyze and enhance the growth of the plant, whether the growth is related to above-ground biomass [15] or related to the below-ground processes [11]. In this context, we delineate the soil sustainability indicators of the degraded area (Barkachha, an area in Mirzapur district in Uttar Pradesh) for decision making processes and promoting onsite strategies for the management of degraded or marginal lands. Therefore, we suggest that the adoption of integrative indigenous technologies with the self-supportive processes that would help to maintain the viability of the lands meant for the long term bioenergy production system.

\section{$2 \quad$ Materials and methods}

Two sets of experiments were conducted regarding the collection of rhizospheric soil samples by considering the different aged plants of D. sissoo namely D1, D2, D3, D4 representing $1^{\text {st }}, 2^{\text {nd }}, 3^{\text {rd }}, 4^{\text {th }}$ year respectively in two seasons (summers and winters). The collected samples were then subjected to the analyses of their physico-chemical and biological properties including $\mathrm{pH}$, electrical conductivity (EC), bulk density (BD), moisture content (MC), cation exchange capacity (CEC), total organic carbon (TOC), available nitrogen (AN), available phosphorus (AP), available potassium (AK), microbial biomass carbon (MBC), soil dehydrogenase, urease and peroxidase activity (SDA, SUA \& SPA).

\subsection{Study Area}

The study area selected for this work is the region that fall under the Indo-Gangetic Plains (IGP) of Uttar Pradesh, India (Figure 1). 
$10^{\text {Th }}$ International Conference on Sustainable Energy and Environmental Protection (June $27^{\mathrm{TH}}-30^{\mathrm{TH}}, 2017$, Bled, Slovenia), Bioenergy AND BIOFuels

S. Adil Edrisi \& P. Chirakkuzhyil Abhilash: Managing Soil Sustainability Indicators for Sustainable Bioenergy Production

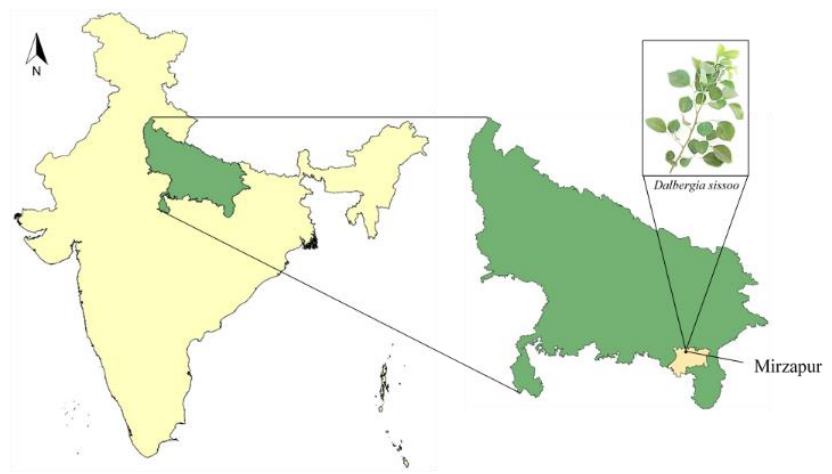

Figure 1. Geographical location of the study area.

More particularly the region is Mirzapur $\left(25^{\circ} 8^{\prime} 59.99^{\prime \prime} \mathrm{N}, 82^{\circ} 35^{\prime} 59.99^{\prime \prime}\right.$ E). The geographical and the meteorological characteristics have been provided in the (Table 1). Another reason for selecting the site is that it represent warm and arid type of climate that requires the use of intense irrigational practice of the crop production.

Table 1. Geographical and meteorological characteristics of the area studied (Mirzapur).

\begin{tabular}{|l|l|l|l|}
\hline 1. & $\begin{array}{l}\text { Geographical } \\
\text { characteristics* }\end{array}$ & $\begin{array}{l}\text { Total geographic } \\
\text { area }\left(\mathrm{km}^{2}\right)\end{array}$ & 4,521 \\
\cline { 3 - 4 } & & $\begin{array}{l}\text { Mean elevation } \\
(\mathrm{m})\end{array}$ & 80 \\
\hline 2. & Meteorological & Climate pattern* & $\begin{array}{l}\text { Warm and } \\
\text { tropical dry }\end{array}$ \\
\cline { 3 - 4 } & characteristics & $\begin{array}{l}\text { Mean annual } \\
\text { temp. }\left({ }^{\circ} \mathrm{C}\right) \pm \text { SD\# }\end{array}$ & 5.25 \\
\cline { 3 - 4 } & & $\begin{array}{l}\text { Mean Annual } \\
\text { precipitation }\end{array}$ & 975.00 \\
& & \\
\cline { 3 - 4 } & & (mm)\# & \\
\hline
\end{tabular}

*Zonal Project Directorate Kanpur (Available at: www.zpdk.org.in). \#Weather Underground (Available at: www.wunderground.com).

\subsection{Soil Sample Collection and Experimental Analyses}

The rhizospheric soil samples from the plants of D. sissoo were collected the depth of 10$15 \mathrm{~cm}$ confirming the presence of the mesh of the root hairs and the vertical roots in the pit. The soil samples were collected from the three points around the plant stem of each selected plant and further the samples were subjected to experimental analyses for the different soil physico-chemical and biological parameters. 
$10^{\mathrm{TH}}$ INTERNATIONAL CONFERENCE ON SUSTAINABLE ENERGY AND ENVIRONMENTAL Protection (June $27^{\mathrm{TH}}-30^{\mathrm{TH}}, 2017$, BLED, Slovenia), Bioenergy ANd Biofuels S. Adil Edrisi \& P. Chirakkuzhyil Abhilash: Managing Soil Sustainability Indicators for Sustainable Bioenergy Production

\subsection{Physico-chemical Analyses}

viz., the $\mathrm{pH}$ (pH meter; Cyber Scan-500) and EC (EC meter; Cyber Scan-500) with 1:1 $\mathrm{w} / \mathrm{v}$ of aqueous solution [16]. Simultaneously, the samples were also analysed for the BD, WHC, CEC according to $[17,18]$ and TOC as proposed by $[19,20]$. TN was determined through acid digestion (conc. $\mathrm{H}_{2} \mathrm{SO}_{4}$ and conc. $\mathrm{HNO}_{3}$ ) followed by the steam distillation method [21]. However, TP was estimated via the acid digestion with $60 \% \mathrm{HClO}_{3}$ followed by the filtration and colorimetric analysis [22] Further, the AN, AP and AK were estimated according to [23-25].

\subsection{Biological Analyses}

MBC and MBN were estimated on the basis of methodologies proposed by [26, 27]. Bacterial isolation and the enumeration of colony forming units (CFU) were carried out from the soil samples of both the planted and the open sites in accordance of standard procedures published earlier [28, 29]. SUA (EC 3.5.1.5; URE) was measured by indophenol colorimetry considering urea as a substrate. The amount of $\mathrm{NH}_{4}{ }^{+}$released over $24 \mathrm{~h}$ was assayed colorimetrically at $578 \mathrm{~nm}$ and expressed as $\mu \mathrm{mol} \mathrm{NH}_{4}{ }^{+} \mathrm{g}^{-1}$ dry sample $[30,31]$. SDA was determined by monitoring the conversion rate of $2,3,5-$ triphenyltetrazolium chloride (TTC) to the reddish pink, water insoluble triphenylformazan (TPF) obtained after the incubation for $24 \mathrm{~h}$ at $30^{\circ} \mathrm{C}$ followed by the colorimetric analysis at $485 \mathrm{~nm}$ [32]. SPA was performed with 3,3',5,5'tetramethylbenzidine (TMB) as a substrate depicting the method of [33].

\subsection{Data Analyses}

One-way ANOVA (analysis of variance) was performed to analyze the improvements in the soil characteristics with respect to the control that is unplanted. The significant $F$ value was estimated and the differences between individual means were tested using DMRT (Duncan's Multiple Range Test), at 0.05 significance level. For PCA, regression equations, scoring functions; Microsoft Excel version 13.0 and SPSS for windows version 16.0 (SPSS Inc., Chicago, USA) packages were used.

\section{$3 \quad$ Results and Discussion}

\section{Soil physico-chemical parameters}

The physico-chemical characteristics of rhizospheric soil of D. sissoo growing in the degraded regions are given in Table 2 . The higher bulk density $\left(1.48 \mathrm{~g} \mathrm{~cm}^{-3}\right)$ was found in the control site (unplanted) as compared to the planted area with D. sissoo, depict that the plantation and the growth of the plants could be beneficially related in lowering of the bulk density. Other parameters that contributes in the higher bulk density are fundamentally the soil texture, aggregation, lack of organic matter and higher stone content. Also the moisture content was found to be lower in the control unplanted site as 
388 10 $10^{\mathrm{TH}}$ International Conference on Sustainable Energy and EnVironmental Protection (June 27 $7^{\mathrm{TH}}-30^{\mathrm{TH}}, 2017$, Bled, Slovenia), BioENERGy AND Biofuels

S. Adil Edrisi \& P. Chirakkuzhyil Abhilash: Managing Soil Sustainability Indicators for Sustainable Bioenergy Production

compared to planted areas (Table 2). Similarly, water holding capacity was also found higher in planted areas than the control sites.

\section{Soil biological parameters}

The biological parameter s were also found to increase with the growth of the plant species i.e., D. sissoo, that has been shown in the (Figure 2). The results clearly depicts that lowered enzymatic activities of the studied enzymes in winter as compared to that of summers are may be due to the change in the temperature of the concerned region. However, the enzymatic activities were also enhanced with the growth of the plant species.
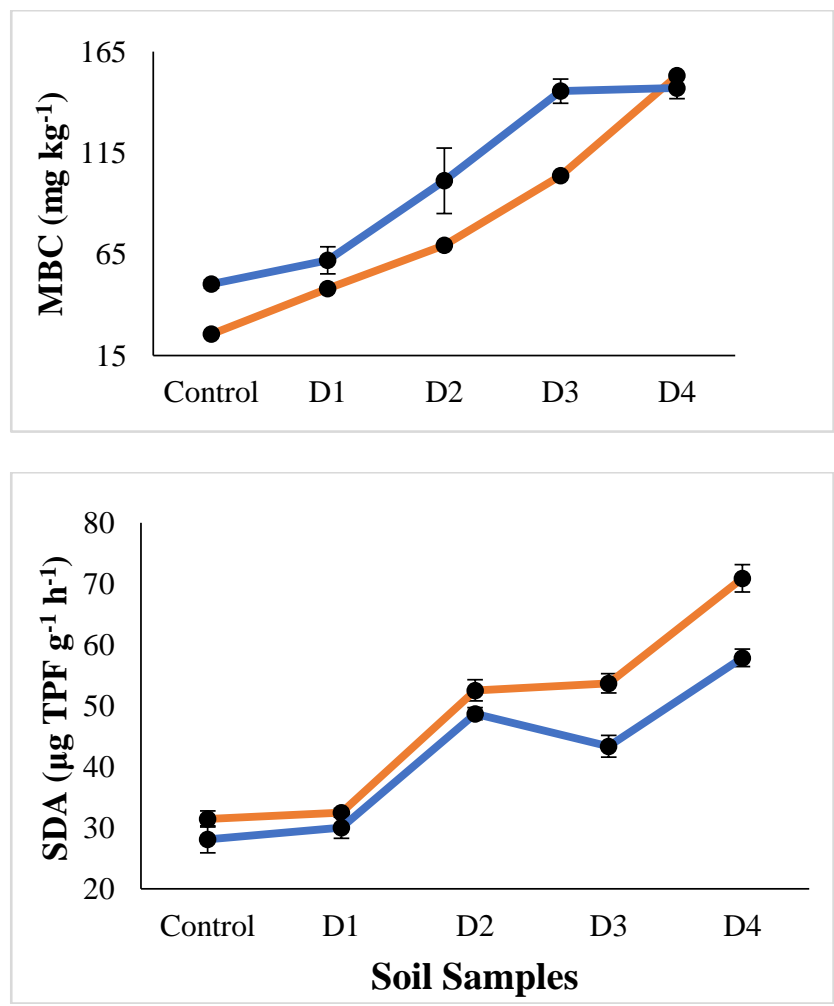
Protection (June $27^{\mathrm{TH}}-30^{\mathrm{TH}}, 2017$, BLed, Slovenia), Bioenergy ANd Biofuels

S. Adil Edrisi \& P. Chirakkuzhyil Abhilash: Managing Soil Sustainability Indicators for Sustainable Bioenergy Production
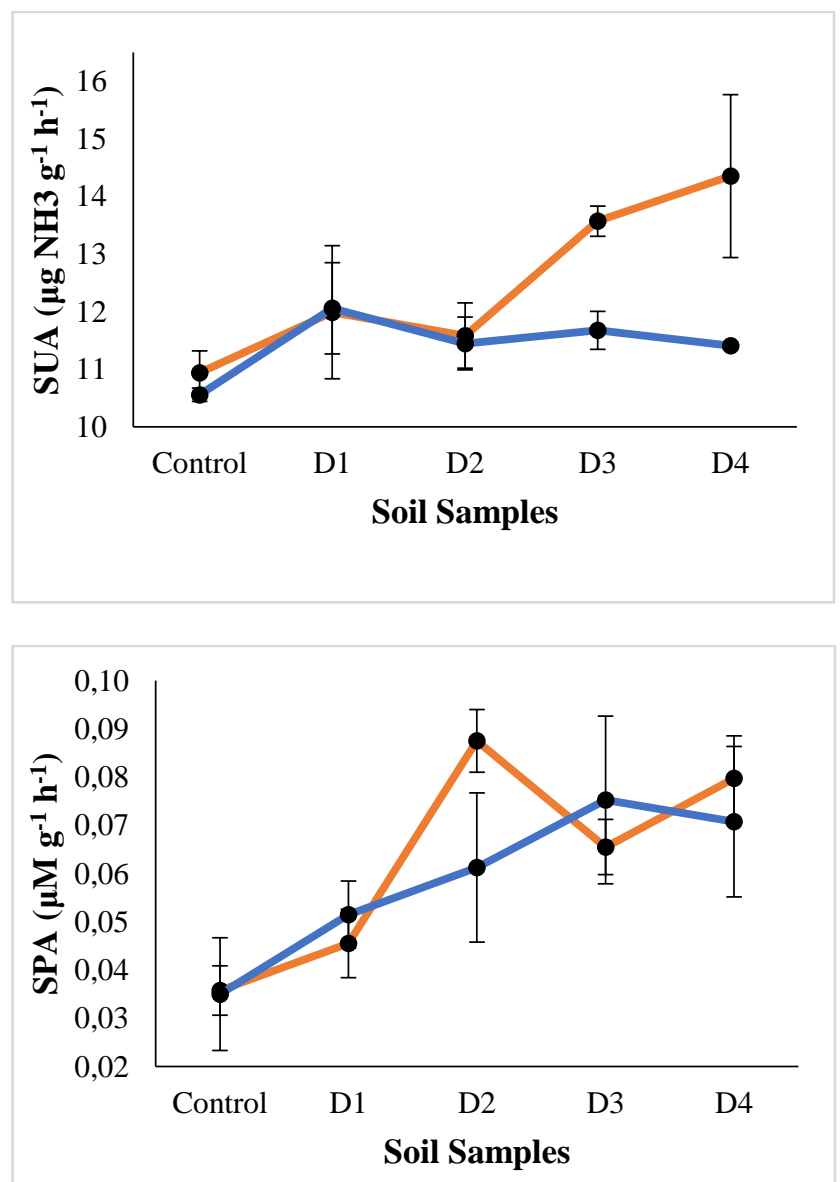

Figure 2: biological characterization of degraded soil and rhizospheric soil collected from Dalbergia sissoo.

Further PCA analysis (Figure 3 and Table 3) clearly depicts that the BD, AN and AK, $\mathrm{MBC}, \mathrm{SDA}, \mathrm{MC}$ and SUA are the major factors which influence the overall development of soil health. 
$390 \quad 10^{\text {TH }}$ International CONFERENCE ON Sustainable ENERGy AND ENVIRONMENTAL Protection (June $27^{\mathrm{TH}}-30^{\mathrm{TH}}, 2017$, BLed, SLOVENiA), Bioenergy AND Biofuels

S. Adil Edrisi \& P. Chirakkuzhyil Abhilash: Managing Soil Sustainability Indicators for Sustainable Bioenergy Production

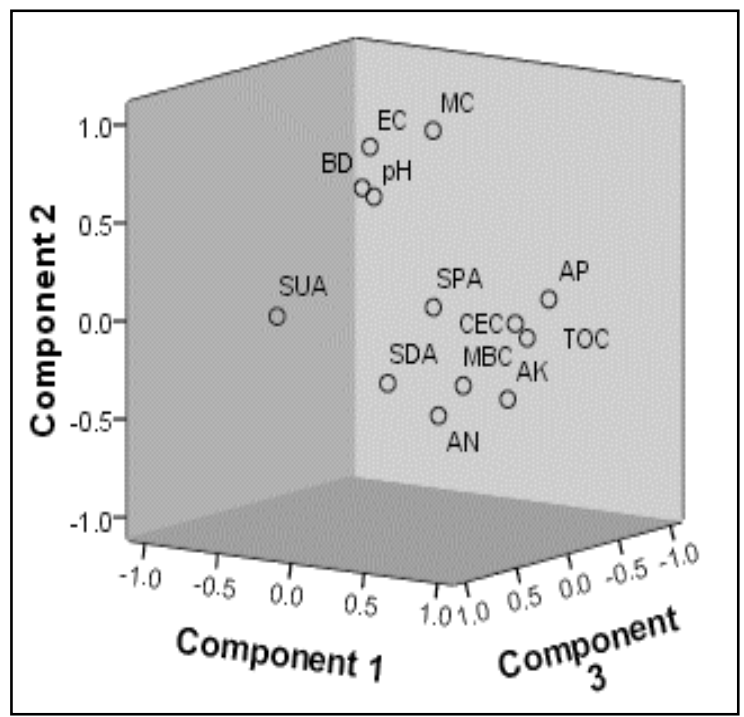

Figure 3: Component plot in the rotated space depicting the factor loading on the respective axes.

Table 3: Results of principal component analysis of rhizosphere soil parameters under D. sissoo growing in the degraded area of Barkachha of Mirzapur district in Uttar Pradesh.

\begin{tabular}{|l|l|l|l|}
\hline Principal components & PC-1 & PC-2 & PC-3 \\
\hline Elgen values $^{\text {a }}$ & 7.616 & 1.650 & 1.184 \\
\hline Variation (\%) & 58.584 & 12.690 & 9.111 \\
\hline Cumulative variation (\%) & 58.584 & 71.274 & 80.386 \\
\hline Eigenvectors ${ }^{\text {b }}$ & & & \\
\hline Bulk density & $-0.96 *^{*}$ & 0.189 & -0.035 \\
\hline Moisture content & -0.288 & $0.870 *$ & -0.011 \\
\hline pH (1:4; w/v) & -0.812 & 0.217 & -0.039 \\
\hline EC (1:4; w/v) & -0.696 & 0.567 & 0.097 \\
\hline Organic carbon & 0.779 & 0.248 & -0.294 \\
\hline Available N & $0.932^{*}$ & -0.089 & 0.094 \\
\hline Available P & 0.486 & 0.302 & -0.472 \\
\hline Available K & $0.941^{*}$ & -0.009 & -0.215 \\
\hline CEC & 0.781 & 0.333 & -0.216 \\
\hline Microbial biomass carbon & $0.951^{*}$ & 0.086 & 0.023 \\
\hline Dehydrogenase activity & $0.855^{*}$ & 0.065 & 0.351 \\
\hline Urease activity & 0.399 & 0.225 & $0.782^{*}$ \\
\hline Peroxidase activity & 0.682 & 0.393 & 0.159 \\
\hline
\end{tabular}

${ }^{a}$ Boldface eigenvalues correspond to the PCs examined for the index.

b Boldface factor loadings are considered highly weighted; bold-asterisked factors correspond to the parameters included in the index. 


\section{$4 \quad$ Conclusions and Future Recommendations}

Fundamentally the ultimate aim of any reclamation program is to maintain a good substrate for better plant establishment and growth. PCA of soil properties under $D$. sissoo growing in restoring site reveal that $\mathrm{BD}, \mathrm{AN}$ and $\mathrm{AK}, \mathrm{MBC}, \mathrm{SDA}, \mathrm{MC}$ and SUA are the major factors which influence the overall development of soil health (Figure 3 and Table 3). Further, restored degraded soil Index (RDSI) could also be developed which can suggest some revegetation practices via the selective plant species depending on the extent of degradation and the climate suitability. Further, it can be comprehended by adopting various sustainable practices like no-tillage or mulching or even both could be more effective in retaining the soil sustainability indicators for the growing bioenergy crops. Hence, the study conclude that the adoption of integrative indigenous technologies with the management of self-supportive processes would help to maintain the viability of lands meant for the long term sustainable bioenergy production system.

However, the study is related to the performance of $D$. sissoo in the concerned site, hence it only suggest the influential parameters beneficial to its development under the concerned climatic conditions. Further, the potentialities of the indigenous energy crops needs to be assessed. Therefore, more and more plant species should be incorporated and tested at a field level to enhance the efficiency of any restoration vis-à-vis bioenergy production program. Lastly, a strong policy formulation yet to be done to enhance the efficiency of the restoration process.

Table 2. Physico-chemical characteristics of the rhizospheric soil samples of Dalbergia sissoo growing the degraded area of Barkachha, Mirzapur

\begin{tabular}{|c|c|c|c|c|c|c|c|c|c|}
\hline \multicolumn{10}{|c|}{ Summer Season } \\
\hline Soil Samples & $\mathrm{BD}\left(\mathrm{g} \mathrm{cm}^{-3}\right)$ & MC $(\%)$ & $\mathrm{pH}(1: 4 \mathrm{w} / \mathrm{v})$ & EC $\left(\mathrm{ds} \mathrm{m}^{-1}\right)$ & TOC $(\%)$ & $\mathrm{AN}\left(\mathrm{mg} \mathrm{kg}^{-1}\right)$ & $\mathrm{AP}\left(\mathrm{mg} \mathrm{kg}^{-1}\right)$ & AK $\left(\mathbf{m g ~ k g}{ }^{-1}\right)$ & CEC $\left(\mathrm{cmol} 100 \mathrm{~g}^{-1}\right)$ \\
\hline Control (unplanted) & $1.48=0.03^{\mathrm{d}}$ & $2.33=1.33^{\mathrm{a}}$ & $7.46 \pm 0.08^{b}$ & $0.23 \pm 0.01^{c}$ & $0.36 \pm 0.01^{\mathrm{a}}$ & $66.40 \pm 7.36^{\mathrm{a}}$ & $4.56=0.03^{\mathrm{a}}$ & $21.87 \pm 2.02^{6}$ & $12.92 \pm 0.05^{\mathrm{a}}$ \\
\hline D1 & $1.56=0.01^{\mathrm{e}}$ & $8.16=1.70^{b}$ & $7.91=0.06^{c}$ & $0.29=0.009^{\mathrm{e}}$ & $0.35 \pm 0.35^{\mathrm{a}}$ & $70.46 \pm 3.57^{\mathrm{a}}$ & $4.75=0.17^{\mathrm{a}}$ & $18.04 \pm 2.67^{\mathrm{a}}$ & $13.21 \pm 0.10^{b}$ \\
\hline D2 & $1.45 \pm 0.02^{c}$ & $5.82 \pm 1.90^{b}$ & $7.62=0.06^{\mathrm{d}}$ & $0.27 \pm 0.004^{\mathrm{d}}$ & $0.38 \pm 0.38^{b}$ & $89.00 \pm 4.71^{b}$ & $5.11=0.18^{b}$ & $28.14 \pm 1.73^{c}$ & $14.64 \pm 0.11^{d}$ \\
\hline D3 & $1.34=0.01^{b}$ & $5.99 \pm 1.37^{b}$ & $7.49 \pm 0.05^{b}$ & $0.19=0.002^{b}$ & $0.43 \pm 0.43^{c}$ & $121.67 \pm 6.73^{c}$ & $5.41=0.33^{b}$ & $32.69 \pm 1.01^{d}$ & $16.30 \pm 0.20^{\mathrm{e}}$ \\
\hline D4 & $1.23=0.01^{\mathrm{a}}$ & $1.61 \pm 0.53^{\mathrm{a}}$ & $7.24=0.08^{\mathrm{a}}$ & $0.18 \pm 0.004^{a}$ & $0.49 \pm 0.49^{\mathrm{d}}$ & $194.11 \pm 7.38^{d}$ & $5.36 \pm 0.18^{b}$ & $35.40 \pm 0.82^{\mathrm{d}}$ & $14.40 \pm 0.03^{c}$ \\
\hline \multicolumn{10}{|c|}{ Winter Season } \\
\hline Control (unplanted) & $1.47 \pm 0.04^{\mathrm{d}}$ & $1.88 \pm 0.17^{\mathrm{a}}$ & $7.31=0.04^{\mathrm{ab}}$ & $0.19 \pm 0.01^{a}$ & $0.41=0.03^{\mathrm{a}}$ & $67.74 \pm 4.81^{\mathrm{a}}$ & $5.19 \pm 0.16^{\mathrm{a}}$ & $25.84 \pm 3.05^{\mathrm{a}}$ & $13.61 \pm 0.03^{\mathrm{a}}$ \\
\hline D1 & $1.51=0.01^{d}$ & $7.78=1.00^{c}$ & $7.84=0.18^{c}$ & $0.27 \pm 0.02^{b}$ & $0.44=0.44^{a b}$ & $85.45 \pm 7.36^{b}$ & $5.39=0.37^{a}$ & $23.45 \pm 0.48^{\mathrm{a}}$ & $14.66 \pm 0.05^{b}$ \\
\hline D2 & $1.41=0.03^{c}$ & $6.13=0.60^{b}$ & $7.43=0.20^{b}$ & $0.26 \pm 0.01^{b}$ & $0.46 \pm 0.46^{b}$ & $104.36 \pm 4.36^{\mathrm{C}}$ & $6.32=1.43^{a}$ & $31.75 \pm 1.75^{b}$ & $14.77 \pm 0.07^{\mathrm{b}}$ \\
\hline D3 & $1.30=0.01^{b}$ & $6.12=0.28^{b}$ & $7.32=0.12^{\mathrm{ab}}$ & $0.18=0.01^{\mathrm{a}}$ & $0.51=0.57^{c}$ & $140.42 \pm 4.97^{\mathrm{d}}$ & $6.09=1.07^{\mathrm{a}}$ & $38.32 \pm 1.80^{c}$ & $15.75 \pm 0.03^{c}$ \\
\hline D4 & $1.21=0.01^{\mathrm{a}}$ & $2.79 \pm 0.62^{\mathrm{a}}$ & $7.18=0.05^{\mathrm{a}}$ & $0.17 \pm 0.01^{2}$ & $0.57 \pm 0.51^{d}$ & $212.46 \pm 4.76^{\mathrm{e}}$ & $6.14 \pm 0.65^{\mathrm{a}}$ & $41.16 \pm 0.90^{c}$ & $16.37 \pm 0.12^{d}$ \\
\hline
\end{tabular}

\section{Acknowledgements}

The authors like to thank the organizing committee to provide an opportunity to present their paper. SAE is also thankful to UGC and DST-SERB for providing financial and travel assistance to present the paper in the conference.

\section{References}

[1] Bauen, A., Berndes, G., Junginger, M., Londo, M., Vuille, F., 2009. Bioenergy- A Sustainable and Reliable Energy Source, Main Report, IEA Bioenergy.

[2] Chakravorty, U., Hubert, M., Nøstbakken, L., 2009. Fuel versus Food (No. 2009-20), Annual Review of Resource Economics. Alberta. 
$10^{\mathrm{TH}}$ InTERNATIONAL CONFERENCE ON Sustainable ENERGy AND ENVIRONMENTAL Protection (June $27^{\mathrm{TH}}-30^{\mathrm{TH}}, 2017$, BLED, Slovenia), Bioenergy AND Biofuels S. Adil Edrisi \& P. Chirakkuzhyil Abhilash: Managing Soil Sustainability Indicators for Sustainable Bioenergy Production

[3] Kauffman, N.S., Hayes, D.J., 2013. The trade-off between bioenergy and emissions with land constraints. Energy Policy 54, 300-310. doi:10.1016/j.enpol.2012.11.036.

[4] Edrisi, S.A., and Abhilash, P.C., 2016. Exploring marginal and degraded lands for biomass and bioenergy production in India. Renew. Sust. Energ. Rev. 54, 1537-1551.

[5] Edrisi, S.A., and Abhilash, P.C., 2015. Sustainable bioenergy production from woody biomass: prospects and promises. J. Clean. Prod. 102, 558-559.

[6] Heink, U., Kowarik, I., 2010. What are indicators? On the definition of indicators in ecology and environmental planning. Ecol. Indic. 10, 584-593.

[7] McBride, A.C., Dale, V.H., Baskaran, L.M., Downing, M.E., Eaton, L.M., Efroymson, R. a., Garten Jr., C.T., Kline, K.L., Jager, H.I., Mulholland, P.J., Parish, E.S., Schweizer, P.E., Storey, J.M., 2011. Indicators to support environmental sustainability of bioenergy systems. Ecol. Indic. 11, 1277-1289. doi:10.1016/j.ecolind.2011.01.010.

[8] De Graff, M.-A., van Groenigen, K.-J., Six, J., Hungate, B., van Kessel, C., 2006. Interactions between plant growth and soil nutrient cycling under elevated CO2: A metaanalysis. Glob. Chang. Biol. 12, 2077-2091. doi:10.1111/j.1365-2486.2006.01240.x.

[9] Abhilash, P.C., Dubey, R.K., 2014. Integrating aboveground-belowground responses to climate change. Curr. Sci. 106, 1637-1638.

[10] Kumar, J.I.N., Patel, K., Kumar, R.N., Kumar, R., 2010. An evaluation of fuelwood properties of some Aravally mountain tree and shrub species of Western India. Biomass and Bioenergy 35, 411-414. doi:10.1016/j.biombioe.2010.08.051.

[11] Niranjan, R., Mohan, V., Rao, V.M., 2007. Effect of Indole Acetic Acid on the Synergistic Interactions of Bradyrhizobium and Glomus fasciculatum on Growth, Nodulation, and Nitrogen Fixation of Dalbergia sissoo Roxb. Arid L. Res. Manag. 21, 329-342. doi:10.1080/15324980701603573.

[12] Kanime, N., Kaushal, R., Tewari, S.K., Raverkar, K.P., Chaturvedi, O.P., Section, A., Management, P., Division, P.S., Soil, C., Conservation, W., 2013. Forests, Trees and Livelihoods Biomass production and carbon sequestration in different tree-based systems of Central Himalayan Tarai region. For. Trees Livelihoods 22, 38-50. doi:10.1080/14728028.2013.764073.

[13] Guleria, V., Vashisht, A., Gupta, A., Salven, T., Thakur, C., Kumar, P., 2014. Carbon stocks and soil properties under nitrogen-fixing trees on degraded site in subtropical Himalayan region. Indian J. Soil Conserv. 42, 293-297.

[14] Hunter, I., 2001. Above ground biomass and nutrient uptake of three tree species (Eucalyptus camaldulensis, Eucalyptus grandis and Dalbergia sissoo) as affected by irrigation and fertiliser, at 3 years of age , in southern India. For. Ecol. Manage. 144, 189-199.

[15] Mishra, a., Sharma, S.D., Khan, G.H., 2002. Rehabilitation of degraded sodic lands during a decade of Dalbergia sissoo plantation in Sultanpur district of Uttar Pradesh, India. L. Degrad. Dev. 13, 375-386. doi:10.1002/ldr.511.

[16] McLean, E.O., 1982. Soil pH and lime requirement. In: Page, A.L., et al. (Eds.), Methods of Soil Analysis. Part 2., 2nd edn. ASA and SSSA, Madison, WI, pp. 199-224, Agron. Monogr. No. 9.

[17] Blake, G.R., Harte, K.H., 1986. Bulk density. In: Klute, A. (Ed.), Methods of Soil Analysis. Part 1. Physical and Mineralogical Methods., 2nd edn. American Society of Agronomy and Soil Science Society of America, Madison, Wisconsin, USA, pp. 363375.

[18] Estefan G, Sommer R, Ryan J. 2013. Methods of Soil, Plant, and Water Analysis: A manual for the West Asia and North Africa region. International Center for Agricultural Research in the Dry Areas (ICARDA). Edition 3rd: 143pp. 
[19] Walkley, A. A critical examination of a rapid method for determining organic carbon in soils: Effect of variations in digestion conditions and of organic soil constituents. Soil. Sci., 63, 251-263 (1947).

[20] FAO. The Euphrates Pilot Irrigation Project. Methods of soil analysis, Gadeb Soil Laboratory (A laboratory manual). Food and Agriculture Organization, Rome, Italy (1974).

[21] Kalra, Y. P. \& Maynard, D. G. Methods Manual for Forest Soil and Plant Analysis. Northern Forestry Centre, Northwest Region, Forestry Canada, Edmonton, Alberta. Information Report NOR-X-319 (1991).

[22] Olsen, S.R. and Sommers, L.E., 1982. Phosphorus in Methods of Soil Analysis Part 2. Chemical and Microbiological Properties.

[23] Subbiah, B.V., Asija, G.L., 1956. A rapid procedure for the determination of available nitrogen in soils. Curr. Sci. 25, 259-260.

[24] Olsen, S.R., 1954. Estimation of available phosphorus in soils by extraction with sodium bicarbonate. United States Department of Agriculture; Washington.

[25] Toth, S.J. and Prince, A.L., 1949. Estimation of cation-exchange capacity and exchangeable $\mathrm{Ca}, \mathrm{K}$, and $\mathrm{Na}$ contents of soils by flame photometer techniques. Soil Science, 67(6), pp.439-446.

[26] Vance, E.D., Brookes, P.C., Jenkinson, D.S., 1987. An extraction method for measuring soil microbial biomass C. Soil Biol. Biochem. 19, 703-707

[27] Brookes, P.C., Landman, A., Pruden, G. and Jenkinson, D.S., 1985. Chloroform fumigation and the release of soil nitrogen: a rapid direct extraction method to measure microbial biomass nitrogen in soil. Soil biology and biochemistry, 17(6), pp.837-842.

[28] De Leij, F.A.A.M., Whipps, J.M. and Lynch, J.M., 1994. The use of colony development for the characterization of bacterial communities in soil and on roots. Microbial ecology, 27(1), pp.81-97.

[29] Olsen, R.A. and Bakken, L.R., 1987. Viability of soil bacteria: optimization of platecounting technique and comparison between total counts and plate counts within different size groups. Microbial Ecology, 13(1), pp.59-74.

[30] Guan, S.Y., 1986. Soil Enzyme and its Research Approaches. China Agriculture Press, Beijing (In Chinese).

[31] Wang, B., Xue, S., Liu, G.B., Zhang, G.H., Li, G. and Ren, Z.P., 2012. Changes in soil nutrient and enzyme activities under different vegetations in the Loess Plateau area, Northwest China. Catena, 92, pp.186-195.

[32] Casida Jr., L.E., Klein, D.A., Santoro, T., 1964. Soil dehydrogenase activity. Soil Sci. 98, 371-376

[33] Johnsen, A.R. and Jacobsen, O.S., 2008. A quick and sensitive method for the quantification of peroxidase activity of organic surface soil from forests. Soil Biology and Biochemistry, 40(3), pp.814-821. 


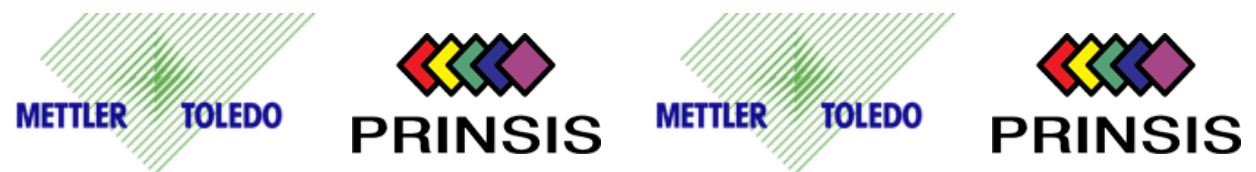

$€$ energetika ljubljana $€$ energetika ljubljana

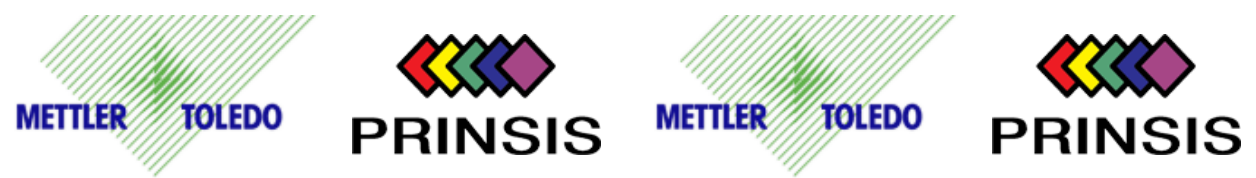

$€$ energetika ljubljana $€$ energetika ljubljana

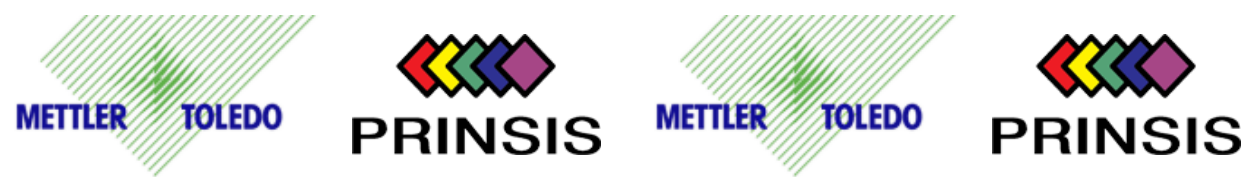

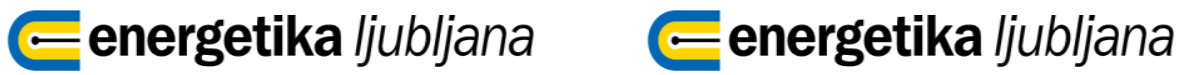

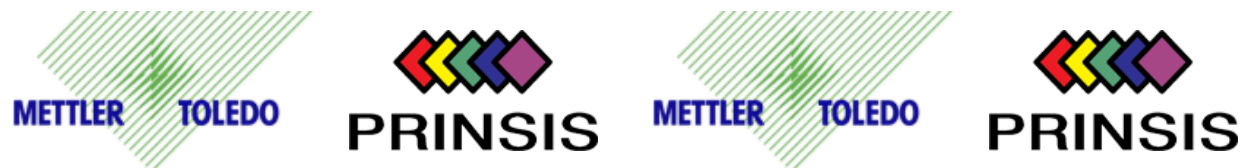

$€$ energetika ljubljana $€$ energetika ljubljana

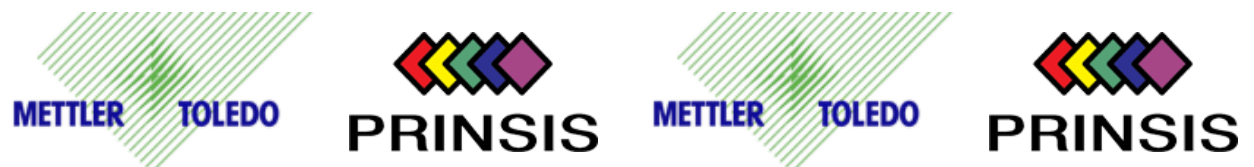

$€$ energetika ljubljana $€$ energetika ljubljana 